AUTARQUIA ASSOCIADA À UNIVERSIDADE DE SÃO PAULO

\title{
CRYSTALWALK: UM SOFTWARE DIDÁTICO-INTERATIVO \\ PARA SÍNTESE E VISUALIZAÇÃO DE ESTRUTURAS CRISTALINAS
}

\author{
Fernando Bardella
}

Tese apresentada como parte dos requisitos para obtenção do Grau de Doutor em Ciências na Área de Tecnologia Nuclear - Materiais

Orientador:

Prof. Dr. Ricardo Mendes Leal Neto 
INSTITUTO DE PESQUISAS ENERGÉTICAS E NUCLEARES

Autarquia associada à Universidade de São Paulo

\title{
CRYSTALWALK: UM SOFTWARE DIDÁTICO-INTERATIVO \\ PARA SÍNTESE E VISUALIZAÇÃO DE ESTRUTURAS CRISTALINAS
}

\author{
Fernando Bardella
}

Tese apresentada como parte dos requisitos para obtenção do Grau de Doutor em Ciências na Área de Tecnologia Nuclear - Materiais

Orientador:

Prof. Dr. Ricardo Mendes Leal Neto

Versão Corrigida

Versão Original disponível no IPEN

São Paulo

2016 
Recordamos com apreço os professores brilhantes, mas com gratidão para com aqueles que tocaram nossos sentimentos humanos. O currículo é tanto matéria-prima necessária, mas o calor é o elemento vital para o crescimento da planta e para a alma da criança.

[Man blickt mit Anerkennung an die brillante Lehrer, aber mit Dankbarkeit an diejenigen, die unsere menschlichen Gefühle berührt. Der Lehrplan ist so sehr notwendige Material, aber Wärme ist das Lebenselement für die wachsende Pflanze und für die Seele des Kindes.]

Carl Gustav Jung (1972), tradução do autor

Dedicado à memória do Prof. Dr. Nelson Infanti Jr., pela sua tutoria, estímulo e dedicação no ensino das ciências naturais, aos quais marcaram minha infância e toda minha existência. 


\section{AGRADECIMENTOS}

Dedicar-se à vida acadêmica é, continua e incansavelmente, uma opção de trabalho árduo e abdicações, sobretudo dos amiúdes da vida pessoal. A realização deste trabalho só foi possível graças à colaboração e contribuição, de forma direta e indireta, de um grande número de pessoas e instituições. Gostaria de dirigir algumas sinceras palavras de profunda gratidão particularmente a algumas delas.

A Cristiana Bardella, grande amor e companheira, pelo apoio permanente e incondicional, por estar ao meu lado nos melhores e piores momentos da vida e por todas as horas das quais abdiquei de estarmos juntos para que este trabalho pudesse ser concluído.

A toda minha família, em especial aos meus pais, Mario e Marisa, pelo exemplo de caráter e de espírito trabalhador dado ao longo da vida e pelo incessante estímulo para que eu acreditasse sempre em meus propósitos e ideais. Aos meus irmãos, Alexandre, Juliana e Ricardo, e, em especial, ao meu irmão mais velho, Klaus Fickert, não apenas pelas inúmeras contribuições à realização deste trabalho, mas também por me mostrar, desde criança, a importância do estudo e do aprendizado.

Ao meu amigo e orientador, professor Ricardo Mendes Leal Neto, pela liberdade e confiança depositada a mim neste projeto, mas, principalmente, por sua generosidade em me acolher sob a tutela de sua orientação desde a minha graduação no Instituto de Física da Universidade de São Paulo (IFUSP). Obrigado, professor, pelas incansáveis horas de trabalho árduo e dedicação, pelos puxões de orelha paternais e por ser minha referência de competência de como a relação professor-estudante deve ser dentro e fora da sala de aula.

Aos amigos e colegas do Grupo de Visualização Científica em Materiais (GVCM), André Montes, André Gomes, Rafael Castilho, e, do Polytechnion Kritis, Thanos Saringelos e Alex Karatzaferis, pelos enormes esforços coletivos que deram existência ao CrystalWalk. Aos amigos e colegas Bóris Fatigati e André Montes, pelas incansáveis contribuições e revisões a esta tese.

Aos amigos e professores Vera Mazzochi, Carlos Parente, Claudio Rocha, Dolores Lazar, Michelangelo Durazzo, Arnaldo Andrade, do Instituto de Pesquisas Energéticas e Nucleares (IPEN), Marcello Zuffo, Roseli de Deus Lopes, Romero Tori e André Tschiptschin, da Escola Politécnica da Universidade de São Paulo (POLI-USP), Kevin Hussey, da Caltech, e Marcos deArruda, da Drexel University, 
pelo exemplo de dedicação e também pelas inúmeras contribuições ao longo do desenvolvimento deste trabalho.

Aos estudantes das disciplinas IPN0012 - Caracterização física de materiais, graduação, USP, turmas 2014, 2015 e 2016, TNM5811 - Técnicas de caracterização física e química de materiais, pós-graduação, USP, 2014-2015, TNM5803 - Ciência dos materiais, pós-graduação, USP, 2016, 261.1609.1 - Metalurgia física I, graduação, Universidade Presbiteriana Mackenzie, turmas 2012 e 2013, 261.1708 .8 - Metalurgia física II, graduação, Universidade Presbiteriana Mackenzie, turmas 2012 e 2013, por todas as intervenções, participações e imensuráveis contribuições aos experimentos deste trabalho.

Aos inúmeros amigos, gestores e colegas da Shire Pharmaceuticals que me apoiaram ao longo destes anos na realização deste trabalho: Aos grandes mentores Jeff Poulton - que me convenceu, definitivamente, a fazer parte de seu time na América Latina - e Bill Ciambrone - com quem continuo aprendendo sobre a importância da academia e da educação sólida na formação de um líder. Aos grandes líderes Anjana Harvey, Paul Cassidy e Dan Hearne, que sempre me estimularam e apoiaram a perseguir meu desenvolvimento profissional tanto dentro como fora do mundo corporativo. Aos grandes exemplos Gaby Pittis, Glen Sunohara e Eli Lakryc, por servirem de motivação e inspiração de que as vidas acadêmica, corporativa e pessoal podem coexistir de maneira harmoniosa. Aos grandes colegas de trabalho Mike Ciaccio, Lynn Nestor, Yesim Birlesik, Ale Leo, Jon Quinn, Andy Sontag, Shaunak, Greg, Nick Stathes, Erika Morris, Zoe Evans, Brian Grubb, Fabio Yoshida e Bianca Nogueira e a todo o time de LATAM, Eduardo Marques, Eli Lakryc, Eric Fialho, Evandro Fraga, Julie Guerra, Humberto Giraldo, Mauricio Pinheiro, Miguel Coego, Reinaldo Silveira, Renato Coelho e Solange Oliveira: obrigado a todos por sempre me apoiarem na realização deste trabalho e na sua conclusão.

Aos grandes amigos do IFUSP, Gomes, Chaps, Vitão, Danosa, AlQueda, Mano, Kami, Hellmans e Ismael, pela parceria e companheirismo que extrapola os anos de graduação para toda a vida.

Por fim, agradeço à Coordenação de Aperfeiçoamento de Pessoal de Nível Superior (CAPES), ao Conselho Nacional de Desenvolvimento Científico e Tecnológico (CNPq), à Comissão Nacional de Energia Nuclear (CNEN) e ao Instituto de Pesquisas Energéticas e Nucleares (IPEN) pelo apoio institucional e financeiro a esta pesquisa. 
Faça tudo da forma mais simples possível, mas não simplista. [Man muß die Dinge so einfach wie möglich machen. Aber nicht einfacher.]

Albert Einstein 


\title{
CRYSTALWALK: UM SOFTWARE DIDÁTICO-INTERATIVO PARA SÍNTESE E VISUALIZAÇÃO DE ESTRUTURAS CRISTALINAS
}

\author{
Fernando Bardella
}

\begin{abstract}
RESUMO
Este trabalho documenta o processo de desenvolvimento de um software didático-interativo para síntese e visualização de estruturas cristalinas intitulado CrystalWalk (CW). Sua criação foi justificada inicialmente pela percepção, colhida junto a atores sociais, de deficiências nas ferramentas de ensino-aprendizagem relacionadas ao estudo de estruturas cristalinas de materiais. Posteriormente, um levantamento do estado da arte dos softwares cristalográficos existentes revelou oportunidades para o desenvolvimento de um novo software com preocupação eminentemente didática. $\mathrm{Na}$ especificação e elaboração do $\mathrm{CW}$, foram preconizados os princípios do software livre, da acessibilidade e da democratização do conhecimento. Adotou-se o estado da arte de tecnologias e serviços para desenvolvimento de aplicações web interativas, tais como plataforma HTML5/WebGL, arquiteturas orientadas a serviços (SOA) e sistemas distribuídos responsivos, resilientes e elásticos. Para facilitar o entendimento e a síntese de estruturas cristalinas, foi proposto um inédito processo passo a passo baseado no conceito "rede + motivo = estrutura cristalina", que exige a participação ativa e consciente do usuário. Inseriu-se também uma ferramenta denominada "narrativa didática", por meio por meio da qual o usuário registra sequências de visualização acompanhadas de anotações e que podem ser compartiIhadas - múltiplas narrativas permitem atender a diferentes perfis de aprendizagem. Também foram incorporadas com sucesso funcionalidades didáticas eficazes para garantir plena acessibilidade aos recursos do CW e para aumentar seu alcance social, tais como o suporte à interação avançada e às tecnologias de interface de realidade virtual, o suporte à impressão 3D e a oferta de uma plataforma de publicação online. $\mathrm{Na}$ avaliação dos produtos gerados, o principal critério foi o atendimento às demandas dos atores sociais, que foram empoderados ao final do processo. $\mathrm{O} C W$ é a primeira plataforma a superar a maioria dos problemas apontados e das limitações encontradas nos instrumentos didáticos existentes sobre a temática deste trabalho, impactando positivamente o acesso e a democratização do conhecimento, por meio da construção coletiva, do estímulo à colaboração e da autonomia e independência tecnológicas.
\end{abstract}




\title{
CRYSTALWALK: AN EDUCATIONAL INTERACTIVE SOFTWARE FOR SYNTHESIS AND VISUALIZATION OF CRYSTAL STRUCTURES
}

\author{
Fernando Bardella
}

\begin{abstract}
This work documents the process of development of an educational interactive software for synthesis and visualization of crystal structures (crystallographic software) named CrystalWalk (CW). The development of CW was justified by educational problems that were the identified and defined from direct stakeholder's inquiry process about the lack of proper didatic tools for teaching crystal structure topic in materials science and engineering disciplines. Further, an evaluation of the existing crystallographic softwares has shown opportunities for the development of a new software, focused on the educational approach. The process of development and implementation of CrystalWalk was guided by principles of free software, accessibility and democratization of knowledge, adopting state of art technologies for the development of interactive web applications, such as HTML5/WebGL, service oriented architecture (SOA) and responsive, resilient and elastic distributed systems. CW proposes an unprecedented step-by-step crystal structure creation approach, imparting the concept of lattice and motif through active and conscious user interaction. Additionally, a comprehensive set of didactic functionalities was also successfully implemented, as an online content publication platform for sharing interactive crystal structures, a "didactic narratives" tool that enables users to generate interactive classes based on predefined animated sequences as well the support for advanced interaction and virtual reality technologies as Oculus Rift, Google Cardboard, LEAP Motion, multi-touch devices and 3D printing technologies. Project deliverables were evaluated under action-research premises based on identified problems' resolution and overall stakeholder's acquired knowledge - or empowerment . CW has successfully resolved most of the identified problems identified, empowering students, professors and researchers through positive impact in the democratization of knowledge and technological autonomy and independence.
\end{abstract}




\section{SUMÁRIO}

Página

LISTA DE TABELAS

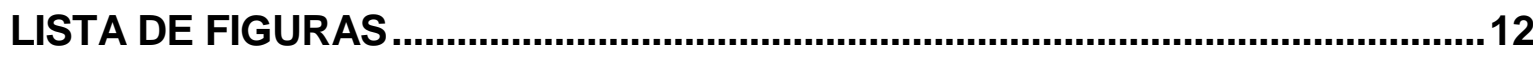

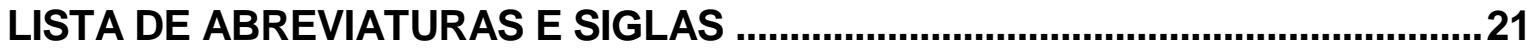

LISTA DE SÍMBOLOS

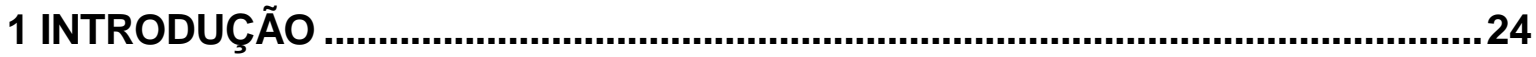

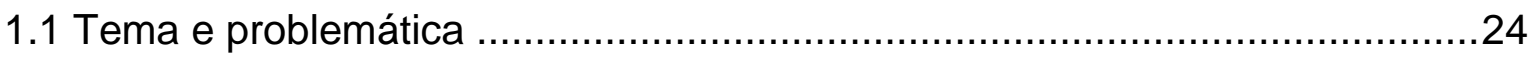

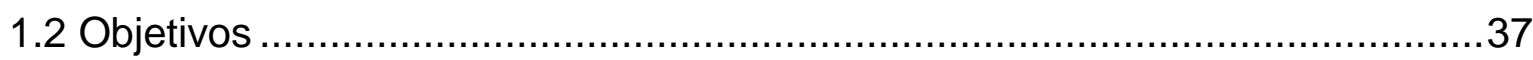

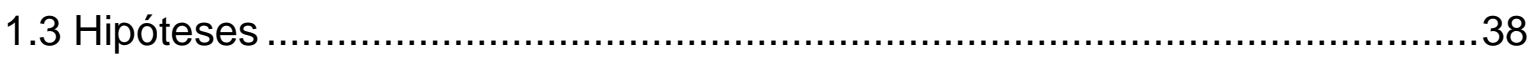

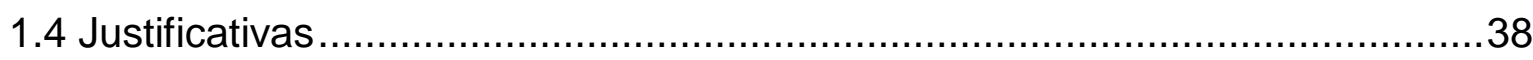

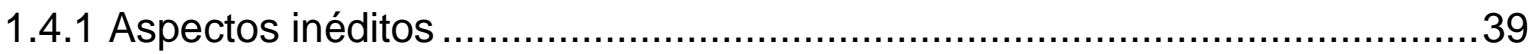

1.4.2 Contribuições científicas e sociais ..........................................................40

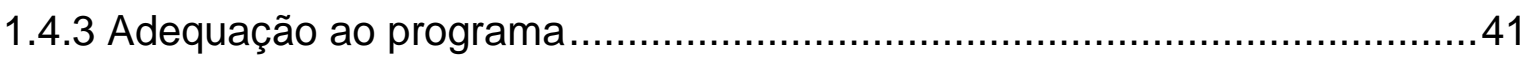

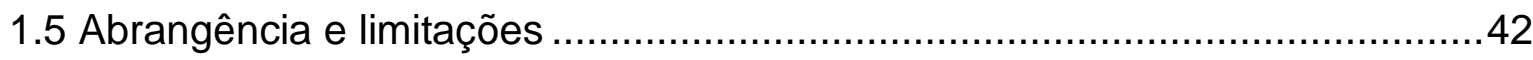

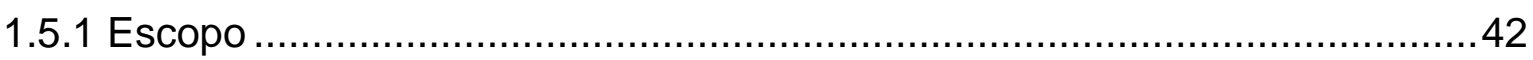

1.5.2 Aspectos pedagógicos e cognitivos: discussão e testes ……………….....42

1.5.3 Limitações do processo de revisão da literatura ....................................... 42

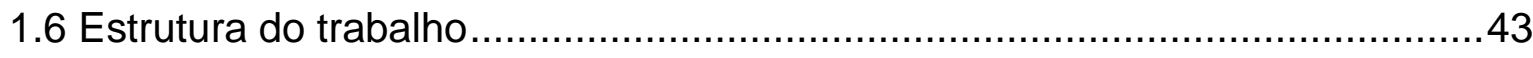

2 METODOLOGIA

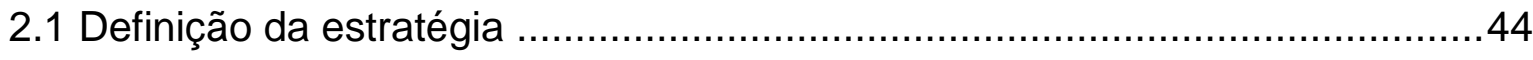

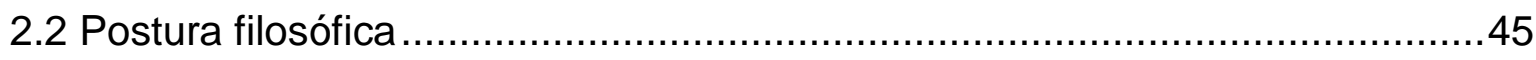

2.3 Aspectos epistemológicos, teóricos e metodológicos ....................................47

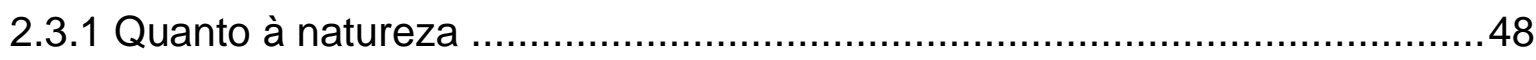

2.3.2 Quanto à forma de abordagem do problema ........................................... 48

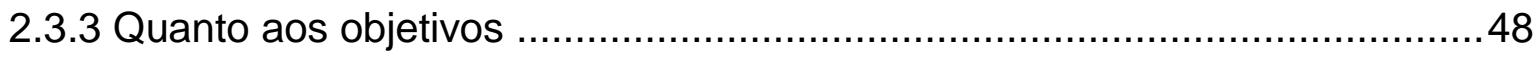

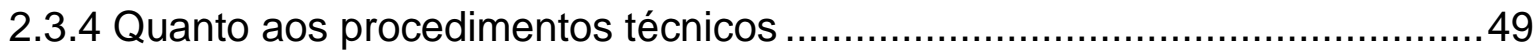

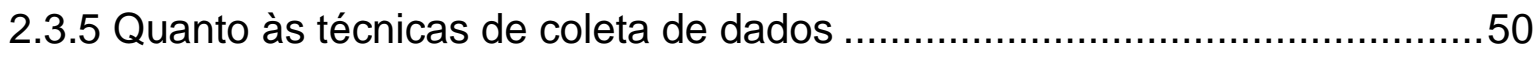

2.3.6 Síntese dos aspectos epistemológicos, teóricos e metodológicos.................52 


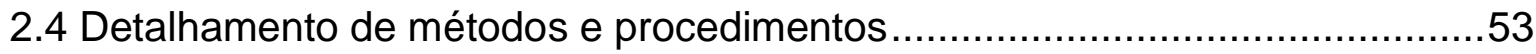

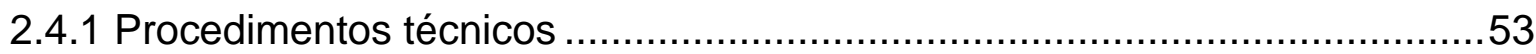

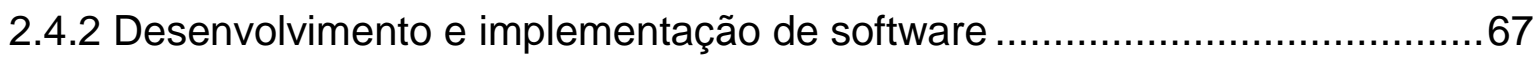

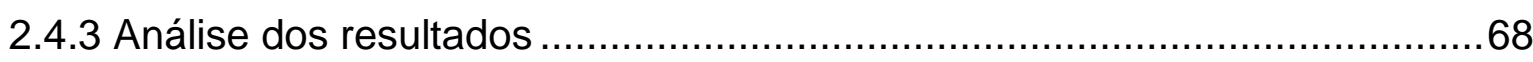

2.4.4 Sumário dos métodos e procedimentos ..................................................

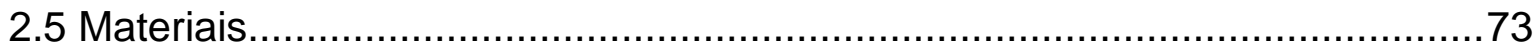

2.6 Descrição e cronograma das atividades planejadas .....................................75

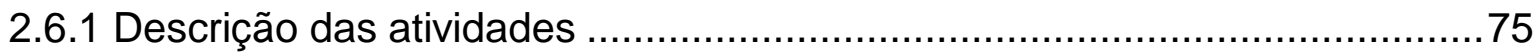

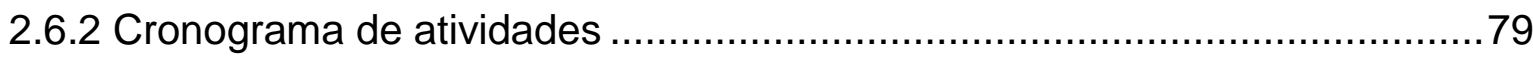

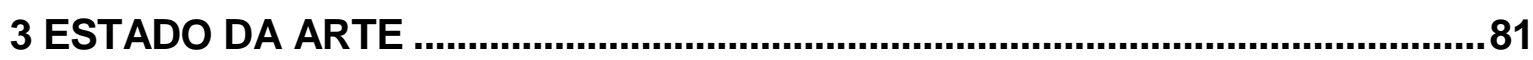

3.1 Problemas técnicos e conceituais no ensino de estruturas cristalinas .............81

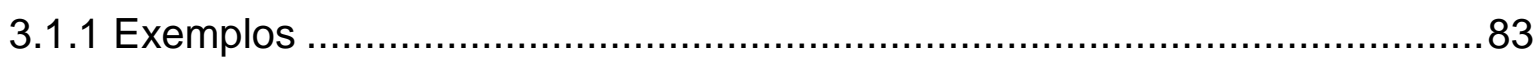

3.1.2 Problemas na representação de estruturas cristalinas em obras de referência ....91

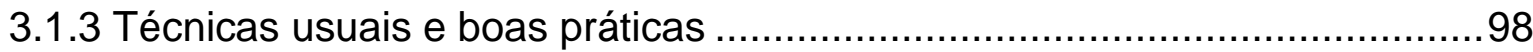

3.2 Benefícios do uso de mídias digitais tridimensionais interativas no ensino.......99

3.2.1 A importância da estratégia pedagógica para o aprendizado .....................100

3.2.2 Benefícios de modelos tridimensionais .................................................103

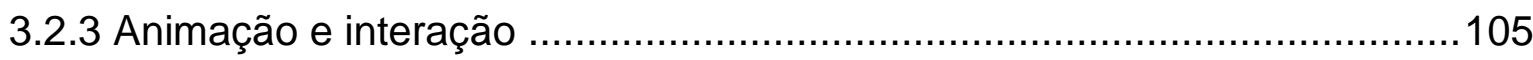

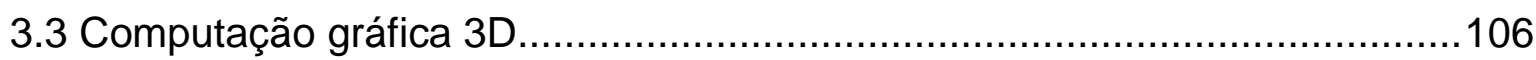

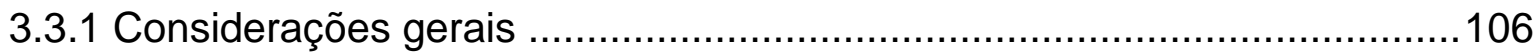

3.3.2 Fundamentos tecnológicos .................................................................106

3.3.3 Métodos de representação geométrica .................................................110

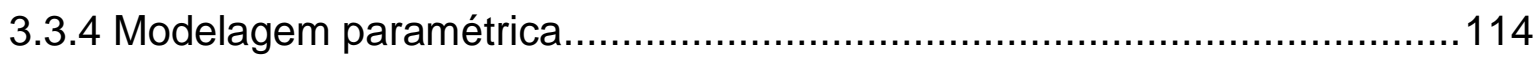

3.3.5 Aplicações da computação gráfica tridimensional...................................116

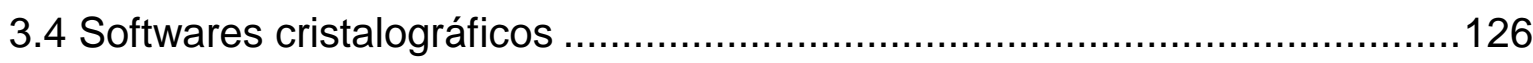

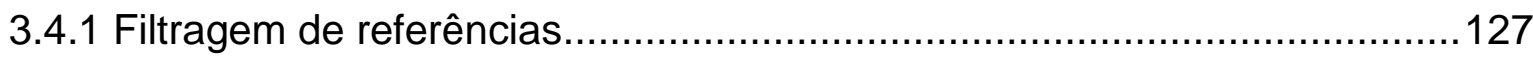

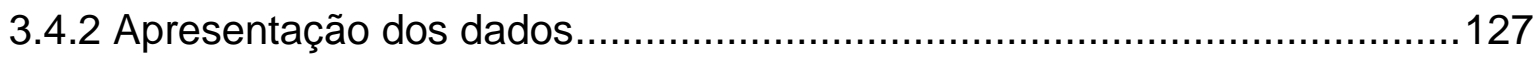

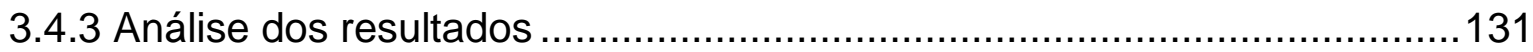

3.4.4 Considerações finais sobre os resultados ............................................131

3.5 Planejamento e desenvolvimento de software ..........................................132

3.5.1 Metodologias ágeis de desenvolvimento ............................................133

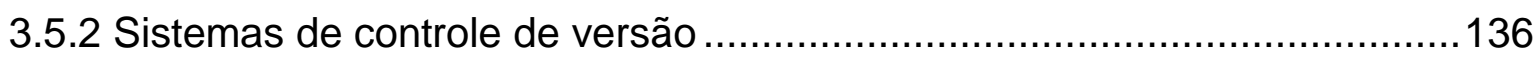

3.5.3 Conceitos, tecnologias e plataformas para aplicações web interativas......139

4 DESENVOLVIMENTO E RESULTADOS...........................................................162 


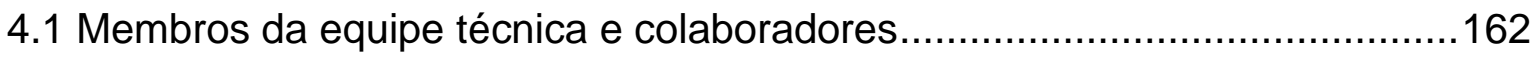

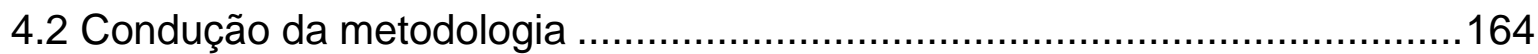

4.2.1 Implantação da pesquisa-ação e Scrum …………………………........165

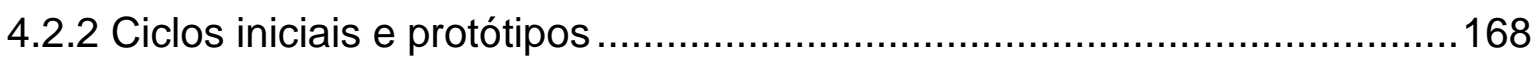

4.3 Problemas levantados junto aos atores sociais, ações tomadas e resultados

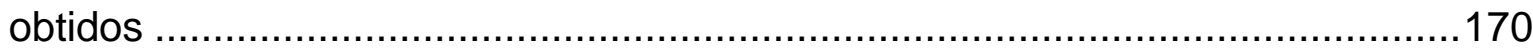

4.3.1 Proposta final de especificação para a aplicação CrystalWalk ..................173

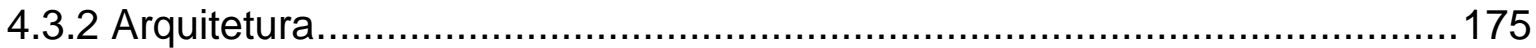

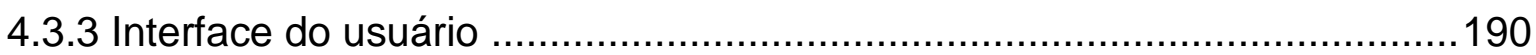

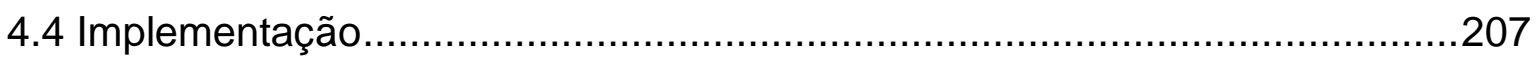

4.4.1 Processo de avaliação de serviços de computação em nuvem .................207

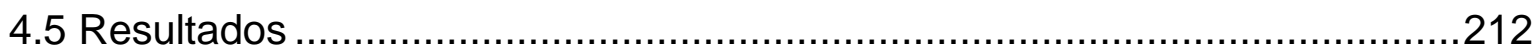

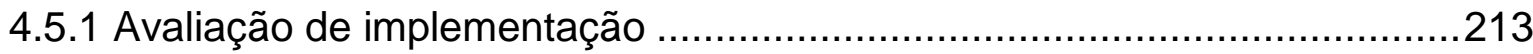

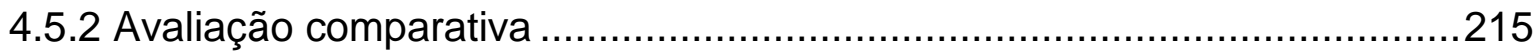

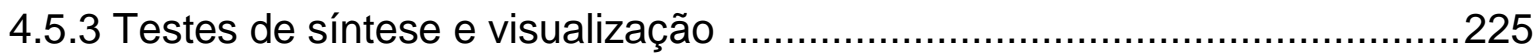

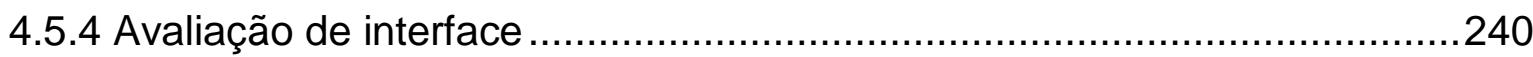

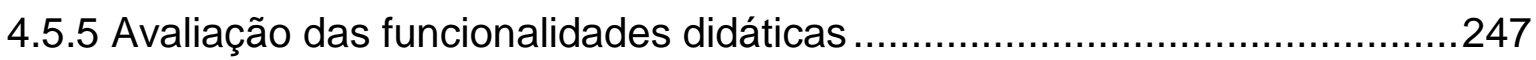

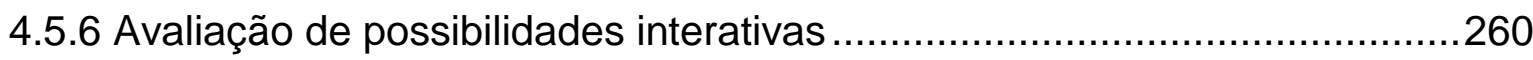

4.5.7 Avaliação de empoderamento dos atores sociais ...................................274

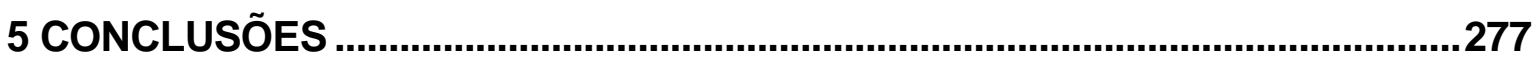

APÊNDICE A - Lista de softwares cristalográficos analisados .........................280

APÊNDICE B - Detalhamento dos critérios e parâmetros dos questionários de

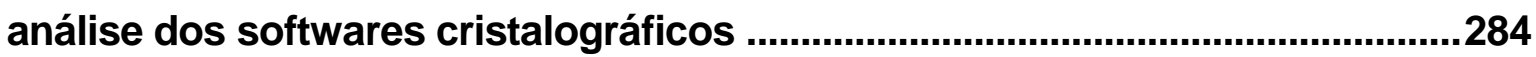
APÊNDICE C - Detalhamento dos dados resultantes da avaliação comparativa

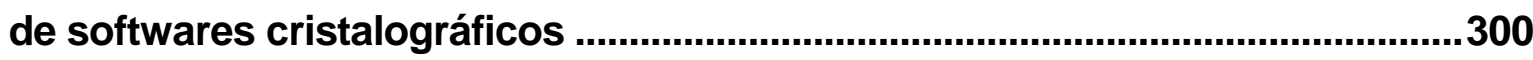
APÊNDICE D - Detalhamento dos problemas levantados junto aos atores

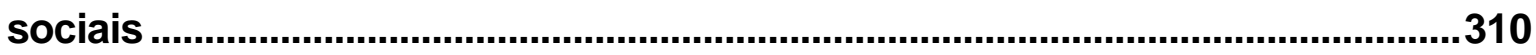

ÍNDICE

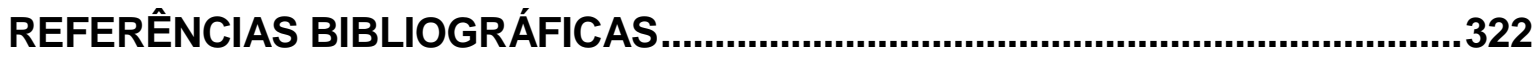




\section{LISTA DE TABELAS}

TABELA 1 - Avaliação das tecnologias de computação gráfica para web. 155

TABELA 2 - Estado do suporte a tecnologia WebGL nos navegadores mais populares em suas versões mais populares. 156

TABELA 3 - Situação das principais bibliotecas WebGL (fevereiro de 2016). ...157 TABELA 4 - Problemas levantados junto aos atores sociais, ações tomadas e resultados obtidos.

TABELA 5 - Descrição dos principais elementos de cena e seus respectivos módulos, parâmetros e atributos referente ao objeto visão da aplicação. 182 TABELA 6 - Descrição das estruturas de dados dos principais objetos primitivos em cena e seus respectivos módulos, parâmetros e atributos referentes ao objeto modelo da aplicação.

TABELA 7 - Descrição dos principais métodos do módulo lattice.js (estrutura cristalina), referente ao objeto controlador. 185

TABELA 8 - Descrição dos principais métodos do módulo motifEditor.js (motivo), referente ao objeto controlador. 186

TABELA 9 - Descrição dos rotas, verbos e parâmetros da interface REST, referentes à aplicação CWLY...

TABELA 10 - Descrição do esquema híbrido do banco de dados, referente à aplicação CWLY.

TABELA 11 - Parâmetros de configuração das instâncias de roteamento e resolução de DNS no serviço (laaS) Amazon Route 53.

TABELA 12 - Parâmetros dos Web Dynos utilizados no serviço (PaaS) na plataforma Heroku

TABELA 13 - Repositórios de código do CrystalWalk, disponibilizados através do serviço (SaaS) Github.

TABELA 14 - Avaliação dos experimentos de imersão, segundo os modelos propostos por Thon (2008) e McMahan (2011). .273 


\section{LISTA DE FIGURAS}

FIGURA 1 - (a) O Cubo de Necker e suas interpretações e (b) união de interpretações em uma representação impossível. Fonte: (a) do autor; (b) Escher (1958) (adaptado). .25

FIGURA 2 - (a) Obra Waterfall, de M.C. Escher; (b) ambiguidades das perspectivas isométricas exploradas na obra. Fonte: (a) Escher (1961); (b) do autor.

FIGURA 3 - Células unitárias das estruturas cúbica simples (CS), cúbica de corpo centrado (CCC) e cúbica de face centrada (CFC): (a) representação com átomos reduzidos em diâmetro; (b) representação com esferas rígidas em corte. Fonte: Callister e Rethwisch (2007) (adaptado). .27

FIGURA 4 - Representações da estrutura cristalina do Manganês- $\alpha$ : (a) modelo digital; (b) ilustração de 1913. Fonte: (a) U.S. Navy et al ([s.d.]); (b) Ewald (1913) (adaptado).

FIGURA 5 - Comparação de modelo físico com imagem gerada pelo primeiro software cristalográfico, o ORTEP, em 1965. Fonte: Felknor (1965). .31

FIGURA 6 - Exemplos de maquetes físicas: (a) representação da estrutura cristalina da calcita utilizando maquete de estruturas plásticas autoencaixáveis; (b) vista do Atomium; (c-d) modelo de estrutura cristalina do $\mathrm{NaCl}$ de 3 metros de lado. Fonte: (a) Calcilte ([s.d.]); (b) do autor; (c-d) Krickl (2014) (adaptado)..........32 FIGURA 7 - Modelo do $\mathrm{NaCl}$ gerado pelo software cristalográfico VEST14 ilustrando diversos pontos de vista e capacidade de desconstruir átomos do modelo: (a) vistas ortogonais em x e y; (b) perspectiva axonométrica (à esquerda) e modelo desconstruído (à direita). Fonte: VEST14 (adaptado). .33

FIGURA 8 - Modelo do $\mathrm{CsCl}$ gerado pelo software cristalográfico CMAK15, ilustrando o mecanismo de rotação, estereoscopia anaglífica (vermelho e azul) e artifícios de visualização (em pontilhado). Fonte: CMAK15 (adaptado).

FIGURA 9 - Imagens do software cristalográfico PLAT13: (a) interface de usuário do tipo texto; (b) representações tridimensionais geradas a partir de comandos digitados pelo usuário. Fonte: PLAT13.

FIGURA 10 - Definição dos parâmetros de rede e grupos de simetria durante a criação e exibição de uma estrutura cristalina no VEST14. Fonte: VEST14 (adaptado). 
FIGURA 11 - 37 passos necessários para a criação e exibição de uma estrutura cristalina no ATOM11. Fonte: ATOM11 (adaptado).

FIGURA 12 - Diagrama-síntese da construção da problemática da pesquisa. Fonte: do autor.

FIGURA 13 - Síntese dos níveis de classificação da pesquisa científica e seus respectivos parâmetros conforme Gil (2008), Marconi e Lakatos (2003), Bardin (2009), Silva (1998) e Creswell (2002). Fonte: do autor.

FIGURA 14 - Diagrama-síntese das frentes desta pesquisa. Fonte: do autor. ....50 FIGURA 15 - Classificação deste trabalho segundo os níveis e parâmetros de classificação da pesquisa científica conforme Gil (2008), Marconi e Lakatos (2003), Bardin (2009), Silva (1998) e Creswell (2002). Fonte: do autor. 53 FIGURA 16 - Diagrama-síntese das etapas da pesquisa-ação conforme Susman e Evered (1978), Baskerville (1999), Kock (2004), Tripp (2005), Checkland (1991) (adaptado). Fonte: do autor. .56

FIGURA 17 - Diagrama-síntese da estratégia de pesquisa (métodos e procedimentos). Fonte: do autor. .72

FIGURA 18 - Cronograma de atividades da pesquisa. Fonte: do autor. .80 FIGURA 19 - Exemplificação de rede e motivo de estruturas planas. Fonte: Graef e McHenry (2007, p. 56) (adaptado).

FIGURA 20 - (a) Célula unitária da estrutura do cloreto de césio ( $\mathrm{CsCl}$ ), indicando o motivo; (b) figura ressaltando as duas redes cúbicas simples, de césio (Cs) e de cloro (Cl), interpenetradas. Fonte: Chen, ([2002]). .86 FIGURA 21 - Exemplos de representação da estrutura do $\mathrm{CsCl}$ extraídos de obras de referência (livros didáticos ou obras correlatas). Fonte: (a) West (2014); (b) Barrett (1943); (c) Callister e Rethwisch (2007); (d) Graef e McHenry (2007) (adaptado). ...87 FIGURA 22 - Estrutura hexagonal compacta $(\mathrm{HC})$ : (a) célula unitária; (b) célula unitária da rede espacial hexagonal; (c) célula unitária $\mathrm{HC}$ com indicação do motivo estrutural. Fonte: (a) Callister e Rethwisch (2007); (b) Barret (1943); (c) Olander (1976) (adaptado).

FIGURA 23 - Vista em planta da célula unitária da estrutura hexagonal compacta (a) vizinhança do átomo central do plano basal; (b) vizinhança de um dos átomos do plano à meia-altura. Fonte: Leal Neto (2016) (adaptado). .89 
FIGURA 24 - Células unitárias da fluorita: (a) com átomos de cálcio externos, nas faces e vértices da célula; (b) com átomos de cálcio internos. Fonte: (a) Askeland (1990); (b) Callister e Rethwisch (2007) (adaptado).

FIGURA 25 - llustração das vizinhanças de cada um dos átomos de flúor do motivo da fluorita. Fonte: Leal Neto (2016) (adaptado). .90

FIGURA 26 - Recursos para lidar com oclusão: (a) modelo "balls and sticks"; (b) perspectiva cônica; (c) diminuição do tamanho dos átomos. Fonte: (a) Callister e Rethwisch (2007); (b) Kittel (1996); (c) Padilha (1997) (adaptado). .93 FIGURA 27 - Uso de simbolismo gráfico para lidar com oclusão: (a) linhas pontilhadas auxiliares; (b-c) linhas pontilhadas para objetos em profundidade; (d) transparência. Fonte: (a) Barrett (1943); (b) Padilha (1997); (c-d) Callister e Rethwisch (2007). .93

FIGURA 28 - Uso de corte para lidar com oclusão: (a) parte interna da célula unitária; (b) corte em plano compacto. Fonte: Callister e Rethwisch (2007) (adaptado).

FIGURA 29 - Uso de referências geométricas para ilustrar posição relativa de átomos: (a) subdivisões da célula unitária; (b) linhas parciais; (c) planos. Fonte: (a) Barrett (1943); (b) van Vlack (1966); (c) Callister e Rethwisch (2007). .95 FIGURA 30 - Recursos para ilustrar posição relativa de átomos: (a) medidas numéricas; (b) projeções; (c) guias de alinhamento. Fonte: (a) Barrett (1943); (b) West (2014); (c) van Vlack (1966).

FIGURA 31 - Recursos para prover senso de profundidade: (a) sombreamento; (b) linhas pontilhadas. Fonte: van Vlack (1966). .96

FIGURA 32 - Recursos para distinção e classificação de elementos: (a) indicação textual; (b) planos. Fonte: (a) West (2014); (b) Callister e Rethwisch (2007) (adaptado)

FIGURA 33 - Exemplo do uso de perspectiva cônica com sombreamento. Fonte: Kittel (1996). .98

FIGURA 34 - Categorias do domínio cognitivo e ações a elas relacionadas conforme Anderson et al. (2001) em revisão à Taxonomia de Bloom. 102 FIGURA 35 - Diagrama de elementos de cena do WebGL. Fonte: do autor......107 FIGURA 36 - Exemplo do sistema de coordenadas adotado pelo WebGL para construção e representação de modelos tridimensionais. Fonte: Sakurambo, 2007. 
FIGURA 37 - Exemplo de malhas (mesh), usadas na construção e representação de modelos tridimensionais. Neste caso, as malhas representam uma esfera, em diferentes níveis de detalhe. Fonte: do autor. 108 FIGURA 38 - Exemplo do uso de atributos de superfície na construção e representação de modelos tridimensionais. Fonte: Bjerke (2004) (adaptado)....108 FIGURA 39 - Esquema do frustum: (a) para projeção em perspectiva cônica; (b) para projeção em perspectiva axonométrica. Fonte: Three.js (2016) (adaptado).

FIGURA 40 - Exemplos de shaders na construção e representação de modelos tridimensionais. Fonte: do autor.

FIGURA 41 - Modelos de representação: a) representação de borda (B-Rep); (b) geometria sólida construtiva (CSG); (c) subdivisão espacial. Fonte: Xu (2014) (adaptado)

FIGURA 42 - Exemplos de técnicas para lidar com oclusão em modelos tridimensionais: (a) corte; (b) transparência. Fonte: Dassault Systemes Solidworks Corporation ([s.d.]) (adaptado)

FIGURA 43 - Continuum realidade-virtualidade. Fonte: Milgram et al. (1994) (adaptado)

FIGURA 44 - Exemplos de utilização de RV imersiva: (a) treinamento militar; (b) instrumento musical virtual. Fontes: (a) U.S. Navy ([s.d.]); (b) Rodrigues et al. (2015). 122

FIGURA 45 - Exemplo de aplicação de visualização volumétrica: distribuição de temperatura em uma chama de hidrogênio através do mapeamento de cores. Fonte: Bell (2007). 125 FIGURA 46 - Representação tridimensional do corpo humano por tomografia por ressonância magnética. Fonte: Magnetic Resonance Research Facility ([s.d.]) (adaptado) 126

FIGURA 47 - Processo de afunilamento do universo de softwares compreendidos no levantamento. Fonte: do autor.

FIGURA 48 - Resultado da análise dos softwares compreendidos no levantamento, segundo softwares mais bem avaliados em cada critério. Fonte: do autor. 128 
FIGURA 49 - Resultado da análise dos softwares compreendidos no levantamento, segundo critérios negligenciados. Fonte: Bardella (2016a) (adaptado).

FIGURA 50 - Relações entre (roles), cerimônias (cerimonies) e artefatos (artifacts) no Scrum. Fonte: Scrum Alliance (2002) (adaptado). 135 FIGURA 51 - Diagrama exemplificando novas versões e uma operação de ramificação. Fonte: Estublier et al. (2000). 137

FIGURA 52 - Diagrama exemplificando modelo centralizado de controle de versão. Fonte: Ernst (2012) (adaptado).

FIGURA 53 - Diagrama exemplificando modelo distribuído de controle de versão. Fonte: Ernst (2012) (adaptado). 139

FIGURA 54 - Relacionamentos entre aplicação cliente, provedor e registro de serviços na arquitetura SOA. Fonte: do autor.

FIGURA 55 - Distribuição de responsabilidades entre provedor e cliente nos diversos tipos de serviços em nuvem. Fonte: Liu et al. (2001) (adaptado). 146

FIGURA 56 - Ciclo investigação-sprint. Fonte: do autor. 166 FIGURA 57 - Protótipos da aplicação CrystalWalk desenvolvidos em Java representando: (a) estrutura cúbica simples; (b) planos (111). Fonte: do autor..169 FIGURA 58 - Protótipo da aplicação CrystalWalk desenvolvido em WebGL representando pontos de rede e átomos em uma estrutura cúbica simples genérica. Fonte: do autor. 170 FIGURA 59 - Interação entre componentes da plataforma CrystalWalk. Fonte: do autor.

FIGURA 60 - Interação entre o módulo roteador e os outros módulos. Fonte: do autor. 178

FIGURA 61 - Fluxo de eventos determinado pelo padrão CW4P. Fonte: do autor. 178

FIGURA 62 - Componentes da aplicação CWAPP. Fonte: do autor. 179 FIGURA 63 - Implementação da arquitetura MVC na aplicação CWAPP. Fonte: do autor.

FIGURA 64 - Implementação Publish/Subscribe via módulo menu.js. Fonte: do autor.

FIGURA 65 - Funcionamento dos principais módulos do objeto visão. Fonte: do autor. 
FIGURA 66 - Funcionamento dos principais métodos e funções do módulo de estrutura cristalina, referente aos objetos modelo e controlador. Fonte: do autor.

FIGURA 67 - Funcionamento dos principais métodos e funções do módulo de motivo, referente aos objetos modelo e controlador. Fonte: do autor. 187

FIGURA 68 - Componentes do CWLY. Fonte: do autor. 188 FIGURA 69 - Diagrama do fluxo de eventos da aplicação CWLY. Fonte: do autor.

FIGURA 70 - Elementos do modo tutorial no CrystalWalk: (a) menu inicial para escolha dos modos de uso; (b) descrição de um passo; (c) destaque visual em elementos do menu; (d) balão (tooltip) com descrição dos elementos do menu; (e) destaque de uma etapa no elemento Gearbox. Fonte: Bardella (2016d) (adaptado).

FIGURA 71 - Interface principal do CrystalWalk. Fonte: Bardella (2016d) (adaptado).

FIGURA 72 - Interface com menu acionado: abas de síntese (a - rede; b motivo), abas de visualização (c - parâmetros; d - planos e direções); (e ferramenta Gearbox; $f$ - submenu Toggle). Fonte: Bardella (2016d) (adaptado).

FIGURA 73 - Detalhes da aba de parâmetros de rede: (a) escolha do tipo de rede e parâmetros de repetição; (b) parâmetros de visualização da célula; (c) parâmetros da rede escolhida; (d) opção para alterar livremente os parâmetros de rede. Fonte: Bardella (2016d) (adaptado).

FIGURA 74 - Janela para escolha do tipo de rede, dentre as 14 redes de Bravais. Há 15 opções de escolha, pois, no caso da rede hexagonal, o usuário poderá escolher a célula unitária da rede primitiva ou não primitiva. Fonte: Bardella (2016d) (adaptado).

FIGURA 75 - Detalhes da aba de parâmetros do motivo: (a) adição de um novo átomo; (b) parâmetros do motivo; (c) lista de átomos componentes do motivo; (d) exibição dinâmica dos parâmetros de rede; (e) configurações de cor e opacidade do átomo. Fonte: Bardella (2016d) (adaptado).

FIGURA 76 - Modo de visualização do motivo: (a) vista da célula unitária; (b) vista do cristal; (c-e) vistas ortogonais do motivo. Fonte: Bardella (2016d) (adaptado). 
FIGURA 77 - Tabela periódica para escolha de elementos do motivo. Fonte: Bardella (2016d) (adaptado).

FIGURA 78 - Aba de planos e direções: (a) criação de planos; (b) criação de direções; (c) índices de Miller; (d) configurações de nome, cor e opacidade; (e) lista de elementos criados. Fonte: Bardella (2016d) (adaptado). 199 FIGURA 79 - Aba de parâmetros de visualização: (a-d) Modelos de representação; (e) Parâmetros de renderização; (f-k) Técnicas estereoscópicas e interativas experimentais; (I) ajuste de tamanho de menus. Fonte: Bardella (2016d) (adaptado).

FIGURA 80 - Ferramentas de interação do CrystalWalk: (a) AtomView; (b) vista resultante, centrada em um átomo; (c) Gearbox; (d) Projection Cube. Fonte: Bardella (2016d) (adaptado). .203 FIGURA 81 - Modo de interação: (a) com o dispositivo Leap Motion; (b) em dispositivos de toque. Fonte: do autor. .205 FIGURA 82 - Utilização de dispositivos com o CrystalWalk: (a) Leap Motion; (b)

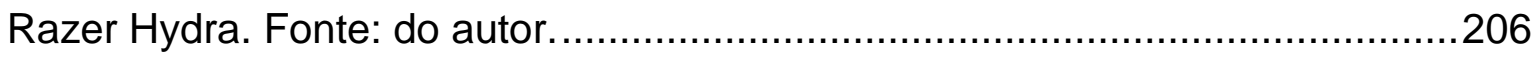
FIGURA 83 - Diagrama-síntese da avaliação comparativa. Fonte: do autor......225 FIGURA 84 - Exemplos de ilustrações do $\mathrm{NaCl}$ em obras de referência clássicas (livros didáticos e correlatos). Fonte: (a) van Vlack (2007); (b) Callister e Rethwisch (1996); (c) Kittel (1966) (adaptado)... .226 FIGURA 85 - Diferentes estilos de representação de células unitárias das redes de Bravais encontrados em obras de referência clássicas (livros didáticos e correlatos). Fonte: (a) van Vlack (1966); (b) Barret (1943); (c) Graef e McHenry (2007); (d) Schwarzenbach (1996).

FIGURA 86 - Sequência de passos para obtenção de dados e criação de uma estrutura em softwares cristalográficos (CMAK15 e VEST14) que exigem inserção manual de parâmetros cristalográficos. Fonte: do autor. .230 FIGURA 87 - Exemplo de ferramentas interativas: (a-c) rotações automáticas; (d) vistas preconfiguradas. Fonte: Bardella (2016d) (adaptado). .233 FIGURA 88 - Exemplo de uso de: (a-c) configurações visuais; (d) navegação em primeira pessoa. Fonte: Bardella (2016d) (adaptado). 233 FIGURA 89 - Recursos para visualização de cristais: (a) vista da célula unitária; (b) vista do cristal (células múltiplas). Fonte: Bardella (2016d) (adaptado). .234 
FIGURA 90 - Recursos para visualização do motivo com dois átomos: (a) vista da célula unitária em perspectiva; (b) vista do motivo isolado na célula unitária; (c-e) vistas ortogonais . Fonte: Bardella (2016d) (adaptado).

FIGURA 91 - Uso do Gearbox na exploração das vizinhanças: (a) pontos de rede; (b) motivo; (c) célula unitária construtiva; (d) célula unitária; (e) célula unitária cortada; (f) cristal. Fonte: Bardella (2016d) (adaptado). .235 FIGURA 92 - Um motivo composto por dois elementos pode ser interpretado como duas redes interpenetradas. (a) rede de $\mathrm{Cl}$; (b) o $\mathrm{CsCl}$; (c) rede de Cs. Fonte: Bardella (2016d) (adaptado). 235 FIGURA 93 - Demonstração dos recursos do CrystalWalk na visualização de vizinhanças para: (a) Cloreto de Césio (CsCl); (b) Magnésio (Mg); (c) Fluorita; (d) Grafite. Fonte: Bardella (2016d) (adaptado) .237 FIGURA 94 - Identificação de contatos atômicos: (a) no motivo isolado; (b) por meio de corte no perímetro da célula unitária; (c) utilizando transparência ou ocultando átomos; (d) por visualização do espaço vazio. Fonte: Bardella (2016d) (adaptado).

FIGURA 95 - Visualização de planos e empilhamentos: (a) confirmação de contatos no plano (110), em uma estrutura CCC; (b) visualização do plano compacto (111), em uma estrutura CFC; (c) visualização dos planos compactos com auxílio de planos paralelos; (d) uso de perspectiva cônica e alteração visual do raio atômico para visualização dos planos compactos em uma estrutura CFC. Fonte: Bardella (2016d) (adaptado). .239

FIGURA 96 - Identificação de contatos, planos compactos e de empilhamento no Magnésio (Mg) e Grafite: (a) contato no motivo; (b) planos de empilhamento do tipo ABAB; (c) plano A; (d) plano B. Fonte: Bardella (2016d) (adaptado). ..........240 FIGURA 97 - Modelos produzidos por estudantes de graduação: (a) uso de destaques visuais planos e arestas; (b) planos e direções cristalográficos; (c) corte nos limites da célula unitária; (d) espaço negativo; (e) exploração livre dos parâmetros de rede. Fonte: Bardella (2016d) (adaptado). .243 FIGURA 98 - Aula experimental utilizando o CrystalWalk: (a) situação de aula; (bc) exemplos de estruturas criadas no CrystalWalk por estudantes. Fonte: (a) do autor; (b-c) Bardella (2016d) (adaptado). .246 
FIGURA 99 - Exemplo de imagens geradas pelo CrystalWalk: contendo link encurtado para o projeto salvo e QR code para acesso rápido. Fonte: do autor.

FIGURA 100 - Comparação entre tipos de modelos poligonais de esferas: (a) icosferas; (b) esferas UV. Fonte: do autor. 250

FIGURA 101 - Processo de produção de um modelo impresso: (a-b) modelo do $\mathrm{NaCl}$ produzido no CrystalWalk; (c) alteração estrutural no modelo; (d-e) modelo pronto. Fonte: (a-b) Bardella (2016d) (adaptado); (c-d) do autor. 251

FIGURA 102 - Exemplo de encaixe por rosca para criação de modelos desmontáveis por tecnologia de impressão 3D. Fonte: do autor. 253 FIGURA 103 - Narrativas didáticas podem ser produzidas pelo CrystalWalk por meio da (a) criação de anotações, (b) anotações essas que podem ser sequenciadas. Fonte: Bardella (2016d) (adaptado). 255 FIGURA 104 - Uso da ferramenta de anotação em um passo de uma narrativa didática. Fonte: Bardella (2016d) (adaptado). .257 FIGURA 105 - llustração do procedimento para salvar uma estrutura: (a) salvar uma estrutura na biblioteca de estruturas, utilizando título, descrição e tags; (b) endereço encurtado e QR code para resgate; (c) busca e resgate na biblioteca por palavra-chave. Fonte: Bardella (2016d) (adaptado) 259 FIGURA 106 - Experimento de progressão imersiva: (a) PC com mouse e teclado; (b) tabletop ou tablet de grandes dimensões; (c) dispositivo Leap Motion e monitor normal; (d) Leap Motion e monitor 3D em modo anaglifo; (e) Leap Motion e monitor 3D em modo polarizado; (f) HMD Oculus Rift e Razer Hydra. Fonte: do autor. ....262 FIGURA 107 - Interfaces para HMDs: (a) renderização adaptada para lidar com distorções de lentes; (b) menus flutuantes temporários; (c) visor sobreposto à visão, ou heads-up display (HUD) virtual; (d) menus associados a objetos da cena. Fonte: Leap Motion, Inc. ([s.d.]). 271 FIGURA 108 - Outras tecnologias interativas: (a) Google Cardboard; (b) mouse 3D. Fonte: do autor. .272 FIGURA 109 - Diagrama-síntese do nível de imersividade dos experimentos de imersão, segundo os modelos propostos por Thon (2008) e McMahan (2011). Fonte: do autor. .273 


\section{LISTA DE ABREVIATURAS E SIGLAS}

AMD: Asynchronous Module Definition

API: interface de programação de aplicações (application programming interface)

ASD: Adaptive Software Development

B-Rep: representação de bordas (boundary representation)

BSON: binary JavaScript object notation

CAD: desenho auxiliado por computador (computer aided design)

CAE: engenharia auxiliada por computador (computer aided engineering)

CAM: manufatura auxiliada por computador (computer aided manufacturing)

CAPES: Coordenação de Aperfeiçoamento de Pessoal de Nível Superior

CCC: estrutura cristalina cúbica de corpo centrado

CCP 14: Collaborative Computational Project Number 14

CCTM-IPEN: Centro de Ciência e Tecnologia de Materiais do Instituto de Pesquisas Energéticas e Nucleares

CFC: estrutura cristalina cúbica de face centrada

CIF: crystallographic information file

CLI: interface linha de comando (command line interface)

CNPq: Conselho Nacional de Desenvolvimento Científico e Tecnológico

CS: estrutura cristalina cúbica simples

CW: CrystalWalk

CW4P: CrystalWalk Design Pattern [componente do CW]

CWAPP: CrystalWalk Client Application [aplicação cliente do CW]

CWLY: Encurtador de URL e API de Persistência de Dados [componente do CW]

DBMS: database management system

DPI: pontos por polegada (dots per inch)

GUI: interface gráfica do usuário (graphical user interface)

GVCM: Grupo de Visualização Cientifica em Materiais

HMD: head-mounted display

HTTP: protocolo de transferência de hipertexto (hypertext transfer protocol)

HUD: heads-up display

laaS: infraestrutura como serviço (infrastructure as a service)

IFUSP: Instituto de Física da Universidade de São Paulo 
IPEN: Instituto de Pesquisas Energéticas e Nucleares

IUCr: International Union of Crystallography

JSON: JavaScript object notation

LAN: rede local (local area network)

LSI-POLI-USP: Laboratório de Sistemas Integráveis da Escola Politécnica da Universidade de São Paulo

MOOCS: cursos on-line massivos e abertos (massive open online courses)

MVC: modelo-visão-controlador (model-view-controller)

PaaS: plataforma como serviço (platform as a service)

PC: computador pessoal (personal computer)

POLI-USP: Escola Politécnica da Universidade de São Paulo

PubSub: sistema publicação-subscrição (publish-subscribe pattern)

REST: transferência de estado representacional (representational state transfer)

SaaS: software como serviço (software as a service)

SGBD: sistema de gerenciamento de banco de dados

SLA: acordo de nível de serviço (service level agreement)

SOA: arquiteturas orientadas a serviços

STEM: ciência, tecnologia, engenharia e matemática (science, tecnology, engineering, and mathematics)

USP: Universidade de São Paulo

UX: user experience

VCS: sistema de controle de versão (version control system)

W3C: World Wide Web Consortium

WIMP: janelas, ícones, menus, apontador (windows, icons, menus, pointer)

WS-I: Web Services Interoperability Organization

$\mathrm{XP}$ : extreme programming 


\section{LISTA DE SÍMBOLOS}

GB: gigabytes

kB: kilobytes

MB: megabytes

mm²: milímetros quadrados

ms: milissegundos

p: linhas de resolução de tela horizontal, em varredura progressiva px: pixels

USD\$: dólares estadunidenses 


\section{INTRODUÇÃO}

\subsection{Tema e problemática}

Este trabalho se originou de experiências do orientador com o ensino de ciência dos materiais e metalurgia física em cursos de graduação e pósgraduação. Por meio dessas experiências, verificou-se que muitos estudantes têm grandes dificuldades para entender conceitos pertinentes ao estudo de estruturas cristalinas e a assuntos correlatos. Observou-se ainda que essas dificuldades e os problemas delas decorrentes tendem a se agravar ao longo do percurso acadêmico, pois tais temas são pontos de partida para a introdução de outros conceitos. As causas dessas dificuldades são muitas, e, haja vista os propósitos específicos deste trabalho, não caberia realizar aqui uma ampla discussão sobre tais causas. Entretanto, dessas causas, é possível ao menos destacar uma, subjacente à maioria das queixas: a dificuldade em visualizar estruturas tridimensionais em representações bidimensionais. Diversos autores discutem o problema nesse contexto específico, no que diz respeito à representação de elementos químicos, de moléculas e de estruturas cristalinas (Krause et al., 2012b; Bodner e Guay, 1997; Herman et al., 2006; Pavlinic et al., 2001).

Os recursos pedagógicos e de apoio didático mais usualmente empregados em sala de aula - a lousa, os livros e as apresentações multimídia - são essencialmente baseados em projeções bidimensionais, sejam elas representações planas ou perspectivas. Apesar de muitas vezes viabilizarem o estudo de sistemas e estruturas cristalinas básicas, tais representações não bastam para a compreensão de estruturas mais complexas, seja por limitações visuais de natureza geométrica, seja por limitações cognitivas (Krause et al., 2012b; Herman et al., 2006).

Para certos indivíduos, imagens estáticas bastam para a compreensão geométrica de estruturas. Para outros, entretanto, são necessários processos mentais de rotação, reflexão e inversão de objetos. O nível de proficiência nessas operações é denominado habilidade espacial, e existem métodos para sua avaliação (Bodner e Guay, 1997). Um marco relativo ao entendimento desse problema cognitivo foi o estudo de Guay (1977), que se dedicou a avaliar a habilidade es- 
pacial e sua influência na aprendizagem. Tal avaliação foi realizada com base em resultados do Teste de Visualização de Rotações de Purdue, empregado por Bodner (1997) em química e em problemas de cristalografia. A avaliação revelou que a falta de habilidade espacial pode tanto prejudicar a compreensão de certos tópicos essenciais à cristalografia como abalar a capacidade de resolver problemas práticos das profissões relacionadas ao tema.

O cristalógrafo suíço Louis Albert Necker, já em 1832, estudava o problema de representação, inspirado em seus trabalhos de cristalografia (Necker, 1832). Em seus estudos, Necker abordou principalmente as ambiguidades geradas por imagens bidimensionais em perspectiva ortográfica (Sorensen, 2002, p. 354). O exemplo clássico resultante de seus trabalhos é o cubo de Necker (FIG. 1), por meio do qual o autor demonstra que, para um cubo em perspectiva desprovido de dicas visuais de profundidade, há duas interpretações possíveis. Em um caso extremo, ao permitir a união de interpretações, gera-se uma representação do impossível (Sorensen, 2002, p. 353).

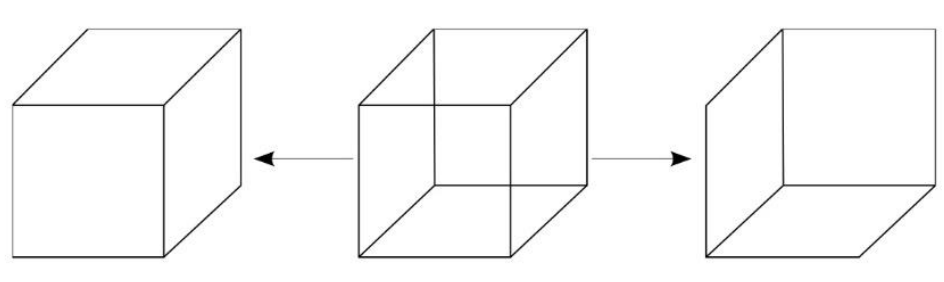

(a)

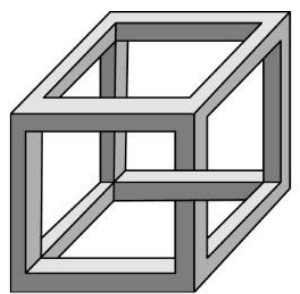

(b)

FIGURA 1 - (a) O Cubo de Necker e suas interpretações e (b) união de interpretações em uma representação impossível. Fonte: (a) do autor; (b) Escher (1958) (adaptado).

As representações impossíveis inspiradas no cubo de Necker foram levadas ao extremo nas obras do artista Maurits Cornelis Escher, cujo propósito era justamente jogar com as ambiguidades visuais (Sorensen, 2002, p. 362). As representações realizadas por Escher com base em Necker eram extremamente técnicas e abstratas, a fim de testar a interpretação visual na ausência das dicas normalmente presentes nos ambientes reais. Na obra Waterfall (FIG. 2), Escher envolve o espectador utilizando elementos de realismo, confundindo-o na tentativa de ler a queda-d'água. Neste caso, é feita uma "representação" do impossível, valendo-se das propriedades da perspectiva isométrica -que se caracteriza por 
partes simultaneamente verticais e horizontais. Apesar de serem situações deliberadamente forçadas, essas iniciativas demonstraram que a representação do tridimensional através de projeções e simplificações não é trivial e que podem ser geradas ambiguidades na interpretação.

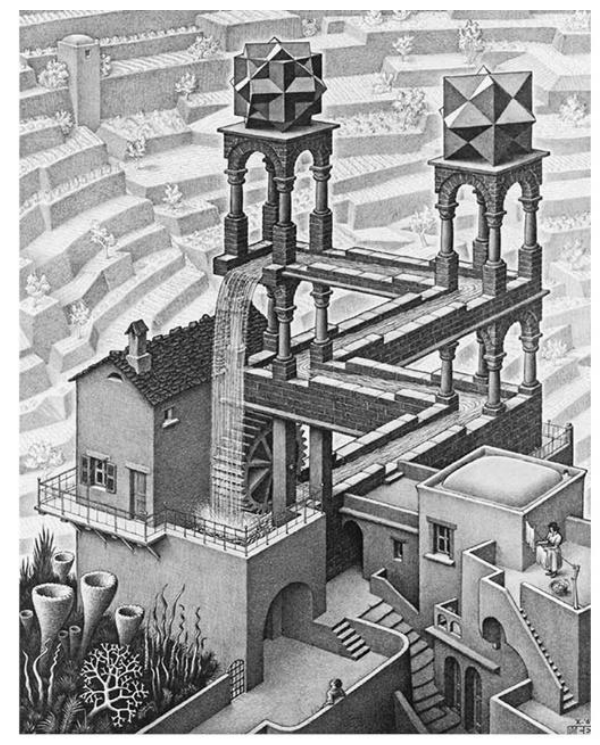

(a)
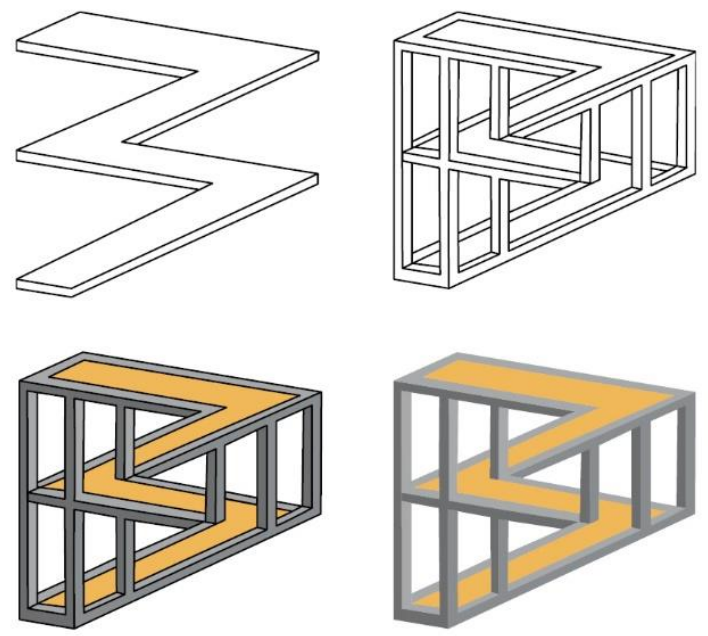

(b)

FIGURA 2 - (a) Obra Waterfall, de M.C. Escher; (b) ambiguidades das perspectivas isométricas exploradas na obra. Fonte: (a) Escher (1961); (b) do autor.

Com os exemplos mostrados a seguir, pretende-se exemplificar como essas questões comprometem a representação de estruturas cristalinas (Krause et al., 2012b, Bodner e Guay, 1997). A FIG. 3, proveniente de Callister e Rethwisch (2007), um dos livros didáticos ${ }^{1}$ mais adotados em disciplinas de ciência e engenharia de materiais, contêm representações de células unitárias de estruturas cristalinas do tipo cúbica simples (CS), cúbica de corpo centrado (CCC) e cúbica de face centrada (CFC). É possível perceber como a complexidade visual aumenta conforme são adicionados átomos à célula unitária, restringindo pro-

\footnotetext{
1 Para efeito de clareza às discussões pertinentes ao presente trabalho, entende-se por livros didáticos aqui aqueles textos introdutórios sobre ciência e engenharia de materiais adotados em cursos de graduação ou pós-graduação, como Callister e Rethwisch (2007), Askeland (1990) e Van Vlack (1966), Shackelford (2008), entre outros. Não se enquadram nessa definição livros de escopo mais específico, como Cullity (2001), dedicado à difração, Barret (1943) e Graef e McHenry (2007), ambos dedicados à cristalografia, entre outros.
} 
gressivamente a visibilidade de elementos e da estrutura como um todo (Krause et al., 2012b; Bodner e Guay, 1997). Aparentemente, nestes exemplos, o autor lida com o problema omitindo da representação sólida (FIG. 3b) os átomos em segundo plano, cuja visibilidade é restrita. No entanto, a ausência de partes visíveis no segundo plano pode confundir até mesmo um observador atento.

Apesar do cubo ser uma forma facilmente representada em perspectiva isométrica, estruturas cristalinas cúbicas, tais como as exemplificadas na FIG. 3, demonstram que a falta de dicas visuais neste tipo de perspectiva leva o observador a perder a referência de localização de um ponto especifico. $O$ terceiro exemplo da FIG. 3a ilustra esse ponto. Nele, é muito difícil detectar a posição precisa de todos os átomos da estrutura, requerendo do observador uma inferência por meio de artifícios visuais (linhas pontilhadas) e pelo alinhamento com outros pontos ou elementos da estrutura. Problemas como os descritos são ainda agravados por representações errôneas ou equivocadas - a exemplo da representação com esferas rígidas em corte da estrutura CCC, na qual nota-se um erro de contato (FIG. 3b).
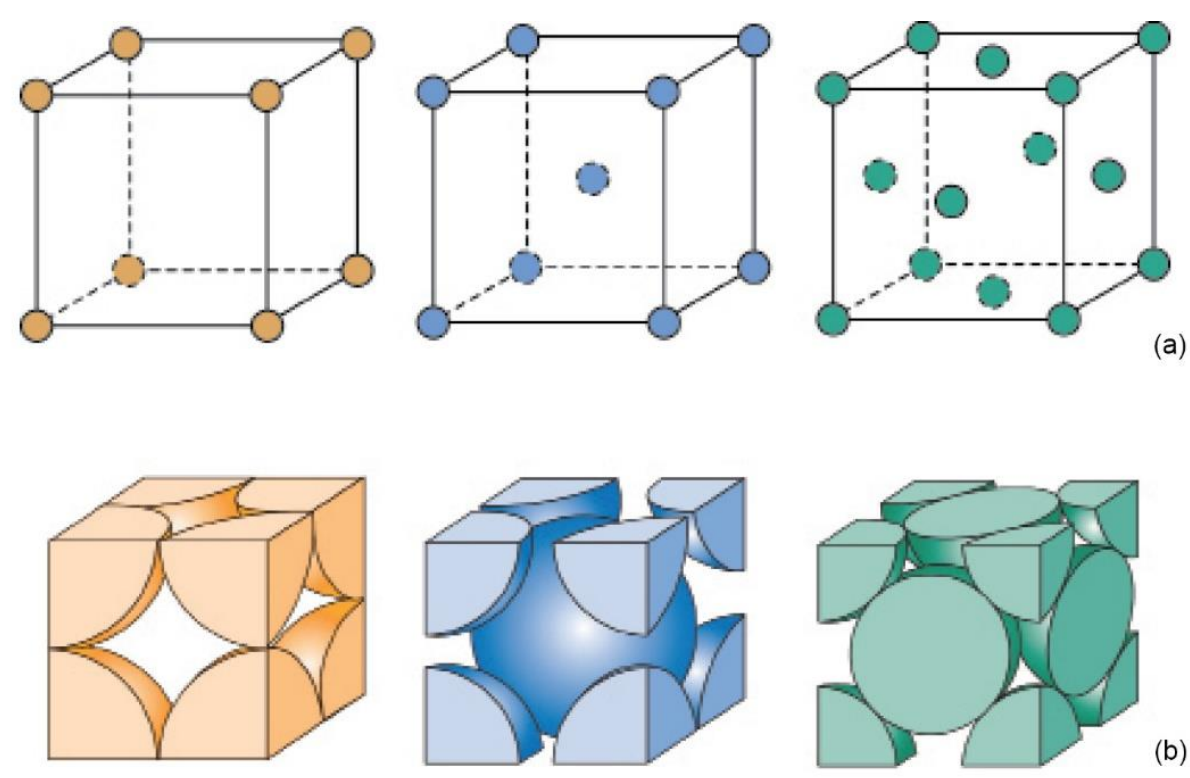

FIGURA 3 - Células unitárias das estruturas cúbica simples (CS), cúbica de corpo centrado (CCC) e cúbica de face centrada (CFC): (a) representação com átomos reduzidos em diâmetro; (b) representação com esferas rígidas em corte. Fonte: Callister e Rethwisch (2007) (adaptado).

Considerando uma estrutura cristalina como a do Manganês-a (FIG. 4), ficam evidentes as dificuldades de representação de geometrias e topologi- 
as complexas devido à dificuldade de visualização do mapeamento espacial. O posicionamento dos átomos carece de elementos visuais adicionais para permitir sua precisa localização dentro do cubo. Ao comparar as duas figuras, pode-se afirmar que a mais antiga (FIG. 4b) possibilita localizar parte dos átomos internos, pois adota artifícios visuais como a divisão em cubos menores e linhas estruturais.

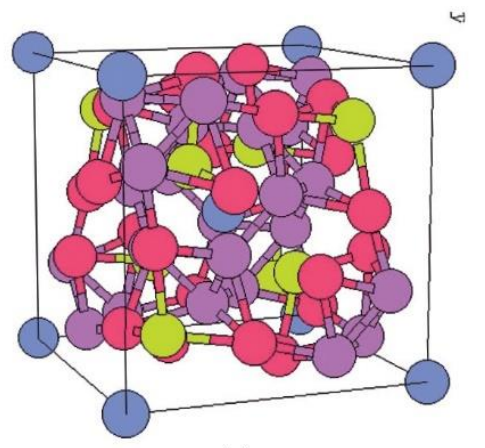

(a)

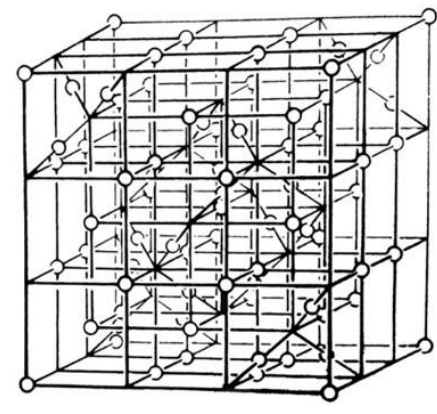

(b)

FIGURA 4 - Representações da estrutura cristalina do Manganês-a: (a) modelo digital; (b) ilustração de 1913. Fonte: (a) U.S. Navy et al ([s.d.]); (b) Ewald (1913) (adaptado).

No ensino de ciência dos materiais, existem ainda outros problemas além da dificuldade de compreensão espacial. Mesmo que a informação esteja amplamente disponível, a estratégia pedagógica tradicional falha em integrar o material mental existente e demonstrar sua utilidade na resolução de problemas reais (Bransford, Brown e Cocking, 1999; Krause, Kelly e Baker, 2012). Essas estratégias também falham em despertar o interesse e a curiosidade (Medeiros e Medeiros, 2002). Conforme discutido pela literatura, o mundo "micro" é percebido de maneira descontextualizada e abstrata (Krause et al., 2012a, 2012b; Bodner e Guay, 1997; Krause et al., 2003), contribuindo para a baixa aceitação da disciplina, especialmente em ciências aplicadas como a engenharia civil, por refletir a realidade profissional de forma bastante limitada (Hansen, 2009).

No caso de ciência dos materiais, alguns autores (Krause et al., 2012a; Torraca, 2009) indicam que o maior desafio é vencer a barreira entre as escalas micro e macroscópica. A correta compreensão das propriedades dos materiais depende do entendimento da dinâmica entre as escalas, ou seja, da apreensão da relação entre os parâmetros microestruturais e o comportamento 
macroestrutural (Krause et al., 2012a). Desta maneira, torna-se necessário investir na criação de uma ponte entre as escalas, seja conceitual, seja perceptiva. Essa integração de escalas é um problema a ser resolvido até mesmo nos aplicativos de simulação (Interagency Group on Advanced Materials, 2011). Trata-se, portanto, de um tema de grande interesse tanto para o ensino como para o desenvolvimento de ferramentas digitais para a ciência dos materiais.

Autores como Dale (1954), Chan e Black (2006) e Krause et al. (2012a) indicam caminhos para solucionar o problema da lacuna entre as escalas. Segundo esses estudos, o entendimento das características dos materiais poderia ser melhorado no contato mais "direto" com os fenômenos físicoquímicos pertinentes. No âmbito da ciência dos materiais e do ensino, a adoção desta estratégia depende de recursos modernos e filosofias didáticas inovadoras (Krause et al., 2012a). De acordo com a linha de argumentação exposta até aqui, muitos autores (Resta, 2002; Maizan, 2000; Maturana \& Varela, 2001) indicam que as soluções mais promissoras seriam aquelas que adotam o uso de representações tridimensionais aliado à interatividade e à participação ativa, pautadas por estratégias pedagógicas eficientes.

Maturana e Varela (2001) deixam claro que modelos de ensino baseados na exposição passiva de conteúdos são falhos, pois a construção de conhecimentos se dá por meio da interação ativa com o mundo e com seus fenômenos. Estudos recentes demonstraram que a reflexão sobre o próprio processo de aprendizado e a participação no delineamento desse processo (por meio de procedimentos como autoanálise e autoavaliação) potencializam o aprendizado (Krause et al., 2012a; Bransford et al., 1999) e que o estímulo é essencial (Krause et al., 2012a; Byrne, 1996). Nesse sentido, métodos que enfatizam o aspecto interativo ou lúdico do aprendizado tendem a estimular o interesse. Isso pode ser realizado por meio do projeto das interfaces, dos métodos de manipulação, do estilo de representação visual e em outros fatores envolvidos no processo de ensino-aprendizagem.

A literatura indica que a persistência de interpretações e conhecimentos errôneos entre os estudantes ao longo de seu processo de formação pode ter graves consequências quando esses estudantes passam ao exercício profissional. Autores como Bodner (1997) constataram tais consequências para estudantes de cursos de química, física e correlatos, como biologia. No caso das 
engenharias, segundo Soboyejo (2003, p. 32), o entendimento incorreto dos constituintes microestruturais e de sua relação com o comportamento geral dos materiais pode levar a erros de projeto, especialmente em situações excepcionais, onde fórmulas e padrões comumente utilizados não respondem adequadamente aos fatores inéditos. Já Watt (2008) afirma que o desempenho de produtos de engenharia depende do equacionamento de diversas questões, exigindo bom domínio de disciplinas como física, química e, especialmente, ciência dos materiais (Watt, 2008, p. 34). Ainda que o estudante e futuro profissional das áreas de ciências e engenharia possua bom conhecimento teórico, uma baixa habilidade espacial pode abalar o desempenho na resolução de problemas nessas áreas (Bodner, 1997). No entanto, tal capacidade pode ser melhorada por meio da prática (Sorby, 2009; Battista et al., 1982).

Modelos físicos e virtuais são tradicionalmente utilizados como alternativa para abordar as limitações de visualização previamente discutidas, possibilitando rotacionar, refletir e inverter vistas em perspectiva para resolver ambiguidades visuais e localizar com maior precisão objetos internos a uma estrutura de referência (Bodner e Guay, 1997).

Modelos físicos permitem a manipulação tátil e exploração tanto de aspectos sinestésicos e lúdicos como do senso de profundidade natural. O emprego de kits contendo estruturas autoencaixáveis para a construção de maquetes tridimensionais de estruturas cristalinas é ainda hoje expressivo no ensino de ciência dos materiais, em decorrência da dificuldade intrínseca em alcançar um mapeamento visual eficaz com representações bidimensionais (FIG. 5). Trabalhos revelaram que $o$ uso de modelos físicos potencializa o aproveitamento de outras mídias, especialmente no caso de estruturas cristalinas de alta complexidade geométrica (Herman et al., 2006; Pavlinic et al., 2001). 


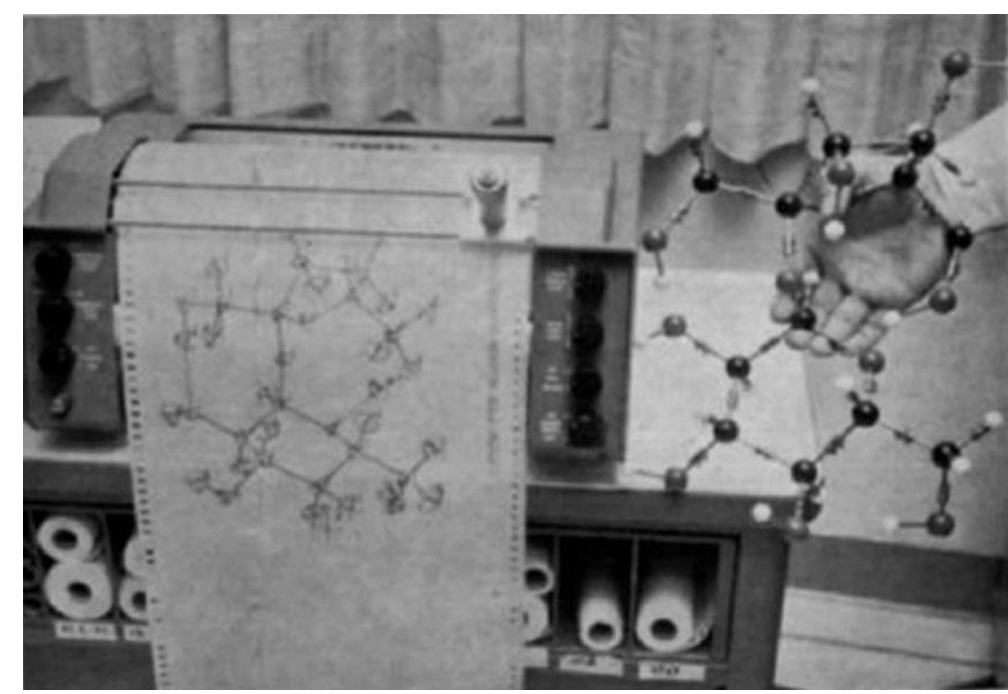

FIGURA 5 - Comparação de modelo físico com imagem gerada pelo primeiro software cristalográfico, o ORTEP, em 1965. Fonte: Felknor (1965).

Entretanto, o uso de maquetes, na prática, limita-se a estruturas mais simples, pois as mais complexas são de confecção mais difícil e morosa. Essa limitação tende a ser revertida com a recente popularização das tecnologias de impressão 3D, cuja produção de modelos ainda é custosa e demorada (Herman et al., 2006). As maquetes tradicionais também carecem de flexibilidade. Não é comumente possível, por exemplo, simplesmente retirar um ou mais átomos da montagem, a fim de facilitar a visualização de alguma região específica em seu interior, e ainda retorná-los às posições originais, sem comprometer a integridade do todo. É também frequente a necessidade de se visualizarem determinados planos ou direções da estrutura, tarefa tão ou mais difícil que a anterior. Modelos desmontáveis podem ser impressos em 3D, a fim de se poder revelar seus aspectos internos (Herman et al., 2006). Porém, o projeto de tais modelos não é trivial, além de existirem limites sobre quantos aspectos podem ser enfatizados, demandando a criação de modelos redundantes. A FIG. 6a ilustra a maquete da Calcita, na qual se pode verificar as complexidades aqui mencionadas.

As maquetes físicas também não permitem a miniaturização do observador, salvo algumas exceções, excêntricas, mas de relevância didática para a disciplina de ciência dos materiais (Pinto, 2012). O Atomium (FIG. 6b), de Bruxelas, na Bélgica, é uma grande escultura de uma célula cúbica de corpo centrado que permite observar os detalhes e as disposições dos átomos a partir de ângulos diversos (Pinto, 2012). Outro caso é um modelo de estrutura cristalina do $\mathrm{NaCl}$ de 3 metros 
de lado, contendo 42.875 átomos, construído em Viena, na Áustria (FIG. 6c-d), considerado o maior modelo físico (em quantidade de átomos) de estrutura cristalina existente (Krickl, 2014). No entanto, os ângulos de visualização são finitos e restritos à configuração arquitetônica e à disposição física do complexo. Além disso, a escala do modelo é estática, e o observador não pode apreciá-lo segundo quaisquer pontos de vista - isso sem falar da velocidade de interação.

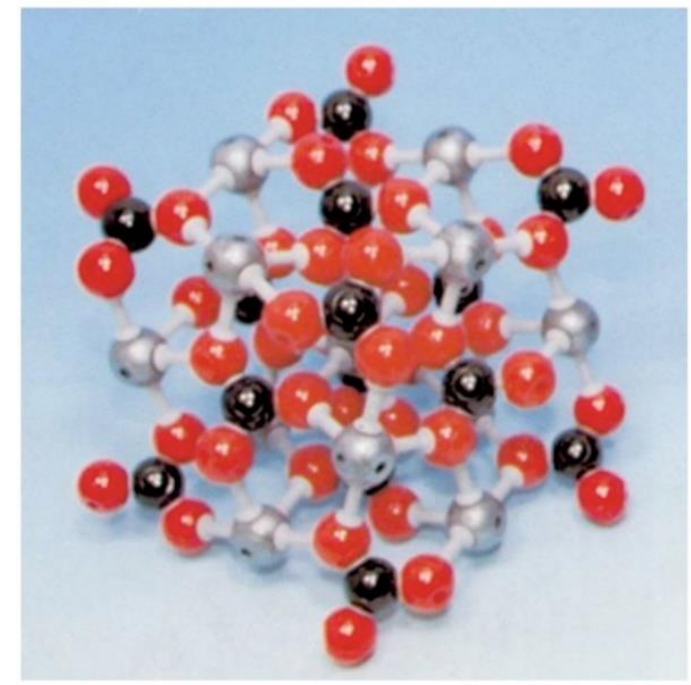

(a)

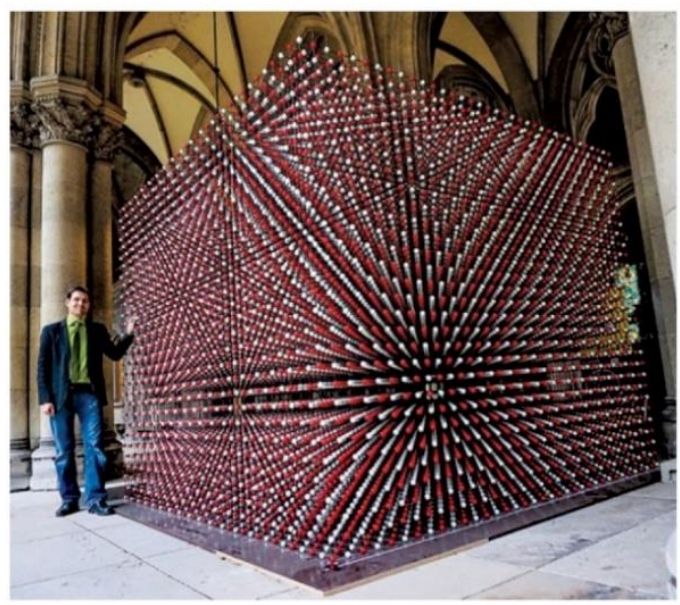

(c)

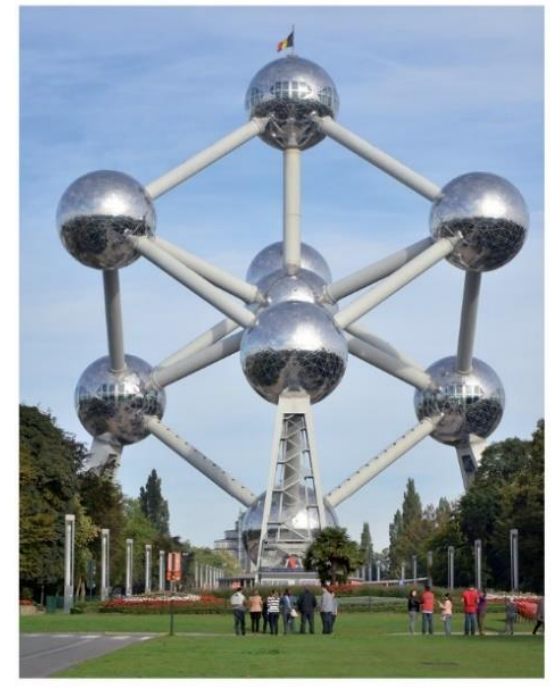

(b)

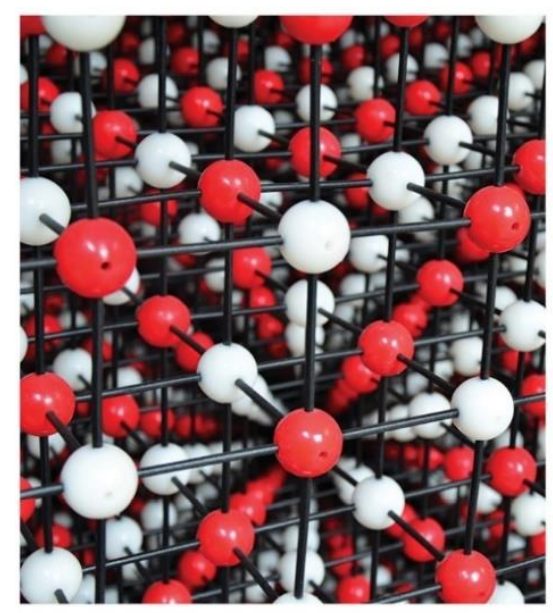

(d)

FIGURA 6 - Exemplos de maquetes físicas: (a) representação da estrutura cristalina da calcita utilizando maquete de estruturas plásticas autoencaixáveis; (b) vista do Atomium; (c-d) modelo de estrutura cristalina do $\mathrm{NaCl}$ de 3 metros de lado. Fonte: (a) Calcilte ([s.d.]); (b) do autor; (c-d) Krickl (2014) (adaptado).

De um modo sucinto, as limitações e os custos associados aos modelos físicos podem ser superados com o uso de tecnologias de visualização mo- 
dernas. A grande vantagem é a exploração e navegação em diferentes escalas, ângulos, perspectivas e velocidades, sem o ônus da construção física do modelo, a exemplo dos modelos mostrados na FIG. 6 . Além disso, modelos virtuais podem ser "desmontados" sem preocupação com a integridade física, conforme ilustrado na FIG. 7. Finalmente, conforme ilustrado na FIG. 8, o uso de tecnologias estereoscópicas e interativas modernas também permite explorar características tipicamente associadas aos modelos físicos, tais como o senso de profundidade natural e, em certa medida, o tátil.
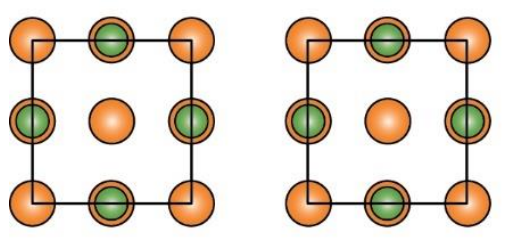

(a)

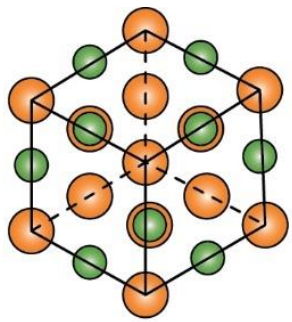

(b)

FIGURA 7 - Modelo do $\mathrm{NaCl}$ gerado pelo software cristalográfico VEST14 ilustrando diversos pontos de vista e capacidade de desconstruir átomos do modelo: (a) vistas ortogonais em x e y; (b) perspectiva axonométrica (à esquerda) e modelo desconstruído (à direita). Fonte: VEST14 (adaptado).
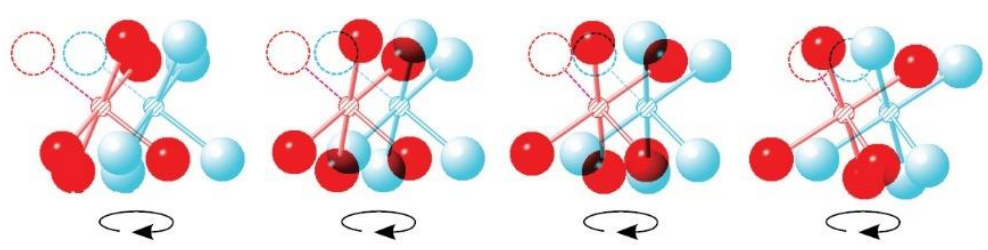

FIGURA 8 - Modelo do CsCl gerado pelo software cristalográfico CMAK15, ilustrando o mecanismo de rotação, estereoscopia anaglífica (vermelho e azul) e artifícios de visualização (em pontilhado). Fonte: CMAK15 (adaptado).

No entanto, a construção de modelos virtuais representa um desafio. A confecção manual é impraticável, pois, além de uma grande quantidade de esforço ser requerida para cada modelo, são exigidos também conhecimentos tanto da disciplina de ciência dos materiais e de estruturas cristalinas como de aplicações de modelagem 3D especializadas. Resta (2002) afirma que a combinação destas habilidades é rara entre os instrutores e professores. Como alternativa, softwares cristalográficos e estruturas cristalográficas prontas podem ser utilizados para a confecção destes modelos. 
Os softwares cristalográficos são capazes de produzir modelos digitais de estruturas cristalinas. Uma definição mais precisa, adotada neste trabalho, é a de sistemas computacionais de síntese e visualização de estruturas cristalinas 3D. A determinação de estruturas cristalinas requer processamento e refinamento de grandes quantidades de dados de difração de raios $X$, tarefa bastante complexa e que, até o advento desses softwares, era realizada manualmente (Ewald, 1962; Barrett, 1943). O desenvolvimento dos softwares cristalográficos, iniciado na década de 1950, veio para automatizar essas tarefas. Atualmente, muitos dos softwares cristalográficos disponíveis no mercado são capazes de produzir visualizações 3D com certo grau de interatividade.

Entretanto, apesar desses softwares terem automatizado tarefas, é evidente a sua abordagem pouco didática, refletida em interfaces complexas e funcionalidades altamente específicas, requerendo de seus usuários uma prévia e ampla fundamentação teórica, mesmo para utilização básica. Aos olhos de um estudante de graduação, ou mesmo de pós-graduação, de engenharia, física ou química, conhecimentos de cristalografia, como grupos espaciais e posições de Wyckoff, estão distantes de sua realidade de estudo, dificultando a utilização de tais softwares.

O caráter especializado e pouco didático dos softwares cristalográficos também é observado nos aspectos relativos à interação com o usuário. A necessidade de se digitar comandos em um terminal de texto, além de interfaces de usuário complexas ou pouco funcionais, limita seu uso principalmente por estudantes. A FIG. 9a ilustra uma interface de usuário do tipo texto de um software cristalográfico (PLAT13), desenvolvida no final da década de 1970, mantida e utilizada até hoje. Neste software cristalográfico, representações tridimensionais são geradas e parametrizadas a partir de comandos digitados pelo usuário, como mostra a FIG. 9b, o mesmo ocorrendo em outro software (VEST14), exemplificado na FIG. 10. Já na FIG. 11, são representados os 37 passos necessários para gerar a visualização gráfica de uma estrutura cristalina simples no software ATOM11.

O estado da arte dos softwares cristalográficos atuais será apresentado na seção 3.4, na qual serão discutidas também outras características relevantes à problemática apresentada. 


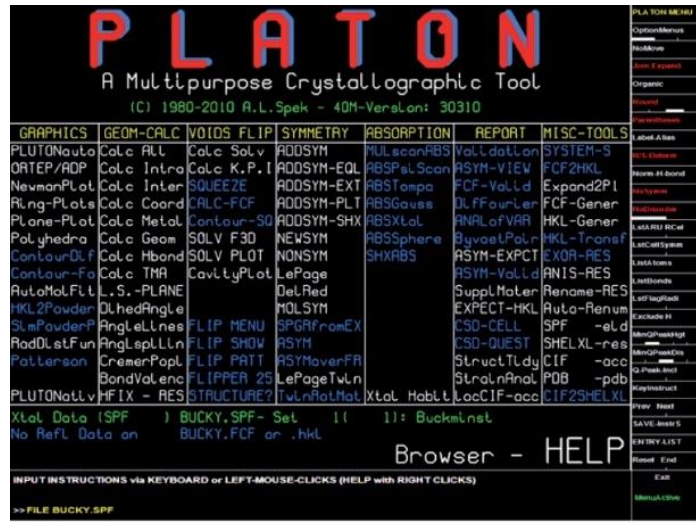

(a)

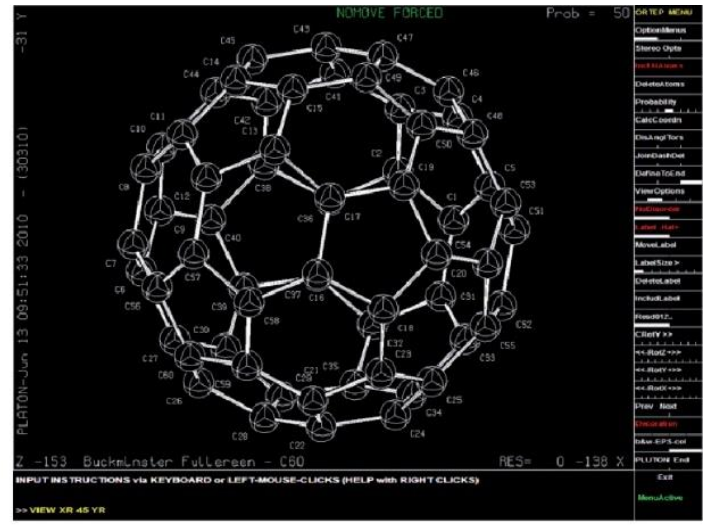

(b)

FIGURA 9 - Imagens do software cristalográfico PLAT13: (a) interface de usuário do tipo texto; (b) representações tridimensionais geradas a partir de comandos digitados pelo usuário. Fonte: PLAT13.

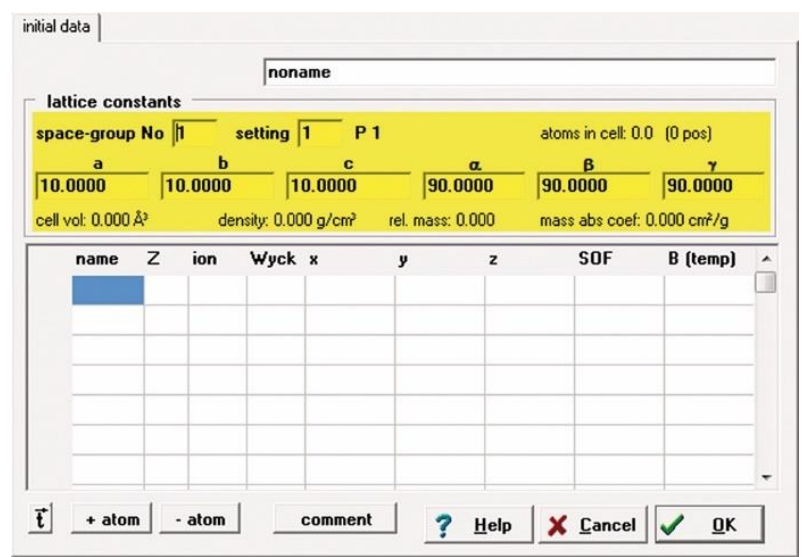

FIGURA 10 - Definição dos parâmetros de rede e grupos de simetria durante a criação e exibição de uma estrutura cristalina no VEST14. Fonte: VEST14 (adaptado).

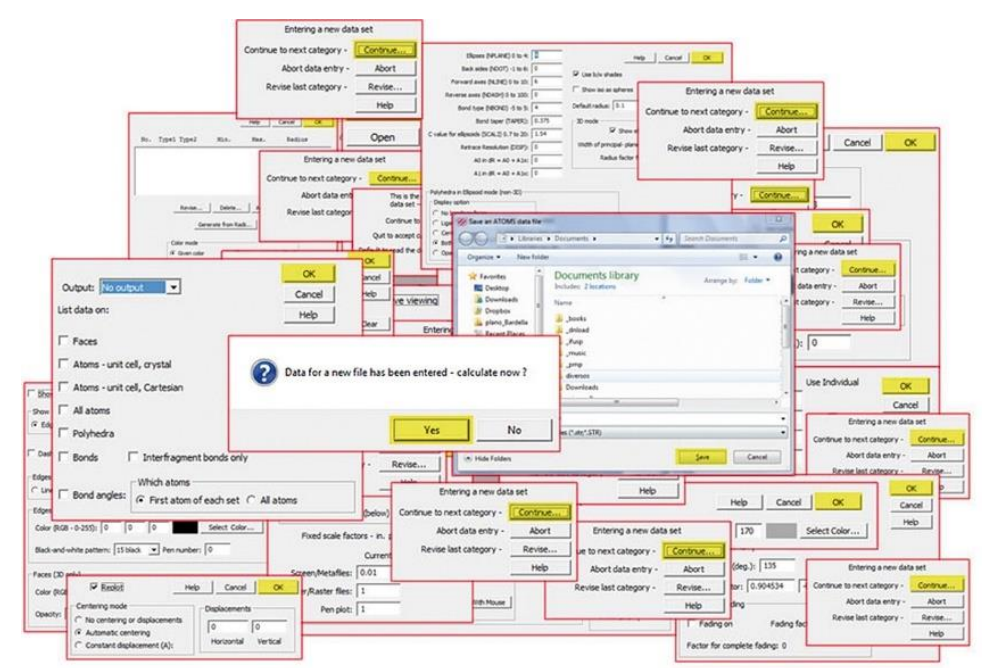

FIGURA 11 - 37 passos necessários para a criação e exibição de uma estrutura cristalina no ATOM11. Fonte: ATOM11 (adaptado). 
Em suma, a literatura demonstra as limitações das representações bidimensionais tradicionais para o entendimento de tópicos essenciais de ciência dos materiais, como ligações atômicas, estrutura eletrônica, arranjos atômicos e estrutura cristalina, defeitos, difusão e deformação, processamento e microestrutura, relações entre as propriedades mecânicas e a estrutura e processamento (Krause et al., 2003). Modelos físicos são tradicionalmente utilizados para tentar contornar essas limitações, entretanto, sua natureza material impõe restrições de interação e incorre em custos de produção. Modelos virtuais não possuem tais restrições, mas sua utilização é dificultada porque professores e instrutores, em sua maioria, não possuem treinamento em softwares de modelagem $2 \mathrm{D}$ ou 3D (Unesco, 2002). Softwares cristalográficos geram representações visuais tridimensionais úteis, porém, os métodos e procedimentos de síntese por eles adotados são pouco didáticos, exigindo conhecimentos avançados tanto para lidar com os parâmetros como para criar visualizações. Além disso, possuem interfaces pouco amigáveis ao público não especializado e são desenvolvidas por pesquisadores com finalidades específicas. Finalmente, cabe ressaltar que um empecilho para melhorar a experiência do usuário leigo é o fato de muitos dos softwares mais atuais estarem sob licenças comerciais e seu código-fonte não ser universalmente disponibilizado, o que dificulta tentativas de integrar as ferramentas existentes.

Torna-se assim necessária a criação de ferramentas apropriadas às aplicações didáticas, que sejam práticas, integradas, acessíveis e de baixo custo, para aumentar a autonomia de professores, instrutores, estudantes e até de pesquisadores. Tal esforço se enquadra no cenário de modernização do ensino almejado pela Unesco (Unesco, 1998). Essa organização frisa que a informatização é condição necessária para a modernização da educação, o que permitirá a transição de um modelo reprodutivo de aprendizado a um modelo independente, que promova o protagonismo e a criatividade (Unesco, 2002). Para isso, recomenda o acompanhamento ativo do desenvolvimento técnico e a exploração do potencial das novas tecnologias, o que pode ser atingido com investimentos públicos e privados nas atividades de pesquisa e desenvolvimento de aplicativos, no aprimoramento de recursos humanos e na compra de equipamentos modernos.

A FIG. 12 sintetiza a construção da problemática da pesquisa. 


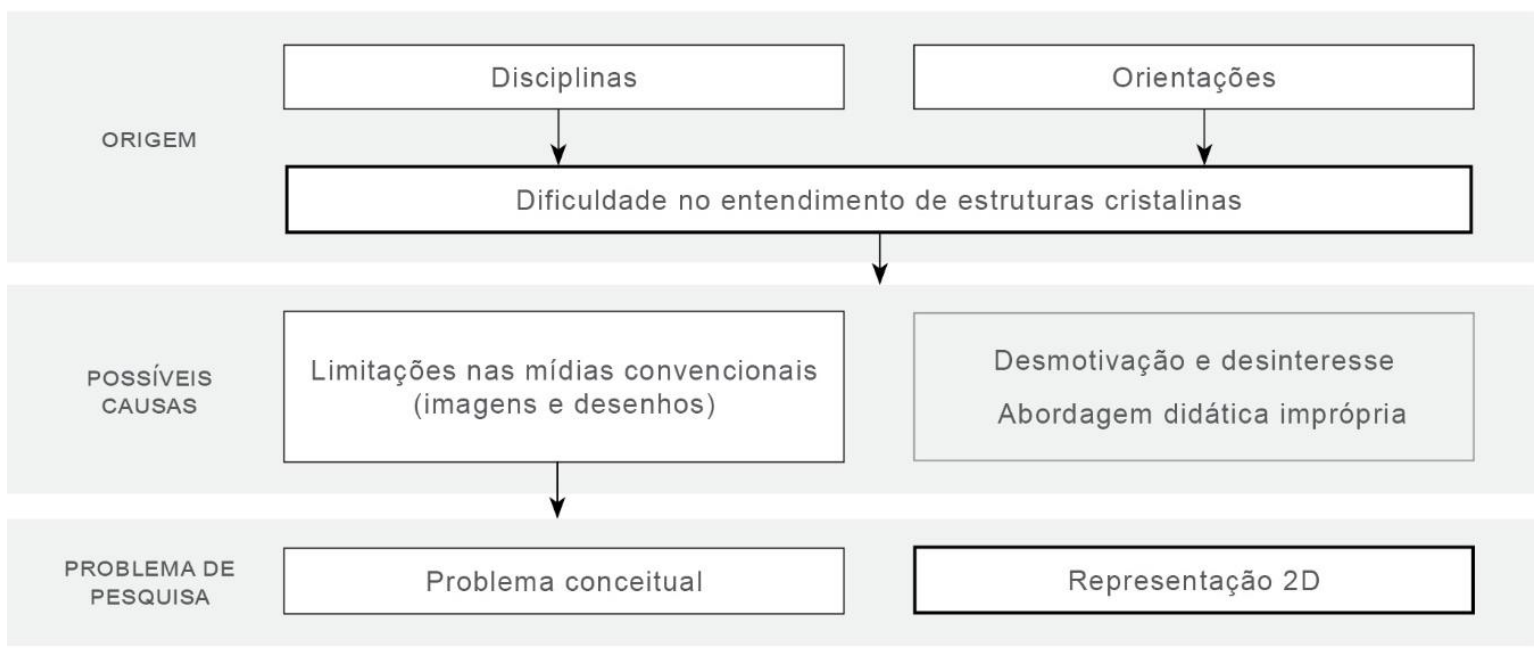

FIGURA 12 - Diagrama-síntese da construção da problemática da pesquisa. Fonte: do autor.

\subsection{Objetivos}

Partindo do cenário descrito na seção 1.1, entende-se que o passo seguinte seria especificar e desenvolver métodos de síntese e visualização de estruturas cristalinas mais adequados ao problema.

Desta maneira, o principal objetivo do presente trabalho foi desenvolver um software cristalográfico visando diminuir a dificuldade de síntese e visualização de estruturas cristalinas, incorporar funcionalidades didáticas e contribuir para a democratização do conhecimento, favorecendo o processo de ensinoaprendizagem e o entendimento deste tópico tão fundamental à ciência dos materiais. Portanto, a proposta consistiu no desenvolvimento de um software cristalográfico denominado CrystalWalk (CW), disponível em <http://cw.gl>, e detalhado neste trabalho.

Para atingir este objetivo, foram consideradas quatro metas principais:

- Explicitar as principais dificuldades de entendimento de estruturas cristalinas e identificar estratégias pedagógicas que as abordem de maneira mais eficiente.

- Mapear o estado da arte dos softwares cristalográficos, identificando as funcionalidades de síntese, visualização e manipulação de estruturas cristalinas já existentes, além de características positivas em contexto didático. Destaque será dado às lacunas existentes, que contribuirão para o ineditismo e valor do trabalho. 
- Identificar no campo da computação gráfica características e aspectos desejáveis a uma plataforma destinada à síntese, visualização e manipulação de estruturas cristalinas 3D.

- Propor, especificar e desenvolver um software cristalográfico orientado às demandas específicas dos professores, pesquisadores e estudantes envolvidos no trabalho e do seu time de desenvolvimento (denominados "atores sociais"), que possibilite o aperfeiçoamento dos modelos e representações adotados em softwares cristalográficos existentes, bem como dos respectivos métodos computacionais necessários para sua implantação.

\subsection{Hipóteses}

Para atingir os objetivos propostos, foram formuladas as seguintes hipóteses de pesquisa, baseadas nos pressupostos teóricos apresentados até este momento e no capítulo 2:

- Considerando o contexto didático, um método de síntese de estruturas cristalinas baseado no conceito "rede + motivo $=$ estrutura cristalina" facilita a criação de estruturas cristalinas, quando comparado ao método baseado em grupos espaciais.

- A aplicação de métodos e técnicas modernas de computação gráfica em conformidade com achados de pesquisas das ciências cognitivas reduz a dificuldade de visualização de estruturas cristalográficas.

Deve ser frisado que a validação dessas hipóteses é limitada aos grupos representados pelos atores sociais envolvidos e será conduzida de acordo com os pressupostos científicos decorrentes da abordagem multilateral adotada neste trabalho (seção 2.2).

\subsection{Justificativas}

Este trabalho se justifica pela relevância dos problemas científicos e sociais supracitados (seção 1.1) e pelo ineditismo de suas propostas de soluções, contribuindo para o acesso e a difusão do conhecimento técnico-científico nos diferentes campos da ciência dos materiais. 


\subsubsection{Aspectos inéditos}

Dentre as inúmeras contribuições deste trabalho, as seguintes destacam-se por seu ineditismo técnico e científico:

- Realização de uma rigorosa pesquisa do estado da arte dos softwares cristalográficos (seção 3.4) permitiu explicitar diversas lacunas e possibilidades de desenvolvimento, seja quanto aos métodos didáticos de síntese e visualização de estruturas cristalinas, seja quanto à democratização do conhecimento e da tecnologia. As referências foram avaliadas de acordo com diversos critérios, sendo selecionados aqueles que melhor abordavam as questões levantadas pela problemática deste trabalho. Nenhum software existente ou trabalho cientifico experimental foi capaz de satisfazer a todos os critérios listados, revelando um fértil campo de pesquisa-ação a ser explorado pelo projeto CrystalWalk.

- Especificação e desenvolvimento de um software cristalográfico com as seguintes características e funcionalidades exclusivas e inéditas:

- Método ágil e simplificado de criação e manipulação de estruturas cristalinas por meio da associação entre um motivo e pontos da rede cristalina, eliminando a necessidade do conhecimento de grupos espaciais e posições de Wyckoff, geralmente mais bem compreendidos por especialistas em cristalografia.

- Métodos de visualização, navegação e interação informados por princípios didáticos e cognitivos, abordando as principais dificuldades identificadas na literatura e no contexto do grupo de pesquisa no qual se desenvolveu o projeto, buscando incrementos substanciais no entendimento de estruturas cristalográficas.

- Arquitetura de software multiplataforma de alta portabilidade, que viabilize a convergência do aplicativo em diferentes plataformas (Windows, Linux, MacOS) e dispositivos (computadores de mesa, notebooks, telefones, tablets).

- Ambiente de desenvolvimento colaborativo e aberto, baseado nos princípios do software livre, oferecendo acesso irrestrito ao código-fonte e a liberdade para estudá-lo, modificá-lo e desenvolvê-lo. 
- Integração inovadora (em caráter experimental) de recursos avançados de visualização, como estereoscopia e dispositivos multissensoriais.

\subsubsection{Contribuições científicas e sociais}

Com o desenvolvimento e a disponibilização do CrystalWalk, pretendese trazer várias contribuições à comunidade científica e à sociedade em geral, dentre as quais destacam-se:

- Incrementar o diálogo entre a visualização científica, a realidade virtual e os fundamentos da ciência dos materiais e da engenharia de materiais para propor e aplicar mecanismos de visualização com fins didáticos, contribuindo para o ensino e o estudo das características e propriedades de materiais e promovendo avanços na computação gráfica.

- Incrementar as possibilidades disponíveis aos estudantes de engenharia para simular problemas e condições propostos em livros ou em aulas, atuando como ferramenta de suporte para visualização, estudo e investigação de conceitos fundamentais de estruturas cristalinas e ciência dos materiais.

- Possibilitar aos professores produzir modelos virtuais interativos de apoio que permitam expor de forma intuitiva conceitos de tópicos mais complexos abordados em sala de aula, além de estimular a participação e o questionamento por parte dos estudantes.

- Oferecer um sistema integrado e de livre acesso para produzir ilustrações para apresentações, publicações digitais ou impressas e trabalhos científicos.

- Incrementar os meios disponíveis a pesquisadores de diferentes áreas para síntese e visualização de estruturas cristalinas.

- Oferecer aos usuários mais avançados o acesso ao código-fonte da aplicação e a liberdade de estudá-lo e modificá-lo, o que contribuirá para o próprio desenvolvimento e manutenção do projeto CrystalWalk.

- Incentivar a educação à distância e o estudo livre e independente, viabilizando a realização de atividades educacionais em locais e horários alternativos ou à distância. 
- Promover novos métodos e paradigmas de aprendizagem baseados na cooperação e interação por meio do fornecimento de um ambiente virtual que estimule a participação ativa dos estudantes.

- Colaborar para o desenvolvimento de uma educação livre e mais acessível, principalmente para estudantes de baixa renda, muitas vezes privados do acesso a recursos de visualização devido aos elevados custos de materiais didáticos e softwares atualmente disponíveis no mercado.

\subsubsection{Adequação ao programa}

O Programa de Pós-Graduação em Tecnologia Nuclear do Instituto de Pesquisas Energéticas e Nucleares (IPEN) tem por finalidade formar, em nível de mestrado e doutorado, pesquisadores no campo da tecnologia nuclear e em áreas a ela correlatas. É um ambiente no qual diplomados em cursos de graduação de diversas áreas realizam seu aprimoramento científico - o que denota a natureza interdisciplinar do programa, refletida também neste trabalho.

Entende-se que as competências prioritárias para condução desta tese de doutoramento estão ligadas ao estudo dos materiais, especialmente em escalas microscópicas, aprendizado desenvolvido no Centro de Ciência e Tecnologia de Materiais (CCTM) do IPEN. A instituição tem sólida reputação na área de ciência dos materiais, decorrente da qualidade técnica de seus laboratórios e da excelência de seus professores, pesquisadores e funcionários.

Compreende-se que este trabalho se insere no referido programa como uma iniciativa interdisciplinar na linha de Ciência e Tecnologia de Materiais, envolvendo os fundamentos da ciência e engenharia de materiais, da computação gráfica e da análise e desenvolvimento de sistemas. $O$ tema de pesquisa surgiu de problemas e desafios identificados em disciplinas conduzidas na instituição, resultando na criação do Grupo de Visualização Cientifica em Materiais (GVCM). O projeto CrystalWalk representa uma das frentes de desenvolvimento do grupo, buscando criar ferramentas didáticas para melhor compreensão das características e propriedades de materiais. Suas contribuições serão benéficas ao ensino e pesquisa de ciência dos materiais de forma geral, principalmente nas áreas mais dependentes desta disciplina, tais como a tecnologia nuclear. 


\subsection{Abrangência e limitações}

\subsubsection{Escopo}

Este trabalho pretende atuar em um dos aspectos fundamentais do problema discutido nas seções anteriores, sendo apenas um dos passos necessários à obtenção de melhorias no ensino de tópicos complexos de ciência dos materiais. Questões pedagógicas e materiais de apoio diversos, a respeito dos quais já existem pesquisas avançadas, ficaram em segundo plano - pesquisas estas, contudo, que foram adotadas como referência para a construção deste trabalho. Por outro lado, ficou clara a limitação dos recursos existentes na frente didática, tanto na geração como na representação visual de estruturas cristalinas. Espera-se, portanto, que este trabalho gere avanços especificamente nesta frente.

\subsubsection{Aspectos pedagógicos e cognitivos: discussão e testes}

Por um lado, não é possível analisar, muito menos testar com toda profundidade as questões cognitivas envolvidas na visualização e no entendimento de objetos e situações complexas, como é o caso das estruturas cristalinas. Por outro lado, baseando-se em boas práticas da pesquisa aplicada, é perfeitamente possível fundamentar o desenvolvimento da ferramenta em princípios sólidos, preocupação esta refletida principalmente na interface e nos métodos de visualização. Tal procedimento busca aumentar a possibilidade de sucesso do projeto, sem incorrer em grandes custos para o seu desenvolvimento. Além do referenciamento teórico, optou-se por uma avaliação integrada ao processo de desenvolvimento ágil adotado, recorrendo a ciclos de avaliação com os atores sociais. Esse processo será detalhado no capítulo 2.

\subsubsection{Limitações do processo de revisão da literatura}

A análise de softwares de referência eliminou aqueles cujo propósito era muito específico e se restringiu aos que possuem interface de visualização dos modelos produzidos. Apesar de todo o processo ter sido documentado, visando sua verificação e expansão por pesquisadores interessados, admite-se que alguns aplicativos dotados de características interessantes para este trabalho possam ter escapado ao processo de busca. No entanto, devido à grande quantidade de referências avaliadas, considera-se que as mais relevantes foram verifi- 
cadas e que é baixa a probabilidade de que características diferenciadas tenham sido ignoradas no levantamento. Deve-se considerar também a possibilidade de haver bons trabalhos ainda em andamento, não publicados ou publicados em meios de difícil rastreamento ou acesso. Todavia, considera-se que, para este tipo de referência ser relevante, é necessário um relativo grau de sucesso no mercado, na comunidade tecnológica e/ou na comunidade cientifica.

\subsection{Estrutura do trabalho}

Esta tese encontra-se organizada em cinco capítulos:

No capítulo 1, apresenta-se o trabalho como um todo, a definição do problema, seus pressupostos e seus objetivos. Destaca-se ainda a justificativa do tema proposto, sua contribuição teórica, a adequação ao programa de pósgraduação, escopo e limitações.

No capítulo 2, apresenta-se a metodologia geral do trabalho, descrevem-se os processos de levantamento bibliográfico e de levantamento sistemático de softwares cristalográficos, os métodos de desenvolvimento de software utilizados e o protocolo de testes.

No capítulo 3, apresenta-se uma revisão sobre tópicos fundamentais para o desenvolvimento do trabalho, como ensino de ciência dos materiais, técnicas de realidade virtual e visualização científica, estado da arte dos softwares cristalográficos, metodologias de desenvolvimento de software e sistemas computacionais.

No capítulo 4, descreve-se a execução e os resultados do trabalho, apresentando a condução do desenvolvimento, os protótipos e a especificação, as características e as funcionalidades da última versão do software. A segunda parte do capítulo é dedicada à avaliação multilateral de desempenho da implementação do CrystalWalk em relação aos objetivos e às metas do trabalho.

No capítulo 5, apresentam-se as conclusões, sugestões e recomendações do trabalho.

Ao final, são ainda apresentados os apêndices, o glossário e as referências bibliográficas. 


\section{METODOLOGIA}

Neste capítulo, serão apresentados os procedimentos metodológicos, os processos envolvidos na pesquisa, a revisão da literatura, bem como a escolha dos instrumentos e técnicas empregados. Serão, por fim, justificados a estratégia e o plano de pesquisa desenvolvidos no trabalho. Foram adotadas referências consagradas na área de metodologia científica, conforme detalhado a seguir. Julgou-se importante também descrever o processo de seleção e aplicação da metodologia de desenvolvimento de software empregada, tendo em vista a abordagem não convencional e o número de adaptações necessárias para este fim específico. Na FIG. 17 (seção 2.4.4) são sintetizados a estratégia e o método de pesquisa empregados neste trabalho.

\subsection{Definição da estratégia}

Segundo Bicudo (1993), a interrogação, o cuidado, o rigor e a sistematicidade são aspectos essenciais da pesquisa que devem ser assumidos independentemente da área a ser desenvolvida. Ainda nessa mesma perspectiva, para Silva (1998), é importante que o pesquisador, para não exercer uma prática de pesquisa alienada, situe o campo em que se insere seu trabalho, de onde se originaram seus pressupostos teóricos e metodológicos, como se coletaram os dados e quais referenciais precederam a análise, para, assim, justificar os resultados obtidos.

"É necessário que o pesquisador, muito mais do que saber
defender sua posição metodológica em oposição a outras,
saiba que existem diferentes lógicas de ação em pesquisa e
que o importante é manter-se coerentemente dentro de cada
uma delas. [...] Além disso, é necessário que o pesquisador
saiba explicitar em seu relato de pesquisa a sua opção me-
todológica e todo procedimento desenvolvido na construção
de sua investigação e os quadros de referência que o infor-
mam." (SILVA, 1998, p. 159).

Autores como Kitchenham e Charters (2007) e Easterbrook (2007) discutem a adequação de métodos tradicionais de pesquisa a trabalhos de desenvolvimento de sistemas, um ramo multidisciplinar que demanda a investigação tanto 
das ferramentas como dos processos sociais e cognitivos envolvidos. Por esse motivo, muitos métodos de pesquisa são baseados em disciplinas que estudam o comportamento humano em nível individual e organizacional. No entanto, todos os métodos possuem falhas conhecidas, de modo que as estratégias mais adequadas são aquelas que combinam métodos complementares (Creswell, 2002).

\subsection{Postura filosófica}

Independente dos métodos, não é possível conduzir uma pesquisa sólida nem avaliar seus resultados sem uma definição relativamente clara do que se considera como conhecimento válido (Easterbrook, 2007). Essa validade é determinada pela postura filosófica adotada, sendo as principais, segundo Creswell (2002): positivismo, construtivismo, teoria crítica e pragmatismo. Cabe destacar que, na prática de pesquisa e desenvolvimento em engenharia de software, a postura filosófica raramente é mencionada. A seguir, é apresentada uma breve descrição dessas quatro principais posturas filosóficas, em conformidade com Easterbrook (2007):

- O positivismo é a postura científica clássica das ciências naturais, que sustenta que todo conhecimento deve ser baseado em inferência lógica de um conjunto de fatos observáveis. Positivistas são adeptos do experimento controlado e de métodos que se baseiam em teorias precisas das quais hipóteses podem ser extraídas e testadas em isolamento para sua validação.

- O construtivismo aceita que o conhecimento não pode ser separado de seu contexto humano. Ao invés de provar teorias, concentra-se em entender como as diferentes pessoas compreendem seu mundo e como atribuem significado às ações. Os métodos preferidos são baseados em coleta de dados qualitativos sobre atividades humanas. Nessa postura, entende-se que validação é uma noção muito positivista e assume-se que a realidade é múltipla e construída. Assim, os resultados verificados em um contexto não podem ser inteiramente replicados em outros contextos (Sandelowski, 1993).

- A teoria crítica tem foco em aumentar o poder de um determinado grupo social por meio da aquisição de conhecimento, preferindo abordagens participatórias. Replicação de resultados também não faz sentido nesta postura, pois cada problema depende de um con- 
texto especifico. O método da pesquisa-ação é, segundo Easterbrook (2007), o que mais reflete a filosofia da teoria crítica.

- O pragmatismo é menos dogmático e assume que todo conhecimento é aproximado e incompleto. O conhecimento é julgado pelo seu grau de utilidade para resolver problemas práticos, sendo a "verdade" aquilo que funcionar em um determinado período, relativa ao observador e determinada por consenso entre os participantes. Os métodos de pesquisa preferidos são os mistos, pois tendem a iluminar o problema de diversos pontos de vista, o que ajuda a descobrir um universo maior de soluções possíveis.

Devido à natureza tanto prática como social deste trabalho, como já discutido, justifica-se uma postura multilateral. A adoção de elementos do pragmatismo justifica-se pelo caráter aplicado dos produtos da pesquisa, que devem ser avaliados com relação ao seu grau de atendimento às especificações técnicas desejadas. A teoria crítica se mostra relevante devido aos objetivos sociais deste trabalho, definidos em conformidade com os princípios da pesquisa-ação e cuja validação se dá pela mensuração do conhecimento ou do "poder" adquiridos pelo grupo social alvo e pelo grau de atendimento às deficiências detectadas (Easterbrook, 2007). A postura positivista está presente em métodos auxiliares utilizados neste trabalho, como o levantamento sistemático (seção 2.4.1.3), para os quais são essenciais a rastreabilidade e reprodutibilidade dos resultados. Contudo, mesmo dentro da postura multilateral aqui adotada, o construtivismo tem papel central. Isso se deve aos fins didáticos pretendidos, que determinam, em última instância, como os resultados deste trabalho devem ser validados. Creswell (2002) propõe as seguintes estratégias para validar pesquisas de orientação construtivista: usar múltiplas fontes de dados para corroborar os resultados; verificar se a interpretação dos achados da pesquisa por parte dos atores sociais envolvidos no problema de pesquisa confere com a visão dos pesquisadores; realizar descrições detalhadas para explicitar os parâmetros e os achados da pesquisa; ser honesto com os possíveis vieses e adotar autorreflexão; reportar não apenas os resultados que confirmam as hipóteses do estudo, mas também aqueles que possam problematizá-las ou até mesmo negá-las; promover contato suficiente com os atores sociais envolvidos para garantir um entendimento razoável das questões sendo estudadas; recorrer a auditores internos e externos para revisar 
os procedimentos e achados. Muitas dessas estratégias de validação foram adotadas neste trabalho, e a sua implementação é apresentada na seção 2.4.3.

\subsection{Aspectos epistemológicos, teóricos e metodológicos}

Empregam-se neste trabalho as proposições de Bicudo (1993), Silva (1998), Bardin (2009) e Gil (2008) para a classificação da pesquisa científica no que diz respeito ao seu delineamento (natureza, abordagem, objetivos e procedimentos técnicos) e às técnicas e instrumentos de coleta de dados. A classificação proposta por tais autores é resumida na FIG. 13. Na sequência (seções 2.3.1 a 2.3.5), o presente trabalho será situado em cada um desses níveis de classificação.

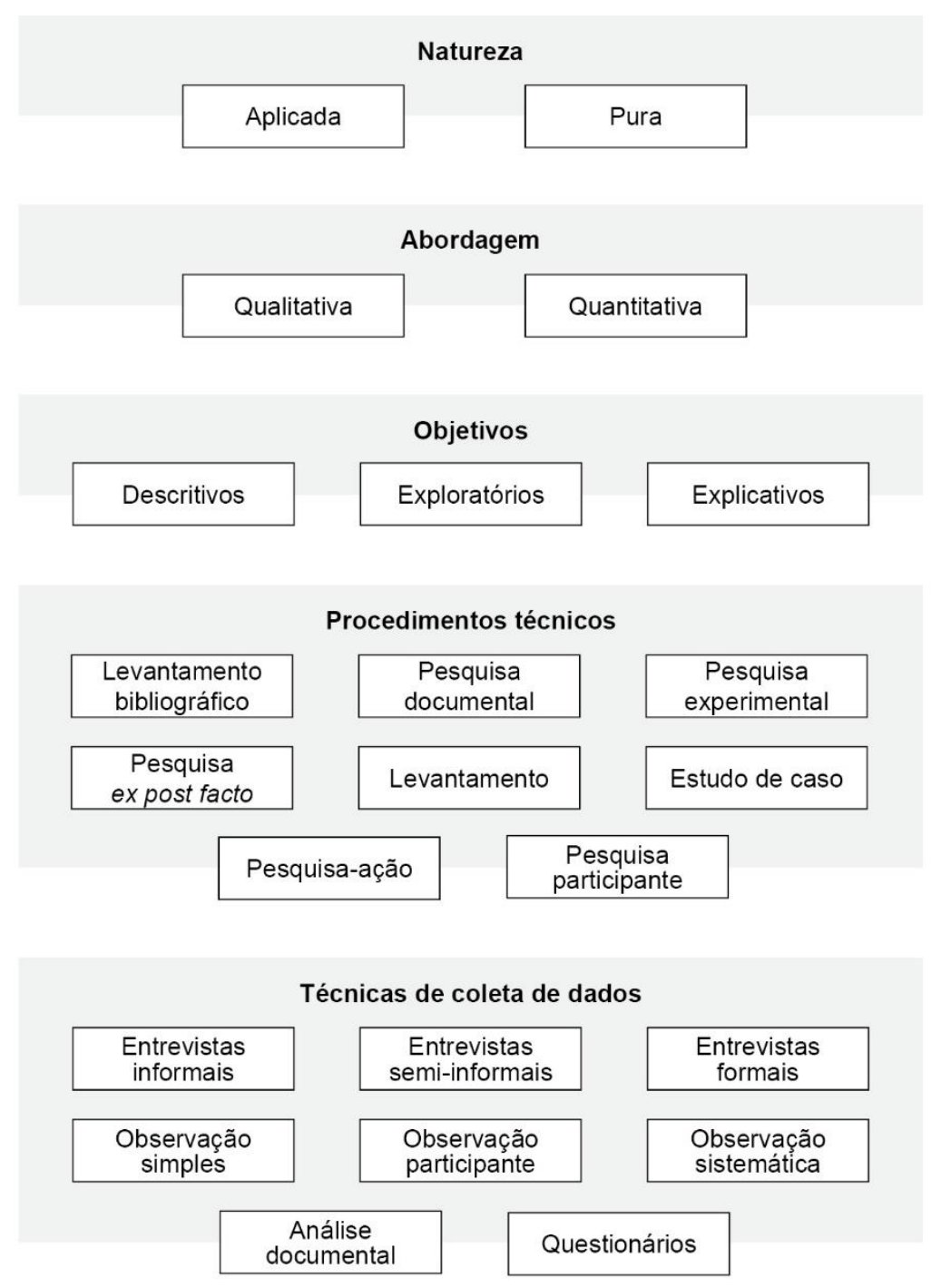

FIGURA 13 - Síntese dos níveis de classificação da pesquisa científica e seus respectivos parâmetros conforme Gil (2008), Marconi e Lakatos (2003), Bardin (2009), Silva (1998) e Creswell (2002). Fonte: do autor. 


\subsubsection{Quanto à natureza}

Segundo Gil (2008), Silva e Menezes (2000) e Marconi e Lakatos (2003, p. 19), classifica-se uma pesquisa, quanto à sua natureza, como aplicada. ou básica (pura). O presente trabalho caracteriza-se como uma pesquisa aplica$d a$, pois visa produzir conhecimento para solucionar problemas concretos, práticos e operacionais - ou "contribuir para fins práticos, visando à solução mais ou menos imediata do problema encontrado na realidade" (Barros e Lehfeld, 2000, p. 78). Para detalhamentos sobre os problemas concretos, práticos e operacionais envolvidos nos objetivos desta pesquisa, ver seção 1.2.

Cabe ainda apontar que outra categoria aplicável a esta pesquisa, em conformidade com alguns dos autores já mencionados, é a de pesquisa empírica. Em trabalhos dessa natureza, o pesquisador precisa ir a campo, conversar com pessoas e presenciar relações sociais. $\mathrm{O}$ trabalho, portanto, envolve verdades $\mathrm{e}$ interesses locais (Yin, 2003, p. 1).

\subsubsection{Quanto à forma de abordagem do problema}

Segundo Creswell (2002, p. 11) e Gil (2008, p. 175), classifica-se uma pesquisa quanto à sua forma de abordagem do problema como qualitativa ou quantitativa. Para Minayo (2001, p. 21), a pesquisa qualitativa se preocupa com um nível de realidade que não pode ser quantificado, operando em uma dimensão mais profunda, de relações, processos e fenômenos que não podem ser reduzidos à operacionalização de variáveis. Segundo estas definições, a abordagem do presente trabalho é qualitativa, pois nele se pretende abordar a qualidade do aprendizado de um tema especifico de ciência dos materiais em um complexo contexto social. Desta forma, a melhoria da qualidade do aprendizado deve ser mensurada com base em uma avaliação das mudanças no conhecimento adquirido. Pressupõe-se que a qualidade do ensino vai melhorar com a adoção de métodos inovadores em um software cristalográfico.

\subsubsection{Quanto aos objetivos}

Segundo Gil (2008, p. 27), Marconi e Lakatos (2003, p. 19) e Vergara (2000, p. 44), as pesquisas podem ser classificadas, no que diz respeito aos seus objetivos, em três diferentes grupos: pesquisas exploratórias, pesquisas descritivas e pesquisas explicativas. Os objetivos desta pesquisa permitem caracterizá-la 
como exploratória e descritiva, devido à abordagem multilateral adotada. Os elementos exploratórios podem ser localizados na etapa de embasamento do trabaIho, pois nela se buscam experiências, exemplos e referências para criar familiaridade entre o pesquisador e os temas inerentes ao problema de pesquisa, com vistas a aprimorar ideias, desenvolver intuições e, posteriormente, construir hipóteses mais estruturadas (Gil, 2008, p. 27). Já os elementos descritivos podem ser localizados na etapa propositiva do trabalho, na qual se busca solucionar um problema complexo, o que depende de estabelecer relações entre variáveis, ou, em outras palavras, envolve uma avaliação da influência das características das propostas na solução dos problemas colocados.

\subsubsection{Quanto aos procedimentos técnicos}

À medida que a formulação do problema, a construção de hipóteses e a identificação das relações entre variáveis vão se consolidando em um sistema conceitual da pesquisa, o trabalho de investigação assume o caráter de um sistema coordenado e coerente de conceitos e proposições. Torna-se, pois, necessário, para confrontar a visão teórica do problema com os dados da realidade, definir o delineamento da pesquisa.

Segundo Gil (2008, p. 49) e Marconi e Lakatos (2003, p. 62), o delineamento dos procedimentos técnicos adotados em pesquisa refere-se ao planejamento em sua dimensão mais ampla, envolvendo tanto a sua diagramação como a previsão de análise e interpretação dos dados. Entre outros aspectos, considera o ambiente em que são coletados os dados, bem como as formas de controle das variáveis envolvidas. Segundo os autores, tais procedimentos podem ser classificados em 8 grupos: levantamento bibliográfico, pesquisa documental, pesquisa experimental, pesquisa ex-post facto, levantamento, estudo de caso, pesquisa-ação, pesquisa participante. Reconhecendo que todos os procedimentos técnicos possuem limitações e que as fraquezas de uns podem ser compensadas pelas forças de outros (seção 2.4), a abordagem geral de pesquisa escolhida foi mista. Foram escolhidos três procedimentos técnicos, que serão aqui tratados como frentes de pesquisa: o levantamento bibliográfico, o levantamento e a pesquisa-ação.

A primeira frente, de levantamento bibliográfico, buscou na literatura fundamentação teórica para os temas pertinentes ao trabalho. Na segunda, de levantamento, foi delineado o estado da arte dos softwares cristalográficos, 
estabelecendo uma base para a proposição de funcionalidades inéditas. Na terceira, de pesquisa-ação, ocorreu a especificação e o desenvolvimento do software em si, utilizando como base os conhecimentos das outras frentes e também a experiência dos atores sociais envolvidos. Tais frentes e as relações entre elas estão sintetizadas na FIG. 14.

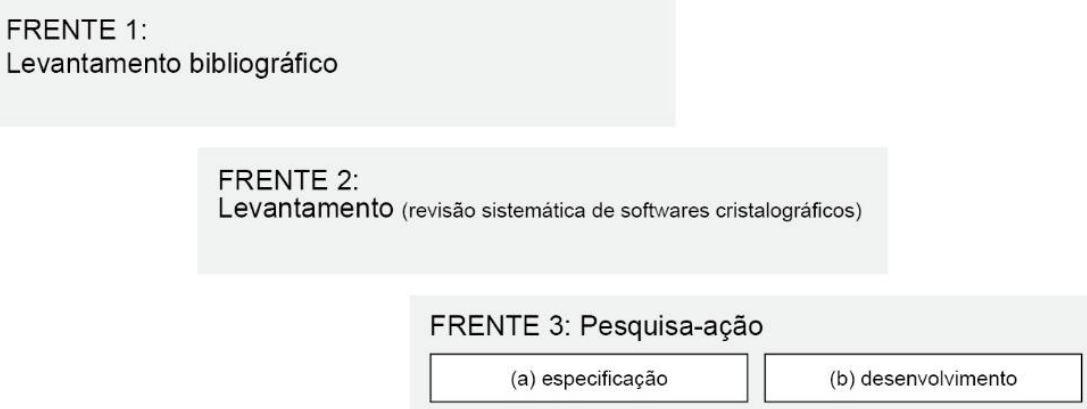

FIGURA 14 - Diagrama-síntese das frentes desta pesquisa. Fonte: do autor.

\subsubsection{Quanto às técnicas de coleta de dados}

Segundo Gil (2008, p. 31) e Marconi e Lakatos (2003, p. 32), a etapa de coleta de dados é fundamental a qualquer pesquisa científica, apesar de muitas vezes não ser registrada de maneira explícita. Ainda segundo estes autores, apesar de existirem inúmeras técnicas de coleta de dados disponíveis, a escolha e a adequação dessas técnicas dependem da problemática, das hipóteses e dos objetivos específicos da pesquisa (Gil, 2008, p. 31). Destacam também a importância do rigor no controle da aplicação dos instrumentos de pesquisa como fator fundamental para evitar erros e defeitos ao longo do processo (Marconi e Lakatos, 2003, p. 32). De acordo com a bibliografia consultada, essas técnicas de coleta poderiam ser agrupadas em:

- Entrevistas (informais, semi-informais, formais): segundo Marconi e Lakatos (2003, p. 94), nas entrevistas informais, o entrevistador tem liberdade para desenvolver cada entrevista na direção que considerar mais adequada. As entrevistas semiestruturadas são guiadas por um roteiro com perguntas básicas, mas o entrevistador tem liberdade para extrapolar esse roteiro conforme o contexto. As entrevistas estruturadas são guiadas por um roteiro com perguntas mais específicas, e devem seguir esse roteiro estritamente. 
- Observação (simples, participante, sistemática): na observação simples, o pesquisador observa a situação ou grupo social que constitui o objeto de sua pesquisa, mas sem se integrar a essa situação ou grupo. Já a observação participante consiste na integração do pesquisador ao seu objeto, ou seja, o pesquisador se incorpora ao grupo e participa das atividades com a finalidade de obter informações (Marconi e Lakatos, 2003, p. 85). Já a observação sistemática tem como objetivo analisar com precisão o objeto de pesquisa, por meio de observação controlada e obedecendo a critérios ou procedimentos predeterminados.

- Análise documental: análise de fontes documentais, que, segundo Marconi e Lakatos (2003), são bastante diversificadas e dispersas, incluindo livros, revistas, documentos legais, softwares, sites e arquivos em mídia eletrônica.

- Questionários: instrumentos constituídos por uma série ordenada de perguntas, podendo ser elaborados com questões abertas, fechadas ou de múltipla escolha (Marconi e Lakatos, 2003, p. 98). Segundo Gil (2008, p. 51) é um meio rápido e barato de obtenção de informação.

Segundo Gil (2008), a principal técnica de coleta de dados a ser utilizada nos procedimentos de levantamento e de levantamento bibliográfico é a análise documental, por ser alinhada à natureza documental de tais procedimentos. Ainda segundo Gil (2008, p. 175) e também segundo Thiollent (2011, p. 60-63), as principais técnicas de coleta de dados utilizadas no procedimento da pesquisaação são: entrevistas (informais, semi-informais, formais), observação (simples, participante, sistemática) e questionários, por se alinharem com aspectos típicos da pesquisa-ação, como a pesquisa de campo e a interatividade.

Fundamentando-se nesse referencial teórico, selecionaram-se as seguintes técnicas de coleta de dados para a realização deste trabalho: análise documental (para a frente de levantamento bibliográfico e para a frente de levantamento), questionários (para a frente de levantamento e para a frente de pesquisa-ação) e entrevistas informais e observação participante (para a frente de pesquisa-ação).

No contexto específico da frente de levantamento bibliográfico, como sugerido por Marconi e Lakatos (2003, p. 71), a técnica de análise documental mos- 
trou-se a mais adequada. Essa técnica forneceu o apoio e a fundamentação teórica necessários à fase de embasamento do trabalho, assim como otimizou o tempo a ser gasto no entendimento de temas e questões concernentes ao problema de pesquisa, muitos deles já explorados pela bibliografia especializada.

No contexto específico da frente de levantamento, a técnica de coleta de dados por questionários mostrou-se a mais adequada. Essa técnica permitiu estruturar o processo de análise de campo do levantamento sistemático, provendo uma plataforma comum de investigação de todos os softwares cristalográficos pesquisados.

No contexto específico da frente de pesquisa-ação, as técnicas de coleta de dados por entrevistas informais, observação participante e questionários mostraram-se as mais adequadas. Essas técnicas evitaram a submissão dos atores sociais envolvidos a procedimentos formais invasivos e demorados, que tenderiam a intervir negativamente na dinâmica social e, em muitos casos, inviabilizar a contribuição de participantes cruciais ao projeto, devido à escassez de tempo.

\subsubsection{Síntese dos aspectos epistemológicos, teóricos e metodológicos}

Na FIG. 15, é apresentada uma síntese da classificação deste trabalho segundo os níveis e parâmetros de classificação explicitados ao longo da seção 2.3. 


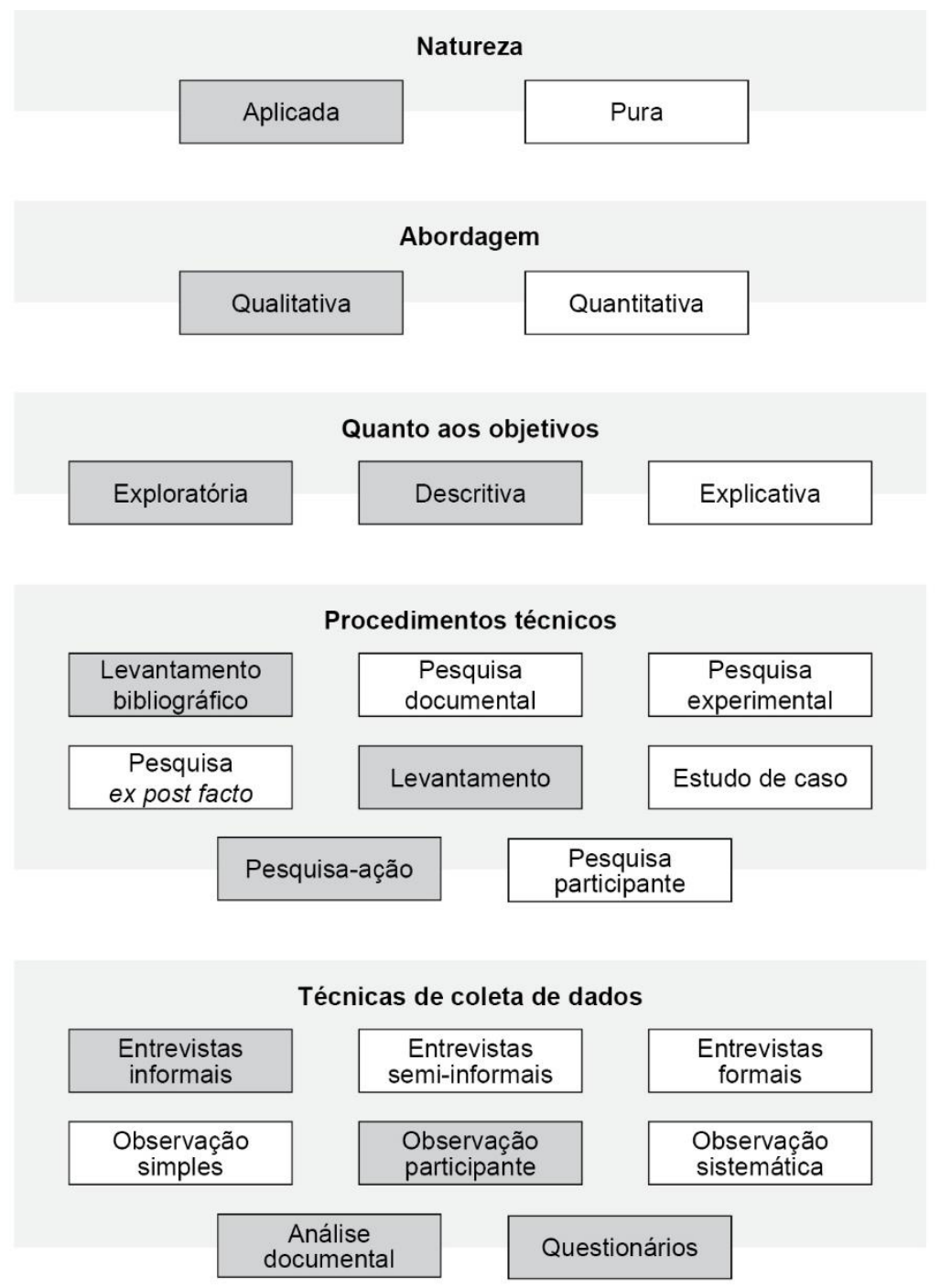

FIGURA 15 - Classificação deste trabalho segundo os níveis e parâmetros de classificação da pesquisa científica conforme Gil (2008), Marconi e Lakatos (2003), Bardin (2009), Silva (1998) e Creswell (2002). Fonte: do autor.

\subsection{Detalhamento de métodos e procedimentos}

Nesta seção, será explicitado como os procedimentos de pesquisa adotados neste trabalho, previamente descritos e classificados (seção 2.3), foram integrados e executados, com base na estratégia e no plano de trabalho da pesquisa.

\subsubsection{Procedimentos técnicos}

Ao longo das seções anteriores, pôde-se notar a relevância de diversos termos e conceitos relacionados à pesquisa-ação, desde as etapas de formulação do problema e definição da hipótese da pesquisa científica até o processo de condução da pesquisa, coleta e análise de dados. Os fatores a seguir explicitam a 
decisão de organizar a fundamentação metodológica deste trabalho em torno da pesquisa-ação:

- O principal ponto da pesquisa-ação é estudar uma situação social com o propósito de melhorá-la, algo muito propício a trabalhos de natureza aplicada, a exemplo de projetos de desenvolvimento de sistemas. Thiollent (2011) afirma que a pesquisa-ação pode ser aplicada a qualquer problemática de pesquisa envolvendo processos e interações sociais, motivação que, segundo Mathiassen et al. (2012), levou muitos pesquisadores de sistemas de informação a adotar a postura da pesquisa-ação em seus trabalhos.

- O método já foi muito utilizado no campo da educação, pois estratégias educacionais podem ser mais bem investigadas em um período extenso de tempo - situação na qual o presente trabalho se encaixa perfeitamente. Yin (2003, p. 5) destaca que esta abordagem de questionamento empírico deve ser utilizada quando há a necessidade de entender fenômenos sociais complexos, por permitir ao pesquisador uma visão holística de eventos dentro de um contexto de vida real.

- As características da pesquisa-ação sintonizam-se com metodologias de desenvolvimento ágil de software e tornam o processo mais sistemático, do ponto de vista cientifico (Baskerville, 1996).

A centralidade da pesquisa-ação neste trabalho é ilustrada pela FIG. 14 (seção 2.3.4). Nesse diagrama, é possível notar que a frente de pesquisa-ação ocorre concomitantemente a frentes auxiliares, que a ela fornecem suporte e atuam nas suas limitações.

\subsubsection{Pesquisa-ação}

A pesquisa-ação é intimamente associada à posição filosófica da teoria crítica (Easterbrook, 2007; ver também seção 2.2). Considera-se normalmente evidente que o problema precisa de solução e que a solução adotada é desejável, pois o conhecimento adquirido capacita um grupo particular e facilita uma mudança mais ampla. Devido a essa postura, há um imperativo moral para intervir e solucionar o problema, e, portanto, nenhuma tentativa é feita para se criar um grupo de controle. 
A pesquisa-ação adota uma abordagem cíclica, na qual a prática é constantemente transformada pela reflexão (Thiollent, 2011, p. 15).

Ainda segundo esse autor, a pesquisa-ação se diferencia dos demais métodos qualitativos por oferecer bases e procedimentos para o pesquisador fazer intervenções em um ambiente real e encontrar soluções práticas relevantes, uma demanda contemporânea de empresas e indústrias. $\mathrm{O}$ alto grau de envolvimento do pesquisador, tanto por intervir no problema como por estar em contato direto com os atores sociais envolvidos (quando o próprio pesquisador não é um deles), possibilita que ele obtenha mais informações sobre o ambiente e as utilize na sua pesquisa. Por fim, o autor destaca que a característica iterativa deste método de pesquisa possibilita que as ações já realizadas sejam revistas pelo pesquisador, redirecionando o rumo da pesquisa conforme os resultados obtidos (Thiollent, 2011, p. 16).

David Tripp considera "pesquisa-ação" um termo genérico utilizado para definir qualquer processo que siga um ciclo, no qual se aprimora a prática por meio da oscilação sistemática entre agir no campo da prática e investigar a respeito dela: "Planeja-se, implementa-se, descreve-se e avalia-se uma mudança para a melhora de sua prática, aprendendo mais no decorrer do processo, tanto a respeito da prática quanto do próprio processo de investigação" (Tripp, 2005).

Segundo Ferrance (2000), em grande parte das definições de pesquisa-ação, estrutura-se a investigação de modo a confrontar continuamente quatro temas básicos: a colaboração por meio da participação, a aquisição de conhecimento, o empoderamento dos participantes e a mudança social. Autores como Tripp (2005), Baskerville (1999), Kock (2004) e Susman e Evered (1978) propõem um ciclo básico, denominado por Tripp (2005) de ciclo de investigação-ação, composto por 5 etapas iterativas que, sucessivamente, refinam o conhecimento adquirido nos ciclos anteriores: (1) diagnóstico, (2) planejamento da ação, (3) tomada da ação, (4) avaliação e (5) aprendizado. Tripp (2005) destaca que as etapas do ciclo-base podem ser desenvolvidas de maneiras distintas, dependendo dos objetivos, das circunstâncias e dos participantes envolvidos na pesquisa, obtendo-se resultados diferentes ao final desse processo. A FIG. 16 ilustra o encadeamento dessas etapas, que também serão detalhadas na sequência (seções 2.4.1.1.1 a 2.4.1.1.3), em consonância com a literatura recente sobre o tema. 


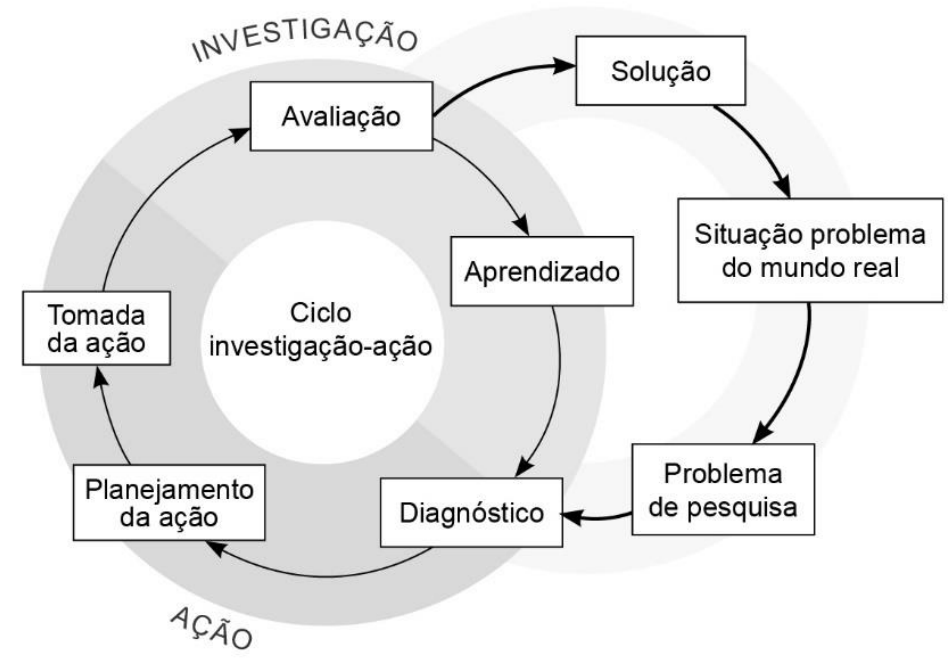

FIGURA 16 - Diagrama-síntese das etapas da pesquisa-ação conforme Susman e Evered (1978), Baskerville (1999), Kock (2004), Tripp (2005), Checkland (1991) (adaptado). Fonte: do autor.

\subsection{Estratégia}

A etapa de diagnóstico envolve a identificação, por parte do pesquisador, de um problema no ambiente social, cuja formulação ele pode desenvolver e a partir do qual se obterá um conhecimento relevante (Kock, 2004). Segundo Baskerville (1999), o diagnóstico permitirá desenvolver pressupostos teóricos sobre a natureza da organização, das partes interessadas, bem como do problema. Neste trabalho, as duas outras frentes adotadas - levantamento bibliográfico (seção 2.4.1.2) e levantamento (seção 2.4.1.3) - auxiliaram esta etapa (FIG. 14).

Fundamentando-se nos pressupostos anteriores, as etapas seguintes, que são as de planejamento e tomada de ação, como seus respectivos nomes sugerem, envolvem a atuação dos pesquisadores e atores sociais no planejamento e na realização da mudança (Baskerville, 1999), bem como no entendimento de quais as possíveis ações para resolver o problema observado na etapa de diagnóstico (Susman e Evered, 1978). Baskerville (1999) ressalta a flexibilidade da pesquisa-ação, uma vez que, nesse procedimento, dependendo do ambiente, dos atores sociais e da problemática da pesquisa, são construídas hipóteses e consideradas outras estratégias de pesquisa auxiliares. Para Kock (2004), a tomada da ação é exclusivamente o que define o processo de mudança no ambiente. Neste trabalho, a ação principal é o desenvolvimento incremental de um aplicativo. 
Após as ações planejadas terem sido tomadas, durante a etapa de avaliação, uma análise é realizada para mensurar o impacto e as consequências dessas ações (Susman e Evered, 1978), dando uma oportunidade aos pesquisadores e aos atores sociais de avaliar se a mudança no ambiente atingiu o resultado esperado ou se existe a necessidade de planejar uma nova iteração (Baskerville, 1999).

Por fim, independentemente do resultado obtido ao final de cada etapa, durante a realização de cada ciclo acumula-se conhecimento (Susman e Evered, 1978). Durante a etapa de aprendizado, é realizada uma reflexão sobre todas as etapas anteriores (Kock, 2004). Kock et al. (1997) afirmam que a abordagem cíclica-iterativa da pesquisa-ação aumenta o rigor da pesquisa, uma vez que a cada ciclo sucessivo ela passa por nova revisão crítica, possibilitando encontrar erros, inconsistências ou vieses anteriormente não identificados. Essa abordagem cíclica é totalmente compatível com o método de desenvolvimento ágil de software adotado neste trabalho (seção 2.4.2).

\subsection{Limitações}

Conforme proposto por Baskerville (1996), ponderaram-se também três limitações comumente apontadas por diversos autores em relação à pesquisa-ação:

- Apesar de ser uma técnica bastante flexível, é criticada pelo risco de rebaixar o nível de exigência acadêmica e pela falta de rigor científico geralmente atribuído não só à pesquisa-ação, mas aos métodos qualitativos em geral (Thiollent, 2011, p. 8; Baskerville, 1996; Westbrook, 1995; Coughlan e Coghlan, 2002).

- A relativa imaturidade e falta de domínio da técnica de pesquisa (Easterbrook, 2007), sobretudo na área de engenharia de sistemas (Baskerville, 1996; Kitchenham e Charters, 2007).

- Devido ao fato de a pesquisa-ação ser dependente de um contexto específico, há um possível comprometimento do fator causalidade no modelo hipotético-dedutivo (Baskerville, 1996).

Com relação ao primeiro ponto, qualquer método de pesquisa científica deve ser pautado na validade e confiabilidade, características que determinam sua qualidade ou rigor científico. Easterbrook (2007) afirma que a adoção explícita do método e o reconhecimento de sua base filosófica, além de suas 
características e limitações, permite torná-lo mais rigoroso. Neste sentido, conforme descrito anteriormente, houve neste trabalho uma preocupação em precisar os múltiplos aspectos que caracterizam a natureza do trabalho (seção 2.3) e as posturas filosóficas nele adotadas (seção 2.2), bem como em construir uma abordagem de pesquisa que se alinhasse com esses aspectos. Deve ser frisado que, apesar de a pesquisa-ação ser a espinha dorsal do projeto, ela está integrada a uma abordagem mista de pesquisa, que utiliza diversos métodos complementares de investigação, específicos ao contexto deste trabalho (Baskerville, 1999; Kock, 2004). Finalmente, determinados métodos auxiliares à pesquisa-ação podem criar pontes com a postura positivista (Creswell, 2002).

Com relação ao segundo ponto, segundo Baskerville (1996), Kock (2004) e Easterbrook (2007), tomados os devidos cuidados, a pesquisa-ação é considerada uma técnica apropriada à pesquisa na área de sistemas de informação. Easterbrook (2007) recomenda uma preparação adequada do pesquisador em métodos de pesquisa qualitativos executados em campo e típicos das ciências sociais, com foco no treinamento em observação e registro do comportamento social. Apesar da quantidade de publicações relativas à utilização da pesquisa-ação ainda não ser expressiva, particularmente na área de engenharia de sistemas, é possível observar um gradual suporte da literatura em sua utilização na área (Collins, 1995; Avison et al., 1999; 2007; Baskerville, 1996, 1999; Devilliers, 2005; Wilson, 2000; Byrne, 2005), refletindo em maior adoção do método (Davison et al., 2004; Devilliers, 2005), bem como no incremento do ensino desse método (Byrne, 2005).

Com relação ao terceiro ponto, Easterbrook (2007) coloca que a pesquisa-ação se baseia em diferentes posturas filosóficas que a afastam do modelo hipotético-dedutivo clássico, mas que, em contrapartida, determinam formas específicas de validação (seção 2.2). Assim, conforme destacado por Thiollent (2011), estes riscos também existem em outras técnicas e são superáveis mediante planejamento adequado e embasamento metodológico (Thiollent, 2011, p. 10), justificando, uma vez mais, a necessidade de se atentar constantemente ao método e à estratégia de pesquisa empregados.

\subsection{Adequação}

Tendo em vista estas questões, a pesquisa-ação foi considerada um método de pesquisa adequado para conduzir as investigações realizadas neste 
trabalho. Adotando-se a estruturação metodológica proposta por Thiollent (2011), Tripp (2005) e Baskerville (1996) e considerando-se a problemática da pesquisa científica no contexto específico de engenharia de sistemas, como proposto por Baskerville (1996), Kitchenham e Charters (2007) e Easterbrook (2007), implementou-se o ciclo base de investigação-ação segundo Tripp (2005), Baskerville (1999), Kock (2004) e Susman e Evered (1978).

A seção 2.4.2 descreve o alinhamento entre a pesquisa-ação e a metodologia de desenvolvimento de software implementados neste trabalho.

A seção 2.4.3 descreve o modelo de análise dos resultados desta pesquisa dentro da estruturação metodológica apresentada.

\subsubsection{Levantamento bibliográfico}

A primeira frente caracteriza-se como levantamento bibliográfico por, segundo Vergara (2000, p. 34) e Gil (2008), compreender um levantamento do estado da arte de referências teóricas disponíveis na literatura, constituídas principalmente de livros, monografias, teses e publicações periódicas, como jornais e revistas. Para Marconi e Lakatos (2003, p. 71), todo trabalho científico deve se pautar na pesquisa bibliográfica para que se evite perder tempo resolvendo problemas já bem solucionados e se possa concentrar no levantamento de soluções ou em outras questões mais relevantes. Neste trabalho, como consequência da abordagem multilateral, foram utilizados de maneira integrada procedimentos técnicos de pesquisa de naturezas distintas. Essa abordagem é defendida por Cervo e Bervian (1983, p. 55), para os quais a pesquisa bibliográfica deve ser realizada de forma independente, embora em conjunto com outros procedimentos técnicos de pesquisa.

Apesar do levantamento bibliográfico ter sido realizado em caráter exploratório e sem documentação sistemática, recorreu-se a fontes de alta credibilidade, dentro dos limites de acesso a publicações científicas no âmbito da Universidade de São Paulo (periódicos, revistas, dissertações, livros).

Os temas abordados no levantamento foram:

- Aspectos didáticos na ciência dos materiais.

- Visualização computacional: realidade virtual, visualização cientifica.

- Arquitetura, desenvolvimento e engenharia de sistemas web 3D na nuvem. 


\subsubsection{Levantamento}

$\mathrm{Na}$ frente de levantamento, definiu-se o estado da arte dos softwares cristalográficos, base de partida para a proposta de funcionalidades inéditas. Por isso, decidiu-se adotar um levantamento mais rigoroso, por meio do procedimento de revisão sistemática, muito utilizado na área de engenharia de sistemas (Kitchenham e Charters, 2007). Como detalhado na seção 2.4.2.1.4.1, antes do levantamento sistemático, foi realizado um levantamento prévio exploratório. A partir das definições expostas a seguir, é possível notar que, por meio do levantamento sistemático, são incorporados à estratégia de pesquisa elementos típicos da postura positivista (seção 2.2).

A revisão sistemática é um método de pesquisa voltado a adquirir e avaliar evidências sobre um tópico central, seguindo um procedimento definido por um protocolo (Biolchini et al., 2005). A revisão sistemática vai além da tradicional, por revelar preocupações metodológicas mais profundas, documentando todo o processo e deixando-o transparente, de modo que os vieses possam ser detectados. A diferença principal jaz, portanto, no esforço adicional para planejar, estabelecer procedimentos, testar e documentar todo o processo (Kitchenham e Charters, 2007).

No entanto, existem limitações na comparação de dados de estudos primários, devido a diferenças metodológicas entre os trabalhos e à dificuldade de obtenção dos dados originais. Esse fato reforça a complementaridade entre a pesquisa primária e a revisão sistemática na produção de conhecimento (Biolchini et al., 2005). O tipo e a qualidade dos estudos primários são fatores essenciais, pois definem o grau de confiança da informação. No caso da engenharia de software, as especificidades da área dificultam a obtenção de evidências. São escassos os estudos primários e existem poucos trabalhos voltados à avaliação tanto de novas soluções, como das existentes. As evidências obtidas são limitadas, fragmentadas e carecem de um padrão (Biolchini et al., 2005).

Kitchenham e Charters (2007), ao constatarem a falta de rigor nos trabaIhos de pesquisadores da engenharia de software, desenvolveram diretrizes adaptadas aos problemas específicos da área, a partir das utilizadas em medicina. $\mathrm{O}$ processo de revisão sistemática segue, de maneira iterativa, as seguintes fases:

- Formulação do problema: propõe-se uma questão central, seu escopo, os principais termos-chave, o que será observado, os resulta- 
dos esperados, as métricas, os grupos observados, as áreas de aplicação e os métodos estatísticos que serão aplicados nos dados coletados.

- Coleta de estudos primários: a fim de levantar evidências relevantes, definem-se métodos de busca e palavras-chave significativos, além de restrições (por exemplo, a linguagem do manuscrito). Criase uma lista de referências, avaliada por especialistas.

- Avaliação dos estudos: define-se quais fontes serão utilizadas a partir de critérios de seleção (por exemplo, o tipo de estudo).

- Análise da informação: são definidos e aplicados procedimentos para extrair e analisar (estatisticamente) os dados dos estudos primários e padronizar sua apresentação.

- Apresentação: são escolhidos e apresentados os dados que serão inclusos no relatório final.

Cada fase deve ter um planejamento, registrado no protocolo de revisão (Kitchenham e Charters, 2007), contemplando os pontos listados anteriormente. Idealmente, esse planejamento deve ser avaliado por especialistas ou por meio de testes em um conjunto de amostras (Biolchini et al., 2005).

A execução da revisão inicia-se com a avaliação das capacidades e limitações dos diversos mecanismos de busca cogitados (digitais ou físicos), seguida pela busca das palavras-chave em todas as bases de dados e aplicação dos procedimentos de seleção de estudos primários. A busca deve ser documentada para explicitar sua abrangência e torná-la replicável (Pavlinic et al., 2001). Devem ser selecionados os estudos que forneçam evidência direta sobre o tópico de pesquisa e registrados os motivos de exclusão dos outros. As informações são extraídas dos estudos primários por meio de métodos de coleta, que documentam as fontes (título, autores, métodos, efeitos, limitações). Os resultados são reunidos, submetidos à aplicação de métodos estatísticos, sua robustez é atestada por análise de sensitividade e, por fim, eles são plotados em tabelas e gráficos. Os comentários finais devem explicitar o número de estudos utilizados, os possíveis vieses (busca, seleção e extração de dados) que podem comprometer os resultados e a aplicabilidade dos resultados. 


\subsection{Protocolo de revisão}

O protocolo de revisão, detalhado a seguir, foi criado com base em $\mathrm{Bi}$ olchini et al. (2005) e Kitchenham e Charters (2007). A revisão foi feita em três iterações, devido à longa duração do projeto, visando tanto manter a atualidade dos dados como incorporar as considerações dos atores sociais envolvidos na pesquisa. Os únicos parâmetros afetados durante o período foram o controle e a população de referências.

Cabe ressaltar que os softwares compreendidos no levantamento foram referenciados ao longo da tese por um código alfanumérico formado pela abreviação do nome do software e pelos últimos dois dígitos de seu ano de publicação. As correspondências desses códigos podem ser consultadas no APÊNDICE A.

\subsection{Objetivos e escopo}

- Objetivo primário: identificar o estado da arte de softwares cristalográficos.

- Questão primária: características específicas de softwares cristalográficos que abordem visualização de estruturas cristalinas.

- Intervenção: características específicas.

- Controle: não houve controle na primeira iteração. A segunda e terceira iterações usaram os resultados das anteriores e as considerações dos atores sociais como controle.

- População: principais softwares cristalográficos que abordem visualização de estruturas cristalinas. Apesar da fonte de referências e dos critérios de busca se manterem iguais, a população se ampliou ao longo das três iterações.

- Resultados: características desejáveis e lacunas dos sistemas existentes, no que diz respeito a suas aplicações didáticas.

- Aplicação pretendida: especificação de um sistema de síntese e visualização de estruturas cristalinas, com enfoque didático.

\subsection{Estratégia de busca}

- Fontes cogitadas: base de dados eletrônicas indexadas - International 
Union of Crystallography (IUCr) e Collaborative Computational Project Number 14 (CCP 14).

- Idioma dos softwares (interface): inglês, por essa ser a língua internacionalmente aceita para a redação de trabalhos científicos. Considera-se que trabalhos brasileiros de maior relevância serão encontrados em inglês.

- Palavras-chave cogitadas: Visualization, Graphics, Virtual reality, Teaching, Modelling, Materials science.

- Período: trabalhos publicados após 1980, cujo desenvolvimento ainda é mantido, devido a questões de atualidade, compatibilidade e relevância histórica.

\subsection{Critérios para seleção de softwares}

Critérios de inclusão: apenas relacionados à temática de visualização de estruturas cristalinas; apenas compatíveis com sistemas operacionais Linux, Mac OS X e Windows.

Critérios de exclusão: anteriores a 1980; listados mas descontinuados por seus autores; obsoletos e/ou tecnologicamente incompatíveis; cujos autores não proveram uma cópia ou licença para testes.

\subsection{Processo de seleção de softwares}

Construir string de busca formada pela combinação dos sinônimos das palavras-chave identificadas. Essas strings serão testadas e submetidas às máquinas de busca relacionadas. A relevância de um trabalho será avaliada aplicando os critérios de inclusão listados acima, na leitura do título, do resumo e da introdução, conforme necessário.

\subsection{1 Pesquisa exploratória}

$\mathrm{Na}$ ausência de uma referência de controle, verificou-se por meio de pesquisa exploratória se as strings de busca retornavam os softwares cristalográficos publicados no Journal of Applied Crystalography, considerada uma publicação relevante na área. Os softwares mais relevantes identificados foram: CMAK15, JMOL15, VEST14 e MERC15. 


\subsection{2 Strings de busca}

A busca do banco de dados da IUCr contém palavras-chave preconfiguradas, agrupadas em categorias. As palavras adotadas foram: "Visualization", "Graphics", "Virtual reality", "Teaching", "Modelling", e "Materials science" (categoria "categorias de aplicação"); "Linux", "MacOs", "MS Windows" ou "Web" (categoria "sistemas operacionais"). Não havia filtragem por data no mecanismo de busca, mas recorreu-se ao campo intitulado "Entered", que identifica a data de entrada de cada registro no banco de dados, para identificar os softwares publicados entre 1980 e 2015.

O banco de dados CCP14 ([s.d.]) possui uma quantidade bastante limitada de softwares. Por essa razão, foram inclusos todos os registros na revisão.

\subsection{Extração e sumarização dos resultados}

Os softwares selecionados foram explorados pelo revisor e descritos e avaliados segundo um formulário unificado, elaborado especificamente para o presente trabalho. Por meio desse formulário, foram registradas informações básicas dos softwares (nome do software, autores, site do projeto, descrição na fonte - APÊNDICE A) e a avaliação dos softwares segundo uma série de parâmetros estabelecidos pelo pesquisador (APÊNDICE C).

Tais parâmetros fundamentam-se nas considerações e expectativas dos atores sociais e nos objetivos deste trabalho. Após a primeira fase de interação com os atores sociais e a experiência da primeira avaliação, os parâmetros foram divididos em cinco grupos, ou questionários: tecnológico, de síntese, de visualização, de navegação e interatividade, e didático. Tais questionários e os parâmetros de avaliação que os compõem são descritos sumariamente a seguir (seção 2.4.2.1.5.1). As expectativas dos atores sociais relacionadas a cada um desses parâmetros, e que os originaram, são descritas no APÊNDICE B.

Os softwares foram classificados de acordo com um procedimento de pontuação. Foi atribuída uma quantidade igual de pontos a cada parâmetro de avaliação, e a soma de pontos de cada software foi comparada à soma normalizada de todos os parâmetros, resultando em uma classificação. Além dessa classificação, os dados obtidos, em conjunto com as considerações dos atores sociais, serviram de base para definir uma especificação para o desenvolvimento da ferramenta. 
A síntese dos dados foi feita em tabelas comparativas (APÊNDICE C) e gráficos do tipo bolha (bubble charts) interativos, utilizando a biblioteca D3 (Bostock et al., 2011). A biblioteca D3 específica do projeto CrystalWalk está disponível on-line em Bardella et al. (2016a). Esse mecanismo busca facilitar a visualização do ranqueamento dos softwares e as diferenças entre eles, considerando a avaliação realizada.

\subsection{1 Questionário de avaliação dos softwares}

- (1) Parâmetros do questionário tecnológico

- (1.1) Nível de atividade

- (1.1.1) Frequência de atualização

○ (1.2) Portabilidade da aplicação

- (1.2.1) Portabilidade da aplicação

- (1.2.2) Plataforma de desenvolvimento

- (1.2.3) Sistemas operacionais compatíveis

- (1.2.4) Requer instalação

- (1.2.5) Multiplataforma

○ (1.3) Uso, distribuição e modificação

- (1.3.1) Licença de uso, distribuição e modificação

- (1.3.2) Modelo de desenvolvimento colaborativo

○ (1.4) Suporte a tecnologias de interface

- (1.4.1) Dispositivos base (HID)

- (1.4.2) Dispositivos avançados de interação

- (2) Parâmetros do questionário de síntese

- (2.1) Método de síntese

- (2.2) Processo de síntese interativo

- (2.3) Restrições ou limitações à síntese

○ (2.4) Seleção e edição interativas de átomos

- (3) Parâmetros do questionário de visualização

○ (3.1) Representação

- (3.1.1) Modelo de representação atômico molecular

- (3.1.2) Modelo de representação da célula unitária 
- (3.1.3) Planos de Miller

- (3.1.4) Direções de Miller

- (3.1.5) Artifícios de suporte

(3.1.5.1) Células múltiplas

(3.1.5.2) Cortes

(3.1.5.3) Vetores do eixo da rede

(3.1.5.4) Recursos auxiliares de rede

○ (3.2) Visualização

- (3.2.1) Recursos de percepção visual

- (3.2.2) Tipo de projeção

- (3.2.3) Suporte estereográfico

- (3.2.4) Modos de renderização

- (4) Parâmetros do questionário de navegação e interatividade

○ (4.1) Interface de usuário

○ (4.2) Interação base

- (4.3) Interação avançada

- (4.3.1) Rotações automáticas

- (4.3.2) Animações guiadas

- (4.3.3) Transição de escala

- (4.3.4) Gerenciamento dinâmico de oclusões

- (4.3.5) Perspectiva/pontos de vista preconfigurados

- (5) Parâmetros do questionário didático

- (5.1) Conhecimentos requeridos do usuário

- (5.2) Suporte a publicações

- (5.2.1) Suporte à visualização/portabilidade externa

- (5.2.2) Suporte à impressão 2D

- (5.2.3) Suporte à impressão 3D

- (5.2.4) Plataforma de publicação na internet

○ (5.3) Funcionalidades didáticas

- (5.3.1) Suporte à narrativa didática

- (5.3.2) Biblioteca de estruturas cristalográficas

- (5.3.3) Construção e visualização incremental de estruturas 
○ (5.4) Suporte e documentação

- (5.4.1) Suporte

- (5.4.2) Documentação

\subsection{Condução da revisão}

O período de análise para cada iteração durou aproximadamente duas semanas. O primeiro período refere-se à fase exploratória deste trabalho (semestre 1). O segundo período compreende as primeiras fases de desenvolvimento do software (semestre 6) e já inclui considerações dos atores sociais. O terceiro período ocorreu na fase final do trabalho (semestre 10), incorporando tanto a experiência obtida no desenvolvimento da ferramenta como a resultante da pesquisaação. As únicas mudanças foram as que ocorreram na população das referências e as provenientes da contribuição dos atores sociais, de grande importância no contexto do projeto. Os resultados da revisão aqui expostos (APÊNDICE C) referem-se apenas ao último período.

\subsubsection{Desenvolvimento e implementação de software}

Durante as etapas preliminares do projeto, não houve nenhuma preocupação metodológica formal com relação ao desenvolvimento do software, sobretudo em razão da natureza exploratória dessas etapas. Apenas posteriormente, conforme se estruturava o processo de desenvolvimento, em conjunto com a adição de novos recursos e novas tecnologias e com o aumento do número de atores sociais envolvidos, houve, de fato, uma preocupação em coordenar e melhorar o processo de gestão do desenvolvimento. Visando preencher as lacunas então existentes, realizou-se um levantamento informal de métodos de desenvolvimento de software que se adaptariam aos propósitos desta pesquisa.

Neste contexto, para escolher a metodologia de desenvolvimento de software a ser utilizada neste trabalho, priorizaram-se abordagens alinhadas com a complexidade inerente à pesquisa-ação - ou, como definido por Ogunnaike e Ray (1994), uma abordagem voltada a processos empíricos. No âmbito das engenharias, Schwaber e Beedle (2002) propõem que estes processos, por estarem em constante mudança, requerem ciclos de iteração e comunicação mais curtos e frequentes, encontrados naquilo que se convencionou chamar de metodologias 
ágeis de desenvolvimento. Schwaber e Beedle (2002) destacam que, de maneira análoga ao ciclo base de ação-interação na pesquisa-ação, a abordagem empírica é ideal para o ambiente de desenvolvimento de software, pois ela propicia maneiras de melhor inspecionar e corrigir tanto o produto como o processo em si. Além dos desafios de gerenciamento de recursos, como destacado pelos autores, na pesquisa-ação é constante a preocupação em melhorar a eficácia desse ciclo, principalmente quanto à comunicação, colaboração, produtividade e motivação do time do projeto (Collins, 1995).

Desta forma, considerando principalmente a dinâmica da metodologia da pesquisa-ação, a limitação de recursos disponíveis e as recomendações da literatura (Collins, 1995; Avison et al., 1999; Baskerville, 1999; Devilliers, 2005; Wilson, 2000; Byrne, 2005; Avison et al., 2007), concluiu-se que metodologias ágeis de desenvolvimento seriam as mais adequadas aos objetivos do trabalho.

Dentre as metodologias ágeis conhecidas, optou-se por aquela denominada Scrum. Essa escolha se justificou pelos seguintes fatores: ampla documentação, vasta disponibilidade de literatura, suporte e ferramentas de apoio, além de experiência prévia do pesquisador. A metodologia também tem foco na obtenção rápida de resultados de alto valor, fator essencial quando os recursos de desenvolvimento são escassos, como é normalmente o caso de pesquisadores. Em outras palavras, quando as equipes são pequenas, o tempo disponível dos membros deve ser otimizado. Os detalhes históricos e técnicos da técnica do Scrum serão apresentados na seção 3.5.1.1.

\subsubsection{Análise dos resultados}

A partir da estratégia e da metodologia de pesquisa detalhadas nas seções 2.4.1 e 2.4.2, elaborou-se um modelo de análise dos resultados buscando avaliar em que nível o software produzido diminuiu a dificuldade de criação e visualização de estruturas cristalinas e quanto contribuiu com a democratização do conhecimento no contexto deste projeto - ou seja, se os objetivos do trabalho foram atingidos segundo uma validação de viés construtivista (seção 2.2). Em uma pesquisa-ação, a avaliação final dos resultados, pelo viés da teoria crítica, deve verificar, com base nas impressões dos atores sociais, em que grau o problema social colocado foi atendido e o nível de empoderamento conquistado. Desta maneira, como delineado na seção 2.4.1.1, essa avaliação foi dominada por análises 
qualitativas baseadas na experiência dos atores sociais com as diversas versões incrementais do CrystalWalk, sendo muitas delas realizadas de maneira contínua, a cada ciclo de desenvolvimento, e outras aplicadas apenas à versão final do aplicativo. No entanto, alguns itens do problema, seguindo a listagem do APÊNDICE B, podem ser avaliados objetivamente segundo a postura pragmática. Foram utilizados diferentes procedimentos de avaliação geral, um para avaliação da implementação da instância do aplicativo e outros dois para avaliar separadamente os aspectos de síntese e visualização.

Cabe frisar que as recomendações de Creswell (2002), comentadas ao longo da seção 2.3, foram aplicadas nestas avaliações para aprimorar o rigor da pesquisa qualitativa. A abordagem multilateral garantiu múltiplas fontes de dados para corroborar os resultados. A experimentação durante um longo período garantiu uma exposição suficiente com os participantes para garantir um entendimento razoável das questões sendo estudadas, além de consistência da interpretação dos dados com a visão do grupo. Outra recomendação é detalhar as descrições para explicitar os parâmetros e os achados da pesquisa, o que foi feito tanto no levantamento e amadurecimento dos requerimentos como nas múltiplas e longas avaliações realizadas. Essas descrições podem ser encontradas no capítulo 4 e no APÊNDICE B. Membros selecionados entre os atores sociais, bem como revisores externos, atuaram como auditores dos procedimentos e resultados. Finalmente, é possível verificar em todas as avaliações uma postura autorreflexiva e ética, garantindo que tanto os pontos positivos como as limitações tenham sido devidamente apresentados e discutidos.

Na sequência, serão detalhadas as avaliações contínuas, realizadas a cada nova versão do desenvolvimento do CrystalWalk, e as avaliações realizadas na versão corrente.

\subsubsection{Avaliação contínua}

A avaliação específica do processo de síntese de estruturas cristalinas ocorreu por meio de testes de construção de algumas estruturas clássicas selecionadas (seção 4.5.3.1). A eficácia dos métodos de síntese propostos foi mensurada a cada ciclo de desenvolvimento. A eficácia da última versão foi atestada por meio de uma comparação com os três melhores softwares segundo o quesito síntese, avaliando a possibilidade e a dificuldade de se construirem as estruturas 
propostas nos testes com base em dados obtidos em material didático comumente utilizado no ensino das engenharias.

Por meio da avaliação especifica dos aspectos de visualização de estruturas cristalinas, verificou-se como cada funcionalidade do CrystalWalk atende aos problemas didáticos identificados (seção 3.1.2). Ou seja, se essas funcionalidades permitem, e em que grau, o entendimento do conceito "rede + motivo = estrutura cristalina" e a identificação de contatos, distâncias atômicas e empilhamentos de planos (seção 4.5.3.2). Em suma, esses problemas podem ser reduzidos a explicitar a organização geométrica da célula unitária e do cristal. Os testes de visualização utilizaram-se das mesmas estruturas propostas nos testes de síntese e foram também aplicados a cada ciclo de desenvolvimento.

A interface do aplicativo também foi avaliada ciclicamente, a cada nova versão do aplicativo. No caso das tarefas de síntese, a interface foi avaliada pela fluidez da sequência das atividades, ou seja, quão bem essas atividades estavam encadeadas, considerando a organização da interface gráfica. Nas tarefas de visualização, foi verificado se as opções de visualização estavam bem organizadas e encadeadas e se eram acessíveis e compreensíveis pelo usuário. Essa avaliação, inspirada em pesquisas de experiência do usuário, ou user experience (UX), foi feita inteiramente com base nas impressões dos atores sociais, cujos depoimentos foram registrados e dos quais alguns trechos serão apresentados.

\subsubsection{Avaliações da versão final}

O primeiro método de avaliação geral da versão final do CrystalWalk foi analisá-la segundo os mesmos critérios a que haviam sido submetidos os softwares encontrados na frente de levantamento. Os resultados dessa avaliação podem ser conferidos na seção 4.5.2. Os softwares que atenderam a um número maior de itens da lista de critérios foram considerados os melhores - em outras palavras, são os que melhor atendem aos problemas levantados junto aos atores sociais envolvidos (para um detalhamento desses problemas, ver APÊNDICE D). Portanto, somaram-se pontos para cada item atendido pela solução e comparouse esse resultado com a soma total, considerada solução ideal. Julgou-se propício comparar com os melhores softwares existentes, considerando os três melhores em cada grupo de critérios, evitando vieses na avaliação. Nesse sentido, deve ser frisado que não foi adotada nenhuma ponderação dos itens, ou seja, a todos foi 
atribuído o mesmo valor. A última instância pública do CrystalWalk também foi avaliada quanto à sua implementação. Buscou-se atestar o atendimento de uma parte das especificações técnicas da aplicação (avaliação cujos resultados se encontram na seção 4.5.1).

O segundo método de análise geral da versão final do CrystalWalk foi mensurar, em caráter preliminar, o impacto das diversas possibilidades interativas propiciadas por recursos emergentes da área de realidade virtual selecionados, como estereoscopia e captura de movimento das mãos (seção 4.5.6). Nesta análise, o intuito foi verificar quais benefícios ou limitações os aspectos únicos desses recursos trouxeram à resolução dos diversos problemas identificados, quando comparados aos meios mais tradicionais, partindo do pressuposto de que uma interação mais próxima à experimentada no mundo real propicia resultados superiores. Dessa forma, projetou-se e executou-se um experimento no qual o grau de imersão foi incrementado progressivamente e as reações dos usuários, observadas e analisadas. Maiores detalhes sobre essas tecnologias e os conceitos relacionados a imersão são apresentados na seção 3.3.5.1.

Finalmente, o quesito democratização foi avaliado separadamente (seção 4.5.7), dada a sua relação com um aspecto essencial da pesquisa-ação, que é o empoderamento (ampliação da capacitação ou do poder; empowerment) do grupo social afetado pela ação. O empoderamento foi avaliado com base no incremento oferecido, por meio da solução proposta, em termos de acesso ao conhecimento e às ferramentas e funcionalidades essenciais para a melhoria do ensino. Seguindo a justificativa deste projeto, entende-se que qualquer facilitação conquistada nos processos de síntese e visualização e as possíveis melhorias de compreensão propiciadas pela ferramenta proposta também propiciam maior acesso ao conhecimento da área em questão.

\subsubsection{Sumário dos métodos e procedimentos}

Após determinadas a natureza, a forma, os objetivos e as técnicas pertinentes à metodologia de pesquisa empregada, foi estabelecido um plano com atividades detalhadas, conforme será apresentado no item 2.6. A FIG. 17 sumariza a estratégia de pesquisa adotada para este trabalho. 


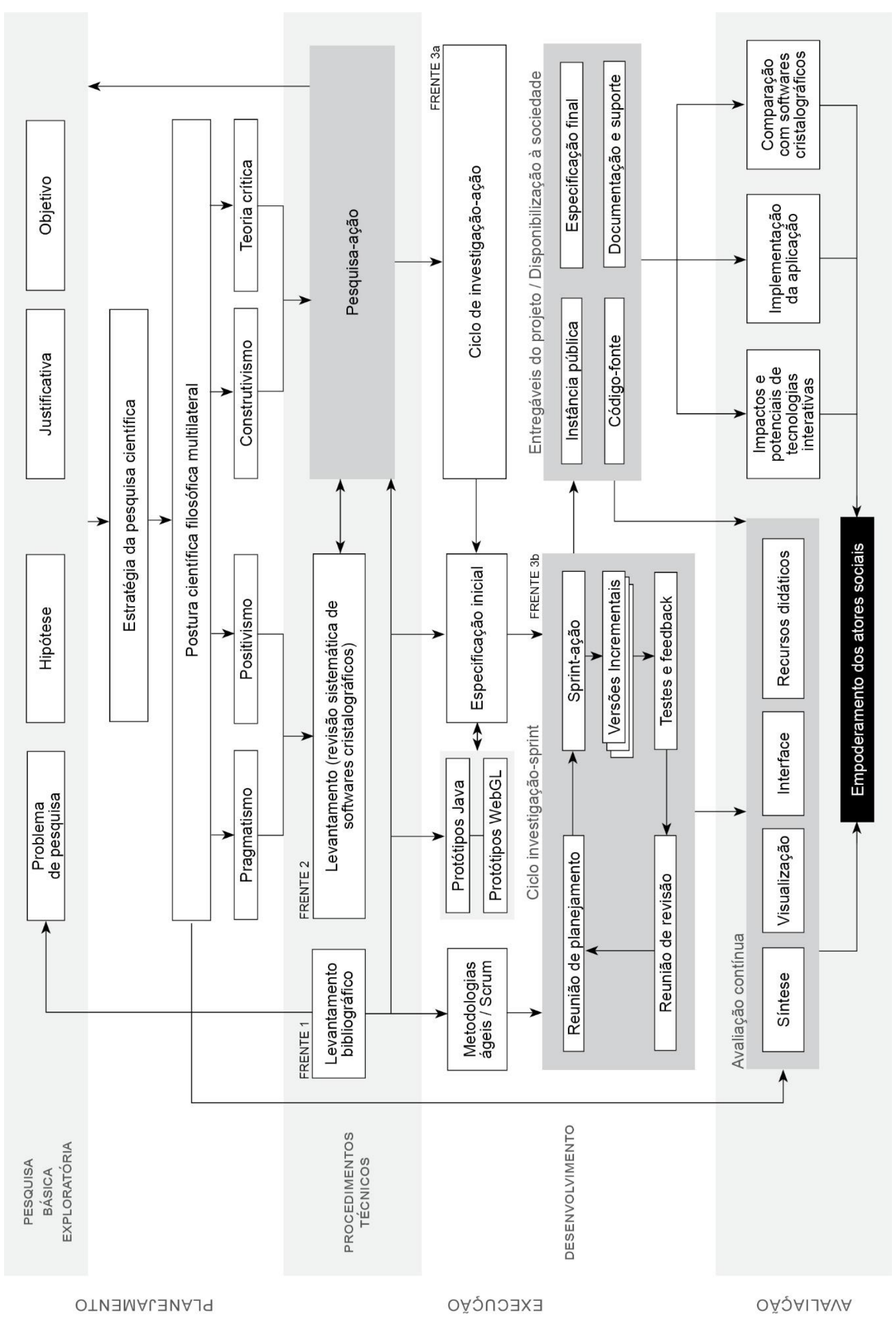

FIGURA 17 - Diagrama-síntese da estratégia de pesquisa (métodos e procedimentos). Fonte: do autor. 


\subsection{Materiais}

Devido ao pioneirismo do projeto CrystalWalk, foi necessário utilizar equipamentos e materiais específicos, ao longo das diferentes etapas do projeto, para desenvolver e implementar suas funcionalidades. Esses equipamentos e materiais são listados a seguir:

- Computadores pessoais: diversos computadores pessoais, em diferentes configurações e plataformas, foram utilizados pelo pesquisador e pela equipe do projeto em diversos momentos da realização desta pesquisa.

- Tabletop Lenovo Horizon 2 Full HD 27": utilizado principalmente no teste de métodos de interação avançados, neste caso, no que diz respeito ao recurso de toque de tela multitoque e para simulação da apresentação de um pôster interativo.

- Monitor/TV 3D 4K (3840 × 2160) LG 65" UF9500: utilizado em testes de funcionalidades de visualização em alta resolução e estereoscópicas.

- Plataforma livre Oracle VirtualBox (Oracle, 2015): utilizada para virtualização do parque de testes. Utilizou-se a plataforma para virtualização local de 5 instâncias de sistemas operacionais diferentes (Windows XP, Windows 7, Linux Ubuntu 14, Linux CentOS 6 e MacOS Mavericks). Cada máquina virtual utilizou a mesma configuração padrão (2 núcleos de processamento virtuais - vCPUs, 8 GB de memória, 100 GB de armazenamento) em 2 aplicações específicas:

- Instalação, teste e análise dos softwares da revisão sistemática, sendo as máquinas configuradas de acordo com os requerimentos específicos de cada software.

- Teste e controle de qualidade da aplicação CrystalWalk durante seus diversos estágios de desenvolvimento, realizados em navegadores e plataformas distintas. A lista dos navegadores com que o CrystalWalk é compatível pode ser conferida na seção 4.5.1.

- Plataforma livre de desenvolvimento Eclipse (Eclipse Foundation, [s.d.]): utilizada no desenvolvimento da aplicação-conceito e no desenvolvimento da aplicação WebGL. 
- Plataforma livre de desenvolvimento Atom (Atom Editor, [s.d.]): utilizada no desenvolvimento da aplicação WebGL.

- Vim (VimOnline Development, [s.d.]): utilizada no desenvolvimento da aplicação WebGL.

- Aplicação livre Gimp (Gimp Team, 2015): utilizada na elaboração e desenvolvimento gráficos da interface.

- Aplicação livre Inkscape (Inkscape Team, 2015): utilizada na elaboração e desenvolvimento gráficos da interface.

- Suíte de aplicações Microsoft Office (Microsoft Corporation, 2016), disponibilizada por meio do convênio acadêmico entre USP e Microsoft: utilizada na edição do texto e das planilhas da tese.

- Impressoras 3D modelos UPrint SE (Stratasys) e Dream Builder (Dremel): utilizadas na confecção de modelos físicos a partir de modelos STL de estruturas cristalinas produzidas no CrystalWalk.

- Oculus Rift DK2: utilizado no desenvolvimento e no teste de mecanismos de visualização avançados, neste caso, a estereoscopia.

- Dispositivo de interface Leap Motion: utilizado desenvolvimento e no teste de métodos de interação avançados, neste caso, utilizando captura de movimentos da mão.

- Dispositivo de interface Razer Hydra: utilizado no desenvolvimento e no teste de métodos de interação avançados, neste caso, utilizando captura de movimentos da mão. Dispositivo complementar ao Leap Motion, por possuir maior alcance de captura de movimento e menor susceptibilidade a interferências.

- Servidores e plataformas de computação em nuvem: uma descrição mais precisa de quais serviços e parâmetros de configuração foram utilizados na implementação do CrystalWalk, bem como uma breve introdução aos conceitos e justificativas pertinentes, são apresentados em detalhes no capítulo 4.

- Amazon Web Services (diversas instâncias dos serviços Route 53, EC2 e DBS): usado no processo de testes e desenvolvimento e na implementação final da aplicação do projeto.

- Heroku (diversos Dynos de diferentes servidores de aplica- 
ções): utilizados tanto no processo de testes e desenvolvimento, como na implementação final da aplicação do projeto.

- GitHub: Utilizaram-se diversas instâncias git do serviço de repositório de código.

- Bases de dados de periódicos e trabalhos acadêmicos (Portal de Periódicos da Coordenação de Aperfeiçoamento de Pessoal de Nível Superior - CAPES - e bases de dados como ScienceDirect, Scopus, IEEE Xplore e ACM): utilizadas para o levantamento bibliográfico (seção 2.4.1.2) para formação do acervo bibliográfico da pesquisa. As bases foram acessadas on-line via portal Sibinet (Universidade de São Paulo, [s.d.]).

\subsection{Descrição e cronograma das atividades planejadas}

Para realizar os objetivos deste trabalho (seção 1.2), as atividades deste trabalho foram organizadas em algumas etapas. A seguir, são apresentadas uma lista dessas etapas e atividades, com descrições detalhadas (seção 2.6.1), e o cronograma de sua execução no decorrer do trabalho (seção 2.6.2).

\subsubsection{Descrição das atividades}

\subsubsection{Fase 1 - Estudo e levantamento}

- Atividade 1.1 - Cumprimento dos créditos necessários em disciplinas obrigatórias e eletivas (semestres 1 a 8 )

- Cumprimento de créditos em disciplinas exigidos pelo programa de pós-graduação. Dentre as disciplinas eletivas, escolheram-se aquelas com ênfase nas áreas de ciência dos materiais, computação gráfica e educação, além de caracterização física e química de materiais.

- Atividade 1.2 - Identificação dos objetivos específicos e escopo do trabalho (semestres 1 e 2 )

- Abordagem da temática do problema junto aos atores sociais participantes. Iniciou-se o processo de investigação dos requisitos do software e dos objetivos específicos do trabalho. 
- Atividade 1.3 - Detalhamento dos problemas e necessidades pedagógicas (semestres 1, 5 e 8)

- Participação do pesquisador, como ouvinte e expositor, em aulas de graduação e pós-graduação e coleta de feedback por meio de entrevistas desenvolvidas junto a estudantes, professores e pesquisadores da área. As disciplinas envolvidas foram: caracterização física e química de materiais (graduação e pós-graduação), metalurgia física (graduação) e ciência dos materiais (pós-graduação).

- Atividade 1.4 - Levantamento bibliográfico dos temas pertinentes (semestres 1 a 4 )

- Levantamento bibliográfico das áreas específicas relacionadas ao projeto: ensino de estruturas cristalinas, visualização computacional, desenvolvimento de software e tecnologias para desenvolvimento de aplicações interativas web.

- Atividade 1.5 - Levantamento sistemático (semestres 1, 6 e 10)

- Mapeamento do estado da arte dos softwares cristalográficos, em três diferentes fases do projeto, visando identificar funcionalidades de construção, visualização e manipulação de estruturas cristalinas existentes sob a perspectiva das necessidades e problemas didáticos levantados pelos atores sociais participantes. Houve preocupação especial em destacar as lacunas existentes, que contribuíram para confirmar o ineditismo e o valor do trabalho.

- Atividade 1.6 - Aprofundamento dos fundamentos cognitivos pertinentes (semestre 2)

- Aprofundamento nos tópicos cognitivos a fim de obter conhecimentos específicos para discutir os problemas didáticos identificados e embasar as possíveis soluções. 
- Atividade 1.7 - Levantamento de tecnologias para a infraestrutura operacional (semestres 3 a 8 )

- Visitações a outros centros de visualização científica e realidade virtual e realização de pesquisas e entrevistas com centros de excelência e fabricantes de hardware e software.

- Atividade 1.8 - Levantamento e escolha de tecnologias para o desenvolvimento da plataforma (semestres 3 e 7 )

- Análise e definição de plataformas de desenvolvimento disponíveis no mercado capazes de atender aos requisitos definidos, principalmente tecnologias gráficas e infraestrutura computacional. Além do estudo de casos da literatura, desenvolveram-se programas-conceito específicos para o teste destas plataformas.

- Atividade 1.9 - Estudos e modelos de técnicas de desenvolvimento de software (semestres 1 a 9 )

- Atualização do know-how e do conhecimento necessário das técnicas de desenvolvimento utilizadas, principalmente metodologias ágeis.

\subsubsection{Fase 2 - Desenvolvimento e aplicação}

- Atividade 2.1 - Construção de modelo e prototipação da implementação de infraestrutura operacional (semestres 3 e 6)

- Construção de um protótipo da infraestrutura operacional objetivando testar a aplicação das tecnologias otimizadas para o uso especificado.

- Atividade 2.2 - Análise, integração e implementação de infraestrutura operacional (semestres 4, 5, 7 e 8)

- Definição e consolidação da plataforma computacional, dos dispositivos de interação e exibição, além de bibliotecas e software de apoio. 
- Atividade 2.3 - Ciclo de análise, desenvolvimento e implementação de métodos e técnicas de síntese de modelos cristalográficos, visualização e interação (semestres 4 a 10)

- Validação das especificações técnicas de todos os requisitos funcionais, durante cada um dos sprints, em sincronia com os ciclos de pesquisa-ação, bem como a análise, construção e otimização dos modelos de dados de aplicação. Assim como recomendado pela metodologia Scrum, cada ciclo durou em média 4 semanas.

- Atividade 2.4 - Ciclo de testes e avaliações (semestres 4 a 10)

- Implementação de uma metodologia de avaliação específica a cada sprint, em sincronia com os ciclos de pesquisa-ação, em colaboração com os atores sociais. Por meio dessas avaliações, o código produzido foi corrigido e aprimorado e verificou-se se 0 atendimento aos requerimentos previamente especificados.

\subsubsection{Fase 3 - Análise dos resultados e apresentação}

- Atividade 3.1 - Análise comparativa (semestre 10)

- Avaliação da última versão do CrystalWalk tendo como parâmetros os requisitos e as referências.

- Atividade 3.2 - Testes comparativos de síntese e visualização (semestre 10)

- Síntese e visualização de estruturas cristalinas a partir de informações disponíveis em livros didáticos e em outras obras de referência correlatas, usando a última versão do CrystalWalk e outros softwares analisados. Buscou-se comparar a dificuldade de criação das estruturas e a qualidade da visualização, tendo como parâmetros os problemas didáticos identificados.

- Atividade 3.3 - Avaliação das possibilidades interativas (semestre 10) 
- Teste, junto aos atores sociais, de tecnologias interativas emergentes, buscando abordar os possíveis benefícios e também limitações, tendo como parâmetros os objetivos deste trabalho.

- Atividade 3.4 - Sumarização dos resultados (semestre 10)

- Avaliação integrada dos resultados tendo como parâmetros os objetivos do trabalho.

- Atividade 3.5 - Redação de artigos científicos (semestre 10)

- Redação de artigos científicos e participação em reuniões científicas afeitas ao tema.

\subsubsection{Fase 4 - Requerimentos do programa de pós-graduação}

- Atividade 4.1 - Preparação e apresentação do exame de qualificação (semestre 5)

- Preparação de apresentação eletrônica, relatório e exemplos.

- Atividade 4.2 - Redação da tese (semestres 4 a 10)

- Organização, escrita e revisão do texto; preparação de imagens e vídeos; revisão e documentação de código para publicação.

- Atividade 4.3 - Preparação e defesa da tese (semestres 9 e 10)

- Revisão final da tese com auxílio de auditores externos e atores sociais, criação de apresentações eletrônicas e documentos de apoio, preparação de infraestrutura para demonstrações de exemplos.

\subsubsection{Cronograma de atividades}

Na FIG. 18, são apresentados o cronograma completo de atividades da pesquisa. 
Fases/Atividades

\section{Fase 1 - Estudo e levantamento}

1.1 - Cumprimento dos créditos necessários em disciplinas obrigatórias e eletivas

1.2 - Identificação dos objetivos específicos e escopo do trabalho

1.3 - Detalhamento dos problemas e necessidades pedagógicas

1.4 - Levantamento bibliográfico dos temas pertinentes

1.5 - Levantamento sistemático

1.6 - Aprofundamento dos fundamentos cognitivos pertinentes

1.7 - Levantamento de tecnologias para a infraestrutura operacional

1.8 - Levantamento e escolha de tecnologias para o desenvolvimento da plataforma

1.9 - Estudos e modelos de técnicas de desenvolvimento de software

Fase 2 - Desenvolvimento e aplicação

2.1 - Construção de modelo e prototipação da implementação de infraestrutura operacional

2.2 - Análise, integração e implementação de infraestrutura operacional

2.3 - Ciclo de análise, desenvolvimento e implementação de métodos e técnicas de síntese de modelos cristalográficos, visualização e interação

2.4 - Ciclo de testes e avaliações

Fase 3 - Análise dos resultados e apresentação

3.1 - Análise comparativa

3.2 - Testes comparativos de síntese e visualização

3.3 - Avaliação das possibilidades interativas

3.4 - Sumarização dos resultados

3.5 - Redação de artigos científicos

Fase 4 - Requerimentos do programa de pós-graduação

4.1 - Preparação e apresentação do exame de qualificação

4.2 - Redação da tese

4.3 - Preparação e defesa da tese $\begin{array}{lllll}\text { ANO } 1 & \text { ANO } 2 & \text { ANO } 3 & \text { ANO } 4 & \text { ANO } 5\end{array}$

$\begin{array}{llllllllll}\text { S1 } & \text { S2 } & \text { S3 } & \text { S4 } & \text { S5 } & \text { S6 } & \text { S7 } & \text { S8 } & \text { S9 } & \text { S10 }\end{array}$

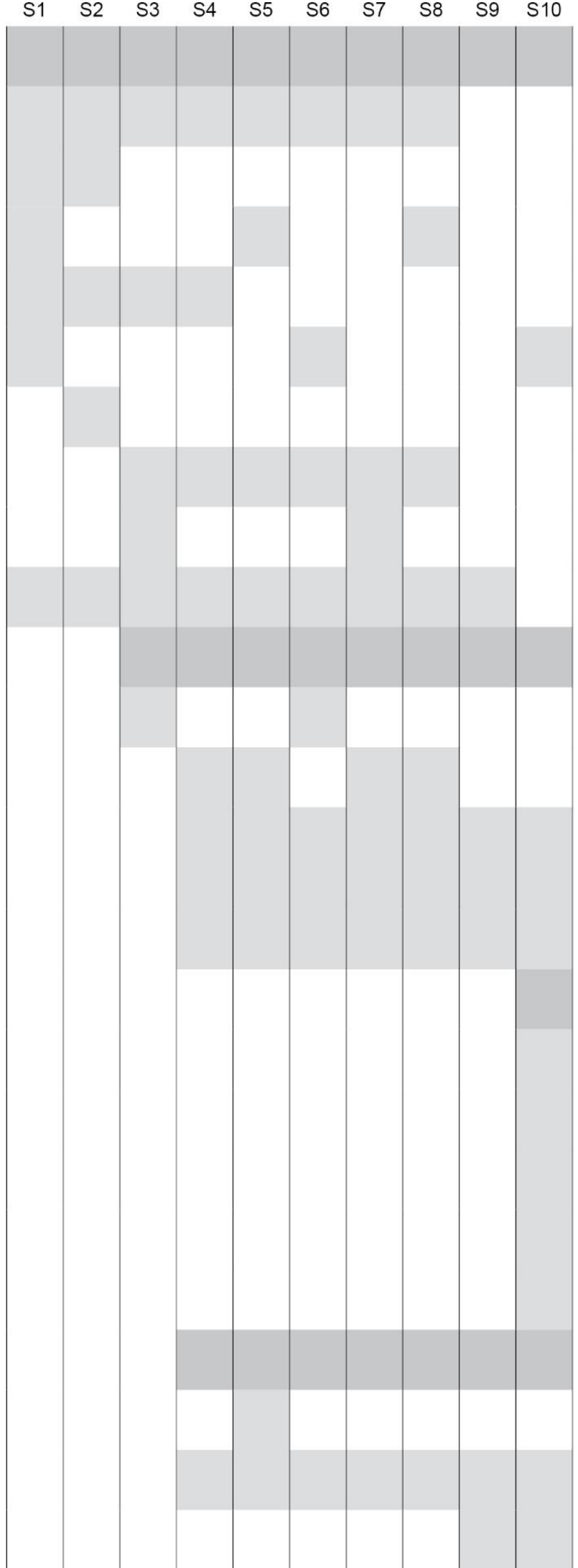

FIGURA 18 - Cronograma de atividades da pesquisa. Fonte: do autor. 


\section{ESTADO DA ARTE}

Neste capítulo, são apresentadas as informações obtidas por meio de levantamento bibliográfico a respeito de tópicos fundamentais para o desenvolvimento do trabalho. Entre os tópicos contemplados, estão: ensino de ciência dos materiais; aspectos cognitivos do uso de mídias tridimensionais interativas; técnicas de computação gráfica, realidade virtual e visualização cientifica; metodologias de desenvolvimento de software e de sistemas computacionais. Em seguida, ainda neste capítulo, são apresentados os resultados do levantamento sistemático do estado da arte de softwares cristalográficos.

\subsection{Problemas técnicos e conceituais no ensino de estruturas cristalinas}

Um cristal é costumeiramente definido como um sólido composto de átomos distribuídos espacialmente segundo um arranjoorganizado (padrão) e periódico (repetitivo). Salvo pequenas variações, é esta a essência do conceito de cristal encontrada em vários livros sobre ciência e engenharia de materiais ou correlatos, desde os mais antigos até os mais recentes. Esta definição resume as colocações de diversos autores consultados (livros didáticos ou obras de referência correlatas): Barrett (1943), Kittel (1996 [1953]), van Vlack (1964, 1966), Schwarzenbach (1996 [1993]), Padilha (1997), Callister e Rethwisch (2007), Graef e McHenry (2007); Szwacki e Szwacka (2010); West (2014).

Estudam-se estruturas cristalinas pois sabe-se que muitas propriedades dos materiais delas dependem em maior ou menor grau. Um exemplo disso são as propriedades mecânicas de cristais cúbicos de face centrada (CFC) ou de corpo centrado (CCC), muito comuns entre os metais. Metais CFC, como o ouro, a prata, o cobre e o alumínio, são relativamente mais dúcteis que metais CCC, como o ferro (à temperatura ambiente), o nióbio, o tungstênio ou o molibdênio. A causa principal é a existência de direções e planos compactos na estrutura CFC, cujo cisalhamento requer menor tensão aplicada, o que facilita sobremaneira a deformação plástica. Entenda-se aqui planos compactos como aqueles de máxima densidade atômica, conforme designação costumeira encontrada em livros de 
metalurgia física (Adda et al., 1987; Guy, 1962; Reed-Hill, 1982; Reed-Hill e Abbaschian, 1994). Já na estrutura CCC, tais planos não existem, porém, aqueles planos de maior densidade atômica e que possuem direções compactas são preferencialmente cisalhados. É oportuno observar que materiais policristalinos hexagonais compactos são relativamente frágeis, apesar de possuir planos compactos (planos basais), pois há outros fatores que determinam a ductilidade.

Outro exemplo, muito abordado em livros didáticos, é o da alotropia do carbono. Esse elemento pode se apresentar na natureza de duas formas: grafite e diamante. As estruturas cristalinas destes materiais são completamente diversas (o diamante é cúbico e o grafite é hexagonal), fruto de ligações químicas diferentes, o que confere, por exemplo, propriedades mecânicas muito distintas: o grafite é utilizado como lubrificante sólido e o diamante é o material natural de maior dureza conhecida.

Um aspecto costumeiramente negligenciado na maioria dos livros didáticos envolvendo ciência dos materiais é a relação entre as redes espaciais (ou de Bravais) e as estruturas cristalinas. O número de redes espaciais é 14, uma vez que não há mais que 14 possibilidades ou maneiras de pontos serem distintamente arranjados no espaço tridimensional de forma que cada ponto tenha exatamente a mesma vizinhança (Atkins e de Paula, 2014). Aliás, tal propriedade das redes espaciais - de qualquer rede de pontos, na verdade, pois o mesmo se verifica em uma, duas ou $\mathrm{n}$ dimensões - é também ignorada nesses mesmos livros. A multiplicidade de estruturas cristalinas frente ao reduzido número de redes espaciais por si só indica que ambas (rede e estrutura) não são a mesma coisa, ao contrário do que os livros didáticos podem fazer parecer ao omitir a diferença conceitual entre elas. O fato é que, na estrutura de qualquer cristal, os átomos estão dispostos de tal modo que há um padrão fundamental que se repete ou é replicado em cada ponto da rede espacial pertinente a um cristal em particular, ou seja, é a rede espacial que define este esquema de repetição. Como bem observa Barrett (1943), "não raro o termo rede (do inglês 'lattice') é empregado indiscriminadamente como sinônimo de estrutura, o que se revela uma prática incorreta e passível de confusão". A mesma confusão poderá advir da omissão mencionada anteriormente. Tome-se, por exemplo, o que ocorre em Materials science and engineering: An introduction (Callister e Rethwisch, 2007), talvez o livro mais difundido sobre o assunto entre cursos de graduação e pós-graduação, onde sequer 
as 14 redes espaciais são apresentadas. No capítulo intitulado "The structure of crystalline solids", o autor discorre sobre estruturas cristalinas mais comuns entre os metais e apresenta as células unitárias dos sete sistemas cristalinos. A certa altura, o autor assume equivocadamente que os pontos da rede coincidem com os átomos do cristal, o que só ocorrerá quando o motivo for formado por apenas um átomo, como será exemplificado adiante. Considera-se que este é um erro primário em uma publicação de tamanha relevância e que pode suscitar a construção de bases conceituais equivocadas.

Prosseguindo com os conceitos de rede e estrutura, a correlação entre os dois pode ser simplificada pela seguinte "equação":

estrutura cristalina $=$ rede + motivo (ou base)

Será adotada aqui a designação "motivo" em vez de base. Motivo é tradução mais óbvia para o português dos termos motif, igualmente usado em francês (Adda et al., 1987) e em inglês (Buerger, 1956), e Motiv, do alemão (Ewald e Hermann, 1943). O termo "motivo" significa um tema recorrente ou um padrão repetitivo, portanto, é plenamente coerente com objeto em pauta.

O motivo mencionado refere-se ao átomo ou conjunto de átomos, dispostos segundo um arranjo particular (o padrão fundamental citado anteriormente), que será replicado em cada ponto da rede. Dessa forma, cada ponto da rede deve ser considerado como endereço de um único átomo ou de vários (pertencentes ao motivo). Naqueles casos onde o motivo é constituído por um único átomo, a designação de rede e estrutura coincide. Este é certamente um aspecto gerador de confusão, sobretudo quando forem consideradas estruturas com mais do que um átomo no motivo. Para ilustrar esta problemática, bem como os conceitos apresentados, alguns exemplos são analisados a seguir.

\subsubsection{Exemplos}

Todos os exemplos desta seção foram ilustrados com imagens extraídas de obras de referência (livros didáticos ou outras obras correlatadas) ou produzidas manualmente, justamente para demonstrar as limitações das representações e dificultades do processo. 


\subsubsection{Exemplo 1 - Rede plana}

A estratégia normalmente utilizada para apresentar os conceitos de rede e estrutura é abordar o que ocorre em duas dimensões (plano), o que facilita a visualização e, consequentemente, a compreensão. A FIG. 19 ilustra esta estratégia de forma bem simples.

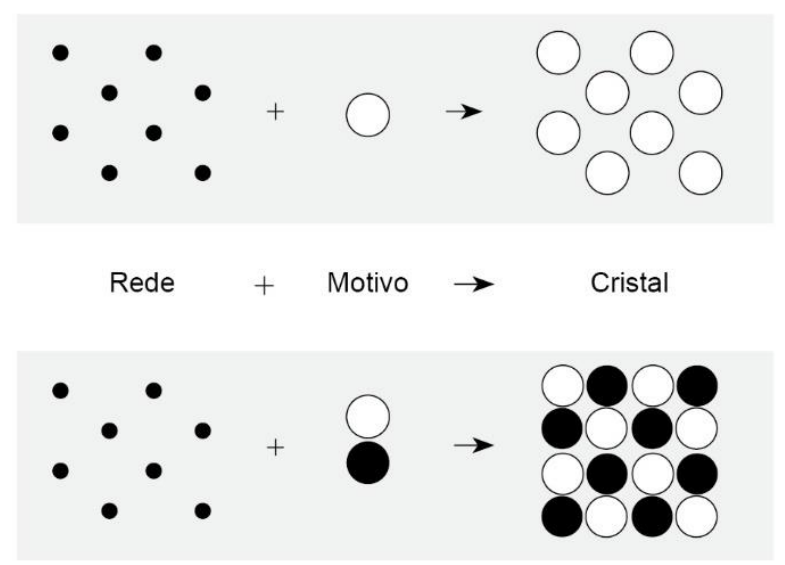

FIGURA 19 - Exemplificação de rede e motivo de estruturas planas. Fonte: Graef e McHenry (2007, p. 56) (adaptado).

Conforme se observa na FIG. 19, as duas estruturas - uma com círculos brancos e outra com círculos brancos e pretos - são descritas pela mesma rede de pontos, neste caso, uma rede quadrada. O que diferencia as duas estruturas é o motivo: na primeira estrutura, o motivo é um círculo branco, replicado em cada ponto da rede; na segunda, um círculo preto é adicionado ao motivo da primeira. Em outras palavras, a multiplicidade de estruturas, que compartilham determinada rede, origina-se da multiplicidade de motivos. Convém notar ainda alguns aspectos relevantes, pertinentes à FIG. 19, e particularmente importantes no presente trabalho:

a) O círculo branco foi posicionado sobre os pontos da rede nos dois casos, o que é arbitrário. Os pontos da rede poderiam recair sobre os círculos pretos e as estruturas finais seriam as mesmas. Os pontos da rede poderiam ainda não coincidir com nenhum dos dois círculos, e nada seria alterado. O importante 
a ressaltar, então, é que a replicação do motivo a partir de sua translação deve seguir o mesmo padrão de translação verificado na rede de pontos (quanto à distância e direção das translações).

b) O círculo preto que integra o motivo da segunda estrutura está abaixo do círculo branco, o que também é arbitrário, pois qualquer dupla de círculos branco e preto é válida.

c) A vizinhança de um determinado círculo branco na primeira estrutura é idêntica a qualquer outro, compatível, portanto, com a vizinhança verificada em cada ponto da rede em questão. A obviedade desta constatação resulta de que o motivo é formado por apenas um círculo, e é necessária para ressaltar o que ocorre na segunda estrutura. Nesta última, a vizinhança de cada círculo branco é idêntica entre todos os círculos brancos, o mesmo acontecendo com a vizinhança de cada círculo preto. Entretanto, as vizinhanças dos dois círculos não são idênticas entre si. Isto pode ser facilmente constatado com a análise apenas dos primeiros vizinhos, para simplificar. O número (4) e a distribuição espacial (norte, sul, leste e oeste) dos primeiros vizinhos de cada círculo branco ou preto são idênticos, mas os primeiros vizinhos dos círculos brancos são círculos pretos, e vice-versa. Em outras palavras, deve ser considerada a vizinhança da dupla de círculos do motivo, e não de cada círculo individualmente.

d) Decorre da observação anterior que a segunda estrutura pode ser interpretada como formada por duas redes quadradas interpenetradas de círculos brancos e pretos, o que pode ser notado ao se reparar apenas nos círculos brancos ou pretos, separadamente.

Uma consequência geral importante dessa análise da FIG. 19 é que cada integrante do motivo apresenta um padrão particular de distribuição espacial, idêntico ao da rede espacial subjacente. Tal consequência não é ressaltada pela bibliografia consultada, mas é fundamental para a compreensão de cristais segundo o conceito "rede + motivo = estrutura cristalina". 


\subsubsection{Exemplo 2 - A estrutura do $\mathrm{CsCl}$}

A estrutura do cloreto de césio ( $\mathrm{CsCl})$, cuja célula unitária está ilustrada na FIG. 20, é a mais simples dentre aquelas formadas por um motivo constituído por apenas dois átomos. Cada átomo de cloro $(\mathrm{Cl})$ possui oito átomos primeiros vizinhos, todos de césio (Cs), localizados nos vértices da célula cúbica. Já a primeira vizinhança de cada átomo de césio é formada por oito átomos de cloro, também dispostos nos vértices de um cubo imaginário, caso fosse considerada uma célula unitária com um átomo de césio no centro (o que é perfeitamente possível, pois a célula unitária é arbitrária). O motivo, portanto, é formado por dois átomos, um de cloro e outro de césio, ambos distribuídos no espaço segundo uma rede cúbica simples, de modo que um deles fique na eventual origem de um sistema de coordenadas vetoriais - $(0,0,0)-e$, outro, na posição $(1 / 2,1 / 2,1 / 2)$.

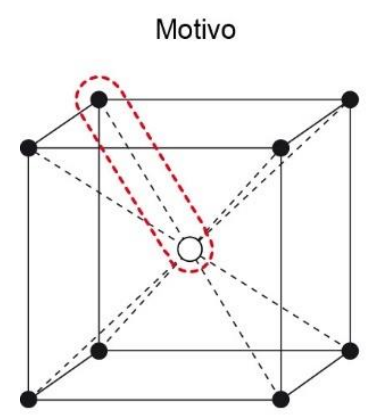

(a)

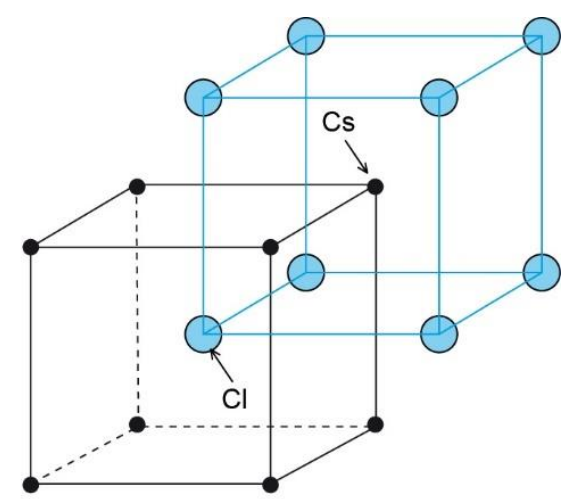

(b)

FIGURA 20 - (a) Célula unitária da estrutura do cloreto de césio ( $\mathrm{CsCl}$ ), indicando o motivo; (b) figura ressaltando as duas redes cúbicas simples, de césio (Cs) e de cloro $(\mathrm{Cl})$, interpenetradas. Fonte: Chen, ([2002]).

No modelo de esferas rígidas do $\mathrm{CsCl}$ (FIG. 21), o átomo central, qualquer que seja ele, deve tocar os átomos dos vértices. Os oito átomos dos vértices só se tocarão entre si caso o raio do átomo central seja igual ou inferior ao raio do interstício central formado por eles, o que não ocorre no caso do $\mathrm{CsCl}$. A rede espacial do $\mathrm{CsCl}$ é, portanto, cúbica simples, e não cúbica de corpo centrado, pois assim seria somente se os átomos dos vértices e do centro fossem todos do mesmo elemento químico, caso do ferro alfa e do nióbio, para citar apenas dois exemplos.

O $\mathrm{CsCl}$ é protótipo estrutural, ou seja, sua estrutura é referência para denominar estruturas similares ("estrutura do tipo CsCl"). O mesmo ocorre com 
outros protótipos, analisados a seguir. Fases de outros materiais cristalizam-se da mesma forma que o $\mathrm{CsCl}$, como o latão beta $(\mathrm{Cu}-\mathrm{Zn})$ e as fases intermetálicas dos sistemas níquel-alumínio (NiAl) e titânio-ferro (TiFe). Não serão abordadas aqui outras nomenclaturas estruturais, embora bastante utilizadas, como a do Strukturbericht (Ewald e Hermann, 1943) e da notação de Pearson, pois nada acrescentariam à discussão conceitual empreendida neste trabalho. Importante salientar que muitos livros didáticos afeitos à ciência dos materiais apresentam a estrutura do $\mathrm{CsCl}$ mas não explicitam sua rede ou motivo.

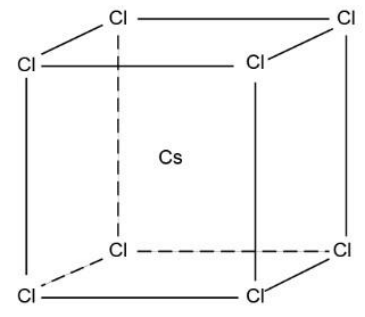

(a)

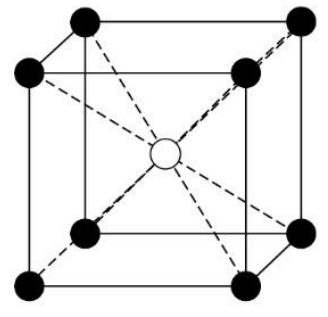

(b)

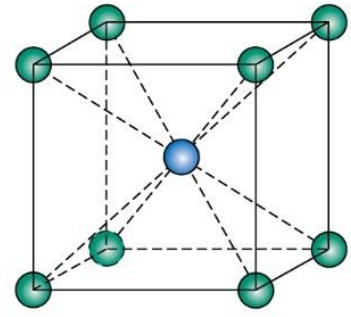

(c)

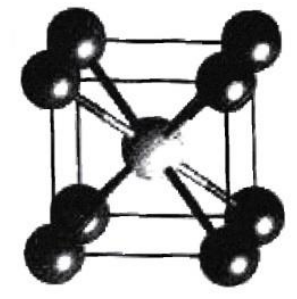

(d)

FIGURA 21 - Exemplos de representação da estrutura do $\mathrm{CsCl}$ extraídos de obras de referência (livros didáticos ou obras correlatas). Fonte: (a) West (2014); (b) Barrett (1943); (c) Callister e Rethwisch (2007); (d) Graef e McHenry (2007) (adaptado).

\subsubsection{Exemplo 3 - A estrutura do magnésio}

O magnésio é protótipo da estrutura denominada hexagonal compacta (HC) (FIG. 22a). Trata-se da rede hexagonal com motivo formado por dois átomos do mesmo elemento químico.

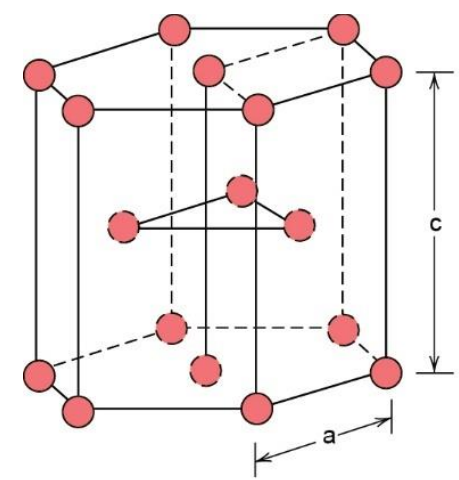

(a)

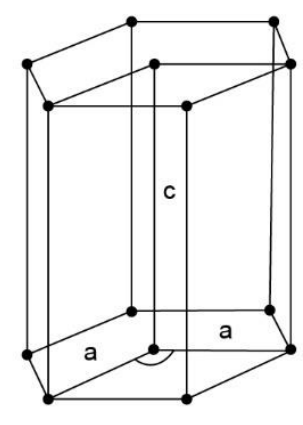

(b)

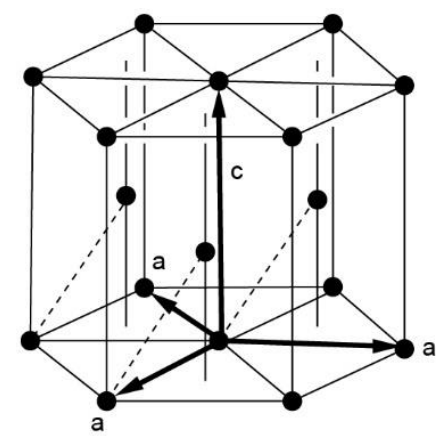

(c)

FIGURA 22 - Estrutura hexagonal compacta $(\mathrm{HC})$ : (a) célula unitária; (b) célula unitária da rede espacial hexagonal; (c) célula unitária HC com indicação do motivo estrutural. Fonte: (a) Callister e Rethwisch (2007); (b) Barret (1943); (c) Olander (1976) (adaptado). 
A estrutura HC é comumente apresentada nos livros didáticos, pois é uma das mais frequentes entre os metais, ao lado das estruturas cúbica de corpo centrado (CCC) e cúbica de face centrada (CFC). Também com relação a este exemplo, a maioria dos livros não relaciona esta estrutura com alguma rede de Bravais. Neste caso, a rede espacial óbvia é a hexagonal (FIG. 22b), cuja célula unitária é formada por pontos nos vértices do prisma hexagonal e no centro das bases (faces horinzontais). Salienta-se que não há quaisquer pontos de rede à meia-altura da célula, como poderia fazer crer a presença dos três átomos de magnésio à meia-altura na célula da estrutura (FIG. 22a). Na verdade, cada um dos três átomos compõe o motivo com um dos átomos do plano basal (FIG. 22cas linhas tracejadas unem os dois átomos que integram cada um dos motivos indicados). Cada átomo de magnésio do motivo forma uma sub-rede hexagonal (duas, portanto), que se interpenetram, de modo que os átomos à meia-altura se encaixam nos vales formados pelos átomos do plano basal. Os planos basais e 0 plano à meia-altura são idênticos e compactos e seu empilhamento ocorre na sequência $A B A B$... É desta alternância de planos que se originam os átomos do motivo, os quais podem ser deduzidos ou melhor entendidos a partir da análise de suas vizinhanças. Cada átomo dos planos basais do prisma hexagonal toca seis outros do mesmo plano, além de três no plano imediatamente acima e abaixo, totalizando doze átomos.

Na FIG. 23a, que ilustra uma projeção do prisma hexagonal segundo a direção do eixo vertical, o átomo central do plano basal do prisma foi realçado, e os três primeiros vizinhos no plano à meia-altura foram coloridos de cinza. Qualquer átomo dos planos basais tem a mesma vizinhança do átomo realçado na FIG. 23a. Já na FIG. 23b, foi realçado um dos átomos do plano à meia-altura, e os três primeiros vizinhos no plano basal foram pintados de cinza. Também agora, qualquer átomo do plano à meia-altura tem a mesma vizinhança do átomo realçado na FIG. 23b. Entretanto, fica evidente que as vizinhanças de um átomo do plano basal e de outro átomo do plano à meia-altura são diferentes, não em relação ao número de primeiros vizinhos (doze em ambos os casos), mas em relação à disposição dos átomos nos planos adjacentes. Dois átomos, portanto, formam o motivo da estrutura hexagonal compacta. 


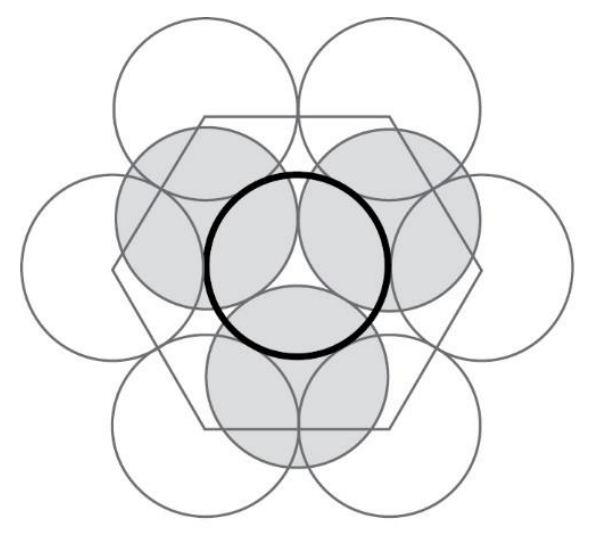

(a)

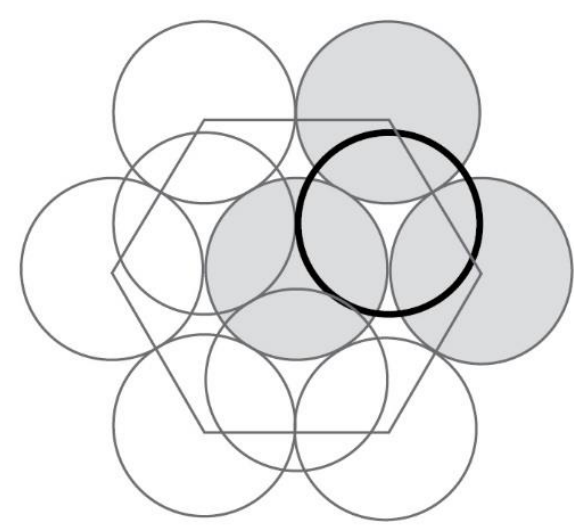

(b)

FIGURA 23 - Vista em planta da célula unitária da estrutura hexagonal compacta (a) vizinhança do átomo central do plano basal; (b) vizinhança de um dos átomos do plano à meia-altura. Fonte: Leal Neto (2016) (adaptado).

\subsubsection{Exemplo 4 - A estrutura do $\mathrm{CaF}_{2}$}

O fluoreto de cálcio - ou fluorita, como é mais conhecido - $\left(\mathrm{CaF}_{2}\right)$, apresenta uma estrutura não tão simples como as anteriores, com três átomos no motivo estrutural. Neste caso, será oportuno ressaltar que há uma diferença entre o motivo adotado neste trabalho e aquele considerado em cristalografia. Tal diferença será esclarecida mais adiante, após a análise da estrutura do $\mathrm{CaF}_{2}$, à luz do conceito de vizinhança, como anteriormente.

$\mathrm{Na}$ estrutura da fluorita, ilustrada na FIG. 24a (Askeland, 1990), os átomos de cálcio estão arranjados de forma a ocupar posições equivalentes aos pontos da rede cúbica de face centrada. Os átomos de flúor estão distribuídos segundo um arranjo cúbico simples, como melhor ilustrado na FIG. 24b (Callister e Rethwisch, 2007). Entretanto, o arranjo cúbico simples dos átomos de flúor é apenas aparente, como será demonstrado a seguir. O motivo estrutural será elucidado a partir da análise da vizinhança dos átomos de flúor e cálcio, com o auxílio da visualização das células unitárias (FIG. 24). 


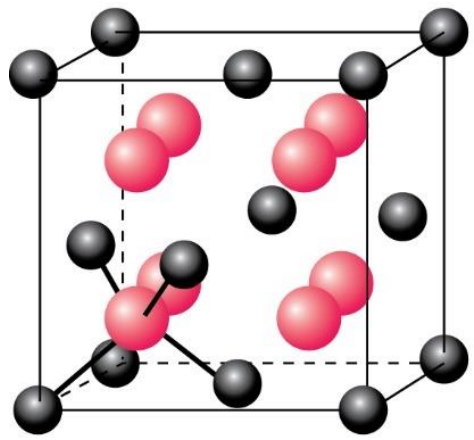

(a)

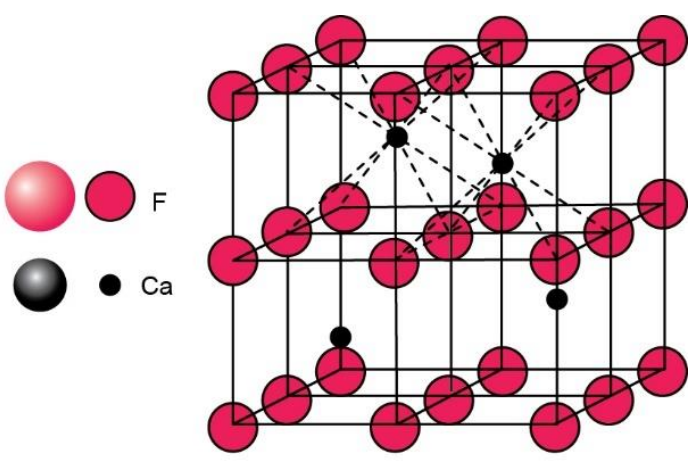

(b)

FIGURA 24 - Células unitárias da fluorita: (a) com átomos de cálcio externos, nas faces e vértices da célula; (b) com átomos de cálcio internos. Fonte: (a) Askeland (1990); (b) Callister e Rethwisch (2007) (adaptado).

Qualquer átomo de cálcio da fluorita possui oito primeiros vizinhos constituídos por átomos de flúor, como pode ser melhor percebido na FIG. 24b. Os átomos de cálcio (círculos pretos) estão no centro de um cubo formado pelos átomos de flúor. A FIG. 24b é bastante útil para a visualização da vizinhança dos átomos de cálcio, porém, o entendimento de que a distribuição de tais átomos obedece o padrão da rede cúbica de face centrada não é trivial neste caso, o que só ocorre com o auxílio da FIG. 24a. Nenhuma das figuras anteriores favorece a análise da vizinhança dos átomos de flúor, o que pode ocorrer com a FIG. 25, onde estão representados cubos de lado correspondente à metade do lado do cubo da célula unitária da FIG. 24a.

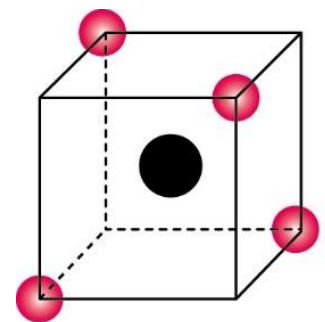

(a)

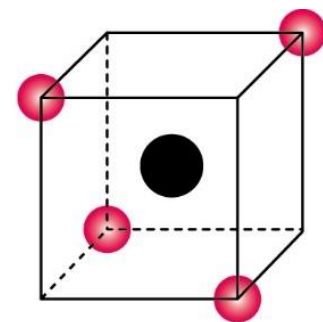

(b)

FIGURA 25 - Ilustração das vizinhanças de cada um dos átomos de flúor do motivo da fluorita. Fonte: Leal Neto (2016) (adaptado).

No centro do cubo da FIG. 25a, está o átomo de flúor, cujas ligações com os átomos de cálcio foram realçadas na FIG. 24a. O átomo de flúor da FIG. 25 b é o átomo que se encontra à direita do anterior. Nota-se claramente que os dois átomos possuem quatro átomos de cálcio como primeiros vizinhos, porém, com disposição distinta. Sob este ponto de vista (vizinhança), há então dois tipos 
de átomos de flúor. Qualquer outro átomo de flúor da estrutura apresentará uma das duas vizinhanças ilustradas. Tal aspecto implica que os dois tipos de átomos de flúor compõem o motivo da estrutura da fluorita, conjuntamente com um átomo de cálcio. Cada um dos átomos do motivo (incluindo, claro, os de flúor) estão distribuídos segundo uma sub-rede cúbica de face centrada. A distribuição dos átomos de flúor, portanto, não segue um padrão cúbico simples, como aparenta, mas é oriunda da interpenetração de duas redes cúbicas de face centrada (uma para cada tipo de átomo de flúor). A visualização destas duas redes não é trivial, mas será muito facilitada com o uso do software proposto, o CrystalWalk, conforme será visto na seção 4.5.3. Cabe ressaltar que a análise aqui exposta não foi encontrada em nenhuma das referências citadas na bibliografia.

\subsubsection{Considerações gerais sobre os exemplos apresentados}

Posto isso, pode-se agora discorrer sobre a aludida diferença entre o tipo de motivo considerado neste trabalho e o adotado em cristalografia. Esse conceito de motivo, tal como descrito por Graef e McHenry (2007), Hammond (2009) e Tilley (2006), pode ser chamado de completo ou "translacional", visto que se trata daquele conjunto de átomos cuja simples translação entre pontos da rede é capaz de reproduzir os átomos de determinada estrutura cristalina. Tal motivo "translacional" não é o adotado em cristalografia. Os cristalógrafos enfatizam as operações de simetria pertinentes a cada estrutura cristalina, de forma que adotam um motivo assimétrico, posto que é formado por um número mínimo de átomos, a partir do qual as operações de simetria pontual geram outros átomos do motivo "translacional" adotado neste trabalho. No exemplo da fluorita, o motivo cristalográfico contém um átomo de cálcio e apenas um átomo de flúor, pois o outro é gerado por uma operação de simetria. Considerase, portanto, que a adoção do motivo cristalográfico não é apropriada ao contexto didático, pois a teoria de grupos espaciais é muito complexa para fases introdutórias de aprendizado do tema, com grande potencial de provocar confusões entre estudantes, mesmo em nível de pós-graduação.

\subsubsection{Problemas na representação de estruturas cristalinas em obras de referência}

Com o objetivo de superar limitações inerentes à representação bidimensional, livros didáticos e outras obras de referência valem-se de diversos recur- 
sos gráficos para compensar a falta de estímulos propiciados pela experimentação e interação natural e tridimensional com objetos reais. Neste item, a partir de uma análise da abordagem de visualização adotada por autores clássicos, foram compilados os problemas de visualização encontrados, para, então, avaliar a eficácia das soluções propostas nas obras de referência e definir o que seriam boas práticas que possam ser incorporadas à especificação proposta para o CrystalWalk. Para tal fim, foram consultados: van Vlack (1966), Callister e Rethwisch (2007), Barrett (1943), Kittel (1996), Graef e McHenry (2007), West (2014) e Padilha (1997).

Em suma, os principais problemas encontrados foram:

- oclusão devido a pontos de vista fixo;

- posição ambígua de elementos, na ausência do senso de profundidade;

- imprecisão na profundidade dos elementos, na ausência da tridimensionalidade;

- deformação de forma e tamanho quando do uso de perspectivas técnicas, que alteram o senso de proporção;

- dificuldades de distinção (classificação e agrupamento) entre elementos ou grupos, quando da utilização de representações abstratas.

Esses problemas, bem como as soluções adotadas pelos livros analisados, serão detalhados nas seções 3.1.2.1 a 3.1.2.5.

\subsubsection{Oclusão}

A oclusão ocorre quando um objeto impede a visão de outros. Seja dada uma estrutura cristalina, haverá, na representação de sua célula unitária, sob qualquer ponto de vista, um certo grau de oclusão. No entanto, na representação de seu cristal, haverá um grau de oclusão ainda maior. A primeira medida comumente adotada é reduzir natural ou propositalmente elementos à frente ou ao fundo. A perspectiva cônica é uma maneira natural, mas raramente usada pelas referências, sendo Kittel (1996) uma das exceções (FIG. 26b). Essa perspectiva, geralmente, auxilia a detectar átomos mais ao fundo mesmo em situações de confusão visual. Já a redução proposital dos átomos é uma solução mais comum, na maioria dos casos realizada por meio da representação "balls and sticks" ("bolas e palitos") (FIG. 26a) ou com o uso de vistas ortogonais e cores diferenciadas para 
cada plano de empacotamento, diminuindo propositadamente o tamanho dos átomos a cada novo plano representado (FIG. 26b).

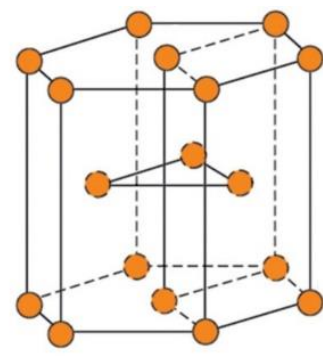

(a)

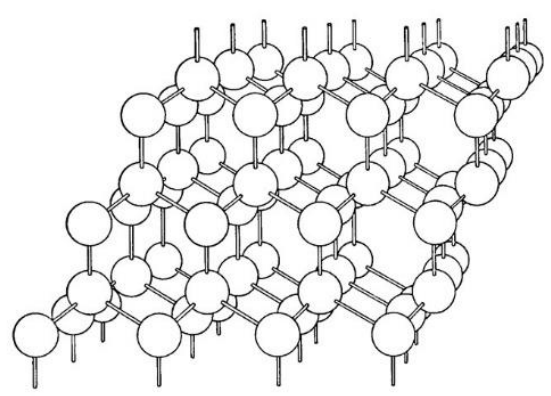

(b)

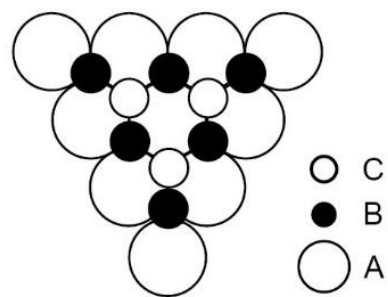

(c)

FIGURA 26 - Recursos para lidar com oclusão: (a) modelo "balls and sticks"; (b) perspectiva cônica; (c) diminuição do tamanho dos átomos. Fonte: (a) Callister e Rethwisch (2007); (b) Kittel (1996); (c) Padilha (1997) (adaptado).

Outra solução para a oclusão é a adoção de simbolismo gráfico como linhas contínuas ou pontilhadas. Autores como Barrett (1943) demonstram sensibilidade no uso de linhas continuas (FIG. 27a), mas outros usam-nas em situações inadequadas, causando poluição do desenho e confusão (FIG. 27b). Um uso corrente e considerado adequado é indicar átomos oclusos ao fundo com contorno em linha pontilhada (FIG. 27c). Uma solução análoga é o uso da transparência aliada à cor. Como exemplo, Callister e Rethwisch (2007) recorreram a essa solução para demonstrar planos de empacotamento mantendo o tamanho dos átomos (FIG. 27d).
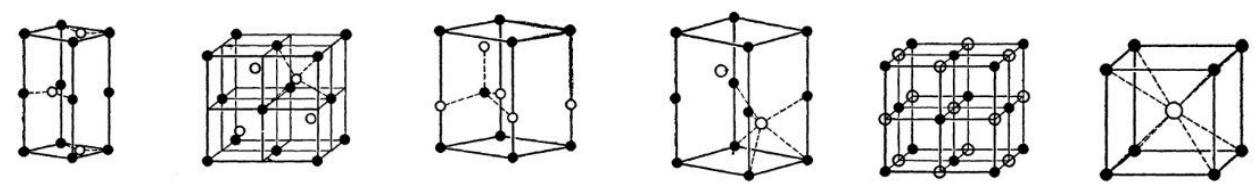

(a)

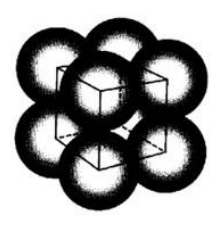

(b)

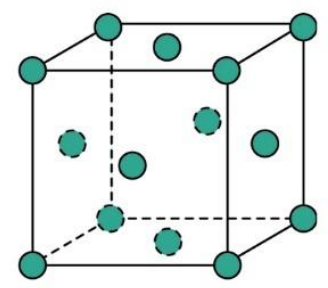

(c)

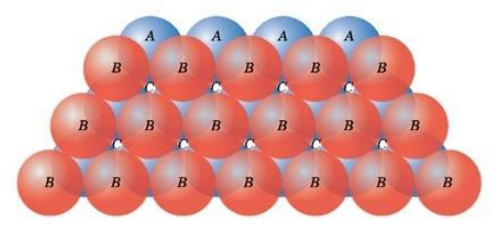

(d)

FIGURA 27 - Uso de simbolismo gráfico para lidar com oclusão: (a) linhas pontilhadas auxiliares; (b-c) linhas pontilhadas para objetos em profundidade; (d) transparência. Fonte: (a) Barrett (1943); (b) Padilha (1997); (c-d) Callister e Rethwisch (2007). 
Cortes também solucionam a oclusão, sendo tradicionalmente executados nos limites da célula unitária (FIG. 28a) e, eventualmente, em determinados planos em vista ortogonal, para evidenciar contatos atômicos (FIG. 28b).

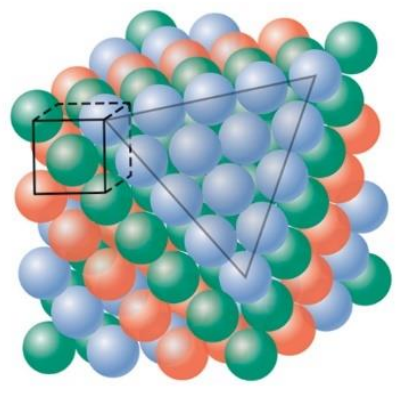

(a)

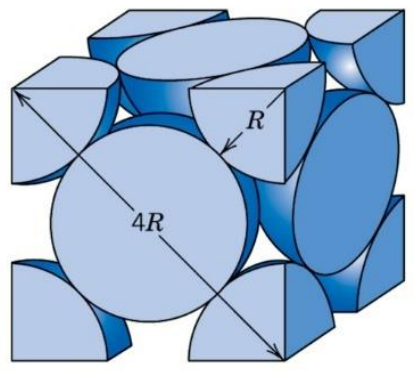

(b)

FIGURA 28 - Uso de corte para lidar com oclusão: (a) parte interna da célula unitária; (b) corte em plano compacto. Fonte: Callister e Rethwisch (2007) (adaptado).

\subsubsection{Posição relativa}

A verificação da posição relativa entre dois objetos depende de condições de visualização favoráveis e de pontos ou estruturas de referência para confirmar a angulação e a distância. A oclusão pode impedir um posicionamento ideal e determinados pontos de vista e tipos de perspectiva podem prejudicar a correta percepção.

Diversas soluções são propostas nesta frente, devido à necessidade primária de explicitar a estrutura geométrica. A solução mais recorrente é oferecer referências simbólicas com linhas contínuas ou pontilhadas. $O$ desenho de geometria da célula unitária muitas vezes confunde, pois linhas contínuas atropelam os átomos, perdendo o senso de profundidade (FIG. 27b). Divisões adicionais da célula unitária são usadas para explicitar posições de outros átomos mais internos (FIG. 29a), solução cuja eficácia depende da complexidade da estrutura (FIG. 4b, seção 1.1). Linhas diagonais pontilhadas podem indicar átomos fora dos vértices - a exemplo da estrutura do CsCl (FIG. 27a) -, solução efetiva, pois usa apenas dois pontos como referência, facilitando traçar uma linha. Linhas avulsas podem também ser usadas para situar átomos mais internos, o que geralmente confunde, mas também para indicar conexões fora da célula unitária, tal como feito por van Vlack (1966), o que pode auxiliar a determinar a posição aproximada do átomo dentro da célula (FIG. 29b). Além de linhas, planos também podem ser referência 
de alinhamento, artifício mais eficaz quando combinado a cor e transparência e quando seus vértices se encontram nos centros de átomos (FIG. 29c). Apesar de ser incomum, referências auxiliares como eixos xyz ou abc, com marcações, auxiliam a identificar alinhamentos e proporções em perspectivas. Quando linhas e grids são adotados, a indicação de ângulos e dimensões repetitivas explicita pontos de maior relevância.

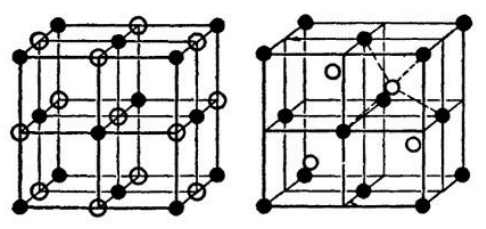

(a)

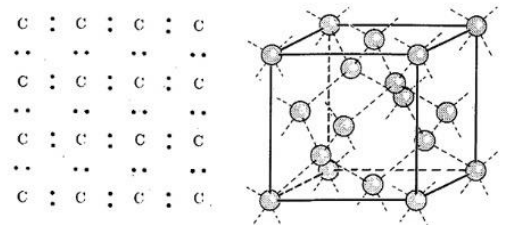

(b)

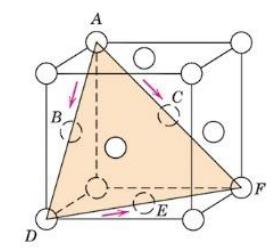

(c)

FIGURA 29 - Uso de referências geométricas para ilustrar posição relativa de átomos: (a) subdivisões da célula unitária; (b) linhas parciais; (c) planos. Fonte: (a) Barrett (1943); (b) van Vlack (1966); (c) Callister e Rethwisch (2007).

Vistas ortogonais auxiliares são muito usadas para situar precisamente os átomos nos eixos $\mathrm{x}, \mathrm{y}$ e $\mathrm{z}$, indicando eventualmente, a exemplo de Barrett (1943), medidas numéricas auxiliares (FIG. 30a). Também é possível indicar ângulos e distâncias ortogonais para átomos em planos diferentes, tal como exemplificado em Padilha (1997) para planos de empacotamento (FIG. 26c). West (2014) usa diversas vistas simultaneamente para explicitar os planos (FIG. 30b).
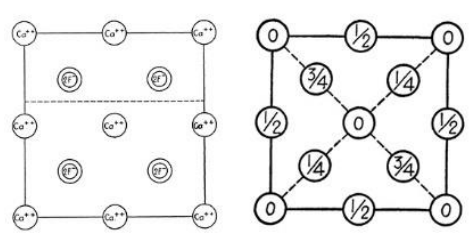

(a)

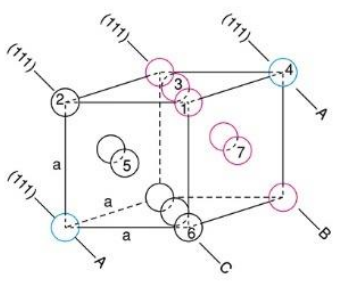

(b)

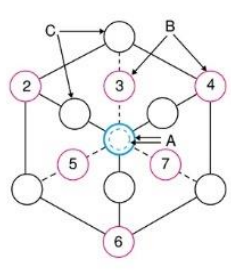

)

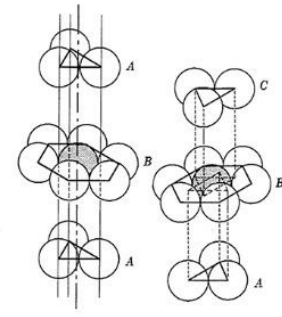

(c)

FIGURA 30 - Recursos para ilustrar posição relativa de átomos: (a) medidas numéricas; (b) projeções; (c) guias de alinhamento. Fonte: (a) Barrett (1943); (b) West (2014); (c) van Vlack (1966).

Partindo do mesmo princípio das vistas ortogonais, cortes em um ou mais planos ou o alinhamento de eixos de perspectiva (como na perspectiva cava- 
leira) com determinados planos (FIG. 30b, inferior, a esquerda), permitem precisar a posição relativa entre átomos e também, em especial, os pontos de contato.

A FIG. 28b demonstra o uso de repetição de elementos ou agrupamentos em 3D para explicitar empilhamentos, utilizando opcionalmente cores para diferenciar os planos de empacotamento. Por fim, van Vlack (1966) usa vistas explodidas dos planos de empacotamento com guias de alinhamento auxiliares (FIG. 30c).

\subsubsection{Senso de profundidade}

O senso de profundidade é dado por um conjunto de estímulos, como a visão estereoscópica, o sombreamento e referências a outros objetos. Existem diversas técnicas de produção de imagens bidimensionais para que elas repliquem tais estímulos. Uma solução prática é o uso de fotografias de maquetes físicas, proporcionando sombreamento e perspectivas naturais. Também são técnicas muito comuns nas referências o uso de padrões gráficos (hachuras) ou de desenhos com sombreamento artístico (FIG. 27b, 30a).

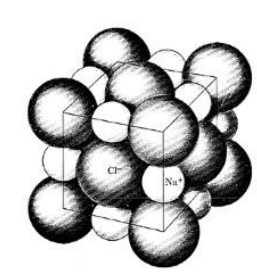

(a)

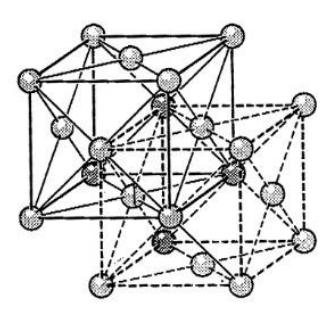

(b)

FIGURA 31 - Recursos para prover senso de profundidade: (a) sombreamento; (b) linhas pontilhadas. Fonte: van Vlack (1966).

Simbolismos como linhas de fundo pontilhadas podem ser eficientes, mas causam poluição visual e confusão quando empregados em situações inadequadas (FIG. 31b). Recurso similar é a transparência, adotada em referências mais atuais e, normalmente, aliada a cor, permitindo distinguir os objetos e os níveis de profundidade.

Outro recurso é a perspectiva cônica, embora raramente usada em ilustrações. Um exemplo (FIG. 26a) extraído de Kittel (1996) demonstra que a detecção de átomos mais ao fundo é mais intuitiva, mesmo em situações de oclusão e confusão visual. 


\subsubsection{Forma e tamanho relativo}

É necessário representar com precisão a forma e tamanho das células unitárias, assim como indicar proporções entre os átomos, especialmente em perspectivas.

A forma pode ser indicada por técnicas de sombreamento, muito utilizadas para representar a forma esférica de átomos - em alguns casos, unidas à indicação numérica do raio e ao destaque dos pontos centrais, seja em transparência, seja em corte. Cortes nos limites da célula unitária são extremamente comuns e úteis para confirmar forma e proporções (FIG. 28b).

\subsubsection{Agrupamento e classificação}

A correta distinção entre elementos ou o destaque dos mais relevantes depende de um adequado tratamento das representações. Os itens destacados pelos autores são elementos químicos, planos, direções cristalinas e células unitárias, além de empilhamentos de grupos atômicos.

Átomos são diferenciados com cores, diferença de raio, indicação textual, legenda ou mesmo por meio de símbolos (FIG. 32a). Células unitárias são normalmente representadas por cubos compostos por linhas ou faces coloridas transparentes. Planos são destacados por hachuras (linhas direcionais) ou cores transparentes.

No caso de distinção de planos compactos e explicitação de empilhamentos, são usados cortes no cristal ou alinhamento da perspectiva com determinados planos (FIG. 30b; 32b), repetição de planos paralelos em 2D ou 3D, usando cores diferenciadas para cada plano (FIG. 28b), variação do raio atômico ou transparência em vistas ortogonais (FIG. 26c; 27d).

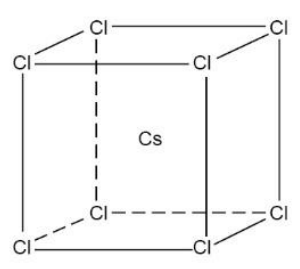

(a)

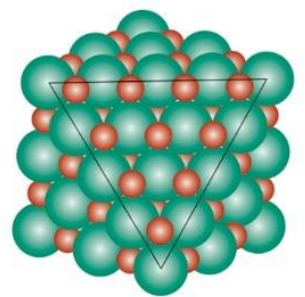

(b)

FIGURA 32 - Recursos para distinção e classificação de elementos: (a) indicação textual; (b) planos. Fonte: (a) West (2014); (b) Callister e Rethwisch (2007) (adaptado). 


\subsubsection{Técnicas usuais e boas práticas}

Por meio da análise empreendida na seção 3.1.2, entendeu-se que Barrett (1943) foi o autor cujas representações mais se destacaram entre os casos analisados. Apesar de ser uma das obras mais antigas do conjunto analisado, suas representações demonstram clareza, equilíbrio e elegância, possivelmente decorrente de sua experiência didática e de seu domínio de geometria e desenho técnico. Dentre as referências mais recentes, West (2014) utiliza técnicas contemporâneas de maneira mais criativa, manipulando parâmetros da perspectiva e características visuais dos elementos, além de incluir informações textuais adicionais de maneira equilibrada. Pode-se dizer que West (2014) pôde usufruir das boas práticas e da experiência dos autores anteriores, além de todas as tecnologias de computação gráfica contemporâneas.

Foi possível identificar algumas técnicas que permitem contornar, com razoável eficiência e/ou de maneira mais intuitiva, mais que um dos problemas identificados. O raro uso de perspectiva cônica nas referências é inusitado, pois se trata da forma como o ser humano enxerga o mundo. Todavia, quando as referências mais antigas surgiram, era um tipo de representação difícil, custoso e pouco acessível. A combinação da perspectiva cônica com técnicas de sombreamento gera representações intuitivas que se valem do capital sensorial visual humano (FIG. 33). Além disso, se combinada com visão estereoscópica, essa forma de representação atinge um nível de fidelidade muito próximo à experiência com modelos físicos.

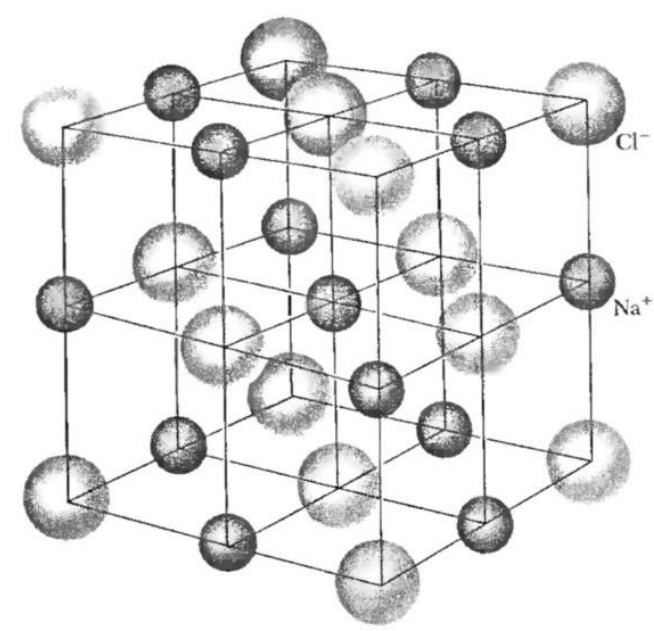

FIGURA 33 - Exemplo do uso de perspectiva cônica com sombreamento. Fonte: Kittel (1996). 
O simbolismo gráfico é tradicional na geometria descritiva e muito eficiente para criar estruturas espaciais auxiliares, tais como a representação da célula unitária, eixos, subdivisões e grids espaciais, além de linhas ou planos contrastantes alinhados com centros de átomos ou referências na célula unitária ou no cristal. Cores, símbolos, legendas, ícones, linhas e vértices são eficientes para destacar ou agrupar objetos (elementos atômicos, grupos de átomos) ou atributos relevantes de objetos, tais como os centros atômicos, magnitude dos raios e pontos de contato. Artifícios graficamente mais avançados como transparência, se bem combinados com os outros supracitados, permitem uma exploração muito rica e precisa de estruturas cristalinas.

Cortes e vistas ortogonais, artifícios igualmente herdados do desenho técnico, são amplamente utilizados, pois permitem filtrar informação visual e atingir regiões internas dos modelos, usufruindo dos alinhamentos proporcionados pelas diversas referências espaciais presentes em uma estrutura cristalina, tais como suas faces, arestas e vértices, além dos planos e direções cristalinas. Outro artifício relacionado e raramente utilizado - apesar de seu amplo emprego nas engenharias - são as vistas explodidas. A separação sistemática e estruturada dos elementos permite remover a oclusão, mantendo o ordenamento e posição relativa. A alteração do tamanho dos átomos é mais utilizada e permite diminuir a oclusão sem alterar a posição dos elementos.

Por fim, a repetição de elementos tais como motivos (multiplicados na rede cristalina) e células unitárias (compondo cristais) ou o empilhamento de diversos planos compactos proporcionam uma visão das estruturas cristalinas em múltiplas escalas e, possivelmente, uma compreensão espacial superior.

\subsection{Benefícios do uso de mídias digitais tridimensionais interativas no ensino}

O mero uso de tecnologia não garante melhorias no aprendizado ou nas técnicas de ensino (Kelly, 2001). Estudos indicam que a estratégia pedagógica é mais relevante para a efetividade do aprendizado que as mídias e meios utilizados (Clark e Feldon, 2005; Bernard et al., 2004).

Segundo Shepard (2003), as mídias educacionais bem projetadas podem trazer benefícios diversos. Entre eles, o desenvolvimento de habilidades como resolução de problemas, decisão, pensamento de alto nível, entendimento sistêmico, autonomia e foco. Além disso, tais mídias podem favorecer o controle 
sobre o encadeamento e sequenciamento de informações, o acesso a informações auxiliares e de apoio, a diversidade de pontos de vista, a participação ativa e a aplicação de conhecimentos em tarefas contextualizadas.

Assim, a criação de novas ferramentas baseadas em tecnologias interativas requer o suporte de princípios e abordagens didáticas eficientes, fundadas nas teorias de aprendizagem, visando aumentar o potencial de aprendizado. Esse conhecimento informará os métodos de apresentação e manipulação dos modelos criados. A literatura sobre a utilização de meios visuais no ensino é vasta, e este tópico 3.2 será dedicado a discutir o potencial dessas tecnologias, especialmente de modelos tridimensionais interativos.

\subsubsection{A importância da estratégia pedagógica para o aprendizado}

A psicologia cognitiva buscou evidências da aprendizagem nas alterações que ocorrem no comportamento das pessoas, como resultado da experiência vivenciada pelo aprendiz (Lefrançois, 2008). A psicologia cognitiva tem interesse nos processos mentais superiores, ou seja, processos que envolvem percepção e reconhecimento, resolução de problemas e tomada de decisões, planejamento e raciocínio, memória, aprendizado, compreensão, leitura, fala e audição e processamento de informações (Preece, 2005; Ferraz e Belhot, 2010, 2007).

O cognitivismo se ocupa de entender como o indivíduo conhece (cognição), como se constrói sua estrutura cognitiva (metacognitiva) e como os eventos e objetos do universo são interpretados pelo aprendiz, atribuindo significados, armazenando, modificando e compreendendo a informação. Essa vertente também é conhecida na literatura como construtivismo, termo derivado de um de seus princípios básicos: o entendimento de que o conhecimento se dá por construção (Moreira, 1999). Segundo essa visão, o processo de aprendizagem consiste em incrementar, combinar e rearranjar coleções de mapas cognitivos, muitos deles sobrepostos ou interconectados em uma complexa rede de associações (Unesco, 2002).

No entanto, o sistema educacional predominante vigente é orientado a categorizar o conhecimento e a analisar recortes dele, ao invés de abordar o conhecimento de forma integrada (Bruer, 1993). Bronowski (1990) afirma que, na perspectiva construtivista, a realização de conexões mentais é um ato criativo e consciente. O "ato de unificação" postula que as conexões podem até ser explici- 
tadas, mas só pode ser consumada pelo estudante. No entanto, Bransford et al. (2000) sugerem que esse ato de integração só pode ser realizado na ausência de barreiras ao aprendizado, ou seja, o desenvolvimento de redes de conhecimento requer que o estudante esteja motivado e aprenda sobre um tópico de maneira que se demonstre relevante e importante a ele. À luz dessas afirmações, é alarmante a colocação de Torraca (2009), que afirma ser comum que estudantes de engenharia e arquitetura tenham pouco interesse em ciência dos materiais. A fim de reverter problemas como este, estudos indicam que o interesse pode ser estimulado em contextos de alta interatividade, como é o caso de aplicações de realidade virtual (Byrne, 1996).

O aprendizado também pode ser otimizado quando o estudante desenvolve estratégias metacognitivas, expondo conhecimentos anteriores e criando oportunidades de corrigir erros e de verificar onde se inserem os novos conceitos (Bransford et al., 2000). O estudante autorregulado tem consciência sobre seu conhecimento de um assunto, sendo a autorregulação crucial em todas as fases do aprendizado, com o potencial de aumentar substancialmente o significado e valor do aprendizado (Schoenfeld, 1987). Nessa perspectiva, Hsiao (1999) indica que as tecnologias digitais podem ser utilizadas para expor o conhecimento dos estudantes, favorecendo o desenvolvimento das habilidades metacognitivas e formando estudantes reflexivos e autorregulados. Nesta linha, o estudante também pode se tornar consciente da maneira como apreende os conteúdos, pois a forma ótima de aquisição do conhecimento é muito individual. Alguns aprendem melhor visualmente, outros, verbalmente, outros ainda, por meio de exploração e dedução. Assim, as técnicas de visualização podem ser usadas no processo de ensino-aprendizagem para adaptá-lo a diferentes formas de aquisição de conhecimento, favorecendo o desenvolvimento cognitivo em diferentes níveis de aprendizagem (Nunes, 2014).

Segundo Gobert (2000), existem três tipos de modelos pertinentes ao processo de aprendizagem. Modelos mentais são representações individuais usadas para raciocinar sobre problemas e eventos. Modelos expressos são aqueles externalizados por meio da fala, escrita e desenhos, sendo que, quando são negociados e aceitos por um determinado grupo, são denominados modelos conceituais. Já modelos de ensino são aqueles desenvolvidos e usados por educadores para promover o entendimento de um certo sistema. Diversos modelos de 
ensino podem se referir a um mesmo tópico, e as diferenças decorrem da ênfase em um determinado aspecto.

O construtivismo postula que os indivíduos constroem seu conhecimento de maneira a dar sentido ao mundo onde vivem, assim, o modelo mental deve se mostrar funcional ao individuo que o constrói. Essa postura filosófica ajuda a explicar a costumeira disparidade entre o modelo mental do estudante e os modelos conceituais ensinados em sala de aula (Kelly, 2001).

Ajustes no processo de ensino dependem do diagnóstico e mensuração das disparidades entre os modelos mentais individuais e os modelos de ensino. A Taxonomia de Bloom (Bloom et al., 1956) é um dispositivo que foi criado para apoiar a classificação dos objetivos educacionais, tendo sido amplamente utilizada na área educacional, por ser adaptável a todos os domínios de conhecimento (Ferraz e Belhot, 2010). A taxonomia estrutura a aquisição de conhecimento em seis níveis de complexidade - conhecimento, compreensão, aplicação, análise, síntese e avaliação - criando uma hierarquia de competências cognitivas e relacionando a aquisição de conhecimento à mudança de comportamento do aprendiz. Posteriormente, tornou-se mais flexível, admitindo que nem todos os níveis ocorrem em todos os casos e que raramente ocorrem na sequência definida. De acordo com a revisão dessa taxonomia realizada por Anderson et al. (2001), existem ações relacionadas a cada categoria do domínio cognitivo, conforme sintetizado na FIG. 36. A Taxonomia de Bloom oferece, portanto, uma abordagem prática para identificar e mensurar o aprendizado.

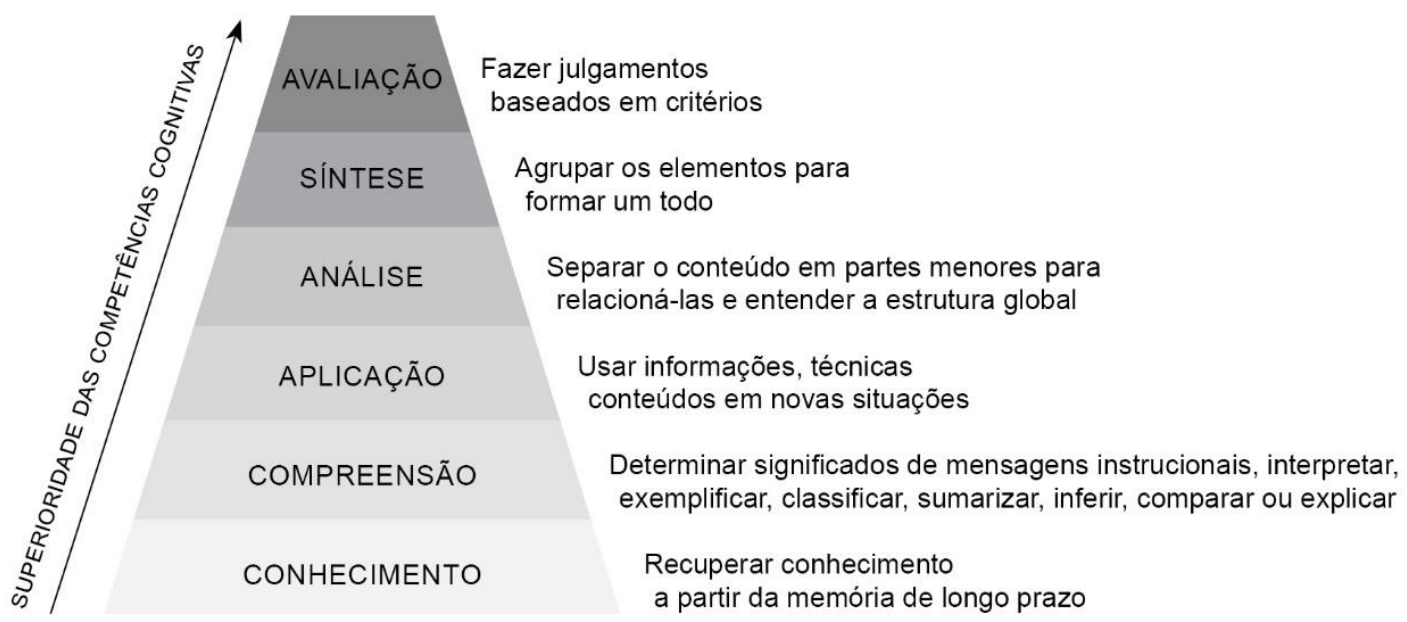

FIGURA 34 - Categorias do domínio cognitivo e ações a elas relacionadas conforme Anderson et al. (2001) em revisão à Taxonomia de Bloom. 
Em suma, as estratégias didáticas devem reduzir barreiras ao aprendizado, expor concepções errôneas ou preconceituosas, empolgar o estudante e estimular o desejo de aprender, demonstrar a utilidade da informação em contextos reais de aplicação, identificar o estilo de aprendizagem individual e transmitir informação de forma facilitada. Refletir sobre o processo de produção do conhecimento e sobre o processo de aprendizado permite identificar os mecanismos ótimos de aprendizagem individuais e facilita a integração do conhecimento. Sistemas didáticos modernos adaptativos podem identificar tanto os estilos de aprendizagem individuais como disparidades entre os modelos mentais e os modelos de ensino.

\subsubsection{Benefícios de modelos tridimensionais}

Modelos tridimensionais podem ser considerados, segundo a classificação de Harrison e Treagust (2000), modelos analógicos. Tais modelos pretendem reproduzir diretamente um ou mais atributos do objeto a ser estudado, refletindo correspondências (objeto real $\leftrightarrow$ modelo) para o conjunto de atributos que se pretende reproduzir e elucidar. Seguindo essa definição e tendo como base tecnologias atuais de computação gráfica, modelos 3D podem tanto reproduzir algumas características da realidade, de maneira abstrata, como reproduzir todas as características esperadas, seguindo uma abordagem hiper-realista.

Tori (2010) afirma que há uma série de vantagens cognitivas em se utilizarem interfaces tridimensionais como meio de navegação em aplicações educacionais. Tais vantagens estão relacionadas principalmente com a familiaridade e naturalidade do domínio - o cérebro processa naturalmente modelos tridimensionais para interpretar o meio ambiente, mesmo que a complexidade visual e o volume de dados sejam enormes.

Devido a essa familiaridade, modelos tridimensionais são fáceis de compreender (Robertson et al., 1991). De acordo com Tori (2010) mais capacidade cognitiva fica à disposição do usuário quando navega por interfaces que simulam ambientes reais. A diminuição de complexidade do conteúdo apresentado (Fairchild, 1993; Ware, 1994) reduz a sobrecarga cognitiva e possibilita o aumento da quantidade de dados com a qual o usuário é capaz de interagir (Fairchild et al., 1988; Robertson et al., 1991; Ware, 1994). Estudos sobre aprendizado também indicam que a apreensão de conteúdos é mais rápida e 
persistente quanto mais direto (menos abstrato) for o contato com o fenômeno estudado (Huk, 2006).

Outra vantagem é a maior naturalidade de interação com objetos virtuais tridimensionais. O usuário interage diretamente - dependendo da tecnologia envolvida, pode explorar inclusive os movimentos do corpo - e orienta-se mais facilmente ao navegar por uma interface tridimensional, comparado a uma constituída apenas de ícones e/ou menus (Tori, 2010). Os ambientes 3D também facilitam a sensação de imersão e aumentam as percepções de presença e proximidade, estimulando a participação ativa do estudante (Tori, 2010).

No entanto, não se pode dizer que o uso de modelos tridimensionais leva necessariamente a melhorias no processo de aprendizado. Roth e Bowen (2002) verificaram que, se os estudantes não são treinados para interpretar dados visuais, o impacto de recursos multimídia no aprendizado é mínimo. De fato, Keehner et al. (2004) observaram um uso mais prolongado de modelos tridimensionais por estudantes com alta habilidade espacial. Huk (2006) indica que essa habilidade diminui a carga cognitiva, assim, estudantes espacialmente menos habilidosos são prejudicados pela sobrecarga e tendem a não usufruir de modelos tridimensionais.

McGee (1979) demonstrou que existe alta correlação entre a habilidade espacial e o sucesso em engenharia e matemática. Outros trabalhos (Smith, 1964; Pellegrino et al.,1984) também reforçam a importância da habilidade espacial na resolução de problemas em outras áreas, como design, arquitetura, física e matemática. As atividades sugeridas para aprimorar esta habilidade são similares às conduzidas no ensino de desenho técnico, disciplina comum nos cursos de engenharia (Baartmans e Sorby, 1996a; 1996b; Ben-Chaim et al.,1985; Smail, 1983). Dixon (1995) sugere que a experiência prática com computação gráfica também pode aumentar as habilidades espaciais dos usuários. Já Lord (1987) apoia atividades espaciais em geral para desenvolver essa habilidade.

Desta forma, a habilidade espacial deve ser um fator comum aos estudantes de engenharia, especialmente nos mais treinados em desenho manual (técnico e artístico, bidimensional e tridimensional) ou digital e em montagem de modelos físicos. Espera-se, portanto, que esses estudantes se beneficiem com o uso desses modelos. Além disso, segundo Harrison e Treagust (2000), estudantes mais esclarecidos assumem que nenhum modelo é suficiente para reproduzir 
completamente um fenômeno. Desta maneira, a variedade de facetas, seja dos diversos modelos de ensino existentes para um mesmo fenômeno, seja dos diversos modelos tridimensionais derivados, pode ser benéfica ao aprendizado e à construção de modelos mentais mais complexos e completos. Sistemas digitais de visualização podem viabilizar a mudança ágil e sutil entre modelos, auxiliando a superar as lacunas entre o modelo criado na mente do estudante e o que se pretende ensinar.

\subsubsection{Animação e interação}

Estudos indicam que a exploração dinâmica de modelos tridimensionais, por meio de rotas animadas ou movimentação espontânea, também pode potencializar o aprendizado, devido justamente à exposição eficiente de diversos pontos de vista, principalmente os de maior relevância. Park e Gittelman (1992) sustentam que animações ilustram eficientemente relações estruturais complexas entre objetos e eventos, permitindo aos usuários formar representações esquemáticas enquanto aprendem conceitos abstratos. Chanlin (1998) indica que, na animação, os elementos estruturais e espaciais têm grande papel na decodificação de informação.

Segundo Chan e Black (2006), animações aliadas à interação são mais eficientes no ensino de sistemas complexos, em comparação aos métodos que utilizam apenas texto ou imagens estáticas. Os autores sustentam que a manipulação direta da animação permite aos estudantes refletir sobre interações causais e relações funcionais, facilitando a construção de modelos mentais. Dixon (1995) conclui que a exploração dos conceitos geométricos de reflexão e rotação - em ambientes didáticos que utilizam instrução dinâmica digital - podem trazer benefícios ao aprendizado. Apesar de não comprovar a superioridade dos métodos de realidade virtual, Byrne (1996) também conclui que a interatividade é um fator importante na motivação e no aprendizado.

Desta forma, a exploração, manipulação e interação com objetos virtuais tridimensionais pode auxiliar o entendimento de formas espaciais e de suas características, relações e configurações (Piaget e Inhelder, 1956), além de meIhorar o entendimento de fenômenos e sistemas complexos e das relações semânticas entre elementos. No entanto, habilidade espacial também é essencial para o aproveitamento cognitivo das animações (Hays, 1996). Os mais habilido- 
sos podem se concentrar mais no aprendizado, em vez de se concentrarem na decodificação espacial.

\subsection{Computação gráfica 3D}

A criação efetiva de sistemas de visualização com as características abordadas anteriormente (seção 3.2) depende do conhecimento das tecnologias atuais, principalmente de suas capacidades e limitações. Nesta seção, serão apresentados brevemente fundamentos tecnológicos da computação gráfica 3D, assim como aplicações consideradas relevantes a este trabalho, especialmente realidade virtual e visualização científica. Também serão abordados em detalhes outros aspectos da computação gráfica: a criação de modelos tridimensionais e os mecanismos de visualização e interação.

\subsubsection{Considerações gerais}

A pesquisa em representações computacionais de modelos sólidos foi iniciada incipientemente na metade da década de 1960, tomando força no início da década de 1970 (Requicha e Rossignac, 1992). O principal interesse era o desenvolvimento de ferramentas e sistemas voltados a projeto e produção de bens, denominados como CAD (Computer Aided Design [desenho auxiliado por computador]), CAE (Computer Aided Engineering [engenharia auxiliada por computador]) e CAM (Computer Aided Manufacturing [manufatura auxiliada por computador]). Esse conhecimento acumulado começou a ser integrado apenas na década de 1990 (Requicha e Rossignac, 1992). O interesse inicial residia em criar equivalentes digitais dos modelos e métodos de modelagem tradicionais.

Modelos sólidos são amplamente utilizados na construção civil, em circuitos integrados, medicina, engenharia (mecânica, automobilística, aeronáutica), desenho industrial, ciências exatas, dentre outros (Requicha e Rossignac, 1992). O estudo de métodos de representação digital de objetos sólidos é relevante para o ensino e o melhor entendimento de tópicos de ciência dos materiais tais como estruturas cristalinas, grãos e constituintes microestruturais.

\subsubsection{Fundamentos tecnológicos}

A obra Parisi (2012) sobre WebGL tece um panorama muito sucinto das características básicas de sistemas de computação gráfica tridimensional. É 
possível observar na estrutura geral do WebGL (FIG. 35), elementos típicos de todo sistema de computação gráfica tridimensional, como a cena, câmera, luzes, malhas (geometria definida por vértices e faces) e seus materiais.

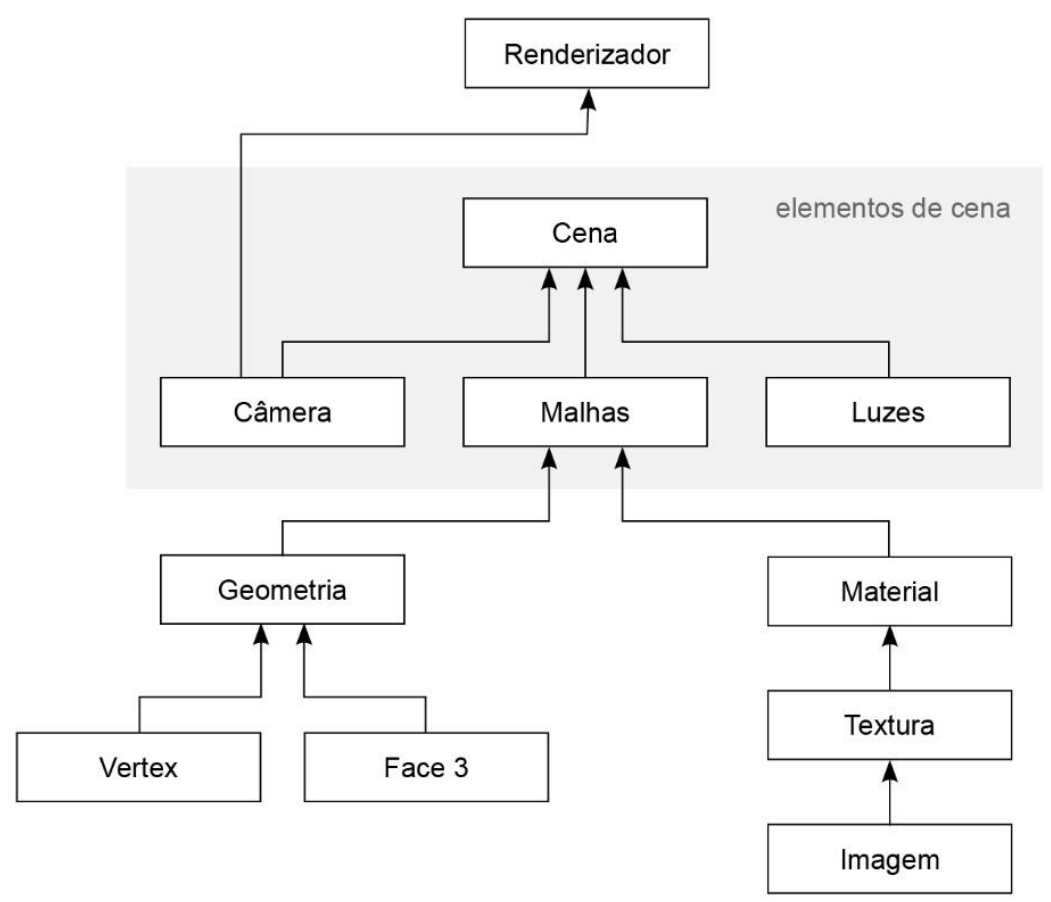

FIGURA 35 - Diagrama de elementos de cena do WebGL. Fonte: do autor.

Para viabilizar a construção e representação de modelos tridimensionais é necessário utilizar um sistema de coordenadas (FIG. 36). No caso do OpenGL e WebGL, esse sistema tem um plano horizontal definido pelas coordenadas $x$ e $z$ (apontando para fora da tela) e um plano vertical definido por $x$ e y (vertical). Todos os objetos possuem posições relativas a esse centro de referência.

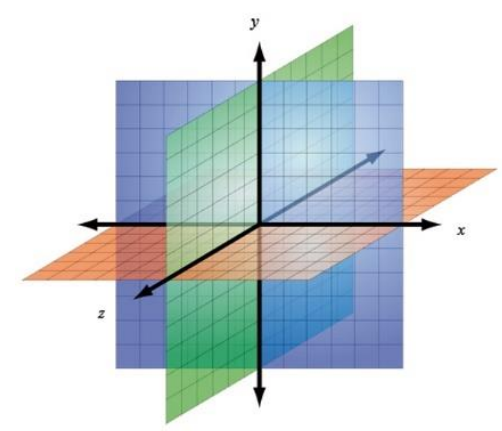

FIGURA 36 - Exemplo do sistema de coordenadas adotado pelo WebGL para construção e representação de modelos tridimensionais. Fonte: Sakurambo, 2007. 
A geometria dos modelos tridimensionais é representada comumente por malhas (meshs), compostas por faces poligonais definidas por um conjunto de coordenadas (ênupla $x, y, z)$ (FIG. 37). Outros métodos de representação são descritos a seguir (seção 3.3.3). Os polígonos mais utilizados são triângulos (grupo de três vértices) e quadriláteros. As malhas são manipuladas por meio de operações denominadas transformações, que executam movimentação, rotações a partir de eixos determinados e aumento ou diminuição de tamanho da malha (escala). Essas operações computam as transformações por meio de matrizes matemáticas.
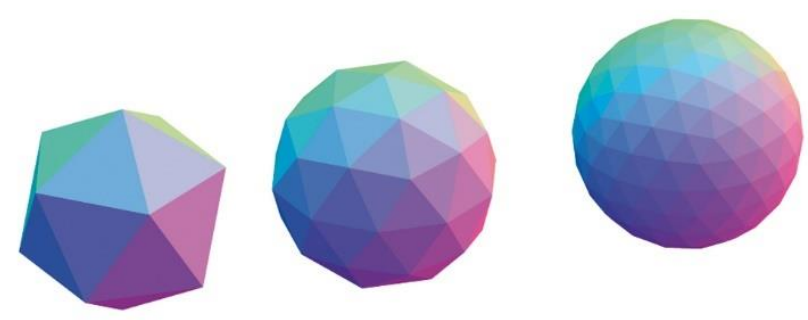

FIGURA 37 - Exemplo de malhas (mesh), usadas na construção e representação de modelos tridimensionais. Neste caso, as malhas representam uma esfera, em diferentes níveis de detalhe. Fonte: do autor.

Os atributos de superfície (FIG. 38) são comumente agrupados sob o termo material. Um material define a cor, comportamento da luz e texturas, imagens usadas para mapear ressaltos, ondulações e rugosidade. Materiais normalmente precisam de uma ou mais fontes de luz para ser adequadamente exibidos.

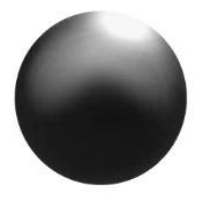

opaco

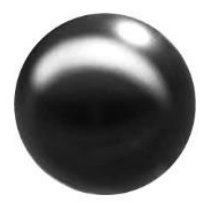

brilhante

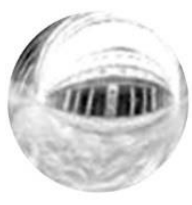

reflexivo

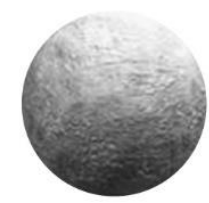

rugosidade

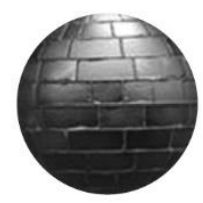

ressaltos

FIGURA 38 - Exemplo do uso de atributos de superfície na construção e representação de modelos tridimensionais. Fonte: Bjerke (2004) (adaptado).

Uma câmera define o ponto de vista do observador relativo à cena e quais objetos serão considerados na visualização. Esse volume visível (uma pirâmide) é denominado frustum, determinado pelo ângulo de abertura da câmera e 
por dois planos de corte, sendo: um próximo à câmera (equivalente ao plano da tela) e outro no ponto visível mais distante (FIG. 39). Câmeras são representadas por duas matrizes, uma que define a posição e orientação no espaço (assim como as matrizes de transformação nos objetos) e outra representando a translação das coordenadas tridimensionais ao espaço bidimensional do campo de visão (matriz de projeção). A câmera define a relação do observador com a cena e a combinação dos parâmetros de câmera determina o resultado visual. O funcionamento desse sistema é exemplificado na FIG. 39.
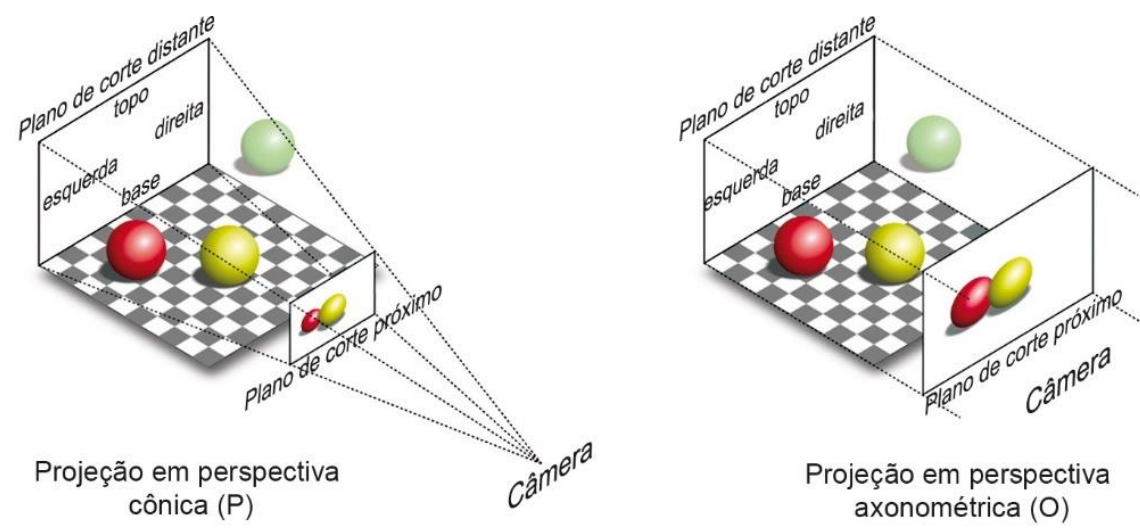

FIGURA 39 - Esquema do frustum: (a) para projeção em perspectiva cônica; (b) para projeção em perspectiva axonométrica. Fonte: Three.js (2016) (adaptado).

Um mecanismo fundamental em sistemas de computação gráfica é o shader, pois determina as interações entre todos os elementos supracitados para a produção de projeções bidimensionais. Um shader é comumente escrito em linguagens de alto nível como $\mathrm{C}$ e compilado para unidades especializadas em processamento gráfico (GPU) - presentes em praticamente todos os dispositivos modernos. O shader é o meio pelo qual uma GPU traduz conceitos de alto nível, como materiais e luzes, para pixels em uma tela. Apesar de ser uma propriedade avançada na maioria dos sistemas gráficos 3D, implementações do WebGL exigem a criação de shaders, mas bibliotecas como o ThreeJS oferecem diversos tipos predefinidos aos desenvolvedores. Na prática, os shaders são usados para implementar modelos de iluminação como Lambert, Toon, Blinn e Phong, possibilitando tanto a obtenção de hiper-realismo ou a criação de novas linguagens visuais (FIG. 40). 


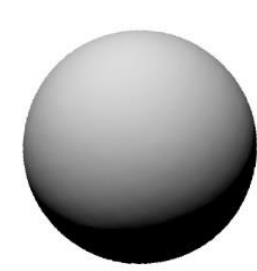

Lambert

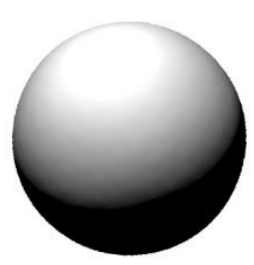

Toon

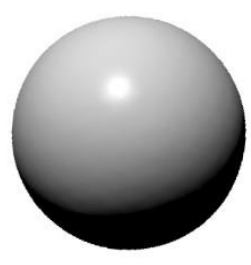

Blinn

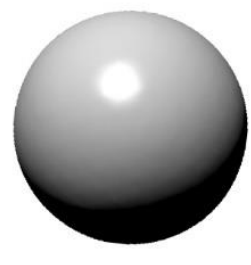

Phong

FIGURA 40 - Exemplos de shaders na construção e representação de modelos tridimensionais. Fonte: do autor.

\subsubsection{Métodos de representação geométrica}

O estudo dos métodos de representação geométrica é relevante devido às possibilidades, mas, principalmente, às limitações e restrições que podem impor à criação de geometria e à implementação de recursos avançados de visualização e interação.

Os modelos tridimensionais utilizados nos sistemas de computação representam digitalmente um objeto físico sólido (Requicha e Rossignac, 1992). A computação gráfica dispõe de diversos métodos para a representação de modelos tridimensionais, selecionados de acordo com as aplicações pretendidas. As implementações das representações de sólidos digitais exploram bases matemáticas herdadas da geometria algébrica e topológica, além de estruturas de dados clássicas, como as árvores de dados. Nos aplicativos geométricos, há três opções básicas para representação dos sólidos (Requicha e Rossignac, 1992):

- Por seu invólucro: representação de bordas (boundary representation - B-Rep) (seção 3.3.3.1).

- Por uma sequência de operações em sólidos elementares: representação construtiva (constructive solid geometry - CSG) (seção 3.3.3.2).

- Por grids volumétricos: subdivisão espacial (seção 3.3.3.3).

Além das estruturas de representação dos objetos, os aplicativos possuem mais dois componentes principais: métodos de análise e de manipulação dos objetos (operações) e ferramentas de criação de conteúdo (Requicha e Rossignac, 1992).

É comum nos aplicativos a manutenção simultânea de ao menos dois tipos de representação, pois cada tipo possui métodos específicos para o proces- 
samento e manipulação da informação. Algumas operações são mais viáveis ou mais simples de serem executadas em um determinado tipo de representação geométrica. A conversão de um tipo em outro não é sempre trivial e, em alguns casos, pode ser inviável (Hoffmann e Vanecek Jr., 1991). Dentre as operações mais importantes destacam-se a detecção de colisão e as operações booleanas (união, subtração e interseção), técnicas fundamentais à visualização das estruturas internas, mas que demandam cuidados no momento da síntese dos modelos. Requicha e Rossignac (1992), em um trabalho consagrado, revisam os modelos de representação existentes, brevemente descritos a seguir.

\subsubsection{Modelos tipo B-Rep}

Boa parte dos aplicativos de modelagem tridimensional utiliza representações B-Rep de seus objetos. As B-Rep utilizam malhas, já discutidas anteriormente (seção 3.3.2), armazenando os elementos básicos que constituem a envoltória do sólido e as relações entre eles (FIG. 41c). Os elementos geométricos básicos são os vértices, as arestas e as faces. Outros mecanismos armazenam a topologia, ou seja, a relação entre os elementos geométricos. Da combinação de geometria e topologia, tem-se uma representação do tipo B-Rep (Hoffmann e Vanecek Jr., 1991). Quando se procede à visualização do interior do objeto através de secções, observa-se a parte interna das faces, prejudicando a percepção do objeto como um sólido. Para evitar isso, alguns aplicativos mantêm representações alternativas, reconstroem o perímetro do sólido ou utilizam algoritmos de visualização para corrigir o problema visual. Desta maneira, realizar cortes e operações booleanas (união, interseção e subtração) demanda identificar as curvas de interseção entre as faces dos dois sólidos, além da classificação das partes internas e externas de cada face, resultando em um novo sólido.

\subsubsection{Modelos tipo CSG}

A geometria sólida construtiva (constructive solid geometry - CSG) descreve um sólido em termos de operações básicas realizadas em volumes primitivos, que constituem a unidade básica deste tipo de representação (FIG. 41a). A estrutura utilizada é a árvore de dados (octree), composta por nós que representam a sequência de operações realizadas e armazenam as primitivas utiliza- 
das. As operações disponíveis são as transformações básicas (translação, rotação e escala) e as booleanas (adição, subtração e interseção). As primitivas mais comuns são os cubos, esferas, cones, cilindros e toroides, mas outras podem ser obtidas por operações simples, tais como extrusões lineares e radiais. A execução de operações booleanas em sólidos CSG é trivial, já que fazem parte do cerne deste tipo de representação. A avaliação das superfícies é uma operação mais complexa, sendo necessário percorrer a árvore de dados e identificar as faces limítrofes das primitivas. Essa avaliação é necessária principalmente para executar a conversão de um modelo CSG para um B-Rep.

\subsubsection{Modelos tipo subdivisão espacial}

Nesta representação, o objeto preenche posições em um grid tridimensional (FIG. 41b), obtido pela divisão do espaço com células poliédricas regulares ou irregulares, preferencialmente de tamanho uniforme (Hoffmann e Vanecek Jr, 1991). As células mais adotadas são do tipo cúbico, que, conforme o nível de detalhamento necessário nas bordas, são divididas recursivamente. O modelo é representado pela estrutura de dados denominada árvore hierárquica (octree), representando quais setores contém maior número de células. É nítido que, em alguns casos, as bordas podem ficar "voxelizadas" (um "pixel" tridimensional), o que confere um aspecto visual irregular, muitas vezes indesejado.

(a)

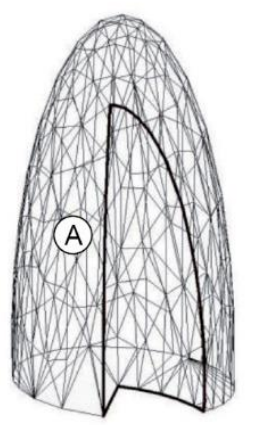

(b)

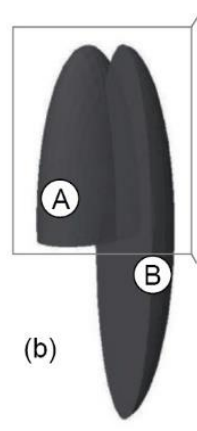

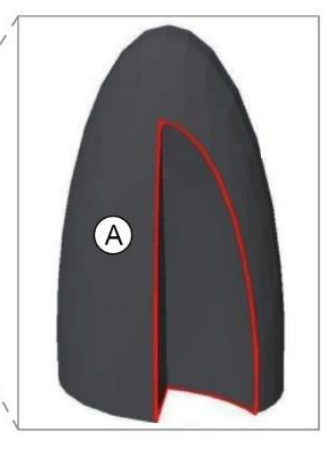

(c)

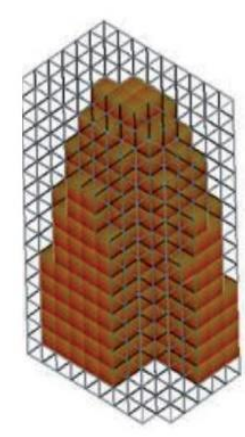

FIGURA 41 - Modelos de representação: a) representação de borda (B-Rep); (b) geometria sólida construtiva (CSG); (c) subdivisão espacial. Fonte: Xu (2014) (adaptado).

De fato, o tamanho das árvores de dados é diretamente proporcional à área superficial dos modelos e à resolução das bordas (Navazo, 1986). Desta 
maneira, o tamanho dos modelos é sensível à rotação e à complexidade da forma do objeto. Um problema clássico desse método é a dificuldade em obter informações sobre as bordas do objeto, pois é necessário encontrar os nós que contém células de borda. Cada face se estende por muitos nós da árvore, e, normalmente, se usam representações de borda alternativas para a execução de operações que envolvam as faces do objeto.

Operações booleanas podem ser executadas facilmente; porém, os sólidos resultantes podem conter imprecisões, devido tanto a diferenças dimensionais entre as células como a diferenças de orientação dos grids dos dois sólidos envolvidos. As operações booleanas são executadas percorrendo as árvores e identificando os nós que ocupam a mesma posição. Como as células dos dois sólidos dificilmente coincidem em tamanho e forma, os nós são recursivamente subdivididos de maneira a atingir a resolução necessária para executar a operação.

\subsubsection{Operações de visualização em sólidos}

Cortes e representações do espaço negativo são operações fundamentais para a boa compreensão de modelos internamente complexos ou com muita oclusão (FIG. 42), tal como estruturas cristalinas. Muitas vezes, estes procedimentos também impõem grandes desafios de implementação, especialmente quando são utilizados múltiplos planos ou volumes de corte. Os métodos utilizados dependem do tipo de representação adotada pelo aplicativo, mas normalmente são utilizadas operações booleanas. A visualização de cortes é comumente feita a partir de um ou mais planos de corte, definidos pelo usuário. Também é possível definir um objeto de corte, sendo o cubo e a esfera os mais utilizados. Após a escolha do objeto, procede-se à realização de uma ou mais operações booleanas entre o sólido de interesse e o objeto de corte. Caso o volume de interesse seja composto por diversos objetos, é executada uma operação por objeto. No caso de representações do tipo B-Rep, verifica-se a interseção entre os planos de corte e as faces do sólido. Após essa operação, é necessário computar as faces resultantes da interseção e integrar um novo sólido. Alguns algoritmos computam apenas as interseções e não recomputam as faces, gerando resultados visuais indesejáveis, como já discutido, pois é possível observar as faces internas dos objetos. Quando rapidez de visualização é 
imprescindível, são utilizados algoritmos aproximados, devido ao custo computacional das operações booleanas.

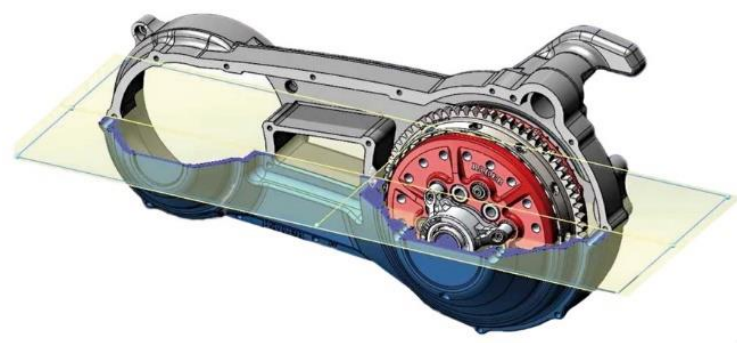

(a)

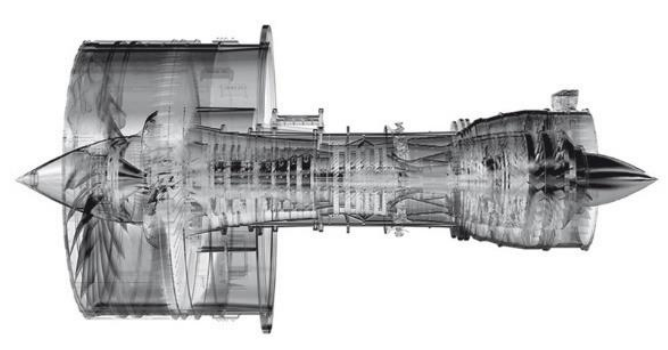

(b)

FIGURA 42 - Exemplos de técnicas para lidar com oclusão em modelos tridimensionais: (a) corte; (b) transparência. Fonte: Dassault Systemes Solidworks Corporation ([s.d.]) (adaptado).

Nos modelos CSG, a operação de corte é feita diretamente, sendo executada em cada primitiva intersecionada pelos planos de corte, incluindo na árvore de dados tanto o objeto de corte como a operação de interseção. $O$ custo de cada operação é baixo, mas o processo pode demorar caso existam muitas primitivas para processar. Finalmente, no caso dos modelos de subdivisão espacial, busca-se os nós intersecionados pelos planos de corte. Para agilizar o processo, é possível adotar uma simplificação na operação, evitando a recursão nos nós que demandam maior resolução - o que, por outro lado, prejudica a qualidade de visualização.

\subsubsection{Modelagem paramétrica}

O processo de criação de modelos também é um tópico abordado pela computação gráfica. Os paradigmas de modelagem estão intimamente relacionados com os tipos de representação geométrica adotados pelo sistema de computação gráfica. Sistemas de modelagem tradicionais são comumente implementados com representações geométricas do tipo B-Rep, e o usuário manipula a geometria de maneira mais direta. Exemplos típicos são sistemas com foco em aplicações artísticas e visuais como Blender, Maya e 3D Max. No entanto, tal como colocado pela problemática deste trabalho, a criação de modelos de estruturas cristalinas com sistemas de modelagem tradicionais constitui uma tarefa bastante complexa, sendo necessário conhecimento não apenas de modelagem, mas de diversas disciplinas, como estatística e ciência dos materiais. 
Em aplicações de engenharia como Catia, Solidworks e Autodesk Inventor, a principal preocupação é a precisão das relações semânticas e geométricas entre os elementos, relacionando características dos modelos a processos de produção industriais. Devido à precisão matemática e consistência projetual requisitadas pelas áreas de aplicação, esses sistemas são implementados utilizando representações do tipo CSG, e as ferramentas adotam o paradigma da modelagem paramétrica, que restringe e guia as ações do usuário de acordo com as práticas e o conhecimento de projeto da disciplina compreendida pela aplicação (Sacks et al., 2004). A adoção de conceitos do design paramétrico viabiliza a obtenção de objetos complexos dotados de características específicas, como é o caso em questão.

Na definição de Ibrahim et al. (1999), modelagem paramétrica é o controle ou manipulação de entidades gráficas utilizando variáveis matemáticas (parâmetros) que descrevem os atributos de uma entidade. Ao descrever modelos com parâmetros, permite-se ao usuário ajustar ou atualizar os atributos das entidades sem a necessidade de alterar a geometria explicitamente, algo apropriado ou até mesmo necessário quando um modelo é muito complexo. Para Aish (1992), modelagem paramétrica envolve o uso de restrições geométricas e relações dimensionais para controlar a definição da forma. Os valores internos às expressões paramétricas podem ser modificados e então propagados automaticamente em um modelo. Assim, a geometria associativa permite a manipulação dinâmica de relações de dependência definidas pelo usuário (Aish, 2005). Ou seja, o papel do usuário é definir as relações internas e as restrições, e o papel do sistema é encontrar configurações que respeitem esses parâmetros, atualizando-as conforme os parâmetros são alterados.

Pode-se dizer então que os elementos essenciais das definições descritas acima são as relações entre os componentes da estrutura e as restrições impostas a elas, cabendo ao usuário manipular essas relações e restrições. Assim, em um sistema paramétrico, nada pode ser criado que não se encaixe na estrutura pré-programada. Nesse sentido, a parametrização pode melhorar a busca por opções mais apropriadas ao contexto, reduzir o tempo e esforço necessários para execução de mudanças e permitir melhor entendimento da estrutura conceitual de um modelo (Aish, 2005). Quando aplicados a áreas ou domínios específicos, os aplicativos de modelagem paramétrica definem relações e restri- 
ções que expressam a lógica ou a natureza profunda do modelo, definindo relações de interdependência específicas, ou seja, necessárias ou mesmo obrigatórias entre os objetos do sistema em questão (Sacks et al., 2004).

Os conceitos do design paramétrico são bastante apropriados para o caso em questão. Em um sistema de modelagem 3D tradicional, a flexibilidade de criação é maior, mas o usuário precisa possuir todo o conhecimento, ficando a cargo do aplicativo prover os elementos básicos de produção. Em um sistema paramétrico, a flexibilidade é reduzida devido à especificidade da aplicação, mas o usuário não precisa possuir todo o conhecimento necessário para produzir aquele objeto. Pode-se dizer, portanto, que a criação de estruturas cristalinas é uma tarefa que exige muito conhecimento e mesmo um especialista não conseguiria ser produtivo usando aplicativos de criação tridimensional, pois não existe nenhum que possua os elementos básicos e muito menos métodos para lidar com eles.

Assim, apesar da regulagem de parâmetros ficar a cargo do usuário, toda a complexidade de composição dos elementos é conduzida pelo aplicativo, por meio de princípios e regras apropriados. Quando a tarefa é extremamente complexa, é possível ainda aumentar o grau de interação do sistema com o usuário, transferindo a ele a tarefa de fazer algumas escolhas iniciais e de avaliar as melhores opções. De qualquer maneira, um sistema paramétrico promete diminuir a complexidade da tarefa e aumentar a velocidade do processo, mantendo certos parâmetros dentro de limites aceitáveis, permitindo que usuários de diversos níveis de conhecimento utilizem a ferramenta, mesmo que muita interação seja necessária ao longo do processo.

De fato, os softwares cristalográficos tendem a ser paramétricos e os parâmetros estão intimamente relacionados com a aplicação. O conhecimento incorporado nessas aplicações relaciona grupos de simetria e parâmetros de rede e dos elementos químicos para construir estruturas cristalinas. Portanto, de acordo com os conceitos discutidos neste item, essas relações determinam os limites na criação de qualquer estrutura nesses aplicativos.

\subsubsection{Aplicações da computação gráfica tridimensional}

Atualmente, técnicas de realidade virtual $(R V)$ e visualização científica (VC) são consideradas tecnologias de ponta para aprendizagem, pois oferecem 
ferramentas para a melhoria dos processos de aquisição e construção do conhecimento (Clark, 1983), incentivando a pesquisa e educação (Frederick, 1999). Através da combinação destas duas técnicas, softwares de simulação educacionais de alta qualidade têm sido desenvolvidos com sucesso em inúmeras áreas de aplicação, tais como prototipagem, modelos físicos e linguagens de programação (Barnes, 1996).

\subsubsection{Realidade virtual}

As origens da realidade virtual $(\mathrm{RV})$ remontam ao período pós-Segunda Guerra Mundial, quando foram desenvolvidos os primeiros simuladores de vôo com o objetivo de ensinar pilotos a navegar nos instrumentos à noite e em condições atmosféricas adversas (Vince, 1995; Burdea e Coiffet, 2003; Krueger, 1991; Kalawsky, 1993). Impulsionados pelo advento da computação de alto desempenho e do avanço das tecnologias de processamento de dados e imagens, um avanço significativo ocorreu no final da década de 1980 com o surgimento dos primeiros simuladores capazes de produzir imagens renderizadas, texturas e mudança de orientação espacial (Schroeder, 1993).

O crédito do termo realidade virtual é comumente atribuído a Jaron Lanier, que, nos anos 1980, usou essa expressão para diferenciar simulações feitas em um ambiente computadorizado compartilhado (Araújo e Kirner, 1996), Desenvolvedores, pesquisadores e acadêmicos conceituam-na baseados em sua própria experiência, promovendo uma abrangente área de conhecimento com inúmeras definições na literatura. Burdea e Coiffet (2003), assim como outros autores, procuram caracterizar a RV por meio de seus pilares: imersão, interatividade e imaginação, denominados como os três "i"s da RV. Sherman e Craig (2003) a caracterizam pelo seguinte aspecto: permitir que os usuários visualizem, interajam e se movimentem em um ambiente tridimensional sintético gerado em tempo real (Sherman e Craig, 2003; Frederick, 1999; Bryson, 1996). Autores como Bryson (1996) definem a RV segundo aspectos mais tecnológicos, como "interfaces entre homem e máquinas capazes de criar a sensação de mundos virtuais onde existem objetos capazes de interagir com uma elevada sensação de presença".

Alguns autores definem RV como a forma mais avançada de interface entre o ser humano e o computador (Hancock, 1995). É também uma área multi- 
disciplinar que reúne conhecimentos de computação, eletrônica e psicologia. Usuários interagem com a máquina através de uma interface de simulação (Latta e Oberg, 1994) por meio de visualização, produção de respostas e manipulação de representações complexas (Steve e David, 1992). Essas representações, apesar de artificiais, podem ser consideradas reais pelo usuário no momento da simulação (Hand, 1996). Utilizando-se dos mesmos recursos cognitivos discutidos na seção 3.2.2, é criada a ilusão de se estar em um ambiente físico, graças ao estímulo dos sentidos (visão, audição, tato e olfato) relacionados à imersão, à interação e à imaginação (Burdea e Coiffet, 2003). Nesse sentido, os sistemas de RV também permitem extrapolar os limites espaço-temporais, possibilitando, por exemplo, a exploração virtual de mundos microscópicos como estruturas atômicas ou mundos extensos demais para que possam ser visualizados como um todo (Vendruscolo et al., 2005).

No Brasil, a RV tomou grande impulso a partir dos anos 2000 com a criação do primeiro sistema imersivo brasileiro do tipo CAVE por pesquisadores da Escola Politécnica da Universidade de São Paulo (POLI-USP), denominado Caverna Digital (Zuffo et al., 2001). Este sistema CAVE é um espaço cúbico no qual cinco faces recebem projeções de imagens estereoscópicas de alta resolução e os usuários podem interagir por meio de objetos rastreáveis. Esse tipo de ambiente permite alta imersão perceptiva, possivelmente a característica mais valorizada e perseguida pelos pesquisadores de RV, pois o usuário fica cercado pelo mundo virtual. O conceito de imersão, devido a sua relevância tanto para a RV como para o presente trabalho, será discutido na sequência, seguido de outros conceitos correlatos igualmente relevantes.

\subsection{Imersão}

A imersão é determinada pelas configurações físicas de interface do usuário (hardware) e pela aplicação do sistema de RV. Ela é definida como o "estado mental onde o usuário sente-se presente dentro do computador" (Slater e Steed, 2000). Segundo Thon (2008), sistemas imersivos capturam a atenção do usuário por meio do conteúdo audiovisual (objetos tridimensionais), além dos eventos e ações relevantes às decisões imediatas e futuras. As relações entre esses elementos são definidas no desenrolar da interação e consolidadas em modelos mentais, comentados na seção 3.2. 
O conceito de imersão implica em uma transferência de atenção do mundo real a um mundo fictício. Diferentes sistemas utilizam formas distintas de estímulo, definindo diferentes níveis de imersão: plataformas completamente imersivas (as que utilizam capacetes de visualização), semi-imersivas (grandes telas de projeção) ou não imersivas (baseadas em aplicativos desktop). Este tipo de classificação depende de o quanto o usuário é capaz de perceber (ver, escutar, tocar) o mundo virtual durante a simulação (Sherman e Craig, 2003). No entanto, essa classificação baseia-se somente na dimensão perceptiva, onde a imersão aumenta conforme se bloqueia o contato com o mundo externo. McMahan (2011) e Ragan et al. (2015) propõem um método de análise da imersão baseado nesta dimensão, sendo a experiência humana considerada a imersão plena. As propriedades consideradas básicas por esses autores são estereoscopia, resolução visual, campo de visão, extensão (a extensão do ambiente virtual que pode ser vista considerando os limites de rotação da cabeça e do corpo) e taxa de atualização (quadros por segundo, ou framerate). Conforme essas propriedades se aproximam aos valores máximos, diz-se que a imersão se aproxima daquela experimentada na realidade. No entanto, os autores não consideraram todas as propriedades interativas dos sistemas, apenas os parâmetros visuais. Extendendo a mesma lógica às demais propriedades, interações do mundo real permitem uso pleno das mãos, com sensação tátil e navegação bípede, por exemplo. Assim, considera-se que reduções nas abstrações de interação também aumentam o nível de imersão.

Thon (2008) propõe uma forma mais completa para descrever a experiência imersiva do usuário em ambientes tridimensionais, utilizando outros fatores que atraem a atenção do usuário para o interior do mundo virtual e não apenas o isolamento perceptivo ou a mimetização de interações naturais. De fato, o termo usado na área de RV para descrever o estado de consciência em que o usuário se envolve com o mundo virtual é "imaginação", ou "presença", relacionada à sensação de "estar lá" (Bowman e McMahan, 2007). No entanto, Thon considera a imaginação como uma imersão psicológica, definição considerada mais apropriada no âmbito deste trabalho.

Para Thon (2008) a imersão é multidimensional, composta por quatro dimensões. A dimensão espacial refere-se ao desvio de atenção promovido pelos objetos tridimensionais. Os setores do cenário mais relevantes para as ações do 
usuário vão compor o modelo mental, sendo que o fator mais importante para a construção deste modelo é a consistência espacial. A dimensão lúdica refere-se à mudança de atenção promovida pela interação com o sistema, determinado pelas regras e consequências. O modelo mental é incrementado, portanto, com as possibilidades de ação no mundo fictício, que restringem a liberdade de ação do usuário e determinam os desafios a ser superados para evoluir. Nesse sentido, a atenção é atraída para os elementos mais relevantes da atividade desafiadora. A dimensão narrativa refere-se à mudança de atenção promovida pelo desenvolvimento das atividades rumo a um ou mais objetivos. O modelo mental é incrementado com a lógica do mundo fictício, construída pelos elementos e eventos. A atenção é dominada principalmente pela expectativa de atingir metas e objetivos. Finalmente, em sistemas com múltiplos usuários, a dimensão social refere-se à mudança da atenção promovida pela interação entre usuários. O modelo mental é incrementado com a estrutura social resultante das interações, definindo as relações e papéis dos atores sociais. A atenção é atraída pelos aspectos cooperativos ou competitivos da interação com outros jogadores.

O conceito multidimensional de imersão é muito relevante, pois permite analisar a questão mesmo em sistemas que não possuem isolamento perceptivo. Neste caso, o maior desafio é determinar quais dimensões são mais relevantes ao sistema e como estabelecer e medir as correlações entre a estrutura do sistema de visualização e a experiência de imersão resultante, ou seja, estabelecer ou determinar quais elementos contribuem para cada dimensão da imersão. De fato, o famoso conceito de flow, cunhado por Csikszentmihalyi (1990), hipotetiza um estado de imersão máxima em sistemas interativos, baseado nas múltiplas dimensões supracitadas e atingido, em linhas gerais, quando os níveis de dificuldade do desafio e de proficiência do usuário estão balanceados.

\subsection{Interação}

A interação é determinada também pelas configurações físicas de interface do usuário (hardware), mas principalmente pela aplicação do sistema de RV. Ela é definida como a capacidade dada ao usuário de investigar e manipular os objetos do mundo virtual. A interação relaciona-se com a capacidade de aproveitar os sentidos humanos, particularmente os movimentos naturais do corpo no espaço, para transpor o usuário para o interior do mundo virtual. Logo, através de 
dispositivos como capacetes de visualização (head-mounted displays - HMD), luvas, joysticks e outros rastreadores de movimento ou até mesmo esteiras de navegação interativa, é possível explorar o ambiente e manipular objetos de forma bastante natural.

Atualmente, existem tecnologias de interface, visualização e processamento disponíveis para a construção de praticamente qualquer nível de imersão, interação e imaginação. Para melhor compreensão e classificação destes diferentes tipos de tecnologia, Milgram et al. (1994) propuseram uma escala de classificação de simulações de RV, que pode ser observada na FIG. 43.

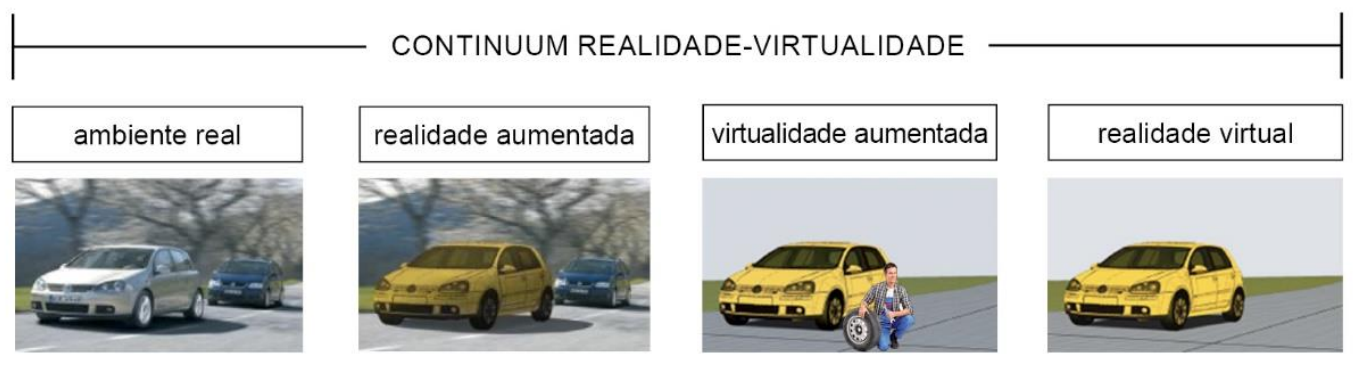

FIGURA 43 - Continuum realidade-virtualidade. Fonte: Milgram et al. (1994) (adaptado).

Em um dos extremos desta escala, está a realidade virtual pura, uma situação onde o usuário é completamente isolado do mundo real e tudo o que é percebido é artificial. No outro extremo, localiza-se o ambiente real, sem nenhum estímulo gerado por computador. Entre os dois extremos encontram-se níveis como a realidade aumentada e a virtualidade aumentada, que são simulações capazes de combinar elementos reais e virtuais (Milgram et al., 1994).

Sistemas de RV imersivos têm sido utilizados com sucesso para simulação em diversas aplicações (Roussos, 1999), tais como o treinamento de pilotos na aviação civil (Vince, 1995), procedimentos cirúrgicos (Ferreira, 2004), aplicações militares (Hogue, 2000) e aeroespaciais (Plotnikova e Trivailo, 2002), estudo de moléculas (Bryson, 1996), instrumentos musicais virtuais (Rodrigues et al., 2016) (FIG. 44), entre outros.

Estes simuladores têm possibilitado a transformação de grandes quantidades de informação em modelos sintéticos artificiais, permitindo visualizar e interagir com um conjunto de dados complexos (Queau, 1993). Essa interação dos 
sentidos com o objeto virtual de estudo possibilita desenvolver um relacionamento espacial com a informação (Frederick, 1999). Sendo esta realidade artificial e sintética, é possível criar um mundo virtual capaz de reproduzir qualquer tempo ou escala física. Assim, essas tecnologias proporcionam melhores condições para a construção do conhecimento (Zeltzer, 1990) do que as salas de aula tradicionais, pois possibilitam que estudantes, professores e pesquisadores interajam em primeira pessoa com variáveis abstratas naturalmente invisíveis aos nossos sentidos. Na sequência, será introduzida e discutida uma área multidisciplinar que visa justamente produzir e avaliar visualizações dessas variáveis, a visualização científica.

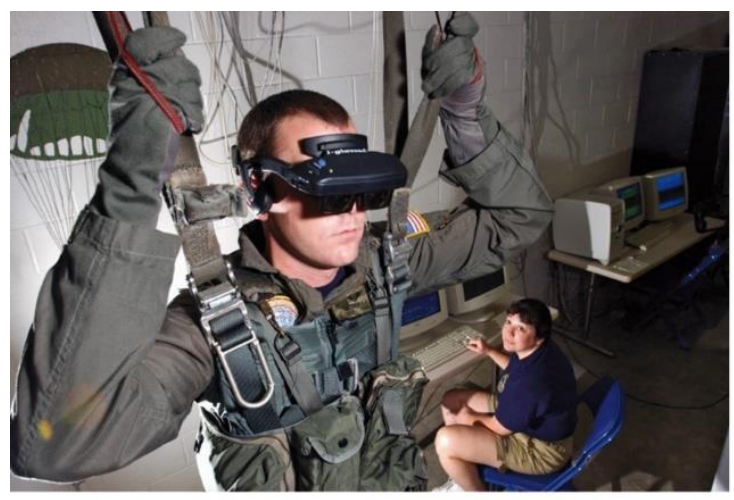

(a)

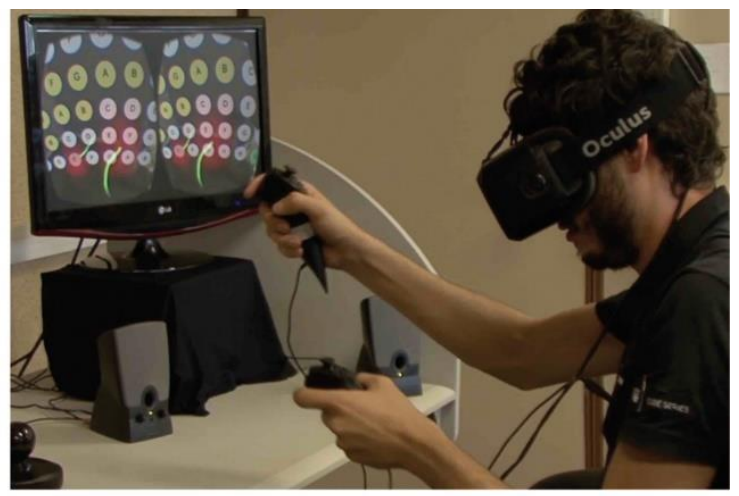

(b)

FIGURA 44 - Exemplos de utilização de RV imersiva: (a) treinamento militar; (b) instrumento musical virtual. Fontes: (a) U.S. Navy ([s.d.]); (b) Rodrigues et al. (2015).

\subsubsection{Visualização científica}

Como discutido na seção 3.2, o uso de mídias e sistemas tridimensionais interativos pode aprimorar substancialmente o entendimento de temas complexos como ciência dos materiais, se formatados de acordo com princípios didáticos adequados, refletidos nos métodos de exposição da informação visual disponível. No entanto, é necessário que existam tecnologias que permitam a implementação de novos sistemas, que suportem a natureza dos dados dos modelos a ser explorados didaticamente e possuam as ferramentas de visualização e capacidades de interação adequadas. Como será abordado nesta seção, a área da visualização científica oferece simultaneamente uma aproximação aos conceitos cognitivos discutidos anteriormente e sugere tecnologias para a criação de novos sistemas híbridos voltados à visualização de geometria e outros tipos de dados. 
Apesar da computação gráfica ter suas origens na década de 1950, no estudo de problemas científicos, historicamente sua utilização sempre foi muito restrita devido à falta de poder computacional e gráfico (Friendly e Denis, 2001). Subsequentes desenvolvimentos tecnológicos na aquisição e processamento de dados impulsionaram, na década de 1960, o desenvolvimento das primeiras técnicas de visualização (Collins, 1993). Entretanto, foi apenas em 1987 que se utilizou, pela primeira vez, o termo "visualização científica": no relatório Visualization in scientific computing (McCormick, 1988), desenvolvendo um novo domínio na apresentação da informação científica através da visualização de dados. Desde então, a visualização científica é reconhecida como uma disciplina formal (Schroeder et al., 2000).

Diferentes definições formais para visualização científica podem ser encontradas na literatura. McCormick (1988) define a visualização científica como o uso de computação gráfica para criar representações visuais que ajudam na compreensão de conceitos científicos ou resultados complexos, frequentemente associados a representações numéricas volumosas. De forma semelhante, para Wolff e Yaeger (1993), a visualização científica é a utilização de técnicas de computação gráfica e de processamento de imagens para representar visualmente um conjunto de dados. Para Foley e Ribarsky (1994), trata-se de um mapeamento de dados para uma representação que pode ser percebida de modo visual, sonoro e tátil, ou ainda olfativo e gustativo, separadamente ou conjuntamente. Gershon (1992) a considera um processo em que a informação é transformada em uma forma visual que possibilite a cientistas e engenheiros observá-la, percebendo padrões nos dados, nem sempre óbvios, mas fundamentais para sua análise exploratória. Intuitivamente, segundo Schroeder et al. (2000), a visualização científica é definida como a "transformação de dados e informações em figuras", ou, sinteticamente, segundo Hunter apud Owen (1999), "gráficos analíticos". Em suma, as definições apresentadas convergem para um objetivo principal da visualização científica: criar uma ponte perceptiva com o intuito de facilitar a apreensão de grandes volumes de informação ou de conceitos complexos.

As técnicas de visualização científica podem ser organizadas em três etapas: aquisição, transformação e representação de dados (Schroeder et al., 2000). Na etapa de aquisição, algoritmos de processamento selecionam e extraem informações de interesse de um conjunto complexo de dados. Em seguida, na 
etapa de transformação, estes dados são agrupados e transformados para um formato mais flexível de ser manipulado, para que, na etapa de representação, obtenha-se o conhecimento por meio da análise e visualização dos resultados gerados.

Devido às limitações no processo de cognição, a representação de dados abstratos tende a ser ainda mais difícil, por tais dados não poderem ser observados de um modo direto. Em muitos casos, são necessários teoremas, abstrações e desenvolvimentos matemáticos complexos para que se possa verificá-los. Há, portanto, uma dificuldade intrínseca em propiciar um aprendizado envolvendo esses dados e sua efetiva aplicação no mundo real.

A visualização científica faz uso de mecanismos que exploram as vantagens da percepção humana para estimular o reconhecimento de padrões nos dados (Robertson et al., 1991). Segundo estudos, a representação dos dados em espaços de percepção 3D, quando comparados com espaços de menor dimensão, tornam-nos mais acessíveis e compreensíveis (Fairchild, 1993; Ware, 1994). Assim, aumenta-se significativamente a quantidade de informações com as quais o usuário é capaz de interagir simultaneamente (Robertson et al., 1991; Fairchild et al., 1988). Consequentemente, ao convidar o usuário a explorar e manipular conjuntos de dados complexos, como os obtidos por simulações ou amostragens, a compreensão é simplificada. Através de recursos gráficos como vetores, linhas de contorno ou linhas de fluxo, torna-se possível a representação de variáveis abstratas, como campos, fluxo ou, ainda, temperatura, dependentes ou independentes de escalas, como as escalas físicas ou temporais.

Em suma, as técnicas filtram dados de uma amostra, realizando a tradução a uma linguagem de representação apropriada, tornando possível apreender de maneira controlada um conjunto de dados complexos. Adicionalmente, o uso de artifícios gráficos - como destaques (bordas, contornos, interfaces), variação na transparência e na luminosidade, planos de corte e projeções ortogonais torna possível a representação de dados não geométricos. Pela alta especificidade e complexidade dessas técnicas, desenvolver softwares que as utilizem tende a ser uma tarefa árdua e complexa. No entanto, bibliotecas gráficas e de manipulação de dados e toolkits específicos disponíveis atualmente fornecem desde funções de processamento de dados até interfaces com o hardware gráfico, facilitando significativamente muitas das etapas envolvidas nesse desenvolvimento (Azevedo e Conci, 2003). 
Assim, por meio de uma linguagem visual capaz de aproximar o mundo concreto do mundo abstrato, dos conceitos e modelos, a visualização científica tornou-se uma área multidisciplinar, capaz de prover um modo de observar fenômenos naturais cuja observação, devido à sua escala física, temporal ou de localização, seriam difícil ou impossível (Furness, 1997). A visualização científica constitui-se, portanto, numa ferramenta de incentivo à pesquisa e desenvolvimento das ciências e da educação (McCormick, 1988).

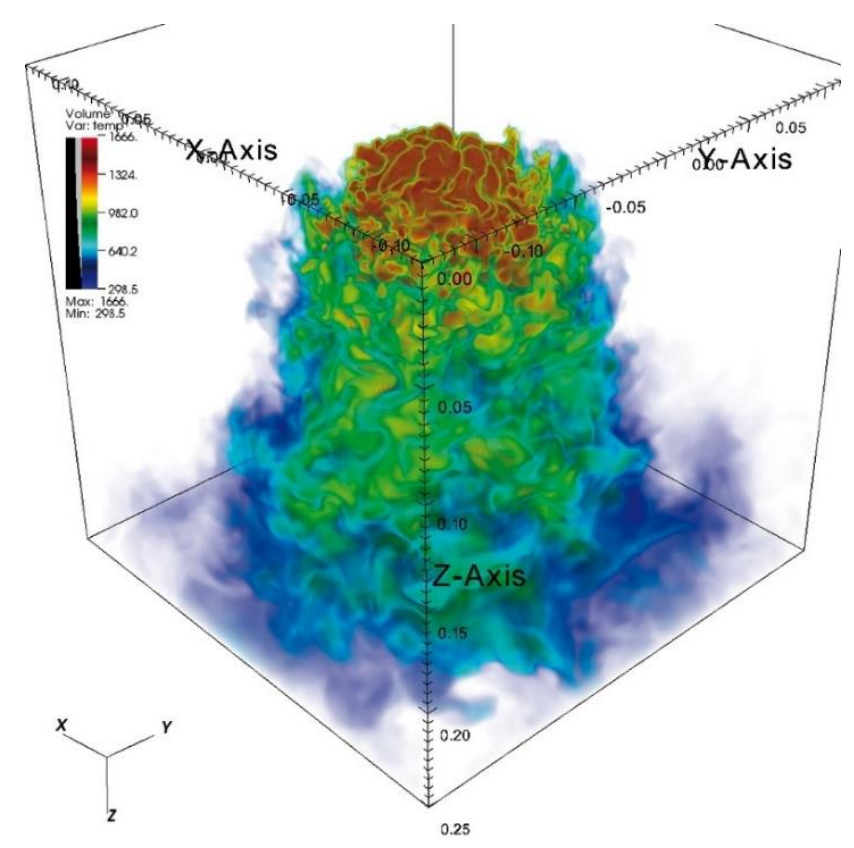

FIGURA 45 - Exemplo de aplicação de visualização volumétrica: distribuição de temperatura em uma chama de hidrogênio através do mapeamento de cores. Fonte: Bell (2007).

Atualmente a visualização cientifica em 3D é um campo emergente. Aplicações de representações visuais 3D podem ser encontradas nas mais diversas áreas da ciência e tecnologia. A criação de imagens através de ressonância magnética e PET, uma das grandes revoluções da medicina moderna, permite representações tridimensionais precisas do corpo humano (FIG. 46). A visualização científica em 3D tem impulsionado ciências como meteorologia, astrofísica e ciências da terra, por permitir representações de fenômenos naturais como a formação de furacões e tornados ou de como a camada de ozônio e o clima de nosso planeta têm mudado ao longo dos anos.

$\mathrm{Na}$ física e na química, a construção de modelos computadorizados das representações das estruturas internas de átomos não apenas possibilitou 
aos pesquisadores da área o estudo dessas estruturas abstratas e complexas, mas também a difusão de tais conhecimentos perante a comunidade científica.

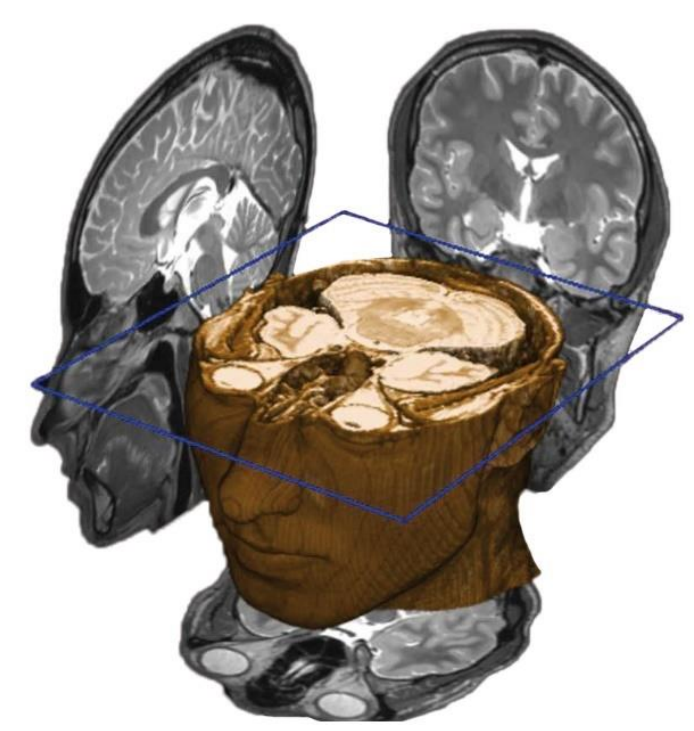

FIGURA 46 - Representação tridimensional do corpo humano por tomografia por ressonância magnética. Fonte: Magnetic Resonance Research Facility ([s.d.]) (adaptado).

Por fim, merece destaque uma vertente recente da visualização científica denominada visual analytics. Essa vertente trata do suporte ao raciocínio analítico por interfaces interativas baseadas em princípios cognitivos, explorando velocidade de processamento dos computadores e a alta capacidade de apreensão de padrões visuais do sistema visual humano (Cook e Thomas, 2005). Esse conceito atribui maior valor aos aspectos cognitivos da visualização computacional, muitos deles já destacados no item 3.2, e sintoniza plenamente com os princípios didáticos desta pesquisa. A visualização eficiente dos resultados e, consequentemente, a apreensão de informações, é muito favorecida pelo uso de linguagens visuais apropriadas e recursos interativos que permitam conhecer $e$ visualizar todas as partes relevantes do objeto.

\subsection{Softwares cristalográficos}

Conforme apresentado na seção 2.4.1.3, foi executado um levantamento sistemático para levantar informações sobre os softwares cristalográficos mais relevantes a esse estudo. O protocolo adotado no levantamento foi detalhado na seção 2.4.1.3.1. Ao longo desta seção, será descrita a execução desse levantamento. 


\subsubsection{Filtragem de referências}

Partiu-se de um universo de 804 referências. Foram então aplicados os filtros de busca do banco de dados do IUCr (International Union of Crystallography, 2016) e do CCP14 (CCP14, [s.d.]), restringindo a busca a um subgrupo de 200. Realizou-se uma pré-análise deste subgrupo, descartando 133 referências que, no campo "descrição", não atenderam aos critérios de inclusão e exclusão especificados no protocolo. Após esse processo, restaram 67 referências, que foram submetidas ao processo de download e instalação da aplicação. Excluíram-se nesta etapa: 19 referências cujo download ou instalação não foi possível, devido à descontinuação dos projetos por parte de seus respectivos autores; outras 4 referências incluídas em duplicidade; e mais 2 referências cujos autores se negaram a fornecer uma cópia ou licença de demonstração para a realização dos testes. Após esse processo, restaram 42 referências para análise. Após a instalação das aplicações, constatou-se que 16 delas não atendiam aos critérios de inclusão especificados no protocolo, de modo que um total de 26 referências passaram à etapa seguinte de análise (FIG. 47).

\begin{tabular}{|c|c|c|c|}
\hline Categoria de exclusão & \multicolumn{2}{|c|}{ Quantidade de referências } & \multirow[b]{2}{*}{$100 \%$} \\
\hline $\begin{array}{l}\text { TOTAL DE REFÊNCIAS } \\
\text { NO BANCO DE DADOS }\end{array}$ & $0(-100 \%)$ & $804(100 \%)$ & \\
\hline Tipo de Aplicação & $-604(-75.12)$ & $200(24.87)$ & $24.87 \%$ \\
\hline $\begin{array}{l}\text { Pré-Análise - critérios do } \\
\text { protocolo }\end{array}$ & $-133(-16.54)$ & $67(8.33)$ & $8.33 \%$ \\
\hline Descontinuidade do Projeto & $-19(-2.36)$ & $48(5.97)$ & $5.97 \%$ \\
\hline Duplicidade & $-4(-0.49)$ & $44(5.47)$ & $5.47 \%$ \\
\hline Não fornecimento de licenças & $-2(-0.24)$ & $42(5.22)$ & $5.22 \%$ \\
\hline Análise - critérios do protocolo & $-16(-1.99)$ & $26(3.23)$ & $3.23 \%$ \\
\hline $\begin{array}{l}\text { TOTAL DE REFERÊNCIAS } \\
\text { OBSERVADAS }\end{array}$ & \multicolumn{2}{|c|}{26} & \\
\hline
\end{tabular}

FIGURA 47 - Processo de afunilamento do universo de softwares compreendidos no levantamento. Fonte: do autor.

\subsubsection{Apresentação dos dados}

Segundo o modelo de análise das referências, a FIG. 48 destaca os melhores softwares na classificação geral e a FIG. 49, os critérios negligenciados pelas referências. 


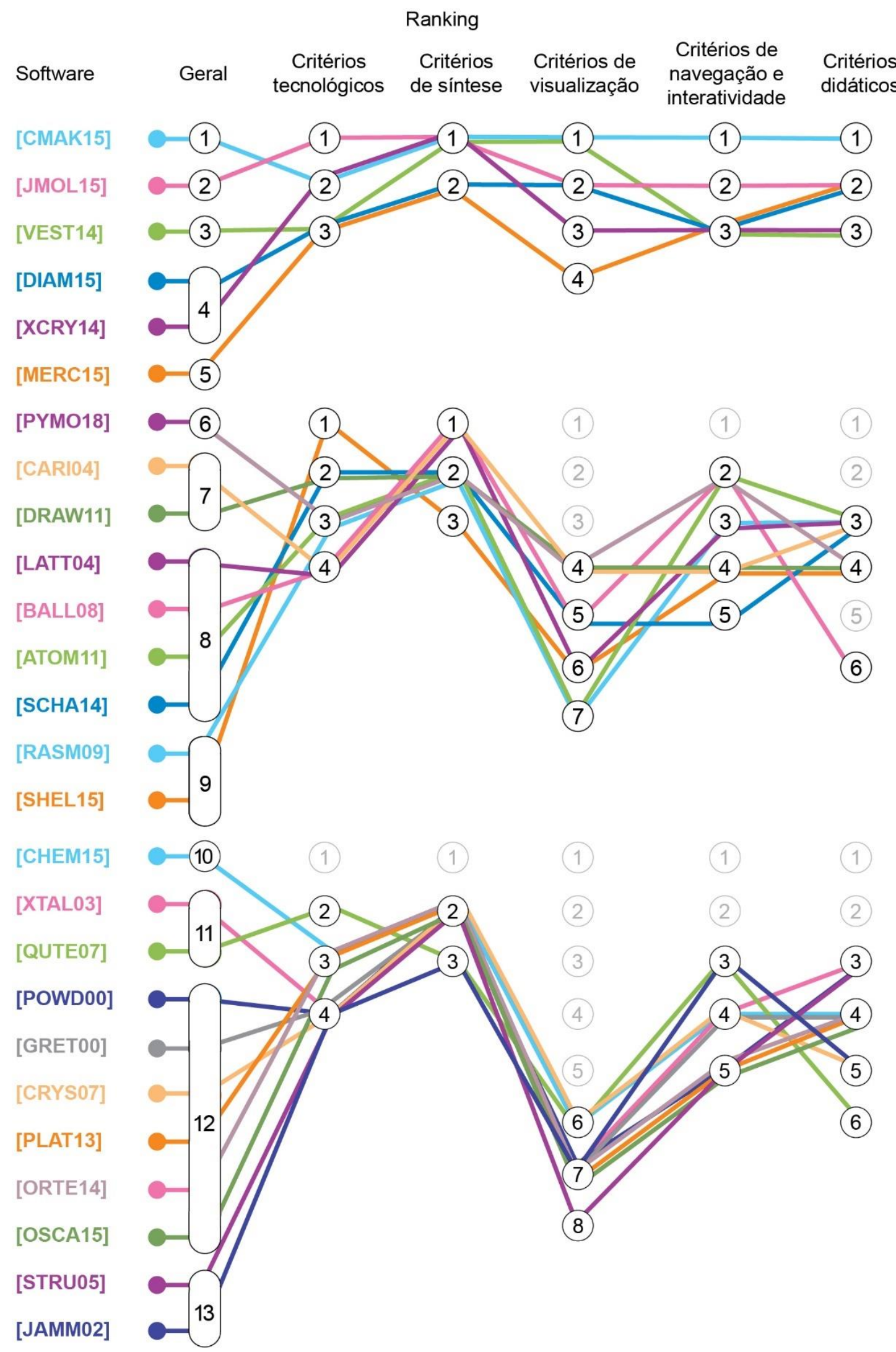

FIGURA 48 - Resultado da análise dos softwares compreendidos no levantamento, segundo softwares mais bem avaliados em cada critério. Fonte: do autor. 
5.4.2 Documentação

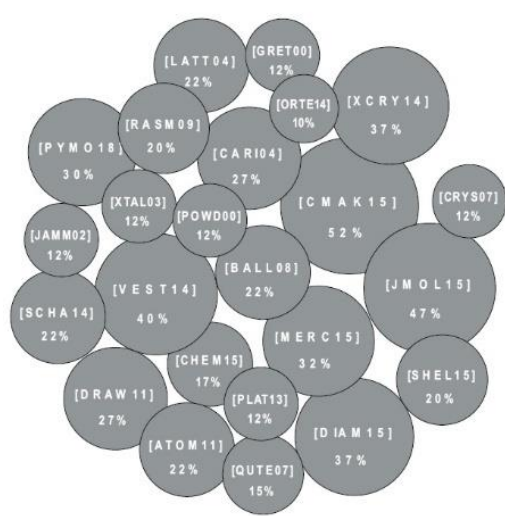

5.4.1 Suporte

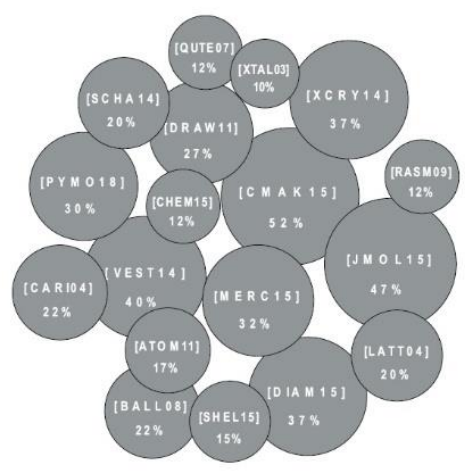

5.2.2 Suporte à impressão $2 \mathrm{D}$

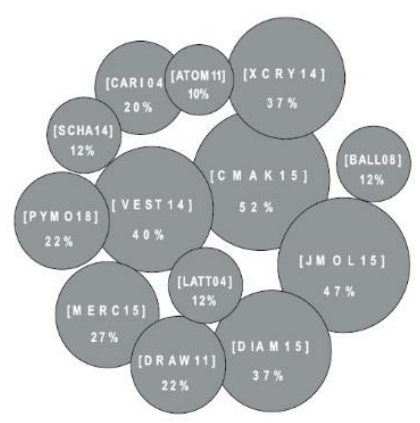

2.4 Seleção e edição interativas de átomos

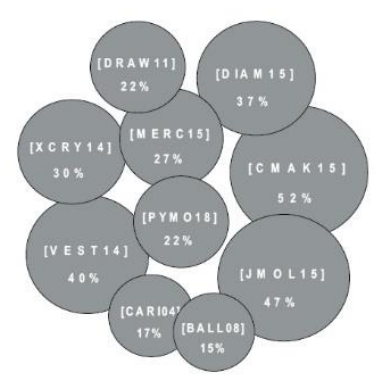

2.3 Restrições ou limitações à síntese

3.1.5.1 Células múltiplas

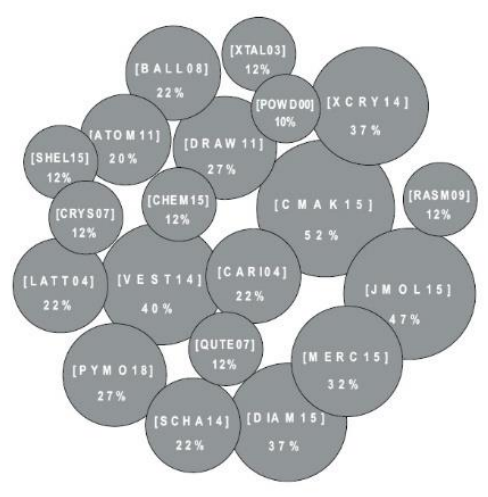

4.2 Interação base

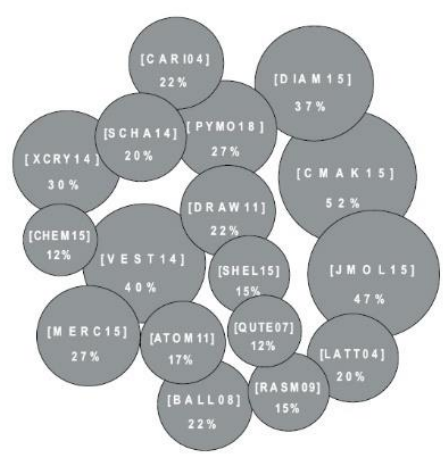

3.2.2 Tipo de projeção

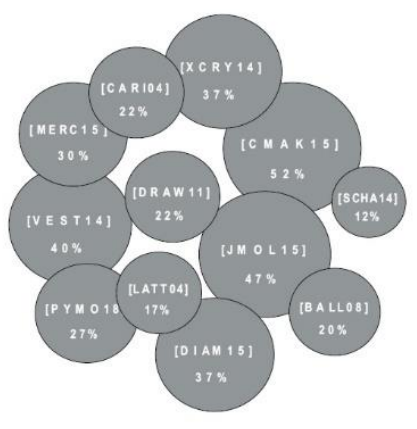

4.1 Interface de usuário

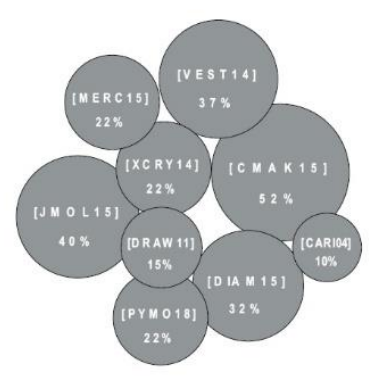

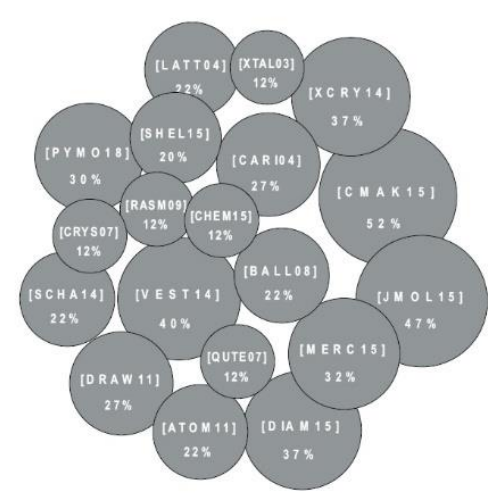

1.1.1 Frequência de atualização

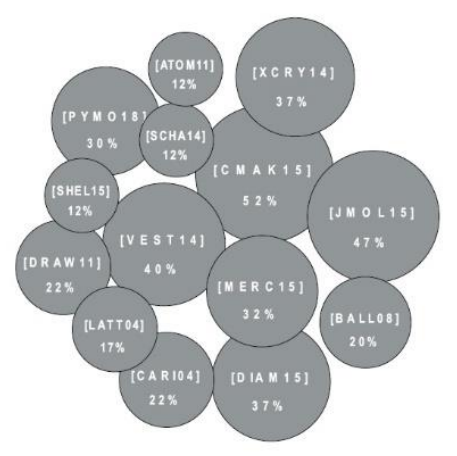

3.2.4 Modos de renderização

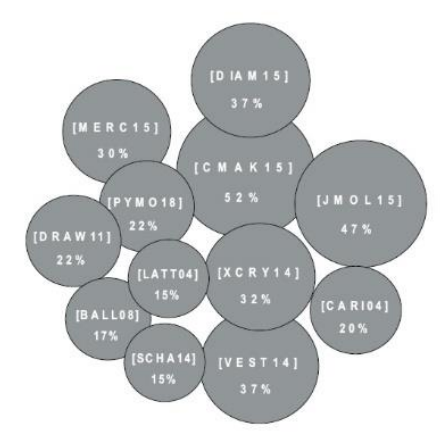

3.2.1 Recursos de percepção visual

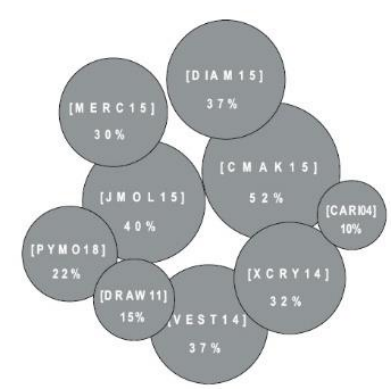




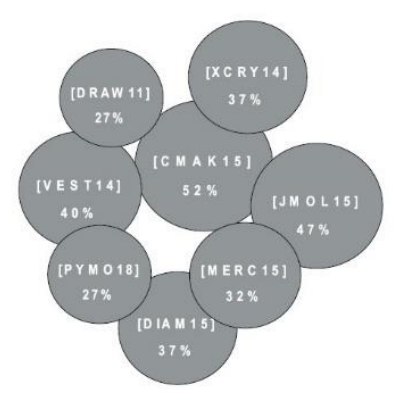

3.1.5.2 Cortes

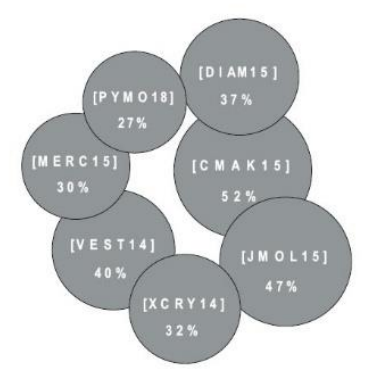

3.1.5.3 Vetores do eixo da rede

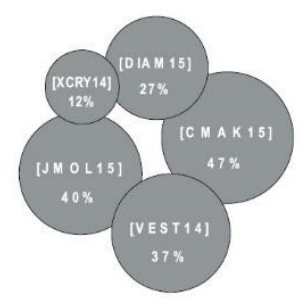

1.3.2 Modelo de desenvolvimento colaborativo

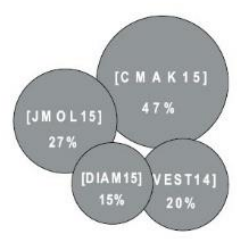

1.4.1 Dispositivos base (HID)

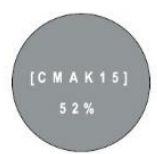

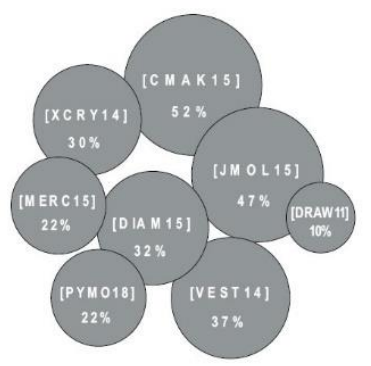

5.3.2 Biblioteca de estruturas cristalográficas

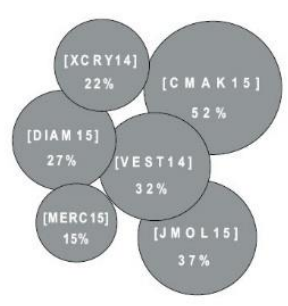

3.1.5.4 Recursos auxiliares de rede

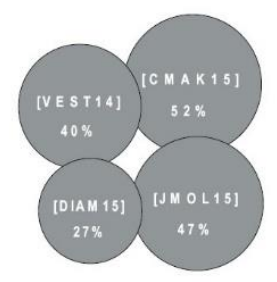

5.2.1 Suporte à visualização/ portabilidade externa

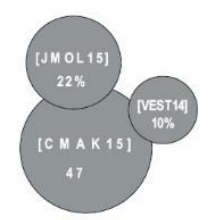

Critérios não atendidos:

1.2.1 Portabilidade da aplicação | 1.2.2 Plataforma de desenvolvimento 1.4.2 Dispositivos avançados de interação

2.1 Método de síntese | 2.2 Processo de síntese interativo

3.1.1 Modelo de representação atômico molecular

3.1.2 Modelo de representação da célula unitária

4.3.4 Gerenciamento dinâmico de oclusões

5.3.1 Suporte à narrativa didática

5.3.3 Construção e visualização incremental de estruturas

FIGURA 49 - Resultado da análise dos softwares compreendidos no levantamento, segundo critérios negligenciados. Fonte: Bardella (2016a) (adaptado). 


\subsubsection{Análise dos resultados}

Os softwares CMAK15 (1ㅇ), JMOL15 (2으) e VEST14 (3으) foram os meIhores posicionados na avaliação geral (FIG. 48), mesmo considerando a variância nos grupos de critérios. CMAK15 (1ㅇ) e JMOL15 (2으) demonstraram menor variância dentre os três primeiros. Uma segunda análise diz respeito aos atendimento aos 8 critérios mais negligenciados pela amostra (FIG. 49). Nessa análise, o CMAK15 (1ㅇ) e o JMOL15 (2ㅇ) foram os superiores, atendendo a 5 desses critérios, seguidos do VEST14 (3ㅇ), que atendeu a 3. Dessa forma, os três melhores foram adotados como referência tanto para a especificação como para a avaliação do CrystalWalk. Os softwares DIAM15 (4ㅇ lugar), DRAW11 (7으) e CARI04 (7우) também foram referências para a especificação, por se destacarem no atendimento a critérios comumente negligenciados pela amostra. Quinze critérios não foram atendidos por nenhum software e, portanto, representam funcionalidades inéditas do CrystalWalk.

\subsubsection{Considerações finais sobre os resultados}

A seção 3.4 apresentou a execução e os resultados gerais do levantamento sistemático do estado da arte em softwares cristalográficos. Foi estabelecido e seguido um protocolo de revisão, e, após a aplicação de diversos filtros, os 804 softwares inicialmente levantados foram reduzidos a apenas 26 , submetidos então à revisão. Todas as strings de busca foram documentadas, de forma que é possível expandir essa revisão, quando necessário, valendo-se da classificação aqui proposta.

Considera-se que as questões de pesquisa definidas pelo protocolo de revisão foram respondidas satisfatoriamente. Foi possível identificar os softwares mais relevantes, tanto para extração de características desejáveis, como para estabelecer referências para comparação e avaliação. A classificação anterior de características que devem ser analisadas facilitou o processo de levantamento de informações e simplificou a tarefa de sumarização e análise dos dados. Além de atender aos objetivos do presente trabalho, este levantamento pode servir como base para os desenvolvedores de qualquer um dos softwares analisados ou de novos aplicativos, caso Ihes interesse melhorar o desempenho nos aspectos didáticos e de visualização. 


\subsection{Planejamento e desenvolvimento de software}

Conforme discutido na seção 3.2.1, para colocar em prática estratégias didáticas inovadoras no o ensino de ciência dos materiais, apostou-se em mídias e tecnologias digitais contemporâneas. Foram estabelecidos alguns princípios essenciais, o que influiu na escolha de paradigmas e tecnologias ou mesmo determinou essa escolha. Os conceitos de democratização do conhecimento e de educação livre implicam princípios como máxima acessibilidade e mínimo custo das ferramentas de ensino. As tecnologias contemporâneas permitem colocar esses princípios e conceitos em prática.

Segundo o Instituto Brasileiro de Geografia e Estatística (2014), 54,4\% da população brasileira de 10 ou mais anos de idade - ou seja, 95,4 milhões de brasileiros - possui acesso à internet. Essa parcela sobe significativamente considerando a população que ingressa no Ensino Superior. Pode-se considerar, portanto, que uma parcela significativa dos estudantes que ingressam no Ensino Superior tem acesso a internet. Logo, a abordagem adotada neste trabalho, de desenvolver um aplicativo on-line, é adequada aos objetivos propostos (seção 1.2).

A adoção de certas arquiteturas de software permite diminuir consideravelmente a exigência de desempenho dos dispositivos e também a necessidade de banda de internet. $O$ uso de um servidor é necessário para qualquer aplicação on-line e implica em investimentos constantes em infraestrutura. Uma opção bastante promissora é a adoção de serviços de nuvem, pois a maioria dos provedores de serviços em nuvem disponibiliza contas gratuitas, caracterizadas por baixo poder computacional e pequena capacidade de armazenamento. No contexto deste projeto, essas contas devem ser suficientes para as fases iniciais. Mesmo no caso de pagamento pelos serviços, existe grande vantagem, pois seu custo é proporcional ao uso de recursos, um modelo mais econômico e racional que a aquisição de equipamentos. Desta maneira um modelo baseado em serviços de computação em nuvem foi escolhido para a implementação do projeto.

Após uma avaliação das opções disponíveis e considerando aplicativos interativos baseados em WebGL, não havia nenhuma arquitetura compatível ou padrões que proporcionassem a responsividade desejada. Segundo Philip (1998), a programação orientada a eventos possui suma relevância para as aplicações voltadas à interação com usuários, por proporcionar benefícios significativos em termos de responsividade, escalabilidade e resiliência. No paradigma de orienta- 
ção a eventos, o fluxo da programação é determinado por ações, tais como cliques de mouse, digitação de teclas ou trocas de mensagens com outros módulos da aplicação.

Em segundo lugar, para abordar os problemas de colaboração, para dar suporte a um time crescente, distribuído e heterogêneo, além de facilitar o desenvolvimento das diversas funcionalidades, adotou-se uma metodologia de desenvolvimento baseada em métodos ágeis, bem como uma filosofia modular, na qual os componentes do software podiam ser desenvolvidos e testados independentemente. Os trabalhos de Osmani (2015) e Zakas (2012) e a especificação asynchronous module definition (AMD) são referências adotadas como boas práticas no desenvolvimento de interfaces em aplicações web. Além de abordar os problemas de desenvolvimento, essas opções também impactam positivamente no desempenho do software (Osmani, 2015).

Em suma, do ponto de vista do desenvolvimento de sistema, o projeto tem como requisitos principais diminuir custos com hardware, facilitar e agilizar o desenvolvimento do software, viabilizar o reuso de módulos e soluções, criar um serviço distribuído, escalável, robusto e acessível. Serão, portanto, apresentados neste capítulo conceitos, técnicas e tecnologias que representam o estado da arte em desenvolvimento de aplicações interativas baseadas na internet, tais como arquiteturas orientadas a serviços (SOA), a especificação AMD (Osmani, 2015; Zakas, 2010), o padrão model-view-controller (modelo-visão-controlador - MVC), o padrão publish-subscribe, o estilo representational state transfer (transferência de estado representacional - REST) e objetos JavaScript object notation (JSON). A combinação dessas boas práticas no desenvolvimento de aplicações web interativas permitirá construir uma arquitetura e bases tecnológicas apropriadas ao projeto, com o objetivo principal de viabilizar o paradigma de programação reativa a aplicações que utilizam tecnologia WebGL.

\subsubsection{Metodologias ágeis de desenvolvimento}

A literatura destaca que, para atender às constantes alterações de demandas no ambiente contemporâneo de desenvolvimento de software, estão, frequentemente, também sujeitos a alterações os requisitos da aplicação e as tecnologias e pessoas envolvidas durante todo o seu ciclo de desenvolvimento (Rising e Janoff, 2000). Estes desafios, apesar de bastante atuais no contexto 
empresarial (Rising e Janoff, 2000), são frequentes também em trabalhos de pesquisa no contexto acadêmico, nos quais pesquisadores são expostos a questões complexas e impossíveis de serem simuladas dentro de laboratórios (Grudin, 1994).

\subsubsection{Scrum}

A denominação ágil, no que diz respeito a metodologias de desenvolvimento, é um termo "guarda-chuva" surgido a partir do Manifesto para desenvolvimento ágil de software, publicado em 2001 (Beck et al., 2001). A essência desse movimento é a definição de um novo enfoque de desenvolvimento de software, calcado na agilidade, na flexibilidade, nas habilidades de comunicação e na capacidade de oferecer novos produtos e serviços de valor ao mercado em curtos períodos de tempo (Highsmith, 2004). Segundo Angioni (2006), metodologias ágeis são ideais em ambientes inovadores por facilitar o processo de tomada de decisões. Isso porque permitem adaptar esse processo às constantes alterações de requisitos e de escopo do produto, típicas desses ambientes.

As primeiras técnicas de desenvolvimento ágil de produtos de software surgiram em meados da década de 1990, inspiradas nas melhores práticas da indústria japonesa, particularmente pelos princípios de lean manufacturing desenvolvidos pela Toyota (Hopp e Spearman, 2004). Dentre as mais conhecidas, destacam-se: Scrum (Schwaber e Beedle, 2002), extreme programming (XP) (Beck e Andres, 2004) e adaptive software development (ASD) (Highsmith, 2000), entre outras. Todas estas metodologias compartilham dos mesmos fundamentos definidos em Beck et al. (2001).

O Scrum foi desenvolvido por Jeff Sutherland em 1993, baseado em um artigo de Takeuchi e Nonaka (1986) que discutia as vantagens de equipes pequenas e multidisciplinares no desenvolvimento de produtos. Seguindo os princípios das metodologias ágeis, no Scrum eliminam-se práticas de controle desnecessárias, inadequadas e burocráticas, concentrando-se na essência do processo de desenvolvimento (Schwaber e Beedle, 2002). Assim, apesar de uma abordagem relativamente recente, seu emprego tem aumentado bastante nos últimos anos, impulsionado por pesquisas que demonstram que, em comparação com métodos tradicionais, seu uso aumenta a satisfação dos clientes e diminui o atraso em projetos (Mann e Maurer, 2005). 
A FIG. 50 ilustra os principais fundamentos do Scrum: seus papéis (roles), cerimônias (cerimonies) e artefatos (artifacts) (Scrum Alliance, 2002).

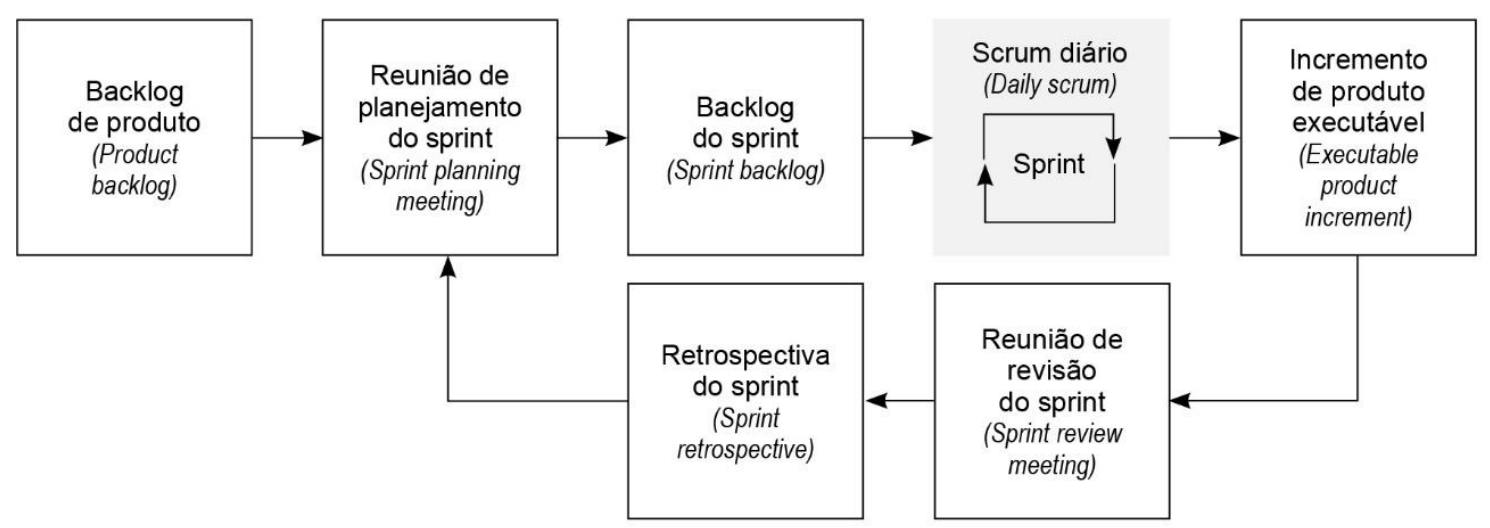

FIGURA 50 - Relações entre (roles), cerimônias (cerimonies) e artefatos (artifacts) no Scrum. Fonte: Scrum Alliance (2002) (adaptado).

O dono do produto (product owner) é o indivíduo responsável por manter e priorizar uma lista de todos os requisitos do sistema que está sendo construído ou otimizado. Ele faz parte da equipe de desenvolvimento, sendo responsável por interagir com o cliente, listar suas necessidades, mostrar as possibilidades e limitações técnicas e, principalmente, identificar prioridades. Esta lista de requisitos inclui novas características e funcionalidades, mas também adaptações às mudanças de variáveis de ambiente, tais como tempo, recursos e tecnologia.

É durante os sprints, ciclos de trabalho com duração de 2 a 4 semanas, que a equipe do projeto implementa um conjunto predefinido desses requisitos, num procedimento denominado sprint backlog. O planejamento desses ciclos é feito em uma reunião (sprint planning meeting) na qual as partes interessadas definem o sprint backlog e se comprometem com a realização do mesmo durante o ciclo de sprint. Ao longo do sprint, a equipe do projeto reúne-se diariamente por 15 minutos (daily scrums), a fim de controlar o progresso e identificar possíveis riscos. Ao final de cada ciclo de sprint, produz-se uma versão incremental do produto contendo todas as adaptações e novas funcionalidades planejadas.

Antes do início de um novo ciclo, é realizada uma reunião de revisão (sprint review meeting) na qual se reforçam os aspectos positivos e discutem-se e buscam-se soluções para problemas, dando à equipe do projeto uma oportunidade para aprender e melhorar a cada sprint. 


\subsubsection{Sistemas de controle de versão}

Segundo Mason (2006), um sistema de controle de versão (version control system - VCS) consiste fundamentalmente em um repositório para armazenamento de artefatos gerados durante o processo de desenvolvimento de um projeto de software. Segundo Loeliger (2012), sistemas de controle de versão devem registrar e gerenciar todas as diferentes versões não apenas dos códigosfonte, como também da documentação e de todos os arquivos de suporte produzidos pelo projeto, disponibilizando um histórico de revisões e o detalhamento de todas as modificações realizadas anteriormente. Existe atualmente uma grande quantidade de sistemas de controle de versão disponíveis, com características e funcionalidades bastante específicas e adequadas às necessidades de diversos tipos de projeto, desde projetos pessoais pequenos e simples até projetos comerciais de grande porte (Loeliger, 2012).

Segundo Estublier et al. (2000), as principais características comuns a um sistema de versionamento são:

- Item de configuração (configuration item): todos os elementos de informação criados ou requeridos durante o desenvolvimento de um produto de software, tais como arquivos de código-fonte, documentos, diretórios e atributos em bancos de dados. Eles devem ser identificados de maneira única, e sua evolução deve ser passível de rastreamento.

- Repositório (repository): local de armazenamento de todas as versões dos itens de configuração,

- Versão (version): representa o estado de um item de configuração que está sendo modificado. Toda versão deve possuir um identificador único (version identifier - VID).

- Revisão (revision): versão que resulta de correção de defeitos ou implementação de uma nova funcionalidade. As revisões evoluem de maneira sequencial, conforme ilustrado na FIG. 51. 


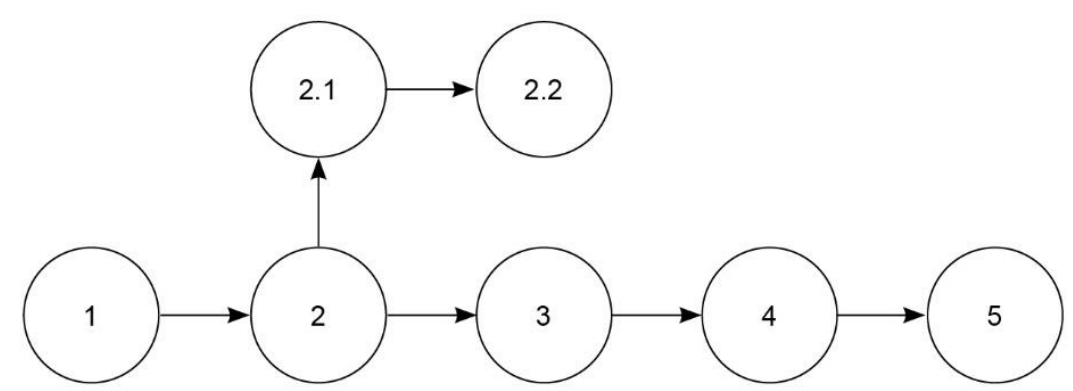

FIGURA 51 - Diagrama exemplificando novas versões e uma operação de ramificação. Fonte: Estublier et al. (2000).

- Ramo (branch): uma versão paralela usada concorrentemente, em configurações alternativas. Na FIG. 51, a versão 3.1 é um ramo por ser considerada uma versão alternativa à versão 3.

- Espaço de trabalho (workspace): espaço temporário para manter uma cópia local da versão a ser modificada. Ele isola as alterações feitas por um desenvolvedor de outras alterações paralelas, tornando essa versão privada.

- Check out (clone): ação de criar uma cópia ou clone de trabalho local do repositório.

- Update: ação de submeter à área de trabalho as modificações contidas no repositório.

- Commit: ação de criar o artefato no repositório pela primeira vez ou criar uma nova versão do artefato quando este passar por uma modificação.

- Merge: ação de consolidação entre versões diferentes, objetivando gerar uma única versão que agregue todas as alterações realizadas.

Segundo Chacon (2009), sistemas de controle de versão podem ser divididos em três tipos, ou modelos, fundamentais: locais, centralizados e distribuídos.

Sistemas de controle de versão locais utilizam uma abordagem monousuário. $O$ controle do repositório é realizado de maneira incremental através de scripts de revisão aplicados diretamente nos arquivos do projeto. Apesar de ser bastante simples e não requerer repositório central, possui a limitação de ser restrito a um único usuário e não viabilizar o desenvolvimento colaborativo e simultâneo. O Revision Control System (RCS) (RCS Mantainers, 2011), desenvol- 
vido por Walter F. Tichy, da Purdue University, em 1983, é uma das ferramentas de controle de versão local mais conhecidas e usadas até hoje.

Nos modelos centralizados, existe apenas um único repositório que centraliza todas cópias de trabalho, executando operações de commit, update e merge entre o servidor e diversos desenvolvedores. A FIG. 52 ilustra a operação deste sistema. Apesar de possibilitarem o trabalho colaborativo entre as equipes de desenvolvimento, SCV centralizados possuem a limitação de seu modelo de versionamento ser ineficiente quando múltiplas atualizações (commits e merges) são realizadas ao mesmo tempo (Chacon, 2009). Há também o risco de disponibilidade, uma vez que o repositório é centralizado em um único ponto de falha. Um exemplo de SCV centralizado é o Subversion® (Apache Software Foundation, [2015]).

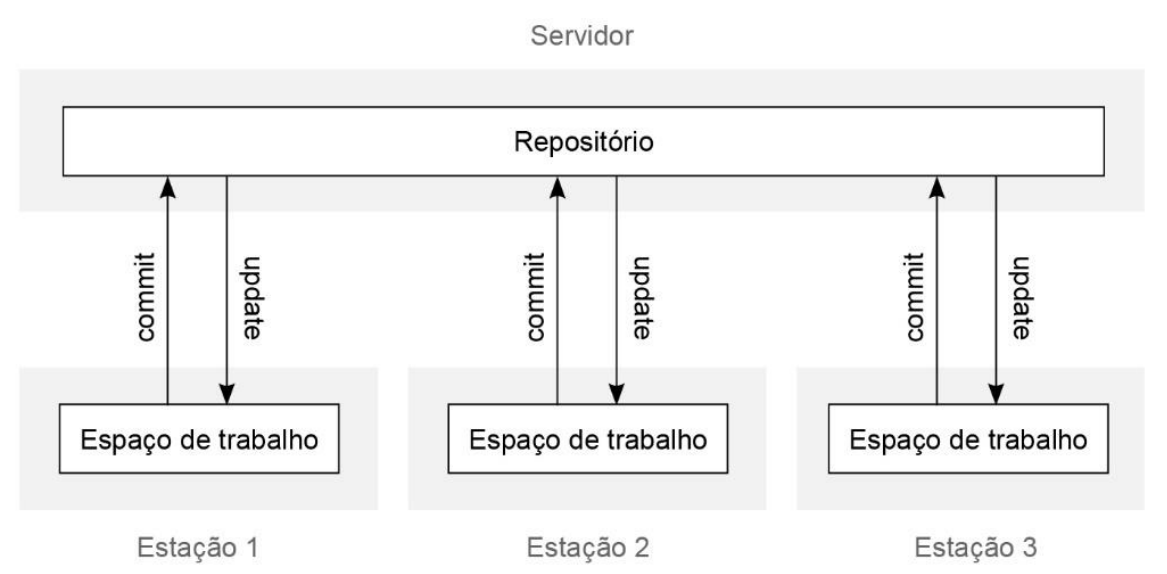

FIGURA 52 - Diagrama exemplificando modelo centralizado de controle de versão. Fonte: Ernst (2012) (adaptado).

Os modelos distribuídos, ou descentralizados, são mais recentes e considerados uma evolução por resolver problemas e ineficiências dos SCV antecessores. Nesse tipo de SCV, cada desenvolvedor possui um repositório e área de trabalho próprios em seu computador. Isso possibilita fluxos de trabalho mais otimizados, já que as atualizações de commits, updates e merges ocorrem no repositório local, e a sincronização com o repositório principal (pull e push) é realizada com muito menos frequência. Assim, contrastando com os sistemas centralizados, qualquer repositório de qualquer um dos clientes pode ser utilizado como backup caso ocorra alguma falha em algum servidor (Chacon, 2009). A FIG. 53 ilustra a operação deste sistema. Exemplos de SCV distribuídos são Git (Git Project, [s.d.]), Mercurial (Mercurial Community, [s.d.]) e Darcs (Darcs Community, [s.d.]). 


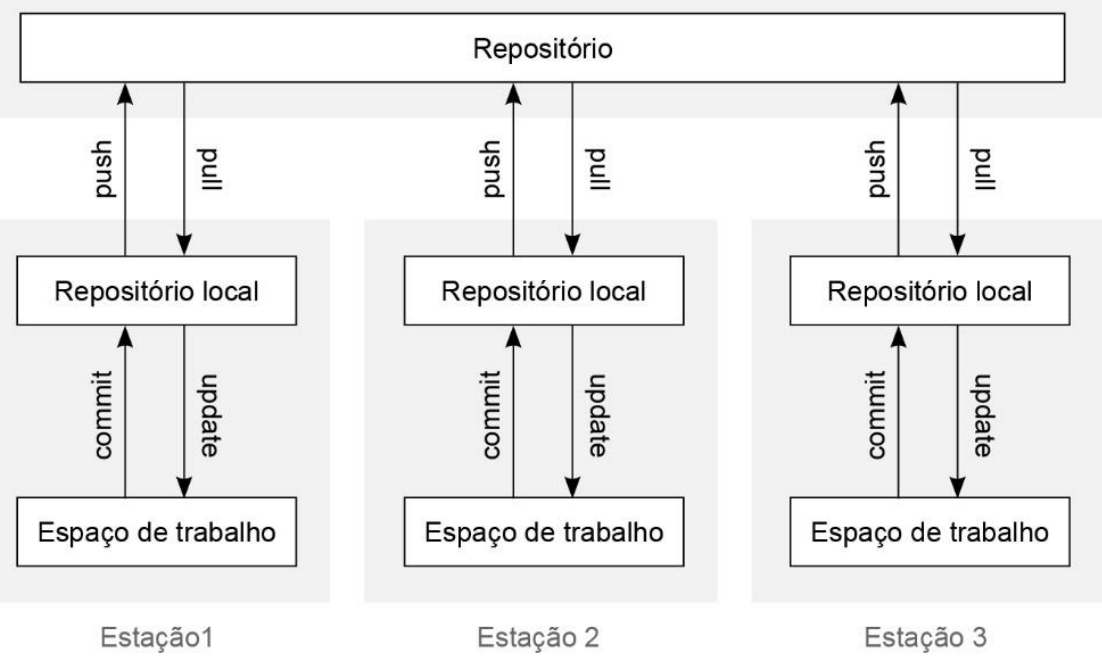

FIGURA 53 - Diagrama exemplificando modelo distribuído de controle de versão. Fonte: Ernst (2012) (adaptado).

Devido à natureza distribuída e descentralizada, esse tipo de SCV é ideal para metodologias ágeis nas quais funcionalidades e correções são incrementais e iterativas. Muitos projetos que utilizam este SCV adotam também um modelo de software como serviço (software as a service - SaaS) (seção 3.5.3.2.1), que, além de facilitar e simplificar o fluxo de trabalho dos usuários, apresenta alta escalabilidade, sendo bastante eficientes para colaboração em equipes distribuídas (Chacon, 2009).

\subsubsection{Conceitos, tecnologias e plataformas para aplicações web interativas}

\subsubsection{SOA}

Hassan (2012) coloca sete estágios para o lançamento de uma aplicação na nuvem: projeto da aplicação, implementação local da aplicação, simulação local da aplicação, lançamento da aplicação no ambiente de nuvem, simulação e testes da aplicação na nuvem, e aplicação operacional no ambiente de nuvem.

Idealmente, o projeto da aplicação se inicia com decisões de alto nível e a materialização de uma arquitetura. A arquitetura define de maneira formal o particionamento de um sistema de software em componentes, protocolos para interação e linguagens de comunicação entre eles, além de padrões de comunicação entre terminais (Lampesberger, 2015). Arquitetura pressupõe a separação 
de preocupações, ou seja, separação de um problema em diversas partes para se concentrar em um aspecto por vez, permitindo a evolução independente das partes do sistema (Lampesberger, 2015).

Serviços podem ser definidos como componentes de software distribuídos e acessíveis na rede por meio de métodos de comunicação estabelecidos. Uma característica da orientação a serviços é prover funcionalidades e conteúdo para diversas plataformas de hardware e software. Os elementos de arquiteturas orientadas a serviços (SOA) operam em alto nível de abstração, ficando mais próximos do modelo de negócio e independentes das plataformas de TI, que podem ser heterogêneas. Além dos usuários, um serviço também pode ser consumidor de serviços em uma interação serviço-serviço (Lampesberger, 2015). De fato, a orientação a serviço é um princípio recomendado para aplicações na nuvem (Zhang, 2009). Segundo Radosevic e Balatinac (2014), a computação em nuvem e as SOA deverão, no futuro, conviver, complementar e dar suporte uma à outra.

As SOA têm se mostrado promissoras para integração e manutenção de sistemas de informação distribuídos, complexos e heterogêneos. A localização geográfica do serviço não é relevante; ao mesmo tempo, o serviço está disponível em qualquer ponto do sistema (ubiquidade). Novos serviços do sistema podem ser compostos a partir de serviços já existentes. SOA não é uma tecnologia, mas um paradigma para organizar e utilizar capacidades distribuídas que podem estar sob o controle de diferentes domínios proprietários, extraindo seu verdadeiro valor da reutilização de componentes e da agilidade proporcionadas ao desenvolvimento de sistemas em software. Representa as interfaces dos componentes como serviços reutilizáveis, distribuídos, pouco acoplados e padronizados (Vogel, 2011).

A comunicação entre os elementos de SOA se dá por troca de mensagens de rede, por um protocolo padrão adotado e uma interface bem definida. Assim, as SOA são independentes de plataformas e linguagens de programação, necessitando somente de interfaces bem definidas nos serviços e um protocolo padrão de comunicação em rede, de preferência aberto, para a interoperabilidade de serviços. Gorton (2011) afirma que as tecnologias de serviços web (web services) são as únicas atualmente que permitem a construção de arquiteturas baseadas em serviços realmente interoperáveis. 


\subsection{Web services e REST}

Web services procuram fornecer uma integração entre sistemas dependendo apenas de protocolo de transferência de hipertexto (hypertext transfer protocol - HTTP), permitindo o uso de plataformas distintas e não dependendo de tecnologias proprietárias e/ou restritivas. Web service é, portanto, uma arquitetura em software projetada para suportar interoperabilidade entre máquinas em rede (Gorton, 2011). Para Daigneau (2010), serviços podem ser considerados qualquer função de software que carregue alguma tarefa de negócio, como a execução de alguma transação ou acesso a determinados arquivos. Serviços podem ser utilizados por diversos tipos de aplicações, promovendo a reutilização de componentes e a colaboração entre sistemas. Web services procuram fornecer uma integração entre sistemas dependendo apenas de HTTP, permitindo o uso de plataformas distintas e não dependendo de tecnologias proprietárias e/ou restritivas. O foco está na simplicidade e interoperabilidade (Gorton, 2011). O conteúdo tem se desvinculado da forma, permitindo que diversas fontes de informação apenas postem as informações na rede, deixando livre para cada aplicação decidir como e de que forma publicar a informação. Em vez de serem consumidas na forma de linguagem de marcação de hipertexto (hypertext markup language - HTML) formatado por navegadores, as informações são apresentadas na forma de linguagem de marcação extensiva (extensible markup language - XML) (W3C, [s.d.]b) ou JSON ou outro formato que possa ser compreendido por máquinas (Richardson et al., 2007).

Os web services garantem a interoperabilidade de serviços com mensagens XML sobre protocolo simples de acesso a objetos (simple object access protocol - SOAP), independente da linguagem de programação ou plataforma de hardware. SOAP é um protocolo de serviço baseado em XML e, assim como este, também especificado pela World Wide Web Consortium (W3C). Esse protocolo permite a troca de dados entre os clientes e o web service. Mensagens SOAP são tipicamente transmitidas usando HTTP, com serialização XML em conjunto com outras normas relacionadas à web (W3C, 2004).

Uma aplicação cliente encontra um serviço de interesse através de um serviço de registros universal description, discovery and integration (UDDI)

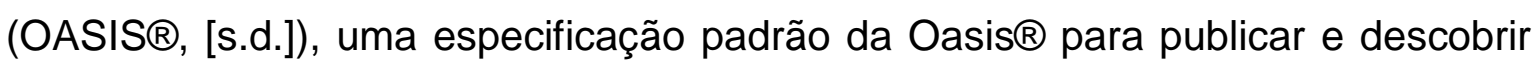
serviços em SOA. O web service da rede que presta o serviço de registro UDDI publica os contratos recebidos de forma centralizada, permitindo que aplicações 
cliente encontrem mais facilmente web services e serviços disponíveis na rede. Com a informação da localização do web service que hospeda o serviço desejado, o cliente solicita o contrato de serviço via SOAP, sobre HTTP. Com o contrato de serviço denominado web services description language (WSDL), o cliente implementa métodos de interface com o serviço desejado e passa a consumi-lo via SOAP sobre HTTP. O WSDL descreve em XML as interfaces de métodos disponíveis em um web service. Esse processo é ilustrado pela FIG. 54.

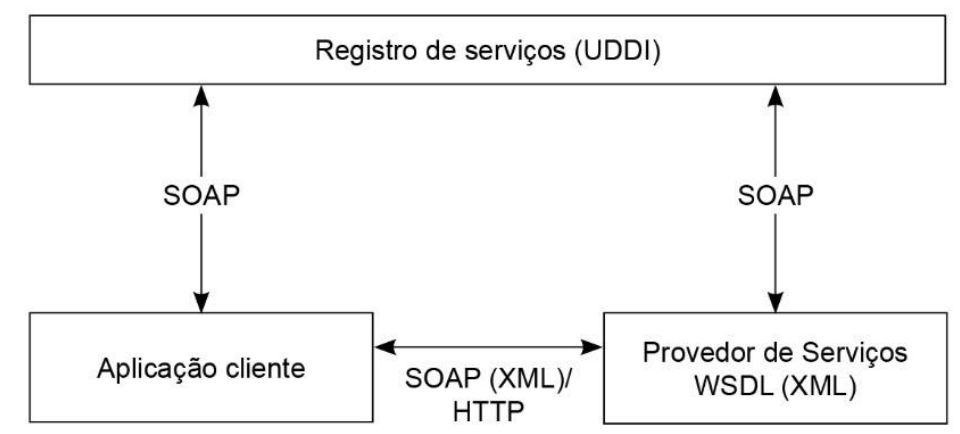

FIGURA 54 - Relacionamentos entre aplicação cliente, provedor e registro de serviços na arquitetura SOA. Fonte: do autor.

Embora XML, SOAP e WSDL tenham especificações bem definidas (W3C, [s.d.]b; [s.d.]d; 2011), existem diversas maneiras de utilizar essas tecnologias para implementar web services, o que leva a conflitos a respeito da interoperabilidade de serviços. Com o objetivo de manter a interoperabilidade entre web services, existem inúmeros esforços de padronização de web services, mantido por organizações como Web Services Interoperability Organization (WS-I), Oasis $\AA_{\text {e }}$ W3C.

\subsection{REST}

O HTTP é um protocolo base para a comunicação de dados da web que opera sobre o protocolo TCP (segundo o modelo OSI) e funciona através da transmissão de mensagens de requisição e resposta. Alguns web services utilizam o HTTP apenas como meio de transporte de dados; outros, o utilizam como um protocolo completo (Daigneau, 2010).

A arquitetura REST utiliza apenas recursos do HTTP e foi concebida por Roy Thomas Fielding para a construção de web services consistentes e coe- 
sos, enfatizando a escalabilidade na interação entre os componentes, a generalidade de interfaces e a implantação (deploy) independente dos componentes de um sistema (Fielding, 2000). REST não se trata de uma tecnologia, mas de um estilo de arquitetura baseado em recursos e nas representações desses recursos. Basear-se em recursos significa referir-se a objetos, em vez de referir-se a ações (Masse, 2011).

Em REST, assume-se a separação de responsabilidades entre cliente e servidor e deve ser definida uma interface entre eles. Essa separação implica que clientes não devem tratar de armazenamento de dados e que o servidor não se preocupa com a interface do usuário, tampouco com o estado do mesmo. Com uma interface bem definida, a arquitetura se torna mais simples e desacoplada, de modo que cada parte da aplicação pode ser desenvolvida de forma independente. Em REST, as interações entre cliente-servidor não possuem estados ou sessões. A independência do estado da aplicação provê grande escalabilidade, já que o servidor não mantém o estado da aplicação e, com isso, balanceadores de carga não precisam se preocupar com sessões de usuário. No entanto, o cliente deve incluir toda informação que o servidor precisa para processar cada requisição.

Quando uma interface de programação de aplicação (application programming interface - API) é exposta na web e segue os princípios REST, esta pode ser chamada de uma REST API, tornando o web service um RESTful (Masse, 2011). Web services denominados RESTful utilizam o protocolo HTTP como base única e suficiente para a criação de aplicações expostas na forma de serviços, focando na identificação e disposição de recursos ao invés da troca individual de transações (Bean, 2010). Uma importante funcionalidade do HTTP é negociação da representação de dados, o que permite que os sistemas que o utilizam para comunicação sejam construídos de forma independente dos dados que estão sendo transferidos (Lampesberger, 2015). O REST é baseado em recursos e nos estados desses recursos, identificados por identificadores uniformes de recursos (uniform resource identifiers - URI) e acessados por representações como XML ou JSON (Fielding, 2000). Com os meios para identificar e representar recursos, resta saber como interagir com eles, o que é feito por verbos HTTP. Os verbos mais utilizados são GET, POST, PUT, DELETE. Um exemplo clássico de aplicação baseada em REST é uma aplicação Create, Read, Update and Delete (CRUD), implementada com os verbos supracitados. 
O HTML, XML e JSON são as linguagens mais influentes para troca de informação na web. As linguagens baseadas em texto possuem menor densidade de informação se comparadas às baseadas em bits (binárias), mas, em contrapartida, podem ser compreendidas por humanos. O JSON é um formato de texto simples usado para serializar informação como pares estruturados de chavevalor, sendo conhecido pela facilidade com que seu conteúdo pode ser lido e escrito por humanos. Sua sintaxe é um subconjunto do JavaScript, e um documento JSON é analisado (parsed) ou avaliado (evaluated) para um objeto em tempo real. Dentre as vantagens do formato JSON sobre XML, além da melhor legibilidade, está a notória redução na quantidade de dados das estruturas de organização e a simplicidade dos parsers JSON comparado aos XML. JSON também é completamente independente de linguagens, porém, utiliza convenções que são familiares a programadores de linguagens da família do $\mathrm{C}$, incluindo $\mathrm{C}_{++}, \mathrm{C \#}$, Java, JavaScript, Perl, Python e muitas outras. Estas características fazem do JSON uma linguagem de troca de dados bastante generalista. Assim como na maioria das linguagens baseada em texto, o JSON possui ainda um equivalente binário (binary JavaScript object notation - BSON), o que diminui a sobrecarga computacional da etapa de avaliação de texto (Lampesberger, 2015). Finalmente, os navegadores modernos já incorporaram o suporte nativo ao JSON, anulando os custos de desempenho associados às bibliotecas JavaScript. $O$ suporte nativo veio após uma proposta de inclusão na especificação ECMAScript 3.1 (versão esboço), em maio de 2008. Assim, o emprego de JSON em sistemas RESTful tem se popularizado, principalmente em sistemas que prezam pela simplicidade e racionalização dos recursos computacionais.

\subsubsection{Computação em nuvem}

A tendência da computação é explorar cada vez mais os recursos compartilhados na internet. A "nuvem" é resultado da mudança da computação desktop para uma orientada a serviços, utilizando clusters e bancos de dados localizados em grandes datacenters (Hwang et al., 2011). Pode ser vista como a industrialização da provisão e da entrega de serviços via internet, usando tecnologias consagradas da web e de serviços empresariais (enterprise services) (Lampesberger, 2015). A tendência é simplificar o modelo tradicional, onde o cliente detém e administra toda a infraestrutura (FIG. 52a), transferindo boa parte 
das tarefas de administração para terceiros (Hwang et al., 2011). O conceito básico da computação em nuvem é administrar e agendar recursos computacionais conectados em rede e provê-los a diversos usuários de acordo com suas necessidades, negociadas no acordo de nível de serviço (service level agreement SLA). Os recursos estão sempre disponíveis ao usuário e podem ser escalados, sendo a cobrança feita de acordo com o uso (Jain e Kumar, 2014).

A nuvem oferece mais opções às organizações para a implantação de infraestrutura de tecnologia da informação. É dirigida por princípios econômicos e busca reduzir substancialmente o investimento inicial e os custos de posse e operação (FIG. 55) em grandes datacenters (Hwang et al., 2011), além de transferir diversos riscos para terceiros (Gorelik, 2013). As empresas não precisam se preocupar com instalação de servidores, armazenamento e interfaces de rede, segurança e disponibilidade (Rodger, 2011), e os custos de hardware são compartilhados entre os vários clientes. Isso faz da computação em nuvem uma alternativa mais econômica, se comparada aos custos de aquisição, administração e atualização de um servidor próprio. Além disso, os recursos estão prontos para uso imediato, e atualizações de software são garantidas e executadas com maior agilidade (Liu et al., 2011).

A elasticidade e escalabilidade, aliadas ao modelo de cobrança por uso, permitem absorver picos na carga de trabalho com maior eficiência técnica e econômica, comportando tanto o crescimento como a redução no uso de um serviço (Hwang et al., 2011). Esses aspectos são bastante explorados por startups, um tipo de empreendimento que precisa se posicionar rapidamente no mercado e ter capacidade para comportar picos de uso caso a demanda se materialize (Weidong et al., 2010).

Do ponto de vista do desenvolvedor, a computação em nuvem pode facilitar o teste e desenvolvimento de aplicações por meio de ambientes preconfigurados e prontos para uso, permitindo integrar serviços e funções de uma organização com aquelas disponibilizados na nuvem ou construir rapidamente serviços em ambientes de desenvolvimento da nuvem (Vogel, 2011). Finalmente, o usuário final se beneficia por não precisar comprar, instalar e atualizar software. Por serem baseados no navegador, os serviços são acessíveis em diversos tipos de sistemas, plataformas e dispositivos. A interação e comunicação entre os provedores e consumidores é, portanto, um aspecto chave da entrega do serviço (Lampesberger, 2015). 


\subsection{Categorias de serviço}

São três as categorias mais consagradas de serviço (Liu et al., 2011): software como serviço (software as a service - SaaS), plataforma como serviço (platform as a service - PaaS) e infraestrutura como serviço (infrastructure as a service - laaS). Cada tipo expõe o usuário a diferentes tipos de operações administrativas e operacionais e a diferentes pontos de acesso no sistema, o que pode ser observado com maiores detalhes na FIG. 55.

(a)

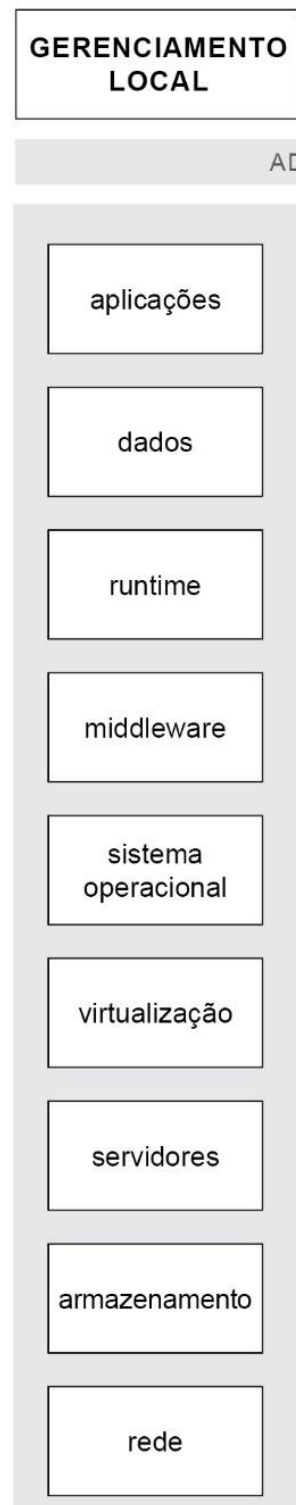

(b)

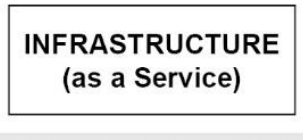

(c)

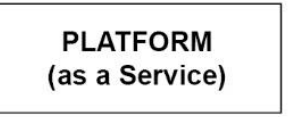

(as a Service)

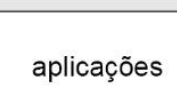$$
\text { aplicaçōes }
$$
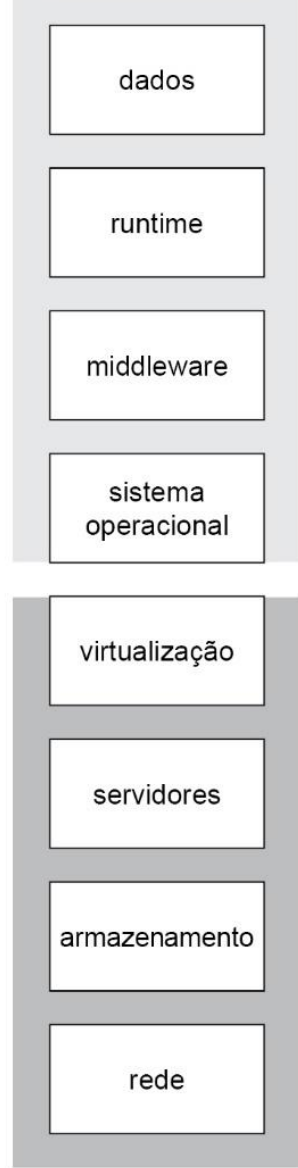
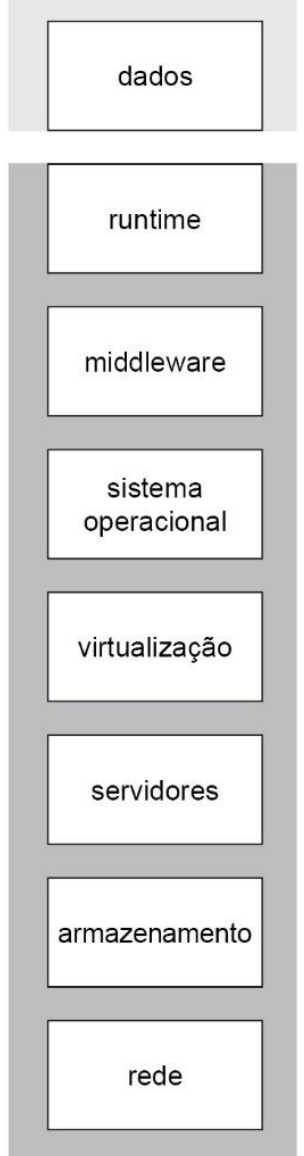

(d)

SOFTWARE

(as a Service)

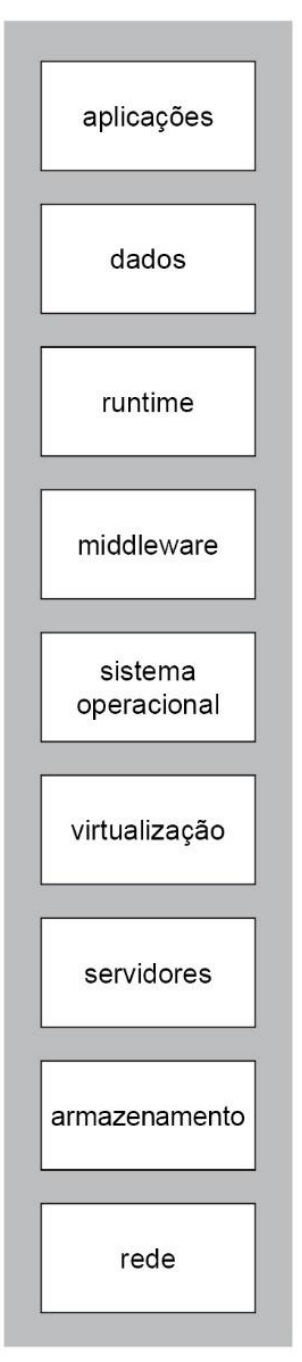

sistema

operacional

virtualização

servidores

ADMINISTRADO PELO PROVEDOR

FIGURA 55 - Distribuição de responsabilidades entre provedor e cliente nos diversos tipos de serviços em nuvem. Fonte: Liu et al. (2001) (adaptado). 
Em um SaaS, são disponibilizadas aplicações diretamente aos usuários finais, acessíveis em diversos dispositivos via navegadores. O consumidor controla, no máximo, algumas opções de configuração da aplicação (FIG. 55d), ficando todo o resto a cargo do provedor (Liu et al., 2011).

O modelo PaaS é constituído por uma coleção de serviços voltados à criação e lançamento de software na nuvem (Devi e Ganesan, 2015). Em termos práticos, o consumidor pode implantar suas próprias aplicações na infraestrutura física da nuvem, utilizando ferramentas fornecidas pelo provedor. Neste caso, não é possível controlar a infraestrutura física, apenas as aplicações em execução (FIG. 55c), e acessar opções de configuração do ambiente de hospedagem (Liu et al., 2011). Tecnicamente, não há acesso direto ao sistema operacional (bancos de dados, plataformas de desenvolvimento, servidores de aplicação), e sim apenas aos ambientes de execução (Gorelik, 2013). Serviços mais comuns dos PaaS são componentes de software preconfigurados, bancos de dados escaláveis, plataformas de integração dos componentes internos ou serviços externos, lançamento e administração automática de aplicações e ambientes de tempo de execução de aplicação web, ferramentas de monitoramento. São PaaS tradicionais: OpenShift, Google App Engine e Heroku (Jurenka, 2015).

Benefícios chave de um PaaS são a minimização de recursos e tempo gastos em manutenção e administração do sistema, além da escalabilidade e flexibilidade automática dos serviços (Mutavdzic, [2010]). Isso permite ao desenvolvedor concentrar-se no processo de desenvolvimento de software (Gorelik, 2013). Um aplicativo pode ser construído com menos linhas de código, permitindo que o desenvolvimento se concentre nas funcionalidades essenciais e na inovação. Devido a essas características, é possível denominá-lo como uma framework "agileready" (Devi e Ganesan, 2015). De fato, muitos times de desenvolvimento adotam métodos de desenvolvimento ágeis em PaaS, em detrimento ao tradicional modelo em cascata (Gorelik, 2013).

O modelo laaS provê recursos computacionais físicos típicos de um datacenter, como servidores, discos, estrutura de rede, além de software de controle básico, como sistemas operacionais e máquinas virtuais (Gorelik, 2013). O consumidor não pode controlar a infraestrutura física (FIG. 48b), mas pode escolher e controlar sistemas operacionais e todas as aplicações e o armazenamento, além de ter acesso a algumas configurações dos componentes de rede (Liu et al., 
2011). O principal benefício de um laaS (Mutavdzic, [2010]) é a redução de custos na aquisição, manutenção e atualização de hardware e software, e a economia devido ao modelo de pagamento por uso (Gorelik, 2013). Existem sete características principais de um laaS (Casalicchio e Silvestri, 2011): modelo de personalização, modelo de cobrança, tipo de interface, balanceamento de carga (load balancing), SLA, serviços de monitoramento e escalabilidade automática. O modelo laaS tende a perder espaço no mercado para os modelos PaaS e SaaS. Exemplos típicos são Google Compute Engine, Microsoft Azure e Amazon Web Services (AWS), sendo que os dois últimos também são comumente classificados como PaaS (Jurenka, 2015).

De fato, não é simples classificar com precisão um serviço de computação na nuvem. Autores como Gorelik (2013) afirmam que as fronteiras entre os modelos estão se tornando mais indefinidas. O banco de dados Amazon RDS, por exemplo, pode ser facilmente classificado tanto no modelo PaaS como no laaS. Isso se deve ao fato que os provedores procuram cada vez mais oferecer melhor produtividade aos seus consumidores, complementando suas ofertas laas com serviços PaaS e até mesmo SaaS. Essa imprecisão deixou o campo aberto para outras classificações, como network as a service (NaaS) (ISO/IEC, 2014), information as a service (INFaaS), integration as a service (INTaaS), storage as a service (STaaS) (Kulkarni et al., 2012) e database as a service (DaaS) (Krishna Anne, 2012).

\subsection{A importância da virtualização}

A virtualização é uma tecnologia vital para operacionalizar o compartiIhamento dos recursos de uma nuvem, além de otimizar sua utilização. Máquinas virtuais permitem a abstração de serviços e aplicações da infraestrutura (Chen et al., 2012). A virtualização de servidores permite criar o servidor lógico independente da estrutura física. A plataforma virtual é elástica e provê hardware, software e dados dinamicamente (Hwang et al., 2011).

Além de máquinas virtuais tradicionais, existe a abordagem dos containers, que promete inúmeras vantagens. Um container é um ambiente de execução autocontido que compartilha o kernel do sistema hospedeiro, podendo ser isolado de outros containers do sistema. Comparados a máquinas virtuais, os containers não têm a mesma sobrecarga computacional (overhead), 
pois requerem apenas a aplicação e suas dependências, compartilhando o kernel do sistema operacional. Essa mesma característica torna a inicialização de containers muito mais rápida do que das máquinas virtuais. Tecnologias comuns são as "zonas" do Solaris, OpenVZ, FreeBSD jails, LXC, Docker e os Dynos (Heroku). A limitação desta abordagem é a restrição ao sistema operacional em uso (Jurenka, 2015).

\subsection{Limitações}

Para organizações, as limitações na adoção de soluções de computação em nuvem decorrem principalmente dos diversos riscos existentes e de questões de desempenho. Liu et al. (2011) destacam que a adoção depende de como o provedor resolve as preocupações de segurança, portabilidade e interoperabilidade. No caso de instituições acadêmicas, não existe acesso a infraestrutura de baixo nível na escala de um datacenter para o teste de algoritmos e sistemas, devido à falta de recursos financeiros ou de relações com a indústria (Barker, 2014). Isso torna difícil a produção de pesquisas significativas na área de computação em nuvem. De acordo com Clarke (2010), os riscos principais podem ser operacionais, de contingência, de segurança e de negócio.

A interoperabilidade é a habilidade de escrever código que funcione diretamente em um ou mais provedores simultaneamente (Devi e Ganesan, 2015). Um problema muito destacado na literatura é o chamado lock-in, ocasionado pela falta geral de interoperabilidade nos serviços de nuvem, ou seja, dificuldade ou impossibilidade de migração de um sistema já estabelecido de uma nuvem a outra. $O$ custo envolvido em uma migração induz a conformação do cliente a condições de desempenho insatisfatório ou custos de operação maiores que a média do mercado (Bessani et al., 2012). Isso quer dizer, na prática, que as soluções de cada provedor são únicas e que os componentes são muito acoplados. Soluções exploradas recentemente para abordar esse problema são imagens de máquinas virtuais que utilizem um padrão aberto interoperável e containers (Devi e Ganesan, 2015).

As questões de desempenho relacionam-se principalmente com a disponibilidade, confiabilidade, compatibilidade, tolerância, recuperação de falhas, elasticidade e escalabilidade (Radosevic e Balatinac, 2014). A elasticidade é uma propriedade fundamental tanto para grandes companhias como para iniciantes. 
Na prática, não existem plataformas infinitamente e instantaneamente elásticas (Radosevic e Balatinac, 2014). Há inevitavelmente um atraso entre a requisição e a disponibilização efetiva de uma aplicação (Brebner, 2012). A escalabilidade é especialmente importante para aplicações SaaS para lidar com uma grande quantidade de requisições simultâneas (Tsai et al., [2012]). Existem ainda provedores laaS que não oferecem serviços como escalabilidade automática e monitoramento avançado (Casalicchio e Silvestri, 2011).

A disponibilidade e confiabilidade relacionam-se principalmente com a capacidade de tolerar erros e a redundância existente no sistema. Muitas arquiteturas existentes são do tipo two-tier (interface no cliente, dados no servidor), que são consideradas mais acopladas e menos confiáveis que as three-tier (camada adicional de aplicação, intermediária) (Phatak e Kamalesh, [2010]). Os provedores precisam, eventualmente, fazer pausas para reparos e atualizações. Boa parte das soluções não possui mecanismos para recuperação no caso de falhas catastróficas (Bessani et al., 2012).

O principal risco enfatizado na literatura de maneira geral é a segurança: do acesso, dos dados e de ataque ao sistema. Essa questão impede a adoção mais generalizada das nuvens públicas, apesar das diversas vantagens econômicas (Devi e Ganesan, 2015). Uma das principais preocupações é a confiança no provedor para garantir privacidade das informações (Radosevic e Balatinac, 2014) e não conhecer a localização dos dados (Begum e Khan, 2011). Para o cliente, é fundamental poder contar com o provedor como parte de uma fundação robusta para construir seu negócio (Bessani et al., 2012). Além disso, o compartilhamento dos recursos de uma nuvem pública com máquinas virtuais cria vizinhanças com outros clientes - que podem ser, inclusive, entidades maliciosas (Chen et al., 2012).

Riscos de segurança relacionam-se à autenticação, autorização, confidencialidade, integridade e resposta a incidentes (Liu et al., 2011). A falha no atendimento a esses requisitos pode levar ao uso não autorizado de recursos e serviços da nuvem e ao roubo de dados (Almutairi et al., 2012). Mesmo provedores consagrados como a Amazon já demonstraram fragilidade de segurança em experimentos, apesar do uso de criptografia avançada (Sarkar et al., [2012]). 


\subsubsection{Aplicações web na nuvem}

\subsection{Tecnologias para cliente}

\subsection{JavaScript}

O JavaScript ou ECMAScript é uma linguagem de programação interpretada multiparadigma e dinâmica, suportando tanto programação orientada a objetos, como imperativa e funcional, de tipagem fraca e implícita. Foi originalmente desenvolvida por Brendan Eich, em 1995, na empresa Netscape, como parte de seu produto principal, o Netscape Navigator. Este era o navegador de internet dominante naquele período. O JavaScript é tradicionalmente utilizado em conjunto com o HTML e o CSS para a construção de páginas web. Ele se tornou a linguagem mais popular do mundo, e é suportada por praticamente todos os navegadores atuais. Ambientes de execução como o Google V8, denominados "motores" JavaScript, estão tipicamente incorporados em navegadores e em serviços como o NodeJS, interpretando o código para linguagem de máquina e estabelecendo diversas restrições no sistema e na rede para aplicar políticas de segurança (Lampesberger, 2015). Os motores JavaScript passaram de interpretadores para compiladores (just-in-time - JIT), como - V8, evolução necessária devido à complexidade crescente das aplicações construídas nessa linguagem (Zakas, 2010). O código JavaScript pode ser diretamente incorporado em HTML ou XHTML ou como conteúdo baseado em texto (Lampesberger, 2015).

\subsection{HTML5}

O HTML foi inicialmente projetado para descrever documentos científicos. Muitas versões do HTML surgiram, levando a implementações incompatíveis ou representações visuais inconsistentes nos navegadores (Lampesberger, 2015). Uma área que não havia sido adequadamente coberta pelo HTML é a área das aplicações web e, por isso, funcionalidades interativas na web dependeram por muito tempo de plugins como Adobe Flash, o que sempre teve impacto na acessibilidade. A especificação HTML5 representa uma tentativa de atingir uma padronização e promete dar suporte a construção de rich web applications (RIA) acessíveis em navegadores e dispositivos móveis. As tecnologias devem melho- 
rar sobremaneira o suporte a aplicações interativas, provendo capacidade nativa de renderização 3D, websockets e eventos enviados pelo servidor (server sent events - SSE), transmissão de mensagens, suporte a diversos formatos de áudio e vídeo, geolocalização e armazenamento local (Pilgrim, 2010).

\subsection{Bootstrap e JQuery}

O Bootstrap é uma framework front-end de CSS extensamente documentado e muito popular, voltado a criar elementos de interface gráfica responsivos em websites. É conhecido por poupar muito do trabalho de escrever CSS, facilitando construir protótipos. Além do sistema de grid, que adapta a interface à tela do dispositivo, oferece uma grande quantidade de componentes, como botões, barras de navegação, ícones, componentes de paginação, dentre vários outros. A biblioteca JavaScript JQuery é comumente utilizada para a programação lógica das interfaces gráficas e criação de elementos animados, lidando com os eventos internos e os produzidos pelo usuário.

\subsection{Tecnologias para servidor}

\subsection{Ruby on Rails}

O Ruby on Rails é uma framework MVC que provê estruturas padronizadas para desenvolvimento de serviços de bancos de dados, web services e páginas web. Foi criada para aumentar a produtividade e a organização do programador, além de reduzir as barreiras ao desenvolvimento de aplicações (Richardson et al., 2007). As aplicações Rails são todas escritas em Ruby, o que permite escrever aplicações altamente legíveis e de maneira ágil. Dentre os princípios que guiam a filosofia do Rails, estão: nunca repetir código (princípio "dry"), e assumir REST como o melhor estilo para se desenvolver aplicações para a web (Richardson et al., 2007). O programador apenas escreve a funcionalidade da aplicação nos modelos, controladores e vistas, e a framework os interliga durante a execução do programa, sem necessidade de intervenção por parte do utilizador. A utilização desta framework facilita a implementação de web services utilizando o padrão REST e formatos XML e JSON para transferência de dados (Costa, 2008). A Ruby on Rails é normalmente lançada com um servidor de banco de dados como o PostgreSQL e um servidor web como o Puma - este escrito em Ruby e co- 
nhecido por sua leveza, velocidade e capacidade de paralelismo. O Puma implementa um servidor HTTP e usa a interface Rack.

\subsection{Sistema de gerenciamento de banco de dados (SGBD)}

Um sistema de banco de dados é um sistema computadorizado para armazenamento de informações e subsequente recuperação e atualização dessas informações. Os sistemas computadorizados responsáveis pelo gerenciamento de bancos de dados são conhecidos por sistemas de gerenciamento de banco de dados (SGBD), ou database management systems (DBMS). Através deles, é possível definir, construir, manipular e compartilhar bancos de dados entre usuários e aplicações. SGBD controlam o meio pelo qual os dados serão armazenados e fornecem as funções que serão expostas aos usuários e aplicações para a consulta (querying) e atualização de dados. Eles permitem que dados sejam normalizados, evitando redundância e inconsistência de dados. Geralmente, eles também fornecem um módulo para processamento e otimização de consultas. Funcionalidades de backup e recuperação também são comuns em SGBD (Date, 2004).

O movimento NoSQL tem como principal objetivo encontrar alternativas para problemas que não podem ser resolvidos por meio dos bancos de dados relacionais. Diferente dos SGBD relacionais, no mundo NoSQL, o esquema dos dados é usualmente responsabilidade da aplicação. Existem ainda outros dois aspectos que diferenciam bancos de dados NoSQL dos relacionais, que são a forma como os dados são armazenados e acessados em disco e os modelos de consultas utilizados (Date, 2004).

Bancos de dados NoSQL do tipo chave/valor utilizam um modelo de dados bem simples, geralmente um mapa (ou HashMap) ou dicionário (ou array associativo), onde clientes armazenam e requisitam valores por meio de chaves. Já os bancos de dados orientados a documentos permitem o armazenamento de informações mais complexas, com pares de chave/valor sendo armazenados na forma de documentos, normalmente adotando o formato JSON (Date, 2004; Strauch, 2011). Uma vantagem clara do uso de documentos é que correspondem aos tipos de dados nativos de diversas linguagens de programação, como o JavaScript. Além de sua presença na programação do lado servidor, o formato para serialização de dados JSON tem sido adotado largamente como uma alternativa ao XML para transferência de dados, como em web services. $O$ formato também 
é utilizado por diversos bancos de dados, como MongoDB e PostgreSQL. Os dados são comumente armazenados no formato BSON, projetado de forma a priorizar três características: leveza, transversalidade (permitir buscas e edições rápidas nos documentos) e eficiência de decodificação.

O NoSQL foi criado com vistas à escalabilidade, escalando horizontalmente com maior facilidade e em hardware comum. Bancos de dados NoSQL também possuem alto fluxo (throughput) de dados (Strauch, 2011). O MongoDB é uma opção open-source muito popular no mercado. No entanto, o recente suporte ao BJSON no PostgreSQL se mostra uma opção de desempenho superior. Os dois bancos de dados são amplamente disponibilizados por diversos provedores de computação em nuvem.

\subsection{GitHub}

Todo sistema moderno em nuvem possui um repositório de códigofonte, que permite desenvolvimento colaborativo, armazenamento de backups, assim como sincronização automática de atualizações. Um dos sistemas mais conhecidos é o Git, inventado por Linus Torvalds para apoiar o desenvolvimento do sistema Linux, devido a limitações nos sistemas da época (Loeliger, 2012). Dentre essas características, estava o desenvolvimento distribuído sem necessidade de sincronização com um repositório central, repositório completo distribuído. O Git é implementado e oferecido pelo serviço de web hosting GitHub.

\subsubsection{Computação gráfica na web}

Foi consultada literatura que se dedica a analisar e comparar as principais tecnologias para desenvolvimento de aplicações 3D (Pattrasitidech, 2014; Petridis et al., 2010; Waerner, 2012). Essa literatura destaca as seguintes tecnologias como flexíveis e repletas de funcionalidades: Unreal/UDK, Blender, Unity 3D, CryEngine, Source e Ogre3D. Entretanto, apontam que tais tecnologias exigem a instalação de aplicativos nos dispositivos do cliente, comprometendo a portabilidade das aplicações. Frente a este cenário, tecnologias para desenvolvimento de aplicações 3D na web são alternativas de maior portabilidade. Segundo Waerner (2012), as principais opções são JOGL, LWJGL, WebGL e Stage 3D. Conforme apresentado na TAB. 1, o WebGL tem nítido destaque considerando todos os critérios de avaliação. 
TABELA 1 - Avaliação das tecnologias de computação gráfica para web.

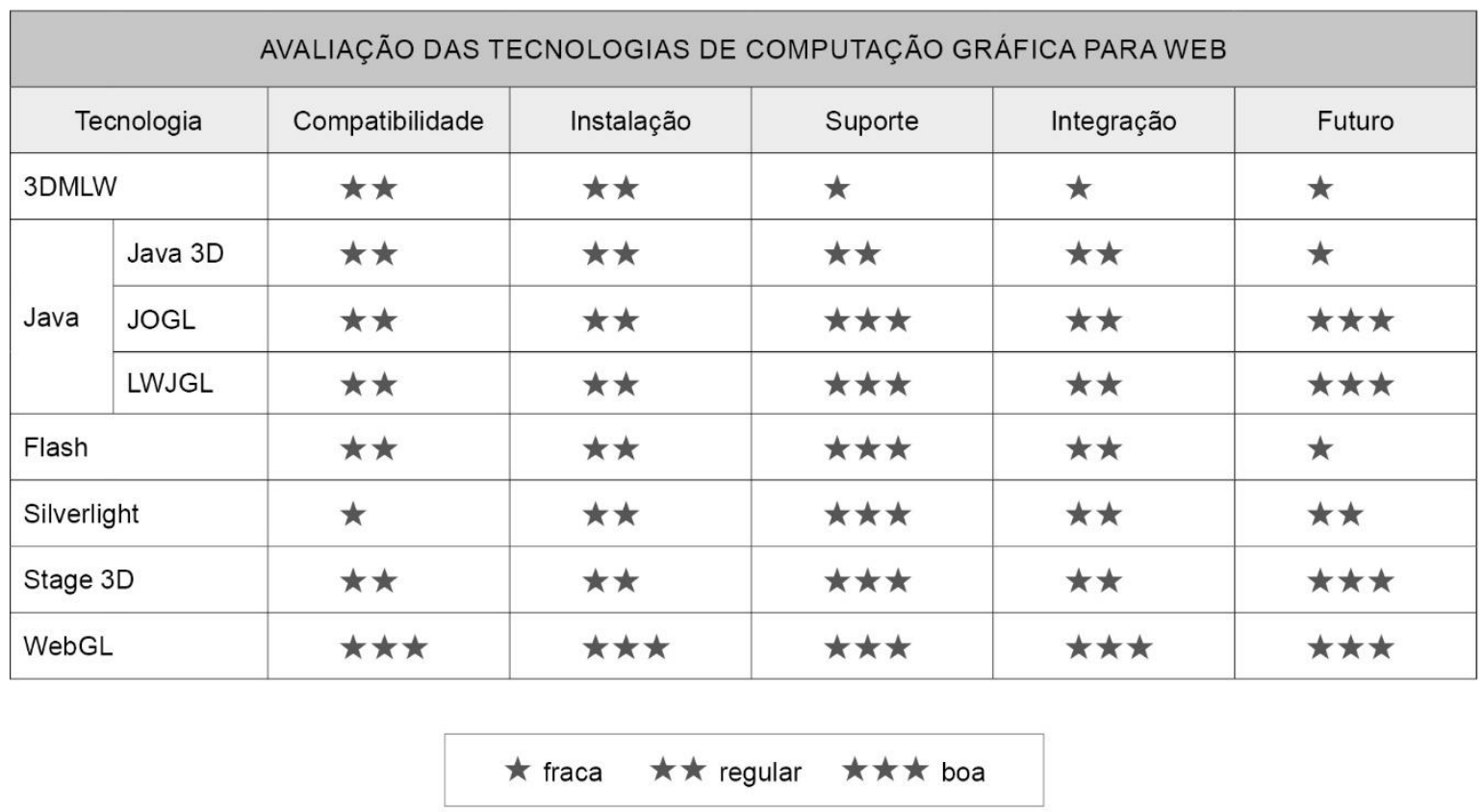

Fonte - Waerner (2012) (adaptado).

Em 2011, como consequência da aquisição da Sun Microsystems pela Oracle, surgiu uma série de incompatibilidades e instabilidades na plataforma Java (Kaspersky Lab, [s.d.]). Isso levou à recomendação, por parte do Departamento de Defesa dos Estados Unidos, de remoção e não utilização da plataforma (Computer Emergency Readiness Team, 2013), e à descontinuação do suporte nativo por parte de uma grande quantidade de navegadores (Gruman, 2013). Consequentemente, as tecnologias derivadas do Java (Java 3D, JOGL e LWJGL) entraram em declínio.

Após a análise das tecnologias disponíveis, entendeu-se que a tecnologia WebGL seria a mais adequada (TAB. 1). Ela foi, então, adotada como a plataforma tecnológica de computação gráfica do projeto. Barbosa (2013) descreve brevemente o histórico do WebGL. Em 2009, o Khronos Group anunciou o desenvolvimento de uma tecnologia open-source capaz de renderizar gráficos 3D acelerados por hardware num navegador, sem a necessidade de instalação de qualquer plug-in. Na especificação do WebGL, estiveram envolvidas empresas como Google, Mozilla, Opera, Apple, NVIDIA e AMD. A versão 1.0 desta tecnologia foi lançada em 2011. Em outubro de 2014, o W3C, consórcio de empresas de tecnologia que coordena os padrões da internet quanto à linguagem, finalizou a recomendação do padrão HTML5. 
Segundo dados de Deveria ([s.d.]), a plataforma WebGL atualmente é suportada pela maioria dos navegadores (TAB. 2). É notório que o Google Chrome está à frente dos concorrentes, tanto no que diz respeito ao suporte ao estado da arte do HTML5, como ao seu domínio como navegador mais utilizado no Brasil e no mundo - posição na qual se mantém desde maio de 2012.

TABELA 2 - Estado do suporte a tecnologia WebGL nos navegadores mais populares em suas versões mais populares.

\begin{tabular}{|c|c|c|c|c|c|c|c|c|c|c|}
\hline \multicolumn{11}{|c|}{$\begin{array}{l}\text { ESTADO DO SUPORTE A TECNOLOGIA WEBGL } \\
\text { NOS NAVEGADORES MAIS POPULARES EM SUAS VERSÕES MAIS POPULARES }\end{array}$} \\
\hline & IE & Edge & Firefox & Chrome & Safari & Opera & $\begin{array}{l}\text { iOS } \\
\text { Safari }\end{array}$ & $\begin{array}{c}\text { Opera } \\
\text { Mini }\end{array}$ & $\begin{array}{l}\text { Android } \\
\text { Browser }\end{array}$ & $\begin{array}{l}\text { Chrome } \\
\text { for } \\
\text { Android }\end{array}$ \\
\hline \multirow[t]{3}{*}{ mais antiga } & & & & 43 & & & & & 4.3 & \\
\hline & & & & 46 & & & & & 4.4 & \\
\hline & 8 & & 43 & 47 & & & & & 4.4.4 & \\
\hline mais popular & 11 & 13 & 44 & 48 & 9 & 34 & 9.2 & 8 & 47 & 47 \\
\hline & & 14 & 45 & 49 & 9.1 & 35 & 9.3 & & & \\
\hline$\downarrow$ & & & 46 & 50 & & 36 & & & & \\
\hline mais recente & & & 47 & 51 & & & & & & \\
\hline
\end{tabular}

Fonte - Deveria ([s.d.]) (adaptado).

O WebGL, baseado no OpenGL ES 2.0, utiliza o elemento canvas do HTML5 e disponibiliza uma API para renderização de gráficos 3D acessível a partir da linguagem JavaScript (Parisi, 2012). O canvas cria gráficos 2D ou 3D utilizando apenas os recursos nativos do navegador, possuindo muitos métodos para desenho de caminhos, caixas, círculos, letras e adição de imagens. Também é possível manipular pixels e extrair fragmentos do conteúdo gráfico gerado. No entanto, o WebGL é uma linguagem de baixo nível, dada a sua conexão direta com o OpenGL.

Rapidamente, surgiram bibliotecas que permitem a programação de ambientes 3D em WebGL em mais alto nível, como o SceneJS, o GLGE, o CopperLicht, o CubicVR 3D, X3DOM e o Three.js (Barbosa, 2013). O SceneJS nunca saiu da fase beta, e é de 2011 a única versão disponível. O GLGE suporta funcionalida- 
des básicas do OpenGL ES. Também tem suporte ao formato COLLADA. Não tem sistema explícito de física e faltam-lhe classes de shader. O CopperLicht é bem documentado e disponibiliza ao programador animações, colisões, módulos matemáticos assim como opções de iluminação. Compila as meshes 3D em arquivos binários de reduzido tamanho. No CubicVR 3D, faltam efeitos mais avançados, que exigem shaders customizados. O X3DOM é uma framework experimental que segue a especificação X3D para conteúdos web 3D, sendo uma vantagem para desenvolvedores já familiarizados com o padrão. Contém uma página web completa, com API detalhada e muitos tutoriais e demonstrações disponíveis. Algumas funcionalidades ainda estão pouco desenvolvidas. O ThreeJS é a API mais popular para WebGL e pode ser usada com SVG, com o elemento canvas do HTML, além do WebGL. O módulo principal é o renderer, que contém uma cena e uma ou mais câmeras. Na cena, estão os objetos (material + geometria) e as luzes. A geometria pode ser criada em código, importada - em formato OBJ (malhas poligonais tridimensionais) ou STL (estereolitografia) - ou podem ser usados os objetos primitivos (esfera, cubos, poliedros) disponibilizados pela biblioteca.

Após um processo de análise das principais bibliotecas WebGL disponíveis (TAB. 3), elegeu-se o ThreeJS como a biblioteca usada no projeto.

TABELA 3 - Situação das principais bibliotecas WebGL (fevereiro de 2016).

\begin{tabular}{|c|c|c|c|c|}
\hline \multicolumn{5}{|c|}{ SITUAÇÃO DAS PRINCIPAIS BIBLIOTECAS WEBGL (FEVEREIRO DE 2016) } \\
\hline Biblioteca & Seguidores & Forks & Documentação & Licença \\
\hline ThreeJS & 1438 & 6632 & Ampla & MIT \\
\hline SceneJS & 39 & 88 & Boa & MIT / GPL \\
\hline X3DOM & 63 & 133 & Boa & MIT / GPL \\
\hline CopperLicht & 3 & 3 & Ampla & CopperLicht \\
\hline CubicVR.js & 42 & 90 & Média & MIT \\
\hline GLGE & 23 & 76 & Boa & BSD \\
\hline
\end{tabular}

Fonte - do autor.

\subsection{Aplicativos web interativos 3D na nuvem}

Até hoje, a computação em nuvem se preocupou em atender os negócios web tradicionais, com soluções de servidores web, serviços de email, pro- 
cessamento de transações, aplicações comerciais, dentre outros. Uma categoria de aplicação ainda pouco explorada são as aplicações multimídia, especialmente aquelas que envolvem capacidades gráficas $3 \mathrm{D}$, tais como jogos e ferramentas de design. Aplicações multimídia e 3D também podem se beneficiar das economias de escala e da elasticidade da computação em nuvem (Weidong et al., 2010).

Espera-se que os dados móveis cresçam $66 \%$ a cada ano (Amin et al., 2013). A introdução da computação em nuvem na internet móvel leva a mudanças na sua arquitetura e levanta problemas como segurança de dados e latência no cruzamento entre domínios e proteção à privacidade (Xiu-Feng et al., [2011]). A banda da internet móvel ainda é limitada e cara, e a latência da rede representa um impeditivo potencial ao acesso de aplicativos 3D na nuvem (Weidong et al., 2010; Wang e Dey, 2013; Chen et al., 2013). Desta maneira, as soluções atuais devem visar a redução da necessidade de dados.

Por outro lado, os dispositivos móveis não possuem desempenho gráfico compatível com os requisitos de qualidade contemporâneos (Wang e Dey, 2013). O advento do HTML5 e do WebGL deve minimizar diversos obstáculos ao desenvolvimento e lançamento pleno de aplicações web genuinamente interativas no espaço móvel, ao melhorar as capacidades interativas e gráficas dos dispositivos atuais. No entanto, as características oferecidas por um navegador HTML5 ainda são consideradas insuficientes aos requisitos das aplicações contemporâneas (Mikkonen e Taivalsaari, 2013). Desta maneira, devem ser buscadas estratégias gráficas que potencializem os escassos recursos dos aparelhos e reduzam o consumo de energia. O suporte computacional dos serviços em nuvem pode viabilizar o uso de dispositivos móveis, cujos recursos são limitados (Radosevic e Balatinac, 2014).

Os serviços em nuvem podem abordar esses desafios de duas maneiras (Sawicki e Chaber, 2013). A primeira é deixar todas as funcionalidades do aplicativo a cargo do serviço na nuvem, transmitindo apenas o vídeo ao cliente, tal como experimentado por diversos autores (Weidong et al., 2010; Lampe et al., 2013; Wang e Dey, 2013; Lu et al., 2015). A segunda abordagem é deixar a renderização a cargo do cliente e prover suporte de processamento no serviço em nuvem, tal como experimentado por outros autores (Sawicki e Chaber, 2013; Ojog et al., 2013; Aderhold et al., 2013; Chen et al., 2013; Kurt et al., 2015). Esta segunda opção é mais flexível e procura equilibrar esforços e custos entre o cliente e o servidor. 


\subsection{Processamento em nuvem}

Esta abordagem é recorrente principalmente no mercado de jogos, devido à necessidade de aumentar a qualidade gráfica em dispositivos móveis e reduzir problemas com direitos autorais. Em geral, são utilizados serviços avançados em nuvem, como servidores especializados em gráfico e compressão de vídeo.

Wang e Dey (2012) avaliaram um sistema de renderização de jogos na nuvem, voltado a dispositivos móveis, baseado em transmissão (streaming) de vídeo. A lógica e renderização são executadas no servidor e o dispositivo serve apenas para visualização e interação. São utilizados três servidores, o de sincronização, o do motor de jogo e o de vídeo. Lampe et al. (2013) avaliaram questões de latência, consumo de energia e custos para jogos na nuvem. A latência é uma questão determinante da qualidade de interação, ficando, no máximo, entre $100 \mathrm{e}$ $150 \mathrm{~ms}$ para jogos em primeira pessoa e $400 \mathrm{~ms}$ para jogos do tipo RPG. A redução da latência depende muito da qualidade da rede de dados, o que é um problema no caso de redes móveis. Para lidar com a variabilidade das redes móveis, Lu et al. (2015) propõem um sistema que se adapta às condições da rede, alterando a qualidade geral de renderização, a profundidade de visão e o detalhamento dos objetos de acordo com a distância, conceito conhecido como "nível de detalhe" (level of detail - LOD). Foram avaliados os impactos das alterações na qualidade na experiência de jogo.

No geral, os autores atingem bons resultados no que tange ao processamento gráfico e de lógica de jogo. No entanto, soluções avançadas em nuvem ainda são caras (servidores gráficos), picos de uso ainda não são bem resolvidos e a variabilidade de velocidade em redes móveis, e mesmo em redes locais (local area networks - LAN) pode prejudicar a interação. Esta solução depende, portanto, de maiores investimentos nos serviços de nuvem e de preocupações com a localização, pois problemas de latência só podem ser efetivamente reduzidos ao diminuir a distância do provedor (Weidong et al., 2010). Além da latência, no caso de dispositivos móveis em redes celulares, o custo dos dados ainda é impeditivo, mesmo para resoluções consideradas normais (HD - 720 p). No geral, as soluções nessa frente devem explorar sistemas LOD que adaptam os parâmetros de qualidade conforme as condições da rede e limitações dos dispositivos, para manter a qualidade de interação (responsividade e quadros por segundo) em níveis aceitáveis e maximizar a qualidade gráfica (Lu et al., 2015). 


\subsection{Renderização no cliente}

No geral, essa abordagem é voltada a dispositivos móveis, visando redução de uso de banda e de energia no dispositivo. A maioria das soluções adota um modelo de pré-processamento de geometria, empacotando modelos na nuvem sob demanda e conforme parâmetros do usuário. Uma preocupação corrente é com a interação do usuário em dispositivos com tela pequena, adotando navegação assistida.

Ojog et al. (2013) criaram uma ferramenta on-line na nuvem voltada a visualização de imagens de diagnósticos, baseada em HTML5, WebGL e implementada em instâncias EC2 de alto desempenho da AWS, equipadas com GPUs Tesla da Nvidia. Cada sessão de visualização gera um aplicativo único, de acordo com o que foi requisitado pelo usuário em um menu inicial. Aderhold et al. (2013) desenvolveram um aplicativo para exibição de artefatos culturais no navegador que utiliza serviços de nuvem para pré-processamento de modelos 3D. Os autores descartaram a abordagem de renderização na nuvem argumentando que a solução não escala bem e que depende de excelentes condições de conectividade. Os modelos também são empacotados em um aplicativo único. Chen et al. (2013) também propuseram um sistema para simplificar e otimizar modelos 3D (redução de triângulos por decimação), visando melhorar a interação básica (rotação e escala), além de ajudar o usuário a acomodar o modelo à tela do dispositivo.

Nesta frente, destaca-se a solução de Sawicki e Chaber (2013), que adotaram transmissão gradual da geometria para renderização no dispositivo, considerando critérios de qualidade de visualização e interação e a capacidade do dispositivo. Em outras palavras, a geometria é carregada em nível de detalhe gradual até um limite de quadros por segundo pré-determinado. A versão simplificada da geometria permite uma visão global do modelo, suficiente para visualização rápida ou para tomar as primeiras decisões em uma visualização mais detalhada, como encontrar regiões de interesse. A partir da interação, a geometria mais detaIhada vai sendo carregada em tempo real, de maneira cumulativa.

No geral, os autores utilizam HTML5 e WebGL e estratégias modulares de implementação dos sistemas, o que resulta em maior acessibilidade e desempenho. As estratégias de mesh streaming de Kurt et al. (2015) e Sawicki e Chaber (2013) são semelhantes e exploram arquiteturas SOA, padrão MVC, biblioteca 3D Three.js e formato JSON para transmissão dos dados. Aderhold et al. (2013) e 
Kurt et al. (2015) carregaram módulos e recursos de maneira assíncrona. A combinação desses conceitos, discutidos anteriormente neste capítulo, colaboram para a construção de software mais econômico e leve tanto para a rede de dados como para os dispositivos. Sawicki e Chaber (2013) demonstraram que, apesar da qualidade de interação ser similar, o consumo de banda do mesh streaming se mostrou muito menor que a renderização em nuvem, especialmente quando a interação com o objeto é intensa.

Desta forma, alguns autores confirmaram a viabilidade de aplicativos 3D interativos quando há internet de alta velocidade disponível e os servidores não estão a uma grande distância do público-alvo. No entanto, além da necessidade de servidores gráficos especiais - um serviço ainda escasso e custoso -, outros autores reportaram limitações da abordagem de renderização externa devido a problemas com latência e custo nas redes de comunicação celular. Isso, certamente, deixa a solução menos atrativa no caso de dispositivos móveis, devido ao alto custo e baixa qualidade da internet móvel no Brasil, mesmo nas regiões metropolitanas. Já a abordagem de renderização no cliente aliada a arquiteturas SOA, conceitos como LOD e mesh streaming, mostra-se mais promissora na utilização mais racional e econômica dos recursos computacionais, equilibrando esforços e custos entre cliente e servidor e tornando os serviços mais acessíveis, especialmente para dispositivos móveis. Essa estratégia pode ser utilizada para permitir a utilização de aplicativos em dispositivos móveis ou computadores de baixo desempenho, no caso de funcionalidades que demandem processamento intensivo de geometria, tal como cortes e visualização do espaço negativo (seção 3.3.3.4). 


\section{DESENVOLVIMENTO E RESULTADOS}

Neste capítulo, são descritos e analisados em detalhes o processo de desenvolvimento e os resultados do trabalho. Na primeira parte (seções 4.2 a 4.4), são apresentados os protótipos do CrystalWalk, a especificação do software após os ciclos iniciais da pesquisa-ação, os detalhes técnicos de escolhas tecnológicas e de implementação, além das características e funcionalidades da última versão do software. Na segunda parte (seção 4.5), são apresentados os resultados e a avaliação multilateral do CrystalWalk em relação aos objetivos e às metas do trabalho: desempenho técnico da implementação, comparação com os softwares cristalográficos, testes do método de síntese, da interface e dos mecanismos de visualização e interação, avaliação das funcionalidades didáticas e das possibilidades interativas e, por fim, uma análise integrada do empoderamento dos atores sociais.

\subsection{Membros da equipe técnica e colaboradores}

O projeto CrystalWalk está disponível em <http://cw.gl>. Foram envolvidos diversos colaboradores de nacionalidades diferentes. Os membros da equipe do projeto CrystalWalk e outros colaboradores são apresentados a seguir:

- Idealizadores

- Prof. Dr. Ricardo Mendes Leal Neto, Centro de Ciência e Tecnologia de Materiais do Instituto de Pesquisas Energéticas e Nucleares (CCTM-IPEN).

- Doutorando Fernando Bardella, CCTM-IPEN.

- Projeto e coordenação geral

- Doutorando Fernando Bardella, CCTM-IPEN.

- Implementação

- Equipe de desenvolvimento:

- Doutorando Fernando Bardella, CCTM-IPEN.

- Athanasios Saringelos, Polytechnion Kritis, Grécia

- Alexandros Karatzaferis, Polytechnion Kritis, Grécia 
- Rafael C. L. de Moraes, Seneca College, Canadá

- Doutorando André M. Rodrigues, Laboratório de Sistemas Integráveis da Escola Politécnica da Universidade de São Paulo (LSI-Poli-USP)

- Equipe de testes:

- André G. da Silva, ex-colaborador CCTM-IPEN

- Doutorando André M. Rodrigues, LSI-Poli-USP.

- Ms. Marcos de Arruda, Dept. of Engineering Technology, College of Engineering, Drexel University, Estados Unidos

- Atores sociais

- Todos os membros da equipe do projeto

- Professores:

- Vera Lúcia Mazzochi, cristalografia, Centro de Tecnologia das Radiações (CTR-IPEN)

- Cláudio J. da Rocha, metais, CCTM-IPEN

- Dolores R. R. Lazar, cerâmicas, CCTM-IPEN

- André P. Tschiptschin, ciência dos materiais, Poli-USP

- Estudantes (por disciplinas):

- IPN0012 - Caracterização física de materiais, graduação, USP, turmas 2014, 2015 e 2016

- TNM5811 - Técnicas de caracterização física e química de materiais, pós-graduação, USP, 2014-2015

- TNM5803 - Ciência dos materiais, pós-graduação, USP, 2016

- 261.1609.1 - Metalurgia física I, graduação, Universidade Presbiteriana Mackenzie, turmas 2012 e 2013

261.1708.8 - Metalurgia física II, graduação, Universidade Presbiteriana Mackenzie, turmas 2012 e 2013

- Edição e revisão geral

- Bóris Fatigati, editor, Brasil

- Doutorando André M. Rodrigues, LSI-Poli-USP

- Auditoria externa

- Bóris Fatigati, editor, Brasil 


\subsection{Condução da metodologia}

Esta seção apresenta o processo de desenvolvimento da pesquisaação e como se deu o alinhamento com a metodologia Scrum.

Como resultado da metodologia proposta, antes da definição do foco e da implantação da pesquisa-ação (seção 2.4.1.1), conduziu-se uma investigação exploratória por meio de levantamento bibliográfico (seção 2.4.1.2) e de um levantamento sistemático dos softwares cristalográficos existentes (seção 2.4.1.3). Isto permitiu identificar e organizar os conceitos relevantes ao trabalho e situá-los no contexto de sua problemática. Apesar de alguns autores considerarem esse processo parte fundamental da pesquisa-ação (Tripp, 2005; Baskerville, 1999; Kock, 2004; Susman e Evered, 1978; Gil, 2008), a investigação exploratória foi, para fins metodológicos, um processo independente. A estratégia metodológica empregada é descrita em detalhes na seção 2.4 e sumarizada na FIG. 17 (seção 2.4.4).

Devido às especificidades deste trabalho, decidiu-se desenvolver a pesquisa-ação em duas fases, de naturezas distintas. Na primeira fase, buscouse abordar sistematicamente o contexto social e os diversos problemas colocados, definindo e validando os requerimentos funcionais e caracterizando o escopo inicial do projeto. Houve uma ampla interação entre o pesquisador e os atores sociais envolvidos no trabalho: membros da equipe, professores e estudantes de diversas disciplinas. Entre as principais constatações desses atores sociais, esteve a necessidade de inovações tanto pedagógicas como tecnológicas para abordar os problemas didáticos. A linha de investigação e intervenção adotada no trabalho voltou-se principalmente à dificuldade de compreensão de conceitos fundamentais relativos às estruturas cristalinas e também aos desdobramentos dessas dificuldades no ambiente didático, confirmando que a baixa adequação dos recursos existentes é o principal problema. Após uma série de iterações, a visão dos atores sociais foi sondada por meio de entrevistas e discussões em grupo, abordando dimensões sociais, culturais, tecnológicas, científicas e pedagógicas. $\mathrm{Na}$ segunda fase - conforme descrito mais adiante (seção 4.2.1) - partindo da especificação obtida, bem como de protótipos, aplicações-conceito e das colocações dos atores sociais, foi desenvolvido o software cristalográfico CrystalWalk.

Na primeira fase, a intervenção realizada permitiu caracterizar detalhadamente as dificuldades que devem ser superadas e definir uma escala de prioridades, além de prover bases para obter os melhores e mais úteis resultados 
possíveis no contexto do trabalho. Assim, a partir do levantamento bibliográfico, do levantamento sistemático de softwares e de uma ampla e explícita interação com os atores sociais já citados, foram identificadas as principais necessidades relativas ao problema de pesquisa e a necessidade de desenvolvimento de um software cristalográfico capaz de se valer de aspectos positivos encontrados no estado da arte e, principalmente, de suprir as lacunas deste. Esse conjunto de características iniciais foi consolidado em uma lista de requerimentos funcionais que caracterizou o escopo inicial do projeto, o principal produto desta primeira fase da pesquisa-ação.

É importante notar que, devido à natureza simbiótica desta colaboração, o desenvolvimento do CristalWalk adquiriu uma dinâmica própria, independente deste trabalho e de seus autores. Conforme observado na seção 2.4.1.1, devido à natureza exploratória e à intensa dinâmica da pesquisa-ação, existe o risco de conduzir a pesquisa com pouco detalhamento ou desviando do foco principal da investigação. No projeto CrystalWalk, são frequentemente solicitadas novas funcionalidades, ajustes e correções de falhas pendentes. Um exemplo disso são as requisições de adaptações do CrystalWalk para visualização de defeitos cristalinos ou para melhorar a compatibilidade com navegadores menos populares. Nesse sentido, seguindo recomendações para a pesquisa-ação, além dos princípios e práticas do Scrum, para fins de elaboração desta tese de doutorado, houve uma preocupação formal em direcionar os esforços da equipe e dos atores sociais aos objetivos e escopo iniciais do projeto. Na seção 4.3.1, é apresentada a proposta de especificação final resultante desse processo. No repositório do projeto (Bardella et al., 2016b), também é possível verificar a evolução histórica dos requerimentos e das alterações, bem como acompanhar solicitações a ser implementadas.

\subsubsection{Implantação da pesquisa-ação e Scrum}

Definida a lista de requerimentos funcionais, a pesquisa-ação evoluiu à fase de desenvolvimento do CrystalWalk. Nessa fase, com características de desenvolvimento tecnológico, o trabalho foi orientado à criação de um software cristalográfico o mais próximo possível do ideal e o mais alinhado possível aos princípios deste projeto, ou seja, o foco didático e o acesso democrático e descomplicado ao conhecimento. Partindo de um conjunto de protótipos e aplicações-conceito que corroboravam os requerimentos funcionais e as expectativas inicialmente identificadas, iniciouse então um processo de retomada e aprofundamento das reflexões dos agentes 
sociais colhidas na fase inicial do trabalho, dando início a um novo ciclo de intervenções. Utilizando-se de técnicas e metodologias modernas de desenvolvimento (seção 2.4.2), adotou-se uma abordagem híbrida específica para este trabalho, na qual fundiram-se valores, princípios e práticas do ciclo básico da investigação-ação (Tripp, 2005; Baskerville, 1999; Kock, 2004; Susman e Evered, 1978) aos do Scrum (Schwaber e Beedle, 2002), em um ciclo denominado investigação-sprint.

Em suma, cada ciclo de investigação-sprint consistiu em uma fase de priorização dos problemas a resolver e das novas funcionalidades (reunião de planejamento), seguido de planejamento e execução das ações (sprint-ação) e, finalmente, avaliação de resultados por meio de testes da versão do software produzida no ciclo (testes e feedback) seguidos de discussões em grupo dos resultados obtidos (reunião de revisão). Ao final de cada ciclo, produzia-se uma nova versão da aplicação, incorporando ajustes e novas funcionalidades. Essa versão era, então, utilizada como ponto de partida para o ciclo seguinte, reiniciando-se o processo. $O$ diagrama apresentado na FIG. 56 sintetiza essa abordagem.

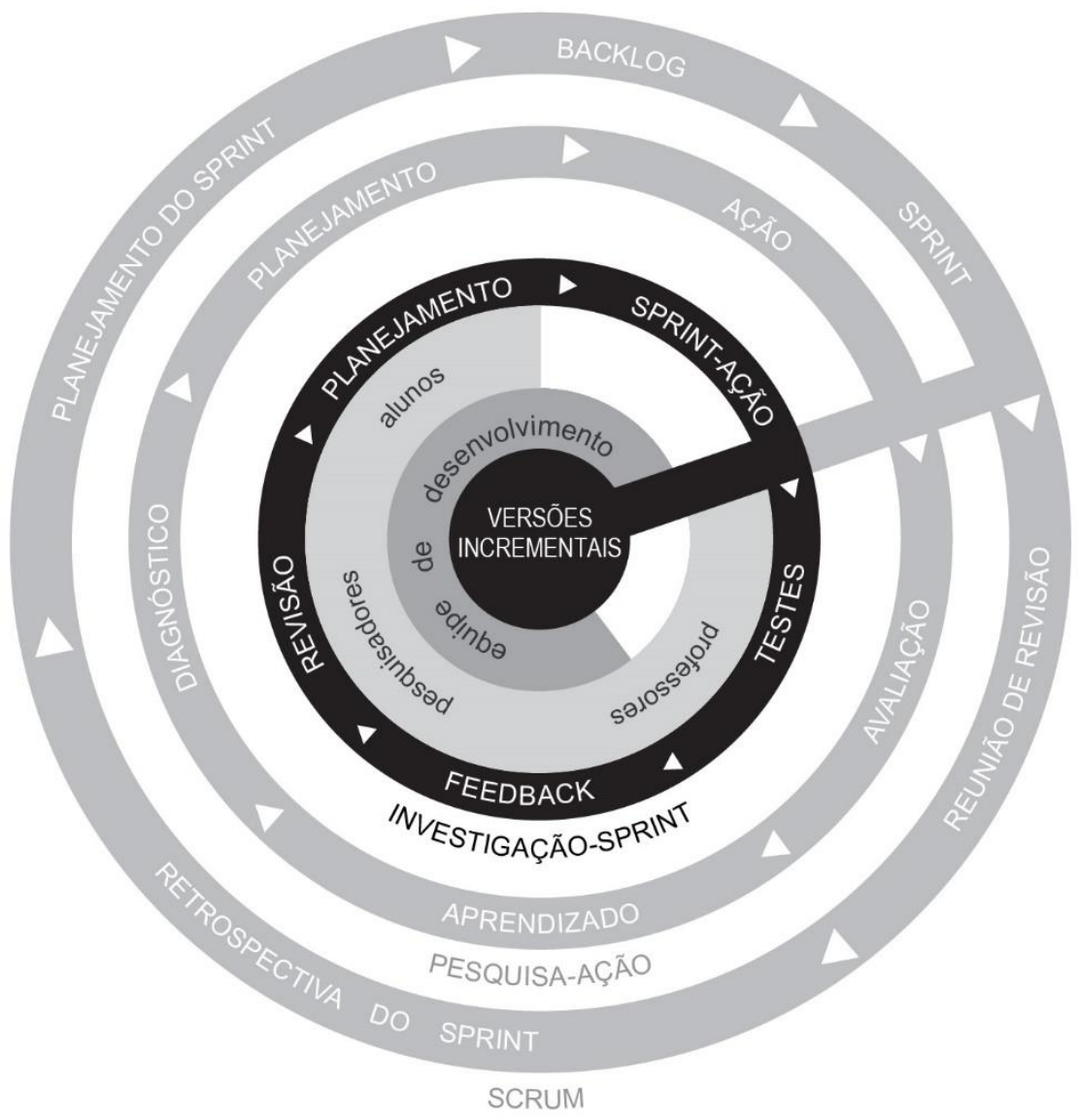

FIGURA 56 - Ciclo investigação-sprint. Fonte: do autor. 
Adotou-se uma política de versões curtas, de até 4 semanas, para sincronizar os sprints com o ciclo básico de interação-ação e, dessa maneira, maximizar as interações entre os agentes sociais do projeto. Todas as partes interessadas participaram na validação do software junto ao time do projeto, durante todo o processo de desenvolvimento.

Entretanto, é importante notar que limitações de recursos, de tempo e de disponibilidade do time do projeto requereram ajustes e adaptações na metodologia empregada. Utilizou-se uma adaptação conhecida por product owner proxy (Judy, 2008), na qual uma mesma pessoa atua simultaneamente como dono do produto (product owner) e desenvolvedor - neste caso, o pesquisador autor deste trabalho. Essa técnica, apesar de facilitar processos de comunicação e de tomada decisão internos, gera também um risco de distanciamento das partes interessadas externas ao time de desenvolvimento, bem como imprecisões na priorização de requerimentos (Judy, 2008). Como o pesquisador faz parte do time de desenvolvimento, pode agir com parcialidade e favorecer os interesses dos desenvolvedores, particularmente, procurando diminuir a complexidade de implementação. No entanto, entende-se que tal problema é bastante atenuado neste caso, pois o pesquisador está interessado na qualidade da solução. Além disso, trata-se de um contexto isento de relações comerciais. Na verdade, sendo um agente central na pesquisa-ação, o pesquisador é considerado o mais apropriado para o papel de product owner, pois tem maior domínio das necessidades e das prioridades dos interessados. Ainda assim, para garantir a imparcialidade, a equipe do projeto foi conscientizada quanto a este risco e adotou o processo de revalidação dos requisitos e das prioridades junto aos atores sociais (professores, pesquisadores e estudantes) durante as reuniões de revisão (sprint review meetings).

Ocorreram também outras adaptações, em situações pontuais e por um período de tempo limitado, com o objetivo de atender a necessidades específicas. A principal dessas adaptações temporárias se deu quando o processo de desenvolvimento teve de ser conduzido exclusivamente pelo pesquisador, situação definida por Auer e Miller (2002) como lone wolf.

Correções e sugestões relativas a funcionalidades já existentes - itens comumente levantados em reuniões de revisão - foram inicialmente compiladas em uma lista de bugs, evoluindo para o sistema de bugtracking, disponibilizado no 
repositório do projeto. Testes de unidade e de aceitação foram executados com regularidade ao longo do projeto, para verificar se as mudanças não estavam quebrando a integridade do software e evitar acúmulo de falhas.

Tal abordagem metodológica e os instrumentos e ferramentas empregados foram fundamentais na condução desta etapa da pesquisa-ação, assegurando que a participação dos atores sociais resultasse em melhorias incrementais no software.

\subsubsection{Ciclos iniciais e protótipos}

Desenvolveram-se diversos protótipos e aplicações-conceito com o objetivo de avaliar tecnologias, arquiteturas, plataformas, frameworks e bibliotecas e iniciar a implementação de funcionalidades consideradas críticas para o projeto. Para tanto, foram realizados levantamentos e testes de viabilidade tecnológica, além de ensaios de soluções e algoritmos específicos. Alguns desses procedimentos foram apresentados na seção 3.5.3.4, e a fundamentação teórica pertinente, na seção 3.5. A seguir, são descritos os protótipos desenvolvidos, divididos em dois grupos, Java e WebGL.

\subsubsection{Protótipos em Java}

O primeiro grupo de protótipos foi desenvolvido com o propósito de testar a plataforma Java e verificar sua adequação frente aos requerimentos e objetivos do projeto. Conforme descrito na seção 3.5.3.4, existem 3 tecnologias baseadas nessa plataforma: Java3D, JOGL e LWJGL. No início do desenvolvimento dos protótipos, em meados de 2010, adotou-se o Java3D, por ser a tecnologia mais madura na época. Ao longo de 18 meses, foram investidas aproximadamente 2 mil horas de desenvolvimento na construção de 42 versões dos protótipos em Java3D, que atenderam a uma parcela significativa dos requerimentos do projeto e consolidaram grande parte dos algoritmos atualmente utilizados pelo CrystalWalk. Em sua última instância, o protótipo P42 (FIG. 57) havia implementado o núcleo do algoritmo de geração de estruturas cristalinas associando o motivo à rede, bem como algumas ferramentas e funcionalidades de visualização, atendendo aos requerimentos mais básicos de interatividade especificados e viabilizando testes preliminares. 


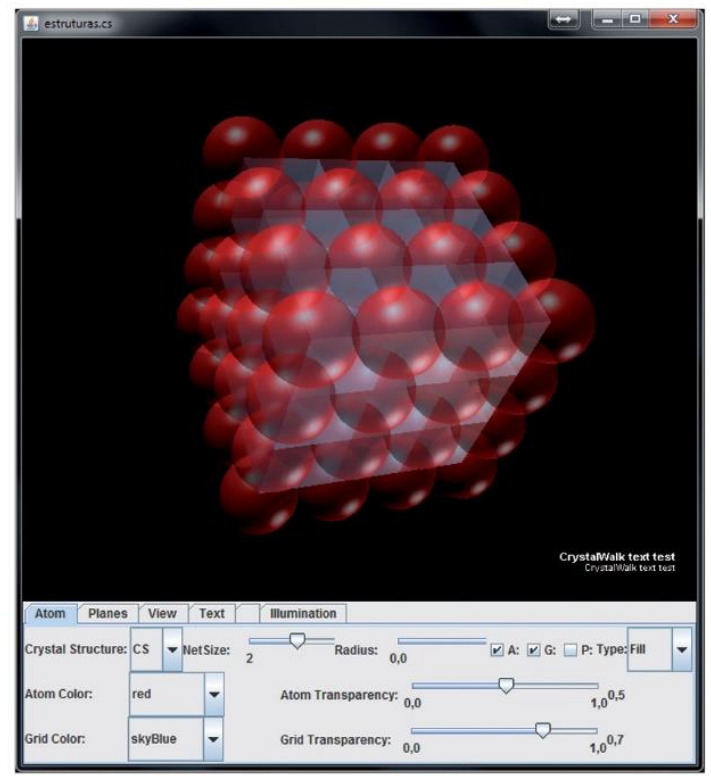

(a)

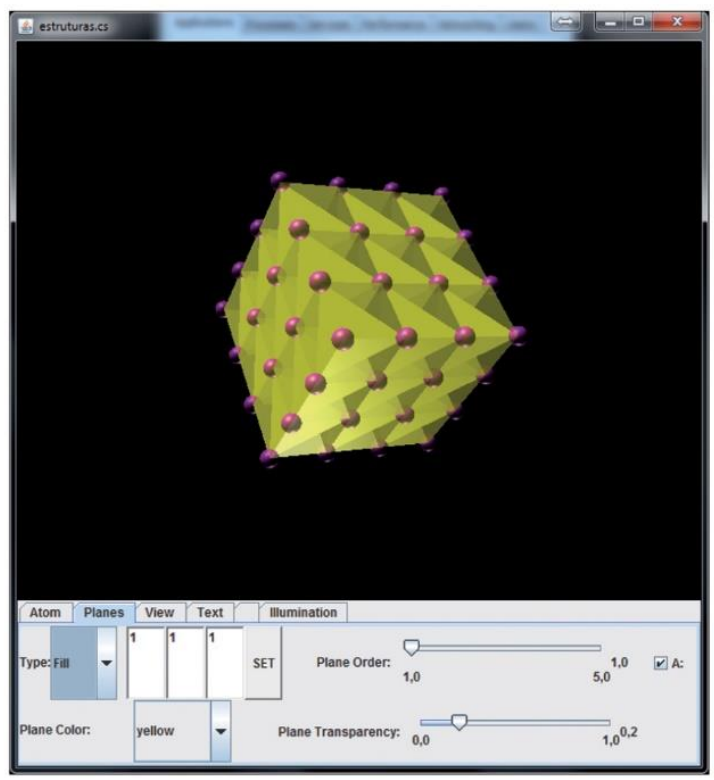

(b)

FIGURA 57 - Protótipos da aplicação CrystalWalk desenvolvidos em Java representando: (a) estrutura cúbica simples; (b) planos (111). Fonte: do autor.

\subsubsection{Protótipos em WebGL}

Com a escolha do WebGL como plataforma padrão, foram produzidas novas aplicações-conceito e protótipos visando, principalmente, avaliar a portabilidade e migrar algoritmos e funcionalidades implementadas anteriormente em Java. No total, foram produzidas 28 aplicações-conceito, ao longo de aproximadamente 5 meses e somando 400 horas de desenvolvimento. Durante esta etapa, foram testadas diferentes arquiteturas, frameworks e bibliotecas disponíveis para a plataforma WebGL (seção 3.5.3.4).

O primeiro protótipo do CrystalWalk no qual foi incorporado de maneira estável o núcleo de funcionalidades dos protótipos em Java surgiu no semestre 8 da pesquisa (ver cronograma na seção 2.6.2). A aplicação já era capaz de exibir as 14 redes de Bravais, agrupadas nos sete sistemas cristalinos. Neste estágio, apesar de ainda limitar a construção de estruturas cristalinas a um motivo simples composto por um átomo genérico (FIG. 58), todos os algoritmos portados da aplicação original se mostraram consistentes e funcionais. 


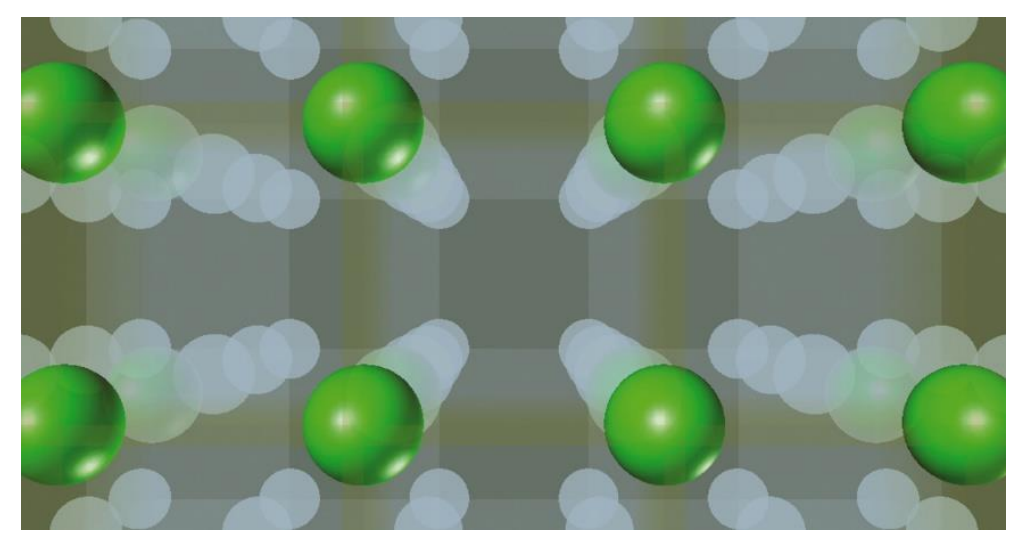

FIGURA 58 - Protótipo da aplicação CrystalWalk desenvolvido em WebGL representando pontos de rede e átomos em uma estrutura cúbica simples genérica. Fonte: do autor.

Concomitantemente ao desenvolvimento dos protótipos (descritos ao longo desta seção 4.2) e como parte da primeira fase da pesquisa-ação, foram detalhados os problemas junto aos atores sociais e sugeridas soluções para cada um, valendo-se do conhecimento e experiência do grupo. Um resumo desta etapa é apresentado na sequência (seção 4.3).

\subsection{Problemas levantados junto aos atores sociais, ações tomadas e resultados obtidos}

A TAB. 4 sumariza os problemas levantados junto aos atores sociais e as ações tomadas e os resultados obtidos, propostos ao longo dos ciclos de interação-sprint. $O$ detalhamento dos problemas levantados pelos atores sociais é apresentado no APÊNDICE D. 
TABELA 4 - Problemas levantados junto aos atores sociais, ações tomadas e resultados obtidos.

\begin{tabular}{|c|c|c|}
\hline \multicolumn{3}{|c|}{ 1. Requerimentos tecnológicos } \\
\hline Parâmetro & Problemas & Ações \\
\hline 1.1. Nível de atividade & $\begin{array}{l}\text { Softwares antigos, negligência na } \\
\text { atualização, projetos abandonados, } \\
\text { ausência de suporte, interfaces e } \\
\text { mecanismos de interação antiquados }\end{array}$ & $\begin{array}{l}\text { Criação de uma comunidade de } \\
\text { colaboradores partindo dos atores sociais } \\
\text { visando conquistar voluntários e seguidores, } \\
\text { por meio de plataformas de desenvolvimento } \\
\text { colaborativo como o GitHub }\end{array}$ \\
\hline 1.2. Portabilidade da aplicação & $\begin{array}{l}\text { Softwares requerem instalação e } \\
\text { dispositivos específicos }\end{array}$ & $\begin{array}{l}\text { Aplicativo on-line (web), acessivel em } \\
\text { qualquer navegador moderno }\end{array}$ \\
\hline 1.3. Uso, distribuição e modificação & Licenças de uso restritivas e caras & Uso livre on-line, licença permissiva \\
\hline $\begin{array}{l}\text { 1.4. Suporte a tecnologias de } \\
\text { interface }\end{array}$ & Interação limitada a teclado e mouse & $\begin{array}{l}\text { Experimentos com as interfaces } 3 D \text { mais } \\
\text { acessíveis disponíveis }\end{array}$ \\
\hline \multicolumn{3}{|c|}{ Resultados obtidos } \\
\hline \multicolumn{3}{|c|}{$\begin{array}{l}\text { Avaliação comparativa de resultados: seção 4.5.2.1 } \\
\text { de possibilidades interativas do CrystalWalk: seções }\end{array}$} \\
\hline \multicolumn{3}{|c|}{ 2. Requerimentos de síntese de estruturas cristalinas } \\
\hline Parâmetro & Problemas & Ações \\
\hline 2.1. Método de síntese & $\begin{array}{l}\text { Softwares não voltados à didática, } \\
\text { baseados em teoria de grupos } \\
\text { espaciais }\end{array}$ & $\begin{array}{l}\text { Método de síntese fundamentado na } \\
\text { combinação de motivos e simetria de } \\
\text { rede translacional }\end{array}$ \\
\hline 2.2. Processo de síntese interativo & $\begin{array}{l}\text { Parâmetros de síntese pouco } \\
\text { intuitivos, ligados à teoria } \\
\text { cristalográfica }\end{array}$ & $\begin{array}{l}\text { Controles interativos dos parâmetros } \\
\text { com resposta em tempo real }\end{array}$ \\
\hline $\begin{array}{l}\text { 2.3. Restrições ou limitações à } \\
\text { síntese }\end{array}$ & $\begin{array}{l}\text { Processo de síntese não permite a } \\
\text { criação de certas estruturas }\end{array}$ & Método rede + motivo, sem restrições \\
\hline $\begin{array}{l}\text { 2.4. Seleção e edição interativas de } \\
\text { átomos }\end{array}$ & $\begin{array}{l}\text { Softwares existentes não permitem } \\
\text { edição interativa e livre dos átomos }\end{array}$ & $\begin{array}{l}\text { Controles interativos, manipulação direta } \\
\text { de átomos }\end{array}$ \\
\hline \multicolumn{3}{|c|}{ Resultados obtidos } \\
\hline \multicolumn{3}{|c|}{$\begin{array}{c}\text { Avaliação comparativa de resultados: seção 4.5.2.2 } \\
\text { Testes de síntese do CrystalWalk: seção 4.5.3.1 }\end{array}$} \\
\hline \multicolumn{3}{|c|}{ 3. Requerimentos de visualização } \\
\hline Parâmetro & Problemas & Ações \\
\hline 3.1. Representação & $\begin{array}{l}\text { Modelo e artifícios de representação } \\
\text { visual não são alinhados com a } \\
\text { didática dos cursos }\end{array}$ & $\begin{array}{l}\text { Modelo de representação de esferas } \\
\text { rígidas, possibilidade de criar planos e } \\
\text { direções cristalográficos e elementos de } \\
\text { apoio à compreensão geométrica }\end{array}$ \\
\hline 3.2. Visualização & Recursos de visualização restritos & $\begin{array}{l}\text { Variedade de recursos de visualização, } \\
\text { baseados em boas práticas de } \\
\text { referências didáticas consagradas, } \\
\text { pesquisas cognitivas e tecnologias } \\
\text { avançadas (estereoscopia) }\end{array}$ \\
\hline \multicolumn{3}{|c|}{ Resultados obtidos } \\
\hline \multicolumn{3}{|c|}{ Avaliação comparativa de resultados: seção 4.5.2.3 } \\
\hline
\end{tabular}


4. Requerimentos de navegação e interatividade

\begin{tabular}{|c|c|c|}
\hline \multicolumn{3}{|c|}{ 4. Requerimentos de navegação e interatividade } \\
\hline Parâmetro & Problemas & Ações \\
\hline 4.1. Interface & $\begin{array}{l}\text { Interfaces pouco intuitivas, de difícil } \\
\text { aprendizado }\end{array}$ & $\begin{array}{l}\text { Hierarquia de menus, descrições } \\
\text { flutuantes dos itens do menu, modo } \\
\text { tutorial }\end{array}$ \\
\hline 4.2. Interação base & Interação tradicional pouco eficiente & Interação básica do tipo orbital \\
\hline 4.3. Interação avançada & $\begin{array}{l}\text { Não existe nenhum mecanismo de } \\
\text { interação com fim didático }\end{array}$ & $\begin{array}{l}\text { Rotações automáticas, transições } \\
\text { animadas, mecanismo de narrativa } \\
\text { didática }\end{array}$ \\
\hline \multicolumn{3}{|c|}{ Resultados obtidos } \\
\hline \multicolumn{3}{|c|}{ Avaliação comparativa de resultados: seção 4.5.2.4 } \\
\hline \multicolumn{3}{|c|}{ 5. Requerimentos didáticos } \\
\hline Parâmetro & Problemas & Ações \\
\hline $\begin{array}{l}\text { 5.1. Conhecimentos requeridos do } \\
\text { usuário }\end{array}$ & $\begin{array}{l}\text { Exigência de conhecimento de } \\
\text { cristalografia }\end{array}$ & $\begin{array}{l}\text { Método de síntese que exija apenas } \\
\text { conhecimento básico de ciência dos } \\
\text { materiais }\end{array}$ \\
\hline 5.2. Suporte a publicações & $\begin{array}{l}\text { Poucas opções e configurações para } \\
\text { saída de resultados }\end{array}$ & $\begin{array}{l}\text { Variedade de opções: salvamento direto } \\
\text { em nuvem e em biblioteca de modelos, } \\
\text { três resoluções de imagens, versão } \\
\text { offline, modelos 3D para visualização } \\
\text { externa e impressão }\end{array}$ \\
\hline 5.3. Funcionalidades didáticas & $\begin{array}{l}\text { Softwares voltados a pesquisadores. } \\
\text { Ausência de recursos que suportem a } \\
\text { narrativa didática }\end{array}$ & $\begin{array}{l}\text { Ferramenta de narrativa didática: } \\
\text { possibilidade de criação e } \\
\text { sequenciamento de anotações } \\
\text { associadas ao estado de visualização do } \\
\text { modelo, além de transição animada de } \\
\text { câmera entre os estados }\end{array}$ \\
\hline 5.4. Suporte e documentação & $\begin{array}{l}\text { Auxílio insuficiente ou ausente } \\
\text { para aprendizado e resolução de } \\
\text { problemas da ferramenta e para } \\
\text { aprendizado dos conceitos envolvidos }\end{array}$ & $\begin{array}{l}\text { Modo tutorial e balões descritivos } \\
\text { ou tutorial escrito para suporte a } \\
\text { aprendizado. Avisos para operações } \\
\text { intensivas ou demoradas. Travamentos } \\
\text { do software não travam o computador, } \\
\text { basta recarregar a aba do navegador. } \\
\text { Resolução de "bugs" por link direto ao } \\
\text { GitHub ou por email ao autor }\end{array}$ \\
\hline \multicolumn{3}{|c|}{ Resultados obtidos } \\
\hline Avaliaçã & Avaliação comparativa de resultados: seção 4.5.2.5 & $\begin{array}{l}4.5 .2 .5 \\
\text { alk: seção } 4.5 .5\end{array}$ \\
\hline
\end{tabular}

Fonte: do autor.

A partir das soluções propostas, foi criada a especificação apresentada a seguir (seção 4.3.1). O detalhamento dos critérios utilizados nesta especificação apresentado no APÊNDICE B. 


\subsubsection{Proposta final de especificação para a aplicação CrystalWalk}

- (1) Requerimentos tecnológicos

○ (1.1) Nível de atividade

- (1.1.1) Frequência de atualização: Ativo

- (1.2) Portabilidade da aplicação: Alta

- (1.2.1) Portabilidade da aplicação: Alta

- (1.2.2) Plataforma de desenvolvimento: WebGL

- (1.2.3) Sistemas operacionais compatíveis: Independente (HTML5 comp.)

- (1.2.4) Requer instalação: Não

- (1.2.5) Multiplataforma: Sim (desktop, mobile, embeddable)

○ (1.3) Uso, distribuição e modificação

- (1.3.1) Licença de uso, distribuição e modificação: Software Livre MIT

- (1.3.2) Modelo de desenvolvimento colaborativo: Sim

○ (1.4) Suporte a tecnologias de interface

- (1.4.1) Dispositivos base (HID): Mouse, teclado, trackeable (Leap Motion)

- (1.4.2) Dispositivos avançados de interação: Sim (monitor 3D, head-mounted display - HMD)

- (2) Requerimentos de síntese

- (2.1) Método de síntese: Rede + motivo

- (2.2) Processo de síntese interativo: Sim

- (2.3) Restrições ou limitações à síntese: Não

- (2.4) Seleção e edição interativas de átomos: Sim

- (3) Requerimentos de visualização

○ (3.1) Representação

- (3.1.1) Modelo de representação atômico molecular: Esferas rígidas

- (3.1.2) Modelo de representação da célula unitária: Células unitárias inteiras, parciais e interstícios

- (3.1.3) Planos de Miller: Sim 
- (3.1.4) Direções de Miller: Sim

- (3.1.5) Artifícios de suporte

○ (3.1.5.1) Células múltiplas: Sim

- (3.1.5.2) Cortes: Sim

- (3.1.5.3) Vetores do eixo da rede: Cartesianos (xyz) e cristalográficos (abc)

- (3.1.5.4) Recursos auxiliares de rede: Bordas e faces

○ (3.2) Visualização

- (3.2.1) Recursos de percepção visual: Formas e perspectiva, cor, opacidade e intensidade luminosa, nuvem de profundidade e som espacial.

- (3.2.2) Tipo de projeção: Perspectiva cônica e axonométrica

- (3.2.3) Suporte estereográfico: Sim (anaglifa, side-byside, $\mathrm{HMD})$

- (3.2.4) Modos de renderização: Sólido, ilustração, foto realístico

- (4) Requerimentos de navegação e interatividade

○ (4.1) Interface de usuário: Interface gráfica ordenada/amigável

- (4.2) Interação base: Zoom, translação e rotação

- (4.3) Interação avançada

- (4.3.1) Rotações automáticas: Sim

- (4.3.2) Animações guiadas: Sim

- (4.3.3) Transição de escala: Sim

- (4.3.4) Gerenciamento dinâmico de oclusões: Transparência, linhas ocultas

- (4.3.5) Perspectiva/pontos de vista preconfigurados: Átomos, direções cristalográficas e perspectivas ortogonais

- (5) Requerimentos didáticos

- (5.1) Conhecimentos requeridos do usuário: Ciência dos materiais básica (rede + motivo)

○ (5.2) Suporte a publicações 
- (5.2.1) Suporte à visualização/portabilidade externa: modelo 3D e aplicativo completo/widget

- (5.2.2) Suporte à impressão 2D: Bitmap

- (5.2.3) Suporte à impressão 3D: Sim (STL)

- (5.2.4) Plataforma de publicação na internet: Sim

○ (5.3) Funcionalidades didáticas

- (5.3.1) Suporte à narrativa didática: Texto/anotações, hiperlinks

- (5.3.2) Biblioteca de estruturas cristalográficas: Sim

- (5.3.3) Construção e visualização incremental de estruturas: $\operatorname{Sim}$

○ (5.4) Suporte e documentação

- (5.4.1) Suporte: Sim (tutorial interno)

- (5.4.2) Documentação: Sim (manuais)

\subsubsection{Arquitetura}

Esta seção detalha a solução tecnológica adotada no projeto e definida com base nos requerimentos funcionais levantados na primeira e segunda fase da pesquisa-ação. O CrystalWalk se propõe a ser uma plataforma pioneira e inovadora e, como tal, fez-se necessário o desenvolvimento de uma arquitetura específica para atender e estruturar as funcionalidades definidas em sua especificação.

O manifesto reativo foi o principal paradigma que delineou a arquitetura do sistema e os fundamentos das tecnologias empregadas, pois foi considerado o melhor para abordar os problemas mais cruciais identificados. Os pilares dos sistemas reativos são orientação a eventos, responsividade, elasticidade e resiliência, refletindo, tecnicamente, em sistemas distribuídos (SOA), interfaces padronizadas para gerenciamento de recursos (REST), sistemas de carregamento assíncrono de módulos independentes (AMD) e comunicação entre componentes através de eventos sistema publicação-subscrição (publish-subscribe pattern PubSub), que representam o estado da arte em desenvolvimento de aplicações na internet (para detalhes, ver capítulo 3). Outro paradigma que orientou em grande medida as decisões de projeto foi o do software livre. Tal paradigma se mostrou adequado a alguns dos maiores princípios norteadores do projeto, como a acessibilidade, a democratização do conhecimento e a colaboratividade no processo de desenvolvimento. 


\subsubsection{Componentes: Implementação}

Para atingir o objetivo de ser distribuído e elástico, adotou-se o padrão SOA e estilo REST na construção e comunicação entre os componentes, resultando na divisão do sistema em três aplicações ou componentes principais da plataforma CrystalWalk: CrystalWalk Design Pattern (CW4P), CrystalWalk Client Application (CWAPP) e Encurtador de URL e API de persistência de dados (CWLY). Este modelo é apresentado na FIG. 59, e cada um de seus componentes é detalhado na sequência (seções 4.3.2.2 a 4.3.2.4).

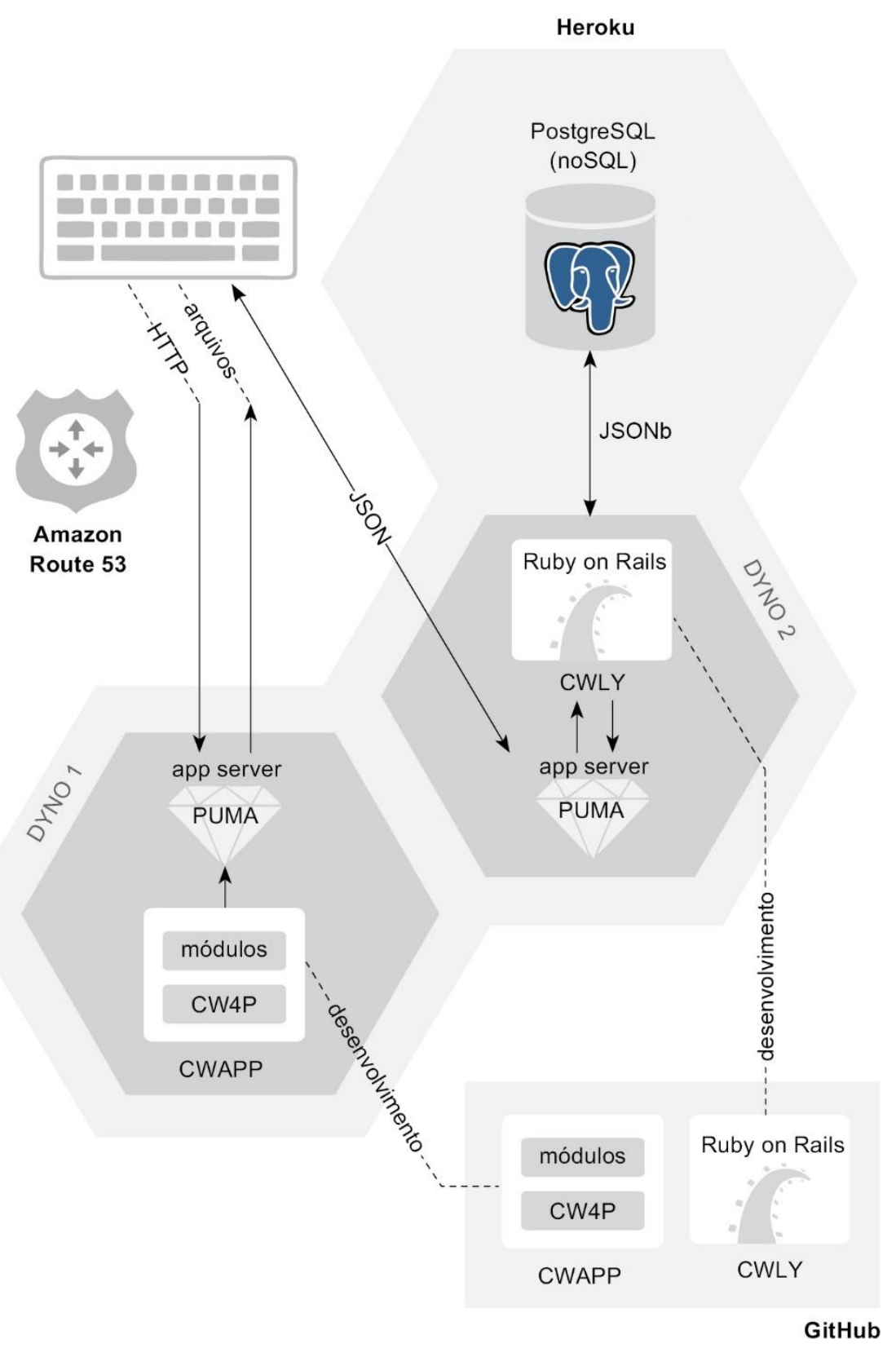

FIGURA 59 - Interação entre componentes da plataforma CrystalWalk. Fonte: do autor. 


\subsubsection{CrystalWalk Design Pattern (CW4P)}

Após uma avaliação das opções disponíveis, concluiu-se que não havia nenhuma arquitetura adequada tanto ao problema como à plataforma escolhida (WebGL). Considerando aplicativos gráficos tridimensionais interativos baseados em web, nenhum dos padrões existentes proporcionava a responsividade nem a escalabilidade e a resiliência adequadas. O paradigma da programação orientada a eventos aborda esses requisitos (seção 3.5). Além dos aspectos de programação reativa, percebeu-se que a maioria das aplicações web não apresentavam uma modularização adequada, definindo o código-fonte em um único arquivo.

Adotando-se boas práticas no desenvolvimento de interfaces em aplicação web, como os trabalhos de Osmani (2015) e Zakas (2012) e a especificação AMD, desenvolveu-se um padrão de estilo de arquitetura próprio para o projeto, denominado CrystalWalk Design Pattern (CW4P), com o objetivo principal de viabilizar o paradigma de programação orientada a eventos a aplicações que utilizam tecnologia WebGL.

De modo sumário, no padrão CW4P: a especificação AMD é implementada por meio da biblioteca RequireJS (RequireJS, [s.d.]); o padrão publishsubscribe é implementado por meio da biblioteca PubSubJS, que determina a comunicação entre componentes em programação orientada a eventos (PubSubJS, 2012); e a tecnologia WebGL é implementada por meio da biblioteca three.js. Nesse contexto, o módulo roteador viabiliza o recebimento e difusão de mensagens aos demais módulos e objetos 3D da aplicação. Na FIG. 60 é apresentado um resumo do conceito deste modelo e na FIG. 61 são apresentados a organização e o fluxo de comunicação entre seus componentes. 
Recebido:

Ação do usuário

(Modificar Objeto 3D)

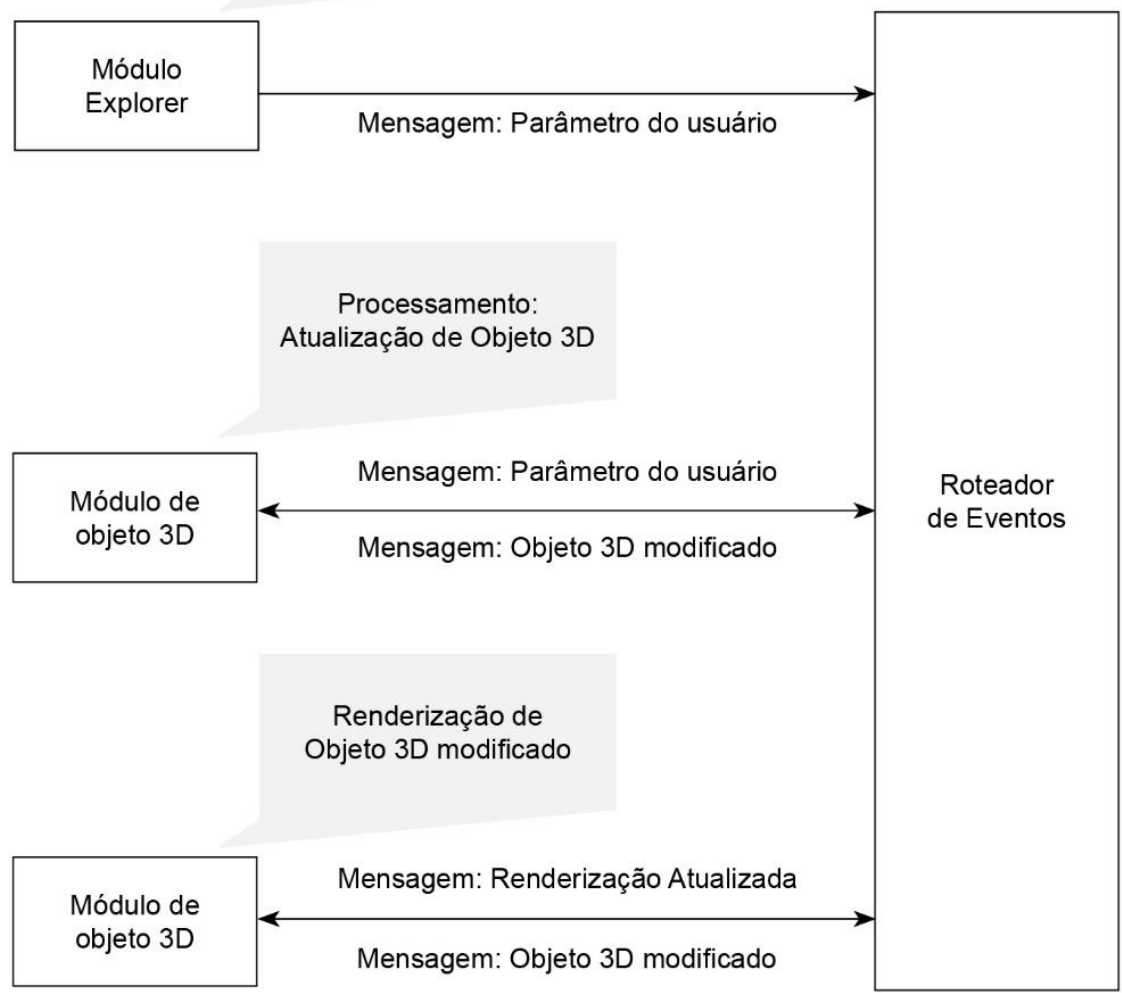

FIGURA 60 - Interação entre o módulo roteador e os outros módulos. Fonte: do autor.

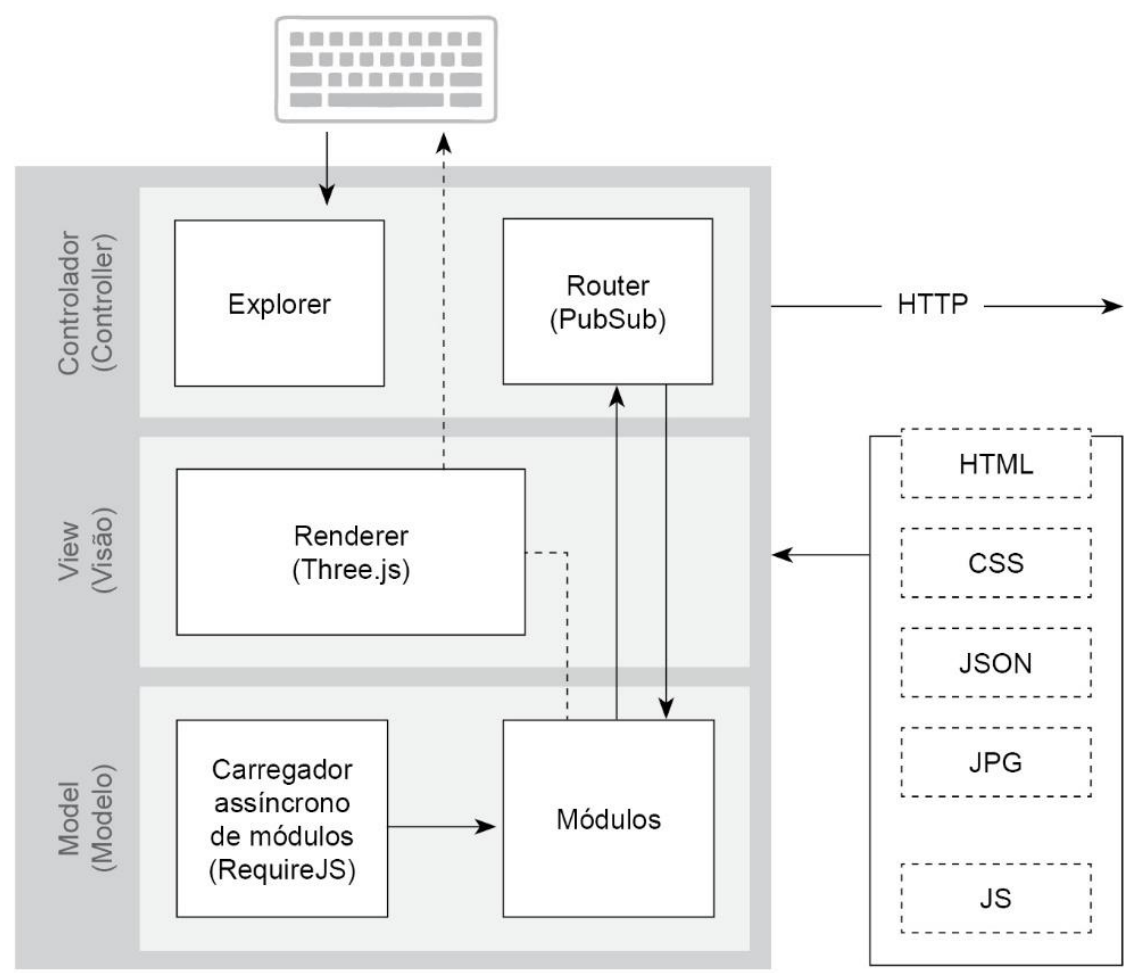

FIGURA 61 - Fluxo de eventos determinado pelo padrão CW4P. Fonte: do autor. 
A seguir, são detalhados a implementação do padrão CW4P na arquitetura do sistema, seus componentes e os processos de comunicação.

\subsubsection{CrystalWalk Client Application (CWAPP)}

Principal componente da plataforma CrystalWalk, o CWAPP é uma aplicação extensão do framework CW4P, responsável pela implementação de todos os requisitos funcionais de interação com o usuário. Conforme ilustrado na FIG. 62, o CWAPP é dividido em três componentes, o framework CW4P, os módulos adicionais da aplicação e uma interface com o servidor web para entrega dos arquivos da aplicação cliente (deployable), desenvolvida em Ruby.

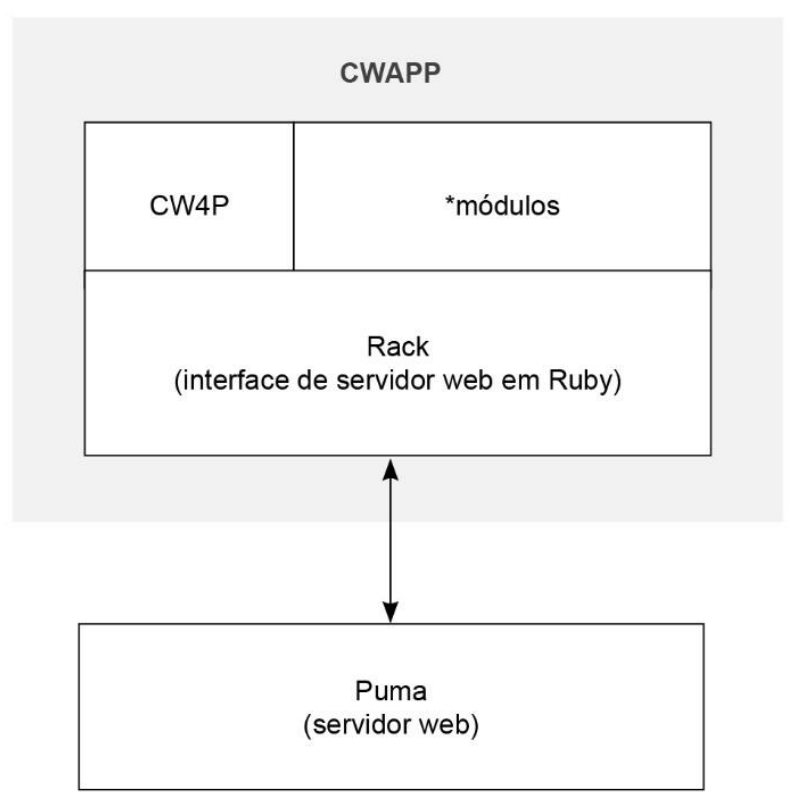

FIGURA 62 - Componentes da aplicação CWAPP. Fonte: do autor.

A arquitetura e a organização dos módulos da aplicação CWAPP são definidas pelo framework CW4P e seguem o estilo model-view-controller (MVC). A inicialização dos módulos e das estruturas de dados que definem a lógica deste modelo, bem como suas respectivas dependências, é realizada pelo módulo principal da aplicação (main.js).

Segundo a aplicação deste estilo de arquitetura, a janela de visualização (view) gera eventos de entrada do mouse ou do teclado que são capturados pelo controlador (controller). Com auxílio de um ou mais modelos (model), o controlador interpreta os eventos de entrada e mapeia as ações do usuário em comandos que geram novos eventos de estados. Mais uma vez, o controlador os 
captura, gerando novos eventos para a janela de visualização, que finalmente exibe as alterações.

O objeto modelo (model) é responsável pelo gerenciamento das estruturas de dados e atualização dos elementos principais de cena - o motivo, célula unitária e cristal - por meio de alterações em suas entidades primitivas, os átomos, células, direções e planos. Por fim, o objeto visão (view) renderiza os elementos de cena e exibe a interface do usuário, comunicando seu estado ao controlador.

Os diferentes módulos que compõem a aplicação são ilustrados na FIG. 63 e descritos na sequência.

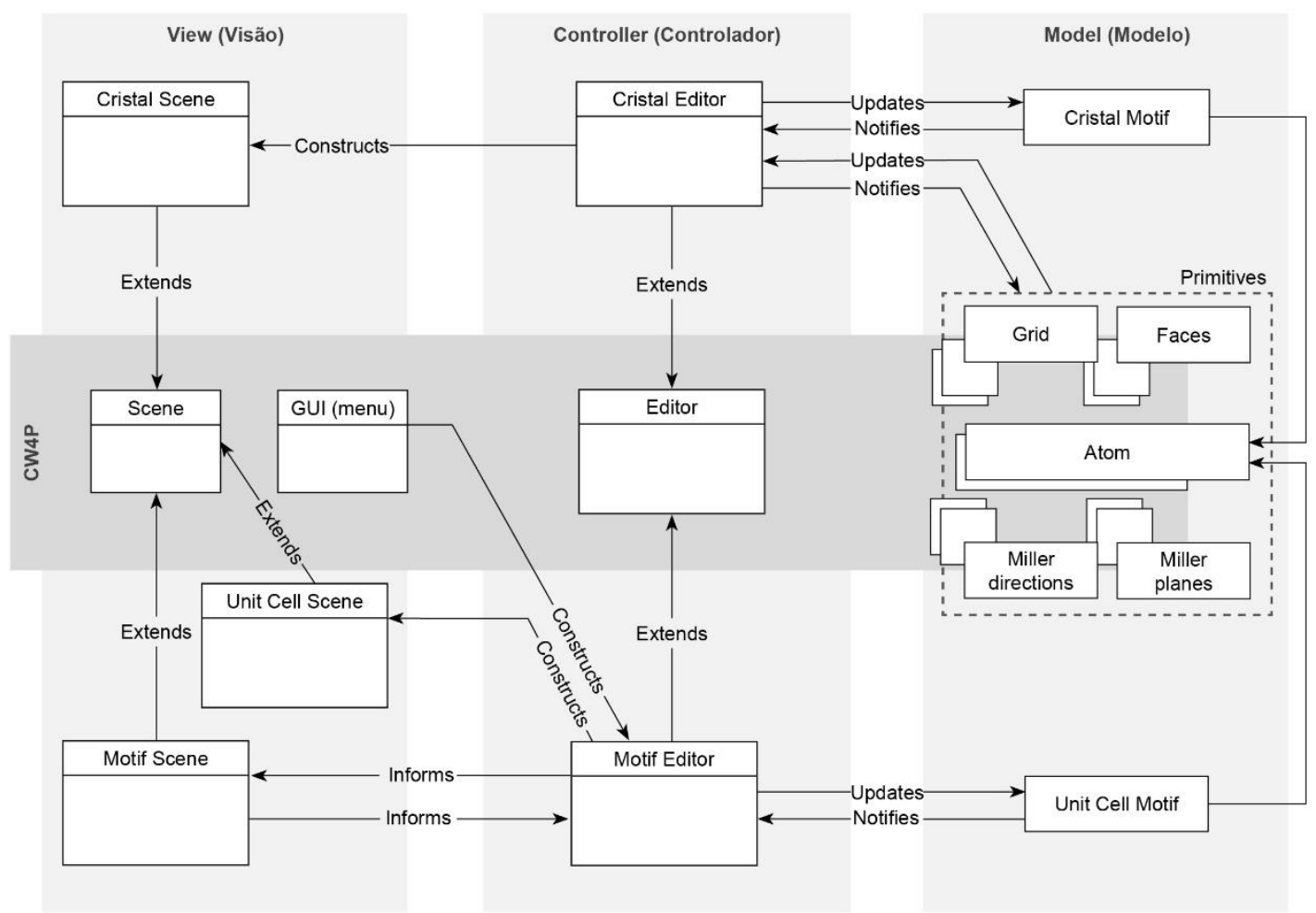

FIGURA 63 - Implementação da arquitetura MVC na aplicação CWAPP. Fonte: do autor.

\subsection{Objeto view (visão)}

\subsection{Módulo de interface do usuário (menu.js)}

O módulo menu.js gerencia ações sobre todos os elementos da interface, identificando e tratando adequadamente o fluxo e o funcionamento da aplica- 
ção. Segundo o paradigma de programação orientada a eventos, este é um componente crítico da aplicação.

Utilizando-se da API PubSub, o módulo menu.js registra todos os elementos e parâmetros de interface (publisher), além de eventos associados (subscribers). Assim, ao interagir com estes elementos, o usuário dispara uma sequência de eventos e aciona um conjunto de módulos e/ou funcionalidades específicas. A FIG. 64 ilustra de maneira simplificada o funcionamento da implementação Publish/Subscribe via módulo menu.js.

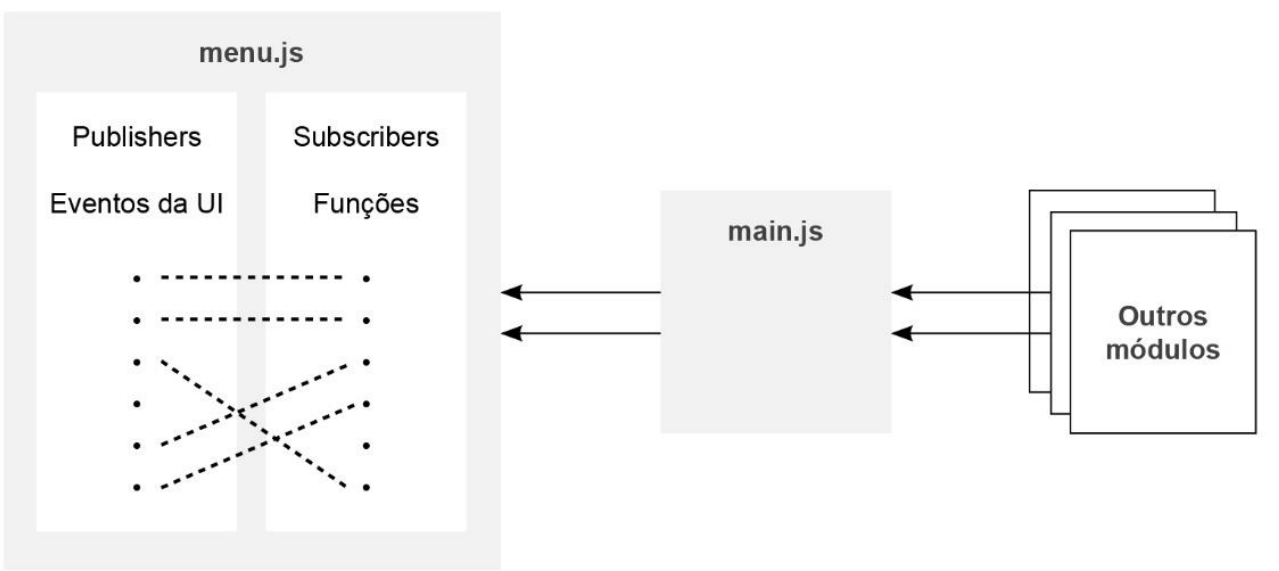

FIGURA 64 - Implementação Publish/Subscribe via módulo menu.js. Fonte: do autor.

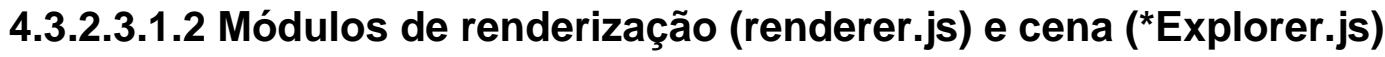

Os módulos renderer.js e *Explorer.js são responsáveis pela construção da cena e renderização do motivo (motiffExplorer.js), da célula unitária (unitCellExplorer.js) e da estrutura cristalina (crystalExplorer.js) - os objetos primitivos da aplicação.

Cada cena possui um conjunto de parâmetros e atributos específicos e independentes, tais como objetos a exibir, fontes de iluminação, câmeras, controles de posição e ângulos, dentre outros. A seção 3.5.3.4 apresenta uma breve revisão da literatura sobre computação gráfica e como estes conceitos são implementados pelo WebGL e three.js. A TAB. 5 descreve os elementos de cena da aplicação e a FIG. 65 ilustra a composição e organização destes. 
TABELA 5 - Descrição dos principais elementos de cena e seus respectivos módulos, parâmetros e atributos referente ao objeto visão da aplicação.

\begin{tabular}{|l|l|l|l|}
\hline \multicolumn{2}{|c|}{ DESCRIÇÃO DOS PRINCIPAIS ELEMENTOS DE CENA E SEUS RESPECTIVOS MÓDULOS, PARÂMETROS E } \\
ATRIBUTOS REFERENTE AO OBJETO VISÃO DA APLICAÇÃO
\end{tabular}

Fonte - do autor.

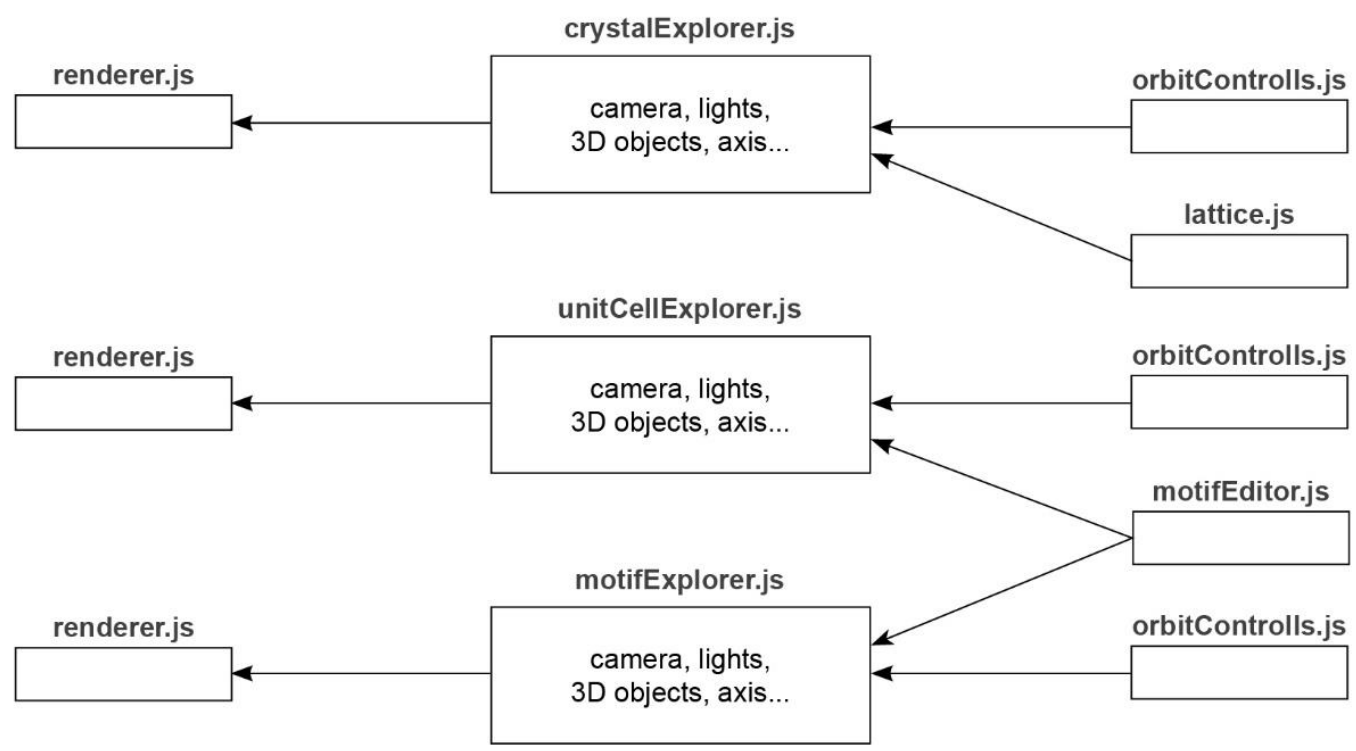

FIGURA 65 - Funcionamento dos principais módulos do objeto visão. Fonte: do autor. 


\subsection{Objeto model (modelo)}

\subsection{Módulos dos modelos primitivos da aplicação}

Os módulos definidos no objeto modelo (model) gerenciam as estruturas de dados dos objetos primitivos em cena, o motivo, a célula unitária e o cristal. A TAB. 6 descreve cada um destes módulos.

TABELA 6 - Descrição das estruturas de dados dos principais objetos primitivos em cena e seus respectivos módulos, parâmetros e atributos referentes ao objeto modelo da aplicação.

\begin{tabular}{|c|c|c|c|}
\hline \multicolumn{4}{|c|}{$\begin{array}{l}\text { DESCRIÇÃO DAS ESTRUTURAS DE DADOS DOS PRINCIPAIS OBJETOS PRIMITIVOS EM CENA E SEUS } \\
\text { RESPECTIVOS MÓDULOS, PARÂMETROS E ATRIBUTOS REFERENTES AO OBJETO MODELO DA APLICAÇÃO }\end{array}$} \\
\hline $\begin{array}{c}\text { Objetos } \\
\text { primitivos }\end{array}$ & $\begin{array}{l}\text { Módulo } \\
\text { principal }\end{array}$ & $\begin{array}{l}\text { Descrição do } \\
\text { módulo }\end{array}$ & Parâmetros e atributos principais \\
\hline $\begin{array}{l}\text { Ponto de } \\
\text { rede }\end{array}$ & point.js & $\begin{array}{l}\text { Construção e } \\
\text { armazenamento } \\
\text { de objetos } \\
\text { utilizados na } \\
\text { representação } \\
\text { de pontos de } \\
\text { rede }\end{array}$ & $\begin{array}{l}\text { Object3d(THREE.Mesh), Geometry(THREE. OctahedronGeometry), } \\
\text { Position (THREE.Vector3) determinam parâmetros da geometria do } \\
\text { objeto e sua posição } \\
\text { Visible(boolean), RenderingMode(string), Material(THREE. } \\
\text { MeshBasicMaterial) determinam propriedades e parâmetros visuais do } \\
\text { objeto, como visibilidade, cor e modo de renderização }\end{array}$ \\
\hline Átomo & $\begin{array}{l}\text { atomSphere.js } \\
\text { crystalAtom.js } \\
\text { unitCellAtom.js }\end{array}$ & $\begin{array}{l}\text { Construção e } \\
\text { armazenamento } \\
\text { de objetos } \\
\text { utilizados na } \\
\text { representação } \\
\text { de átomos } \\
\text { do motivo, } \\
\text { definidos pelo } \\
\text { usuário em } \\
\text { diferentes } \\
\text { módulos da } \\
\text { aplicação }\end{array}$ & $\begin{array}{l}\text { Object3d(THREE.Mesh), Geometry(THREE.OctahedronGeometry), } \\
\text { Radius (float), Position (THREE.Vector3) determinam parâmetros da } \\
\text { geometria do objeto e sua posição } \\
\text { Visible(boolean), Opacity(float), Color(string), } \\
\text { RenderingMode(string), Material(THREE.MeshBasicMaterial) } \\
\text { determinam propriedades e parâmetros visuais do objeto, como } \\
\text { visibilidade e transparência, cor e modo de renderização } \\
\text { ID(integer) identificador único do átomo } \\
\text { ElementName(string) nome do elemento químico do átomo } \\
\text { IonicIndex(integer) íon do elemento químico do átomo }\end{array}$ \\
\hline $\begin{array}{l}\text { Plano de } \\
\text { Miller }\end{array}$ & millerPlane.js & $\begin{array}{l}\text { Construção e } \\
\text { armazenamento } \\
\text { de objetos } \\
\text { utilizados na } \\
\text { representação } \\
\text { de planos de } \\
\text { Miller }\end{array}$ & $\begin{array}{l}\text { Object3d(THREE.Mesh), Geometry(THREE.Geometry), Position } \\
\text { (THREE.Vector3) determinam parâmetros da geometria do objeto e } \\
\text { sua posição } \\
\text { Visible(boolean), Opacity(float), Color(string), } \\
\text { RenderingMode(string), Material(THREE.MeshBasicMaterial) } \\
\text { determinam propriedades e parâmetros visuais do objeto, como } \\
\text { visibilidade e transparência, cor e modo de renderização } \\
\text { Name(string) nome do Plano de Miller }\end{array}$ \\
\hline
\end{tabular}




\begin{tabular}{|l|l|l|l|}
\hline $\begin{array}{l}\text { Direção } \\
\text { de Miller }\end{array}$ & millerVector.js & $\begin{array}{l}\text { Construção e } \\
\text { armazenamento } \\
\text { de objetos } \\
\text { utilizados na } \\
\text { representação } \\
\text { de direções de } \\
\text { Miller }\end{array}$ & $\begin{array}{l}\text { Object3d(THREE.Mesh), Geometry(THREE.Geometry), } \\
\text { Start(THREE.Vector3), End(THREE.Vector3), Radius(Float), } \\
\text { Length(Float), Position (THREE.Vector3) determinam parâmetros da } \\
\text { geometria do objeto e sua posição }\end{array}$ \\
\hline $\begin{array}{l}\text { Bordas } \\
\text { de Célula }\end{array}$ & Grid.js & $\begin{array}{l}\text { VenderingMode(string), Material(THREE.MeshBasicMaterial) } \\
\text { determinam propriedades e parâmetros visuais do objeto, como } \\
\text { visibilidade e transparência, cor e modo de renderização }\end{array}$ \\
& $\begin{array}{l}\text { Construção e } \\
\text { armazenamento } \\
\text { de objetos } \\
\text { utilizados na } \\
\text { representação } \\
\text { de bordas de } \\
\text { célula }\end{array}$ & $\begin{array}{l}\text { Object3d(THREE.Mesh), Geometry(THREE.Geometry), Scale(Float), } \\
\text { Length(Float), Position (THREE. Vector3) determinam parâmetros da } \\
\text { geometria do objeto e sua posição }\end{array}$ \\
\hline $\begin{array}{l}\text { Visible(boolean), Color(string), RenderingMode(string), } \\
\text { Material(THREE.MeshBasicMaterial) determinam propriedades } \\
\text { e parâmetros visuais do objeto, como visibilidade, cor e modo de } \\
\text { renderização }\end{array}$ \\
\hline
\end{tabular}

Fonte - do autor.

\subsection{Módulo de persistência (storeProject.js)}

O estado atual da aplicação é caracterizado pelos valores de atributos dos módulos. Quando o usuário salva as configurações, o objeto view dispara um evento, capturado pelo módulo controlador da estrutura cristalina, que, por sua vez, envia os valores de atributos da aplicação ao módulo de persistência. Estes atributos são convertidos pelo módulo de persistência em um documento no formato JSON, enviado para a API da aplicação CWLY. Quando o usuário recupera as configurações, o módulo de persistência recupera o documento JSON previamente armazenado e dispara um evento de reconstrução da sessão, capturado pelos demais módulos da aplicação. Cada módulo redefine os objetos a partir do documento JSON e, como resultado, a aplicação retorna ao seu estado anterior.

\subsection{Objeto controller (controlador)}

\subsection{Módulo de estrutura cristalina (lattice.js)}

O módulo lattice.js define e gerencia o comportamento de todos os elementos e parâmetros associados à estrutura cristalina. Segundo o paradigma de programação orientada a eventos, este é um componente crítico da aplicação, pois controla a maior parte do fluxo de eventos do objeto view (visão) do cristal.

Utilizando-se da API PubSub, o módulo lattice.js atua entre os elemen- 
tos de cena da estrutura cristalina (objeto view) e sua estrutura de dados (objeto model), mapeando as ações da interface (subscribers) para chamadas de modelo que acionam um conjunto de funcionalidades específicas, permitindo ao usuário visualizar e interagir com a estrutura cristalina e seus componentes. O módulo lattice.js tem acesso aos outros módulos do modelo (pontos de rede, átomos, planos e direções) e suas estruturas de dados, aplicando as "regras de negócio" em seus métodos. Tais regras visam controlar a criação de objetos e o acesso aos dados, restringindo, por exemplo, valores máximos e mínimos aceitáveis. Na FIG. 66, é ilustrada de maneira simplificada a composição e organização do módulo, e, na TAB. 7 , são descritos os seus principais métodos e funções.

TABELA 7 - Descrição dos principais métodos do módulo lattice.js (estrutura cristalina), referente ao objeto controlador.

\begin{tabular}{|c|c|c|}
\hline \multicolumn{3}{|c|}{$\begin{array}{l}\text { DESCRIÇÃO DOS PRINCIPAIS MÉTODOS DO MÓDULO LATTICE.JS (ESTRUTURA CRISTALINA), } \\
\text { REFERENTE AO OBJETO CONTROLADOR }\end{array}$} \\
\hline Métodos & Descrição dos métodos & Parâmetros e atributos principais \\
\hline $\begin{array}{l}\text { transformationMatrix() } \\
\text { updatePoints() } \\
\text { transform() }\end{array}$ & $\begin{array}{l}\text { Definem matrizes de transformação e calculam } \\
\text { as coordenadas atualizadas para todos } \\
\text { os objetos primitivos em cena (pontos de } \\
\text { rede, átomos, planos e direçães). O método } \\
\text { transformationMatrix() define as matrizes de } \\
\text { transformação utilizando os parâmetros (a,b,c, } \\
\alpha, \beta, \gamma) \text { existentes, fornecidos pelo método } \\
\text { updatePoints() quanto os parâmetros ( } a^{\prime}, b^{\prime}, c^{\prime}, \\
\left.\alpha^{\prime}, \beta^{\prime}, \gamma^{\prime}\right) \text { definidos pelo usuário. Por fim o método } \\
\text { transform() aplica as matrizes de transformação às } \\
\text { coordenadas de todos os primitivos em cena }\end{array}$ & $\begin{array}{l}\text { Object3d(THREE.Mesh), Position } \\
\text { (THREE.Vector3), Point(), Atom(), } \\
\text { Direction(), Plane(), Face(), } \\
\text { Grid(), determinam os parâmetros } \\
\text { de rede e as posições existentes } \\
\text { dos objetos primitivos em cena } \\
\text { Callbacks de interface que } \\
\text { provêm os parâmetros de rede } \\
\text { determinados pelo usuário, } \\
\text { conforme descritos na TAB. } 6 \text { do }\end{array}$ \\
\hline RecreateMotif() & $\begin{array}{l}\text { Calculam e aplicam os parâmetros de rede da } \\
\text { estrutura com base nas configurações dos átomos } \\
\text { da composição do motivo criada pelo usuário. O } \\
\text { método é executado toda vez que um átomo do } \\
\text { motivo é adicionado ou atualizado com a opção } \\
\text { "AUTO" é habilitada }\end{array}$ & $\begin{array}{l}\text { Callbacks de interface que } \\
\text { provêm os parâmetros de rede } \\
\text { determinados pelo usuário, } \\
\text { conforme descritos na TAB. } 6 \text { do } \\
\text { objeto modelo }\end{array}$ \\
\hline directionParameterChange() & $\begin{array}{l}\text { Constroem planos de Miller dentro de uma célula } \\
\text { unitária. Este método também é responsável pela } \\
\text { validação e cálculo de coordenadas e construção } \\
\text { de planos paralelos, hexagonais e da identificação } \\
\text { de átomos perpendiculares }\end{array}$ & $\begin{array}{l}\text { Callbacks de interface que provêm } \\
\text { os parâmetros dos planos de } \\
\text { Miller determinados pelo usuário, } \\
\text { conforme descritos na TAB. } 6 \text { do } \\
\text { objeto modelo }\end{array}$ \\
\hline updatePoints() & $\begin{array}{l}\text { Constroem direções de Miller dentro de uma célula } \\
\text { unitária. Este método também é responsável pela } \\
\text { validação e cálculo de coordenadas e construção } \\
\text { de direções hexagonais }\end{array}$ & $\begin{array}{l}\text { Callbacks de interface que } \\
\text { provêm os parâmetros de rede } \\
\text { determinados pelo usuário, } \\
\text { conforme descritos na TAB. } 6 \text { do } \\
\text { objeto modelo }\end{array}$ \\
\hline
\end{tabular}

Fonte - do autor. 


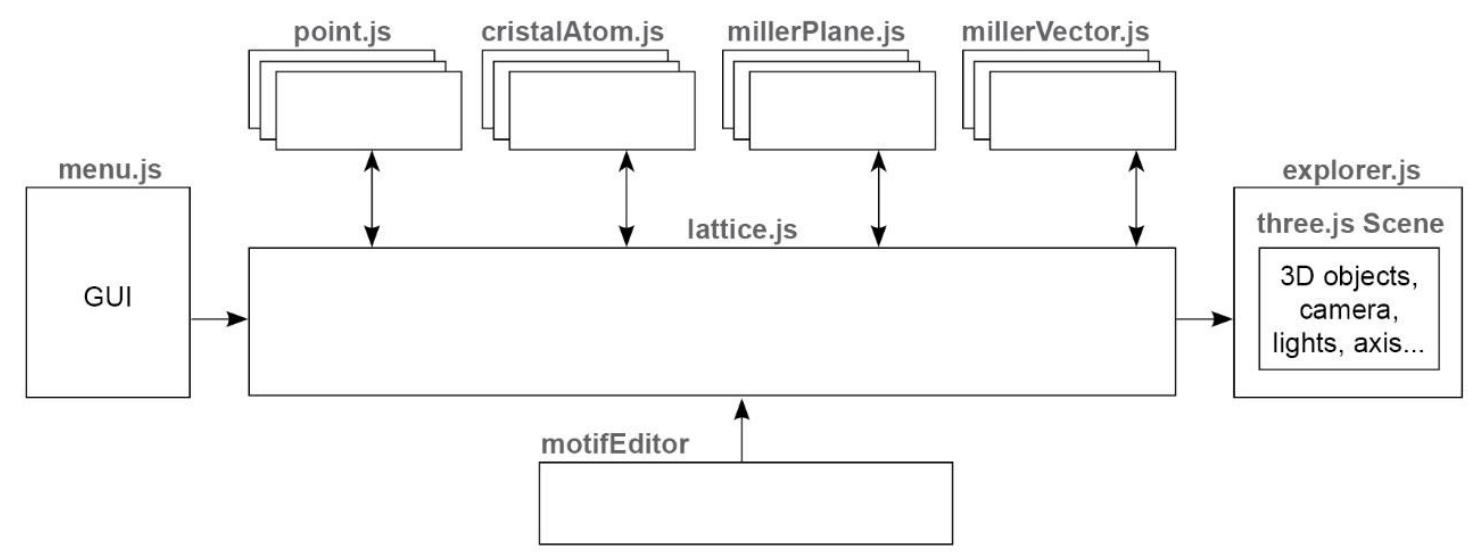

FIGURA 66 - Funcionamento dos principais métodos e funções do módulo de estrutura cristalina, referente aos objetos modelo e controlador. Fonte: do autor.

\subsection{Módulo de motivo (motifEditor.js)}

O módulo motifEditor.js é responsável pela construção e gerenciamento de todos os parâmetros associados ao motivo da estrutura cristalina. Complementar ao lattice.js, este módulo gerencia os parâmetros de inclusão, exclusão e posição dos átomos do motivo, que são fornecidos interativamente pelo usuário através da interface Edição (motifExplorer.js). A FIG. 67 ilustra de maneira simplificada a composição e organização do módulo, e a TAB. 8 descreve os seus principais métodos e funções.

TABELA 8 - Descrição dos principais métodos do módulo motifEditor.js (motivo), referente ao objeto controlador.

\begin{tabular}{|c|c|c|}
\hline $\begin{array}{l}\text { addAtomInCell() } \\
\text { findNewAtomsPos() } \\
\text { configureCellPoints() } \\
\text { findMotifsDimensions() }\end{array}$ & $\begin{array}{l}\text { Calculam coordenadas e adicionam átomos à composição } \\
\text { do motivo criada pela usuário. } \\
\text { O método addAtomlnCell() é responsável pela construção } \\
\text { e adição de novos átomos à composição do motivo. O } \\
\text { método configureCellPoints() calcula as coordenadas de } \\
\text { um novo átomo a partir de seu raio, assim como da rede } \\
\text { de Bravais selecionada e dos parâmetros de coordenadas } \\
\text { e raios de átomos existentes, adquiridos pelo método } \\
\text { findNewAtomsPos(). Por fim, o método findMotifsDimension() } \\
\text { calcula a dimensão da composição do motivo e retorna ao } \\
\text { método updatePoints() do módulo lattice.js para que os } \\
\text { valores de rede da estrutura sejam recalculados e atualizados }\end{array}$ & $\begin{array}{l}\text { Object3d(THREE.Mesh), } \\
\text { Position (THREE. Vector3), } \\
\text { Point(), Atom() determinam } \\
\text { os parâmetros do motivo e as } \\
\text { posições existentes de seus } \\
\text { objetos primitivos em cena } \\
\text { Callbacks de interface que } \\
\text { provêm os parâmetros do motivo } \\
\text { determinados pelo usuário, } \\
\text { conforme descritos na TAB. } 6 \text { do } \\
\text { objeto modelo }\end{array}$ \\
\hline
\end{tabular}

Fonte - do autor. 


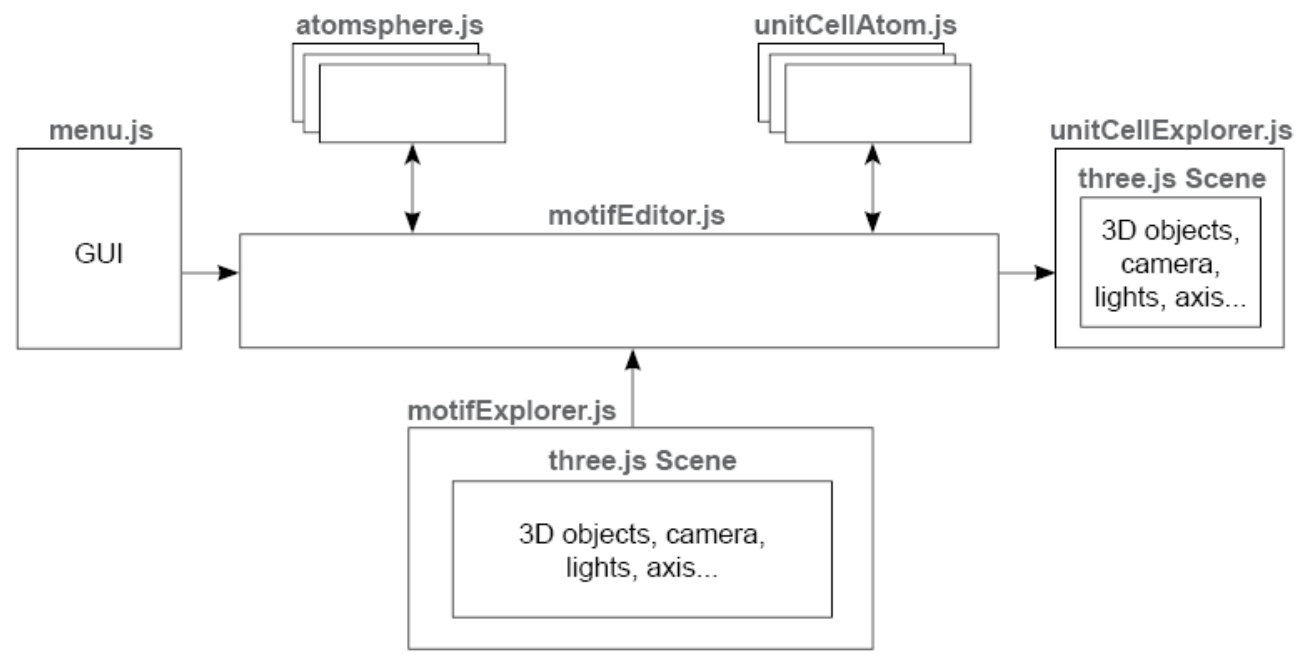

FIGURA 67 - Funcionamento dos principais métodos e funções do módulo de motivo, referente aos objetos modelo e controlador. Fonte: do autor.

\subsubsection{Encurtador de URL e API de persistência de dados (CWLY)}

Componente da plataforma CrystalWalk, o CWLY é a aplicação responsável pelo armazenamento, gerenciamento e transferência de dados entre 0 servidor e a aplicação cliente (CWAPP). Em concordância à arquitetura, padrões e tecnologias utilizados, decidiu-se por uma estratégia de implementação que utilizasse tecnologias capazes de suportar estes fundamentos, tais como a plataforma de desenvolvimento em nuvem Heroku, o framework Ruby on Rails, o uso de sistemas distribuídos (SOA), interfaces padronizadas para gerenciamento de recursos (REST) e uso de banco de dados híbrído (NoSQL/relacional) de alta escalabilidade. Esses conceitos e tecnologias são apresentados em maiores detalhes no capítulo 3.

O CWLY é dividido em três componentes interdependentes, o Encurtador de URL, a API de persistência e a interface de gerenciamento de dados. A aplicação possui também uma interface para implementação no Heroku (deployable), desenvolvida em Ruby. A FIG. 68 ilustra esta arquitetura de maneira simplificada. 
CWLY

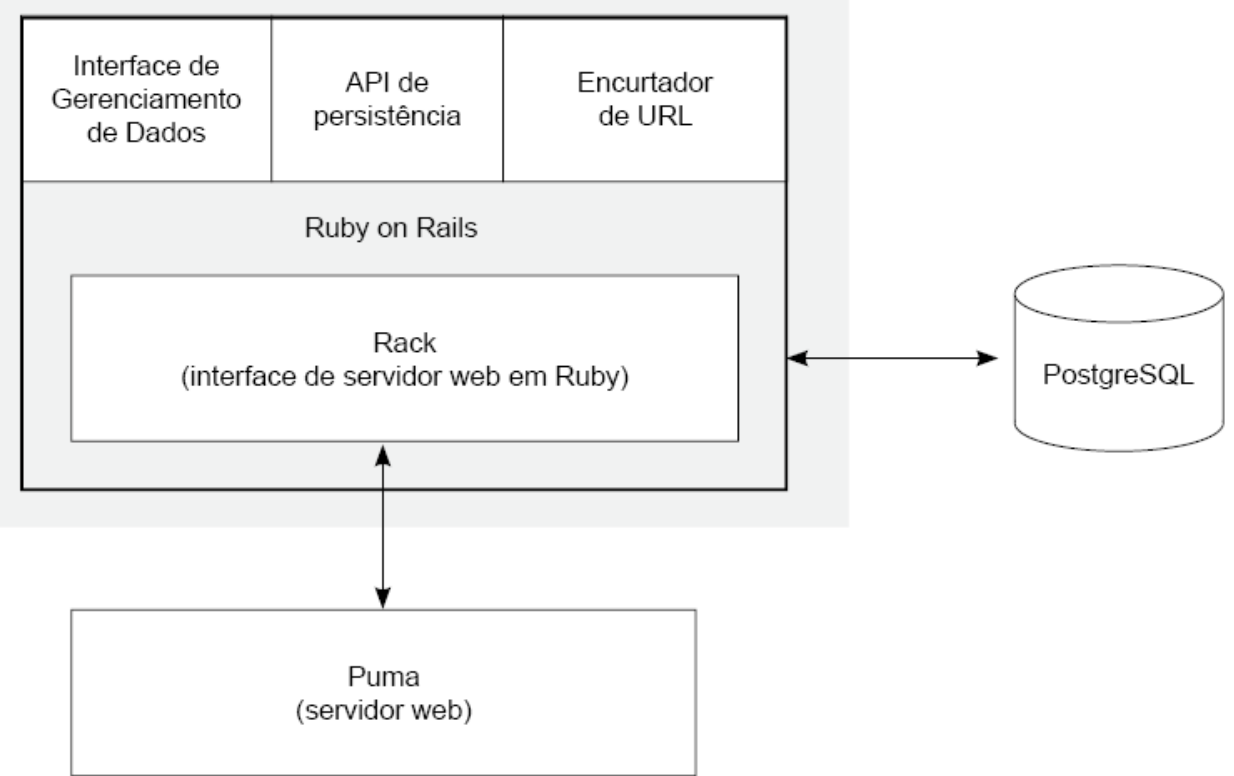

FIGURA 68 - Componentes do CWLY. Fonte: do autor.

O componente de API de persistência da aplicação realiza o armazenamento e recupera documentos JSON no banco de dados. Esse componente possui uma interface REST, cujas rotas são listadas e detalhadas na TAB. 9.

TABELA 9 - Descrição dos rotas, verbos e parâmetros da interface REST, referentes à aplicação CWLY.

\begin{tabular}{|c|c|c|c|c|}
\hline \multicolumn{5}{|c|}{$\begin{array}{c}\text { DESCRIÇÃO DOS ROTAS, VERBOS E PARÂMETROS DA INTERFACE REST, } \\
\text { REFERENTES À APLICAÇÃO CWLY }\end{array}$} \\
\hline Descrição & Verbo HTTP & Caminho & Parâmetros & Resposta \\
\hline $\begin{array}{l}\text { Armazena um documento JSON } \\
\text { especificado pelo parâmetro data }\end{array}$ & POST & ladd & $\begin{array}{l}\text { url=servidor } \\
\text { data=\{"estrutura": } \\
\text { "CubicSimple","title": } \\
\text { "Demonstração 1"\} }\end{array}$ & \{“slug":"\$id"\} \\
\hline $\begin{array}{l}\text { Redireciona uma URL encurtada para } \\
\text { o endereço previamente definido no } \\
\text { parâmetro url, anexando o identificador } \\
\text { único \$id ao endereço de destino }\end{array}$ & GET & $/ \$ i d$ & & $\begin{array}{l}\text { HTTP/1.1 } 301 \text { Moved } \\
\text { Permanently Location: } \\
\text { servidor/\#\$id }\end{array}$ \\
\hline $\begin{array}{l}\text { Realiza uma busca nos registros } \\
\text { existentes com base no critério } \\
\text { especificado }\end{array}$ & GET & $/ q v$ & qs="string de busca" & $\begin{array}{l}\{\text { “documents":"\$id"," } \\
\text { \$url","\$slug", "\$data"\} }\end{array}$ \\
\hline $\begin{array}{l}\text { Recupera um documento JSON } \\
\text { armazenado com base em um } \\
\text { identificador único \$id }\end{array}$ & GET & /\$id.json & & $\begin{array}{l}\{\text { "data": }\{\text { "estrutura": } \\
\text { "CubicSimple","title": } \\
\text { "Demonstração 1"\}\} }\end{array}$ \\
\hline
\end{tabular}

Fonte - do autor 
Ao receber uma solicitação de armazenamento, o componente de API de persistência realiza o registro do documento JSON no banco de dados, retornando um identificador único para cada transação. O componente encurtador de URL utiliza este identificador para redirecionar um endereço de URL encurtada para o endereço da aplicação principal, consultar o banco de dados e recuperar o documento. A FIG. 69 ilustra de maneira simplificada o funcionamento deste mecanismo.

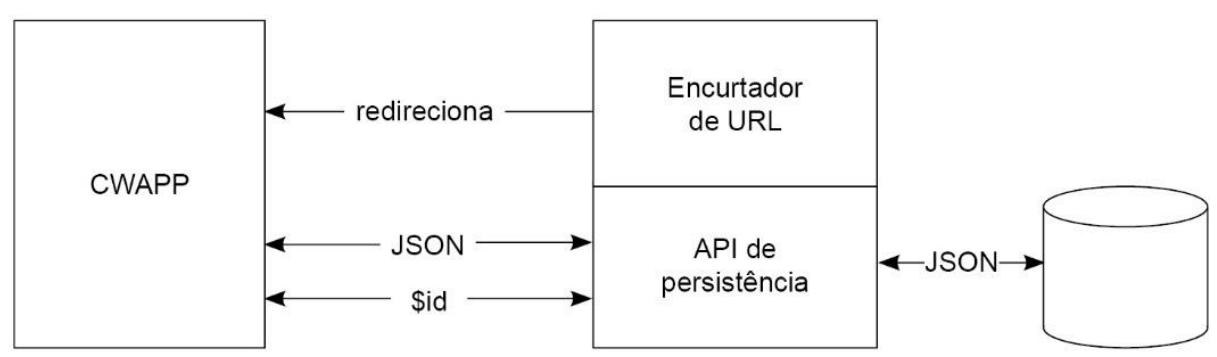

FIGURA 69 - Diagrama do fluxo de eventos da aplicação CWLY. Fonte: do autor.

Em concordância à arquitetura, padrões e tecnologias utilizados, optouse pelo uso de um esquema híbrido (NoSQL/relacional), adotando especificamente o PostgreSQL e o tipo de dados jsonb, devido à superioridade em termos de disponibilidade e elasticidade para a aplicação proposta (PostgreSQL Global Development Group, [s.d.]). O esquema híbrído (NoSQL/relacional) do banco de dados é especificado na TAB. 10. Por fim, o componente gerenciador de dados é uma interface restrita que permite a localização e o gerenciamento de documentos armazenados em banco de dados.

TABELA 10 - Descrição do esquema híbrido do banco de dados, referente à aplicação CWLY.

\begin{tabular}{|l|l|l|l|}
\hline \multicolumn{4}{|c|}{ DESCRIÇÃO DO ESQUEMA HÍBRIDO DO BANCO DE DADOS, REFERENTE À APLICAÇÃO CWLY } \\
\hline \multicolumn{1}{|c|}{ Tabela } & \multicolumn{1}{|c|}{ Coluna } & \multicolumn{1}{|c|}{ Tipo de dados } & \multicolumn{1}{c|}{ Descrição } \\
\hline documents & url & VARCHAR(255) & URL de redirecionamento para a aplicação CWAPP \\
\hline documents & slug (*) & VARCHAR(255) & Identificador único do documento JSON \\
\hline documents & Jsonb & JSON/NoSQL & Estrutura de dados do documento JSON \\
\hline
\end{tabular}

Fonte - do autor. 


\subsubsection{Interface do usuário}

\subsubsection{Especificação da interface}

Apesar do projeto da interface gráfica não ter sido abordado até este momento, entende-se que este elemento merece atenção, pois, do ponto de vista do usuário, o CrystalWalk e tudo o que ele oferece é representado e acessado por meio da interface. Como exposto na problemática do trabalho (seção 1.1), existem softwares cristalográficos equipados com avançadas funcionalidades, mas com interfaces gráficas absolutamente indecifráveis para estudantes de graduação e mesmo pós-graduação, o que limita seu uso no ambiente didático. Desta forma, muitos desses excepcionais programas poderiam ser utilizados por um público mais amplo, se houvesse o devido investimento ou preocupação com o projeto da interface. Especula-se, inclusive, que boa parte desses programas não teve apoio profissional no projeto das interfaces gráficas. Por este motivo, foi incluído o critério "interface gráfica" na avaliação dos softwares cristalográficos (APÊNDICE B, item 4.1; APÊNDICE D, item 4.1), que acarretou na especificação de uma interface gráfica amigável para o CrystalWalk, tendo em vista a aplicação didática e, portanto, dirigida a um público-alvo não especializado.

A especificação e a implementação de boas interfaces gráficas não são triviais, pois envolvem conhecimentos de diversas áreas. De fato, os pesquisadores do tema destacam a experiência do usuário como principal força motriz e apoiam-se nas ciências cognitivas para especificar, desenvolver e testar interfaces gráficas. O clássico trabalho de Carroll (1998) defende um projeto minimalista, que exponha o usuário aos elementos do sistema de maneira controlada, revelando as funcionalidades conforme o contexto. Essa abordagem sintoniza perfeitamente com os princípios e objetivos deste trabalho - a preocupação com a interface gráfica evidencia o inédito caráter didático da ferramenta. Por outro lado, levanta o desafio de organizar, setorizar e sequenciar adequadamente as funcionalidades do CrystalWalk, de forma a evitar a sobrecarga visual e a confusão do usuário com o excesso de informações.

Outro ponto levantado por pesquisadores como Sutcliffe (2009) é o papel da estética e do envolvimento afetivo nas interfaces gráficas. Esses aspectos podem ser favorecidos pelo planejamento detalhado da apresentação visual, ou seja, determinando de maneira holística as formas, cores e relações entre os ele- 
mentos, como proporção, localização relativa e hierarquia. Para interfaces gráficas, não apenas essa tarefa, mas também a implementação do minimalismo, estão no domínio do design gráfico. Pode-se dizer que a abordagem da questão estética em uma interface gráfica pode ser reduzida a especificação e teste de um "estilo visual", que procura agrupar de maneira coerente e equilibrada todos os elementos visuais, além de materializar a hierarquia das funcionalidades do aplicativo que, no caso deste trabalho, foi determinada seguindo o conceito de minimalismo.

Como discutido na seção 1.1, existem diversos fatores que podem representar barreiras ao aprendizado - entre eles, interfaces gráficas desordenadas e sem preocupação estética. Nesse sentido, definir um estilo visual coerente, lógico e alinhado às boas práticas do design gráfico contemporâneo pode levar a uma interface gráfica amigável e que estimule o aprendizado ou, ao menos, reduza barreiras existentes. De fato, é possível especificar estilos visuais mais adequados ao público-alvo ou que sigam tendências contemporâneas, evitando o estranhamento do usuário no uso do sistema. Deve ser frisado que interfaces gráficas são dinâmicas e contêm elementos interativos.

Buscou-se, portanto, inspiração em estilos visuais contemporâneos, para que o usuário sinta familiaridade com a interface gráfica. Adotou-se um estilo visual minimalista típico de dispositivos móveis como tablets e smartphones, caracterizado por: formas elementares (quadrados, círculos), ícones simplificados e padronizados, organização fortemente ortogonal; pouca variação de cores, explorando tons de cinza, branco e preto; abas e menus retráteis; setorização clara, com acesso rápido e direto às funcionalidades e configurações mais populares. Tais características têm relação com o conceito do minimalismo, expondo informação em níveis crescentes de detalhe e profundidade conforme o desejo do usuário e o contexto de uso, mas partindo sempre das funcionalidades mais elementares. Exemplos de interfaces com tais estilos visuais podem ser observados em sistemas operacionais de ampla adoção, como Android, iOS, Mac OS X e últimas versões do Windows.

O primeiro passo foi organizar a interface para que o usuário seguisse intuitivamente a sequência de uso esperada da aplicação, usufruindo de todos os recursos definidos pela especificação. O segundo passo foi agrupar as funcionalidades nos setores síntese, visualização e interação, além de sequenciar os passos internos de cada grupo e restringir ações que dependem de recursos ainda não utilizados. Essas medidas visaram facilitar o acesso ao software, diminuindo 
a curva de aprendizado para usuários iniciantes. Considerando que haverá usuários iniciantes e outros já familiarizados com a ferramenta, foram criados dois modos de uso, selecionados ao acessar o site (FIG. 70a).

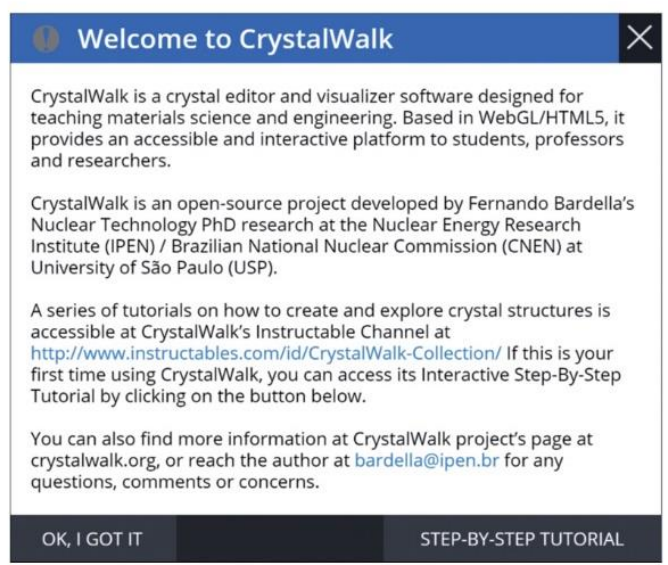

(a)

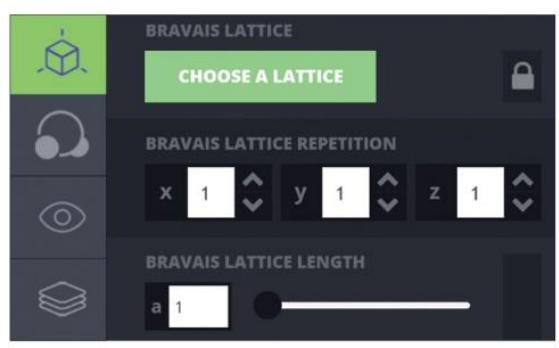

(c)

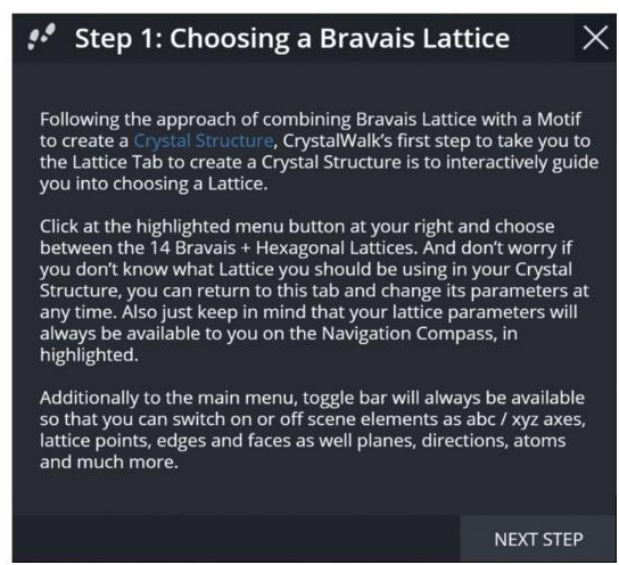

(b)

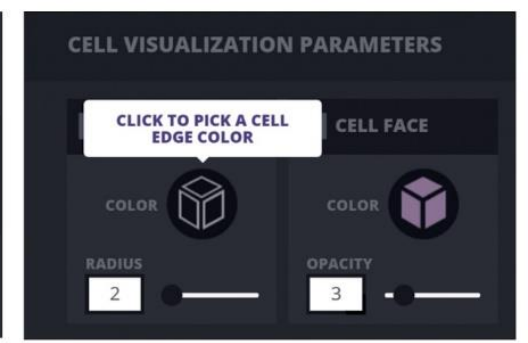

(d)

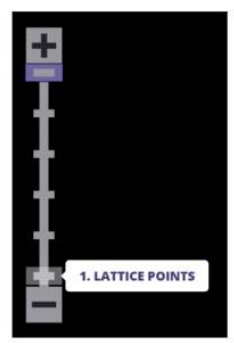

(e)

FIGURA 70 - Elementos do modo tutorial no CrystalWalk: (a) menu inicial para escolha dos modos de uso; (b) descrição de um passo; (c) destaque visual em elementos do menu; (d) balão (tooltip) com descrição dos elementos do menu; (e) destaque de uma etapa no elemento Gearbox. Fonte: Bardella (2016d) (adaptado).

O modo "tutorial" aponta o caminho básico que o iniciante deve percorrer, passo a passo, orientando-o no uso das funcionalidades fundamentais da ferramenta. O sistema mostra um texto de cada etapa principal (68b) e destaca visualmente a sequência de passos para gerar e visualizar determinada estrutura cristalina (FIG. 70c). No modo normal, o usuário interage à vontade com o sistema, sem nenhuma imposição de sequenciamento de ações, mas ainda restrito às disponíveis no momento. Permitir ao usuário explorar opções que dependem de ações prévias não executadas prejudicaria a velocidade de aprendizado e o uso produtivo do software. Finalmente, nos dois modos de uso, foram disponibilizadas descrições de todas as ferramentas em caixas de texto flutuantes, ativadas quan- 
do o usuário passa o cursor do mouse sobre o botão ou campo de cada funcionalidade (FIG. 70d).

Para priorizar a área de visualização das estruturas cristalinas (FIG. 71), onde estão os recursos de interação, os menus são retráteis e emergem ao se posicionar o mouse no canto superior direito (FIG. 72). Os setores de síntese foram organizados na primeira e segunda abas (FIG. 72a-b) e o de visualização, na terceira e quarta abas (FIG. 72c-d).

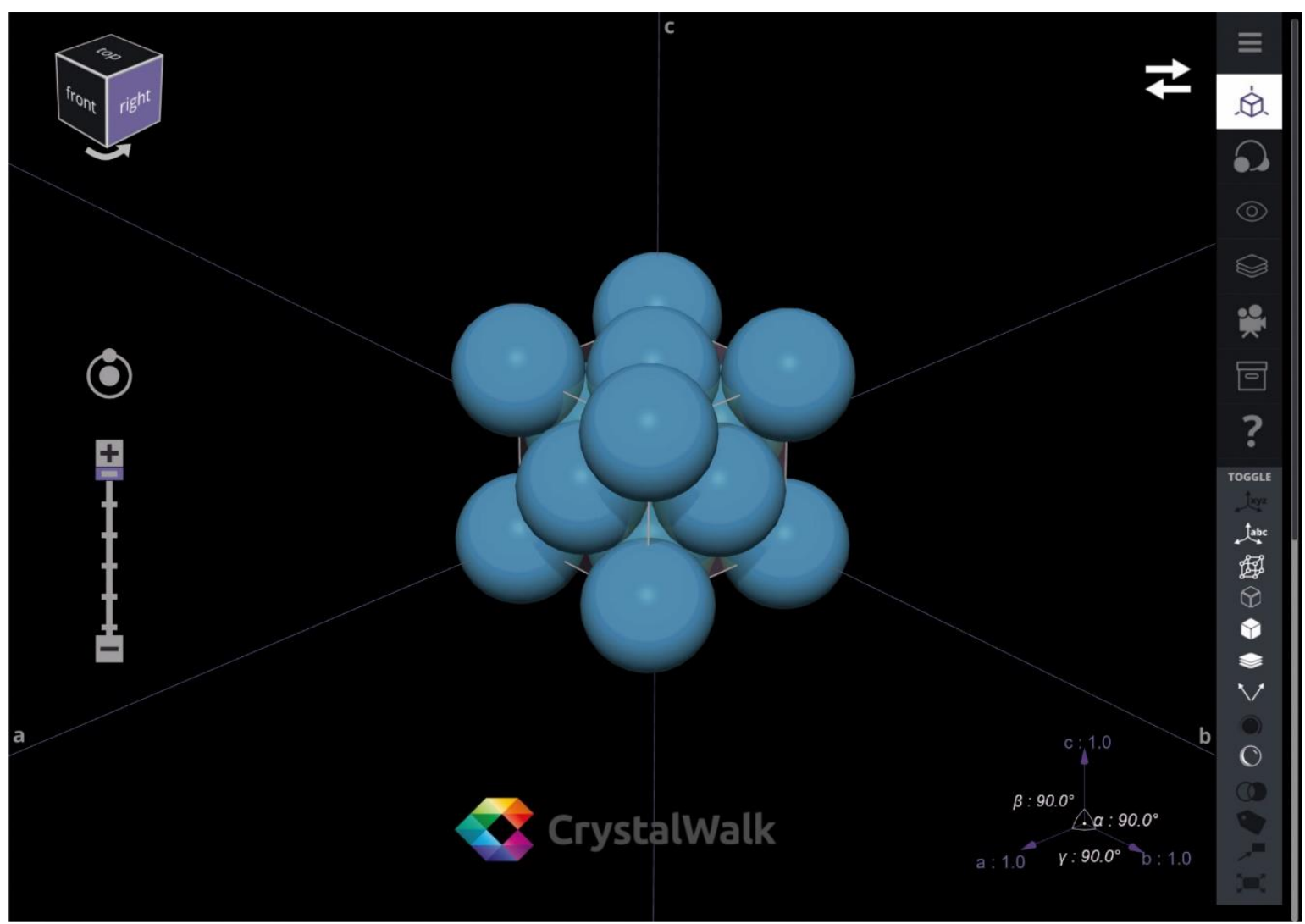

FIGURA 71 - Interface principal do CrystalWalk. Fonte: Bardella (2016d) (adaptado). 


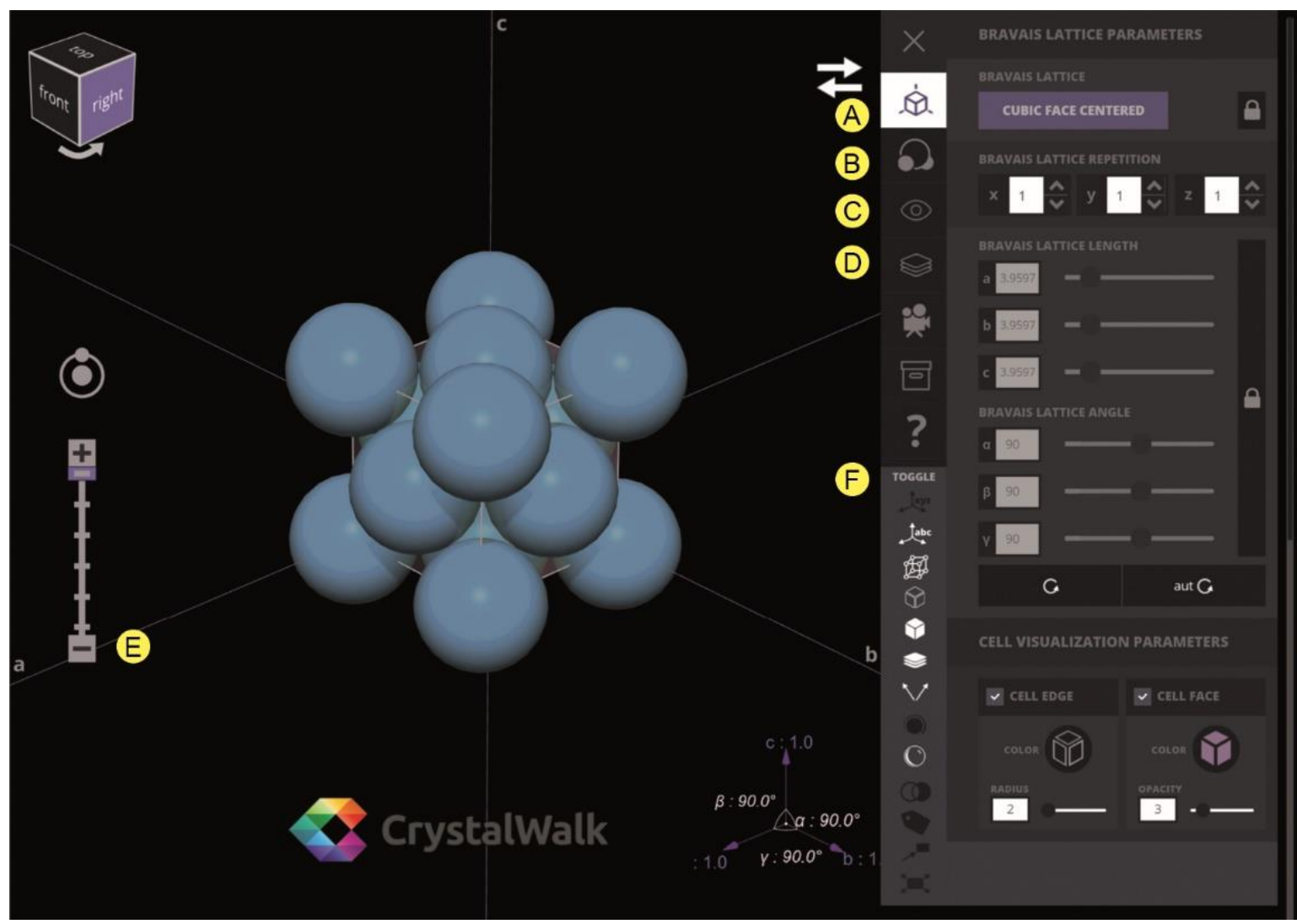

FIGURA 72 - Interface com menu acionado: abas de síntese (a - rede; b - motivo), abas de visualização (c - parâmetros; $d$ - planos e direções); (e - ferramenta Gearbox; f - submenu Toggle). Fonte: Bardella (2016d) (adaptado).

\subsubsection{Síntese}

Todas as opções de síntese estão na primeira e segunda abas do menu retrátil. Apesar de o sistema não definir uma sequência de passos, entende-se que, para começar o processo de síntese, é preciso definir uma estrutura cristalina, seja criando uma ou escolhendo de um banco de estruturas predefinidas. Assim, o primeiro contato do usuário com o sistema fornece opções para a criação da estrutura. Caso o usuário opte por seguir a sequência de passos proposta no modo tutorial, ele poderá utilizar o elemento Gearbox (FIG. 70e; 72e), que sugere, inicialmente, criar uma rede espacial e, depois, escolher um motivo, passos essenciais de síntese de estruturas cristalinas. Seguirá para a visualização do resultado, passando primeiro pela célula unitária cortada, procedendo à célula completa e, finalmente, ao cristal. Entende-se que tal sequência é apropriada à aplicação didática básica da ferramenta, e que o Gearbox a materializa adequadamente. Neste caso, a interface destaca inicialmente o ícone de criação da rede cristalina (FIG. 70c), pois se entende que o usuário iniciante deve primeiramente 
executar esta ação, mas permite também o carregamento de uma estrutura predefinida. No modo normal, caso o usuário queira seguir outra sequência, ainda estará restrito às atividades de síntese. Enquanto a estrutura não for criada, o acesso às outras funcionalidades fica impedido, e o usuário é avisado disso por meio de caixas de texto flutuantes (FIG. 70d).

Ao acessar o menu de criação da rede cristalina (FIG. 73), as tarefas de síntese iniciam-se com a determinação do tipo de rede e parâmetros de repetição para criação de um cristal (FIG. 73a). O tipo de rede é escolhido facilmente em uma janela específica (FIG. 74). Cada escolha do usuário se reflete prontamente na visualização. As células podem ser repetidas nas três direções para formar um cristal. São disponibilizadas referências visuais adicionais, como destaque das arestas e faces das células (FIG. 73b), buscando diminuir as dificuldades dos usuários menos providos de habilidades espaciais. O usuário pode explorar os parâmetros da rede escolhida (FIG. 73c) e também alterar os parâmetros de rede livremente caso deseje (FIG. 73d).

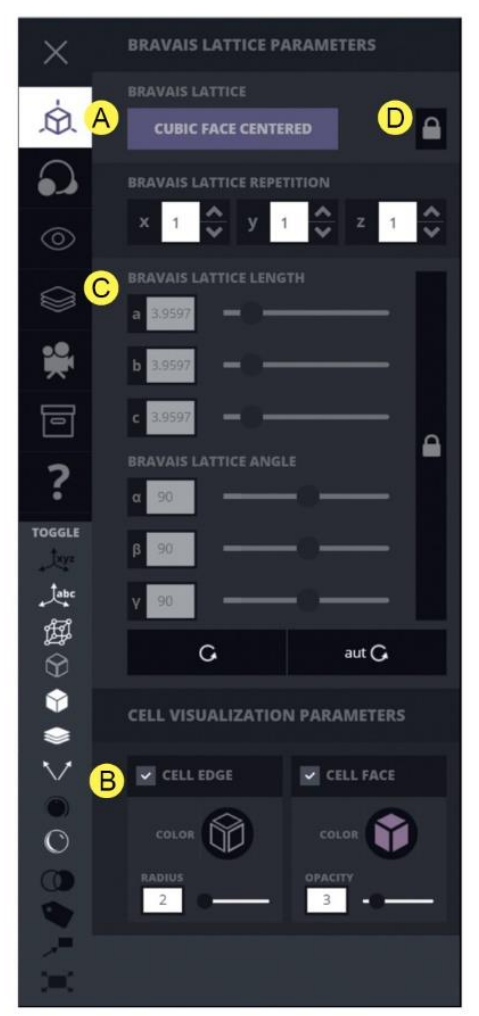

FIGURA 73 - Detalhes da aba de parâmetros de rede: (a) escolha do tipo de rede e parâmetros de repetição; (b) parâmetros de visualização da célula; (c) parâmetros da rede escolhida; (d) opção para alterar livremente os parâmetros de rede. Fonte: Bardella (2016d) (adaptado). 


\section{Bravais Lattice}

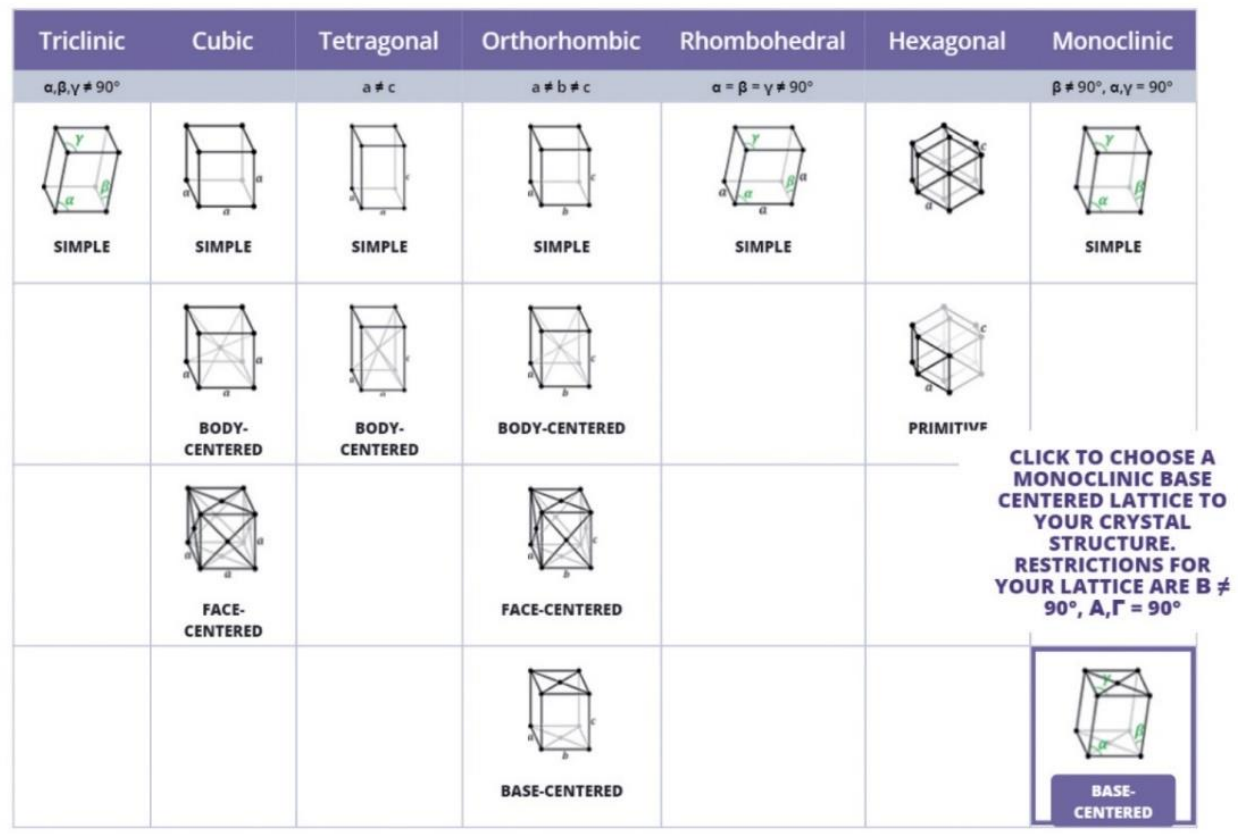

FIGURA 74 - Janela para escolha do tipo de rede, dentre as 14 redes de Bravais. Há 15 opções de escolha, pois, no caso da rede hexagonal, o usuário poderá escolher a célula unitária da rede primitiva ou não primitiva. Fonte: Bardella (2016d) (adaptado).

Após criar a rede, na terceira aba (FIG. 75), estão opções de motivo, nas quais o usuário escolhe os átomos que o comporão. Ao alternar para essa aba, a visualização muda para um modo com cinco vistas, mantendo uma vista da célula unitária (FIG. 76a), outra com o cristal (FIG. 76b) e três vistas adicionais (duas vistas laterais e uma superior) do motivo (FIG. 76c-e). As vistas, em conjunto, apoiam a inserção do motivo. Nesta aba, ao alto, a primeira opção (FIG. 75a) abre a tabela periódica, onde o usuário escolherá um elemento químico para compor o motivo (FIG. 77a), com opção do raio do átomo ou de seus íons (FIG. 77b). Após tais escolhas, o usuário pode alterar as coordenadas e salvar as configurações (FIG. 75b). Se quiser, na sequência, pode adicionar outro átomo ao motivo segundo o mesmo procedimento. Os átomos salvos são exibidos em uma lista e podem ser editados após a criação (FIG. 75c). Ainda nessa aba, existe um setor dedicado à exibição de repercussões das configurações do motivo nos parâmetros de rede (FIG. 75d), para que o usuário não precise transitar entre as abas. 


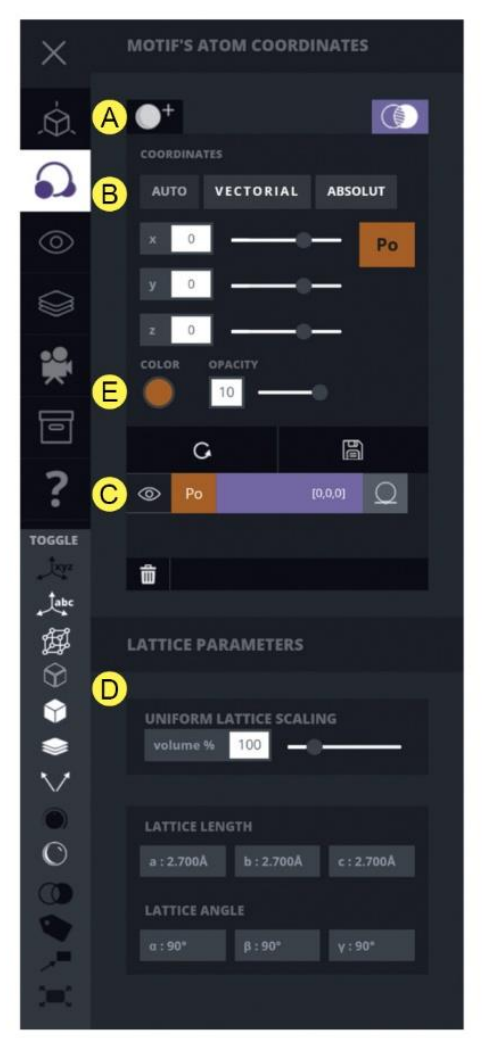

FIGURA 75 - Detalhes da aba de parâmetros do motivo: (a) adição de um novo átomo; (b) parâmetros do motivo; (c) lista de átomos componentes do motivo; (d) exibição dinâmica dos parâmetros de rede; (e) configurações de cor e opacidade do átomo. Fonte: Bardella (2016d) (adaptado).

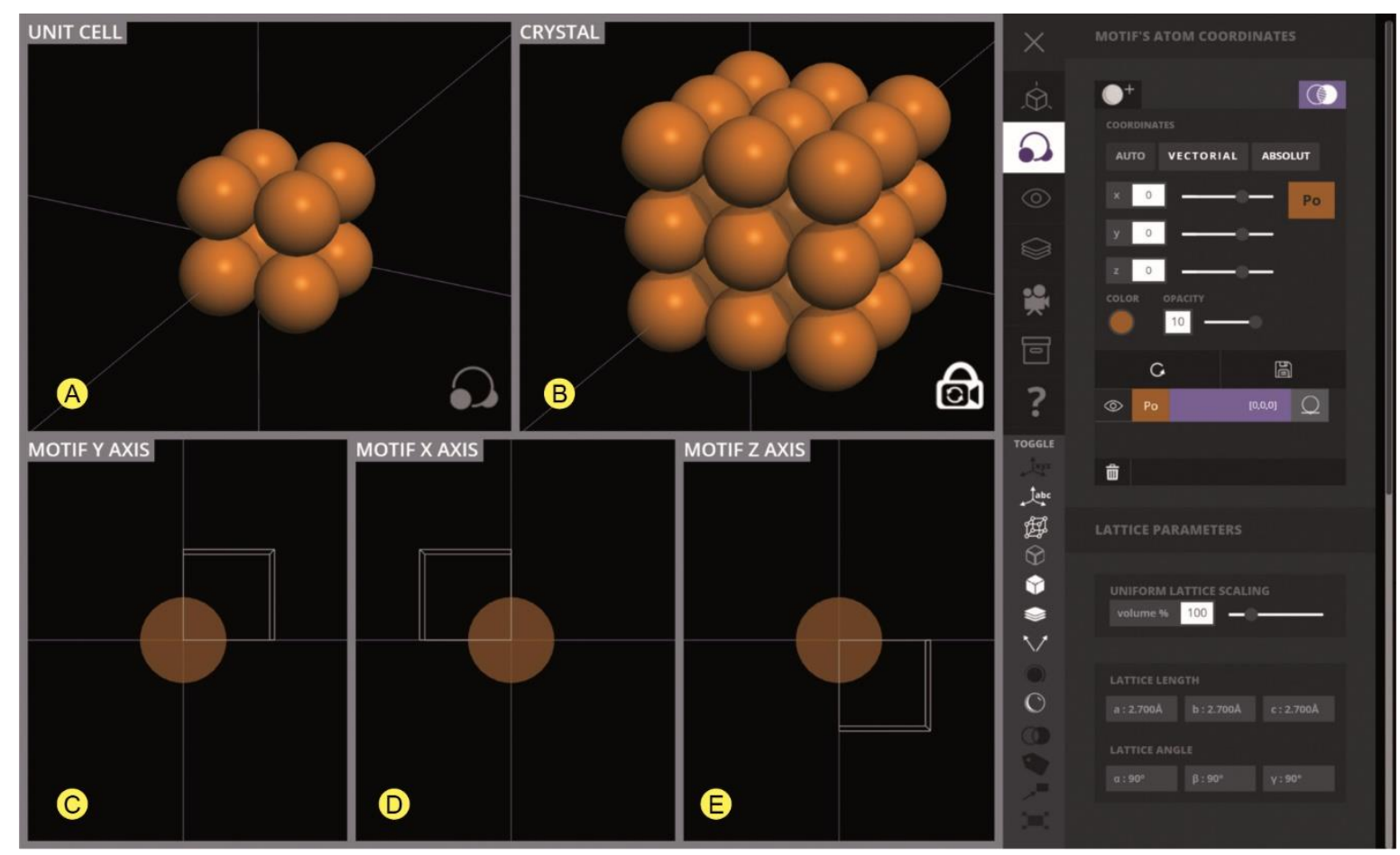

FIGURA 76 - Modo de visualização do motivo: (a) vista da célula unitária; (b) vista do cristal; (c-e) vistas ortogonais do motivo. Fonte: Bardella (2016d) (adaptado). 

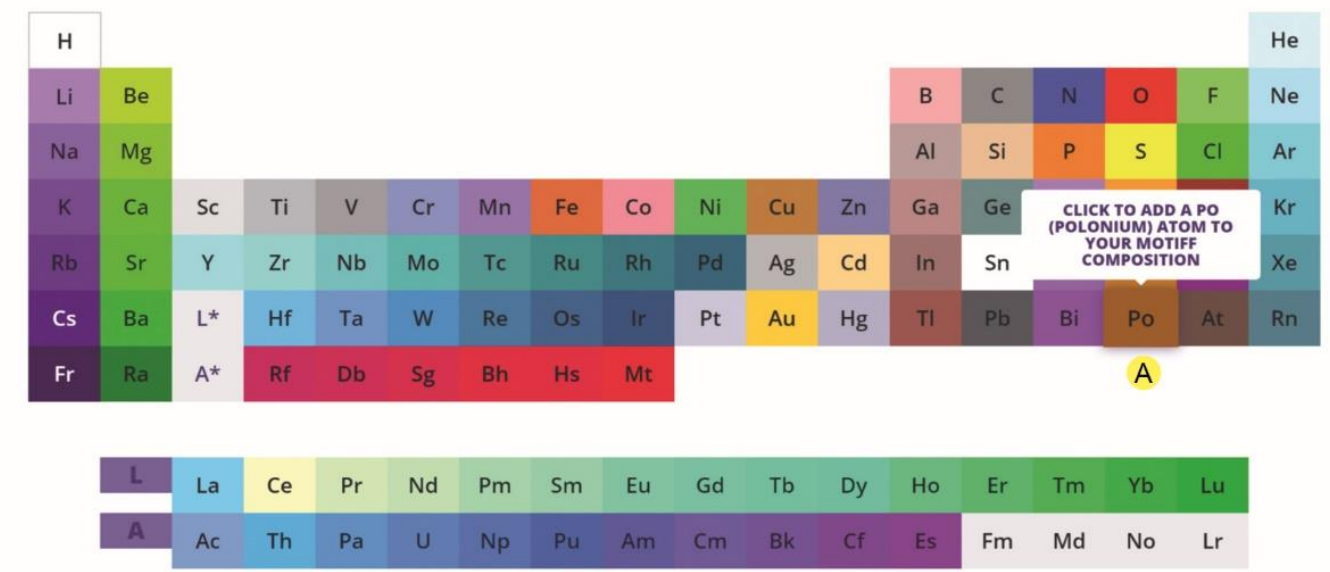

\section{B Po $\begin{array}{cccc}0 & +4.350 \mathrm{~A} & 0.940 \mathrm{~A} & 0.670 \mathrm{~A}\end{array}$}

FIGURA 77 - Tabela periódica para escolha de elementos do motivo. Fonte: Bardella (2016d) (adaptado).

\subsubsection{Visualização}

Os setores de visualização foram organizados na terceira e quarta abas do menu retrátil (FIG. 72c), embora haja opções básicas na tela principal e algumas opções nas abas de síntese. Para exploração inicial das estruturas cristalinas criadas, o sistema oferece diversas opções de visualização, sendo que as mais básicas ficam acessíveis a um clique no submenu Toggle (FIG. 72f), como eixos cartesianos e cristalográficos, pontos, planos e arestas da rede, planos e direções cristalinas, além de configuração do raio atômico visual, detecção de colisões entre átomos, descrição textual dos elementos e modo tela cheia (fullscreen). A exibição dos eixos permite associar mudanças dos parâmetros de rede com a geometria resultante da estrutura cristalina. Em cada aba de síntese, também existem opções de visualização, associadas ao elemento definido em seu contexto. Na aba de rede cristalina, é possível tanto ativar como definir características de planos e arestas (FIG. 73b). Na aba de motivo, existem opções de cor e opacidade para cada átomo que o compõe (FIG. 75e). As três vistas do motivo auxiliam também sua visualização, sobretudo quando o número de átomos é elevado. Estão disponíveis três opções de visualização clássicas associadas ao motivo (alteração de cor, opacidade, exibir ou esconder átomos do motivo), a fim de resolver problemas de oclusão e ambiguidade visual causados pela representação sólida dos átomos. Apesar de aparentemente quebrar o conceito de separação da interface, entende-se que incluir opções de visualização nas abas de síntese estimula a exploração imediata dessas opções. 


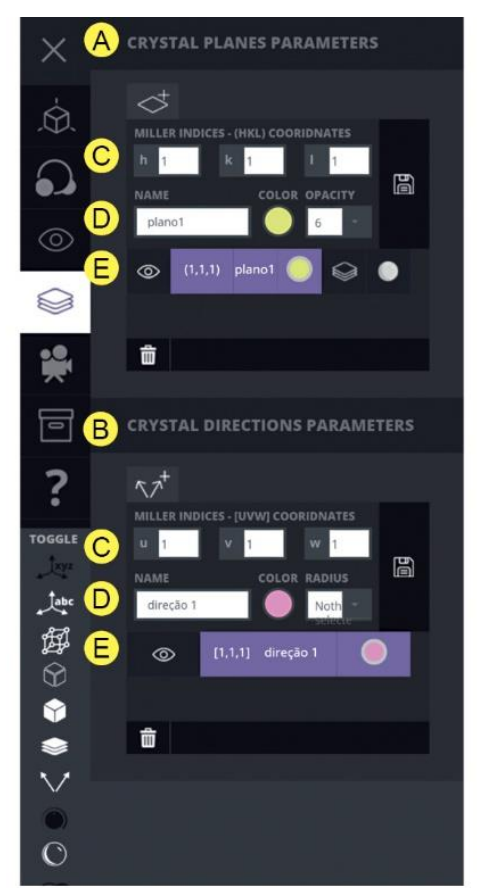

FIGURA 78 - Aba de planos e direções: (a) criação de planos; (b) criação de direções; (c) índices de Miller; (d) configurações de nome, cor e opacidade; (e) lista de elementos criados. Fonte: Bardella (2016d) (adaptado).
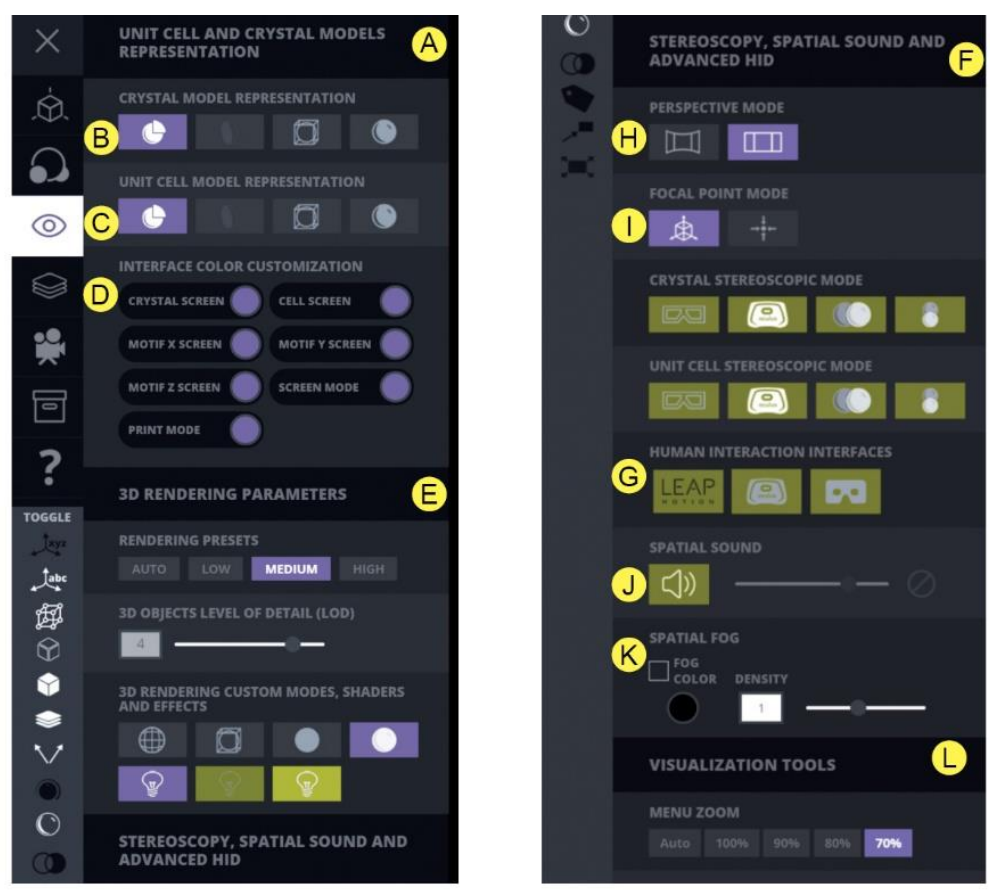

FIGURA 79 - Aba de parâmetros de visualização: (a-d) Modelos de representação; (e) Parâmetros de renderização; (f-k) Técnicas estereoscópicas e interativas experimentais; (I) ajuste de tamanho de menus. Fonte: Bardella (2016d) (adaptado).

Ao acessar a segunda aba, podem ser gerados planos (FIG. 78a) e direções (FIG. 78b) cristalográficos a partir de seus índices de Miller (FIG. 78c), 
classicamente empregados no ensino de ciência dos materiais. Mais uma vez, são disponibilizadas opções de visualização especificas destes planos e direções, como configurações de nome, cor e opacidade (FIG. 78d), possibilitando obter boas visualizações nas mais diversas situações e evitar confusões visuais com outros elementos da estrutura. Planos e direções criados ficam em uma lista (FIG. 78e) para acesso e eventual alteração posterior.

A quarta aba (FIG. 79) oferece vários parâmetros visuais gerais. $\mathrm{Na}$ FIG. 79a, são demonstradas as opções de modelos de representação, definidas na primeira fileira. As mesmas opções estão disponíveis separadamente para as representações do cristal (77b) e da célula unitária (77c). A primeira representação é da célula construtiva, denominação utilizada neste trabalho. Esta célula exibe todos os átomos do motivo, inclusive aqueles externos ao invólucro celular, representação oportuna para auxiliar o entendimento de como cada átomo do motivo está distribuído segundo a rede espacial escolhida no primeiro passo. A segunda executa cortes nos átomos nos limites da célula unitária, um recurso muito útil para visualizar, por exemplo, o ponto de contato entre átomos em diversos tipos de estruturas. Outro modo permite exibir o entre os átomos (ou seja, o espaço intersiticial), algo difícil de mentalizar a partir de imagens bidimensionais. Por fim, existe a opção de representação de célula unitária tradicional, considerando apenas os átomos que se encontram total ou parcialmente no interior da célula.

Na sequência (FIG. 79d), estão opções para alterar o aspecto visual da própria interface, principalmente das janelas, artifício útil principalmente para criar imagens voltadas a apresentações, impressões e outros tipos de mídia.

No setor de parâmetros de configuração 3D (FIG. 79e), é possível alterar separadamente o nível de detalhe da geometria e dos efeitos visuais ou utilizar opções preconfiguradas. Uma das opções disponíveis é a automática, que ajusta os níveis de acordo com as capacidades gráficas do computador, recurso muito utilizado em diversas aplicações gráficas, tanto para reduzir a carga de processamento como para obter diversos efeitos visuais (FIG. 37; seção 3.5.3.4.1). O modo wireframe, por exemplo, permite uma boa representação do volume dos átomos, mas também ver através deles, ajudando a resolver o problema de oclusão.

Técnicas estereoscópicas e interativas experimentais também foram implementadas no CrystalWalk e são acessadas no terceiro setor (FIG. 79f). A 
visualização estereoscópica promete muitos ganhos na exploração de modelos, tal como discutido na seção 3.1.2.3. A visualização anaglifa, apesar de bastante limitada, é extremamente acessível, funcionando mesmo em monitores normais e com óculos de baixo custo. A implementação da estereoscopia passiva pressupôs o uso da tecnologia de polarização, que é a adotada na maioria dos monitores, projetores e televisores 3D disponíveis no mercado brasileiro. Nessa tecnologia, a exigência principal ao software gerador de conteúdo, é criar uma imagem dividida verticalmente ou horizontalmente, uma para cada olho. Foi utilizado um televisor de grande dimensão (65") para os testes. Também existe suporte ao Oculus Rift, uma opção estereoscópica de qualidade muito superior e que tende a ser muito acessível quando lançado ao público. Os dispositivos interativos contemplados (FIG. 79g) são o Leap Motion, Oculus Rift e Cardboard (rastreamento de movimento). Finalmente, são encontradas ainda nesta aba outras opções, como modo de perspectiva (FIG. 79h), localização do ponto focal (FIG. 79i), som espacial (FIG. 79j) e névoa de profundidade (FIG. 79k).

No último setor (FIG. 79I), é possível alterar o tamanho dos menus para ajustá-los a diferentes tamanhos de tela e dispositivos.

As opções de visualização possuem configurações iniciais inspiradas conceitualmente por boas práticas, discutidas na seção 3.1 .3 e determinadas empiricamente durante o desenvolvimento do CrystalWalk. Entende-se que existem inúmeras opções de customização visual e que tamanha diversidade pode representar um problema para usuários pouco experientes ou mesmo para usuários avançados que não querem perder tempo para ajustar os parâmetros. Desta forma, as configurações iniciais foram predefinidas com propósito de propiciar boa qualidade de visualização em diversas condições, não exigindo do usuário muito esforço.

Elementos de apoio de visualização, como eixos de referência e centros atômicos, tipo, distância e ângulos iniciais de câmera, modo de renderização e vistas auxiliares, são ativados e configurados automaticamente de acordo com o modo de uso (tutorial ou avançado) e do contexto (criação da rede, escoIha do motivo).

A paleta de cores padrão dos diversos objetos, assim como níveis de transparência, foram definidos de forma a garantir distinção e contraste para todos os elementos. A espessura inicial de elementos lineares e o raio de elemen- 
tos esféricos foram configurados para assegurar boa visibilidade em monitores com resolução HD $(1280$ × 720 px $)$.

A resolução mínima dos objetos poligonais, além do número inicial de células unitárias e outros objetos repetitivos são definidos de acordo com a capacidade gráfica do dispositivo utilizado ou de acordo com o desejo do usuário. A interface também possui configurações padrão de cor e tamanho, de acordo com o tamanho da tela do dispositivo utilizado.

\subsubsection{Interação}

Todos os mecanismos de interação encontram-se à disposição na tela inicial. É possível interagir no modo básico e avançado. As operações básicas são executadas diretamente com o mouse e as avançadas são acessadas através de ferramentas específicas.

No modo de operação básico, é possível interagir com o modelo, executando-se operações de translação, zoom e rotação, tradicionais em aplicativos tridimensionais e em alguns softwares cristalográficos (APÊNDICE C). Para facilitar a interação, inicialmente, o centro de rotação está fixo e centrado no modelo e o usuário pode explorá-lo apenas rotacionando a vista e aplicando zoom. O usuário pode alterar o centro de rotação ao aplicar uma translação. Entende-se que esse tipo de interação radial é muito adequada para modelos caracterizados por um alto grau de simetria, além de simples e intuitiva para o usuário. Operações básicas com o mouse permitem que o usuário resolva problemas básicos como oclusão e ambiguidades visuais causadas por determinados ângulos de visualização. Também foram criados métodos de interação específicos para dispositivos de toque como tablets, smartphones e tabletops (FIG. 81a). 


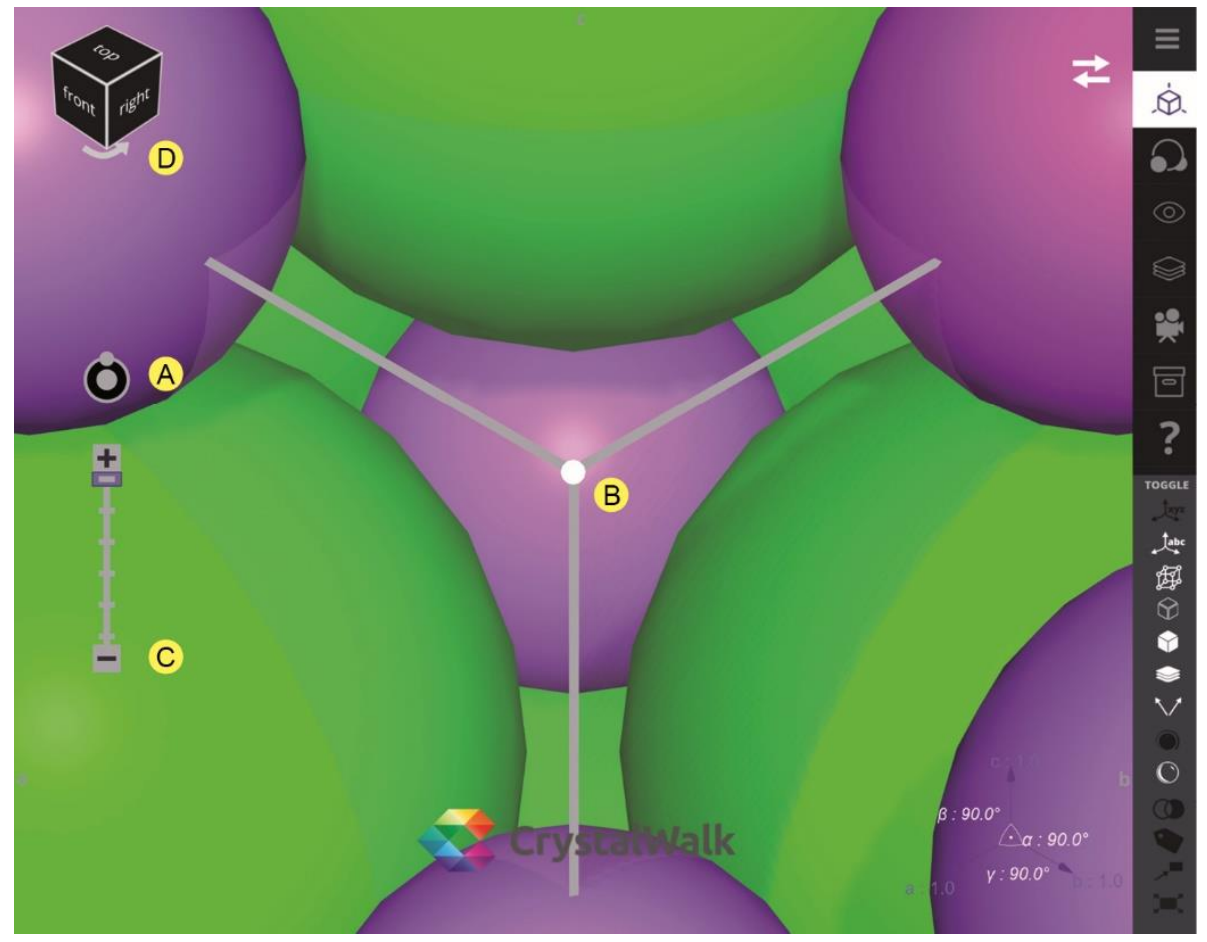

FIGURA 80 - Ferramentas de interação do CrystalWalk: (a) AtomView; (b) vista resultante, centrada em um átomo; (c) Gearbox; (d) Projection Cube. Fonte: Bardella (2016d) (adaptado).

A ferramenta AtomView usa perspectiva cônica (FIG. 80a) e propicia uma visão centrada em um átomo especifico, permitindo explorar o interior dos modelos como se o usuário fosse miniaturizado. Para utilizar a ferramenta, basta posicionar a seta sobre qualquer átomo da estrutura. Este recurso é excepcional para visualizar contatos e vizinhanças entre os átomos (FIG. 80b) e em situações de alta oclusão visual, principalmente quando são utilizados dispositivos estereoscópicos. Além disso, o usuário pode entrar em um modo de navegação em primeira pessoa, típico de jogos 3D, ao usar o mouse para informar a direção frontal e as teclas WASD do teclado para se deslocar. Esse modo de visualização é mais flexível que o radial e, para usuários bem versados nesse modo de interação, é possível extrair uma grande quantidade de informações do modelo. De fato, muitos estudantes de engenharia e mesmo pós-graduandos da área têm experiência em jogos 3D, o que diminui a curva de aprendizado e permite uma exploração mais rica das estruturas. Para voltar ao modo radial, basta clicar novamente no ícone do AtomView (FIG. 80a).

A ferramenta denominada Gearbox (FIG. 80c) permite a transição gradual entre visualizações dos pontos de rede, motivo, célula unitária e estrutura 
cristalina, o que proporciona explorar relações entre os diferentes conceitos que cada representação revela. Como já descrito, o Gearbox também foi utilizado como ferramenta de sequenciamento de ações para usuários iniciantes, especialmente no modo tutorial.

A ferramenta denominada Projection Cube permite obter com facilidade vistas ortogonais (topo e laterais) (FIG. 80d), usadas tradicionalmente em aplicativos de modelagem para resolver ambiguidades visuais das perspectivas, especialmente das isométricas. As transições animadas criadas pela ferramenta permitem rotações em eixos definidos pelo usuário e em baixa velocidade. $\mathrm{Na}$ mesma ferramenta, é possível determinar rotação automática do modelo em qualquer eixo. Em suma, a movimentação planejada e intencional propiciada pela ferramenta permite obter diversos benefícios associados às animações, principalmente construir relações entre as diversas partes do modelo (seção 3.2.3).

Foi implementada integração experimental com o dispositivo Leap Motion, que captura movimentos das mãos e, no caso do CrystalWalk, permite uma navegação mais intuitiva por meio de gestos. Dois modos de interação estão disponíveis, ambos utilizando apenas uma das mãos, devido ao alcance restrito e às limitações do dispositivo. No primeiro modo, o usuário navega em primeira pessoa utilizando um joystick 3D, e a posição inicial da mão define um ponto central de referência. A distância e direção relativa ao centro determinam, respectivamente, a velocidade e a direção de deslocamento, e o ângulo da mão determina as rotações. A navegação é feita com a mão aberta, em um modo similar ao de primeira pessoa propiciado pelo AtomView, mas usufruindo das interações gestuais propiciadas pelo dispositivo Leap Motion. Ao fechar a mão, o segundo modo é ativado e o usuário orbita ao redor do modelo de maneira similar ao modo radial básico, sendo que a distância do centro determina o eixo e a velocidade de rotação (FIG. 82a). 


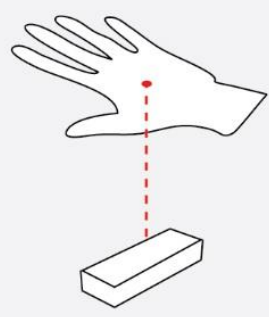

POSIÇÃO NEUTRA

(20 cm acima do dispositivo)

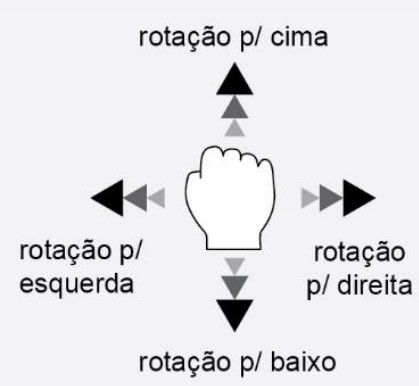

MODO ORBITAL (mão fechada)

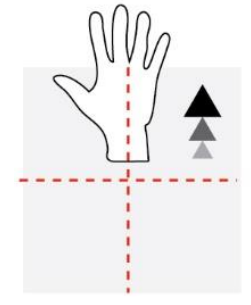

mover para frente

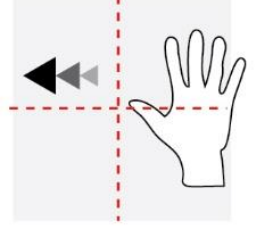

mover para a direita
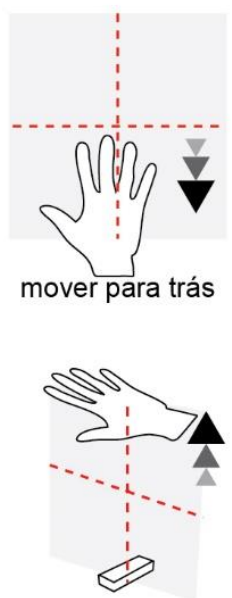

mover para cima

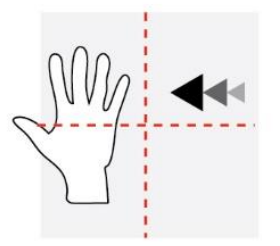

mover para a esquerda

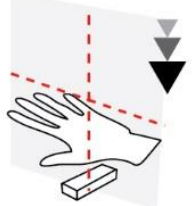

mover para baixo

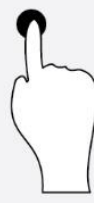

Toque:

Seleção de átomo

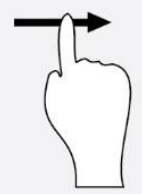

Arrastar: Orbitar

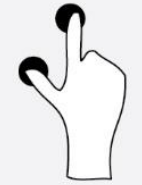

Beliscar: Zoom

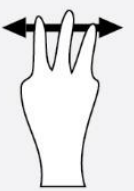

Arrastar com 3 dedos: Translação de Câmera

(b)

FIGURA 81 - Modo de interação: (a) com o dispositivo Leap Motion; (b) em dispositivos de toque. Fonte: do autor.

Também foi implementada integração experimental com o dispositivo Razer Hydra, um joystick duplo rastreável (FIG. 82b). Foram vislumbradas duas formas de interação. A primeira baseia-se no mecanismo de joystick 3D, que resolve simultaneamente a movimentação do usuário e a seleção de objetos. Neste caso, o usuário navega como se estivesse em um avião e as duas mãos operam o manche. No entanto, este manche permite rotações em infinitos eixos. Ao "acelerar", ou seja, colocar o manche para frente, o usuário navega como em um avião. Quando está parado, o usuário pode rotacionar com movimentos naturais das mãos, como se estivesse pegando e manipulando diretamente o objeto à sua frente. Isso diminui ainda mais a abstração, em comparação ao joystick 3D implementado para o Leap Motion. Esse modo permite explorar o melhor de dois mundos: a manipulação natural de uma maquete física em um paradigma "mundo 
em miniatura" (world in miniature - WIM), e a navegação rápida e intuitiva do modo em primeira pessoa. A segunda forma de interação usa os direcionais analógicos do Hydra para navegação em primeira pessoa, familiar a muitos usuários que são ou já foram jogadores.

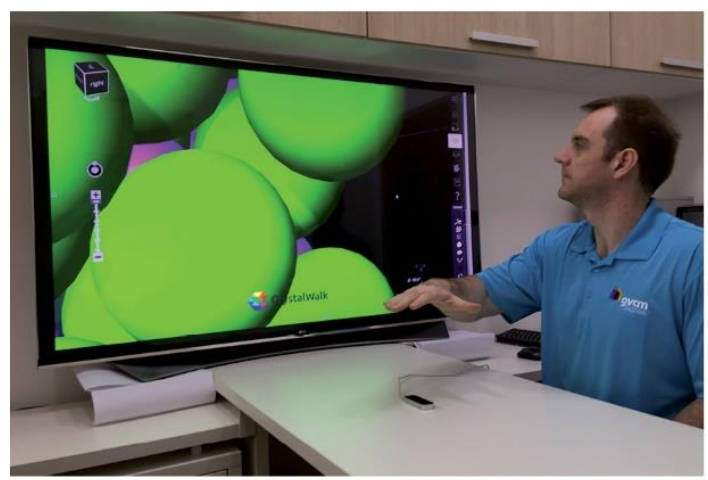

(a)

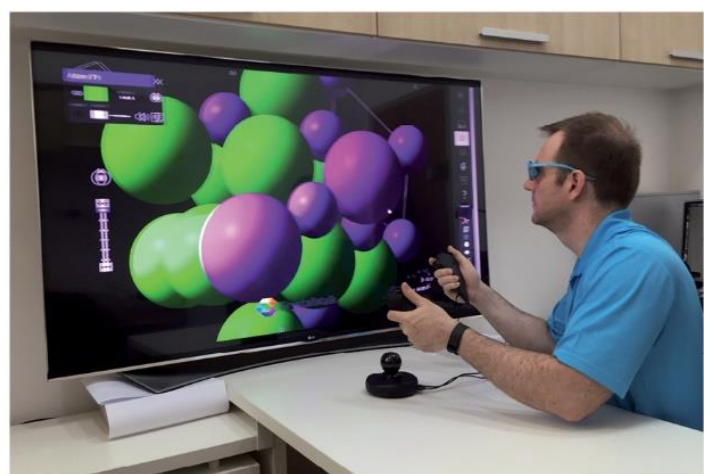

(b)

FIGURA 82 - Utilização de dispositivos com o CrystalWalk: (a) Leap Motion; (b) Razer Hydra. Fonte: do autor.

\subsubsection{Funcionalidades de apoio didáticas}

A última aba concentra funcionalidades que visam apoiar atividades didáticas. Essas funcionalidades são: armazenar as estruturas produzidas, gerar material visual para publicações em outros meios digitais ou impressos; fornecer estruturas prontas e permitir a inclusão de informações adicionais às estruturas produzidas.

A primeira opção, de armazenamento das estruturas produzidas, permite salvar o trabalho on-line ou fazer o download de um arquivo completo para uso off-line. O modo on-line cria um link encurtado para a estrutura produzida, que pode, então, ser acessada por qualquer usuário com acesso à internet. Também pode ser gerado um QR code para acesso direto em dispositivos móveis, sem a necessidade de digitar o link (seção 4.5.5.1). O arquivo off-line pode ser aberto localmente em um navegador. Essa opção permite um fácil acesso às estruturas, mesmo sem conexão com a internet, o que é muito conveniente para professores e estudantes (seção 4.5.5.3).

$\mathrm{Na}$ mesma aba, abaixo, estão opções para obtenção de material visual para uso em outras mídias não interativas, como imagens para apresentações eletrônicas (slides) e documentos digitais ou impressos (notas de aula, pôsteres, 
artigos e livros). Um modelo 3D em formato STL pode ser exportado para exploração em softwares $3 \mathrm{D}$, seja de modelagem, visualização ou processamento geométrico, mas também para impressão 3D (seção 4.5.5.2).

As próximas opções dão acesso a uma biblioteca de estruturas on-line, seja para armazenar as próprias criações, seja para obter estruturas produzidas por outros usuários.

Finalmente, é possível criar narrativas didáticas, incluindo anotações textuais nos modelos e animações de câmera e certas propriedades das estruturas, um recurso útil para professores ou outros usuários adicionarem informações relevantes, favorecendo, por exemplo, uma explanação didática. A seção 4.5.5.4 fornece detalhes sobre essa funcionalidade única do CrystalWalk.

\subsection{Implementação}

Definida a arquitetura da solução tecnológica (ilustrada na FIG. 50), procedeu-se à implementação e disponibilização de uma instância funcional da plataforma CrystalWalk aos atores sociais do projeto e ao público em geral. A concretização desta etapa depende de infraestrutura de internet, ou seja, de um ou mais servidores para prover tanto acesso à plataforma como funcionalidades de armazenamento. A estratégia de implementação foi elencar serviços capazes de suportar a arquitetura, os padrões e tecnologias utilizados, além de respeitar as restrições de recursos do projeto.

A seleção de serviços e fornecedores fundamentou-se, portanto, em dois critérios principais. Devido à restrição de recursos financeiros para o projeto, o critério de custo foi priorizar opções que provessem maior desempenho e/ou armazenamento por menos investimento. Devido à restrição de recursos humanos, o segundo critério foi priorizar opções que propiciassem maior agilidade de implementação e manutenção, mantendo o foco da equipe no desenvolvimento das funcionalidades mais cruciais.

\subsubsection{Processo de avaliação de serviços de computação em nuvem}

Conforme abordado na seção 4.2.2, foram desenvolvidos ao longo do projeto diversos protótipos, visando avaliar a complexidade de implementação de tecnologias, arquiteturas, plataformas, frameworks, bem como garantir o alinhamento com a restrição de recursos disponíveis. Neste processo, também foram 
identificados e avaliados provedores de serviços de computação em nuvem como o Amazon Web Services (AWS), Heroku, IBM Bluemix, Microsoft Azure e Google Cloud. As definições e fundamentos sobre tecnologias de computação em nuvem podem ser consultados na seção 3.5.3.2.

O AWS tornou-se um lançador de tendências em serviços de nuvem e uma referência para outros provedores. O AWS também é o único laaS do mercado a oferecer uma solução de administração de serviços autônoma e integrada. Radosevic e Balatinac (2014) afirmam que o Elastic Compute Cloud (EC2), da AWS, provê o melhor serviço do mercado. Também é o serviço comercial mais usado e investigado em pesquisas acadêmicas, que, apesar de não possuir a estabilidade de desempenho exigida para aplicações científicas, quando comparado a clusters locais, é capaz de acomodar grids inteiros e infraestruturas paralelas de produção.

Assim, após testes preliminares, adotou-se o serviço laaS de servidores virtuais em nuvem Amazon EC2 (Amazon Web Services, [s.d.]a). O Amazon EC2 fornece vários tipos de máquinas virtuais, cada uma com características únicas (capacidade de CPU, capacidade de memória RAM e capacidade de armazenamento), cujos custos e especificações atualizadas são disponibilizados no site do provedor (Amazon Web Services, [s.d.]c).

Por questões de escala e redução de custos operacionais, optou-se por consolidar toda a infraestrutura de servidores da aplicação em uma única instância, abordagem que limita a escalabilidade horizontal da infraestrutura. Utilizando uma instância do tipo small (EC2 ID: t2.small - 2 GB RAM, 1 núcleo, volume EBS de armazenamento de 160 GB, na região de São Paulo) baseada no sistema operacional CentOS 5 (Linux 64 bits), foram criados e administrados os serviços de hospedagem web, onde eram executados os códigos no servidor, entregue o front-end do site e também a instância do bando de dados MongoDB. O custo médio mensal desses serviços no 9 semestre de realização desta pesquisa (ver conograma na seção 2.6.2) era de USD\$20.

Apesar dos benefícios de customização e maior autonomia no quesito escalabilidade, a administração das instâncias era uma atividade que consumia tempo sem agregar valor ao processo de desenvolvimento. A restrição de recursos humanos para conduzir estas atividades, bem como de recursos financeiros para aumentar a escala quando necessário, sempre foram fatores limitantes na 
extração dos benefícios típicos dos serviços de computação em nuvem. Concluiuse, portanto, que, em vez de um serviço do tipo laaS, seria adotado um serviço do tipo PaaS de plataforma de desenvolvimento em nuvem, que diminuísse os custos e permitisse à equipe de desenvolvimento focar na construção de requisitos funcionais da aplicação.

Testou-se, neste conceito, a plataforma BlueMix da IBM, que possui componentes prontos e pacotes preconfigurados de simples utilização, com integração automática. Apesar de serem serviços típicos de um PaaS, a plataforma se mostrou bastante intuitiva e amistosa ao usuário. No entanto, não se mostrou robusta e madura o suficiente para adoção imediata. A equipe de desenvolvimento julgou que se trata de um serviço promissor, mas ainda em desenvolvimento, especialmente no Brasil.

Após uma série de testes e estudos, concluiu-se que o mecanismo de Dynos, tecnologia de virtualização por particionamento (containers) do Heroku, provia uma abordagem simplificada e otimizada para criar, manter e escalar aplicações. Neste momento, adotou-se também a estratégia de migrar a implementação em banco de dados MongoDB para um add-on Heroku PostgreSQL. Além da vantagem da abstração do nível de infraestrutura também do banco de dados, esta abordagem permitia uma implementação híbrida do esquema de banco de dados, resultando em uma combinação das melhores características dos paradigmas NoSQL e relacional, em um banco de dados robusto e estável.

Existe atualmente no mercado uma grande quantidade de serviços de PaaS, disponibilizando tecnologias inovadoras e acessíveis. Dentre essas plataformas, destacam-se RedHat Openshift, Engine Yard e Amazon Elastic Beanstack. Devido aos atuais requisitos da aplicação, isenção quase total dos custos da aplicação na plataforma Heroku e menor maturidade das alternativas, não existe atualmente intenção do time de desenvolvimento em migrar da plataforma.

\subsubsection{Instância de roteamento e resolução de DNS}

Utilizou-se o Amazon Route 53 (Amazon Web Services, [s.d.]b) como serviço laaS de resolução DNS para rotear os acessos aos domínios cw.gl, crystalwalk.com e crystalwalk.org à instância final da aplicação em crystalwalk.herokuapp.com. Para o uso específico da aplicação, o custo é de USD\$0,4 por milhão de requisições (Amazon Web Services, [s.d.]d). 
O serviço implementado foi o Route 53 Hosted Zones com Standard Queries, utilizando-se os parâmetros de configuração descritos na TAB. 11. O redirecionamento da raiz do domínio cw.gl é feito com o suporte do Amazon S3.

TABELA 11 - Parâmetros de configuração das instâncias de roteamento e resolução de DNS no serviço (laaS) Amazon Route 53.

\begin{tabular}{|l|l|l|}
\hline \multicolumn{3}{|c|}{$\begin{array}{l}\text { PARÂMETROS DE CONFIGURAÇÃO DAS INSTÂNCIAS DE ROTEAMENTO E } \\
\text { RESOLUÇÃO DE DNS NO SERVIÇO (IAAS) AMAZON ROUTE 53 }\end{array}$} \\
\hline Nome/host & Tipo de registro & \multicolumn{1}{l|}{ Valor/resposta/destino } \\
\hline cw.gl. & A & s3-website-us-east-1.amazonaws.com \\
\hline cw.gl. & NS & $\begin{array}{l}\text { ns-70.awsdns-08.com } \\
\text { ns-1869.awsdns-41.co.uk } \\
\text { ns-989.awsdns-59.net } \\
\text { ns-1241.awsdns-27.org }\end{array}$ \\
\hline cw.gl. & SOA & $\begin{array}{l}\text { ns-1869.awsdns-41.co.uk } \\
\text { awsdns-hostmaster.amazon.com } \\
\end{array}$ \\
& & 1 7200 900 1209600 86400 \\
\hline www.cw.gl & CNAME & cw.gl \\
\hline
\end{tabular}

Fonte - do autor.

\subsubsection{Instância de plataforma de desenvolvimento em nuvem}

Utilizou-se o Heroku como serviço PaaS de plataforma de desenvolvimento em nuvem para os servidores de aplicação Puma (Rack e Ruby on Rails), conforme ilustrado na FIG. 50.

O serviço foi implementado utilizando-se dois Web Dynos, cada um com um servidor de aplicações Puma, sendo um voltado à provisão dos arquivos da aplicação CWAPP e outro responsável pela viabilização do ambiente de execução para a aplicação CWLY (TAB. 12).

Utilizou-se o Dyno do tipo free (Heroku Dev Center, 2016a), gratuito para até 18 horas de execução diárias e custando USD $\$ 0,05$ por hora excedente. 0 Dyno free é um container de aplicação que possui 512 MB de memória RAM, processador compartilhado (não dedicado), e requer um tempo de hibernação (sleep) de no mínimo 6 horas por dia (Heroku Dev Center, 2016a). O conceito de container é abordado na seção 3.5.3.2.2 deste trabalho.

Entretanto, essa categoria de cobrança possui uma restrição de disponibilidade na qual o servidor de aplicação mantém-se em estado de espera para no- 
vas requisições durante o período de uma hora. Caso não haja novas requisições durante este intervalo, a plataforma Heroku finaliza o processo, colocando o Dyno em um estado de hibernação. Por esta razão, as aplicações CWAPP e CWLY podem demorar alguns segundos (Heroku Dev Center, 2016b), para responder à requisição do usuário, devido ao tempo necessário para que o servidor de aplicação inicialize novamente, restaurando o estado ativo do Dyno. (Pundsack, 2013).

TABELA 12 - Parâmetros dos Web Dynos utilizados no serviço (PaaS) na plataforma Heroku.

\begin{tabular}{|l|l|l|l|}
\hline \multicolumn{3}{|c|}{ PARÂMETROS DOS WEB DYNOS UTILIZADOS NO SERVIÇO (PAAS) NA PLATAFORMA HEROKU } \\
\hline Componente & URL & Tipo de Dyno & Categoria de cobrança \\
\hline CWLY & https://cwgl.herokuapp.com & $\begin{array}{l}\text { Web Dyno Puma } \\
\text { Ruby on Rails }\end{array}$ & Free \\
\hline CWAPP & https://crystalwalk.herokuapp.com & $\begin{array}{l}\text { Web Dyno Puma } \\
\text { Rack }\end{array}$ & Free \\
\hline CWD3 & http://cwd3.herokuapp.com/ & $\begin{array}{l}\text { Web Dyno Puma } \\
\text { Rack }\end{array}$ & Free \\
\hline
\end{tabular}

Fonte - do autor.

\subsubsection{Instância de banco de dados}

Utilizou-se o add-on Heroku PostgreSQL (Heroku, [s.d.]) como serviço PaaS de Banco de Dados PostgreSQL para o fornecimento integrado deste serviço em sua plataforma, conforme especificado na FIG. 59.

O add-on foi implementado utilizando-se as variáveis de esquema do banco de dados para o tipo jsonb, tornando possível o armazenamento de dados no formato JSON/NoSQL (PostgreSQL Global Development Group, [s.d.]). EscoIheu-se o add-on do tipo Hobby Dev, gratuito, para a criação de bancos de dados de até 10 mil registros. Por questões de segurança, o firewall do módulo de segurança foi configurado para restringir o acesso ao servidor de banco de dados exclusivamente à API de persistência.

\subsubsection{Instância de repositório e versionamento de código}

Fundamentando-se nos princípios de código livre e modelo colaborativo de produção intelectual, o código-fonte do CrystalWalk foi disponibilizado integralmente em repositório público sob os termos da licença MIT. 
Para tanto, utilizou-se a ferramenta Git como sistema de controle de versão distribuído e o SaaS Github como serviço de repositório do código-fonte do projeto. Optou-se por esta plataforma por sua disponibilidade, escalabilidade, gerenciamento, custo e integração nativa com o repositório do Heroku (Heroku Dev Center, 2015). O serviço foi implementado criando-se 4 repositórios principais, descritos na TAB. 13.

TABELA 13 - Repositórios de código do CrystalWalk, disponibilizados através do serviço (SaaS) Github.

\begin{tabular}{|c|c|c|}
\hline \multicolumn{3}{|c|}{$\begin{array}{l}\text { REPOSITÓRIOS DE CÓDIGO DO CRYSTALWALK, } \\
\text { DISPONIBILIZADOS ATRAVÉS DO SERVIÇO (SAAS) GITHUB }\end{array}$} \\
\hline Aplicação & Repositório & Instância/endereço de demonstração \\
\hline CWAPP & https://github.com/gvcm/cwapp & https://crystalwalk.herokuapp.com \\
\hline CWLY & https://github.com/gvcm/cwly & http://cw.gl/0 \\
\hline CW4P & https://github.com/gvcm/cw4p & https://cw4p.herokuapp.com \\
\hline CWD3 & https://github.com/gvcm/CWD3/ & http://cwd3.herokuapp.com/ \\
\hline
\end{tabular}

Fonte - do autor.

A integração com o repositório foi realizada através dos parâmetros de deploy do Dyno, nativos do Heroku. Isso permitiu configurar o Dyno para atualizar-se automaticamente a cada publicação, obtendo-se, assim, as vantagens de redução do tempo de publicação, maior agilidade e automação, minimizando riscos de falhas.

\subsection{Resultados}

Retomando a estratégia metodológica detalhada no capítulo 2, devido à natureza tanto prática como social deste trabalho, justifica-se a adoção de uma postura filosófica científica multilateral. No entanto, a pesquisa-ação é a espinha dorsal da metodologia, e a postura construtivista toma papel central, determinando, em último caso, como os resultados deste trabalho devem ser validados.

De forma a contemplar os variados métodos adotados neste trabalho (capítulo 2), a exibição e análise dos resultados será realizada também em variadas frentes de avaliação, a saber: avaliação de implementação (seção 4.5.1), avaliação comparativa (seção 4.5.2), testes de síntese e visualização (seção 4.5.3), 
avaliação de interface (seção 4.5.4), avaliação de funcionalidades didáticas (seção 4.5.5), avaliação de possibilidades interativas (seção 4.5.6) e avaliação de empoderamento dos atores sociais (seção 4.5.7).

\subsubsection{Avaliação de implementação}

Conforme delineado na seção 2.4.3.2, a avaliação de implementação adota elementos do pragmatismo, procurando validar a eficácia da solução tecnológica frente ao problema colocado, especialmente no tocante ao item 1 do questionário tecnológico (APÊNDICE A). Para dar suporte a essa análise, será abordado também o sucesso da implementação, em caráter preliminar, de instâncias funcionais de todas as aplicações da plataforma CrystalWalk (CW4P, CWAPP e CWLY) em termos de capacidade e disponibilidade, além do desempenho do aplicativo em si. Todos os pontos desta avaliação podem ser avaliados objetivamente.

Uma instância do aplicativo CWLY foi implementada com sucesso no serviço PaaS Heroku, utilizando-se um Dyno gratuito do tipo web com servidor de aplicação Puma e add-on PostgreSQL do tipo Hobby Dev, em um esquema de banco de dados híbrido NoSQL/relacional, conforme as especificações detalhadas em 4.3.2. Registrou-se um domínio específico (cw.gl), que foi configurado com sucesso no serviço laaS de resolução de DNS Amazon Route 53 ao custo de USD $\$ 0,4$ por milhão de requisições.

Essa instância do aplicativo CWLY demonstrou-se funcional e fluída nos testes preliminares, atestando que tanto o encurtador de URL e o serviço de roteamento de domínio (Amazon Route 53) como o sistema de salvamento e restauração de sessões foram implementados corretamente, comprovando que os serviços de roteamento de domínio e servidor web foram configurados corretamente. Verificaram-se todas as rotas da interface REST da API de persistência da aplicação, atestando o armazenamento e recuperação dos documentos JSON no banco de dados.

Uma instância do aplicativo CWAPP foi implementada com sucesso no serviço PaaS Heroku, utilizando-se um Dyno gratuito do tipo web com servidor de aplicação Puma. Por ser uma aplicação-extensão do framework CW4P, considera-se também que a arquitetura proposta implementou com sucesso a especificação AMD através da biblioteca RequireJS; o padrão publish-subscribe através da 
biblioteca PubSubJS, e a tecnologia WebGL através da biblioteca three.js, conforme as especificações detalhadas na seção 4.3.2.3.

Conforme discutido na seção 3.5.3.3.1.2, WebGL é uma especificação, cuja implementação tecnológica ainda é bastante emergente. Não houve, portanto, uma preocupação formal em rastrear o suporte a todos os recursos e funcionalidades da aplicação em todos os dispositivos e navegadores existentes. Por isso, adotou-se como plataforma padrão de desenvolvimento computadores de mesa com a seguinte especificação mínima: processador com núcleo simples (ex: Intel Celeron de 1.6 GHz, AMD Sempron, 1.6 GHz), 2 GB de memória RAM e placa de vídeo com suporte a OpenGL ES 3.0 (Intel HD Graphics, a partir de 2011) e o navegador Chrome em sistemas operacionais Windows, Mac OS X e Ubuntu, por prover o suporte mais robusto a HTML5 a estas plataformas (TAB. 2).

Entretanto, esta instância do aplicativo CWAPP demonstrou-se funcional e responsiva nos testes preliminares, verificando-se a portabilidade da aplicação através de testes de acesso e execução em desktops e dispositivos móveis, nas versões mais recentes dos sistemas operacionais Windows, Mac OS X, Ubuntu, iOS e Android. Foram testadas as versões mais recentes dos navegadores Internet Explorer, Edge, Chrome, Firefox, Safari e Opera. Testes em dispositivos móveis foram conduzidos em celulares e tablets Android e Apple, utilizando os navegadores Chrome, Firefox e Safari. De forma consistente com os resultados observados em Deveria ([s.d.]), constatou-se que as versões mais recentes (em novembro de 2015) dos navegadores IE, Firefox, Chrome e Safari, cujo suporte à especificação HTML5 é mais robusto, tiveram melhor desempenho nos testes de compatibilidade. No caso dos dispositivos móveis, apesar do suporte a essas plataformas ainda ser bastante precário, foi possível executar a aplicação nos navegadores Safari e Chrome em dispositivos que suportam o OpenGL ES 3, tal como o iPhone 5.

Observou-se a correta implementação da interface Ruby com o servidor web e entrega dos arquivos da aplicação, carregados em sequência a partir da página e módulos base definidos pelo framework CW4P, consumindo $328 \mathrm{~KB}$ de dados. Em seguida, inicializados pelo módulo roteador, carregaram-se os outros componentes da aplicação, incluindo módulos e bibliotecas de interface, consumindo 6,6 MB de dados. Os componentes restantes, totalizando 8,4 MB, foram carregados em resposta a funcionalidades específicas, requisitados pela interface 
do usuário através do carregamento assíncrono e sob demanda dos módulos da aplicação. Conforme colocado anteriormente, o Dyno pode hibernar após um período de 30 minutos de inatividade. Neste caso, testes confirmaram um tempo de retorno à atividade de aproximadamente 10 segundos.

Observou-se que a aplicação foi executada de maneira estável e responsiva para a maioria das operações e funcionalidades testadas, demonstrando a eficácia da implementação do paradigma reativo por meio da orientação a eventos, responsividade, elasticidade e resiliência da aplicação. Apesar de esporádicos, experimentaram-se travamentos durante a execução de funcionalidades que requerem uso intensivo de recursos computacionais, tais como a replicação de grandes números de átomos e a computação de geometrias diferenciais utilizadas na representação de átomos parciais. Conforme mencionado anteriormente, atribuíram-se essas instabilidades à imaturidade das tecnologias WebGL. Como modo de minimizar efeitos indesejáveis, alertas são exibidos aos usuários advertindo e confirmando a execução destas funções.

\subsubsection{Avaliação comparativa}

A avaliação comparativa é o principal método de avaliação deste trabaIho. Em uma pesquisa-ação, a avaliação final dos resultados deve verificar, com base nas impressões dos atores sociais, em que grau o problema social colocado foi atendido.

Valendo-se dos processos de levantamento bibliográfico, de levantamento sistemático e de uma ampla e explícita interação com os atores sociais, foram identificados os principais problemas (APÊNDICE D) e produzida uma lista de requerimentos funcionais, resultado principal da primeira fase da pesquisaação (seção 2.4.1.1). Estas características foram também utilizadas na configuração dos parâmetros dos questionários da análise sistemática (seção 2.4.1.3.1.5.1 e APÊNDICE B).

O grau de atendimento ao problema social foi calculado somando-se os pontos dos parâmetros atendidos pela solução e comparando-os com a solução ideal, considerada aqui a soma total dos parâmetros. Considerou-se que o grau de atendimento é superior se o software atender mais itens dessa lista. Deve ser frisado que não foi adotado nenhum mecanismo de ponderação dos itens, ou seja, todos eles possuem o mesmo valor. Julgou-se propício também comparar a 
solução com os melhores softwares cristalográficos segundo a revisão sistemática, considerando os três melhores de cada grupo de critérios, evitando vieses na avaliação. A comparação foi realizada por meio de um software baseado na biblioteca D3 (Bardella et al., 2016a), capaz de gerar diagramas interativos do tipo bubble chart (FIG. 49, seção 3.4.2).

Nesta análise, foram seguidas as recomendações de Creswell (2002) para validação de pesquisas construtivistas (seção 2.3.2).

Os parâmetros da avaliação são apresentados e detalhados no APÊNDICE B, e os dados completos resultantes da avaliação são apresentados e detalhados no APÊNDICE C, no formato de tabelas, divididas segundo cada grupo de critérios:

- TAB. 1, APÊNDICE C: critérios tecnológicos

- TAB. 2, APÊNDICE C: critérios de síntese

- TAB. 3, APÊNDICE C: critérios de visualização

- TAB. 4, APÊNDICE C: critérios de navegação e interatividade

- TAB. 5, APÊNDICE C: critérios didáticos

Os resultados mais significativos da avaliação são apresentados a seguir, nas seções 4.5.2.1 a 4.5.2.5. Além disso, na FIG. 83 (seção 4.5.2.6), são apresentados também os principais resultados dessa avaliação, porém ainda mais sumarizados, na forma gráfica.

\subsubsection{Avaliação comparativa segundo parâmetros tecnológicos}

Pela avaliação segundo parâmetros tecnológicos, havia um total de 17,5 pontos possíveis. Analisando-se os resultados dessa avaliação, observa-se que o CrystalWalk foi avaliado com a pontuação máxima, sendo o mais bem posicionado dentre os softwares analisados e tendo conseguido implementar todos os requerimentos de especificação propostos. O bom desempenho era esperado, pois as opções tecnológicas em seu desenvolvimento estiveram em sintonia com as características, filosofias e princípios do projeto. Em seguida, destacaram-se JMOL15 e SHEL15 (7,5 pontos) e CMAK15, DRAW11, PYMO18, QUTE07, SCHA14 e XCRY14 (5 pontos). Os dados completos dessa avaliação podem ser vistos na TAB. 1 - APÊNDICE C e em Bardella et al. (2016a). 
Quanto ao critério portabilidade da aplicação (critério 1.3), o CrystalWalk destacou-se sobretudo devido ao uso da tecnologia WebGL (subcritério 1.3.1), que, além de não requerer nenhum tipo de instalação (subcritério 1.3.3), viabilizou uma plataforma de computação gráfica 3D independente de dispositivo ou sistema operacional do cliente (subcritérios 1.3.4 e 1.3.2), características inéditas quando comparado com outros softwares. Neste quesito, o JMOL15, que utiliza a plataforma Java, também foi destaque, porém tem sua portabilidade comprometida por requerer a instalação de plug-ins específicos e não ser compatível com dispositivos móveis, como celulares e tablets. Na verdade, todos os softwares que visam compatibilidade com dispositivos móveis enfrentam problemas, seja com os plug-ins ou com variações no hardware e nas implementações de padrões nos navegadores. Como discutido anteriormente na avaliação de implementação (seção 4.5.1), não é possível garantir que o CrystalWalk funcionará em qualquer dispositivo móvel, principalmente nos mais antigos, devido às diferenças de suporte ao HTML 5 e ao WebGL, tanto no navegador como no hardware.

No critério licença de uso, distribuição e modificação (critério 1.5), o CrystalWalk destacou-se devido à sua proposta de democratização do conhecimento e da educação livre, o que fundamentou a disponibilização integral de seu código-fonte sob os termos da licença MIT (subcritério 1.5.1), e a escolha do GitHub como repositório de distribuição e plataforma de desenvolvimento colaborativo do projeto (subcritério 1.5.2). Neste quesito, apesar de não explicitarem uma proposta similar, outras plataformas também disponibilizam seu código-fonte e arquivos binários sob licenças permissivas semelhantes, como é o caso de JMOL15, SHEL15, QUTE07, SCHA14 e XCRY14. Entretanto, apenas JMOL15, SHEL15 e QUTE07 adotam um modelo de desenvolvimento colaborativo, o que limita o envolvimento de possíveis interessados no desenvolvimento dos softwares. Claro que a contribuição efetiva de membros voluntários depende de atividades de promoção e engajamento. Após a formação de uma comunidade interessada no desenvolvimento do CrystalWalk, provavelmente formada por professores da área de ciência dos materiais, estudantes, programadores e entusiastas, acredita-se que as atividades de desenvolvimento se tornarão autossustentadas, como observado em projetos similares, a exemplo do JMOL15. Acredita-se que projetos desse tipo sobrevivem apenas se essa massa critica de apoiadores se formar.

Por fim, no critério de suporte a tecnologias de interface, o CrystalWalk 
destacou-se por ter conseguido a integração de dispositivos de interface avançados dentro da plataforma WebGL, tais como interfaces gestuais e interfaces imersivas, como capacetes de realidade virtual (HMD) - este último, mais uma das características inéditas do CrystalWalk. Mantendo a coerência com a proposta de democratização do conhecimento e educação livre, foram escolhidos dispositivos acessíveis e de baixo custo, tal como o Leap Motion e o Oculus Rift (seção 4.3.3.3). Apenas o CMAK15 provê suporte ao Leap Motion, e o PYMO18, aparentemente, suporta uma solução proprietária (plug-in + hardware) de HMD da empresa Virtalis (Virtalis, [s.d.]), mas foi constatado que se trata de uma solução experimental descontinuada, nunca disponibilizada ao público.

Em termos gerais, a avaliação dos parâmetros tecnológicos dos softwares existentes foi considerada ruim perante as expectativas dos atores sociais. Essa avaliação negativa deve-se principalmente à baixa portabilidade das aplicações existentes (critério 1.3), licença de uso, distribuição e modificação prioritariamente comerciais (critério 1.5), e a falta de suporte a dispositivos de interface avançados tais como trackeables e HMDs (critério 1.6). Existe a expectativa de que a tecnologia seja capaz de incentivar a democratização do conhecimento através da educação à distância e do ensino livre, viabilizando a realização de atividades educacionais em outros locais (fora da sala de aula), horários e/ou por meio da internet e promover a aprendizagem cooperativa e interativa e a participação mais ativa do estudante, estimuladas pelos ambientes virtuais.

\subsubsection{Avaliação comparativa segundo parâmetros de síntese}

Pela avaliação segundo parâmetros de síntese, havia um total de 10 pontos possíveis. Analisando-se os resultados dessa avaliação, observa-se que o CrystalWalk foi avaliado com a pontuação máxima, sendo o mais bem posicionado dentre os softwares analisados e tendo conseguido implementar todos os requerimentos de especificação propostos. O desempenho superior deve-se à metodologia de síntese inédita proposta neste trabalho e implementada no CrystalWalk, cujo objetivo é se afastar das complexidades dos grupos espaciais e posições de Wyckoff adotados por muitos cristalógrafos e por todos os softwares analisados, um paradigma pouco didático, conforme analisado na seção 3.4. Tal desempenho ainda denota que as opções tecnológicas tomadas durante o processo desenvolvimento estiveram em sintonia com as características, filosofias e 
princípios do projeto. Em seguida, destacaram-se CMAK15, JMOL15, VEST14, CARI04, BALL08, LATT04 (5 pontos). Todos os outros softwares tiveram 2,5 pontos ou menos. Os dados completos dessa avaliação podem ser vistos na TAB. 2 APÊNDICE C e em Bardella et al. (2016a).

Nos critérios de método (critério 2.1) e processo interativo (critério 2.2) de síntese, o CrystalWalk destacou-se devido a sua proposta didática, adotando um novo método visual e interativo baseado no conceito de redes de Bravais e motivo, melhor alinhado com a metodologia de ensino aplicada em cursos de ciência dos materiais.

O critério de restrição à síntese (critério 2.3) indicou que nem todos os softwares cristalográficos são integrados. Alguns dependem de outras aplicações para síntese, como é o caso do SHEL15, que requer o software ShelX. Outros, ainda, são restritos à exibição de dados cristalográficos parametrizados externamente à aplicação, como no caso do PYMO18 e QUTE07.

Por fim, no critério de seleção e edição de átomos (critério 2.4), o CrystalWalk destacou-se por possibilitar a edição dos parâmetros visuais tanto de átomos individuais como de átomos do motivo, recurso que visa facilitar a interpretação espacial de estruturas cristalinas. Observou-se que os softwares melhor avaliados no questionário de visualização também proviam suporte a este parâmetro em específico, como CMAK15, JMOL15 e VEST14. Entretanto, como consequência do método de síntese exclusivo adotado no CrystalWalk, a edição dos parâmetros visuais de átomos do motivo manteve-se uma característica exclusiva.

Em termos gerais, a avaliação dos parâmetros de síntese dos softwares existentes foi considerada ruim perante as expectativas dos atores sociais, fator atribuído principalmente ao método de síntese (critério 2.1) utilizado pelos softwares existentes. Este, além de pouco interativo (critério 2.2), requer que o usuário forneça os parâmetros de grupos pontuais e espaciais da estrutura, entendimento comumente restrito a cristalógrafos e pesquisadores da área. Existe a expectativa de que ferramentas cristalográficas didáticas sejam interativas, acessíveis e que viabilizem um processo de síntese simplificado e alinhado com a utilização didática, ao menos para estruturas mais simples utilizadas como ferramenta de ensino em sala de aula. Espera-se que o modelo de síntese do CrystalWalk cumpra esse requisito. Tanto a criação de um modelo teórico de síntese de estruturas cristalinas como sua implementação não são tarefas triviais. É 
possível que nem todos os tipos de estrutura sejam implementados ou que o sejam de maneira experimental, em razão de dificuldades metodológicas ou de limitações tecnológicas das bibliotecas e plataformas. Apesar de baseado em sólida revisão da literatura e na experiência do GVCM, é possível que o método simplificado de síntese proposto não impacte como esperado no aprendizado, o que será indicado pelos testes preliminares que serão conduzidos na sequência e que fornecerão indicações da eficiência da abordagem.

\subsubsection{Avaliação comparativa segundo parâmetros de visualização}

Pela avaliação segundo parâmetros de visualização, havia um total de 30 pontos possíveis. Analisando-se os resultados dessa avaliação, observa-se que o CrystalWalk foi avaliado com a pontuação máxima, sendo o mais bem posicionado dentre os softwares analisados e tendo conseguido implementar todos os requerimentos de especificação propostos. Em seguida, destacaram-se CMAK15 e VEST14 (20 pontos) e JMOL15 e DIAM15 (17,5 pontos). Mais da metade dos softwares analisados ficaram com 5 pontos ou menos. Os dados completos dessa avaliação podem ser vistos na TAB. 3 - APÊNDICE C e em Bardella et al. (2016a).

No critério de representação (critério 3.1), o CrystalWalk destacou-se devido ao alinhamento com materiais didáticos utilizados nos cursos de ciência dos materiais, destacando-se a adoção do modelo atômico molecular de esferas rígidas (critério 3.1) e a representação de interstícios da célula unitária (critério 3.2), características inéditas quando comparadas aos demais softwares. $O$ CrystalWalk destacou-se também por disponibilizar mecanismos de representação cruciais no processo de aprendizagem, tais como bordas e faces da célula unitária (subcritério 3.1.5.4), vetores do eixo da rede (subcritério 3.1.5.3), planos (subcritério 3.1.3) e direções (subcritério 3.1.4) de Miller, cortes e projeções (subcritério 3.5.1.2) e células múltiplas (subcritério 3.1.5.1). Apesar dos softwares CMAK15, VEST14 e JMOL15 também disponibilizarem alguns destes recursos, estas funcionalidades são colocadas em segundo plano, comprometendo não apenas a interatividade e acessibilidade, mas também a possibilidade de uso da ferramenta por estudantes.

Por fim, no critério de visualização (critério 3.2), o CrystalWalk destacou-se por explorar as possibilidades da computação gráfica no contexto didático, buscando estimulo da percepção visual e auditiva (subcritério 3.2.1) por meio de 
uma variedade de técnicas de perspectiva (subcritério 3.2.2), estereografia (subcritério 3.2.3) e renderização (subcritério 3.2.4). Apesar de compartilhar mecanismos e ferramentas de visualização com alguns outros softwares, julga-se inédita a combinação delas, permitindo, por exemplo, a produção de conteúdo didático pelo professor e/ou a extração de material gráfico para ilustrar de publicações científicas de pesquisadores (FIG. 105).

Em termos gerais e perante as expectativas dos atores sociais, a avaliação dos parâmetros de visualização dos softwares existentes situa-se entre mediana e ruim, principalmente em razão da baixa adequação dos recursos existentes, quando comparados com as representações comumente utilizadas nos livros e materiais didáticos. Existe a expectativa de que ferramentas cristalográficas didáticas sejam capazes de criar visualizações versáteis, que permitam recriar problemas apresentados em sala de aula, expor as dúvidas dos estudantes e estimular questionamentos. Julga-se que maior impacto na eficiência didática depende mais da integração das funcionalidades de visualização em um sistema coerente. Desta forma, o desafio não está na implementação isolada, mas na integração das ferramentas, devido à falta de referências e ao ineditismo de algumas delas. O comportamento do sistema de visualização como um todo por, bem como a qualidade da integração proposta, foram avaliados por meio de testes de síntese e visualização (seção 4.5.3).

\subsubsection{Avaliação comparativa segundo parâmetros de navegação e interatividade}

Pela avaliação segundo parâmetros de navegação e interatividade, havia um total de 17,5 pontos possíveis. Analisando-se os resultados dessa avaliação, observa-se que o CrystalWalk foi avaliado com 15 pontos, ao implementar 6 dos 7 requerimentos da especificação, sendo o mais bem posicionado dentre os softwares analisados. Em seguida, destacam-se CMAK15 (10 pontos) e JMOL15, PYMO18, BALL08 e ATOM11 (7.5 pontos). Mais da metade dos softwares ficou com 5 pontos ou menos. Os dados completos dessa avaliação podem ser vistos na TAB. 4 - APÊNDICE C e em Bardella et al. (2016a).

Nos critérios de interface (critério 4.1) e interação base (critério 4.2), o CrystalWalk destacou-se por prover uma interface gráfica e ordenada classificada como amigável, e utilizar zoom, translação e rotação como interação base no pro- 
cesso de investigação e manipulação dos objetos do mundo virtual. Estes critérios, qualificados como fundamentais, também foram atendidos por outros softwares analisados, tais como CMAK15, BALL08 e ATOM11.

Nos critérios de interação avançada (critério 4.3), o CrystalWalk destacou-se por prover suporte a certas funcionalidades consideradas, neste trabalho, superiores em termos didáticos. Entre elas, estão as animações guiadas (subcritério 4.3.1), a transição guiada de escala (subcritério 4.3.3) e os pontos de vista guiados por planos e direções cristalográficas ou centrados em átomos (subcritério 4.3.5), viabilizando interações inéditas em softwares cristalográficos, visando facilitar a construção de conceitos no contexto do processo de aprendizagem.

O gerenciamento dinâmico de oclusões (subcritério 4.3.4), apesar de ter sido incluído como parte da especificação proposta, encontra-se em processo de desenvolvimento. Apesar dessa limitação atual, o CrystalWalk provê suporte a rotações automáticas em torno de um eixo definido pelo usuário (subcritério 4.3.1). O gerenciamento de oclusões (subcritério 4.3.4), apesar de bastante comum em ferramentas de modelagem 3D como o SolidWorks (Dassault Systemes Solidworks Corporation, [s.d.]), é tido como inédito em softwares cristalográficos e promete ser muito útil na exploração de estruturas cristalinas.

Em termos gerais, a avaliação dos parâmetros de síntese dos softwares existentes foi considerada ruim perante as expectativas dos atores sociais. Essa má avaliação pode ser atribuída principalmente à falta de adequação dos recursos existentes, principalmente quando comparados com as interfaces e recursos atualmente disponíveis em softwares de modelagem 3D e outras plataformas interativas existentes. Em suma, além de grande parte dos softwares apresentarem interfaces de usuário pouco amigáveis, baseadas em texto (CLI) e/ou não ordenadas (critério 4.1), as possibilidades de interação são muito limitadas, o que cria barreiras ao processo de aprendizagem e à participação ativa do estudante.

Mais uma vez, aqui, deve-se pontuar que a qualidade de interação depende mais da integração de funcionalidades em um todo coerente e bem ordenado. Além disso, existem diversos desafios na implementação de novas tecnologias de interação em plataformas imaturas. Novamente, apesar de fundadas em princípios cognitivos, a eficiência didática e a integração das soluções só podem ser avaliadas por testes que abordem os principais problemas didáticos levantados neste trabalho. A descrição da condução de tais testes é apresentada na seção 4.5.3.2. 


\subsubsection{Avaliação comparativa segundo parâmetros didáticos}

Pela avaliação segundo parâmetros didáticos, havia um total de 25 pontos possíveis. Analisando-se os resultados dessa avaliação, observa-se que o CrystalWalk foi avaliado com a pontuação máxima, sendo o mais bem posicionado dentre os softwares analisados e tendo conseguido implementar todos os requerimentos de especificação propostos. Em seguida, destacaram-se CMAK15 (12,5 pontos) e JMOL15, DIAM15 e MERC15 (10 pontos). Aproximadamente metade dos softwares analisados ficaram com 5 ou menos pontos. Os dados completos dessa avaliação podem ser vistos na TAB. 5 - APÊNDICE C e em Bardella et al. (2016a).

No critério conhecimento requerido do usuário (critério 5.1), o CrystalWalk possibilita um processo interativo (subcritério 5.3.3), destacando-se por sua inédita abordagem didática, sendo o único software que requer apenas fundamentos de ciência dos materiais e geometria básica para criação e visualização de estruturas. Conceitos de cristalografia tais como grupos espaciais e operações de simetria são necessários nos outros softwares para abrir modelos prontos ou criar estruturas com parâmetros já conhecidos, mas é evidente a restrição imposta aos usuários que não detêm estes conhecimentos.

No critério suporte a publicações (critério 5.2), o CrystalWalk destacouse por prover suporte à geração de material de apoio didático e oara trabalhos científicos em diferentes mídias, como imagens bitmap para mídias impressas (subcritério 5.2.2), modelos STL para impressão 3D ou exploração em outros softwares 3D (subcritério 5.2.3) e a portabilidade completa da aplicação em HTML para incorporação em apresentações ou publicações digitais (subcritério 5.2.1). Consequência da arquitetura desenvolvida no CrystalWalk, através da instância pública da aplicação, é disponibilizada também uma plataforma de publicação de conteúdo na internet, característica inédita em comparação com os demais softwares. A publicação de imagens rasterizadas é comum entre a maioria dos softwares. Além do CrystalWalk, apenas o CMAK15 e o MERC15 criam modelos STL. A portabilidade completa também é suportada em dois softwares baseados em Java, mas requerem instalação do Java e, normalmente, alguns ajustes, o que pode representar um desafio para usuários com menor domínio.

No critério funcionalidades didáticas (critério 5.3), o CrystalWalk destacou-se por possibilitar a incorporação de anotações, links e imagens, animação de câmera e propriedades, provendo suporte à narrativa didática (subcritério 5.3.1). 
O CMAK15 possui um mecanismo similar de animação guiada, possibilitando a criação de roteiros didáticos por meio de rotas animadas, no entanto, de difícil utilização. Além disso, outro destaque é disponibilizar em sua instância pública uma biblioteca de exemplos (subcritério 5.3.2), na qual foram armazenadas as estruturas utilizadas neste trabalho, mas que será ainda estendida pelo pesquisador. A biblioteca poderá ser ampliada pelos usuários do software, seguindo o espírito do software livre e do desenvolvimento colaborativo. Estes critérios, qualificados como fundamentais, são parcialmente atendidos por alguns softwares, tal como CMAK15, DIAM15 e MERC15. O software CMAK15 destaca-se por possuir grande quantidade de exemplos em sua biblioteca e por permitir uma navegação simples e intuitiva, orientada a imagens ao invés de arquivos ou descrições textuais.

Por fim, no critério suporte e documentação (5.4), o CrystalWalk destacouse por incorporar tutoriais interativos (subcritério 5.4.2) diretamente em sua interface, guiando o usuário, caso ele assim deseje, no processo de criação de uma estrutura cristalina e de visualização básica dos modelos. Também existem links com orientações para os procedimentos de criação de uma instância da aplicação na internet, para usuários avançados e colaboradores de desenvolvimento. Objetiva-se prover suporte ao público em geral por meio de uma plataforma de registro e rastreio de bugs disponibilizada na plataforma de desenvolvimento colaborativo atualmente disponível, além de fornecer o contato do autor e dos principais desenvolvedores. Salvo algumas poucas exceções, estes critérios são bem atendidos por quase todas os softwares analisados, que contam com fóruns, listas de discussão e grupos de email, além de manuais de uso. No entanto, considera-se que o CrystalWalk provê suporte de maneira mais apropriada a aplicações didáticas, diminuindo a necessidade de recorrer a recursos externos ao próprio software.

Em termos gerais, a avaliação dos parâmetros didáticos dos softwares existentes foi considerada ruim perante as expectativas dos atores sociais, fator atribuído principalmente ao direcionamento de projeto desses softwares, que não contempla o uso em aplicações didáticas. Desta forma, exige-se um conhecimento incompatível com o grau de instrução do usuário, os recursos existentes não estão prontamente disponíveis, agrupados ou organizados e os mecanismos de suporte exigem muito esforço do usuário. Considera-se, portanto, que o sucesso didático depende não apenas das funcionalidades, mas de um projeto de interface que as integre de maneira específica. As funcionalidades mais essenciais nesse quesito limitam-se a fornecer 
suporte à inclusão de informações adicionais e, sobretudo, de maneira ordenada e contextualizada. No CrystalWalk, o mecanismo de anotações permite associá-las aoa elementos do modelo, como átomos, direções e planos, mas também às operações de visualização, de maneira organizada e alinhada com uma narrativa didática.

\subsubsection{Resultados gerais da avaliação}

Na FIG. 83, são apresentados os principais resultados da avaliação comparativa, ainda mais sumarizados, na forma gráfica. Essa representação mostra a superioridade da solução proposta em relação aos outros cinco softwares mais bem avaliados por meio da análise comparativa, tanto em relação a cada um dos cinco grupos de parâmetros como no geral.

$$
\begin{array}{ccccc}
\text { Geral Critérios } & \text { Critérios } & \text { Critérios de } & \text { Critérios de } & \text { Critérios } \\
\text { tecnológicos } & \text { de síntese } & \text { visualizaçãão } & \text { interatividade } & \text { didáticos }
\end{array}
$$

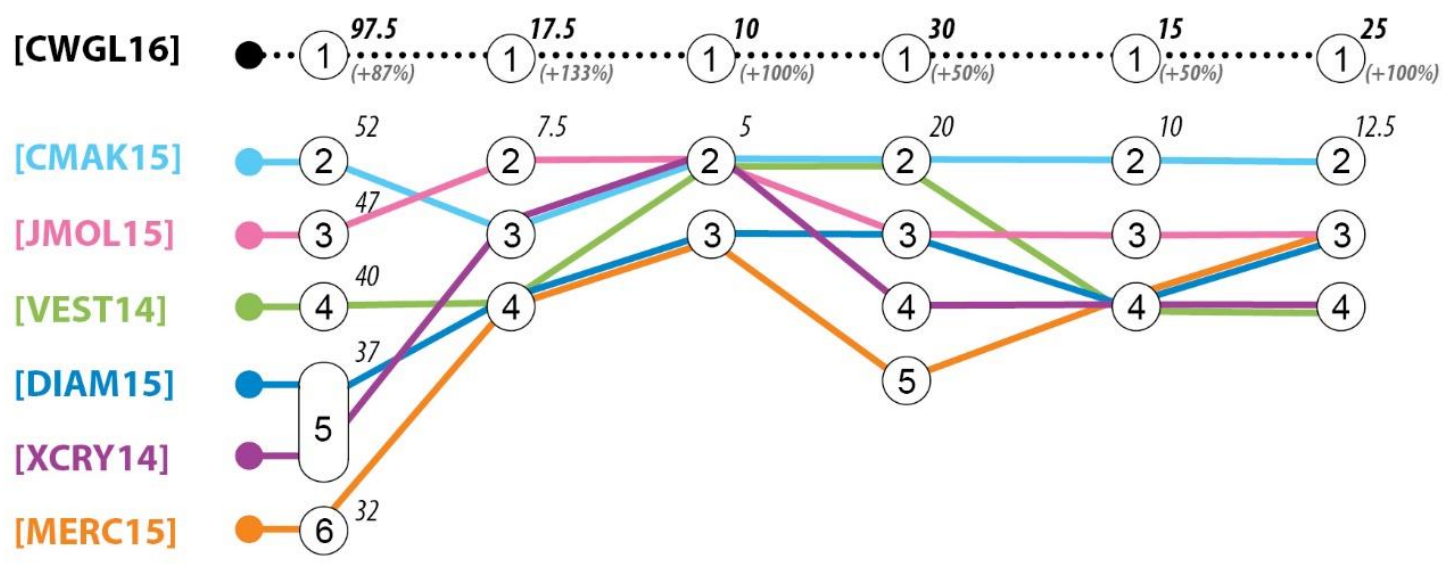

FIGURA 83 - Diagrama-síntese da avaliação comparativa. Fonte: do autor.

\subsubsection{Testes de síntese e visualização}

Para complementar a avaliação e mais compreensiva da ferramenta criada, também foram conduzidas avaliações dos procedimentos de síntese e visualização, abordando os dois pontos principais do problema de maneira mais integrada. Essas análises adotam, portanto, elementos do pragmatismo (seção 2.2), ao averiguar se a aplicação se comporta de fato como esperado e se os modelos de síntese e representação implementados apresentam as características desejadas, definidas nas especificações. Em linhas gerais, avaliou-se qualitativamente em que nível o sof- 
tware produzido diminuiu a dificuldade de criação de estruturas cristalinas e apoiou a visualização de elementos cruciais ao seu entendimento. As avaliações foram conduzidas na última fase do projeto e no contexto da pesquisa-ação, junto aos atores sociais. Ao longo desta seção, são apresentadas colocações de estudantes de disciplinas de graduação e pós-graduação (seção 4.1) junto aos quais foram conduzidas tais avaliações. Outros participantes sem conhecimento sobre o projeto foram convidados, para evitar vieses decorrentes da familiarização com o sistema.

\subsubsection{Síntese}

O primeiro ponto considerado foi a criação descomplicada de estruturas cristalinas. Considera-se que o sucesso nessa questão depende tanto da eficácia dos métodos de síntese e das funcionalidades do software como da clareza da interface da ferramenta. A eficácia de síntese foi atestada por uma comparação do método proposto neste trabalho com o utilizado nos softwares cristalográficos analisados no levantamento, exemplificados aqui pelos três melhores softwares no quesito síntese: CMAK15, JMOL15 e VEST14 (Bardella et al., 2016a). Foi avaliada a possibilidade ou a dificuldade de criação da estrutura a partir de dados de livros didáticos. A clareza da interface foi avaliada comparando a fluidez da sequência de passos, ou seja, quão fácil e intuitivo é encontrar as funcionalidades necessárias e quão bem visualmente encadeados estão os passos.

A FIG. 84 ilustra o modelo comumente adotado por autores consagrados da literatura no ensino de ciência dos materiais, tais como Callister e Rethwisch (2007), Kittel (1996) e van Vlack (1966). Nesse modelo, as estruturas cristalinas são conceituadas fundamentalmente em termos da rede cristalina e do posicionamento relativo entre os átomos que constituem sua célula unitária.

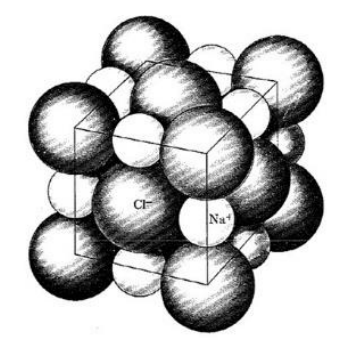

(a)

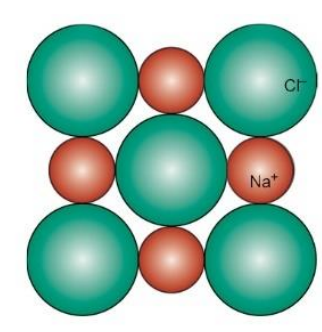

(b)

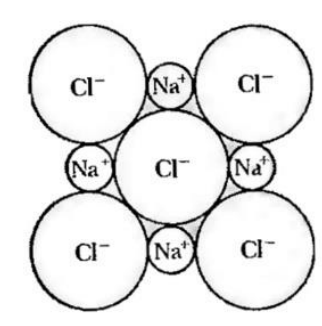

(c)

FIGURA 84 - Exemplos de ilustrações do $\mathrm{NaCl}$ em obras de referência clássicas (livros didáticos e correlatos). Fonte: (a) van Vlack (2007); (b) Callister e Rethwisch (1996); (c) Kittel (1966) (adaptado). 
Segundo esse modelo, átomos são representados por esferas rígidas com raios proporcionais aos raios iônicos da estrutura em questão, o que determina a geometria de empacotamento e, por consequência, os parâmetros de sua célula unitária. Os dados dos raios atômicos foram extraídos de Clementi et al. (1967) e os dos raios iônicos, de Shannon e Prewitt (1969). As cores foram provenientes da variante do modelo de coloração do CPK utilizado no Jmol (Jmol, [s.d.]).

(a) van Vlack

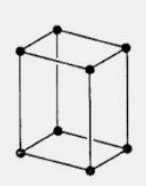

Triclínica

Ortorrômbica

de face

centrada

Hexagonal
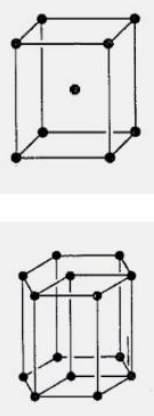

(b) Barret
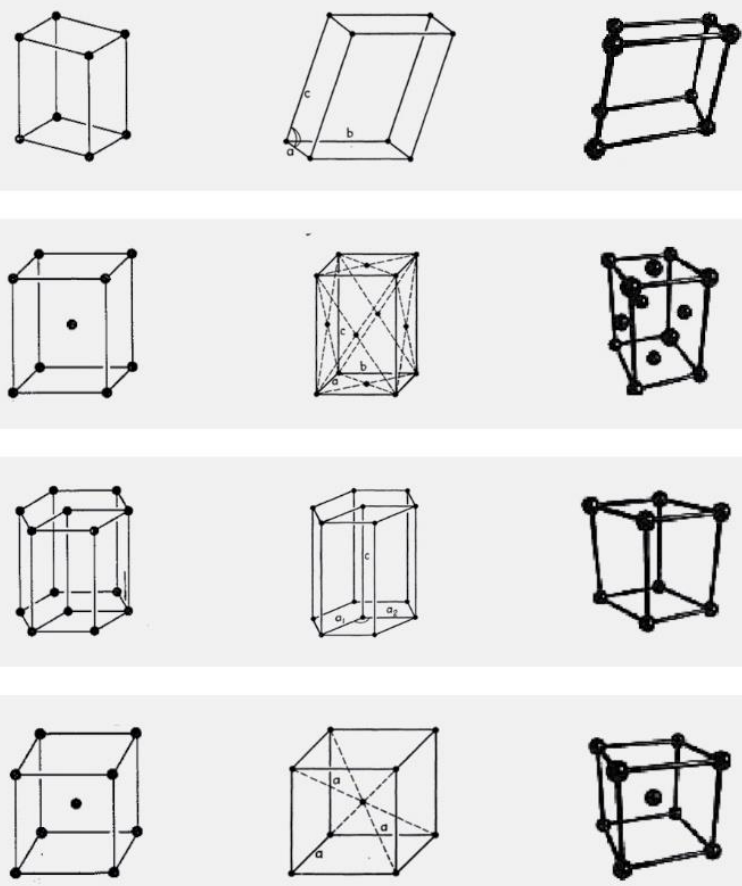

(c) Graef e McHenry

(d) Schwarzenbach
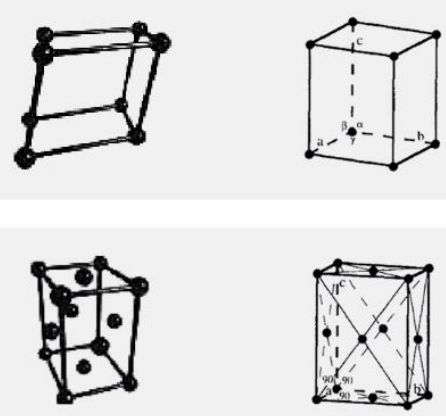

FIGURA 85 - Diferentes estilos de representação de células unitárias das redes de Bravais encontrados em obras de referência clássicas (livros didáticos e correlatos). Fonte: (a) van Vlack (1966); (b) Barret (1943); (c) Graef e McHenry (2007); (d) Schwarzenbach (1996).

Sintonizado com este procedimento didático, o CrystalWalk propõe um método de síntese inovador. Esse método, ao contrário dos softwares cristalográficos existentes, fundamenta-se apenas em conceitos básicos de ciência dos materiais e geometria, requerendo que o usuário informe dois parâmetros de entrada: a rede de Bravais e os átomos do motivo (quais átomos e em que posições).

A FIG. 68 (seção 4.3.3.1) ilustra como o sistema guia o usuário por uma sequência de passos interativos e visuais, aqui exemplificada na criação da estrutu- 
ra $\mathrm{NaCl}$. O processo inicia-se com a escolha de uma dentre as 14 redes de Bravais, apresentadas ao usuário com ilustrações semelhantes às apresentadas nos livros didáticos e em outras obras de referência (FIG. 85). Em seguida, é realizada a composição do motivo pela seleção dos elementos atômicos (átomos neutros ou íons), apresentados ao usuário no formato de uma tabela periódica interativa.

O posicionamento dos átomos pode ser calculado automaticamente pelo CrystalWalk a partir dos parâmetros de rede e das características dos elementos atômicos, ou de maneira livre e interativa pelo próprio usuário. No modo paramétrico, o modelo de esferas rígidas determina tangências entre os átomos. A rede de Bravais escolhida estabelece outras restrições, de modo que o software determina os parâmetros da rede automaticamente a cada interação do usuário. No modo interativo, as restrições são relaxadas ou desabilitadas, possibilitando, a critério do usuário, a experimentação com o motivo, movendo-se os átomos com o mouse ao longo dos eixos abc. O modo paramétrico permite posicionamento absoluto vetorial, em termos da célula unitária ou posição relativa, em termos de distâncias entre átomos existentes. Deve ser frisado que essa interação do usuário no momento da criação da estrutura é considerada crucial para o aprendizado e que apenas o CrystalWalk possui essa característica.

Conforme discutido na avaliação comparativa (4.5.2), é evidente a desconexão entre esta abordagem didática e o método de síntese de estruturas comumente adotado em softwares cristalográficos. Método que, além de pouco interativo, requer que o usuário forneça dados do grupo espacial da estrutura e das posições de Wyckoff, entendimento comumente restrito a cristalógrafos e pesquisadores da área. Esse ponto foi abordado no capítulo 1, no qual as FIG. 10-11, 86d ilustram a requisição destes parâmetros ao tentar criar uma nova estrutura em softwares cristalográficos. O método de síntese é fundamentalmente o mesmo utilizado por todos os softwares, conforme observado no APÊNDICE C.

Aos olhos de um estudante de graduação, ou mesmo de pós-graduação, de engenharia, física ou química, conhecimentos de cristalografia estão distantes não apenas dos materiais e da estratégica didática adotada, como também da realidade de seus estudos. Portanto, torna-se impossível criar estruturas nestes softwares, mesmo as mais triviais, a partir de dados encontrados em livros didáticos.

Entretanto, apesar de não ser uma tarefa trivial, é possível obter tais parâmetros gratuitamente em banco de dados cristalográficos na internet, dispo- 
nibilizados em um formato específico (crystallographic information file - CIF). Os parâmetros são comumente obtidos experimentalmente por meio de difração de raios X. A FIG. 86 ilustra este processo a partir dos dados cristalográficos obtidos para a estrutura do $\mathrm{NaCl}$. O primeiro desafio é fazer a busca pela estrutura correta (FIG. 86a). Os parâmetros são numerosos e pouco claros para quem não é familiarizado com cristalografia. Após uma busca de sucesso, é necessário fazer o download do arquivo CIF (FIG. 86b) e encontrar os parâmetros no texto (FIG. 86c) para, finalmente, inseri-los no software (FIG. 86d).

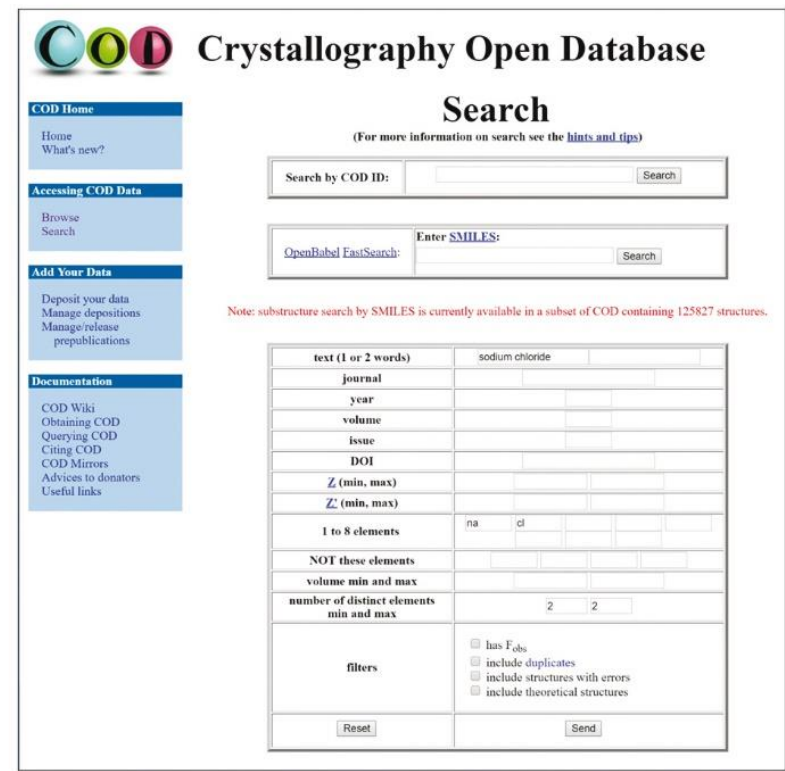

(a)

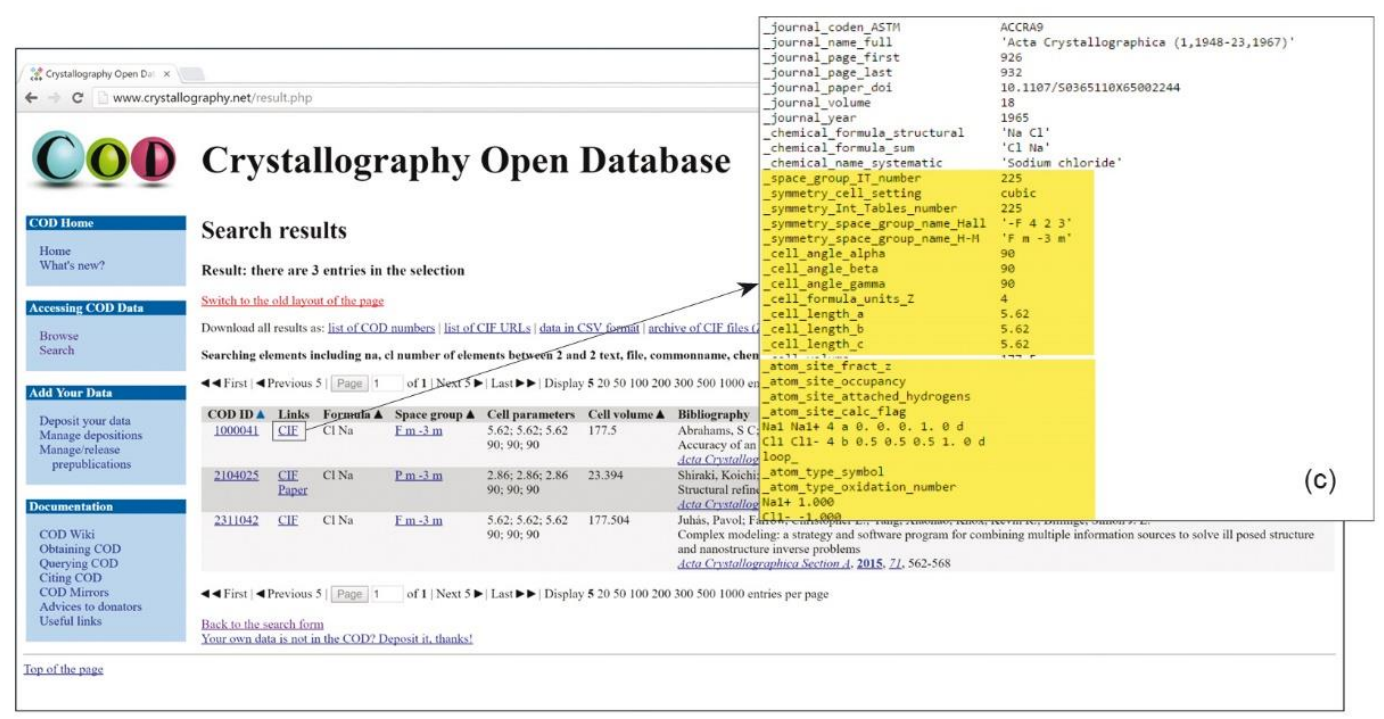

(b) 

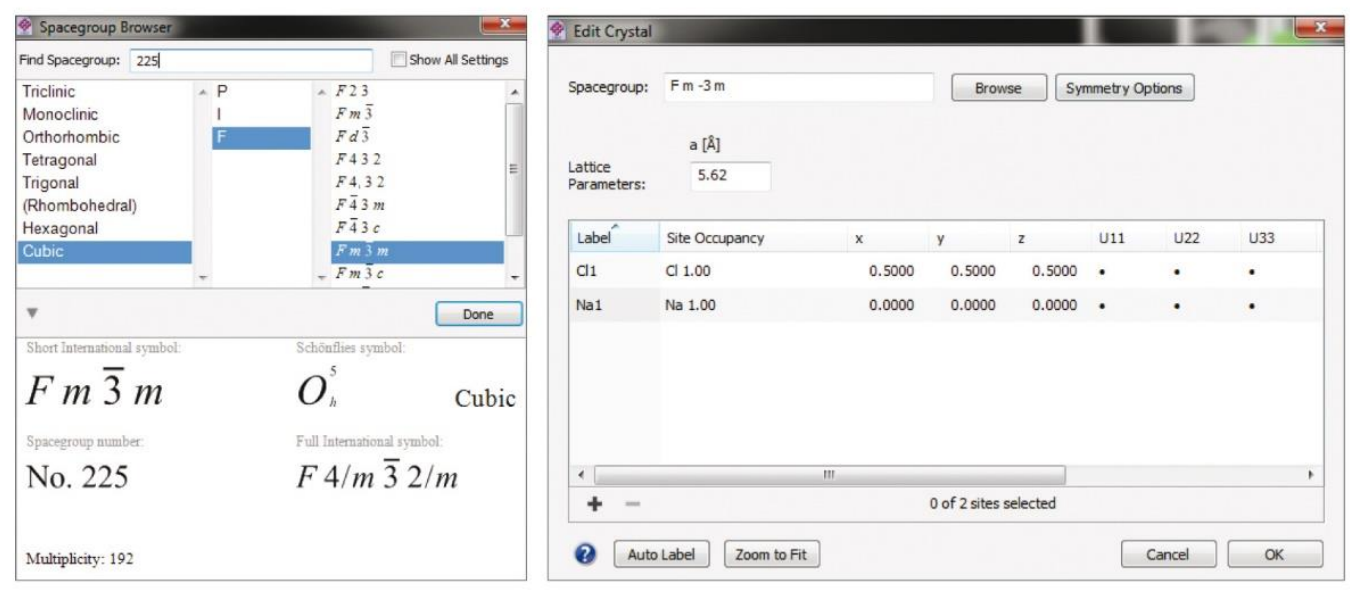

CRYSTALMAKER [CMAK15]
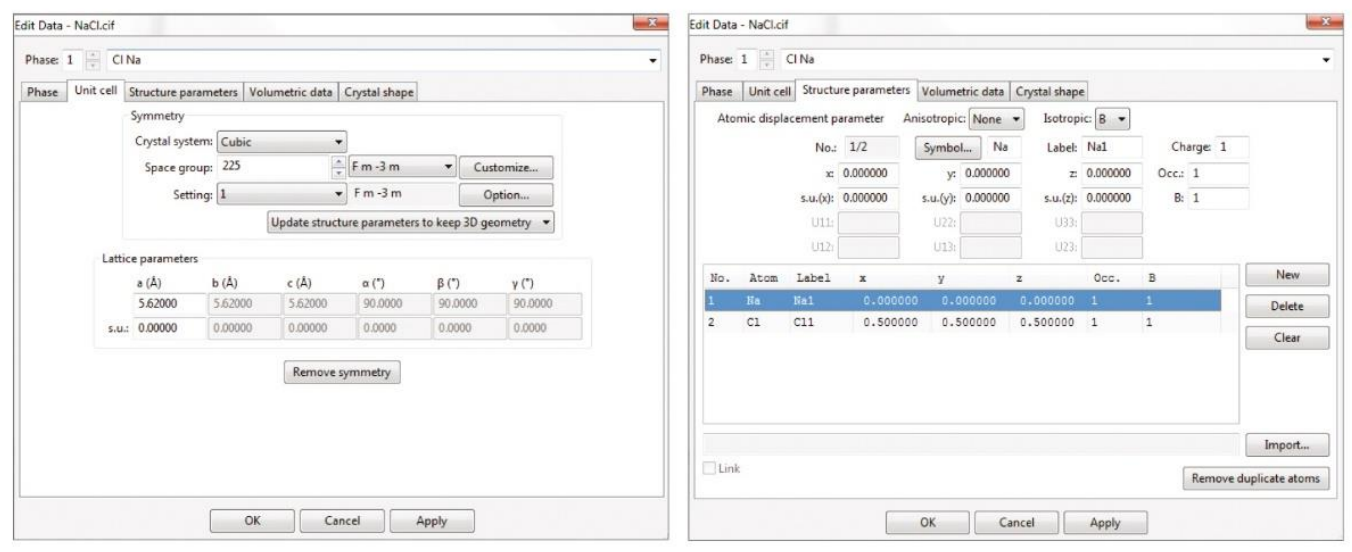

VESTA 3 [VEST14]

(d)

FIGURA 86 - Sequência de passos para obtenção de dados e criação de uma estrutura em softwares cristalográficos (CMAK15 e VEST14) que exigem inserção manual de parâmetros cristalográficos. Fonte: do autor.

Entende-se que, no processo de aprendizado, são utilizadas estruturas mais simples para facilitar a compreensão de conceitos básicos, momento no qual o estudante pode se beneficiar com a experimentação e interação durante a criação da estrutura. No entanto, a partir de uma certa complexidade, são notáveis as limitações atuais do modelo de síntese, tornando-se muito difícil determinar as posições dos átomos que compõem o motivo e, por consequência, criar estruturas complexas no CrystalWalk. Para estes casos, é aceitável determinar os átomos do motivo a partir de parâmetros cristalográficos obtidos experimentalmente e perder os benefícios da interação. Em Bardella (2016), podem ser consultados procedimentos para recuperar informações sobre os átomos do motivo a partir de 
dados cristalográficos. Ainda assim, torna-se possível explorar as funcionalidades didáticas e de visualização do CrystalWalk em estruturas de maior complexidade. Deve ser frisado, no entanto, que tais estruturas não são comumente utilizadas didaticamente. Nesse sentido, em cursos de pós-graduação ou em estágios avançados de disciplinas de graduação, o CrystalWalk pode facilitar o acesso a estruturas mais complexas.

\subsubsection{Visualização}

A principal avaliação do quesito visualização foi verificar se o conjunto de mecanismos de visualização disponibilizado permite e, em que grau, a compreensão geométrica de elementos visuais específicos, considerando problemas didáticos cruciais associados a estruturas cristalinas.

Conforme desenvolvido na seção 3.1 e para facilitar a seguinte análise, foram determinados dois problemas didáticos principais decorrentes do conceito "rede + motivo $=$ estrutura cristalina". O primeiro refere-se à identificação mais precisa e inequívoca de padrões de vizinhança, e o segundo, à identificação de contatos e forma dos interstícios atômicos, tanto entre dois átomos, como de planos compactos e empilhamentos, onde todos os átomos em um determinado plano estão em contato. Em outras palavras, esses problemas se resumem a explicitar a organização geométrica da célula unitária e a do do cristal.

A seguir, por meio de testes com as estruturas do $\mathrm{CsCl}, \mathrm{Mg}$, Fluorita e Grafite, será exemplificado como o CrystalWalk lida com esses problemas. Tais estruturas foram escolhidas por sua importância didática no processo de ensinoaprendizagem, por serem desafiantes na explicitação desses conceitos didáticos, e por sua significância histórica e conceitual no Strukturbericht (Ewald e Hermann, 1943). Para cada estrutura, será mensurada a capacidade de reprodução dos parâmetros visuais do software, além do papel dos recursos interativos presentes na resolução do problema didático.

\subsection{Problema didático 1: Entendimento do conceito "rede + motivo = estrutura cristalina"}

O CrystalWalk possui diversas funcionalidades para auxiliar o ensino e entendimento de estruturas cristalinas baseado no conceito "rede + motivo $=$ estrutura cristalina". Adotando princípios construtivistas, a interação foi projetada 
para que o usuário passe por quatro etapas: a escolha da rede cristalina, a composição do motivo, a criação de um cristal e a exploração da estrutura criada. Os detalhes dessa sequência podem ser apreciados na seção 4.5.3.1. Nesta seção, o foco será nos recursos de visualização, e não na interface (o que será apresentado na seção 4.5.4).

Em cada etapa, foram previstos recursos de visualização que permitem um entendimento progressivo conforme se incrementa a informação visual de maneira consistente. Para promover consistência visual, foi estabelecido um padrão de visualização considerado ótimo, obtido a partir de boas práticas de visualização (seção 3.1.3) e das impressões e recomendações feitas pelos atores sociais conforme iam experimentando o software. Na prática, esse padrão resultou de ajustes dos parâmetros e opções de configuração disponíveis. Deve ser frisado que existem configurações recomendadas para cada etapa de visualização, pois a quantidade e características dos elementos visuais variam e, assim, uma configuração global claramente não atenderá a todas as condições.

Ao escolher uma rede, o sistema adota as configurações de visualização de célula unitária, primeiro, centralizando a câmera, estabelecendo uma vista aproximadamente isométrica, se aproximando à célula criada, ressaltando automaticamente o volume da célula através de faces translúcidas, arestas, e melhor destacando a localização dos pontos de rede (FIG. 87a). Também ao escolher a rede, os eixos cristalográficos abc são automaticamente ajustados. Essas configurações permitem um entendimento rápido da geometria da rede espacial. Para resolver dúvidas, estão à disposição recursos de rotação, zoom, translação, vistas preconfiguradas (FIG. 87d) e rotação automática (FIG. 87a-c), além de todas as outras configurações visuais. O último passo para domínio da geometria da rede é proceder à repetição de células isoladamente em cada um dos eixos ( $x, y$ e z) e, depois, em conjunto, para, então, usar novamente os recursos interativos citados. Para elucidar a forma do cristal resultante e evitar confusão visual com a sobreposição de transparências das diversas células unitárias, é possível reduzir a espessura das arestas e adotar faces totalmente opacas (FIG. 88a-c). Por fim, é possível alterar para o modo de perspectiva cônica, com ou sem estereoscopia, onde o usuário pode navegar tradicionalmente com o mouse ou no modo "avião", explorando a rede como se estivesse miniaturizado (FIG. 88d). 


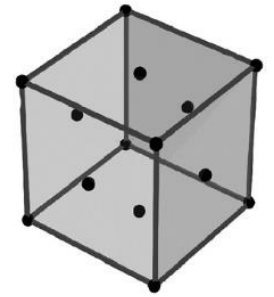

(a)

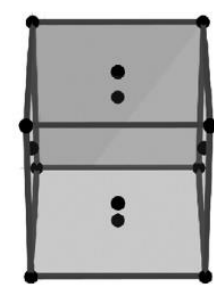

(b)

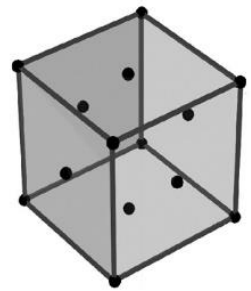

(c)

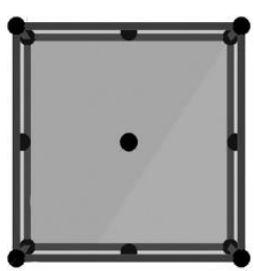

(d)

FIGURA 87 - Exemplo de ferramentas interativas: (a-c) rotações automáticas; (d) vistas preconfiguradas. Fonte: Bardella (2016d) (adaptado).

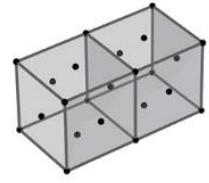

(a)

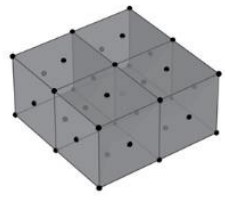

(b)

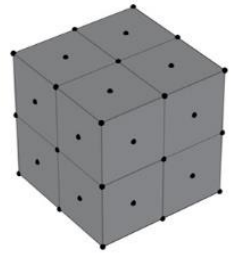

(c)

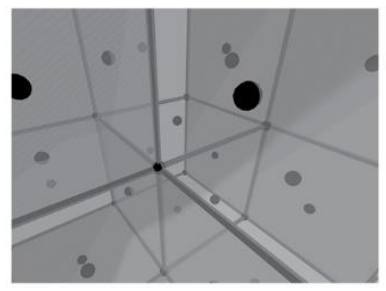

(d)

FIGURA 88 - Exemplo de uso de: (a-c) configurações visuais; (d) navegação em primeira pessoa. Fonte: Bardella (2016d) (adaptado).

Após dominar a geometria da célula unitária, procede-se à inserção do motivo. Aqui, o CrystalWalk muda a visualização para 5 janelas, sendo uma delas o cristal previamente criado, adotando as últimas configurações de visualização e ângulo de câmera, buscando manter a consistência de visualização. Ao adicionar um átomo ao motivo, ele aparece prontamente em todas as janelas. Os átomos são adicionados com leve transparência, e a geometria da célula unitária e do cristal (múltiplas células) é destacada com aumento da espessura das linhas, sendo possível verificar que os átomos se repetem em todos os pontos da rede (FIG. 89a-b). Ao adicionar um segundo átomo ao motivo, a questão da vizinhança fica mais evidente e as janelas de visualização ortogonal do motivo explicitam as relações geométricas dos átomos componentes (FIG. 90). Aqui, os átomos são representados em transparência para permitir verificar qual átomo está à frente em qualquer vista (FIG. 90a). Para complementar as vistas ortogonais, uma das janelas exibe a vista em perspectiva do motivo, situado dentro de uma célula do cristal, reproduzindo-o em apenas um dos pontos de rede (FIG. 90b). Finalmente, a janela restante mostra como o motivo compõe a célula unitária, ou seja, repetindo-se em cada ponto da rede (FIG. 90c-e). Esses recursos permitem compreender o motivo e como ele forma a célula unitária construtiva. 


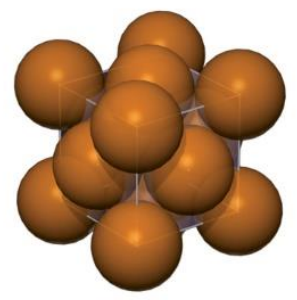

(a)

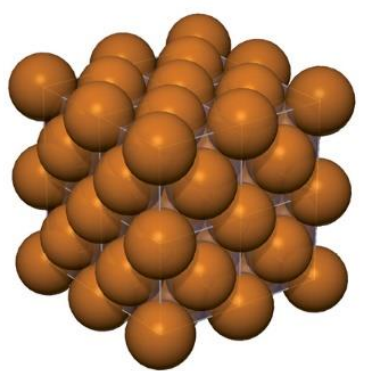

(b)

FIGURA 89 - Recursos para visualização de cristais: (a) vista da célula unitária; (b) vista do cristal (células múltiplas). Fonte: Bardella (2016d) (adaptado).

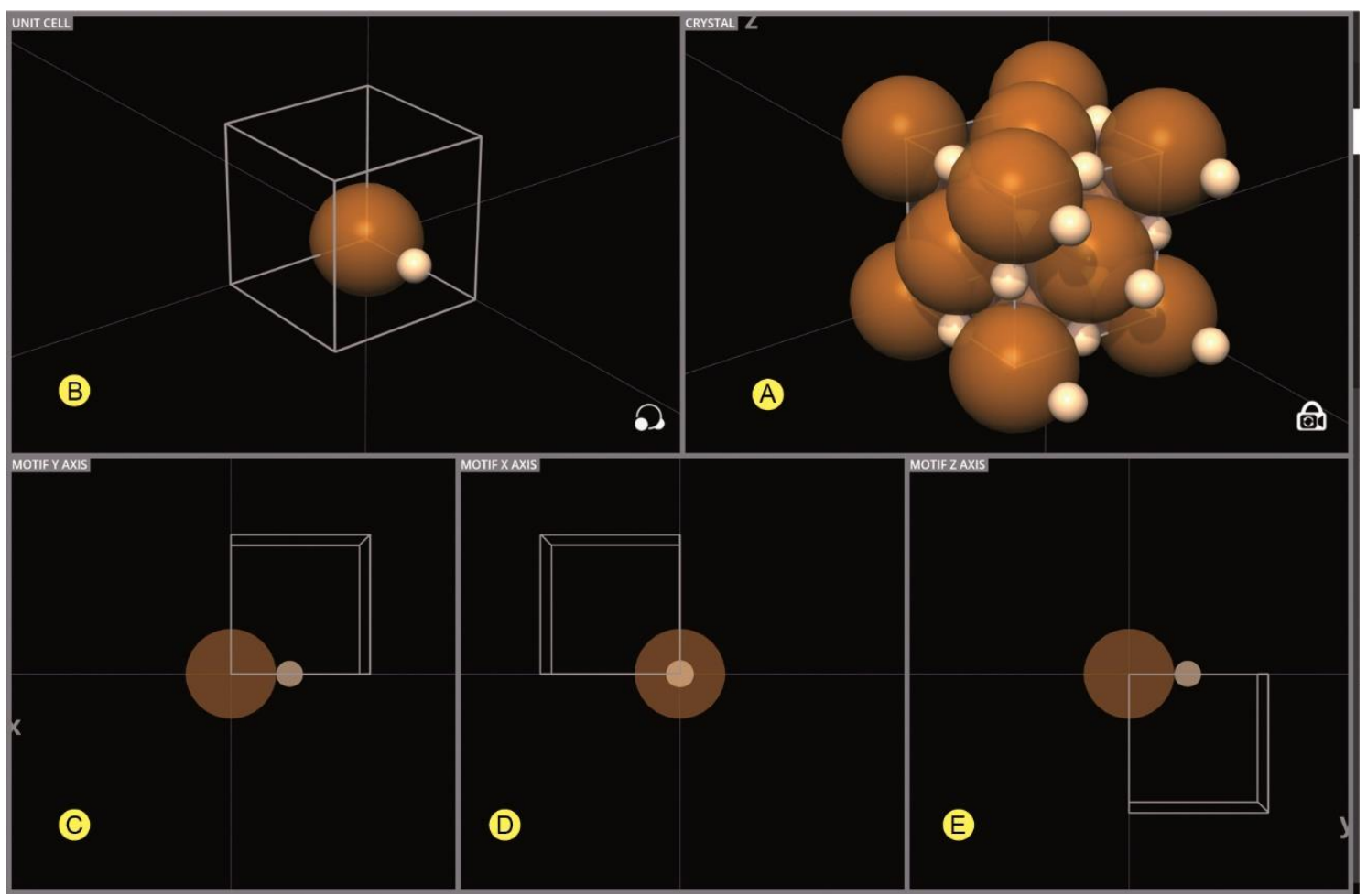

FIGURA 90 - Recursos para visualização do motivo com dois átomos: (a) vista da célula unitária em perspectiva; (b) vista do motivo isolado na célula unitária; (c-e) vistas ortogonais . Fonte: Bardella (2016d) (adaptado).

Na sequência, o usuário pode estudar vizinhanças explorando o modelo de maneira controlada usando o recurso Gearbox, podendo avançar e retroceder de maneira ordenada no processo construtivo desenvolvido até então. $O$ primeiro estágio do Gearbox exibe os pontos de rede (FIG. 91a); o segundo, exibe o motivo isoladamente (FIG. 91b); o terceiro, a célula unitária construtiva (FIG. 91c); o quarto, a célula unitária tradicional (FIG. 91d); o quinto, a célula unitária cortada (FIG. 91e); e o sexto e último, o cristal (FIG. 91f). Em qualquer estágio, o usuário pode interagir e alterar as configurações de visualização. Na visualização 
do motivo, por exemplo, o usuário pode obter uma vista alinhada de um motivo com dois átomos. A célula unitária construtiva aliada à repetição de células do cristal permite visualizar como os átomos não posicionados nos pontos de rede situam-se no interior da célula e perceber como se repetem espacialmente.

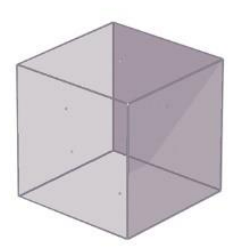

(a)

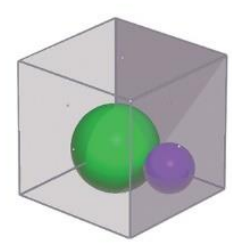

(b)

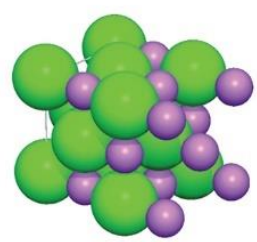

(c)

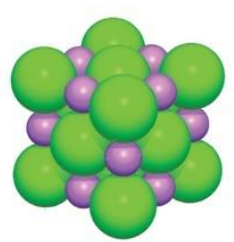

(d)

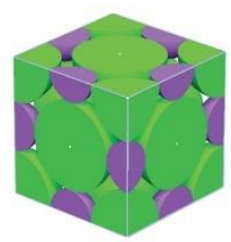

(e)

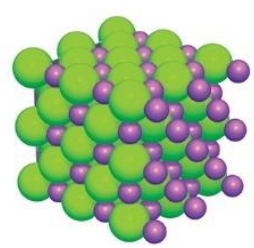

(f)

FIGURA 91 - Uso do Gearbox na exploração das vizinhanças: (a) pontos de rede; (b) motivo; (c) célula unitária construtiva; (d) célula unitária; (e) célula unitária cortada; (f) cristal. Fonte: Bardella (2016d) (adaptado).

Para estruturas com motivos formados por mais de um átomo, como no caso do $\mathrm{CsCl}$, é possível também interpretar que cada átomo do motivo se ordena segundo uma rede espacial particular, interpondo-se entre si. No caso de estruturas do tipo $\mathrm{CsCl}$ (FIG. 92 e FIG. 93a), é possível interpreta-las como duas redes do tipo CS interpenetradas - uma para o Cl (FIG 89a), outra para o Cs (FIG. 92c). Como demonstrado anteriormente (FIG. 80a), em qualquer vista, é possível escolher um dos átomos como ponto de vista usando o recurso AtomView para verificar as vizinhanças em primeira pessoa e alternar de um átomo ao outro diretamente.

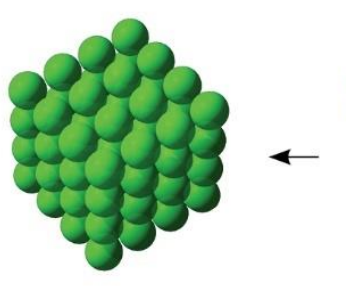

(a)

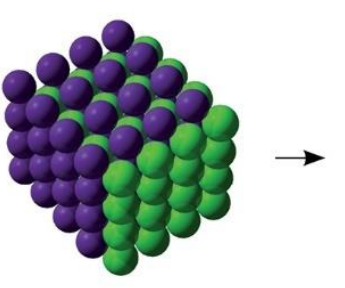

(b)

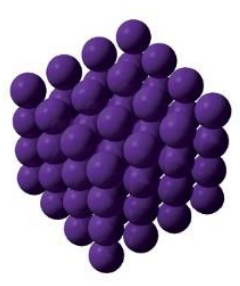

(c)

FIGURA 92 - Um motivo composto por dois elementos pode ser interpretado como duas redes interpenetradas. (a) rede de $\mathrm{Cl}$; (b) ० $\mathrm{CsCl}$; (c) rede de Cs. Fonte: Bardella (2016d) (adaptado).

$\mathrm{Na}$ FIG. 93 são demonstrados esses pontos para o $\mathrm{CsCl}$ (FIG. 93a), Mg (FIG. 93b), Fluorita (FIG. 93c) e Grafite (FIG. 93d). Com o recurso de alterar as propriedades de visualização de cada átomo (cor e opacidade), o usuário pode 
perceber com muita clareza como os átomos do motivo se relacionam na composição da estrutura. No caso do Mg (FIG. 93b), protótipo da estrutrura hexagonal compacta $(\mathrm{HC})$, são duas redes hexagonais interpenetradas, fato quase sempre negligenciado pelos livros didáticos. No caso da Fluorita (FIG. 93c), fica evidente que a rede espacial é do tipo CFC, inclusive para os dois átomos de flúor que compõem o motivo, junto com o átomo de cálcio, ao contrário do que se poderia depreender de representações como as da FIG. 24 (seção 3.1.1.4), de células unitárias aparentemente com uma rede cúbica simples, equívoco cometido por autores como Callister e Rethwisch (2007, p. 442), Hammond (2009, p. 19) e Smart e Moore (2012, p. 34). É digno de nota que autores como van Vlack (1966, p. 205), Graef e McHenry (2007, p. 486) e Tilley (p.10) não cometem esses erros - não por acaso, tais autores exploram o conceito "rede + motivo = estrutura cristalina". No caso do grafite, são quatro redes hexagonais interpenetradas (FIG. 93d), aspecto ignorado pelos livros consultados. 
(a) $\mathrm{CsCl}$
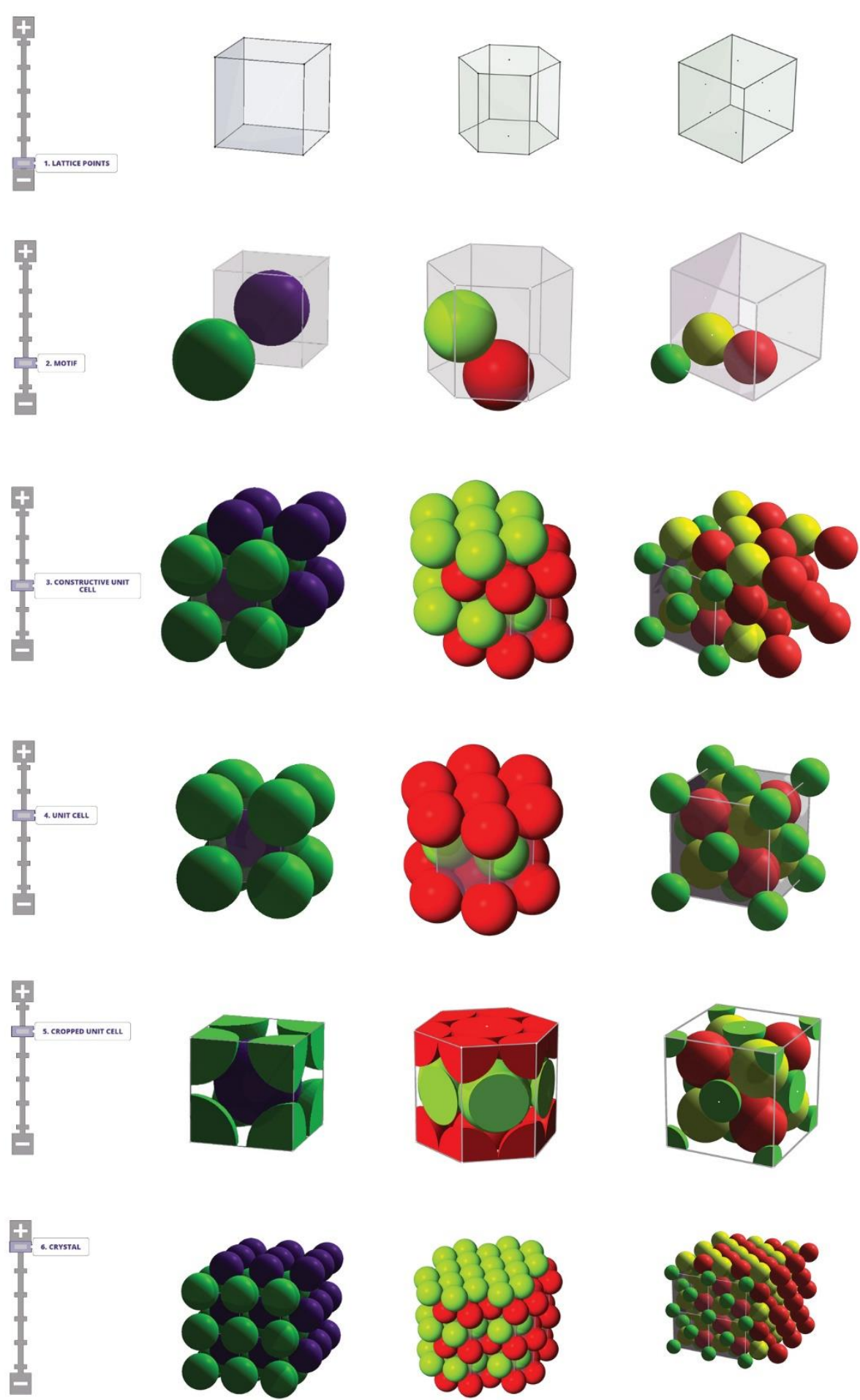

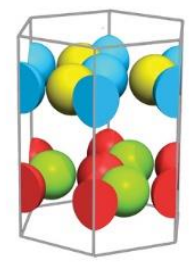

(d) Grafite
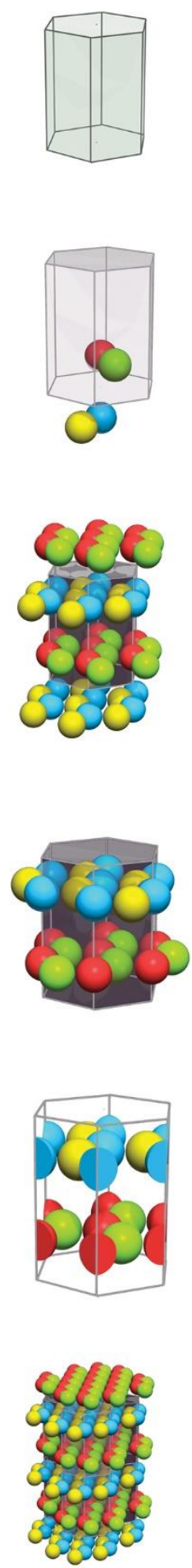

FIGURA 93 - Demonstração dos recursos do CrystalWalk na visualização de vizinhanças para: (a) Cloreto de Césio ( $\mathrm{CsCl}$ ); (b) Magnésio (Mg); (c) Fluorita; (d) Grafite. Fonte: Bardella (2016d) (adaptado).

Nesta seção, buscou-se demonstrar como o CrystalWalk suporta um aprendizado baseado na construção interativa e incremental das estruturas crista- 
linas, partindo da rede, procedendo ao motivo, e seguindo, finalmente, à exploração dos modelos com diversos recursos de visualização, configurados antecipadamente de acordo com a evolução construtiva e o contexto, mas customizáveis pelo usuário.

\subsection{Problema didático 2: Identificação de contatos, distâncias atômicas e empilhamentos de planos}

A compreensão de estruturas cristalinas por meio do conceito "rede + motivo = estrutura cristalina" proposto neste trabalho é facilitada quando são usados modelos atômicos de esferas rígidas, pois é a única que explicita um tipo especial de vizinhança, ou seja, os vizinhos em contato. A esse respeito, a estudante V.K. afirmou: "os pontos de contato entre os átomos só foram possíveis de ver no CrystalWalk [em comparação ao CrystalMaker]". Compreender características como fator de empacotamento, densidade e anisotropia, por exemplo, depende da correta identificação desses contatos, bem como dos espaços (vazios) intersticiais. Para facilitar tal entendimento, o CrystalWalk possui ferramentas que explicitam vários aspectos pertinentes.

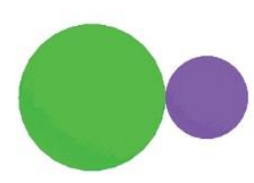

(a)

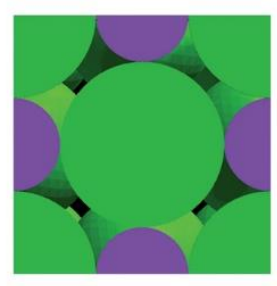

(b)

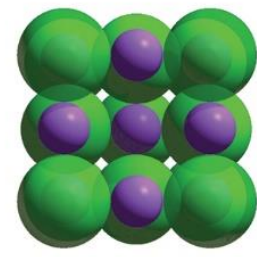

(c)

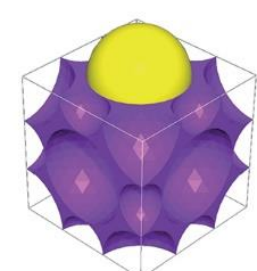

(d)

FIGURA 94 - Identificação de contatos atômicos: (a) no motivo isolado; (b) por meio de corte no perímetro da célula unitária; (c) utilizando transparência ou ocultando átomos; (d) por visualização do espaço vazio. Fonte: Bardella (2016d) (adaptado).

$\mathrm{Na}$ fase de criação do motivo, é possível detectar o contato entre os átomos componentes com o auxílio das vistas ortogonais e também ao interagir com o motivo isolado dentro da rede (FIG. 94a). Na célula unitária construtiva, a rotação combinada ao zoom permite sondar possíveis contatos no perímetro da célula unitária, e a célula cortada permite comprovar diversos contatos, pois muitos ocorrem justamente na superfície de corte (FIG. 94b). No entanto, essas re- 
presentações geralmente não permitem visualizar o interior da célula unitária, devido à oclusão. Neste caso, é possível mudar a transparência ou mesmo ocultar átomos (FIG. 94c), aumentar ou diminuir interativamente o tamanho dos átomos, navegar em primeira pessoa ou com o AtomView, assumindo a posição de um átomo específico (FIG. 94a). Um recurso único no CrystalWalk e de extremo valor é a representação do espaço intersticial entre os átomos. Quando utilizado junto à representação da célula unitária (FIG. 94d) ou com alguns átomos (FIG. 94e), permite uma identificação mais clara dos contatos. Também existe um recurso que identifica quando uma colisão ocorre. O usuário pode aumentar lentamente o tamanho dos átomos para verificar a sequencia de colisões e confirmar os contatos. A esse respeito, a estudante D.C. afirmou: "Embora não tenha conseguido realizar a tarefa anterior, acredito que a opção de alterar a visualização do raio dos átomos é uma maneira de visualizar os átomos em segundo plano, sem alterar a vista. Outra forma é selecionar o átomo e diminuir sua opacidade". Já o estudante R.I.C.S. afirmou: "não foi encontrada uma ferramenta específica para mostrar os átomos oclusos. O que se fez foi retirar da visualização os átomos mais frontais selecionando-os individualmente".

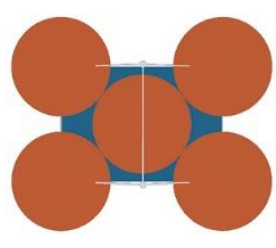

(a)

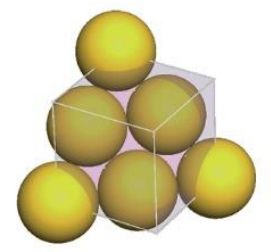

(b)

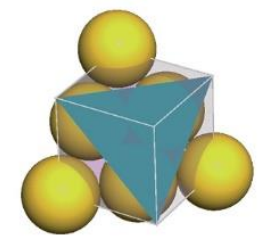

(c)

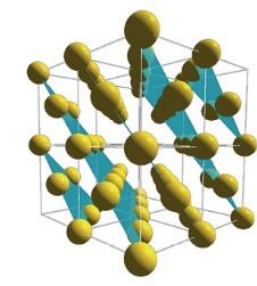

(d)

FIGURA 95 - Visualização de planos e empilhamentos: (a) confirmação de contatos no plano (110), em uma estrutura CCC; (b) visualização do plano compacto (111), em uma estrutura CFC; (c) visualização dos planos compactos com auxílio de planos paralelos; (d) uso de perspectiva cônica e alteração visual do raio atômico para visualização dos planos compactos em uma estrutura CFC. Fonte: Bardella (2016d) (adaptado).

Os recursos citados acima, combinados com direções e planos específicos, permitem a descoberta de planos compactos e de empilhamento. Após a identificação de contatos, o usuário pode criar planos que, supostamente, passam pelos contatos, e exibir apenas os átomos cortados pelo plano (FIG. 95a) e também constatar se de fato trata-se de um plano compacto (FIG. 95b) usando pla- 
nos paralelos (FIG. 95c). O recurso de planos, quando aplicado a todo o cristal, utilizando perspectiva cônica e alterando visualmente o raio atômico, permite visualizar o empilhamento dos planos compactos encontrados (FIG. 95d) ou de qualquer outro plano de interesse do usuário. Em qualquer caso, o usuário pode criar vistas e anotações para registrar todas suas percepções e sequenciá-las de maneira lógica. A esse respeito, o estudante R.I.C.S. afirmou: "A visualização do CrystalWalk favoreceu bastante a identificação da ordem de empilhamento". E o estudante R.G. afirmou: "Utilizando recursos como a transparência dos átomos, as faces das estruturas em tonalidades diferentes facilitaram a observação do plano compacto".

Em suma, o CrystalWalk possui diversos recursos para o estudo de estruturas cristalinas, considerando, em especial, o conceito "rede + motivo $=$ estrutura cristalina". Os recursos discutidos nesta seção foram aplicados às estruturas do Mg (FIG. 96a) e Grafite (FIG. 96b).

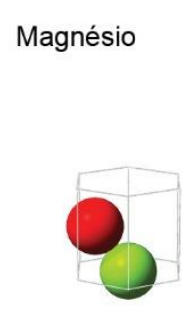

(a)

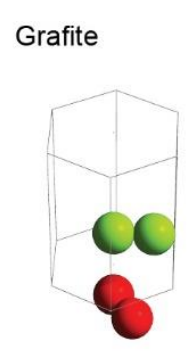

(a)

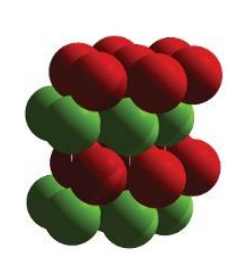

(b)

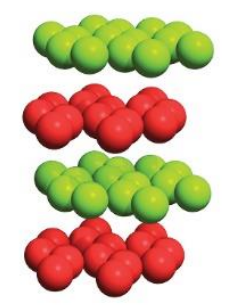

(b)

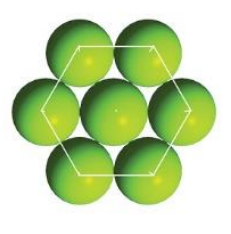

(c)

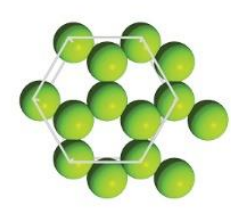

(c)

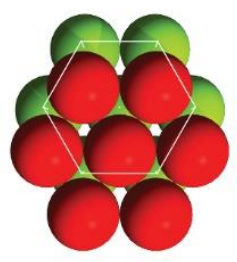

(d)

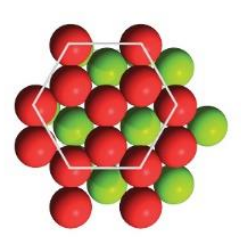

(d)

FIGURA 96 - Identificação de contatos, planos compactos e de empilhamento no Magnésio (Mg) e Grafite: (a) contato no motivo; (b) planos de empilhamento do tipo ABAB; (c) plano A; (d) plano B. Fonte: Bardella (2016d) (adaptado).

\subsubsection{Avaliação de interface}

Até o momento, a análise de resultados contemplou apenas a existência de funcionalidades de visualização, não a facilidade de acesso a elas. Portan- 
to, a clareza da interface também será atestada por meio da avaliação da organização, hierarquização, encadeamento, acessibilidade e compreensão dos mecanismos de visualização. Ao longo desta seção, serão também apresentadas opiniões de estudantes de disciplinas de graduação e pós-graduação, junto aos quais foram realizadas dinâmicas de aplicação e avaliação do CrystalWalk (ver detalhamentos na seção 4.2).

O projeto minimalista da interface foi considerado positivo pela maioria dos usuários, orientando-os intuitivamente pela sequência de passos esperada. A esse respeito, a estudante V.K. afirmou: "Primeiro contato com o software, porém a interface se mostrou bem simples e intuitiva neste primeiro momento". E a estudante M.M.O. pontuou: “[...] o CrystalWalk, apesar de ter sido apresentado em aula, tem suas funções bastante intuitivas, precisando apenas de algumas observações para encontrá-las. Além de seu design, que incentiva o aprendizado [...]" "[...] tem suas ferramentas dispostas de forma clara e intuitiva [...]". Já a estudante D.C. afirmou: "Os ícones são intuitivos e ao abrir o programa é fácil começar a trabalhar nele".

Sem auxílio de tutoriais, manuais ou guias, os usuários conseguiram executar as tarefas de síntese e visualização, além das funcionalidades de apoio didático. A esse respeito, o estudante R.G. afirmou: "[...] o principal ponto positivo [do CrystalWalk] é a facilidade de se utilizar a ferramenta. A utilização de todos os recursos depende do conhecimento sobre a ferramenta, porém nesta, a evolução é mais rápida/fácil". E a estudante V.K. afirmou: "A interface é bem intuitiva, de fácil compreensão, bastando apenas alguns momentos para a familiarização com o software".

A organização sequencial dos menus mostrou-se eficiente, dispondo o setor de síntese na primeira e segunda abas e o de visualização, na terceira e quarta abas. O mecanismo de restrição de ações guiou os usuários quando se sentiam perdidos, impedindo-os de acessar funcionalidades indisponíveis e explicando-Ihes os próximos passos por meio de avisos flutuantes. Outro aspecto apreciado foi o acesso rápido e direto a funcionalidades mais populares. A esse respeito, o estudante I.B.U. afirmou: "[...] as ferramentas de interação são facilmente identificadas a partir das tooltips que o software apresenta [...]".

Notou-se que muitos usuários estão familiarizados com interfaces similares, presentes em dispositivos como celulares, tablets e computadores modernos. Alguns usuários reportaram apreço pelo estilo visual moderno e bem definido 
e que essa preocupação tornou a interface mais amigável e até mesmo estimulante ao aprendizado. A esse respeito, o estudante R.I.C.S. afirmou: "A interface é bem simples e amigável”, o estudante I.B.U. pontuou "Interface gráfica amigável e de fácil interpretação das funcionalidades" e a estudante M.M.O. afirmou "[...] além de seu design que incentiva o aprendizado".

Um caso interessante foi do usuário O.M.J., que não achou a interface clara o suficiente e precisou de apoio para executar as tarefas, e afirmou: "Não consegui utilizá-lo. Somente uma estrutura com os pontos de rede", "Não é amigável". Curiosamente, este mesmo usuário conseguiu executar algumas tarefas em outros softwares com interfaces mais antigas e, inclusive, com uso de linha de comando. Esse episódio trouxe à tona a questão da existência de diferentes perfis de usuários, sendo que nem todos se sintonizam com interfaces mais modernas e minimalistas, preferindo as mais tradicionais, com menus hierárquicos clássicos. Neste caso, uma sondagem da questão junto ao usuário reforçou a necessidade de disponibilizar tutoriais e manuais. Naquele momento, as funcionalidades de suporte, mais especificamente o modo tutorial, ainda não estavam ativas, o que certamente teria auxiliado este usuário, como confirmado pelo próprio.

De fato, algumas funcionalidades da interface não estavam completamente desenvolvidas nos testes, o que, por um lado, impediu uma análise mais abrangente, mas por outro lado, demonstrou que a organização e clareza foram medidas suficientes para guiar boa parte dos usuários. Outra constatação foi que os métodos auxiliares então ainda não finalizados, como o modo tutorial, restrição de ações e descrições flutuantes das ferramentas, certamente resolveriam os casos excepcionais. Como exemplo desse tipo de caso, seguem-se comentários da estudante D.F., que afirmou: "Têm-se as ferramentas básicas e principais para a construção das estruturas cristalinas, mas precisa de um tutorial ou uma melhor forma de apresentá-las [naquele momento, o modo tutorial ainda não estava disponível]" e "Os links das ferramentas não têm nome que faça referência à sua função. Quando se passa o cursor por acima delas, aparece só um numero que não significa nada [no momento, as tooltips ainda não funcionavam]".

Os usuários conseguiram concluir a maioria das tarefas de síntese de cinco estruturas sem auxílio verbal ou de manuais. Observou-se que alguns utilizaram os mecanismos de destaque das arestas e faces das células como referências visuais, buscando facilitar o entendimento espacial (FIG. 97a). 


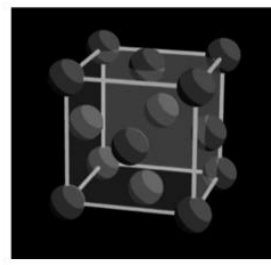

(a)

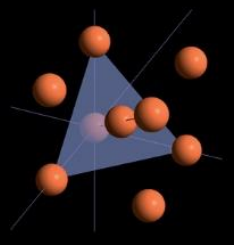

(b)

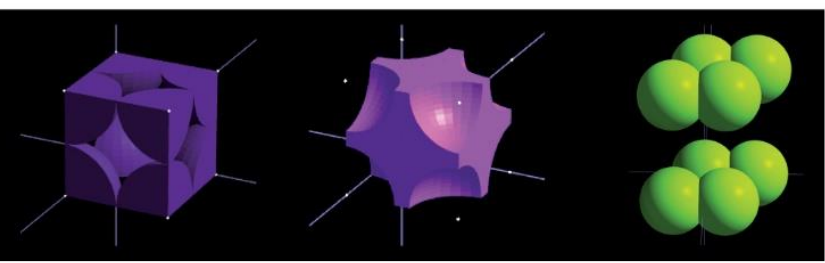

(c)

(e)

FIGURA 97 - Modelos produzidos por estudantes de graduação: (a) uso de destaques visuais planos e arestas; (b) planos e direções cristalográficos; (c) corte nos limites da célula unitária; (d) espaço negativo; (e) exploração livre dos parâmetros de rede. Fonte: Bardella (2016d) (adaptado).

$\mathrm{Na}$ inserção do motivo, o intuito das vistas ortogonais simultâneas é fornecer apoio, o que foi eficiente na experiência de alguns usuários. No entanto, aqueles pouco familiarizados com conceitos de geometria não compreendiam o significado das diferentes vistas ortogonais, apesar da designação explicita de cada janela. Notou-se, durante experimentos em sala de aula, que esses usuários precisam de referências adicionais para entender as vistas ortogonais do motivo. O Projection Cube também se baseia em vistas ortogonais, e praticamente todos entenderam seu funcionamento. A diferença é que este mecanismo utiliza uma representação tridimensional cúbica do espaço, perfeita para vistas ortogonais, juntamente com animações de transição entre vistas. A esse respeito, a estudante V.K. afirmou: "Muito simples com a utilização do cubo na lateral superior esquerda [o Projection Cube]".

As vistas ortogonais do motivo podem ser melhor entendidas por todos os usuários se contarem com medidas similares ao Projection Cube, como o cubo e indicações do ponto de vista do usuário. No ambiente de criação do motivo, já existem vistas em perspectiva. Assim, entende-se que basta adicionar elementos estruturadores para aprimorar a eficiência da interface.

Os testes revelaram o uso frequente das opções de visualização, especialmente daquelas disponíveis em acesso rápido e, inclusive, das dispostas nas abas de síntese - devido, tal como previsto, à tendência de exploração imediata dos recursos conforme são descobertos. A esse respeito, a estudante D.C. afirmou: "Os recursos para visualização do CrystalWalk são fáceis de encontrar e são intuitivos". As abas dedicadas aos planos e direções cristalográficos e aos parâmetros visuais gerais também foram frequentemente utilizadas (FIG. 97b), 
especialmente as opções de representação em corte nos limites da célula unitária (FIG. 97c) e exibição do espaço negativo (FIG. 97d), além dos modos de câmera. A esse respeito, a estudante V.K. afirmou: "Criar o plano e a direção foi bem simples e fácil de encontrar".

Quanto à interação, o modo de interação orbital com o mouse se revelou simples e consideravelmente intuitivo para o usuário, exigindo, em alguns casos, um pouco de exploração e treino. Uma vantagem deste método de interação é permitir rápida experimentação, pois todos os movimentos podem ser executados sem necessidade de um teclado.

Quanto aos métodos avançados e específicos do CrystalWalk, o Gearbox foi muito utilizado e considerado prático, permitindo uma transição rápida e sequencial entre visualizações dos pontos de rede, motivo, célula unitária e estrutura cristalina. A esse respeito, a estudante M.R.M.S. afirmou: "Menu de visualização [referindo-se ao Gearbox] exibindo os diferentes tipos de observação da célula e da estrutura cristalina muito prático e fácil de utilizar". Após a finalização das restrições de ação, dos avisos flutuantes e do modo tutorial, acredita-se que o Gearbox será uma ferramenta central no uso do CrystalWalk, principalmente para usuários iniciantes. Por este motivo, o recurso tem grande exposição, tomando uma posição de destaque na interface do sistema.

O Projection Cube também foi muito utilizado, primeiramente por estar sempre presente e disponível, facilitando sua exploração e o entendimento de seu propósito, principalmente devido às transições graduais e animadas entre diferentes vistas. Usuários revelaram que utilizavam o recurso quando se perdiam ou quando queriam alternar para outras vistas com maior precisão e agilidade. Por outro lado, o AtomView, que permite explorar o interior dos modelos como se o usuário fosse miniaturizado, foi pouco utilizado, e os usuários reportaram certa dificuldade em entender como utilizá-lo e qual seria seu propósito. Entende-se que situações onde o usuário está miniaturizado demandam maior atenção para adicionar valor ao processo de aprendizado. O modo de uso será explicitado com a implementação completa dos avisos flutuantes. No caso da interação, as sugestões convergem em alguns pontos, como adicionar simultaneamente visualizações de contexto global, para que o usuário entenda onde se situa, além de presença de elementos estruturadores adicionais, sendo que alguns já existem, como nomes dos átomos e limites das células unitárias, o que pode ser realizado com presets de visualização. 
De maneira geral, como esperado em qualquer novo aplicativo, a primeira experiência dos usuários não foi totalmente fluida e perfeitamente sequenciada. A esse respeito, a estudante D.C. afirmou: "Para começar um novo projeto, não encontrei facilmente o botão de resetar, então abri nova aba do navegador toda vez que tive que iniciar um novo projeto. Ao tentar salvar o projeto, o botão 'Download to your PC' ['Fazer o download para o seu computador'] aparentemente não estava funcionando, e não consegui ler o QR code [...]. Não consegui compreender muito bem o modo de salvar o projeto. Porém, é útil a opção de salvar o projeto e também poder acessá-lo pelo celular. Outra dificuldade que tive foi a de não conseguir construir a estrutura que tinha mais de um átomo, não consegui encontrar o recurso para fazer essa tarefa". Já a estudante V.K. afirmou: "Apesar da construção da estrutura principal ser bem simples, a adição de um átomo diferente não foi possível. Nenhuma opção foi encontrada para tal”.

Naturalmente, o usuário iniciante explora os elementos disponíveis na tela de maneira livre. É muito difícil evitar este comportamento, que pode, na verdade, ser considerado saudável e benéfico, mas apenas quando não resulta em desorientação e quando permite descobrir como executar as ações importantes em pouco tempo.

É possível citar aqui casos em que os usuários tentaram utilizar logo de início ferramentas como o Gearbox, por este ficar sempre visível na tela. Neste caso, o CrystalWalk impede o acesso, e um aviso flutuante comunica que é necessário, primeiro, criar uma estrutura. $O$ Gearbox foi, de fato, utilizado corretamente por alguns usuários, após gerarem uma estrutura. Em outros casos, tentaram explorar os parâmetros de ângulo da célula, sendo possível quebrar o tipo de rede escolhida (FIG. 97e). Neste caso, o CrystalWalk alerta o usuário que a operação quebra a rede existente e dá a opção de prosseguir. Para outros mecanismos, tal como o Projection Cube, a exploração é permitida e propicia conhecimento de novas ferramentas, para uso quando for conveniente. Uma observação relevante é que usuários mais jovens tendem a possuir maior curiosidade e energia para explorar novidades e acabam descobrindo boa parte das funcionalidades. Por outro lado, usuários mais velhos são mais objetivos e ficam frustrados quando não conseguem executar as tarefas rapidamente.

Em sala de aula (FIG. 98a), o software se mostrou muito eficiente, pois a curva de aprendizado foi favorável e o professor não precisou gastar muito tem- 
po explicando o seu funcionamento. A esse respeito, o estudante I.B.U. afirmou: "O CrystalWalk possibilitou uma rápida construção do cristal de ferro alfa. Isso se deve ao fato também de termos utilizado e estudado o software em aula, assim melhorando o tempo de execução para a construção da estrutura. Não existiu dificuldade para a construção do mesmo". Estruturas mais complexas para o público de estudantes de graduação, como as hexagonais, foram criadas rapidamente pelos estudantes (FIG. 98b). Uma questão importante e que deve ser frisada aqui é que indivíduos pouco familiarizados com o conceito "rede + motivo = estrutura cristalina" não conseguem realizar as atividades de síntese sem apoio, apesar das diversas ferramentas e de um bom projeto de interface. Isso pôde ser observado nos testes com estudantes e com outros atores sociais mais familiarizados com métodos cristalográficos.

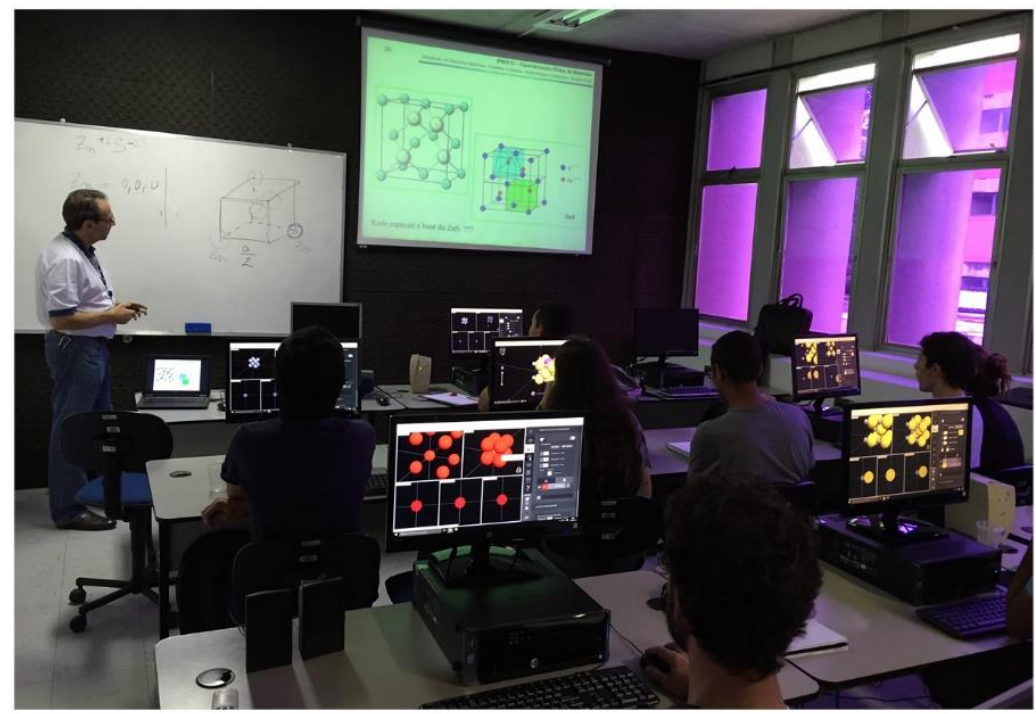

(a)

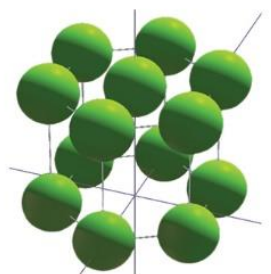

(b)

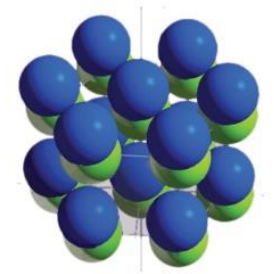

(c)

FIGURA 98 - Aula experimental utilizando o CrystalWalk: (a) situação de aula; (bc) exemplos de estruturas criadas no CrystalWalk por estudantes. Fonte: (a) do autor; (b-c) Bardella (2016d) (adaptado).

Finalmente, entende-se que o conjunto de medidas exposto nesta seção certamente será mais que suficiente para garantir acesso à ferramenta e agilidade na condução de tarefas de síntese, visualização e interação para a maioria dos usuários. Seja para aqueles mais jovens e/ou com maior familiaridade com tecnologias mais recentes, seja para aqueles mais velhos e/ou com maior familiaridade com tecnologias mais tradicionais, diferença que foi detectada e, então, 
materializada nos dois modos de operação da ferramenta: normal e tutorial. Considera-se que a exploração do desconhecido é relevante e saudável para o processo de aprendizado, tal como preconizado pelo construtivismo (seção 2.2), e o CrystalWalk propicia rápida convergência para a sequência recomendada de atividades, se o usuário assim desejar.

\subsubsection{Avaliação das funcionalidades didáticas}

Com a avaliação descrita nesta seção, se pretendeu analisar de maneira integrada a eficácia das funcionalidades didáticas do CrystalWalk. De maneira geral, será avaliada a acessibilidade de cada funcionalidade, a facilidade de uso, a disponibilidade de configurações pertinentes e a qualidade dos recursos produzidos. Entende-se que o sucesso das funcionalidades didáticas é essencial no empoderamento real dos atores sociais, o que será exposto em seção posterior (4.5.7).

Em uma primeira avaliação, abordam-se as possibilidades e características do conteúdo visual, verificando a adequação à publicação em mídias impressas, em documentos digitais e aos procedimentos de impressão 3D. Serão geradas imagens de estruturas, descrevendo os passos necessários e analisando-se a resolução e a qualidade visual. No caso de modelos 3D, será analisada a integridade do modelo e a exemplificação do processo de impressão 3D em duas tecnologias distintas, demonstrando as dificuldades e peculiaridades do procedimento e como o CrystalWalk suporta tais tecnologias.

Outra avaliação é da praticidade e do valor dos mecanismos de apoio didático propostos, como armazenamento e resgate (URL encurtada e QR code) de estruturas (on-line e localmente), da biblioteca de estruturas e das anotações associativas e sequenciais. Para isso, será demonstrado e analisado o processo de salvamento on-line e local, e o resgate por meio de URLs encurtadas e código $\mathrm{QR}$, além do salvamento, resgate e uso da biblioteca de estruturas. Também será analisado o mecanismo de anotações por meio da criação de uma narrativa didática, conforme detalhado na sequência.

Por fim, serão apresentadas demonstrações das possibilidades interativas, utilizando combinações das diversas tecnologias suportadas pelo CrystalWalk. Para isso, será criada uma sequência de experimentos, visando demonstrar o potencial didático das tecnologias e da integração delas, partindo 
do cenário atual, baseado em interações com mouse e teclado em monitores $2 \mathrm{D}$ tradicionais, até um cenário de imersão total, utilizando óculos imersivos e dispositivos de interação 3D.

\subsubsection{Geração de imagens}

Ao solicitar uma imagem na aba "Import \& Export" ("Importar e Exportar"), o CrystalWalk centraliza o modelo e oferece três tamanhos ao usuário, visando aplicações diversas. As imagens têm o formato PNG, tão compacto quanto o JPG e que permite filtrar a imagem facilmente com o uso de fundo branco. Além dessas opções, é possível apreciar na FIG. 99 outras, como a inclusão de um link encurtado e um QR code em mídias digitais e impressas, que remete ao projeto salvo pelo usuário. A imagem menor tem baixa resolução e pode ser usada para publicações mais leves em termos de dados, como sites voltados a dispositivos móveis ou para uso como versões reduzidas de demonstração (thumbnails). A imagem em tamanho intermediário pode ser usada em sites convencionais ou documentos digitais. A imagem em maior resolução pode ser usada como opção aumentada em websites ou para impressão. As imagens geradas demonstraram pouca ou nenhuma distorção de cor em um mesmo monitor e não houve percepção de serrilhado (aliasing).

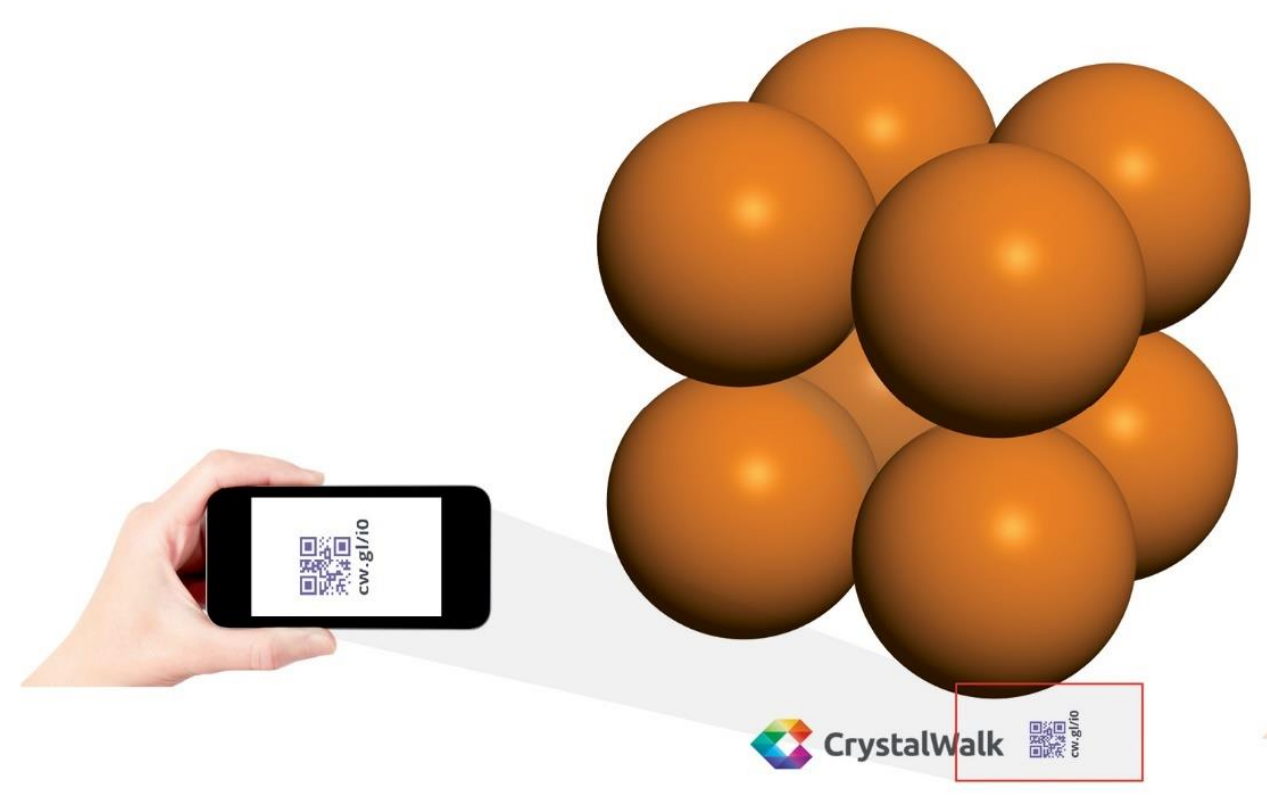

FIGURA 99 - Exemplo de imagens geradas pelo CrystalWalk: contendo link encurtado para o projeto salvo e QR code para acesso rápido. Fonte: do autor. 


\subsubsection{Geração de modelos digitais para impressão 3D}

Para impressão 3D, o primeiro passo é acessar o menu "Export STL", para geração de um arquivo do tipo STL, padrão atual para impressão. O usuário pode ajustar a resolução e definir a densidade de triângulos no modelo. Esse fator pode alterar o tempo de impressão e a qualidade do modelo final. Deve ser frisado que o processo de impressão 3D ainda não é simples ou intuitivo para o usuário final, sendo normalmente executado por prestadores de serviço especializados, que executam ajustes e definem outras configurações, de acordo as especificidades da tecnologia de impressão utilizada. No entanto, a regulagem de resolução diretamente no CrystalWalk facilita o processo, evitando o processamento posterior em outros softwares.

Os arquivos foram gerados com sucesso e adotam modelos esféricos do tipo icosfera, cujas faces possuem a mesma área. Trata-se de um tipo de esfera cuja superfície é formada por segmentos triangulares, cujos vértices são distribuídos de forma homogênea pelo todo da esfera (geodésica). Se comparados com esferas UV, produzem uma topologia mais realista usando uma quantidade muito menor de faces, reduzindo o tamanho final do arquivo (FIG. 100). Esferas UV são divididas em segmentos retangulares latitudinais e longitudinais, em uma construção que acarreta maior número de vértices nas regiões próximas aos pólos. Desta maneira, o ajuste de resolução e a adoção de icoesferas facilita a impressão 3D, mas o usuário ainda depende de um serviço de impressão ou de experiência e conhecimento na tecnologia de impressão que pretende utilizar, caso pretenda executar a impressão pessoalmente.

Por exemplo, impressão aditiva com filamento de plástico normalmente exige criação de geometria de preenchimento e de suporte, realizada automaticamente por software, mas cujos parâmetros são definidos pelo usuário. Impressão por camadas permite a criação de vazios internos, mas exige adaptações no modelo para retirar material em zonas sem acessibilidade, além de posterior processamento manual. Impressão aditiva com resina fotossensível deposita material por camadas apenas nas regiões úteis do modelo e podem necessitar ou não de material de suporte, dependendo da criação de uma estratégia de disposição do modelo. 


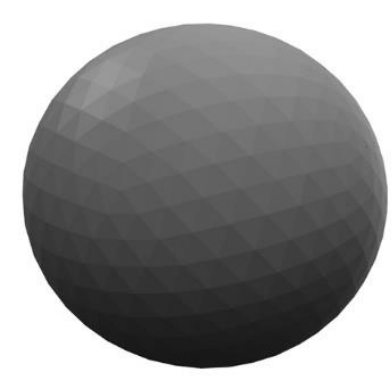

(a)

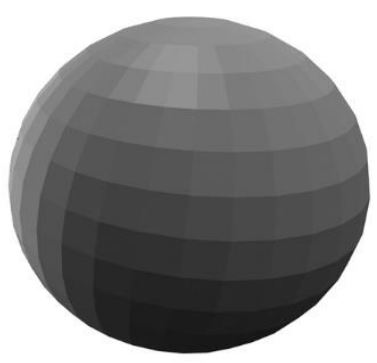

(b)

FIGURA 100 - Comparação entre tipos de modelos poligonais de esferas: (a) icosferas; (b) esferas UV. Fonte: do autor.

Foi conduzido um experimento de impressão com tecnologia aditiva junto a parceiros da Drexel University (Estados Unidos) visando demonstrar essas questões, avaliar a qualidade dos modelos gerados atualmente e coletar informações para futuras melhorias na funcionalidade de impressão 3D do CrystalWalk. Foi criado um modelo de célula unitária do cloreto de sódio utilizando a resolução máxima disponível (FIG. 101a). Esta representação contém apenas os volumes internos à célula unitária, ou seja, os átomos das faces foram representados parcialmente (cortados). Tal representação é inédita em modelos físicos, considerando a experiência dos atores sociais deste projeto.

$\mathrm{O}$ arquivo gerado possui pouco mais de $1 \mathrm{MB}$ e aproximadamente 19 mil triângulos. Na primeira interação com o técnico de impressão, foi requisitado maior contato entre os átomos do modelo para garantir estabilidade estrutural ao fim do processo, pois, no modelo, este contato era feito apenas por um vértice. A tecnologia de impressão utilizada (máquina modelo uPrint SE, fabricante Stratasys) deposita plástico ABS nas áreas sólidas e um material de suporte e preenchimento (SR-30, solúvel) nas áreas vazias para manter o modelo estabilizado durante a impressão e permitir a impressão de diversos modelos de uma só vez. Ao final da impressão, esse material de preenchimento é dissolvido em um tanque e qualquer volume solto será liberado. Desta maneira, é necessário garantir uma área mínima de contato entre os átomos para que o modelo final tenha uma estrutura resistente. A área mínima recomendada pelo técnico para esta tecnologia é de $4 \mathrm{~mm}^{2}$, mas, dependendo do peso das partes, a área deve ser maior. Para este experimento, esta área foi criada no programa Blender 3D, pois o CrystalWalk não oferece essa funcionalidade. No entanto, já foi indicada a necessidade de 
criação de geometria de contato entre os átomos e de oferecer um parâmetro de dimensão ou área de contato, o que poderá ser feito em versões futuras do CrystalWalk.

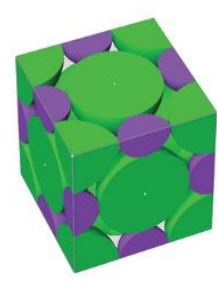

(a)

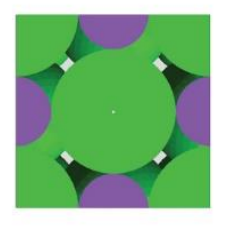

(b)

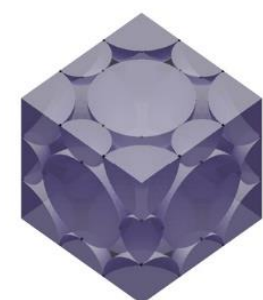

(c)

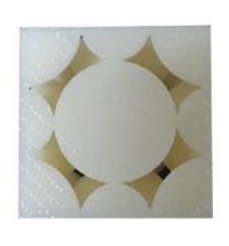

(d)

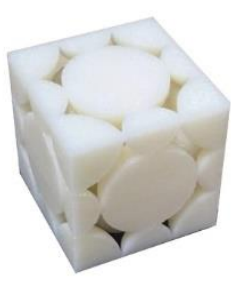

(e)

FIGURA 101 - Processo de produção de um modelo impresso: (a-b) modelo do $\mathrm{NaCl}$ produzido no CrystalWalk; (c) alteração estrutural no modelo; (d-e) modelo pronto. Fonte: (a-b) Bardella (2016d) (adaptado); (c-d) do autor.

A alteração requisitada foi conduzida com a adição manual de um cubo de $5 \mathrm{~mm}$ de lado em cada ponto de contato (FIG. 101b). Para evitar problemas e a possível perda do modelo, o procedimento ideal recomendado pelo técnico foi executar a fusão dos novos elementos ao volume das esferas, o que foi simples de realizar manualmente, especialmente em modelos do tipo B-Rep, representados apenas por suas faces e normais. Como discutido na seção 3.3.3.2, modelos do tipo CSG permitem simples execução desta fusão, especialmente com primitivas como esferas, cubos e cilindros. Isso indica uma opção promissora para o aprimoramento das capacidades de impressão 3D do CrystalWalk.

Para este experimento, optou-se por prosseguir sem a operação de fusão dos volumes, pois, geralmente, fusões simples em modelos de boa qualidade são bem resolvidas pelos programas disponibilizados pelos fabricantes das maquinas de impressão, sendo possível, geralmente, visualizar o modelo de impressão antes da operação. $O$ técnico realizou essa verificação e foi possível executar a impressão, que durou aproximadamente 12 horas, com 4 horas para dissolução do material de suporte, a um custo projetado de USD\$1000. O modelo final (FIG. 101c) reproduz fielmente o virtual, inclusive as facetas triangulares, tem $10 \times 10 \times$ $10 \mathrm{~cm}$, pesa 450 gramas, e possui uma cor denominada "marfim" (ivory, em inglês) muito utilizada em maquetes, por propiciar bom contraste visual. O modelo virtual, por sua qualidade, apesar de ainda não envolver geometria de suporte e contato entre os átomos, trouxe maior segurança no processo de impressão, faci- 
litou a correção de geometria no software da máquina, diminuiu o risco de perda do modelo e, finalmente, resultou em um modelo final com o aspecto visual esperado. Essa qualidade foi atestada pela leveza do modelo em quantidade de dados, regularidade dos triângulos e consistência das normais das faces, além de um arquivo em padrão STL estruturado de acordo com boas práticas.

\subsection{Experiencia com o modelo impresso do $\mathrm{NaCl}$}

Devido à alta qualidade do modelo tridimensional do $\mathrm{NaCl}$ produzido por impressão 3D, julgou-se apropriado expô-lo aos atores sociais para um experimento de interação livre e lúdica, o que se mostrou muito frutífero e trouxe ideias promissoras para o aprimoramento das funcionalidades de impressão 3D do CrystalWalk.

A reação geral ao primeiro contato com o modelo foi de surpresa e empolgação. Alguns ressaltaram a qualidade estética do modelo e quase todos confirmaram que nunca viram um modelo físico de célula unitária similar, caracterizado por átomos secionados e representação dos átomos por esferas rígidas. Aqueles que já tinham contato com modelos físicos conheciam apenas os modelos clássicos do tipo "bola e palito" e suas variações.

A cor foi considerada boa no geral, proporcionando sombras suaves e evitando pontos excessivamente brilhantes mesmo com luz direta. Alguns ficaram curiosos tanto com a textura de linhas paralelas como com as facetas triangulares, levantando questionamentos sobre a tecnologia de impressão, que foram devidamente esclarecidos e ilustrados com fotos do procedimento de impressão. Alguns consideraram o modelo um pouco pesado e ponderaram que os cantos poderiam ser perigosos, recomendando realizar chanfros e polimentos para meIhorar a segurança.

$\mathrm{Na}$ interação, muitos focavam em explorar as partes internas do modelo para tentar visualizar as relações geométricas com o átomo central, principalmente os pontos de contato. Notou-se um fato interessante, que o átomo central não precisaria de união física nesses pontos, pois é enclausurado pelos átomos vizinhos. Propôs-se, para ressaltar essa propriedade, que esse átomo fosse feito ligeiramente menor. Isso adicionaria um efeito lúdico, curiosidade sobre a técnica de produção do modelo e poderia ser interessante do ponto de vista didático, relativo aos contatos atômicos. 
Outra proposição foi criar um modelo que pudesse ser desmontável, o que aumentaria sobremaneira as possibilidades de exploração e de uso didático, permitindo melhor visualização do interior e estimulando a exploração do modelo. Foi proposto um modelo de encaixe com rosca perfeitamente factível por impressão 3D (FIG. 102) e a produção de peças suplementares dos átomos, onde estudantes poderiam ser desafiados a montar a célula unitária corretamente, fazer cálculos de volume atômico e fator de empacotamento de maneira visual, tridimensional e lúdica. Peças suplementares permitiriam visualizar a divisão volumétrica dos átomos e realizar somas de maneira interativa, simplesmente juntando diversas partes para compor um átomo. Por exemplo, os cantos deste modelo do $\mathrm{NaCl}$ representam 1/8 do átomo de cloro. Para constatar isso, o estudante pode juntar 8 partes para formar um átomo de cloro. Já o átomo de cloro posicionado no centro de todas as faces desta célula unitária representa apenas metade, e o estudante forma o átomo completo unindo apenas outra metade. Comparando as composições, o estudante perceberia que os átomos têm o mesmo tamanho. As partes dos átomos também podem ser usadas para compor partes das células unitárias vizinhas adjacentes.

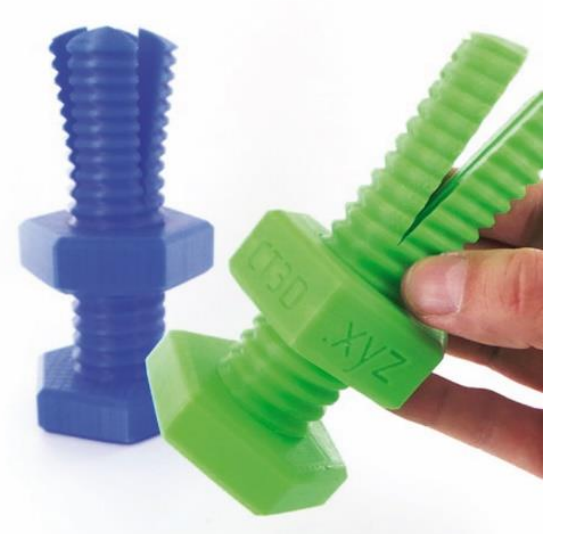

FIGURA 102 - Exemplo de encaixe por rosca para criação de modelos desmontáveis por tecnologia de impressão 3D. Fonte: do autor.

Em suma, o experimento foi muito positivo e levantou diversas ideias interessantes, além de novas possibilidades didáticas para modelos físicos de esferas rígidas produzidos por impressão 3D, o que pode estimular novamente 0 interesse por modelos físicos no ensino de ciência dos materiais. 


\subsubsection{Uso off-line do CrystalWalk}

Outra possibilidade de publicação é por meio da portabilidade completa da aplicação em HTML, permitindo o uso da maioria das funcionalidades do CrystalWalk, mesmo sem acesso à internet. Inclusive, entende-se que o maior valor dessa modalidade de publicação está na possibilidade de armazenar um estado definido anteriormente pelo usuário, contendo um modelo, anotações, referências e outras informações. O usuário obtém o arquivo da aplicação portátil em formato ZIP no menu "Save a CrystalWalk Project" ("Salvar um projeto CrystalWalk"). Ao abrir o HTML em um navegador sem acesso à internet, a aplicação é executada normalmente, exceto as funcionalidades que dependem de conexão, que ficam, então, desabilitadas, como salvar, carregar ou compartilhar um projeto on-line ou acessar itens da biblioteca. O modelo gerado anteriormente foi resgatado corretamente e foi possível interagir e alterar os parâmetros de visualização.

\subsubsection{Criação de uma narrativa didática}

O sistema de anotações associativas permite ao professor adicionar informações para auxiliar o entendimento de conceitos. Para utilizar a funcionalidade, o usuário deve primeiro escolher um um átomo ou configurar uma cena contendo planos, direções e outros elementos visuais auxiliares, como planos e arestas das células unitárias. No caso do átomo, surge um menu flutuante que oferece a opção de criar uma anotação. Um átomo que possui uma anotação recebe um destaque visual em seu perfil (FIG. 103a). Todas as anotações são criadas no menu "Comments \& Narratives" ("Comentários e Narrativas"), no qual o usuário pode dar um título à estrutura produzida e escrever texto ou links para uma página ou para imagens on-line (FIG. 103b). No caso de uma cena, basta configurá-la e vincular uma anotação para que, ao ser resgatada, se restaurem os parâmetros da cena criada.

As anotações, associadas às cenas configuradas pelo usuário, podem ser sequenciadas pelo professor, criando o que foi designado, neste trabalho, pelo termo "narrativa didática". Uma narrativa pode ser comparada a um storyboard, onde uma história é contada sinteticamente com imagens e texto. Cada anotação criada fica em uma lista (FIG. 103b), e o usuário pode ordenar as anotações conforme as cria ou em outro momento que desejar, manipulando a sequência diretamente na lista. Sequências de anotações podem ser armazenadas em registros 
(ou páginas) diferentes, viabilizando a criação de diversas narrativas. A opção de separar por páginas ou registros se mostrou mais prática, pois a criação de listas de anotações separadas poderia confundir o usuário, e o instrutor pode criar uma página para cada assunto que desejar tratar.

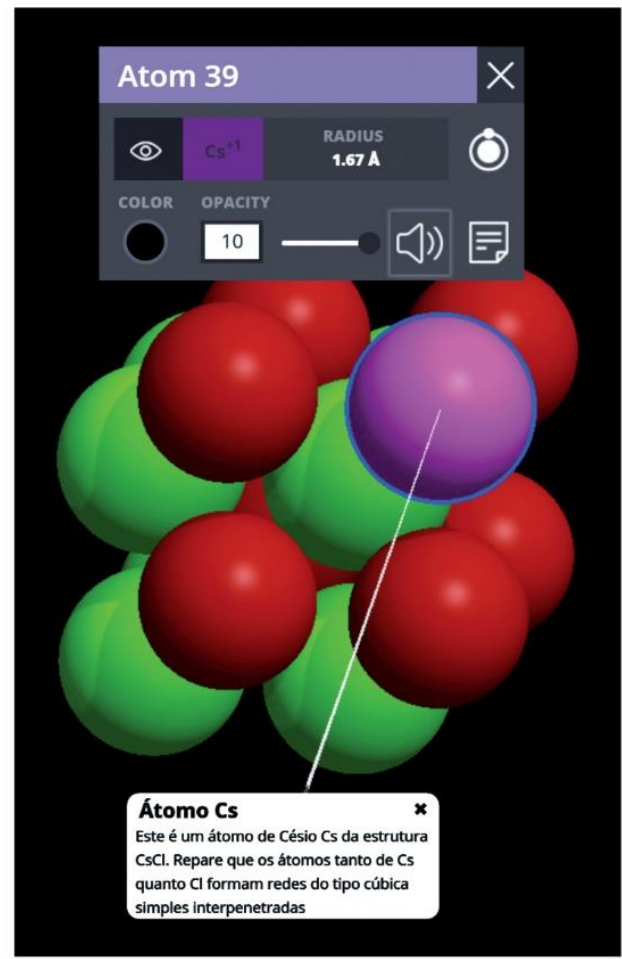

(a)

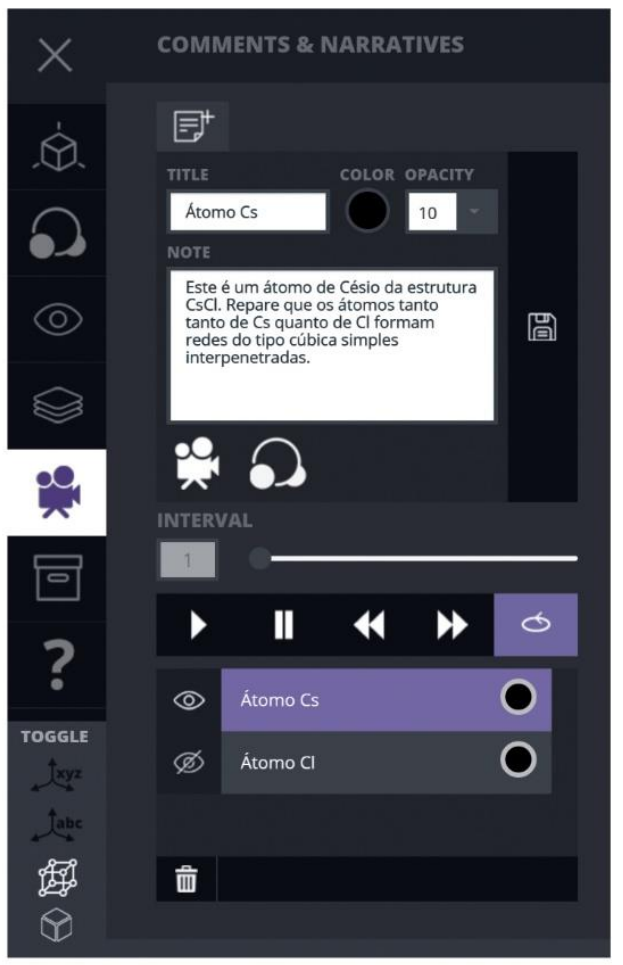

(b)

FIGURA 103 - Narrativas didáticas podem ser produzidas pelo CrystalWalk por meio da (a) criação de anotações, (b) anotações essas que podem ser sequenciadas. Fonte: Bardella (2016d) (adaptado).

A seguir, é apresentada como exemplo de narrativa didática uma narrativa utilizada em aulas experimentais ministradas com o uso do CrystalWalk. Por meio dessa narrativa, o professor procurava abordar a identificação de vizinhanças atômicas no $\mathrm{NaCl}$. $\mathrm{Na}$ seção 4.5.3.2.1, são descritas todas as funcionalidades do CrystalWalk que suportam um melhor entendimento deste problema didático. Deve ser frisado que, na construção da narrativa aqui demonstrada, foram utilizadas apenas algumas das funcionalidades didáticas disponíveis.

- Anotação 1 (FIG. 104): Exibe a rede já criada, centralizada na tela, com arestas e faces representadas e rotação automática ativada. $O$ 
texto junto à ferramenta Projection Cube passa instruções: "Para compreender melhor a geometria desta rede, altere a vista com o mouse e visualize a rotação. Observe também o sistema de coordenadas durante a rotação. A seguir, desative a rotação e explore as diferentes vistas disponíveis no Projection Cube".

- Anotação 2: Mostra o motivo já construído em um ponto da rede, com o seguinte texto junto à ferramenta Gearbox: "Observe o motivo do $\mathrm{NaCl}$. Retorne à célula unitária utilizando o Gearbox, execute rotações e repita. Por fim, obtenha vistas dos eixos $x, y$ e z".

- Anotação 3: Mostra na janela do cristal a mesma vista anterior do motivo e, na janela da célula unitária, a célula unitária completa, adotando o átomo de cloro com uma leve transparência, com a seguinte anotação, posicionada na janela do eixo $Z$ do motivo: "Rotacione a vista acima até obter esta vista. Confirme se está correto na janela da célula unitária. Faça o mesmo para os outros eixos do motivo".

- Anotação 4: É exibida a célula já alinhada com o eixo $Z$ do motivo e uma anotação junto a ela: "Observe na vista ao lado que esta vista coincide com o eixo Z do motivo. Rotacione para o eixo Y (para cima) e repita o movimento algumas vezes, observando a relação geométrica entre as células de Cloro e Sódio".

- Anotação 5: É exibida a célula já alinhada com o eixo $X$ do motivo e uma anotação junto a ela: "Observe na vista ao lado que esta vista coincide com o eixo $X$ do motivo. Rotacione para o eixo $Y$ (direita) e repita o movimento algumas vezes, observando a relação geométrica entre os átomos de Cloro e Sódio".

- Anotação 6: Mostra a célula em rotação automática e uma anotação junto ao menu com as instruções: "Oculte algumas vezes o átomo de cloro durante a rotação. Faça o mesmo para o sódio. Alterne para uma vista de topo e repita".

- Anotação 7: Em uma vista da célula unitária cortada, com faces mais claras para melhor contraste, o texto instrui: "Rotacione a vista até identificar os átomos em contato. Note também os pontos onde os átomos intersecionam as faces da rede". 
- Anotação 8: Em uma vista em perspectiva, o texto solicita: "Navegue em primeira pessoa com o mouse e as teclas WASD e confirme os contatos atômicos presentes".

- Anotação 9: Em uma vista do cristal, a anotação junto ao Gearbox indica: "Explore livremente a passagem entre os níveis do Gearbox".

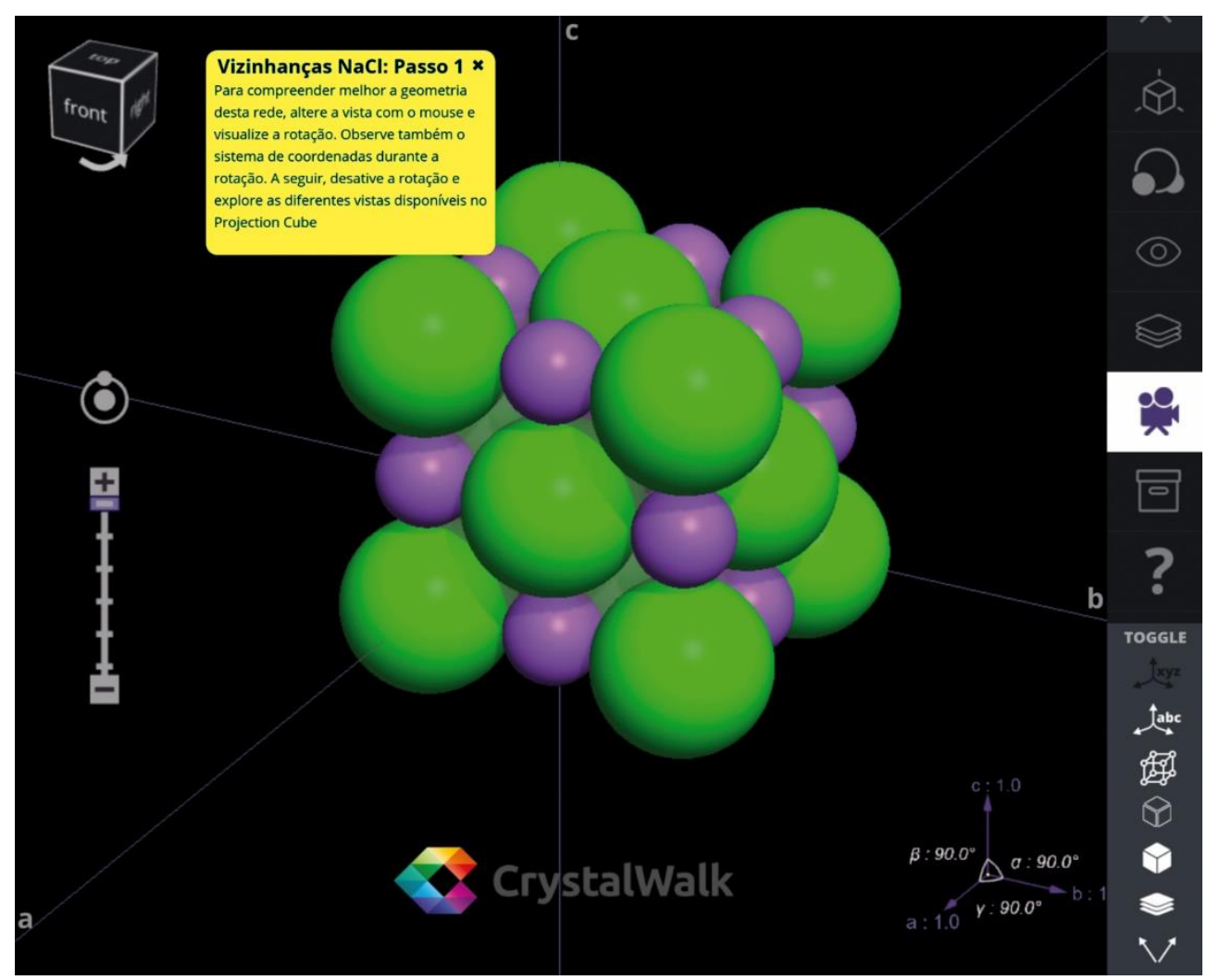

FIGURA 104 - Uso da ferramenta de anotação em um passo de uma narrativa didática. Fonte: Bardella (2016d) (adaptado).

Este foi um exemplo de uso das ferramentas de anotação para a construção de narrativas didáticas e do poder desta técnica no ensino de estruturas cristalinas, valendo-se de todos os recursos do CrystalWalk. Neste experimento, buscou-se expor o estudante ao modelo utilizando visualizações progressivas e dinâmicas, alternando representações como vistas e rotações automáticas buscando o máximo de fluidez, além de filtragem de objetos e interação exploratória. Entende-se que uma experiência suficientemente longa, dinâmica e fluida com o modelo ajuda a compreendê-lo melhor e mais rapidamente. Como demonstrado, é possível registrar estados de visualização, incluindo posição de câmera e configurações visuais, aliando-os a anotações 
textuais, o que favorece a organização do aprendizado e a transmissão de instruções, conceitos e dicas aos estudantes.

Deve ser frisado que existem inúmeras narrativas possíveis, dependendo apenas da criatividade do professor e de seu conhecimento e experiência com o software. A multiplicidade de abordagens narrativas pode trazer inúmeros ganhos no aprendizado, considerando, inclusive, as variações dos perfis dos estudantes. Além disso, o mecanismo de anotações pode ser utilizado também por estudantes, para registrar conceitos desenvolvidos em aula e criar material de estudo individual ou em grupo.

\subsubsection{Biblioteca de estruturas}

A biblioteca de estruturas permite ao usuário explorar estruturas criadas pelo pesquisador, pelo GVCM e também por outros usuários. Essa funcionalidade vale-se do CWLY e de serviços em nuvem descritos na seção 4.4.1. O acesso à biblioteca se dá pelo menu "Load a Saved CrystalWalk Project" ("Carregar e Salvar um Projeto CrystalWalk"), bastando buscar uma palavra-chave. Para salvar uma estrutura na biblioteca, basta construí-la e, no mesmo menu, acionar o botão "Save Online" ("Salvar On-line"), como demonstrado na FIG. 105a. Os testes de acesso foram bem-sucedidos para todas as estruturas armazenadas e para 3 outras criadas posteriormente em dispositivos, redes e dias diferentes, atestando o correto funcionamento do serviço de armazenamento e da funcionalidade. Foi verificado o acesso por link (FIG. 105b) e também por QR code (FIG. 105b-c), sendo este último mais útil no caso de dispositivos móveis. 


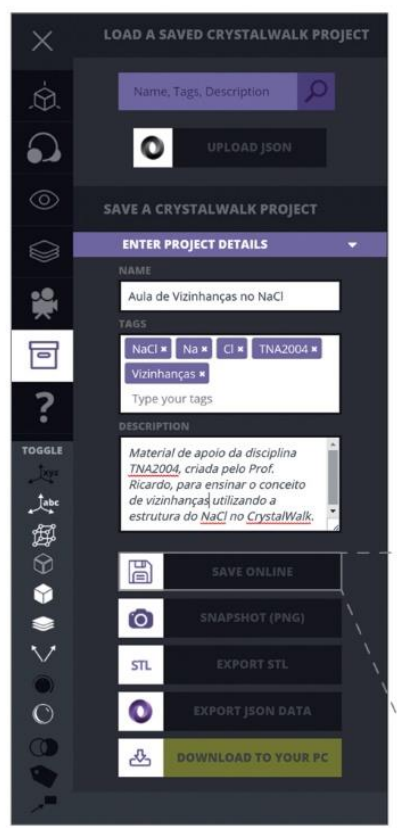

(a)

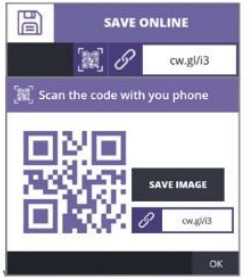

(b)

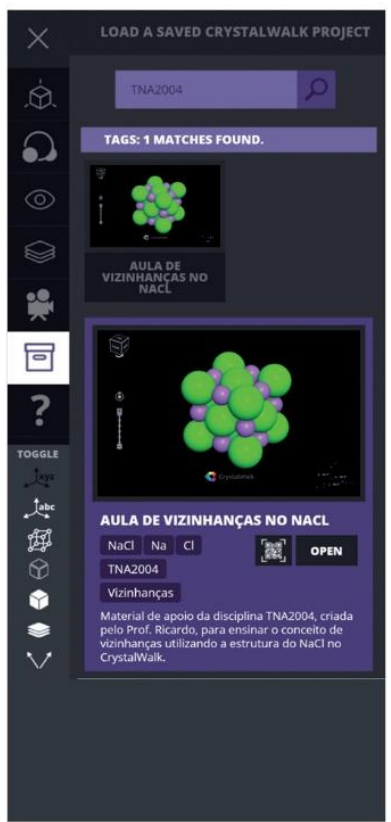

(c)

FIGURA 105 - Ilustração do procedimento para salvar uma estrutura: (a) salvar uma estrutura na biblioteca de estruturas, utilizando título, descrição e tags; (b) endereço encurtado e QR code para resgate; (c) busca e resgate na biblioteca por palavra-chave. Fonte: Bardella (2016d) (adaptado).

\subsubsection{Suporte/tutoriais}

O sistema foi projetado para minimizar a necessidade de meios externos de suporte, como vídeos e documentos de texto. Para isso, foram determinados dois modos de interação - normal e tutorial - e a interface foi ordenada e organizada para refletir a sequencia recomendada de ações. Desta forma, os usuários iniciantes podem escolher o modo tutorial logo ao acessar o site da ferramenta, se assim preferirem. O modo tutorial foi efetivo para instruir os iniciantes, pois induz uma sequência básica e recomendada de ações. Os destaques visuais, aliados às restrições de ações, impedem o uso livre das funcionalidades, praticamente obrigando o iniciante a seguir os passos recomendados. Os usuários seguiram naturalmente os passos e foram instruídos, na sequência, a escolher o modo normal. A maioria dos usuários conseguiu repetir a sequência imposta no tutorial. Ao serem inquiridos sobre a imposição de passos no modo tutorial, os usuários iniciantes não se revelaram incomodados, pois naquele momento desejavam aprender o básico do sistema.

Em outro teste, os usuários foram expostos ao sistema sem nenhum auxilio. Alguns conseguiram realizar atividades de síntese e visualização sem difi- 
culdades, outros tiveram dúvidas, mas as restrições e caixas de diálogo explicativas, em geral, levaram-nos a concluir as tarefas esperadas. No entanto, alguns usuários tiveram dificuldades com a linguagem visual e modo de interação da interface. Especula-se que isso se deve à falta de costume com interfaces minimalistas contemporâneas, pois os mesmos usuários demonstraram preferência por tipos mais antigos de interface, que se valem mais de texto nos menus, ao invés de ícones.

Considera-se que o sistema de tutorial aliado às restrições de funcionalidades e às caixas de texto descritivas foram muito bem-sucedidos para instruir novos usuários, e que a interface forneceu auxílio na descoberta das funcionalidades mais avançadas. Os usuários elogiaram a separação em dois modos de uso, permitindo tanto ao iniciante instruir-se sem recorrer a outros recursos e documentos como ao usuário avançado evitar as restrições do modo tutorial.

\subsubsection{Avaliação de possibilidades interativas}

$\mathrm{Na}$ especificação do CrystalWalk, demonstra-se uma preocupação em prover suporte a tecnologias avançadas de interação e visualização utilizadas em realidade virtual, mas não houve levantamento, detalhamento nem desenvolvimento de funcionalidades específicas para essas tecnologias. Para demonstrar possibilidades, benefícios, limitações e verificar a recepção dos usuários, foram conduzidos experimentos preliminares com as tecnologias consideradas mais acessíveis, seguindo os preceitos deste trabalho. No entanto, deve ficar claro que a maioria dessas tecnologias ainda não foram oficialmente lançadas ao público em geral e, na prática, estão ainda restritas a uma pequena comunidade de desenvolvedores. Por este motivo, existem dificuldades de configuração tipicamente associadas a dispositivos em fase de desenvolvimento que, apesar de não representarem grande barreira a um desenvolvedor, seriam inaceitáveis em produtos regulares. Em muitos casos, os dispositivos apresentam compatibilidade limitada com certos sistemas operacionais e exigem a presença de hardware específico no computador do usuário, o que vai contra os preceitos deste trabalho. Ainda assim, os dispositivos selecionados foram considerados os mais acessíveis no momento e admite-se que tais questões serão abordadas e resolvidas pelos fabricantes para o lançamento das versões finais ao mercado e, portanto, tais questões não influíram nesta avaliação. Já as limitações das funcionalidades essenciais serão plenamente abordadas. 
Sendo a imersão um dos aspectos mais fundamentais da realidade virtual, julgou-se propício basear o experimento no conceito de imersão progressiva, discutido na seção 3.3.5.1.1. A progressão imersiva foi balizada principalmente no modelo perceptivo (visual e interativa) de McMahan (2011) e Ragan et al. (2015), mas buscou-se incorporar também o modelo multidimensional conceitualizado por Thon (2008). Thon (2008) não discute progressão, mas entende-se que seu modelo é compatível com o conceito. Aqui, será considerado que a progressão se dá pelo incremento de dimensões, assim como pelo aprimoramento de cada uma das dimensões. Dentre as propriedades previstas por McMahan (2011), as propriedades visuais consideradas aqui foram estereoscopia e campo de visão, e as interativas, manipulação 2D e 3D.

A sequência de configurações tecnológicas proposta para abordar essa progressão neste trabalho, representada na FIG. 106, foi a seguinte: PC (computador pessoal) tradicional; tabletop ou tablet; PC ou tablet e interação com Leap Motion (em 2D e em 3D); e, por fim, a situação de máxima imersão perceptiva possível, dentro dos limites de recursos do projeto, a combinação de Oculus Rift com Razer Hydra. A fim de comparar as opções, foram escolhidas uma estrutura simples (o cloreto de césio - $\mathrm{CsCl}$ ) e interações básicas (navegação, zoom, rotação e seleção de átomos e planos). Entende-se que a configuração deste experimento privilegia o modelo perceptivo de McMahan (2011). Pode-se dizer que aplicar o modelo proposto por Thon (2008) depende mais de detalhes de projeto relativos à interação do sistema. No entanto, entende-se que as tecnologias aqui experimentadas podem potencializar alguns desses elementos, especialmente nas dimensões espacial e lúdica. As dimensões narrativa e social dependem de recursos do CrystalWalk que não foram explorados neste experimento. Para que todas as funcionalidades sejam acessíveis, é preciso adaptar o sistema para esses dispositivos, o que não foi realizado neste trabalho. Deve ser frisado que o modelo de Thon (2008) depende ainda de experiência e familiarização com o sistema, o que é relevante no caso de dispositivos interativos experimentais, como os utilizados neste trabalho.

Além dos atores sociais do projeto, foram convidados outros 5 participantes. Todos os participantes têm experiência em navegação tradicional e nenhum deles havia experimentado previamente dispositivos estereoscópicos e de interação tridimensional. 


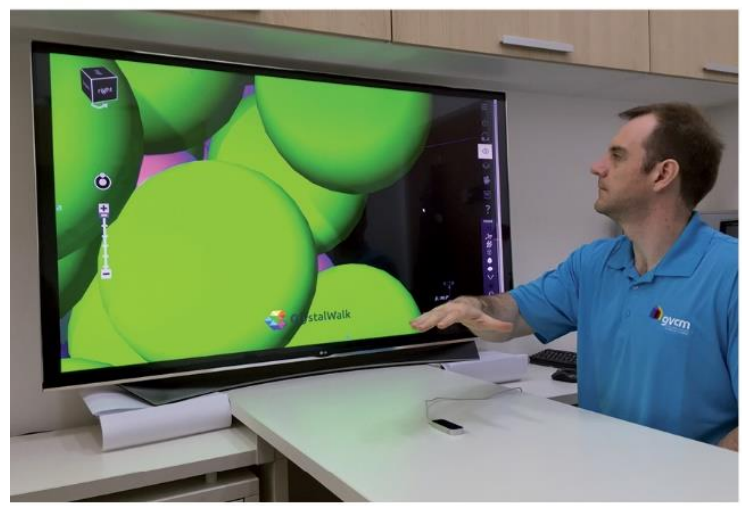

(a)

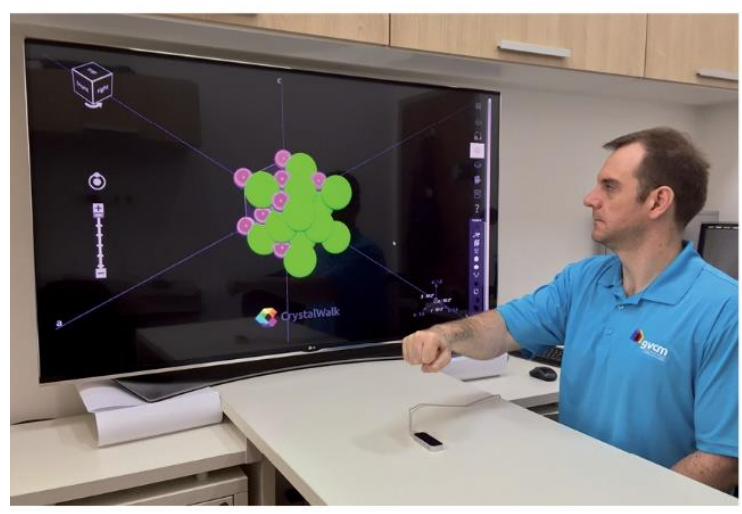

(c)

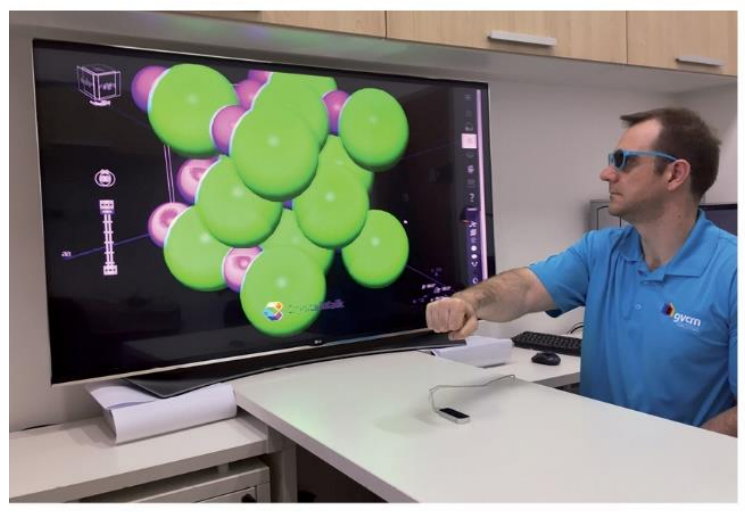

(e)

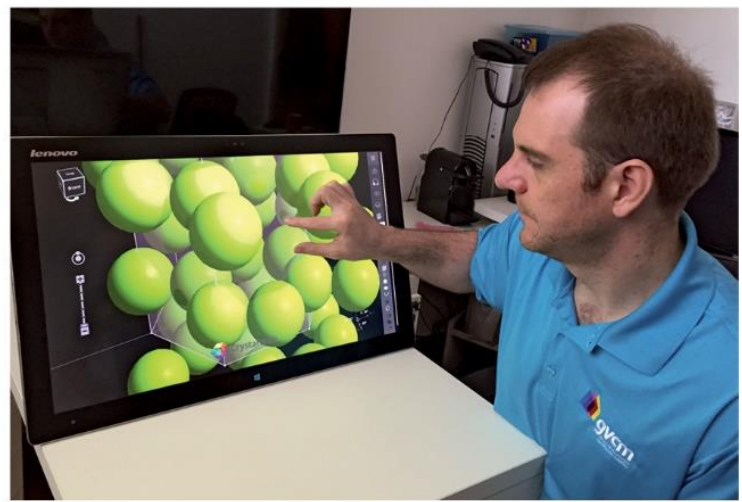

(b)

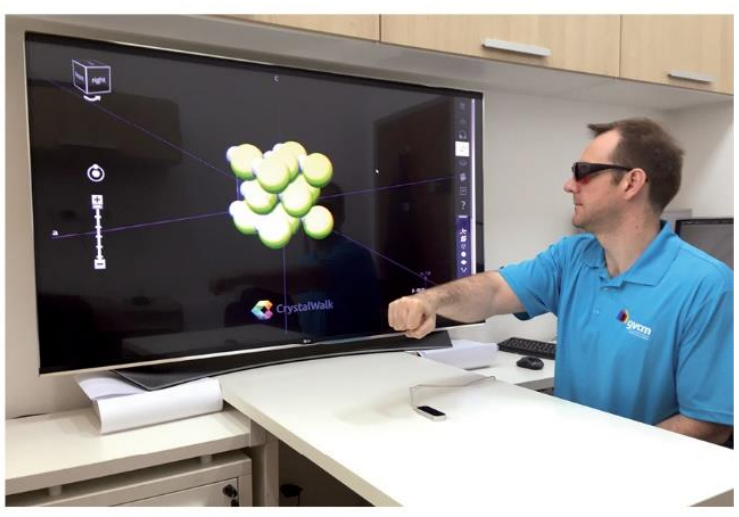

(d)

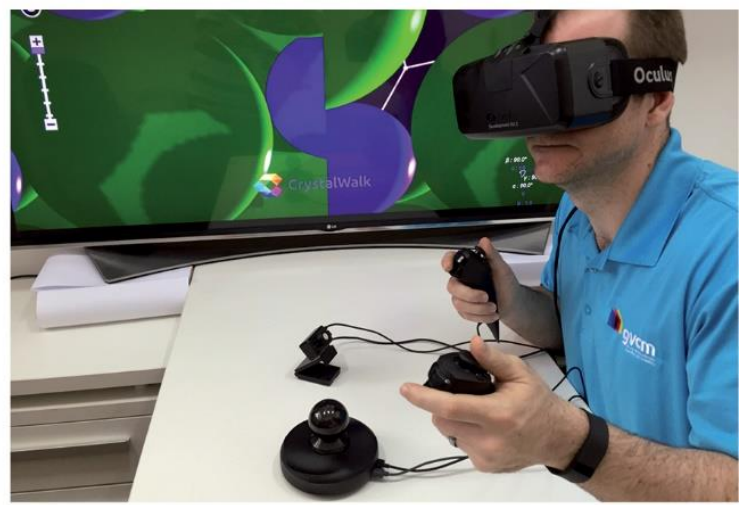

(f)

FIGURA 106 - Experimento de progressão imersiva: (a) PC com mouse e teclado; (b) tabletop ou tablet de grandes dimensões; (c) dispositivo Leap Motion e monitor normal; (d) Leap Motion e monitor 3D em modo anaglifo; (e) Leap Motion e monitor 3D em modo polarizado; (f) HMD Oculus Rift e Razer Hydra. Fonte: do autor.

\subsubsection{PC}

A interação no PC tradicional (FIG. 106a) foi considerada a referência para toda a avaliação de possibilidades interativas apresentada ao longo desta seção. Pode-se considerar que a maioria dos usuários já tem experiência considerável em meios de interação tradicionais como mouse e teclado. 
A partir do exposto na seção 3.3.5.1.1, pode-se inferir que o projeto geral e as funcionalidades do CrystalWalk dão suporte a praticamente todas as dimensões do modelo de imersão multidimensional de Thon (2008), atraindo a atenção do usuário sem se valer do isolamento perceptivo. Em suma, diversos recursos de visualização e contextos de uso destacam os objetos tridimensionais mais relevantes, além de prover a consistência espacial recomendada por Thon para potencializar a dimensão espacial da imersão.

Quanto à dimensão lúdica, a possibilidade de escolha entre os modos tutorial ou normal definem e explicitam as liberdades de ação e o sequenciamento de atividades de síntese e visualização, permitindo foco nos elementos mais relevantes da atividade desafiadora, que é a criação e compreensão de estruturas cristalinas. A presença seletiva de informação adicional e instruções de uso das funcionalidades permitem a adaptação do usuário de acordo com sua experiência.

Quanto à dimensão narrativa, novamente, pode-se afirmar que usuários de diferentes níveis de proficiência têm condições de conhecer a lógica e as regras do ambiente e quais são os objetivos no uso da ferramenta. Ao prover tanto um guia da sequência das atividades como as instruções para executá-las, sobra ao usuário apenas se concentrar em atingir as metas e os objetivos definidos. A sequência sugerida ou induzida para os passos das tarefas de síntese, os mecanismos de persistência dos dados e ferramentas como o Gearbox, que também induz uma sequência de visualização, definem metas intermediárias nítidas que dividem o problema global em passos menores e estimulam a exploração.

Finalmente, a dimensão social também é contemplada em certa medida por interações assíncronas entre usuários, propiciadas tanto pelo mecanismo de anotações como pela biblioteca de exemplos. As anotações promovem diálogos e definem papéis, especialmente de instrutores e aprendizes, que podem mudar ao longo do tempo. Todos os incrementos de informação podem ser preservados e propagados para outros usuários por meio dos mecanismos de salvamento. Esses elementos estimulam a cooperação e interação, incrementando a dimensão social.

\subsubsection{Tabletop}

O tabletop é um tablet de grandes dimensões (FIG. 106b). As interações em tablets podem ser consideradas mais diretas e intuitivas se comparadas 
à interação com mouse e joysticks, devido ao mapeamento direto dos movimentos dos dedos para movimentos no plano da tela. Para interações tridimensionais, o tablet ainda pode reproduzir a interação com o mouse, procedimento usual em muitas aplicações. A dimensão do tabletop permite usufruir plenamente do recurso multitouch, que suporta até 10 dedos, o que não é possível ou prático em tablets tradicionais. A experiência confirmou as expectativas, pois os usuários sentiram-se confortáveis com a interação por toque e interagiram com o modelo sem problemas, apesar da falta de um mouse. Quando comparado a mouse e teclado, a impressão geral foi de maior fluidez e velocidade para acessar menus e opções, selecionar objetos e em operações que utilizam múltiplos dedos ou gestos como zoom. Já as rotações foram conduzidas de maneira similar ao mouse, mas a regulagem da velocidade de giro é mais intuitiva, especialmente em uma tela de grande dimensão. A experiência também gerou ideias interessantes, como o uso de múltiplos dedos para facilitar rotações, escolhendo eixos de maneira precisa, além da navegação, para a qual vislumbra-se melhorar a escolha da direção de navegação. De fato, apesar da interação ainda ser bidimensional, a funcionalidade de toque com múltiplos dedos promete inúmeras melhorias na interação em relação ao mouse e às telas de pequena dimensão. No entanto, os tabletops ainda são custosos, e vislumbra-se seu uso em caráter experimental apenas em instituições de ensino de ponta.

No modelo de Thon (2008) entende-se que houve uma progressão na dimensão lúdica, pois a diminuição de abstração na interação com o ambiente propiciado pela interface sensível ao toque permite direcionar o foco para os desafios mais relevantes para o aprendizado. A mudança do PC para o tabletop preserva todos os recursos visuais que dão destaque aos elementos mais relevantes do cenário virtual e promovem consistência espacial, mantendo a dimensão espacial no mesmo nível que o atingido no PC. As outras funcionalidades não são alteradas; portanto, as dimensões narrativa e espacial também são mantidas no nível da referência.

\subsubsection{Leap Motion + 2D}

O Leap Motion permite interação tridimensional direta com o ambiente virtual (FIG. 106c). Ou seja, a abstração do mouse ou tablet são eliminadas. No entanto, a visão do usuário ainda é bidimensional. A implementação da integração 
com o Leap Motion foi considerada satisfatória, pois não foram detectados atrasos durante a interação. Por outro lado, apesar das alegações dos criadores, a detecção de gestos e dedos não é robusta, o limitado cone de detecção não permite um uso eficiente das duas mãos e o uso de infravermelho sujeita o dispositivo a muitas interferências, de lâmpadas e mesmo da tela de um computador. Foi necessário apagar as luzes do ambiente para evitar tais interferências, o que praticamente inviabilizou o uso do dispositivo nos testes. Constatou-se também que a detecção do centro e ângulo da mão era razoavelmente precisa. Assim, os métodos de interação implementados utilizam apenas uma das mãos. De fato, os usuários precisaram de um tempo de ambientação e demoraram a captar o modo de funcionamento do dispositivo. É necessário manter a mão dentro do cone de visão do sensor, e muitos usuários achavam que o movimento era irrestrito.

No primeiro modo de interação, usa-se a mão como um joystick 3D. Após resolver dúvidas e explicitar os limites de interação, os usuários praticaram o modo de interação Joystick 3D. A navegação e rotação mostraram-se mais intuitivas, pois se diminui a abstração dos dispositivos bidimensionais: basta o usuário virar ou levar a mão para onde deseja, diretamente. O método de joystick 3D mostrou-se efetivo tanto para lidar com as restrições do dispositivo como para explorar as melhores capacidades dele. No entanto, apesar da simplicidade e de existir interações similares no universo de aplicações tridimensionais, os usuários demoram a captar o princípio de funcionamento da técnica. Após um tempo de prática e explicitação da técnica, os usuários conseguiram regular a velocidade de navegação e executar rotações a qualquer momento, o que não é possível com mouse ou tablet e, em comparação a estes, permite maior velocidade de interação. Operações de seleção são simples, mas exigem que o usuário navegue até o objeto e faça o movimento de fechar a mão, como se estivesse realmente agarrando um objeto. Não foi possível utilizar o menu, pois o método de interação é exclusivamente tridimensional, sendo necessário auxilio de mouse e teclado para acesso aos menus e opções. No entanto, isto deve-se apenas ao caráter experimental, sendo possível contornar essa limitação com maior tempo de desenvolvimento.

Alguns usuários também se confundiram com a forma de uso das mãos no joystick 3D, especialmente aqueles com pouca experiência com aplicativos 3D, pois não compreendiam que todos os ângulos e movimentos eram relativos à mão, e não absolutos. Um fato comum no uso do Leap Motion é o cansaço dos 
ombros e, no caso do método de joystick 3D, também do punho. O uso de apoios para o cotovelo diminui o problema, mas restringe a movimentação.

O segundo modo de interação, radial, adota a implementação do joystick 3D, mas permite apenas rotação e movimentação relativas ao centro do modelo. Movimentos laterais da mão causam rotações, e não deslocamentos. Esse modo nitidamente facilita a interação e contorna as confusões do primeiro modo, pois o modelo mantém-se sempre à vista, no centro da tela. No entanto, não permite boa visualização do interior dos modelos. Esse modo pode ser utilizado para os iniciantes na interação com o Leap Motion.

Assim, entende-se que as limitações do dispositivo e da técnica escoIhida levaram a uma forma de interação que funciona bem para um modo em primeira pessoa. Além dos benefícios de navegação, os usuários ficaram empolgados com a novidade do dispositivo e com a inédita experiência propiciada, principalmente com a possibilidade de usar o movimento de agarrar para escolher um objeto. Apesar de suas limitações, o dispositivo é muito compacto e tem um preço muito acessível. Entende-se que qualquer instituição de ensino ou mesmo um instrutor pode adquiri-lo facilmente. Isso certamente ajuda a viabilizar e a trazer a interação 3D para a sala de aula.

Considerando o modelo multidimensional de Thon (2008), mais uma vez as mudanças podem propiciar redução de abstração, mas, neste caso, também podem adicionar desafios indesejáveis, como dificuldades com interferências, com o cone de detecção limitado do Leap Motion ou com a adaptação exigida pelos novos métodos de interação. A impossibilidade atual de interação direta com os menus através do Leap Motion praticamente elimina as dimensões narrativa e social e também introduz dificuldades ou interrupções no fluxo de interação. No entanto, como já discutido, essa não é uma preocupação atual neste experimento. Nesse sentido, tanto a dimensão lúdica como a espacial desta versão ficam ligeiramente comprometidas em comparação ao caso anterior, devido à quebra do fluxo de interação. No entanto, existem duas opções para contornar essa questão e restaurar as dimensões espacial e lúdica a níveis similares aos da referência ou ligeiramente superiores. A primeira é adaptar os menus para funcionarem diretamente com o Leap Motion. A segunda é utilizar um recurso do dispositivo que permite simular uma tela sensível ao toque ou simplesmente controlar a seta do mouse, o que permitiria, no mínimo, utilizar os mesmos menus da aplica- 
ção original e restaurar as dimensões narrativa e social aos níveis da referência. Esta opção é considerada a mais promissora e deve ser explorada em experimentos futuros. Quanto a dificuldades de aprendizado, após experimentação e domínio da técnica de interação, considera-se que as liberdades propiciadas pela interação 3D direta podem incrementar a dimensão lúdica.

\subsubsection{Leap Motion + 3D}

Neste caso, além da interação 3D propiciada pelo Leap Motion e a técnica de joystick 3D, o usuário também tem a visão 3D, propiciada pelo grande monitor estereoscópico passivo (65 polegadas), o que propicia um grande campo de visão (aproximadamente $80^{\circ}$ ), adotando-se a distância mínima (1 metro) recomendada pelo fabricante (FIG. 106d). A implementação da estereoscopia passiva foi considerada satisfatória para a tecnologia de polarização adotada pelo monitor utilizado, pois a imagem ficou nítida e não foram detectados "fantasmas" nas imagens de cada olho. A criação de uma imagem para cada olho foi executada com sucesso pelo CrystalWalk, apesar de exigir mais recursos computacionais, pois cada quadro deve ser gerado duas vezes. Isso não deve ser um problema para pequenos cristais, mas deve prejudicar ou inviabilizar a interação para cristais maiores.

Para evitar confusões e aumentar o campo de visão, o menu foi retirado, assim como no caso anterior. Conforme esperado, as interações se tornaram mais ágeis e intuitivas, pois o senso de profundidade se aproxima do real. Assim, em comparação ao caso anterior, as ações foram mais rápidas. Devido à maior imersão visual, o problema da posição relativa à mão foi reduzido para muitos usuários, enquanto para outros ficou mais difícil manter a mão na restrita área de detecção. No entanto, a técnica do joystick 3D fornece feedback imediato para deslocamentos excessivos, que o usuário pode compensar ativamente, sem precisar olhar para sua mão. A proficiência neste ponto é adquirida com a experiência. Como é comum em técnicas estereoscópicas, alguns usuários sentiram leves tonturas. Mais uma vez, o modo radial simplificou a interação, e a novidade estimulou diversos usuários e despertou maior interesse na exploração de simples estruturas cristalinas. A partir da avaliação do desempenho nas tarefas básicas em comparação aos casos anteriores e das observações dos participantes, temse a percepção que a união de interação 3D e visão estereoscópica levou a expe- 
riência a um outro nível de imersão. Neste, a interação com o mundo virtual fica mais rica e intuitiva, permitindo maior investimento de recursos cognitivos na exploração e compreensão dos modelos.

Considerando o modelo de Thon (2008), além das questões já discutidas sobre o Leap Motion, a introdução do monitor 3D pode propiciar redução de abstração nas operações de visualização, mas também adicionar desafios indesejáveis na manipulação de menus não otimizados para a nova tecnologia, no ajuste de parâmetros estereoscópicos e nas decorrentes dificuldades ou interrupções no fluxo de interação. A estereoscopia adotada por esse dispositivo não é bem aceita por todos os usuários, e impõe desafios consideráveis em calibração e na adaptação dos menus. No entanto, a tridimensionalidade superior das técnicas estereoscópicas pode certamente propiciar ganhos expressivos na dimensão espacial, além de permitir o uso de outros recursos visuais. Após a aquisição de certo nível de experiência e familiaridade com a técnica de interação, as liberdades propiciadas pela combinação da interação e visualização direta em três dimensões podem incrementar a dimensão lúdica, em comparação ao experimento anterior. $A$ manutenção ou incremento das outras dimensões dependem de ajustes para que os menus funcionem corretamente no monitor 3D, desenvolvimento que se mostra mais complexo se comparado ao do Oculus Rift, discutido no próximo experimento. Também seriam necessários ajustes substanciais tanto para o correto funcionamento do Leap Motion como para a estereoscopia, contando com a implementação das propostas comentadas no experimento anterior para lidar com os menus bidimensionais.

\subsubsection{Oculus Rift + Razer Hydra}

A imersão máxima é atingida ao adotar a estereoscopia imersiva em conjunto com uma interação tridimensional mais familiar, se comparada ao método de joystick 3D empregado até então (FIG. 106e). O dispositivo Razer Hydra permite um uso mais efetivo das duas mãos, devido ao maior raio de ação, maior alcance e ausência de interferências. O Oculus Rift tem um bom campo visual, e sua versão DK2 possui uma boa resolução, apesar de pixels ainda serem visíveis. Comparado ao monitor 3D, permite controlar o ângulo de visão diretamente com a cabeça e tem um contraste muito superior, além de barrar a visão do ambiente externo. Buscouse uma interação mais intuitiva e que explorasse os recursos da tecnologia. 
No primeiro modo de interação com o Hydra, a navegação em primeira pessoa com duas mãos foi muito mais ágil se comparada ao joystick 3D. A metáfora do manche propiciou uma boa coordenação das mãos, rotações mais intuitivas e maior controle de velocidade, e os usuários não perderam o senso de posição das mãos. Foi necessário um tempo de experiência para transitar entre os modos de navegação e de manipulação dos objetos. Após a ambientação, a manipulação dos objetos mostrou-se muito próxima àquela executada em modelos físicos. Os usuários reportaram uma experiência de manipulação muito similar à real. Assim, este método realmente explorou eficientemente as vantagens dos modos em primeira pessoa, que são o de usuário em miniatura, e o seu oposto, o modo de usuário magnificado, a manipulação direta do modelo, como um modelo físico real.

No segundo modo, a navegação é feita com os direcionais analógicos e a manipulação é idêntica ao primeiro modo. Para muitos usuários, essa medida tornou mais nítida a distinção entre navegação e manipulação. Pode-se dizer que, neste contexto, a navegação é uma operação menos intuitiva que a manipulação, pois espera-se manipular um objeto diretamente com as mãos e navegar com os pés ou pernas. Assim, a navegação com direcionais, especialmente para pessoas experientes em jogos, torna-se mais simples. Apesar de muitos usuários não serem familiarizados com esse tipo de interação, espera-se que esse modo atinja muitos usuários, pois, afinal, trata-se de um método consagrado. A solução foi considerada bem-sucedida, pois oferece duas diferentes formas de interação para os usuários inexperientes, sendo possível escolher aquela cujo aprendizado for mais simples para cada usuário.

No entanto, ficaram evidentes os conhecidos problemas da imersão estereoscópica, tais como náuseas. Alguns usuários não conseguem usar o sistema por muito tempo. Em especial, na navegação em alta velocidade ou com movimentos bruscos (seja acelerações, frenagens ou mudanças de direção) e na ausência da sensação física de inércia. Apesar de muitos se empolgarem ainda mais com a interação, esses problemas criam desafios. Tais limitações podem ser contornadas, ou seus efeitos, diminuídos, com tempo de experimentação e com o desenvolvimento de mecanismos especiais. De fato, muitos desses problemas ainda estão em estudo no momento, mas as vantagens da imersão superior e de mecanismos mais diretos e intuitivos de interação 3D foram confirmadas neste experimento. 
Considerando o modelo de Thon (2008), comparado ao Leap Motion, devido ao maior raio de ação, uso efetivo das duas mãos e menor suscetibilidade a interferências, o Razer Hydra impõe um menor desafio de aprendizagem e uso, especialmente considerando os dois modos de interação previstos, pois permitem adaptação gradual dos usuários com menor experiência. Novamente, um dispositivo estereoscópico como o Oculus Rift pode propiciar redução de abstração nas operações de visualização, mas também adicionar desafios indesejáveis na manipulação de menus, problemas com enjoos em alguns usuários e ainda maiores dificuldades ou interrupções no fluxo de interação na falta de uma interface adaptada para a nova tecnologia. Nesta versão, o isolamento perceptivo exige a retirada do equipamento para uso dos menus tradicionais em uma tela convencional.

Porém, a estereoscopia em alta resolução propiciada pelo uso do Oculus Rift pode certamente propiciar ganhos expressivos na dimensão espacial, devido ao destaque substancial e esperado da tridimensionalidade dos objetos, além da possibilidade de exploração de outros recursos visuais. Apesar da questão do enjoo em alguns usuários, a percepção de estereoscopia é unanime entre os usuários ao contrário do que se percebe em relação aos monitores 3D passivos. Novamente, após alguma experiência e domínio da técnica de interação, as liberdades propiciadas pela combinação da interação e visualização direta em três dimensões podem incrementar a dimensão lúdica em níveis muito superiores em comparação ao experimento anterior. Ao contrário dos monitores 3D, o Oculus Rift exige adaptações na renderização para lidar com as distorções das lentes utilizadas no dispositivo (FIG. 104a), tornando mais complexa a criação de menus. Assim, para manter ou incrementar as outras dimensões, os menus bidimensionais devem ser definitivamente adaptados para funcionarem com o Oculus Rift e, consequentemente, com o Razer Hydra. Afinal, neste caso, toda a interação ocorre no espaço tridimensional, e não em um espaço misto, como no experimento anterior. Isso pode ser realizado com a criação de menus flutuantes do tipo pop-up (FIG. 104b) ou permanentes, localizados fora do foco visual (104c), ou com menus implementados no espaço 3D, usando, por exemplo, as mãos (104d).

Como exemplificado, todas essas opções já foram testadas em outros projetos, e as limitações atuais dos menus podem ser perfeitamente contornadas. De qualquer maneira, os dispositivos de interação e visão estereoscópica deste experimento se mostraram muito superiores aos dos anteriores, melhorando di- 
versos aspectos da experiência imersiva e prometendo, portanto, os maiores ganhos entre todos os níveis de imersão experimentados. Além disso, avalia-se que as adaptações para integração dessas tecnologias ao sistema e das funcionalidades existentes são mais simples que o caso anterior. Caso todos esses ajustes sejam implementados, espera-se uma experiência imersiva sem precedentes.

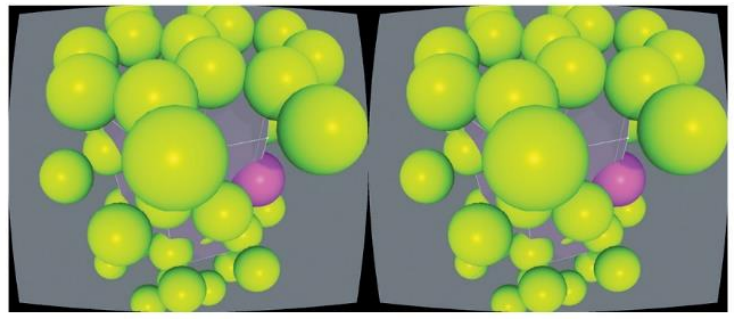

(a)

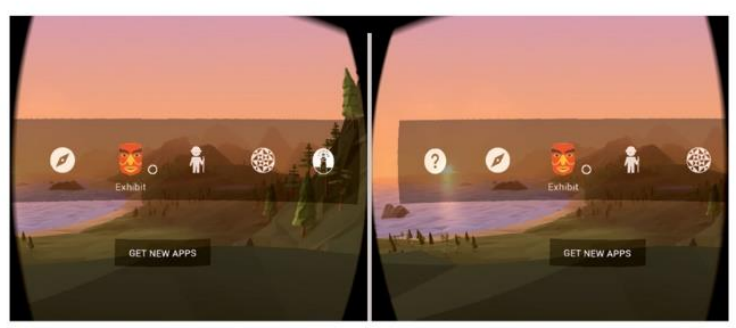

(b)

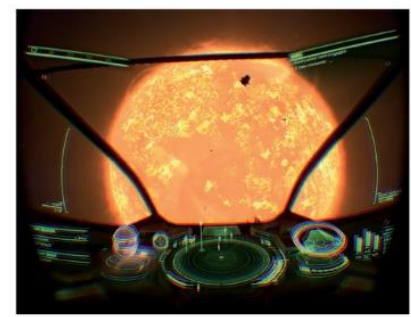

(c)

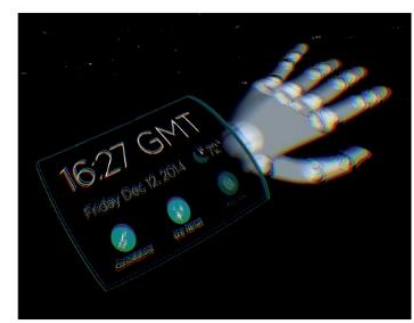

(d)

FIGURA 107 - Interfaces para HMDs: (a) renderização adaptada para lidar com distorções de lentes; (b) menus flutuantes temporários; (c) visor sobreposto à visão, ou heads-up display (HUD) virtual; (d) menus associados a objetos da cena. Fonte: Leap Motion, Inc. ([s.d.]).

\subsubsection{Outras tecnologias interativas}

Existem outras tecnologias com significativo potencial imersivo que não foram abordadas neste trabalho. Isso se deveu principalmente à falta de maturidade dessas tecnologias no período de definição da progressão interativa a ser adotada nos experimentos. Apesar disso, existe suporte experimental destas tecnologias na última versão do CrystalWalk. Um exemplo é o Google Cardboard (FIG. 108a) que permite transformar smartphones em HMDs a um custo muito baixo. No entanto, para obter um desempenho razoável, é necessário possuir um dispositivo com tela razoavelmente grande (4 polegadas) e boa capacidade gráfi$\mathrm{ca}$, o que torna o desenvolvimento de aplicações mais difícil. Apenas recentemente foram lançadas algumas demonstrações e bibliotecas para popularizar o desenvolvimento de aplicações para esse fim. 
Outra tecnologia a ser mencionada é o mouse 3D (FIG. 108b), que, apesar de estar no mercado a um tempo, não teve muita penetração, devido à sua baixa acessibilidade e alto custo e à escassez de aplicações compatíveis. Entretanto, como apontado por alguns atores sociais, o dispositivo tem características interessantes para aplicações em sala de aula, pois tem funcionamento wireless (sem fios) e pode ser usado como mouse comum, como apontador e também como cursor 3D, à maneira do Razer Hydra, mas com o uso de apenas uma mão.

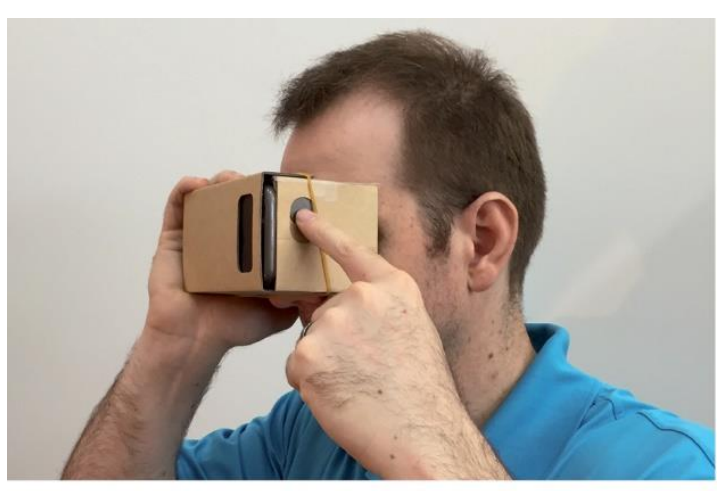

(a)

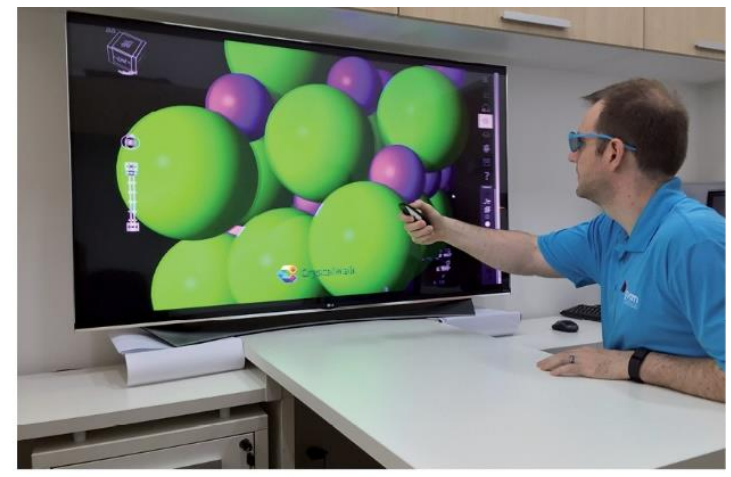

(b)

FIGURA 108 - Outras tecnologias interativas: (a) Google Cardboard; (b) mouse 3D. Fonte: do autor.

\subsubsection{Considerações gerais sobre as possibilidades interativas}

A TAB. 14 sintetiza as considerações e avaliações feitas na seção 4.5.6. A avaliação engloba versões efetivamente implementadas no experimento e outras versões aqui designadas com o termo "potencial". Deve ser frisado novamente que, neste experimento exploratório, não houve preocupação em implementar adaptações dos menus para as tecnologias de interação tridimensionais. Mas que, para manter coerência e demonstrar demandas reais de desenvolvimento decorrentes das novas tecnologias utilizadas, foram mantidos os aspectos de imersão atingidos negativamente na avaliação. Versões hipotéticas buscam ilustrar o potencial de tais tecnologias especialmente nas dimensões afetadas, sendo resultado de ajustes baseados em propostas factíveis do ponto de vista técnico, o que contribui para a validação da avaliação aqui feita. A FIG. 109, apresentada na sequência, sintetiza os resultados do experimento progressivo de imersão, apresentando os diferentes níveis e a curva de imersividade encontrados, segundo os modelos propostos por Thon (2008) e McMahan (2011). 
TABELA 14 - Avaliação dos experimentos de imersão, segundo os modelos propostos por Thon (2008) e McMahan (2011).

\begin{tabular}{|l|l|l|l|l|l|l|l|l|}
\hline \multicolumn{7}{|c|}{ AVALIAÇÃO DOS EXPERIMENTOS DE IMERSÃO PROGRESSÃO, } \\
SEGUNDO OS MODELOS PROPOSTOS POR THON (2008) E MCMAHAN (2011)
\end{tabular}

$\star-\star \star \star \star \star \star \star$ nível de imersão $\lesssim$ nível de imersão (intervalo)

$\checkmark$ sem troca de interface $\quad \downarrow$ exige troca temporária de interface (uso do mouse)

Fonte - do autor.

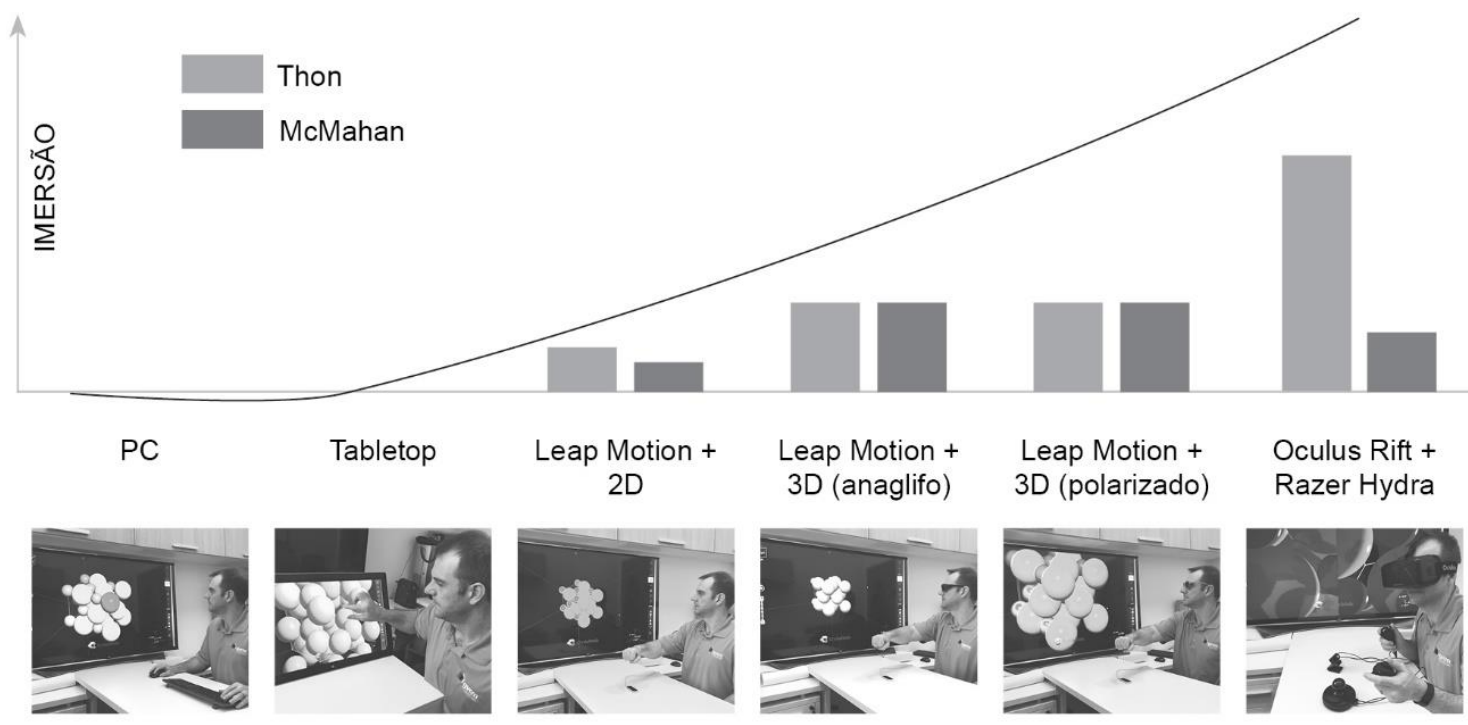

FIGURA 109 - Diagrama-síntese do nível de imersividade dos experimentos de imersão, segundo os modelos propostos por Thon (2008) e McMahan (2011). Fonte: do autor. 


\subsubsection{Avaliação de empoderamento dos atores sociais}

Por fim, apresenta-se a avaliação de empoderamento dos atores sociais. Nessa avaliação, em conformidade com a teoria crítica (seção 2.2), os resultados são validados pela mensuração de conhecimento ou "poder" adquiridos pelo grupo-alvo, o objetivo último de um trabalho orientado pelos princípios da pesquisa-ação. Considera-se que o empoderamento é maior conforme mais objetivos sociais são atingidos. Desta forma, na situação ideal, o empoderamento máximo é obtido quando todos os objetivos são atingidos em sua totalidade.

No entanto, deve ser frisado que o empoderamento efetivo depende da acurácia da caracterização do problema social, que, neste caso, foi materializado na lista de parâmetros do APÊNDICE A.

Apesar desta caracterização estar sujeita a subjetividades, devido ao longo período de desenvolvimento de um trabalho de doutorado, foi naturalmente atendida a recomendação de Creswell (2002) de maximizar o tempo de exposição com os atores sociais para garantir um entendimento superior do problema estudado.

A avaliação holística dos processos de síntese e visualização descritas anteriormente também contribuem para assegurar que os fatores cruciais do problema foram contemplados - ou, ao menos, identificados - pela ferramenta.

O empoderamento pode ser avaliado principalmente por critérios objetivos de disponibilidade, acessibilidade e portabilidade, que constam no grupo 1.0 dos critérios e foram abordados na avaliação de implementação, além do grupo 5.0, de critérios didáticos. Uma nota maior no grupo 1.0 indica um acesso mais amplo e menos restrito ao público em geral. No caso do grupo 5.0, são evidenciadas melhorias no acesso a funcionalidades essenciais para a melhoria do ensino e da difusão por parte de instrutores e pesquisadores. No entanto, seguindo a justificativa deste projeto, entende-se que qualquer facilitação obtida nos processos de síntese, conquistas de visualização e as consequentes melhorias de compreensão propiciadas pela ferramenta também aumentam o poder dos atores sociais e viabilizam maior acesso ao conhecimento. Dessa forma, o atendimento aos itens dos grupos 1.0 e 5.0 definirá em maior grau a avaliação deste quesito, mas os outros grupos também serão considerados. A pontuação resultante será comparada a dos três melhores softwares nos grupos 1.0 e 5.0.

A metodologia de pesquisa-ação unida ao Scrum foi extremamente rica e possibilitou incorporar, de maneira eficiente e incremental, junto aos atores so- 
ciais do projeto, funcionalidades de alto valor em ambientes didáticos. Considerase que a diversidade de perfis dos atores sociais e o tempo de exposição e experimentação foram suficientes para identificar os principais desafios no ensino do tema e desenvolver ferramentas para abordá-los.

No estado atual, a ferramenta pode ser acessada pela internet nos principais sistemas operacionais e sem nenhum custo de software, bastando ter acesso a um dos diversos navegadores modernos disponíveis gratuitamente. Qualquer indivíduo pode utilizar o código-fonte para alterar e estender as funcionalidades. A maioria das funções do aplicativo não exige computadores potentes, embora, para funções mais pesadas, seja apenas necessário maior tempo de processamento. A quantidade de dados exigida é pequena, o que torna viável sua utilização mesmo em redes móveis de dados. $O$ aplicativo também funciona em alguns aparelhos móveis mais recentes, mas sem garantia de estabilidade em todas as situações de uso previstas. Todas essas características resultaram da arquitetura proposta.

As experiências com estudantes em sala de aula e com outros pesquisadores trouxeram feedback valioso para o aprimoramento do CrystalWalk e também demonstraram seu potencial no ensino de estruturas cristalinas. Ficou claro que sua abordagem privilegia a didática e facilita o acesso a esse conhecimento, se comparado com outros softwares. A abordagem baseada no conceito "rede + motivo = estrutura cristalina", aliada a um sequenciamento intencional de atividades explícito no projeto de interface, além dos diversos recursos de visualização, possibilitam abordar os dois principais problemas didáticos identificados para 0 tema. Para guiar usuários de diferentes perfis entre tantas opções e viabilizar fácil acesso à ferramenta, existe a opção do modo tutorial, mecanismos de restrições de ações, diversos balões de informação e fontes adicionais de informação no site do projeto.

A possibilidade de acesso on-line e as diversas formas de publicação previstas e implementadas se revelaram recursos práticos e valorosos para professores, estudantes e pesquisadores. É possível extrair imagens diretamente em diversos níveis de qualidade sem a necessidade de domínio de editores de imagem e posse de licenças desses softwares. Deve ser frisado que imagens geradas pelo CrystalWalk podem elevar sobremaneira a proposta das tradicionais projeções bidimensionais a um modelo de "imagem interativa", por meio dos links 
encurtados e QR code, permitindo acesso direto ao modelo original, provendo acesso a todas as funcionalidades de síntese, visualização e interação. O conceito principal do projeto é oferecer uma alternativa que supere os tipos de representação existentes. Portanto, não faz sentido tentar apenas gerar imagens melhores, pois, como discutido ao longo deste trabalho, a manipulação dos modelos, seja na criação ou na configuração visual, é fundamental para o aprendizado. Mesmo a impressão tridimensional, que ainda é um serviço de difícil acesso, já possui algum suporte no CrystalWalk. Experiências com modelos impressos desmontáveis mostraram o potencial didático dos modelos físicos, o que pode impulsionar novamente essa abordagem. De fato, o experimento foi extremamente positivo e, certamente, as funcionalidades de impressão 3D serão aprimoradas.

O recurso de anotações associativas aliado à biblioteca de estruturas e ao mecanismo de persistência possibilita a acumulação de experiência digital no ensino de estruturas cristalinas. As narrativas didáticas permitiram prototipar abordagens de ensino, revelando-se poderosas ferramentas em sala de aula e para a discussão e aprimoramento dos métodos de ensino. Entende-se que o mais importante não é atingir uma narrativa correta, mas produzir uma grande diversidade de narrativas, que, certamente, servirão a diferentes indivíduos.

Os experimentos com tecnologias interativas modernas em ambientes virtuais imersivos revelaram caminhos promissores para o desenvovimento do CrystalWalk. Além dos aspectos lúdicos da experiência com ambientes virtuais, que estimulam o interesse no aprendizado, as tecnologias de visualização e interação tridimensionais podem diminuir a dificuldade no caso de indivíduos com baixa habilidade espacial. As tecnologias utilizadas foram consideradas as mais acessíveis no momento. Há ainda outras, como o Google Cardboard e suas derivações, que prometem trazer a realidade virtual aos usuários de celulares a um custo muito baixo. 


\section{CONCLUSÕES}

A realização deste trabalho foi orientada, em grande medida, pelos princípios filosóficos, teóricos e metodológicos da pesquisa-ação (seções 2.2, 2.4.1.1 e 4.2.1), que estão, por sua vez, alinhados aos princípios da teoria crítica e do construtivismo (seção 2.2). Essa metodologia se mostrou propícia a um trabalho de desenvolvimento de software, como sinalizado pela literatura revisada nas etapas iniciais do trabalho. Foi estabelecido um grupo denominado de "atores sociais", composto por indivíduos considerados representantes do público-alvo do trabalho, ou, mais especificamente, de seu principal produto final, o software CrystalWalk. Esses indivíduos são professores, pesquisadores e estudantes de Ensino Superior, além do próprio time de desenvolvimento do projeto. Considerase que o grupo representa o público-alvo e que incorporou indivíduos com perfis variados, enriquecendo o projeto e os produtos gerados. Participaram ativamente e interagiram durante todo o projeto, tanto entre si como com os diversos produtos gerados, conforme preconiza o construtivismo. A geração de todos os produtos foi orientada às demandas específicas dos envolvidos no trabalho, e o principal critério de avaliação desses produtos foi o atendimento a essas demandas, seguindo a teoria crítica.

Foi adotada uma abordagem multilateral tanto no levantamento de dados (seção 2.3.5) como na avaliação de resultados (seção 2.4.3; seção 4.5), conforme recomendado pela literatura para trabalhos de pesquisa-ação. Dados sobre o estado da arte dos softwares cristalográficos foram coletados por meio de um levantamento sistemático (seção 3.4), avaliando funcionalidades, identificando as características positivas em contexto didático e as lacunas neles existentes, fatores que contribuíram para o ineditismo e valor do trabalho. Também foram identificados, no campo da computação gráfica, por meio de levantamento bibliográfico, características e aspectos desejáveis à síntese, visualização e manipulação de estruturas cristalinas em ambientes tridimensionais (seção 3.3). Os resultados foram avaliados ciclicamente por meio de testes de implementação (seção 4.5.1), comparação com imagens de livros didáticos e softwares cristalográficos (seção 
4.5.2), testes da interface e das ferramentas de síntese, visualização e interação (seção 4.5.3; seção 4.5.4), além de uma avaliação final que integrou os resultados, verificando o empoderamento dos atores sociais (seção 4.5.7). Considera-se que a abordagem multilateral foi essencial à execução deste trabalho, devido à complexidade das variáveis inerentes a contextos sociais e também à riqueza ímpar de ideias e possíveis soluções que tal abordagem proporciona. No entanto, foi necessário significativo esforço para integrar informações de diversas fontes e naturezas e gerenciar as expectativas das partes envolvidas no projeto.

A pesquisa-ação foi realizada com interações cíclicas em duas fases principais. Na primeira fase, foram especificados métodos de síntese, visualização e interação com estruturas cristalinas considerados mais adequados ao problema (seção 4.3.1). Na segunda fase, foi desenvolvido um software cristalográfico, o CrystalWalk, que possibilitou o aperfeiçoamento dos modelos e representações adotados em softwares cristalográficos existentes, bem como dos respectivos métodos computacionais necessários para sua implementação (seção 4.3.2).

A diminuição da dificuldade de criação de estruturas cristalinas foi abordada com o conceito "rede + motivo = estrutura cristalina", implementado e avaliado de acordo com pressupostos construtivistas. O conjunto de análises apontou que, para os atores sociais do projeto e para estruturas utilizadas normalmente no contexto didático, o método proposto facilitou sobremaneira a criação de estruturas cristalinas, em comparação ao método baseado em grupos espaciais.

As principais dificuldades de entendimento de estruturas cristalinas foram agrupadas em dois problemas didáticos (seção 4.5.3.2), e foram propostas duas estratégias para abordá-los.

A primeira estratégia (seção 4.5.3.2.1) baseia-se no princípio da experimentação ativa preconizado pelo construtivismo, oferecendo diversos recursos de visualização e interação para permitir ao usuário uma experiência diversa e rica com as estruturas criadas. O usuário é instruído com balões descritivos ou com o modo tutorial, e sua liberdade de acesso às ferramentas é restrita ou liberada conforme o perfil do usuário. Os resultados indicaram que a estratégia se mostrou eficaz para atender à diversidade de perfis dos atores sociais, relativo tanto a dificuldades de aprendizado do software como de entendimento de estruturas cristalinas. 
A segunda estratégia (seção 4.5.3.2.2) foi denominada "narrativa didática" e consistiu em uma forma de permitir agregar às funcionalidades do CrystalWalk o conhecimento dos especialistas. Por meio desse recurso, é possível criar uma multiplicidade de sequências didáticas, cada uma agrupando procedimentos de síntese, visualização e interação em passos para guiar o estudante ativamente. Essa estratégia se mostrou promissora para aprimorar os métodos de ensino, pois diversos instrutores ou mesmo estudantes podem criar narrativas diferentes, que podem funcionar melhor para certos indivíduos ou, em grupo, auxiliar o aprendizado geral. Assim, considera-se que, para os atores sociais do projeto, a dificuldade de visualização de estruturas cristalográficas foi diminuída se comparada a softwares e materiais didáticos existentes.

Foram incorporadas com sucesso funcionalidades didáticas que se provaram eficazes para garantir pleno acessibilidade aos recursos do CrystalWalk e aumentar seu alcance. Assim, acredita-se que o projeto contribuiu para a democratização do conhecimento da área de estruturas cristalinas. Além disso, acredita-se que atingiu o principal objetivo de uma pesquisa-ação, segundo a teoria crítica, que é o empoderamento efetivo dos atores sociais envolvidos no projeto, o que, por extensão, denota o empoderamento dos amplos grupos sociais representados por esses indivíduos. Considera-se que tal correspondência é admissível devido à representatividade do grupo de atores sociais e ao longo tempo de exposição e participação ativa por parte destes antes e durante o desenvolvimento do software, como recomendado pela literatura. 
APÊNDICE A - Lista de softwares cristalográficos analisados

\title{
Lista simplificada
}

SPEC16 Especificação final da aplicação (ver seção 4.3.1)

CWGL16 CrystalWalk (versão do semestre 10 da pesquisa)

\author{
ATOM11 Atoms \\ BALL08 Balls \& Sticks \\ CARI04 CaRIne \\ CHEM15 ChemCraft \\ CMAK15 CrystalMaker \\ CRYS07 CrystalOgraph \\ DIAM15 Diamond \\ DRAW11 DRAWxtl \\ GRET00 Gretep \\ JAMM02 JaMM \\ JMOL15 Jmol \\ LATT04 Java Lattice Tool \\ MERC15 Mercury \\ ORTE14 ORTEP \\ OSCA15 Oscail \\ PLAT13 PLATON \\ POWD00 Powder Cell \\ PYMO18 PyMOL \\ QUTE07 QuteMol \\ RASM09 RasMol \\ SCHA14 SCHAKAL \\ SHEL15 ShelXle \\ STRU05 STRUVIR \\ VEST14 VESTA \\ XCRY14 XCrySDen \\ XTAL03 XtalDraw
}




\section{Lista de referências completas}

ATOM11 DOWTY, E. Atoms. Versão 7.3. Kingsport: Shapesoftware, 1989. Última atualização: 1 jun. 2011. Disponível em: <http://www.shapesoftware.com/>. Acesso em 19 fev. 2016.

BALL08 OZAWA, T.C.; KANG, S.J. Balls\&Sticks. Versão 1.77b. [S.I.]: ToyCrate, 2008. Última atualização: 16 jan. 2008. Disponível em:

<http://toycrate.web.fc2.com/bs/index.html>. Acesso em 19 fev. 2016.

CARI04 BOUDIAS, C.; MONCEAU, D. CaRIne Crystallography. Versão 4.0.4.3. [Senlis]: Software CaRIne Crystallography, 1989. Última atualização: 13 nov. 2004. Disponível em: <http://carine.crystallography.pagesproorange.fr/>. Acesso em: 19 fev. 2016.

CHEM15 CHEMCRAFTPROG. ChemCraft. Versão b436. [S.I.]: [s.d.], [s.d.]. Última atualização: 2 jul. 2015. Disponível em: <http://www.chemcraftprog.com/>. Acesso em: 7 maio 2016.

CMAK15 PALMER, D. CrystalMaker. Versão 9.2.1. Oxfordshire: CrystalMaker Software Ltd., 2001. Última atualização: 4 jun. 2015. Disponível em: <http://www.crystalmaker.com/>. Acesso em: 19 fev. 2016.

CRYS07 SCHOENI, N.; CHAPUIS, G. CrystalOgraph. Versão 1.60d. Lausanne: École Polytechnique Fédérale de Lausanne, 2007. Última atualização: 1 jun. 2007. Disponível em: <http://escher.epfl.ch/crystalOgraph>. Acesso em: 19 fev. 2016.

DIAM15 BRANDENBURG, K.; PUTZ, H. Diamond. Versão 4.0.3. [Bonn]: Crystal Impact, 1989. Última atualização: 6 maio 2015. Disponível em: <http://www.crystalimpact.com/diamond/>. Acesso em: 19 fev. 2016.

DRAW11 FINGER, L.W.; KROEKER, M.; TOBY, B.H. DRAWxtl. Versão 5.5. Washington, DC: [s.n.], 2011. Última atualização: 1 mar. 2011. Disponível em: <http://www.ccp14.ac.uk/ccp/webmirrors/larryfinger/home.att.net/ larry.finger/drawxtl/>. Acesso em: 19 fev. 2016. ${ }^{2}$

GRET00 LAUGIER, J.; BOCHU, B. Gretep (Grenoble Thermal Ellipsoids Plot). Versão 2. Grenoble: Laboratoire des Matériaux et du Génie Physique, Ecole Nationale Supérieure de Physique de Grenoble, 2000. Última atualização: 22 nov. 2000. Disponível em: <http://www.ccp14.ac.uk/tutorial//mgp/gretep.html>. Acesso em: 19 fev. 2016.

2 Ver também: FINGER, L.W.; KROEKER, M.; TOBY, B.H. DRAWxtl, an open-source computer program to produce crystal structure drawings. Journal of Applied Crystallography, v. 40, n. 1, p. 188-192, 2007. 
JAMM02 BOLLINGER, J. C. JaMM. Versão 2.3. [Bloomington, IN]: Indiana University, 1999. Última atualização: 1 jan. 2002. Disponível em: <https://www.iumsc.indiana.edu/graphics/jamm2.1.html>. Acesso em: 14 maio 2016.

JMOL15 JMOL PROJECT. Jmol: An open-source Java viewer for chemical structures in 3D. VErsão 14.2.14. [S.I.]: [s.n.], 2015. Última atualização: 23 mar. 2015. Disponível em: <http://www.jmol.org/>. Acesso em: 19 fev. 2016.

LATT04 SCHOENI, N.; CHAPUIS, G. CrystalOgraph Java Lattice Tool. Versão 1.0. Última atualização: 15 set. 2004. Disponível em: <http://escher.epfl.ch/crystalOgraph/>. Acesso em: 16 maio 2016.

MERC15 CAMBRIDGE CRYSTALLOGRAPHIC DATA CENTRE. Mercury. Versão 3.6. Cambridge, UK: Cambridge Crystallographic Data Centre, 2001. Última atualização: 6 jun. 2015. Disponível em:

$<$ https://www.ccdc.cam.ac.uk/Community/csdcommunity/freemercury/>. Acesso em: 19 fev. 2016.

ORTE14 BURNETT, M.N.; JOHNSON, C.K. ORTEP-III (Oak Ridge Thermal Ellipsoid Plot). Versão 3.1.0.3 para Windows. Oak Ridge, TN: Oak Ridge National Laboratory, 2014. Última atualização: 15 set. 2014. Disponível em: <http://web.ornl.gov/sci/ortep/ortep.html>. Acesso em: 19 fev. 2016.

OSCA15 McARDLE, P. Oscail. Versão 4.8.1. Galway: Crystallography Centre, National University of Ireland, 1995. Última atualização: 29 maio 2015. Disponível em: <http://www.nuigalway.ie/cryst/software.html>. Acesso em: 19 fev. 2016.

PLAT13 SPEK, A.L. PLATON: A multipurpose crystallographic tool. Versão 1.17 para Windows. Utrecht: Utrecht University, 2010. Última atualização: 24 abr. 2013. Disponível em: <http://www.cryst.chem.uu.nl/spek/platon/>. Acesso em: 19 fev. 2016.

POWD00 KRAUS, W.; NOLZE, G. Powder Cell. Versão 2.4. [S.I.]: [s.n.], [1996]. Última atualização: 3 ago. 2000. Disponível em: <http://www.ccp14.ac.uk/tutorial/powdcell/>. Acesso em: 19 fev. 2016. ${ }^{3}$

PYMO18 SCHRODINGER. PYMOL. Versão 1.7.4, para Windows (64bit). Última atualização: 25 mar. 2015. Disponível em: <https://www.pymol.org/>. Acesso em: 14 maio 2016.

${ }^{3}$ Ver também: KRAUS, W.; NOLZE, G. POWDER CELL - A program for the representation and manipulation of crystal structures and calculation of the resulting X-ray powder patterns. Journal of Applied Crystallography, v. 29, n. 3, p. 301-303, 1996. 
QUTE07 TARINI, M.; CIGNONI, P. QuteMol. Versão 0.4.1. Pisa: Visual Computing Lab-ISTI-CNR, 2007. Última atualização: 6 jun. 2007. Disponível em: <http://qutemol.sourceforge.net/>. Acesso em: 11 maio 2016.

RASM09 SAYLE, R.A. RasMol. Versão 2.7.5, para Windows [S.I.]: [s.n.], 1995. Última atualização: 1 jun. 2009. Disponível em: <http://www.openrasmol.org/>. Acesso em: 19 fev. 2016. ${ }^{4}$

SCHA14 KELLER, E. SCHAKAL. Versão 99/2014-06-14. Freiburg: Crystallography Institute, University of Freiburg, 2005. Última atualização: 14 jun. 2014. Disponível em: <http://www.krist.unifreiburg.de/ki/Mitarbeiter/Keller/schakal.html>. Acesso em: 19 fev. 2016.

SHEL15 HÜBSCHLE, C.B.; SHELDRICK, G.M.; DITTRICH, B. ShelXIe: a Qt graphical user interface for SHELXL. Versão 1.0.709, para Windows. [S.I.]: [s.n.], 2015. Última atualização: 3 fev. 2015. Disponível: <http://ewald.ac.chemie.uni-goettingen.de/shelx/eingabe.php>. Acesso em: 7 maio $2016 .^{5}$

STRU05 LE BAIL, A. STRUVIR. Versão 1.01, para Windows. Le Mans: Université du Maine, 1996. Última atualização: 1 mar. 2005. Disponível em: <http://www.cristal.org/vrml/struvir.html>. Acesso em: 19 fev. 2016.

VEST14 MOMMA, K.; IZUMI, F. VESTA (Visualization for Electronic and Structural Analysis). Versão 3.2.1, para Windows (64bit). [S.I.]: [s.n.], 2008. Última atualização: 20 ago. $2014 .^{6}$

XCRY14 KOKALJ, A. XCrySDen. Versão 1.5.60 linux_x86_64-semishared. Ljubljana: Dept. of Physical and Organic Chemistry - Jozef Stefan Institute, 2014. Última atualização: 25 jun. 2014. Disponível em: <http://www.xcrysden.org/>. Acesso em: 11 maio 2016. ${ }^{7}$

XTAL03 DOWNS, R.T. XtalDraw. Versão 8 ago. 2003. Tucson: University of Arizona, 2003. Última atualização: 8 ago. 2003. Disponível em: <http://www.geo.arizona.edu/xtal/group/software.htm>. Acesso em: 11 maio 2016.

\footnotetext{
${ }^{4}$ Ver também: SAYLE, R.A.; MILNER-WHITE, E.J. RASMOL: Biomolecular graphics for all. Trends in Biochemical Sciences, v. 20, n. 9, p. 374-376, 1995.

5 Ver também: HÜBSCHLE, C.B.; SHELDRICK, G.M.; DITTRICH, B. ShelXle: a Qt graphical user interface for SHELXL. J. Appl. Cryst., v. 44, pp. 1281-1284, 2011. Disponível: <http://ewald.ac.chemie.uni-goettingen.de/shelx/eingabe.php>. Acesso em: 7 maio 2016.

6 Ver também: MOMMA, K.; IZUMI, F. VESTA: a three-dimensional visualization system for electronic and structural analysis. Journal of Applied Crystallography, v. 41, n. 3, p. 653-658, 2008.

7 Ver também: KOKALJ, A. Computer graphics and graphical user interfaces as tools in simulations of matter at the atomic scale. Comp. Mater. Sci., 2003, v. 28, p. 155. Disponível em: <http://www.sciencedirect.com/science/article/pii/S0927025603001046>. Acesso em: 11 maio 2016.
} 


\section{APÊNDICE B - Detalhamento dos critérios e parâmetros dos questionários de análise dos softwares cristalográficos}

Este apêndice apresenta o detalhamento dos parâmetros que compõem o questionário de análise dos softwares cristalográficos selecionados para o procedimento de levantamento sistemático descrito na seção 2.4.1.3. Cada parâmetro é descrito conforme a seguinte estrutura:

- Descrição do critério: Explica o que se pretende avaliar e descreve termos e conceitos relevantes.

- Parâmetros utilizados: Listagem e descrição de cada alternativa e qual a lógica de avaliação.

\section{(1) Parâmetros do questionário tecnológico}

\section{(1.1) Nível de atividade}

Descrição do critério:

Descreve o nível da atividade do software com base na frequência de atualizações de software disponibilizadas. Um alto nível de atividade indica grande tendência de continuidade e de aprimoramento. Projetos altamente colaborativos indicam envolvimento de uma comunidade específica, além de maturidade e robustez.

Parâmetros utilizados (do pior para o melhor):

- (1.1.1) Frequência de atualização: Inativo, Ativo, Dinâmico.

- Inativo: Não disponibilizaram nenhuma atualização nos últimos 4 anos (em relação ao momento da realização da análise).

- Ativo: Disponibilizaram ao menos uma atualização nos últimos 4 anos (ou seja, versões disponibilizadas a no máximo 4 anos do momento da realização da análise).

- Dinâmico: Disponibilizaram ao menos uma atualização nos últimos 2 meses ao longo dos últimos 6 meses (ou seja, 3 versões disponibilizadas entre os três últimos bimestres em relação ao momento da realização da análise). 


\section{(1.2) Portabilidade da aplicação}

Descrição do critério:

Avalia o nível da portabilidade de aplicação do software com base em critérios de compilação, interpretação, execução e compatibilidade em diferentes sistemas operacionais e plataformas.

- Linguagens compiladas: a exemplo de $\mathrm{C}$ e $\mathrm{C}_{++}$, os programas produzidos rodam nativamente apenas em um sistema operacional e plataforma computacional especificos. É necessário, desta forma, que os desenvolvedores criem versões para cada sistema operacional e plataforma. Apesar de possuírem portabilidade bastante restrita, tendem a apresentar melhor acesso a recursos do sistema e desempenho de execução da aplicação.

- Linguagens interpretadas: a exemplo das plataformas Java, Python e Tcl, os programas produzidos rodam em uma máquina virtual, que funciona em diversas plataformas e sistemas operacionais. Neste caso, é a máquina virtual que é desenvolvida para cada plataforma, facilitando o desenvolvimento de código e o uso da aplicação. Apesar de possuírem alta portabilidade, ainda requerem a instalação prévia de interpretadores e tendem a comprometer o acesso a recursos do sistema e o desempenho de execução da aplicação. Uma discussão mais aprofundada sobre Java3D em particular é apresentada na seção 4.2.1.1.

- Linguagens interpretadas que não requerem instalação: nesse caso, o interpretador já está incorporado em um programa existente e amplamente disponível na maioria das plataformas. A maioria dos navegadores modernos suporta a linguagem WebGL, capaz de processamento de áudio, vídeo, renderização de gráficos e de conteúdo visual. Apesar de sua alta portabilidade, ainda é considerada uma tecnologia em processo de amadurecimento. Uma discussão mais aprofundada sobre esta tecnologia em particular é apresentada na seção 3.5.3.3.1.2. 
Parâmetros utilizados (do pior para o melhor):

- (1.2.1) Portabilidade de aplicação: Baixa, Média, Alta.

- Baixa: aplicações compatíveis com um único sistema operacional ou plataforma.

- Média: aplicações compatíveis com mais de uma plataforma ou dispositivo, que requerem a instalação de binários para sua interpretação ou execução.

- Alta: aplicações compatíveis com mais de uma plataforma e mais de um dispositivo, não requerendo a instalação de binários para sua interpretação ou execução.

- (1.2.2) Plataforma de desenvolvimento: Compilado (C, C++, Fortran, Pascal, Delphi), Interpretado (Java, Python, WebGL).

- (1.2.3) Sistemas operacionais compatíveis: Windows, Linux, Mac, Independente.

- (1.2.4) Requer instalação: Sim, Não.

- (1.2.5) Multiplataforma: Sim (especificar entre: Desktop, Móveis), Não.

- Desktop, neste contexto, é um termo que designa programas voltados para computadores pessoais tradicionais e sistemas operacionais especificos. Já os móveis são produzidos especificamente para uma classe de dispositivos (celulares e tablets de marcas específicas).

\section{(1.3) Uso, distribuição e modificação}

Descrição do critério:

Descreve qual a licença de uso, modificação e distribuição dos arquivos binários do software aplicativo e, caso disponível, do código-fonte do software.

Parâmetros utilizados (do pior para o melhor):

- (1.3.1) Licença de uso, distribuição e modificação: Comercial, Demo, Shareware, Freeware, Livre, Outros (especificar).

- Softwares licenciados ou comerciais: Designam todos os produtos para os quais sejam comercializadas licenças. Geralmente desenvolvidos por uma empresa com o objetivo de 
lucrar com a venda de sua licença e seus termos de uso, normalmente incluem condições restritivas sob as quais o produto pode ser copiado, como o uso de uma única cópia e o uso gratuito por instituições educacionais.

- Software livre: Designa um tipo de licença que permite a qualquer um copiar, usar e distribuir com ou sem modificações, gratuitamente ou por um preço. Exemplos de licença de software livre são GNU, GNU2, MIT e BSD.

- Demo: Esta designação não possui uma definição comumente aceita, apesar de frequentemente ser utilizada para caracterização de uma versão simplificada ou de "demonstração" de um produto maior com mais capacidades e recursos, lançado com a intenção de promover e dar a oportunidade de avaliação a possíveis futuros clientes. Geralmente, designa um tipo de licença que permite o livre uso e redistribuição, apesar de modificações serem restritas e seu código-fonte não ser disponibilizado.

- Shareware: Designa um tipo de licença que permite a livre redistribuição, lançado com a intenção de promover e dar a oportunidade de avaliação do produto a possíveis futuros clientes, mas que, após certo período de tempo, exige a compra de uma licença para que seja possível continuar sua utilização. Modificações são restritas e seu código-fonte geralmente não é disponibilizado.

○ Freeware: Esta designação não possui uma definição comumente aceita, apesar de frequentemente ser utilizada para caracterização de licenças que permitam a livre redistribuição, ainda que modificações sejam restritas e seu código-fonte não seja disponibilizado.

- (1.3.2) Modelo de desenvolvimento colaborativo: Sim, Não.

- Modelo de desenvolvimento colaborativo: Em um cenário de software livre ou aberto, indica se o software utiliza algum modelo de desenvolvimento de software colaborativo ou não. Em um modelo de desenvolvimento de software livre colaborativo, 
dá-se aos usuários a liberdade de acesso ao código-fonte, sendo possível estudá-lo, modificá-lo e desenvolvê-lo, mas também permite a um grupo de voluntários colaborar com o aprimoramento do projeto de forma contínua e mais consistente. O acesso ao código-fonte e aos demais artefatos relacionados é disponibilizado, geralmente, por meio de ferramentas e plataformas de colaboração específicas, como o Git (Git Project, [s.d.]) e o Subversion (Apache Software Foundation, [2015]).

\section{(1.4) Suporte a tecnologias de interface}

Descrição do critério:

Descreve quais tecnologias de interface são compatíveis e suportadas pelo software, bem como suas respectivas opções de interação com os modelos. Uma discussão mais aprofundada sobre estas tecnologias e seu emprego em sistemas educacionais é apresentada na seção 4.3.3.4.

Parâmetros utilizados (do pior para o melhor):

- (1.4.1) Dispositivos base (HID): Teclado, Mouse, Rastreadores, Outros (especificar).

- (1.4.2) Dispositivos avançados de interação: HMD, Monitor 3D, Outros (especificar).

(2) Parâmetros do questionário de síntese de estruturas cristalinas

\section{(2.1) Método de síntese}

Descrição do critério:

Descreve, quando suportado, qual método e processo de síntese de estruturas cristalinas é utilizado pelo software, bem como eventuais limitações ou restrições, buscando avaliar a acessibilidade às funções de síntese do software. 
Parâmetros utilizados (do pior para o melhor):

- (2.1) Método de síntese: Posições de Wyckoff, Rede + motivo.

- Posições de Wyckoff: métodos de síntese fundamentados em grupos de simetria pontuais e espaciais geralmente possuem sua compreensão restrita cristalógrafos e pesquisadores da área, por serem extremamente específicos.

- Rede + motivo: Métodos de síntese fundamentados na combinação de motivos e simetria de rede translacional são mais intuitivos e didáticos, facilitando sua compreensão por estudantes e sua utilização em sala de aula como ferramenta de ensino.

\section{(2.2) Processo de síntese interativo}

Descrição do critério:

Descreve, quando suportado, se o software possibilita a síntese através da direta manipulação de elementos gráficos e representações visuais.

Parâmetros utilizados (do pior para o melhor):

- (2.2) Processo de síntese interativo: Sim, Não.

\section{(2.3) Restrições ou limitações à síntese}

Descrição do critério:

Descreve, quando aplicável, se o software possui alguma limitação ou restrição específica, determinando se é capaz de representar qualquer estrutura cristalina a partir de dados ou parâmetros de entrada.

Parâmetros utilizados (do pior para o melhor):

- (2.3) Restrições ou limitações à síntese: Sim, Não,

\section{(2.4) Seleção e edição interativas de átomos}

Descrição do critério:

Descreve, quando suportado, se o software possibilita a seleção e edição de átomos por meio da manipulação direta de elementos gráficos e representações visuais. 
Parâmetros utilizados (do pior para o melhor):

- (2.4) Seleção e edição interativas de átomos: Sim, Não.

(3) Parâmetros do questionário de visualização

\section{(3.1) Representação}

Descrição do critério:

Avalia a diversidade de opções de representação visual das estruturas cristalinas e o suporte a artifícios visuais clássicos em ciência dos materiais.

Parâmetros utilizados (quanto mais opções, melhor):

- (3.1.1) Modelo de representação atômico molecular: Esferas rígidas, Bolas e palitos, Espaço de preenchimento, Esquelético, Poliedro, Outros (especificar).

- Modelos de representação atômico moleculares são representações geométricas ou topológicas capazes de ilustrar átomos e/ou moléculas com o objetivo de possibilitar a visualização e compreensão de uma aplicação específica, tais como disposição espacial dos diferentes elementos químicos, além de suas ligações químicas. As opções de modelos são apresentadas a seguir:

- Esferas rígidas: Modelos nos quais os átomos são representados por esferas rígidas indivisíveis e impenetráveis. Elementos químicos diferentes são representados por esferas que possuem raios proporcionais ao íon representado. Apesar de existir uma grande variedade de modelos e aplicações, informações sobre aspectos como ligações, direcionalidade e propriedades nucleares, neurônicas e eletromagnéticas tendem a ser bastante simplificados ou não representados. Livros específicos de ciência dos materiais tendem a utilizar um modelo particular de esferas rígidas que, além de representar os pontos de tangência entre os átomos - utilizados para cálculo de parâmetros específicos de célula unitária, representam também a interseção entre a célula unitária e os átomos parciais nela 
contidos, bem como a representação do vazio da célula unitária.

- Bolas e palitos: Modelos nos quais os átomos são representados por esferas que possuem raio e distância proporcionais ao seu número atômico, e as ligações químicas e respectivas direções são representadas por palitos. Apesar de existir uma grande variedade de modelos e aplicações, informações como ligações e direcionalidade, propriedades nucleares, neutrônicas e eletromagnéticas tendem a ser bastante simplificados ou não representados.

- Espaço de preenchimento: Modelos nos quais os átomos são representados por esferas que possuem raio e distância proporcionais ao seu número atômico, bem como superfícies de distribuição eletrônica capazes de representar diferentes tipos de ligações e interações químicas. Existe uma grande variedade de modelos para aplicações bastante específicas, como representação de proteínas, carboidratos, moléculas inorgânicas etc.

- Esqueléticos: Modelos nos quais as ligações químicas são representadas por hastes, cujas intersecções representam os átomos.

- Poliedro: Modelos nos quais as esferas de atuação dos átomos eletronegativos são representadas por meio de poliedros.

- (3.1.2) Modelo de representação da célula unitária: Células unitárias inteiras, Células parciais, Interstícios.

- Indica se o software é capaz de produzir representações alternativas das células unitárias, tais como as exploradas pelos livros didáticos para facilitar a compreensão do arranjo geométrico dos átomos, em especial, a detecção do ponto de tangência entre eles. 
- (3.1.3) Planos de Miller: Sim, Não.

- Indica se o software é capaz de representar planos a partir da entrada dos respectivos índices (hkl) de Miller.

- (3.1.4) Direções de Miller: Sim, Não.

- Indica se o software é capaz de representar direções a partir da entrada dos respectivos índices [uvw] de Miller.

- (3.1.5) Artifícios de suporte

- Indica quais recursos adicionais de apoio à visualização de estruturas cristalinas o software oferece.

- Subcritérios e parâmetros utilizados:

- (3.1.5.1) Células múltiplas: Sim, Não.

- Indica se o software é capaz de representar supercélulas de $\mathrm{N}$ estruturas cristalinas a partir da entrada de índices espaciais (xyz).

- (3.1.5.2) Cortes: Sim, Não.

- Indica se o software é capaz de representar um ou mais cortes perpendiculares a um plano (hkl) a partir da entrada dos respectivos índices de Miller.

- (3.1.5.3) Vetores do eixo da rede: Não, Cartesianos (xyz), Ortogonais (abc).

- Indica se o software é capaz de representar os vetores ortogonais (xyz) e cristalográficos (abc) da rede de Bravais.

- (3.1.5.4) Recursos auxiliares de rede: Não, Faces, Bordas, Outros (especificar).

- Indica se o software é capaz de representar faces e bordas da rede de Bravais.

\section{(3.2) Visualização}

Descrição do critério:

Avalia a diversidade de meios de representação visuais, considerando possibilidades e limitações da computação gráfica. 
Parâmetros utilizados (quanto mais opções, melhor):

- (3.2.1) Recursos de percepção visual: Formas e perspectiva, Cor, Opacidade e intensidade luminosa, Nuvem de profundidade (e som espacial).

- Indica quais estímulos ambientais visuais o software é capaz de representar.

- (3.2.2) Tipo de projeção: Perspectiva cônica, Perspectiva axonométrica.

- Descreve quais tipos de projeção técnica são utilizados pelo software.

- Perspectiva cônica: é utilizada quando se quer dar um aspecto mais familiar a objetos em uma cena, análogo ao experimentado por um observador humano.

- Perspectiva axonométrica: quando são assumidas simplificações que facilitam a manutenção das relações dimensionais entre os objetos de uma cena, mas que produzem projeções distorcidas quando comparadas com a perspectiva cônica.

- (3.2.3) Suporte estereográfico: Filtro (Anaglifo e/ou Polarizado), Estereograma, Outros (especificar).

- Indica se o software é capaz de produzir imagens renderizadas em 3D estereográficas.

- Estereoscopia é qualquer técnica capaz de criar a ilusão de profundidade por meio da geração e combinação de projeções bidimensionais independentes para cada olho, mimetizando a visão humana. Em computação gráfica, este efeito é obtido renderizando-se a mesma cena através de duas câmeras, separadas da distância média que um olho humano tem para o outro, a distância de paralaxe (aproximadamente $7 \mathrm{~cm}$ ). A diferença principal entre as técnicas está no modo com que as projeções são orientadas para cada olho. As técnicas mais comuns são por Filtro (Anaglifo e Polarizado), Estereograma e para dispositivos específicos, como o Oculus Rift. 
- (3.2.4) Modos de renderização: Realístico, Ilustração, Sólido.

- Indica quais os modos de renderização suportados pelo software. Modos de renderização determinam a aparência das superfícies do modelo 3D.

- Realístico: Objetiva a máxima qualidade na representação gráfica da luz, geometria e texturas.

- Ilustração: Cria representações gráficas simplificadas, úteis em representações técnicas ou mídias que possuam restrições quanto ao número de cores e/ou resolução, tais como livros, impressos e jornais.

- Renderização de sólidos: termo utilizado para caracterizar técnicas e algoritmos que utilizam projeções gráficas para criar a falsa impressão de tridimensionalidade. Apesar de mais rápidos, estes métodos não utilizam modelos 3D nem técnicas de renderização 3D (Z-Buffering), o que geralmente limita a representação da luz e da geometria espacial de diferentes perspectivas, comprometendo a representação gráfica da cena.

\section{(4) Parâmetros do questionário de navegação e interatividade}

\section{(4.1) Interface}

Descrição do critério:

Indica a implementação de interface de usuário e de interações básicas do software, buscando avaliar a facilidade de uso do sistema.

Parâmetros utilizados (do pior para o melhor):

- (4.1) Interface de usuário: Amigável (GUI - ordenada), Não amigável (CLI - não ordenada).

- Amigável: Interface que contém mecanismos como menus e janelas e permite o controle por teclado, mouse e todos os outros canais de interação homem-máquina que possibilitem ao usuário manipular e produzir as respostas de suas ações. Seu objetivo é tornar fácil, eficiente e prazerosa a utilização do 
computador, o que, geralmente, significa fazer com que o aplicativo produza os resultados desejados com a menor quantidade de interações e informações possíveis.

- Interface linha de comando (command line interface - CLI): Interface homem-máquina que utiliza linhas de texto digitado pelo usuário para introduzir comandos e informação no computador. CLIs geralmente exibem suas saídas por meios de um terminal de texto, apesar de também serem capazes de produzir gráficos. Seu uso foi o precursor das interfaces de usuário contemporâneas, e ainda são bastante difundidas entre programadores, administradores de sistema e técnicos avançados.

- Interface gráfica do usuário (graphical user interface - GUI): Interface homem-máquina em que dispositivos de entrada como mouse e teclado possibilitam outros tipos de interação além da digitação de texto. Em oposição às CLIs, as GUls possibilitam a ação por meio da direta manipulação de elementos gráficos como janelas, ícones, menus e apontador (windows, icons, menus, pointer - WIMP). Seu uso é intuitivo e está intimamente ligado à popularização do uso do computador nas últimas décadas.

\section{(4.2) Interação base}

Descrição do critério:

Avalia a diversidade de meios e mecanismos de interação tradicionais.

Parâmetros utilizados (quanto mais, melhor):

- (4.2) Interação base: Rotação, Magnificação (zoom), Translação.

- Interação: Possibilidade fornecida ao usuário de investigar e manipular os objetos do mundo virtual por meio dos sentidos. Utilizase do conhecimento intuitivo do usuário sobre o mundo físico para transpô-lo para dentro do mundo virtual por meio de interfaces (hardware). Rotação, translação e aproximação são alguns dos movimentos naturais tridimensionais do corpo que, através de dispositivos como teclado, mouse, HMDs, rastreadores de movi- 
mento ou até mesmo esteiras de navegação, tornam possível a exploração do ambiente e a manipulação natural dos objetos.

\section{(4.3) Interação avançada}

Descrição do critério:

Avalia a presença de meios e mecanismos de interação inteligentes ou assistidos.

Parâmetros utilizados (quanto mais, melhor):

- (4.3.1) Rotações automáticas: Sim, Não.

- Indica se o software suporta o recurso de rotação automática em torno de algum eixo ou objeto relevante.

- (4.3.2) Animações guiadas: Sim, Não.

- Indica se existem meios de interação especificamente projetados para os modelos.

- (4.3.3) Transição de escala: Sim, Não.

- Indica se existem mecanismos para suavização de transição entre escalas espaciais.

- (4.3.4) Gerenciamento dinâmico de oclusões: Sim (especificar), Não.

- Indica se existem mecanismos para detecção visual de objetos relevantes, mesmo quando oclusos por outros objetos, ou para resolver conflitos causados por oclusão.

- (4.3.5) Perspectiva/pontos de vista preconfigurados: Sim (especificar), Não.

- Indica se existem opções para visualização otimizada do modelo como um todo ou partes dele.

\section{(5) Parâmetros do questionário didático}

\section{(5.1) Conhecimentos requeridos do usuário}

Descrição do critério:

Avalia qual o tipo de conhecimento prévio necessário pelo software para criação e interpretação de estruturas cristalinas. 
Parâmetros utilizados (do pior para o melhor):

- (5.1) Conhecimentos requeridos do usuário: Cristalografia (grupos espaciais), Ciência dos materiais.

- Cristalografia (grupos espaciais): Pressupõe-se que o usuário conheça as posições de Wyckoff da estrutura cristalina em questão, ou que possua conhecimentos avançados em cristalografia para criação de estruturas experimentais.

- Ciência dos materiais: Pressupõe-se que o usuário possua conhecimentos básicos das disciplinas de ciência dos materiais e de geometria analitica.

\section{(5.2) Suporte a publicações}

Descrição do critério:

Avalia o suporte à publicação dos modelos produzidos em diferentes tipos mídias, tanto estáticas como interativas.

Parâmetros utilizados (quanto mais parâmetros suportados, melhor):

- (5.2.1) Suporte à visualização/portabilidade externa: Não, Aplicativo Completo, Modelo 3D, Outros (especificar).

- Indica o nível de portabilidade do software. Tecnologias como HTML ou Java possuem portabilidade de aplicação completa, o que torna possível a utilização de todos os recursos, independente do sistema operacional. Modelos tridimensionais podem ser exportados em formatos como o VRML, X3D ou QTVR, possibilitando visualização local dentro de navegadores, em programas como Acrobat Reader ou em qualquer programa de modelagem 3D.

- (5.2.2) Suporte à impressão 2D: Não, Sim (Imagem bitmap, Imagem vetorial).

- Indica se o software é capaz de produzir imagens bitmap rasterizadas ou vetoriais.

Imagem bitmap: Uma imagem rasterizada, também chamada de bitmap, é uma estrutura de dados que representa uma matriz retangular de pixels ou pontos de cor. 
Formatos de arquivo devem considerar requisitos de dimensão (altura e largura em pixels), quantidade de cores (em bits por pixel), e nível de compressão de dados. Imagens de baixa definição podem ser utilizadas em apresentações e websites. Entretanto, para mídias impressas, como painéis e revistas, é preciso gerar imagens de alta resolução - aproximadamente 600 pontos por polegada (dots per inch - DPI).

- Imagem vetorial: Um desenho vetorial é gerado a partir de vetores e funções geométricas que descrevem elementos como pontos, retas, curvas, polígonos, texto e outros elementos. Por armazenar apenas as definições geométricas dos objetos, são representações normalmente mais compactas que imagens rasterizadas. Pelo mesmo motivo, a qualidade não é alterada pelo tamanho, sendo, por isso, preferidas em aplicações em mídias impressas.

- (5.2.3) Suporte à impressão 3D: Sim, Não.

- Indica se o software é capaz de converter modelos atômico moleculares em modelos preparados para impressão 3D. O padrão de modelo mais utilizado é o STL, que utiliza facetas triangulares para descrever as superfícies do objeto e um vetor normal em cada face para distinguir o interior do exterior do objeto. Além do modelo, também são necessários ajustes e elementos auxiliares à impressão, determinados pela tecnologia utilizada.

- (5.2.4) Plataforma de publicação na internet: Sim, Não.

- Indica se o software é capaz de salvar dados e variáveis de estado, publicá-las na internet e compartilhá-las por meio de uma URL.

\section{(5.3) Funcionalidades didáticas}

Descrição do critério:

Indica e avalia o suporte a funcionalidades didáticas que viabilizem expor conteúdo de acordo com os objetivos do professor. Em outras palavras, re- 
cursos que permitam incorporar informações adicionais estruturadas seguindo a narrativa de ensino.

Parâmetros utilizados (quanto mais parâmetros suportados, melhor):

- (5.3.1) Suporte à narrativa didática (salvar preset didático integrado) .

- Descreve se o software oferece recursos de suporte à narrativa didática e, em caso afirmativo, quais são. Entre esses recursos, estão anotações de texto, desenhos espontâneos, referência a sites por hyperlinks, incorporação de imagens e gráficos e mecanismos para ordenar ou sequenciar tais informações.

- (5.3.2) Biblioteca de estruturas cristalográficas.

- Indica se o software reúne exemplos ilustrativos de estruturas cristalinas comumente utilizadas no ensino de ciência dos materiais, metalurgia física e física do estado sólido.

- (5.3.3) Construção e visualização incremental de estruturas

- Descreve se é possível eventualmente criar estruturas de maneira mais livre, manipulando os elementos diretamente, seja por interação ou manipulação de parâmetros puramente geométricos. Esta característica é útil no contexto didático para expor os estudantes aos desafios teóricos envolvidos na determinação das estruturas cristalinas.

\section{(5.4) Suporte e documentação}

Descrição do critério:

Avalia e indica, quando disponíveis, quais canais de suporte, documentações do projeto e do sistema são disponibilizadas pelo software.

Parâmetros utilizados (quanto mais parâmetros, melhor):

- (5.4.1) Suporte: Sim (especificar), Não.

- (5.4.2) Documentação: Sim, Não.

- O fornecimento de documentação e suporte pós-venda para softwares comerciais é obrigatório por lei em certos países. 


\section{APÊNDICE C - Detalhamento dos dados resultantes da avaliação comparativa de softwares cristalográficos}

\begin{tabular}{|c|c|c|c|c|c|c|}
\hline \multicolumn{7}{|c|}{ TABELA 1 - PARÂMETROS DO QUESTIONÁRIO TECNOLÓGICO } \\
\hline \multirow[b]{2}{*}{ Sotware } & \multirow{2}{*}{\begin{tabular}{|l|}
$\begin{array}{c}1.1 \text { Nivel de } \\
\text { atividade }\end{array}$ \\
$\begin{array}{l}1.1 .1 \\
\text { Frequência de } \\
\text { atualização }\end{array}$ \\
\end{tabular}} & \multicolumn{5}{|c|}{ 1.2 Portabilidade da aplicação } \\
\hline & & $\begin{array}{l}1.2 .1 \\
\text { Portabilidade } \\
\text { da aplicação }\end{array}$ & \begin{tabular}{|l|}
1.2 .2 \\
Plataforma de \\
desenvolvimento
\end{tabular} & $\begin{array}{l}\text { 1.2.3 Sistemas } \\
\text { operacionais } \\
\text { compatíveis }\end{array}$ & \begin{tabular}{|l}
1.2 .4 \\
Requer \\
instalação
\end{tabular} & $\begin{array}{l}\text { 1.2.5 Multipla- } \\
\text { taforma }\end{array}$ \\
\hline SPEC16 & Ativo & Alta & HTML5/WEBGL & $\begin{array}{l}\text { Independente } \\
\text { (HTML5 comp.) }\end{array}$ & Não & $\begin{array}{l}\text { Sim (Desktop; } \\
\text { Mobile; Emb.) }\end{array}$ \\
\hline CWGL16 & Ativo & Alta & HTML5/WEBGL & $\begin{array}{l}\text { Independente } \\
\text { (HTML5 comp.) }\end{array}$ & Não & $\begin{array}{l}\text { Sim (Desktop; } \\
\text { Mobile; Emb.) }\end{array}$ \\
\hline CMAK15 & Ativo & Média & Compilado (Não especificado) & Windows; Mac & Sim & Não (Desktop) \\
\hline JMOL15 & Dinâmico & Média & Interpretado (Java) & $\begin{array}{l}\text { Independente (JRE } \\
\text { comp.) }\end{array}$ & Sim/Plugin & $\begin{array}{l}\text { Sim (Desktop; } \\
\text { Emb.) }\end{array}$ \\
\hline VEST14 & Ativo & Média & Compilado $(\mathrm{C}++)$ & Windows; Linux; Mac & Sim & Não (Desktop) \\
\hline DIAM15 & Dinâmico & Baixa & Compilado (Não especificado) & Windows & Sim & Não (Desktop) \\
\hline XCRY14 & Ativo & Média & Intepretado (TCL/Tk) & Windows; Linux; Mac & Sim & Não (Desktop) \\
\hline MERC15 & Ativo & Baixa & Compilado (Não especificado) & Windows; Linux; Mac & Sim & Não (Desktop) \\
\hline PYM018 & Ativo & Média & Intepretado (Python) & Windows; Linux; Mac & Sim & $\begin{array}{l}\text { Sim (Desktop; } \\
\text { Mobile; Emb.) }\end{array}$ \\
\hline DRAW11 & Inativo & Média & Compilado/C++ & Windows; Linux; Mac & Sim & Não (Desktop) \\
\hline CARI04 & Inativo & Média & Compilado (Não especificado) & Windows; Linux & Sim & Não (Desktop) \\
\hline BALL08 & Inativo & Baixa & Compilado (Não especificado) & Windows & Sim & Não (Desktop) \\
\hline LATTO4 & Inativo & Média & Interpretado (Java) & $\begin{array}{l}\text { Independente (JRE } \\
\text { comp.) }\end{array}$ & Sim/Plugin & $\begin{array}{l}\text { Sim (Desktop; } \\
\text { Emb.) }\end{array}$ \\
\hline $\mathrm{SCHA} 14$ & Ativo & Média & Compilado (FORTRAN) & Windows; Linux & Sim & Não (Desktop) \\
\hline ATOM11 & Ativo & Média & Compilado (Não especificado) & Windows; Linux; Mac & Sim & Não (Desktop) \\
\hline SHEL15 & Ativo & Baixa & Compilado $(\mathrm{C}++)$ & Windows; Linux; Mac & Sim & Não (Desktop) \\
\hline RASM09 & Inativo & Média & Compilado $(\mathrm{C}++)$ & Windows; Linux; Mac & Sim & Não (Desktop) \\
\hline CHEM15 & Ativo & Baixo & Compilado (Não especificado) & Windows; Linux & Sim & Não (Desktop) \\
\hline QUTE07 & Inativo & Média & Compilado (C++) & Windows; Mac & Sim & Não (Desktop) \\
\hline XTAL03 & Inativo & Baixo & Compilado (Não especificado) & Windows & Sim & Não (Desktop) \\
\hline CRYS07 & Inativo & Baixa & Compilado (PASCAL) & Windows & Sim & Não (Desktop) \\
\hline POWDO0 & Inativo & Baixa & Compilado (Delphi) & $\begin{array}{l}\text { Windows; Outros } \\
\text { (DOS) }\end{array}$ & Sim & Não (Desktop) \\
\hline PLAT13 & Ativo & Média & Compilado (FORTRAN) & Windows; Linux & Sim & Não (Desktop) \\
\hline GRETOO & Inativo & Baixa & Compilado (Delphi) & Windows & Sim & Não (Desktop) \\
\hline JAMM02 & Inativo & Média & Interpretado (Java) & $\begin{array}{l}\text { Independente (JRE } \\
\text { comp.) }\end{array}$ & Sim/Plugin & $\begin{array}{l}\text { Sim (Desktop; } \\
\text { Emb.) }\end{array}$ \\
\hline ORTE14 & Ativo & Média & Compilado (FORTRAN) & Windows & Sim & Não (Desktop) \\
\hline OSCA15 & Dinâmico & Baixa & Compilado (Não especificado) & Windows & Sim & Não (Desktop) \\
\hline STRU05 & Inativo & Baixa & Compilado (Não especificado) & Windows & Sim & Não (Desktop) \\
\hline
\end{tabular}




\begin{tabular}{|c|c|c|c|c|c|c|}
\hline \multicolumn{7}{|c|}{ TABELA 1 - PARÂMETROS DO QUESTIONÁRIO TECNOLÓGICO (CONT.) } \\
\hline \multirow[b]{2}{*}{ Sotware } & \multicolumn{2}{|c|}{1.3 Uso, distribuição e modificação } & \multicolumn{2}{|c|}{$\begin{array}{l}\text { 1.4 Suporte a tecnologias de } \\
\text { interface }\end{array}$} & \multicolumn{2}{|c|}{ Pontuação } \\
\hline & $\begin{array}{l}\text { 1.3.1 Licença de uso, distribuição e } \\
\text { modificação }\end{array}$ & $\begin{array}{l}\text { 1.3.2 Modelo } \\
\text { de desenvolvi- } \\
\text { mento } \\
\text { colaborativo }\end{array}$ & $\begin{array}{l}1.4 .1 \\
\text { Dispositivos } \\
\text { base (HID) }\end{array}$ & \begin{tabular}{|l}
1.4 .2 \\
Dispositivos \\
avançados \\
de interação \\
\end{tabular} & Soma & Normalizada \\
\hline SPEC16 & Software Livre MIT & Sim & $\begin{array}{l}\text { Mouse; Teclado; } \\
\text { Trackeable }\end{array}$ & $\begin{array}{l}\text { Sim (Monit. } \\
\text { 3D; HMD) }\end{array}$ & 7 & 17,5 \\
\hline CWGL16 & Software Livre MIT & Sim & $\begin{array}{l}\text { Mouse; Teclado; } \\
\text { Trackeable }\end{array}$ & $\begin{array}{l}\text { Sim (Monit. } \\
\text { 3D; HMD) }\end{array}$ & 7 & 17,5 \\
\hline CMAK15 & $\begin{array}{l}\text { Comercial: Binário; Cód. fechado; Demo: } \\
\text { Binário; Cód. fechado }\end{array}$ & Não & $\begin{array}{l}\text { Mouse; Teclado; } \\
\text { Trackeable } \\
\text { (LeapMotion) }\end{array}$ & $\begin{array}{l}\text { Sim (Monit. } \\
\text { 3D) }\end{array}$ & 2 & 5 \\
\hline JMOL15 & Software Livre (GNULesser) & Sim & Mouse; Teclado & Não & 3 & 7,5 \\
\hline VEST14 & $\begin{array}{l}\text { Comercial: Binário; Cód. fechado; } \\
\text { (Estudantes) Freeware: Binário; Cód. } \\
\text { fechado }\end{array}$ & Não & Mouse; Teclado & Não & 1 & 2,5 \\
\hline DIAM15 & $\begin{array}{l}\text { Comercial: Binário; Cód. fechado; Demo: } \\
\text { Binário; Cód. fechado }\end{array}$ & Não & Mouse; Teclado & Não & 1 & 2,5 \\
\hline XCRY14 & Software Livre (GNU) & Não & Mouse; Teclado & Não & 2 & 5 \\
\hline MERC15 & $\begin{array}{l}\text { Comercial: Binário; Cód. fechado; Demo: } \\
\text { Binário; Cód. fechado }\end{array}$ & Não & Mouse; Teclado & $\begin{array}{l}\text { Sim (Monit. } \\
\text { 3D) }\end{array}$ & 1 & 2,5 \\
\hline PYMO18 & $\begin{array}{l}\text { Comercial: Binário; Cód. fechado; } \\
\text { (Estudantes) Python License; Cód. Aberto }\end{array}$ & $\begin{array}{l}\text { Comercial: Não; } \\
\text { Cód.-fonte: Sim }\end{array}$ & Mouse; Teclado & $\begin{array}{l}\text { Sim (Monit. } \\
\text { 3D) }\end{array}$ & 2 & 5 \\
\hline DRAW11 & Software Livre (GNU2) & Sim & Mouse; Teclado & Não & 2 & 5 \\
\hline CARI04 & $\begin{array}{l}\text { Comercial: Binário; Cód. fechado; Demo: } \\
\text { Binário; Cód. fechado }\end{array}$ & Não & Mouse; Teclado & Não & 0 & 0 \\
\hline BALL08 & Freeware: Binário; Cód. fechado & Não & Mouse; Teclado & Não & 0 & 0 \\
\hline LATT04 & N/A: Binário; Código-fonte & Não & Mouse; Teclado & Não & 0 & 0 \\
\hline SCHA14 & Software Livre (GNU) & Não & Mouse; Teclado & Não & 2 & 5 \\
\hline ATOM11 & $\begin{array}{l}\text { Comercial: Binário; Cód. fechado; Demo: } \\
\text { Binário; Cód. fechado }\end{array}$ & Não & Mouse; Teclado & $\begin{array}{l}\text { Sim (Monit. } \\
\text { 3D) }\end{array}$ & 1 & 2,5 \\
\hline SHEL15 & Software Livre (GNU) & Sim & Mouse; Teclado & $\begin{array}{l}\text { Sim (Monit. } \\
\text { 3D) }\end{array}$ & 3 & 7,5 \\
\hline RASM09 & Software Livre (GNU) & Não & Mouse; Teclado & Não & 1 & 2,5 \\
\hline CHEM15 & $\begin{array}{l}\text { Comercial: Binário; Cód. fechado; Demo: } \\
\text { Binário; Cód. fechado }\end{array}$ & Não & Mouse; Teclado & Não & 1 & 2,5 \\
\hline QUTE07 & Software Livre (GNU2) & Sim & Mouse; Teclado & Não & 2 & 5 \\
\hline XTAL03 & Freeware: Binário; Cód. fechado & Não & Mouse; Teclado & Não & 0 & 0 \\
\hline CRYS07 & $\begin{array}{l}\text { Comercial: Binário; Cód. fechado; Demo: } \\
\text { Binário; Cód. fechado }\end{array}$ & Não & Mouse; Teclado & Não & 0 & 0 \\
\hline POWD00 & Freeware: Binário; Cód. fechado & Não & Mouse; Teclado & $\begin{array}{l}\text { Sim (Monit. } \\
\text { 3D) }\end{array}$ & 0 & 0 \\
\hline PLAT13 & $\begin{array}{l}\text { (Original Fortran): Código-fonte; (Port } \\
\text { Windows); Comercial: Binário; Cód. fechado; } \\
\text { (Estudantes) Freeware: Binário; Cód. fechado }\end{array}$ & Não & Teclado & Não & 1 & 2,5 \\
\hline GRET00 & Freeware: Binário; Cód. fechado & Não & Mouse; Teclado & Não & 0 & 0 \\
\hline JAMM02 & N/A: Binário; Cód. fechado & Não & Mouse & Não & 0 & 0 \\
\hline ORTE14 & $\begin{array}{l}\text { (Original Fortran): Cód.fonte; (Port } \\
\text { Windows); Comercial: Binário; Cód. fechado; } \\
\text { (Estudantes) Freeware: Binário; Cód. fechado }\end{array}$ & Não & Mouse; Teclado & Não & 1 & 2,5 \\
\hline OSCA15 & $\begin{array}{l}\text { Comercial: Binário; Cód. fechado; } \\
\text { (Estudantes) Freeware: Binário; Cód. fechado }\end{array}$ & Não & Mouse & Não & 1 & 2,5 \\
\hline STRU05 & Freeware: Binário; Cód. fechado & Não & Mouse; Teclado & Não & 0 & 0 \\
\hline
\end{tabular}




\begin{tabular}{|c|c|c|c|c|c|c|}
\hline \multicolumn{7}{|c|}{ TABELA 2 - PARÂMETROS DO QUESTIONÁRIO DE SÍNTESE } \\
\hline \multirow{2}{*}{ Software } & \multirow{2}{*}{$\begin{array}{l}\text { 2.1 Método de } \\
\text { sintese }\end{array}$} & \multirow{2}{*}{$\begin{array}{l}2.2 \text { Processo de } \\
\text { síntese interativo }\end{array}$} & \multirow{2}{*}{$\begin{array}{l}2.3 \text { Restrições ou } \\
\text { limitações à sintese }\end{array}$} & \multirow{2}{*}{$\begin{array}{l}2.4 \text { Seleção e } \\
\text { edição interativas } \\
\text { de átomos }\end{array}$} & \multicolumn{2}{|c|}{ Pontuação } \\
\hline & & & & & Soma & Normalizada \\
\hline SPEC16 & Rede+ motivo & Sim & Não & Sim & 4 & 10 \\
\hline CWGL16 & Rede + motivo & Sim & Não & Sim & 4 & 10 \\
\hline CMAK15 & Posições de Wyckoff & Não & Não & Sim & 2 & 5 \\
\hline JMOL15 & Posições de Wyckoff & Não & Não & Sim & 2 & 5 \\
\hline VEST14 & Posições de Wyckoff & Não & Não & Sim & 2 & 5 \\
\hline DIAM15 & Posições de Wyckoff & Não & Não & Não & 1 & 2,5 \\
\hline XCRY14 & Posições de Wyckoff & Não & Não & Sim & 2 & 5 \\
\hline MERC15 & Posições de Wyckoff & Não & Não & Não & 1 & 2,5 \\
\hline PYMO18 & Posições de Wyckoff & Não & Sim (Param. externa) & Sim & 1 & 2,5 \\
\hline DRAW11 & Posições de Wyckoff & Não & Não & Não & 1 & 2,5 \\
\hline CARI04 & Posições de Wyckoff & Não & Não & Sim & 2 & 5 \\
\hline BALL08 & Posições de Wyckoff & Não & Não & Sim & 2 & 5 \\
\hline LATT04 & Posições de Wyckoff & Não & Não & Sim & 2 & 5 \\
\hline $\mathrm{SCHA} 14$ & Posições de Wyckoff & Não & Não & Não & 1 & 2,5 \\
\hline ATOM11 & Posições de Wyckoff & Não & Não & Não & 1 & 2,5 \\
\hline SHEL15 & Posições de Wyckoff & Não & $\begin{array}{l}\text { Sim (App. externa } \\
(\text { ShelX)) }\end{array}$ & Não & 0 & 0 \\
\hline RASM09 & Posições de Wyckoff & Não & Não & Não & 1 & 2,5 \\
\hline CHEM15 & Posições de Wyckoff & Não & Sim (Param. externa) & Sim & 1 & 2,5 \\
\hline QUTE07 & Posições de Wyckoff & Não & Sim (Param. externa) & Não & 0 & 0 \\
\hline XTAL03 & Posições de Wyckoff & Não & Sim (Param. externa) & Sim & 1 & 2,5 \\
\hline CRYSO7 & Posições de Wyckoff & Não & Não & Não & 1 & 2,5 \\
\hline POWD00 & Posições de Wyckoff & Não & Não & Não & 1 & 2,5 \\
\hline PLAT13 & Posições de Wyckoff & Não & Não & Não & 1 & 2,5 \\
\hline GRETOO & Posições de Wyckoff & Não & Não & Não & 1 & 2,5 \\
\hline JAMM02 & Posições de Wyckoff & Não & Sim (Param. externa) & Não & 0 & 0 \\
\hline ORTE14 & Posições de Wyckoff & Não & Não & Não & 1 & 2,5 \\
\hline OSCA15 & Posições de Wyckoff & Não & Não & Não & 1 & 2,5 \\
\hline STRU05 & Posições de Wyckoff & Não & Não & Não & 1 & 2,5 \\
\hline
\end{tabular}




\begin{tabular}{|c|c|c|c|c|c|c|}
\hline \multicolumn{7}{|c|}{ TABELA 3 - PARÂMETROS DO QUESTIONÁRIO DE VISUALIZAÇÃO } \\
\hline \multirow{3}{*}{ Software } & \multicolumn{6}{|c|}{ 3.1 Representação } \\
\hline & \multirow{2}{*}{$\begin{array}{l}\text { 3.1.1 Modelo de representação } \\
\text { atômico molecular }\end{array}$} & \multirow{2}{*}{$\begin{array}{l}3.1 .2 \text { Modelo de } \\
\text { representação da célula } \\
\text { unitária }\end{array}$} & \multirow{2}{*}{$\begin{array}{l}3.1 .3 \\
\text { Planos } \\
\text { de } \\
\text { Miller }\end{array}$} & \multirow{2}{*}{$\begin{array}{l}3.1 .4 \\
\text { Direções } \\
\text { de Miller }\end{array}$} & \multicolumn{2}{|c|}{$\begin{array}{l}\text { 3.1.5 Artifícios de } \\
\text { suporte }\end{array}$} \\
\hline & & & & & $\begin{array}{l}3.1 .5 .1 \text { Células } \\
\text { múltiplas }\end{array}$ & $\begin{array}{l}3.1 .5 .2 \\
\text { Cortes } \\
\end{array}$ \\
\hline SPEC16 & Esferas rígidas & $\begin{array}{l}\text { Células unitárias } \\
\text { inteiras; Células parciais; } \\
\text { Interstícios }\end{array}$ & Sim & Sim & Sim & Sim \\
\hline CWGL16 & Esferas rígidas & $\begin{array}{l}\text { Células unitárias } \\
\text { inteiras; Células parciais; } \\
\text { Interstícios }\end{array}$ & Sim & Sim & Sim & Sim \\
\hline CMAK15 & $\begin{array}{l}\text { Bolas e palitos; Espaço de } \\
\text { preenchimento; Outros (Esquelético; } \\
\text { Poliedro) }\end{array}$ & Células unitárias inteiras & Sim & Sim & Sim & Sim \\
\hline JMOL15 & $\begin{array}{l}\text { Bolas e palitos; Espaço de } \\
\text { preenchimento; Outros (Esquelético) }\end{array}$ & Células unitárias inteiras & Sim & Não & Sim & Sim \\
\hline VEST14 & $\begin{array}{l}\text { Bolas e palitos; Espaço de } \\
\text { preenchimento; Outros (Esquelético) }\end{array}$ & Células unitárias inteiras & Sim & Sim & Sim & Sim \\
\hline DIAM15 & $\begin{array}{l}\text { Bolas e palitos; Espaço de } \\
\text { preenchimento; Outros (Esquelético) }\end{array}$ & Células unitárias inteiras & Sim & Sim & Sim & Não \\
\hline XCRY14 & $\begin{array}{l}\text { Bolas e palitos; Espaço de } \\
\text { preenchimento; Outros (Esquelético) }\end{array}$ & Células unitárias inteiras & Sim & Não & Sim & Sim \\
\hline MERC15 & $\begin{array}{l}\text { Bolas e palitos; Espaço de } \\
\text { preenchimento; Outros (Esquelético) }\end{array}$ & Células unitárias inteiras & Sim & Não & Sim & Sim \\
\hline PYMO18 & $\begin{array}{l}\text { Bolas e palitos; Espaço de } \\
\text { preenchimento; Outros (Esquelético) }\end{array}$ & Células unitárias inteiras & Não & Não & Sim & Sim \\
\hline DRAW11 & $\begin{array}{l}\text { Bolas e palitos; Outros (Esquelético; } \\
\text { Poliedro) }\end{array}$ & Células unitárias inteiras & Sim & Sim & Sim & Não \\
\hline CARI04 & $\begin{array}{l}\text { Bolas e palitos; Espaço de } \\
\text { preenchimento; Outros (Poliedro) }\end{array}$ & Células unitárias inteiras & Sim & Sim & Sim & Sim \\
\hline BALL08 & Bolas e palitos; Outros (Poliedro) & Células unitárias inteiras & Não & Não & Sim & Não \\
\hline LATTO4 & Espaço de preenchimento & Células unitárias inteiras & Não & Não & Sim & Não \\
\hline SCHA14 & $\begin{array}{l}\text { Bolas e palitos; Espaço de preenchi- } \\
\text { mento; Outros (Esquelético; Ortep) }\end{array}$ & Células unitárias inteiras & Não & Não & Sim & Não \\
\hline ATOM11 & $\begin{array}{l}\text { Bolas e palitos; Espaço de preenchi- } \\
\text { mento; Outros (Esquelético; Poliedro) }\end{array}$ & Células unitárias inteiras & Não & Não & Sim & Não \\
\hline SHEL15 & Bolas e palitos & Células unitárias inteiras & Não & Não & Não & Não \\
\hline RASM09 & $\begin{array}{l}\text { Bolas e palitos; Espaço de } \\
\text { preenchimento; Outros (Esquelético) }\end{array}$ & Células unitárias inteiras & Não & Não & Sim & Não \\
\hline CHEM15 & $\begin{array}{l}\text { Bolas e palitos; Espaço de } \\
\text { preenchimento; Outros (Esquelético) }\end{array}$ & Células unitárias inteiras & Não & Não & Não & Não \\
\hline QUTE07 & $\begin{array}{l}\text { Bolas e palitos; Espaço de } \\
\text { preenchimento; Outros (Esquelético) }\end{array}$ & Células unitárias inteiras & Não & Não & Não & Não \\
\hline XTAL03 & $\begin{array}{l}\text { Bolas e palitos; Espaço de } \\
\text { preenchimento; Outros (Ortep; Poliedro) }\end{array}$ & Células unitárias inteiras & Não & Não & Não & Não \\
\hline CRYS07 & $\begin{array}{l}\text { Bolas e palitos; Espaço de } \\
\text { preenchimento }\end{array}$ & Células unitárias inteiras & Não & Não & Sim & Não \\
\hline POWD00 & Bolas e palitos & Células unitárias inteiras & Não & Não & Não & Não \\
\hline PLAT13 & $\begin{array}{l}\text { Bolas e palitos; Outros (Esquelético; } \\
\text { Ortep) }\end{array}$ & Células unitárias inteiras & Não & Não & Sim & Não \\
\hline GRETOO & Bolas e palitos & Células unitárias inteiras & Não & Não & Sim & Não \\
\hline JAMM02 & $\begin{array}{l}\text { Bolas e palitos; Espaço de } \\
\text { preenchimento; Outros }\end{array}$ & Células unitárias inteiras & Não & Não & Não & Não \\
\hline ORTE14 & $\begin{array}{l}\text { Bolas e palitos; Outros (Esquelético; } \\
\text { Ortep) }\end{array}$ & Células unitárias inteiras & Não & Não & Sim & Não \\
\hline OSCA15 & $\begin{array}{l}\text { Bolas e palitos; Outros (Esquelético; } \\
\text { Ortep) }\end{array}$ & Células unitárias inteiras & Não & Não & Sim & Não \\
\hline STRU05 & Outros (Poliedro) & Células unitárias inteiras & Não & Não & Não & Não \\
\hline
\end{tabular}


TABELA 3 - PARÂMETROS DO QUESTIONÁRIO DE VISUALIZAÇÃO (CONT.)

\begin{tabular}{|c|c|c|c|c|}
\hline \multirow{3}{*}{ Software } & \multirow{2}{*}{\multicolumn{2}{|c|}{$\begin{array}{c}\text { 3.1 Representação (cont.) } \\
\text { 3.1.5 Artifícios de suporte (cont.) }\end{array}$}} & \multicolumn{2}{|l|}{3.2 Visualização } \\
\hline & & & \multirow[b]{2}{*}{ 3.2.1 Recursos de percepção visual } & \multirow[b]{2}{*}{ 3.2.2 Tipo de projeção } \\
\hline & $\begin{array}{l}\text { 3.1.5.3 Vetores do } \\
\text { eixo da rede }\end{array}$ & $\begin{array}{l}3.1 .5 .4 \\
\text { Recursos } \\
\text { auxiliares } \\
\text { de rede }\end{array}$ & & \\
\hline SPEC16 & $\begin{array}{l}\text { Cartesianos (xyz); } \\
\text { Cristalográficos }(a b c)\end{array}$ & \begin{tabular}{l|} 
Bordas e \\
Faces
\end{tabular} & $\begin{array}{l}\text { Formas e perspectiva; Cor; Opacidade e } \\
\text { intensidade luminosa; Nuvem de profundidade } \\
\text { e (som espacial) }\end{array}$ & $\begin{array}{l}\text { Perspectiva cônica; } \\
\text { Perspectiva axonométrica }\end{array}$ \\
\hline CWGL16 & $\begin{array}{l}\text { Cartesianos (xyz); } \\
\text { Cristalográficos (abc) }\end{array}$ & $\begin{array}{l}\text { Bordas e } \\
\text { Faces }\end{array}$ & $\begin{array}{l}\text { Formas e perspectiva; Cor; Opacidade e } \\
\text { intensidade luminosa; Nuvem de profundidade } \\
\text { e (som espacial) }\end{array}$ & $\begin{array}{l}\text { Perspectiva cônica; } \\
\text { Perspectiva axonométrica }\end{array}$ \\
\hline CMAK15 & Cartesianos (xyz) & $\begin{array}{l}\text { Bordas e } \\
\text { faces }\end{array}$ & $\begin{array}{l}\text { Formas e perspectiva; Cor; Opacidade e } \\
\text { intensidade luminosa e Nuvem de profundidade }\end{array}$ & $\begin{array}{l}\text { Perspectiva cônica; } \\
\text { Perspectiva axonométrica }\end{array}$ \\
\hline JMOL15 & $\begin{array}{l}\text { Cartesianos (xyz); } \\
\text { Cristalográficos (abc) }\end{array}$ & $\begin{array}{l}\text { Bordas e } \\
\text { faces }\end{array}$ & $\begin{array}{l}\text { Formas e perspectiva; Cor; Opacidade e } \\
\text { intensidade luminosa }\end{array}$ & $\begin{array}{l}\text { Perspectiva cônica; } \\
\text { Perspectiva axonométrica }\end{array}$ \\
\hline VEST14 & $\begin{array}{l}\text { Cartesianos (xyz); } \\
\text { Cristalográficos (abc) }\end{array}$ & $\begin{array}{l}\text { Bordas e } \\
\text { faces }\end{array}$ & $\begin{array}{l}\text { Formas e perspectiva; Cor; Opacidade e } \\
\text { intensidade luminosa e Nuvem de profundidade }\end{array}$ & $\begin{array}{l}\text { Perspectiva cônica; } \\
\text { Perspectiva axonométrica }\end{array}$ \\
\hline DIAM15 & $\begin{array}{l}\text { Cartesianos (xyz); } \\
\text { Cristalográficos (abc) }\end{array}$ & Bordas & $\begin{array}{l}\text { Formas e perspectiva; Cor; Opacidade e } \\
\text { intensidade luminosa e Nuvem de profundidade }\end{array}$ & $\begin{array}{l}\text { Perspectiva cônica; } \\
\text { Perspectiva axonométrica }\end{array}$ \\
\hline XCRY14 & Cartesianos (xyz) & Bordas & $\begin{array}{l}\text { Formas e perspectiva; Cor; Opacidade e } \\
\text { intensidade luminosa e Nuvem de profundidade }\end{array}$ & $\begin{array}{l}\text { Perspectiva cônica; } \\
\text { Perspectiva axonométrica }\end{array}$ \\
\hline MERC15 & Cristalográficos (abc) & Bordas & $\begin{array}{l}\text { Formas e perspectiva; Cor; Opacidade e } \\
\text { intensidade luminosa e Nuvem de profundidade }\end{array}$ & Perspectiva axonométrica \\
\hline PYMO18 & Cartesianos (xyz) & Não & $\begin{array}{l}\text { Formas e perspectiva; Cor; Opacidade e } \\
\text { intensidade luminosa e Nuvem de profundidade }\end{array}$ & $\begin{array}{l}\text { Perspectiva cônica; } \\
\text { Perspectiva axonométrica }\end{array}$ \\
\hline DRAW11 & Cristalográficos (abc) & $\begin{array}{l}\text { Bordas e } \\
\text { faces }\end{array}$ & $\begin{array}{l}\text { Formas e perspectiva; Cor; Opacidade e } \\
\text { intensidade luminosa }\end{array}$ & $\begin{array}{l}\text { Perspectiva cônica; } \\
\text { Perspectiva axonométrica }\end{array}$ \\
\hline CARI04 & $\begin{array}{l}\text { Cartesianos (xyz); } \\
\text { Cristalográficos (abc) }\end{array}$ & Bordas & $\begin{array}{l}\text { Formas e perspectiva; Cor; Opacidade e } \\
\text { intensidade luminosa }\end{array}$ & Perspectiva axonométrica \\
\hline BALL08 & Cartesianos (xyz) & Bordas & Formas e perspectiva; Cor & $\begin{array}{l}\text { Perspectiva cônica; } \\
\text { Perspectiva axonométrica }\end{array}$ \\
\hline LATTO4 & Cartesianos (xyz) & Faces & $\begin{array}{l}\text { Formas e perspectiva; Cor; Opacidade e } \\
\text { intensidade luminosa }\end{array}$ & $\begin{array}{l}\text { Perspectiva cônica; } \\
\text { Perspectiva axonométrica }\end{array}$ \\
\hline SCHA14 & Não & Não & $\begin{array}{l}\text { Formas e perspectiva; Cor; Opacidade e } \\
\text { intensidade luminosa e Nuvem de profundidade }\end{array}$ & Perspectiva axonométrica \\
\hline ATOM11 & Cristalográficos (abc) & Faces & Formas e perspectiva; Cor & Perspectiva axonométrica \\
\hline SHEL15 & Cristalográficos (abc) & Bordas & $\begin{array}{l}\text { Formas e perspectiva; Cor; Opacidade e } \\
\text { intensidade luminosa }\end{array}$ & $\begin{array}{l}\text { Perspectiva cônica; } \\
\text { Perspectiva axonométrica }\end{array}$ \\
\hline RASM09 & Não & Não & Formas e perspectiva; Cor & Perspectiva axonométrica \\
\hline CHEM15 & Cartesianos (xyz) & Não & $\begin{array}{l}\text { Formas e perspectiva; Cor; Opacidade e } \\
\text { intensidade luminosa }\end{array}$ & $\begin{array}{l}\text { Perspectiva cônica; } \\
\text { Perspectiva axonométrica }\end{array}$ \\
\hline QUTE07 & Não & Não & $\begin{array}{l}\text { Formas e perspectiva; Cor; Opacidade e } \\
\text { intensidade luminosa e Nuvem de profundidade }\end{array}$ & Perspectiva axonométrica \\
\hline XTAL03 & Cristalográficos (abc) & Bordas & $\begin{array}{l}\text { Formas e perspectiva; Cor; Opacidade e } \\
\text { intensidade luminosa; }\end{array}$ & Perspectiva axonométrica \\
\hline CRYS07 & $\begin{array}{l}\text { Cartesianos (xyz); } \\
\text { Cristalográficos(abc) }\end{array}$ & Bordas & Formas e perspectiva; Cor & Perspectiva axonométrica \\
\hline POWD00 & Cristalográficos (abc) & Bordas & Formas e perspectiva; Cor & $\begin{array}{l}\text { Perspectiva cônica; } \\
\text { Perspectiva axonométrica }\end{array}$ \\
\hline PLAT13 & Cartesianos (xyz) & Não & $\begin{array}{l}\text { Formas e perspectiva; Cor; Opacidade e } \\
\text { intensidade luminosa; }\end{array}$ & Perspectiva axonométrica \\
\hline GRETOO & Cristalográficos (abc) & Bordas & Formas e perspectiva; Cor & Perspectiva axonométrica \\
\hline JAMM02 & Cartesianos (xyz) & Não & $\begin{array}{l}\text { Formas e perspectiva; Cor; Opacidade e } \\
\text { intensidade luminosa e Nuvem de profundidade }\end{array}$ & Perspectiva axonométrica \\
\hline ORTE14 & Cartesianos (xyz) & Não & Formas e perspectiva; Cor & Perspectiva axonométrica \\
\hline OSCA15 & Cartesianos (xyz) & Não & Formas e perspectiva; Cor & Perspectiva axonométrica \\
\hline STRU05 & Não & Não & Formas e perspectiva; Cor & Perspectiva axonométrica \\
\hline
\end{tabular}




\begin{tabular}{|c|c|c|c|c|}
\hline \multicolumn{5}{|c|}{ TABELA 3 - PARÂMETROS DO QUESTIONÁRIO DE VISUALIZAÇÃO (CONT.) } \\
\hline \multirow{2}{*}{ Software } & \multicolumn{2}{|c|}{3.2 Visualização (cont.) } & \multicolumn{2}{|c|}{ Pontuação } \\
\hline & 3.2.3 Suporte estereográfico & 3.2.4 Modos de renderização & Soma & Normalizada \\
\hline SPEC16 & Sim (Anaglifo; Side-by-side; HMD) & Sólido; Ilustração; Realistico & 12 & 30 \\
\hline CWGL16 & Sim (Anaglifo; Side-by-side; HMD) & Sólido; Ilustração; Realistico & 12 & 30 \\
\hline CMAK15 & Filtro (Anaglifo; Polarizado); Estereograma & Sólido; Ilustração; Realistico & 8 & 20 \\
\hline JMOL15 & Filtro (Anaglifo; Polarizado); Estereograma & Sólido; Ilustração; Realistico & 7 & 17,5 \\
\hline VEST14 & Não & Sólido; Realístico & 8 & 20 \\
\hline DIAM15 & Filtro (Anaglifo; Polarizado); Estereograma & Sólido; Ilustração; Realistico & 7 & 17,5 \\
\hline XCRY14 & Filtro (Anaglifo) & Sólido; Ilustração; Realistico & 6 & 15 \\
\hline MERC15 & Filtro (Anaglifo; Polarizado); Estereograma & Sólido; Ilustração; Realistico & 5 & 12,5 \\
\hline PYMO18 & Filtro (Anaglifo; Polarizado); Estereograma & Sólido; Ilustração; Realistico & 5 & 12,5 \\
\hline DRAW11 & Não & Sólido & 5 & 12,5 \\
\hline CARI04 & Não & Sólido & 5 & 12,5 \\
\hline BALL08 & Filtro (Anaglifo) & Sólido; Ilustração; Realistico & 3 & 7,5 \\
\hline LATT04 & Não & Realístico & 2 & 5 \\
\hline $\mathrm{SCHA} 14$ & Filtro (Anaglifo) & Sólido; Ilustração; Realistico & 3 & 7,5 \\
\hline ATOM11 & Filtro (Anaglifo; Polarizado); Estereograma & Sólido; Ilustração & 1 & 2,5 \\
\hline SHEL15 & Filtro (Anaglifo; Polarizado); Estereograma & Sólido; Ilustração; Realistico & 2 & 5 \\
\hline RASM09 & Estereograma & Sólido; Ilustração & 1 & 2,5 \\
\hline CHEM15 & Não & Sólido; Ilustração; Realistico & 2 & 5 \\
\hline QUTE07 & Não & Sólido; Ilustração; Realistico & 2 & 5 \\
\hline XTAL03 & Não & Sólido; Ilustração; Realistico & 1 & 2,5 \\
\hline CRYSO7 & Não & Ilustração & 2 & 5 \\
\hline POWD00 & Estereograma & Ilustração & 1 & 2,5 \\
\hline PLAT13 & Filtro (Anaglifo) & Ilustração & 1 & 2,5 \\
\hline GRETOO & Não & Ilustração & 1 & 2,5 \\
\hline JAMM02 & Filtro (Anaglifo) & Sólido; Ilustração & 1 & 2,5 \\
\hline ORTE14 & Filtro (Anaglifo; Polarizado); Estereograma & Sólido; Ilustração & 1 & 2,5 \\
\hline OSCA15 & Nao & Sólido; Ilustração & 1 & 2,5 \\
\hline STRU05 & Não & Sólido & 0 & 0 \\
\hline
\end{tabular}




\begin{tabular}{|c|c|c|c|c|c|c|}
\hline \multicolumn{7}{|c|}{ TABELA 4 - PARÂMETROS DO QUESTIONÁRIO DE NAVEGAÇÃO E INTERATIVIDADE } \\
\hline \multirow[b]{2}{*}{ Software } & \multirow{2}{*}{\multicolumn{2}{|c|}{ 4.1 Interface de usuário }} & \multirow[b]{2}{*}{4.2 Interação base } & \multicolumn{3}{|c|}{4.3 Interação avançada } \\
\hline & & & & $\begin{array}{l}4.3 .1 \\
\text { Rotações } \\
\text { automáticas } \\
\end{array}$ & $\begin{array}{l}4.3 .2 \\
\text { Animações } \\
\text { guiadas }\end{array}$ & \begin{tabular}{|l|}
4.3 .3 \\
Transição \\
de escala
\end{tabular} \\
\hline SPEC16 & Gráfica; Ordenada & Amigável & $\begin{array}{l}\text { Magnificação (zoom); } \\
\text { Translação; Rotação }\end{array}$ & Sim & Sim & Sim \\
\hline CWGL16 & Gráfica; Ordenada & Amigável & $\begin{array}{l}\text { Magnificação (zoom); } \\
\text { Translação; Rotação }\end{array}$ & Sim & Sim & Sim \\
\hline CMAK15 & Gráfica; Ordenada & Amigável & $\begin{array}{l}\text { Magnificação (zoom); } \\
\text { Translação; Rotação }\end{array}$ & Sim & Sim & Não \\
\hline JMOL15 & Gráfica; Não ordenada & Não amigável & $\begin{array}{l}\text { Magnificação (zoom); } \\
\text { Translação; Rotação }\end{array}$ & Sim & Sim & Não \\
\hline VEST14 & Gráfica; Ordenada & Amigável & $\begin{array}{l}\text { Magnificação (zoom); } \\
\text { Translação; Rotação }\end{array}$ & Não & Não & Não \\
\hline DIAM15 & Gráfica; Não ordenada & Não amigável & $\begin{array}{l}\text { Magnificação (zoom); } \\
\text { Rotação }\end{array}$ & Sim & Sim & Não \\
\hline XCRY14 & Gráfica; Ordenada & Amigável & $\begin{array}{l}\text { Magnificação (zoom); } \\
\text { Translação; Rotação }\end{array}$ & Não & Não & Não \\
\hline MERC15 & Gráfica; Ordenada & Amigável & $\begin{array}{l}\text { Magnificação (zoom); } \\
\text { Rotação }\end{array}$ & Sim & Não & Não \\
\hline PYMO18 & Gráfica; Não ordenada & Não amigável & $\begin{array}{l}\text { Magnificação (zoom); } \\
\text { Translação; Rotação }\end{array}$ & Sim & Sim & Não \\
\hline DRAW11 & Gráfica; Não ordenada & Não amigável & $\begin{array}{l}\text { Magnificação (zoom); } \\
\text { Translação; Rotação }\end{array}$ & Não & Não & Não \\
\hline CARI04 & Gráfica; Não ordenada & Não amigável & $\begin{array}{l}\text { Magnificação (zoom); } \\
\text { Translação; Rotação }\end{array}$ & Não & Não & Não \\
\hline BALL08 & Gráfica; Ordenada & Amigável & $\begin{array}{l}\text { Magnificação (zoom); } \\
\text { Translação; Rotação }\end{array}$ & Sim & Não & Não \\
\hline LATT04 & Gráfica; Ordenada & Amigável & $\begin{array}{l}\text { Magnificação (zoom); } \\
\text { Translação; Rotação }\end{array}$ & Não & Não & Não \\
\hline SCHA14 & Texto; Não ordenada & Não amigável & $\begin{array}{l}\text { Magnificação (zoom); } \\
\text { Rotação }\end{array}$ & Não & Não & Não \\
\hline ATOM11 & Gráfica; Ordenada & Amigável & $\begin{array}{l}\text { Magnificação (zoom); } \\
\text { Translação; Rotação }\end{array}$ & Sim & Não & Não \\
\hline SHEL15 & Gráfica; Não ordenada & Não amigável & $\begin{array}{l}\text { Magnificação (zoom); } \\
\text { Translação; Rotação }\end{array}$ & Não & Não & Não \\
\hline RASM09 & Gráfica; Não ordenada & Não amigável & $\begin{array}{l}\text { Magnificação (zoom); } \\
\text { Translação; Rotação }\end{array}$ & Não & Sim & Não \\
\hline CHEM15 & Gráfica; Não ordenada & Não amigável & $\begin{array}{l}\text { Magnificação (zoom); } \\
\text { Translação; Rotação }\end{array}$ & Não & Não & Não \\
\hline QUTE07 & Gráfica; Ordenada & Amigável & $\begin{array}{l}\text { Magnificação (zoom); } \\
\text { Translação; Rotação }\end{array}$ & Não & Não & Não \\
\hline XTAL03 & Texto; Não ordenada & Não amigável & $\begin{array}{l}\text { Magnificação (zoom); } \\
\text { Translação; Rotação }\end{array}$ & Não & Não & Não \\
\hline CRYS07 & Gráfica; Não ordenada & Não amigável & $\begin{array}{l}\text { Magnificação (zoom); } \\
\text { Translação; Rotação }\end{array}$ & Não & Não & Não \\
\hline POWDO0 & Gráfica; Não ordenada & Não amigável & $\begin{array}{l}\text { Magnificação (zoom); } \\
\text { Rotação }\end{array}$ & Não & Não & Não \\
\hline PLAT13 & Texto; Não ordenada & Não amigável & $\begin{array}{l}\text { Magnificação (zoom); } \\
\text { Rotação }\end{array}$ & Não & Não & Não \\
\hline GRETOO & Gráfica; Não ordenada & Não amigável & $\begin{array}{l}\text { Magnificação (zoom); } \\
\text { Translação; Rotação }\end{array}$ & Não & Não & Não \\
\hline JAMM02 & Gráfica; Ordenada & Amigável & $\begin{array}{l}\text { Magnificação (zoom); } \\
\text { Rotação }\end{array}$ & Sim & Não & Não \\
\hline ORTE14 & Texto; Não ordenada & Não amigável & $\begin{array}{l}\text { Magnificação (zoom); } \\
\text { Rotação }\end{array}$ & Não & Não & Não \\
\hline OSCA15 & Gráfica; Não ordenada & Não amigável & $\begin{array}{l}\text { Magnificação (zoom); } \\
\text { Rotação }\end{array}$ & Não & Não & Não \\
\hline STRU05 & Gráfica; Não ordenada & Não amigável & $\begin{array}{l}\text { Magnificação (zoom); } \\
\text { Rotação }\end{array}$ & Não & Não & Não \\
\hline
\end{tabular}


TABELA 4 - PARÂMETROS DO QUESTIONÁRIO DE NAVEGAÇÃO E INTERATIVIDADE (CONT.)

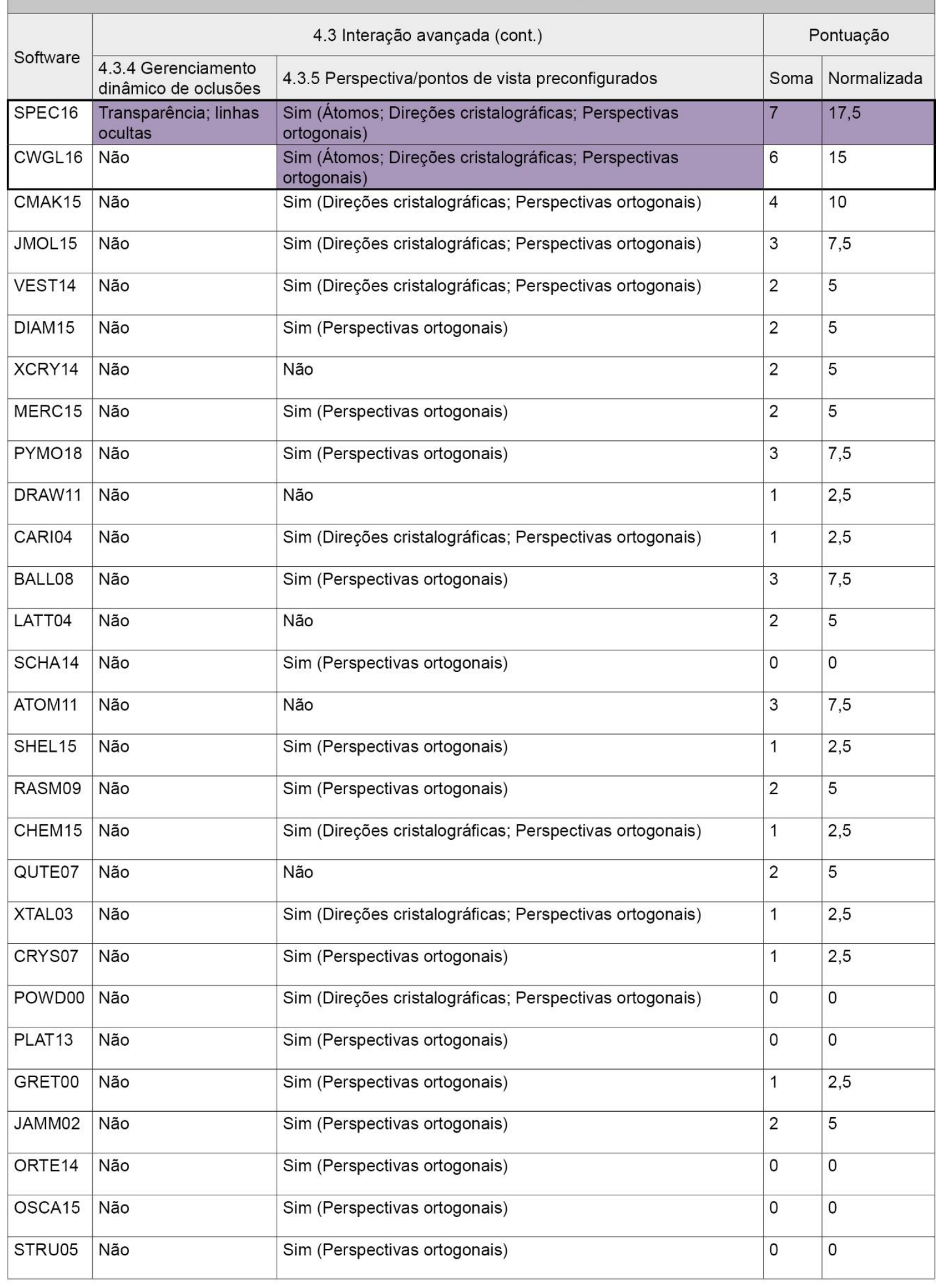




\begin{tabular}{|c|c|c|c|c|c|c|}
\hline \multicolumn{7}{|c|}{ TABELA 5 - PARÂMETROS DO QUESTIONÁRIO DIDÁTICO } \\
\hline \multirow[b]{2}{*}{ Software } & \multirow{2}{*}{$\begin{array}{l}5.1 \text { Conhecimentos } \\
\text { requeridos do usuário }\end{array}$} & \multicolumn{4}{|c|}{5.2 Suporte a publicações } & \multirow{2}{*}{\begin{tabular}{|l}
$\begin{array}{l}5.3 \text { Funcionali- } \\
\text { dades didáticas }\end{array}$ \\
$\begin{array}{l}\text { 5.3.1 Suporte } \\
\text { à narrativa } \\
\text { didática }\end{array}$ \\
\end{tabular}} \\
\hline & & $\begin{array}{l}\text { 5.2.1 Suporte à } \\
\text { visualização/porta- } \\
\text { bilidade externa }\end{array}$ & $\begin{array}{l}\text { 5.2.2 Suporte à } \\
\text { impressão } 2 \mathrm{D}\end{array}$ & $\begin{array}{l}\text { 5.2.3 Supor- } \\
\text { te à impres- } \\
\text { são 3D }\end{array}$ & $\begin{array}{l}\text { 5.2.4 Platafor- } \\
\text { ma de publica- } \\
\text { ção na internet }\end{array}$ & \\
\hline SPEC16 & $\begin{array}{l}\text { Ciência dos materiais; } \\
\text { Geometria básica } \\
\text { (rede + motivo) }\end{array}$ & $\begin{array}{l}\text { Aplicativo } \\
\text { completo; Modelo } \\
\text { 3D (VRML; POV) }\end{array}$ & Imagem bitmap & $\operatorname{Sim}(\mathrm{STL})$ & Sim & $\begin{array}{l}\text { Texto/anotações; } \\
\text { Hiperlinks; } \\
\text { Imagens }\end{array}$ \\
\hline CWGL16 & $\begin{array}{l}\text { Ciência dos materiais; } \\
\text { Geometria básica } \\
\text { (rede + motivo) }\end{array}$ & $\begin{array}{l}\text { Aplicativo } \\
\text { completo; Modelo } \\
\text { 3D (VRML; POV) }\end{array}$ & Imagem bitmap & $\operatorname{Sim}(S T L)$ & Sim & $\begin{array}{l}\text { Texto/anotações; } \\
\text { Hiperlinks; } \\
\text { Imagens }\end{array}$ \\
\hline CMAK15 & $\begin{array}{l}\text { Cristalografia (grupos } \\
\text { espaciais) }\end{array}$ & $\begin{array}{l}\text { Modelo 3D } \\
\text { (VRML; QTR; } \\
\text { POV) }\end{array}$ & $\begin{array}{l}\text { Imagem bitmap; } \\
\text { Imagem vetorial }\end{array}$ & $\operatorname{Sim}(S T L)$ & Não & $\begin{array}{l}\text { Texto/ } \\
\text { anotações }\end{array}$ \\
\hline JMOL15 & $\begin{array}{l}\text { Cristalografia (grupos } \\
\text { espaciais) }\end{array}$ & $\begin{array}{l}\text { Aplicativo } \\
\text { completo; Widget }\end{array}$ & $\begin{array}{l}\text { Imagem bitmap; } \\
\text { Imagem vetorial }\end{array}$ & Não & Não & $\begin{array}{l}\text { Texto/ } \\
\text { anotações }\end{array}$ \\
\hline VEST14 & $\begin{array}{l}\text { Cristalografia (grupos } \\
\text { espaciais) }\end{array}$ & $\begin{array}{l}\text { Modelo 3D } \\
\text { (VRML; POV) }\end{array}$ & $\begin{array}{l}\text { Imagem bitmap; } \\
\text { Imagem vetorial }\end{array}$ & Não & Não & $\begin{array}{l}\text { Texto/ } \\
\text { anotações }\end{array}$ \\
\hline DIAM15 & $\begin{array}{l}\text { Cristalografia (grupos } \\
\text { espaciais) }\end{array}$ & Modelo 3D (POV) & $\begin{array}{l}\text { Imagem bitmap; } \\
\text { Imagem vetorial }\end{array}$ & Não & Não & $\begin{array}{l}\text { Texto/ } \\
\text { anotações }\end{array}$ \\
\hline XCRY14 & $\begin{array}{l}\text { Cristalografia (grupos } \\
\text { espaciais) }\end{array}$ & Não & $\begin{array}{l}\text { Imagem bitmap; } \\
\text { Imagem vetorial }\end{array}$ & Não & Não & Não \\
\hline MERC15 & $\begin{array}{l}\text { Cristalografia (grupos } \\
\text { espaciais) }\end{array}$ & Modelo 3D (POV) & Imagem bitmap & $\operatorname{Sim}(S T L)$ & Não & Não \\
\hline PYMO18 & $\begin{array}{l}\text { Cristalografia (grupos } \\
\text { espaciais) }\end{array}$ & $\begin{array}{l}\text { Modelo 3D } \\
\text { (VRML) }\end{array}$ & Imagem bitmap & Não & Não & Não \\
\hline DRAW11 & $\begin{array}{l}\text { Cristalografia (grupos } \\
\text { espaciais) }\end{array}$ & Modelo 3D (POV) & $\begin{array}{l}\text { Imagem bitmap; } \\
\text { Imagem vetorial }\end{array}$ & Não & Não & Não \\
\hline CARI04 & $\begin{array}{l}\text { Cristalografia (grupos } \\
\text { espaciais) }\end{array}$ & Não & Imagem bitmap & Não & Não & $\begin{array}{l}\text { Texto/ } \\
\text { anotações }\end{array}$ \\
\hline BALL08 & $\begin{array}{l}\text { Cristalografia (grupos } \\
\text { espaciais) }\end{array}$ & Não & Imagem bitmap & Não & Não & Não \\
\hline LATT04 & $\begin{array}{l}\text { Cristalografia (grupos } \\
\text { espaciais) }\end{array}$ & $\begin{array}{l}\text { Aplicativo } \\
\text { completo; Widget }\end{array}$ & Imagem bitmap & Não & Não & Não \\
\hline $\mathrm{SCHA} 14$ & $\begin{array}{l}\text { Cristalografia (grupos } \\
\text { espaciais) }\end{array}$ & Não & $\begin{array}{l}\text { Imagem bitmap; } \\
\text { Imagem vetorial }\end{array}$ & Não & Não & $\begin{array}{l}\text { Texto/ } \\
\text { anotações }\end{array}$ \\
\hline ATOM11 & $\begin{array}{l}\text { Cristalografia (grupos } \\
\text { espaciais) }\end{array}$ & $\begin{array}{l}\text { Modelo 3D } \\
\text { (VRML; POV) }\end{array}$ & $\begin{array}{l}\text { Imagem bitmap; } \\
\text { Imagem vetorial }\end{array}$ & Não & Não & Não \\
\hline SHEL15 & $\begin{array}{l}\text { Cristalografia (grupos } \\
\text { espaciais) }\end{array}$ & Não & Imagem bitmap & Não & Não & Não \\
\hline RASM09 & $\begin{array}{l}\text { Cristalografia (grupos } \\
\text { espaciais) }\end{array}$ & $\begin{array}{l}\text { Modelo 3D } \\
\text { (VRML; POV) }\end{array}$ & $\begin{array}{l}\text { Imagem bitmap; } \\
\text { Imagem vetorial }\end{array}$ & Não & Não & Não \\
\hline CHEM15 & $\begin{array}{l}\text { Cristalografia (grupos } \\
\text { espaciais) }\end{array}$ & Não & Não & Não & Não & $\begin{array}{l}\text { Texto/ } \\
\text { anotações }\end{array}$ \\
\hline QUTE07 & $\begin{array}{l}\text { Cristalografia (grupos } \\
\text { espaciais) }\end{array}$ & Não & Imagem bitmap & Não & Não & Não \\
\hline XTAL03 & $\begin{array}{l}\text { Cristalografia (grupos } \\
\text { espaciais) }\end{array}$ & Não & Imagem bitmap & Não & Não & Não \\
\hline CRYS07 & $\begin{array}{l}\text { Cristalografia (grupos } \\
\text { espaciais) }\end{array}$ & $\begin{array}{l}\text { Modelo 3D } \\
\text { (VRML; POV) }\end{array}$ & Imagem bitmap & Não & Não & Não \\
\hline POWD00 & $\begin{array}{l}\text { Cristalografia (grupos } \\
\text { espaciais) }\end{array}$ & Modelo 3D (POV) & $\begin{array}{l}\text { Imagem bitmap; } \\
\text { Imagem vetorial }\end{array}$ & Não & Não & Não \\
\hline PLAT13 & $\begin{array}{l}\text { Cristalografia (grupos } \\
\text { espaciais) }\end{array}$ & Modelo 3D (POV) & $\begin{array}{l}\text { Imagem vetorial } \\
\text { (PS) }\end{array}$ & Não & Não & Não \\
\hline GRETOO & $\begin{array}{l}\text { Cristalografia (grupos } \\
\text { espaciais) }\end{array}$ & Modelo 3D (POV) & $\begin{array}{l}\text { Imagem bitmap; } \\
\text { Imagem vetorial }\end{array}$ & Não & Não & Não \\
\hline JAMM02 & $\begin{array}{l}\text { Cristalografia (grupos } \\
\text { espaciais) }\end{array}$ & $\begin{array}{l}\text { Aplicativo } \\
\text { completo; Widget }\end{array}$ & Imagem vetorial & Não & Não & $\begin{array}{l}\text { Texto/ } \\
\text { anotações }\end{array}$ \\
\hline ORTE14 & $\begin{array}{l}\text { Cristalografia (grupos } \\
\text { espaciais) }\end{array}$ & Modelo 3D (POV) & Imagem vetorial & Não & Não & Não \\
\hline OSCA15 & $\begin{array}{l}\text { Cristalografia (grupos } \\
\text { espaciais) }\end{array}$ & Modelo 3D (POV) & $\begin{array}{l}\text { Imagem bitmap; } \\
\text { Imagem vetorial }\end{array}$ & Não & Não & Não \\
\hline STRU05 & $\begin{array}{l}\text { Cristalografia (grupos } \\
\text { espaciais) }\end{array}$ & $\begin{array}{l}\text { Modelo 3D } \\
\text { (VRML; POV) }\end{array}$ & $\begin{array}{l}\text { Imagem bitmap; } \\
\text { Imagem vetorial }\end{array}$ & Não & Não & Não \\
\hline
\end{tabular}




\begin{tabular}{|c|c|c|c|c|c|c|}
\hline \multicolumn{7}{|c|}{ TABELA 5 - PARÂMETROS DO QUESTIONÁRIO DIDÁTICO (CONT.) } \\
\hline \multirow[b]{2}{*}{ Software } & \multicolumn{2}{|c|}{ 5.3 Funcionalidades didáticas (cont.) } & \multicolumn{2}{|c|}{5.4 Suporte e documentação } & \multicolumn{2}{|c|}{ Pontuação } \\
\hline & $\begin{array}{l}\text { 5.3.2 Biblioteca } \\
\text { de estruturas } \\
\text { cristalográficas }\end{array}$ & $\begin{array}{l}\text { 5.3.3 Construção e } \\
\text { visualização incremental } \\
\text { de estruturas }\end{array}$ & 5.4.1 Suporte & $\begin{array}{l}5.4 .2 \\
\text { Documentação }\end{array}$ & Soma & Normalizada \\
\hline SPEC16 & Sim & Sim & Sim & $\begin{array}{l}\text { Sim (Manual; } \\
\text { Tutoriais) }\end{array}$ & 10 & 25 \\
\hline CWGL16 & Sim & Sim & Sim & $\begin{array}{l}\text { Sim (Manual; } \\
\text { Tutoriais) }\end{array}$ & 10 & 25 \\
\hline CMAK15 & Sim & Não & $\begin{array}{l}\text { Sim para clientes } \\
\text { (Fóruns; Trackers; } \\
\text { E-mail; Telefone) }\end{array}$ & $\begin{array}{l}\text { Sim (Manual; } \\
\text { Tutoriais) }\end{array}$ & 5 & 12,5 \\
\hline JMOL15 & Não & Não & $\begin{array}{l}\text { Sim (Fóruns; } \\
\text { Trackers) }\end{array}$ & $\begin{array}{l}\text { Sim (Manual; } \\
\text { Tutoriais) }\end{array}$ & 4 & 10 \\
\hline VEST14 & Não & Não & Sim (Fóruns) & Sim (Manual) & 3 & 7,5 \\
\hline DIAM15 & Sim & Não & Sim (Fóruns; E-mail) & Sim (Manual) & 4 & 10 \\
\hline XCRY14 & Não & Não & Sim (Fóruns) & Sim (Manual) & 3 & 7,5 \\
\hline MERC15 & Sim & Não & $\begin{array}{l}\text { Sim para clientes } \\
\text { (Fóruns; Trackers; } \\
\text { E-mail) }\end{array}$ & $\begin{array}{l}\text { Sim (Manual; } \\
\text { Tutoriais) }\end{array}$ & 4 & 10 \\
\hline PYMO18 & Não & Não & $\begin{array}{l}\text { Sim (Fóruns; } \\
\text { Trackers); Sim para } \\
\text { clientes (E-mail) }\end{array}$ & $\begin{array}{l}\text { Sim (Manual; } \\
\text { Tutoriais) }\end{array}$ & 2 & 5 \\
\hline DRAW11 & Não & Não & Não & Sim (Manual) & 2 & 5 \\
\hline CARI04 & Sim & Não & $\begin{array}{l}\text { Sim para clientes } \\
\text { (Fóruns; Trackers; } \\
\text { E-mail) }\end{array}$ & Sim (Manual) & 3 & 7,5 \\
\hline BALL08 & Não & Não & Não & Sim (Manual) & 1 & 2,5 \\
\hline LATTO4 & Sim & Não & Não & Sim (Manual) & 3 & 7,5 \\
\hline $\mathrm{SCHA} 14$ & Não & Não & Sim (E-mail) & Sim (Manual) & 3 & 7,5 \\
\hline ATOM11 & Não & Não & $\begin{array}{l}\text { Sim para clientes } \\
\text { (E-mail) }\end{array}$ & Sim (Manual) & 3 & 7,5 \\
\hline SHEL15 & Não & Não & $\begin{array}{l}\text { Sim (Fóruns; } \\
\text { Trackers) }\end{array}$ & Sim (Manual) & 2 & 5 \\
\hline RASM09 & Não & Não & $\begin{array}{l}\text { Sim (Fóruns; } \\
\text { Trackers) }\end{array}$ & $\begin{array}{l}\text { Sim (Manual; } \\
\text { Tutoriais) }\end{array}$ & 3 & 7,5 \\
\hline CHEM15 & Não & Não & $\begin{array}{l}\text { Sim para clientes } \\
\text { (E-mail) }\end{array}$ & Sim (Manual) & 2 & 5 \\
\hline QUTE07 & Não & Não & Não & Não & 0 & 0 \\
\hline XTAL03 & Sim & Não & Sim (E-mail) & Sim (Manual) & 3 & 7,5 \\
\hline CRYS07 & Não & Não & Não & Sim (Manual) & 1 & 2,5 \\
\hline POWDO0 & Não & Não & Sim (E-mail) & Sim (Manual) & 3 & 7,5 \\
\hline PLAT13 & Não & Não & $\begin{array}{l}\text { Sim para clientes } \\
\text { (E-mail) }\end{array}$ & Sim (Manual) & 2 & 5 \\
\hline GRETOO & Não & Não & Não & Sim (Manual) & 2 & 5 \\
\hline JAMM02 & Não & Não & Não & Não & 1 & 2,5 \\
\hline ORTE14 & Não & Não & $\begin{array}{l}\text { Sim para clientes } \\
\text { (E-mail) }\end{array}$ & Sim (Manual) & 2 & 5 \\
\hline OSCA15 & Não & Não & Não & Sim (Manual) & 2 & 5 \\
\hline STRU05 & Não & Não & $\begin{array}{l}\text { Sim para clientes } \\
\text { (E-mail) }\end{array}$ & Sim (Manual) & 3 & 7,5 \\
\hline
\end{tabular}




\section{APÊNDICE D - Detalhamento dos problemas levantados junto aos atores sociais}

Este apêndice apresenta o detalhamento dos problemas levantados pelos atores sociais, conforme descrito na seção 4.3. Trata-se de observações, percepções, comentários e expectativas dos participantes da pesquisa-ação, tanto sobre o entendimento do critério como sobre sua avaliação.

\section{(1) Requerimentos tecnológicos}

$\mathrm{Na}$ visão dos atores sociais, essas características suportam o modelo de acesso e de desenvolvimento definido para este projeto: aberto, democrático e colaborativo.

- (1.1) Nível de atividade: Estudantes e professores levantaram o problema de que muitos dos softwares cristalográficos utilizados em sala de aula são, em sua maioria, bastante antigos e, inclusive, estão abandonados. Além da questão da tecnologia ultrapassada, a interface e muitas das técnicas de interação utilizadas são antiquadas para os padrões atuais. Observando-se os resultados da análise sistemática (TAB. 1 - APÊNDICE C), é possível verificar dados que corroboram estas percepções. Destes dados, pode-se inferir que apenas 3 dos softwares (1\% do total), possuem frequência de atualização dinâmica (subcritério 1.1.1) e que 12 softwares (46\% do total) foram descontinuados por seus autores. Isso torna evidente, neste requisito, um baixo atendimento às expectativas dos atores sociais.

- (1.2) Portabilidade da aplicação: Professores levantaram o problema de que o acesso a softwares cristalográficos comumente utilizados em sala de aula é, de maneira geral, bastante complicado, requerendo não apenas a compra de licenças, mas também a instalação e configuração da aplicação específica a uma plataforma e/ou dispositivo. Além da restrição ao custo da licença, torna-se bastante difícil assumir que todos os estudantes possuam acesso ao mesmo tipo de dispositivo e plataforma. As mesmas complicações são váli- 
das também no acesso a materiais de suporte de pesquisadores em artigos científicos. Observando-se os resultados da análise sistemática (TAB. 1 - APÊNDICE C), é possível verificar dados que corroboram estas percepções. Destes dados, pode-se inferir que nenhum $(0 \%)$ dos softwares possuem portabilidade de aplicação (critério 1.2). Isso torna evidente, neste requisito, o não atendimento às expectativas dos atores sociais.

- (1.3) Uso, distribuição e modificação: Estudantes e professores levantaram o problema de que softwares cristalográficos comumente utilizados em sala de aula possuem, de modo geral, licenças de uso e distribuição bastante restritivas, tradicionalmente comerciais, distribuídas apenas no formato binário sem o código-fonte e bastante custosas. Restringem-se, portanto, as liberdades dos usuários. Liberdades estas que trazem benefícios variados: para estudantes e professores, a possibilidade de acessar a ferramenta de suporte para estudo e investigação e para criar ilustrações destinadas a apresentações e publicações digitais ou impressas, e, por parte de usuários mais avançados, a possibilidade de estudarem e modificarem o código-fonte da aplicação, contribuindo, assim, de modo colaborativo com o desenvolvimento do projeto. Observando-se os resultados da análise sistemática (TAB. 1 - APÊNDICE C), é possível verificar que apenas 7 softwares possuem licença de uso, distribuição e modelo de desenvolvimento livres (subcritério 1.3.1), dentre os quais exclusivamente 4 ( $15 \%$ do total) possuem modelo de desenvolvimento colaborativo (subcritério 1.3.2). Isso torna evidente, neste requisito, um baixo atendimento às expectativas dos atores sociais.

- (1.4) Suporte a tecnologias de interface: Existe a percepção de que o suporte e a qualidade de interação com tecnologias de interface em softwares cristalográficos são, em geral, limitados a teclado e mouse. A diversidade de opções de interação traz flexibilidade e permite $\mathrm{o}$ acesso a pessoas com diferentes capacidades cognitivas. Devido à raridade esperada, a avaliação deste item exige uma busca mais minuciosa. Observando-se os resultados da análise siste- 
mática (TAB. 1 - APÊNDICE C), é possível verificar dados que corroboram estas percepções. Destes dados, pode-se inferir que apenas 1 software ( $3 \%$ do total) provê suporte a tecnologias de interface para além de mouse e teclado (subcritério 1.4.1), dentre os quais nenhum (0\%) possui suporte a dispositivos ou interfaces de interação avançadas (subcritério 1.4.2). Isso torna evidente, neste requisito, o não atendimento às expectativas dos atores sociais.

\section{(2) Requerimentos de síntese de estruturas cristalinas}

$\mathrm{Na}$ visão dos atores sociais, essas características facilitam o acesso ao conhecimento, especialmente para estudantes, professores e pesquisadores de áreas dependentes da ciência dos materiais, abordando o tema com a profundidade adequada a graduandos na área de ciência, tecnologia, engenharia e matemática (science, tecnology, engineering, and mathematics - STEM) e, até mesmo, a outros níveis e modalidades, como os cursos on-line massivos e abertos (massive open online courses - MOOCS), cursos técnicos, Ensino Fundamental e aprendizado autodidata.

- (2.1) Método de síntese: Estudantes e professores levantaram o problema de que softwares cristalográficos comumente utilizados em sala de aula não são alinhados com a didática adotada em cursos de ciência dos materiais. Isso porque o processo de síntese de estruturas cristalinas neles encontrado adota métodos baseados em grupos espaciais, pouco acessíveis a não especialistas em cristalografia. Observando-se os resultados da análise sistemática (TAB. 2 - APÊNDICE C), é possível verificar dados que corroboram estas percepções. Destes dados, pode-se inferir que todos os softwares (100\%) utilizam o mesmo método de síntese baseado em grupos espaciais (critério 2.1). Isso torna evidente, neste requisito, o não atendimento às expectativas dos atores sociais.

- (2.2) Processo de síntese interativo: Estudantes e professores levantaram o problema de que o processo de síntese de estruturas cristalinas comumente adotado em softwares cristalográficos é, em geral, limitado à manipulação de parâmetros muito específicos e 
pouco intuitivos, ligados de maneira muito rígida à teoria cristalográfica, o que impede o feedback imediato das alterações e a aplicação didática direta das ferramentas. Observando-se os resultados da análise sistemática (TAB. 2 - APÊNDICE C), é possível verificar dados que corroboram estas percepções. Destes dados, pode-se inferir que nenhum dos softwares $(0 \%)$ provê suporte ao processo de síntese interativo (critério 2.2). Isso torna evidente, neste requisito, o não atendimento às expectativas dos atores sociais.

- (2.3) Restrições ou limitações à síntese: Estudantes e professores levantaram o problema de que o processo de síntese de estruturas cristalinas adotado em alguns softwares cristalográficos possui, em alguns casos, limitações e/ou restrições específicas, o que impede a representação de qualquer estrutura a partir de dados ou parâmetros de entrada. Em alguns casos, por exemplo, se representam estruturas apenas a partir de um arquivo cristalográfico com parâmetros predeterminados, ou que necessitam de uma aplicação suplementar para seu funcionamento. Existe a expectativa que softwares cristalográficos devam ser integrados para que possam ser utilizados em situações de aula de maneira autônoma e descomplicada. Observando-se os resultados da análise sistemática (TAB. 2 - APÊNDICE C), é possível verificar dados que corroboram estas percepções. Destes dados, pode-se inferir que apenas 6 softwares (23\% do total), possuem alguma restrição ou limitação no processo de síntese (critério 2.3). Isso torna evidente, neste requisito, o bom atendimento às expectativas dos atores sociais.

- (2.4) Seleção e edição interativas de átomos: Estudantes e professores levantaram o problema de que o processo de seleção e edição de átomos de estruturas cristalinas adotados em alguns softwares cristalográficos não possibilita a seleção e edição de átomos por meio da manipulação direta de elementos gráficos e representações visuais, o que restringe a representação de estruturas e modelos, bem como a aplicação didática direta das ferramentas. Existe a expectativa de que softwares cristalográficos modernos sejam interativos e flexíveis para que possam ser utilizados em salas 
de aula de maneira didática. Observando-se os resultados da análise sistemática (TAB. 2 - APÊNDICE C), é possível verificar dados que corroboram estas percepções. Destes dados, pode-se inferir que apenas 10 softwares ( $38 \%$ do total), provêm suporte à seleção e edição interativas de átomos (critério 2.4). Isso torna evidente, neste requisito, o baixo atendimento às expectativas dos atores sociais.

\section{(3) Requerimentos de visualização}

$\mathrm{Na}$ visão dos atores sociais, essas características suportam a compreensão visual de modelos de estruturas cristalinas, buscando a extração de conhecimento desse tipo de modelo.

- (3.1) Representação: Estudantes e professores levantaram o problema de que tanto o modelo de representação atômico molecular como a capacidade de representação de artifícios visuais típicos associados a estruturas cristalinas e a representação visual em geral em softwares cristalográficos não são alinhados com a didática adotada em cursos de ciência dos materiais. O modelo de esferas rígidas constitui característica fundamental na representação dos pontos de tangência entre os átomos - utilizados para cálculo de parâmetros específicos de célula unitária, na representação de intersecções entre a célula unitária e seus átomos parciais contidos, bem como na representação do vazio da célula unitária. Constatase também que, apesar de algumas ferramentas proverem suporte à representação de planos, direções e outros artifícios de suporte, por serem secundárias, estas funcionalidades são, em sua maioria, pouco acessíveis e de difícil manejo. Observando-se os resultados da análise sistemática (TAB. 3 - APÊNDICE C), é possível verificar dados que corroboram estas percepções. Destes dados, pode-se inferir que nenhum dos softwares $(0 \%)$ utilizam o modelo esferas rígidas (critério 3.1). Isso torna evidente, neste requisito, o não atendimento às expectativas dos atores sociais.

- (3.2) Visualização: Estudantes e professores levantaram o problema de que softwares cristalográficos comumente utilizados em sala de 
aula possuem recursos de visualização restritos em comparação às possibilidades da computação gráfica atualmente disponíveis. Espera-se que disponibilizar opções de visualização traga ganhos no processo de aprendizado, devido à possibilidade de personalização, fornecendo meios de visualização alternativos a indivíduos com perfis cognitivos variados. Observando-se os resultados da análise sistemática (TAB. 3 - APÊNDICE C) é possível verificar dados que corroboram estas percepções. Destes dados, pode-se inferir que, apesar de alguns softwares cristalográficos proverem suporte a uma quantidade variada de recursos de percepção visual e a técnicas de renderização relativamente recentes, estas funcionalidades são, segundo a expectativa dos atores sociais, negligenciadas quanto ao seu potencial no contexto didático e interativo.

\section{(4) Requerimentos de navegação e interatividade}

$\mathrm{Na}$ visão dos atores sociais, a visualização e a interação são aspectos interligados no que tange à experiência de aprendizado. Na especificação das características de interação, pretendeu-se que estas estivessem sintonizadas com as de visualização (APÊNDICE D seção 3) e que dessem suporte à compreensão visual de modelos de estruturas cristalinas, visando extrair conhecimento desse tipo de modelo e simplificar o entendimento de um tópico complexo. Além disso, meios avançados de interação permitem uma exploração mais rica dos modelos e podem atender às diferentes necessidades dos usuários do sistema. Ferramentas digitais com fins didáticos podem e devem oferecer bastante suporte na exploração de modelos complexos, especialmente a usuários inexperientes. As tecnologias modernas também devem ser exploradas para a evolução das práticas de ensino. O suporte oferecido deve considerar a natureza do modelo, as dificuldades de visualização inerentes e que tipo informação se pretende extrair da visualização. Exemplos são animações guiadas e rotações automáticas com foco em objetos relevantes, transições de escala assistidas e mudanças dinâmicas de parâmetros de visualização. Esperava-se que características como essas fossem muito raras em softwares cristalográficos. Observando-se os resultados da análise sistemática (TAB. 4 - APÊNDICE C), é possível verificar dados que corroboram estas percepções. Destes dados, pode-se inferir que, apesar de a interação 
base ser bem suportada pela maioria dos softwares analisados, 18 (69,23\% do total), apenas 9 (34,61\% do total avaliado) possuem interface amigável (critério 4.1) e, não por coincidência, são os únicos a proverem suporte a algum recurso de interação avançado (critério 4.3), como rotações automáticas (subparâmetro 4.3.1), animações guiadas (subparâmetro 4.3.2), transições de escala (subparâmetro 4.3.3), perspectiva/pontos de vista preconfigurados (subparâmetro 4.3.5). 0 subparâmetro 4.3.4, gerenciamento dinâmico de oclusões não é contemplado por nenhum dos softwares ( $0 \%)$. Isso torna evidente, neste requisito, o baixo atendimento às expectativas dos atores sociais.

\section{(5) Requerimentos didáticos}

$\mathrm{Na}$ visão dos atores sociais, essas características têm como finalidade, no geral, adicionar preocupações didáticas negligenciadas pelos softwares cristalográficos existentes e dar maior suporte às atividades de docência, estudo e pesquisa. Isso se traduz em facilidade e flexibilidade de uso, tanto no que diz respeito à adequação ao tipo de usuário (professores, estudantes, pesquisadores) como ao aspecto utilitário (suporte a aulas, criação de imagens e modelos para publicações).

- (5.1) Conhecimentos requeridos do usuário: O processo de síntese de estruturas cristalinas em softwares cristalográficos é, em geral, bastante restrito aos parâmetros de estruturas previamente conhecidas e, portanto, seu uso é possível quase que exclusivamente por cristalógrafos e outros especialistas da área. Por esta razão, espera-se que a maioria das ferramentas adote métodos de síntese baseado em grupos espaciais, requerendo conhecimentos avançados de cristalografia para seu entendimento e compreensão. Observando-se os resultados da análise sistemática (TAB. 5 - APÊNDICE C), é possível verificar dados que corroboram estas percepções. Destes dados, pode-se inferir que todos os softwares (100\%) adotam métodos de síntese baseado em grupos espaciais, corroborando a percepção de que são necessários conhecimentos avançados de cristalografia para seu entendimento e compreensão.

- (5.2) Suporte a publicações: Essas propriedades possibilitam um uso mais amplo e flexível da ferramenta, mesmo para desenvolvi- 
mento de aulas em contextos didáticos tradicionais. Existe a percepção de que o suporte à publicação em softwares cristalográficos é, em geral, limitado a formatos de saída para visualização em tela, devido à baixa resolução. Por esta razão, espera-se que muitas ferramentas ofereçam saída apenas em formato de imagem, algumas poucas capturem vídeos da interface e gerem modelos 3D e que quase nenhuma gere visualizações portáteis interativas para incorporação direta em documentos e websites. Com o advento da impressão 3D, é conveniente a produção de modelos que já incorporem modificações para impressão, mas espera-se que tal característica seja encontrada em poucos softwares, ou em nenhum deles. Finalmente, a possibilidade de recuperação de modelos diretamente por meio de uma URL pública na internet é fundamental para o incentivo à educação à distância e ao estudo independente, viabilizando o acesso e o compartilhamento descomplicados a modelos produzidos pelo professor e estudantes, além da realização de atividades educacionais em outros locais e horários. Observando-se os resultados da análise sistemática (TAB. 5 - APÊNDICE C), é possível verificar dados que corroboram estas percepções. Destes dados, pode-se inferir que, apesar do recurso de impressão 2D (subcritério 5.2.2) por meio da exportação de imagens bitmap ser suportado por quase todos os softwares cristalográficos $(96 \%$ do total), apenas $3(11 \%$ do total), proveem suporte à visualização ou portabilidade externa (subcritério 5.2.1) e 2 (7\% do total) proveem suporte à visualização ou portabilidade externa (subcritério 5.2.1) e nenhum $(0 \%)$ fornece uma plataforma de publicação online na internet (subcritério 5.2.4). Isso torna evidente, nestes requisitos, o baixo atendimento às expectativas dos atores sociais.

- (5.3) Funcionalidades didáticas: Trata-se de um critério especial, considerando o contexto deste trabalho: a criação de uma nova ferramenta digital com ênfase didática, e que, portanto, deve prover suporte à narrativa didática. Por isso, deve possibilitar a contribuição do professor à compreensão do tópico, complementando os modelos gerados com conceitos teóricos relacionados e dicas ou referên- 
cias adicionais. Tradicionalmente, isso é feito graficamente (desenhos manuais, gráficos) ou textualmente (anotações), usando quadro-negro e projeções. Atualmente, isso também pode ser feito por meio de inserção de hipertexto, links e incorporação de imagens. Ainda, essas ferramentas devem, idealmente, contar com bibliotecas de exemplos preconfigurados que incluam modelos e anotações, tanto para exemplificar o uso da ferramenta e demonstrar suas capacidades, como para facilitar as atividades didáticas. Finalmente, a abordagem construtivista de aquisição de conhecimento, que prega a participação ativa, pode ser viabilizada ao permitir um processo interativo de seleção e edição de átomos das estruturas cristalinas, onde o usuário exercita sua curiosidade nos primeiros contatos com o tema, ao invés de regular parâmetros obscuros ou pouco intuitivos para os estágios iniciais do aprendizado. Os modelos produzidos livremente podem ser comparados com as versões produzidas pela ferramenta ou pelo professor. No entanto, os softwares cristalográficos são, em geral, pouco didáticos, pois são voltados a cristalógrafos e especialistas. Por esta razão, espera-se que poucas ferramentas tenham amplo suporte a técnicas didáticas modernas. Observando-se os resultados da análise sistemática (TAB. 5 APÊNDICE C), é possível verificar dados que corroboram estas percepções. Destes dados, pode-se inferir que apenas 6 softwares ( $23 \%$ do total) proveem suporte a algum tipo de biblioteca de estruturas cristalográficas (subcritério 5.3.2) e nenhum (0\%) provê suporte a técnicas didáticas modernas, como suporte à narrativa didática (subcritério 5.3.1) ou construção e visualização incremental de estruturas (subcritério 5.3.3). Isso torna evidente, nestes requisitos, o não atendimento às expectativas dos atores sociais.

- (5.4) Suporte e documentação: Qualquer software, por mais simples e amigável que seja, ainda coloca eventualmente os usuários em situações desafiadoras, seja por dificuldades técnicas ou instabilidades, seja mesmo por dificuldades de aprendizado e na condução de certas operações. Espera-se que suporte técnico esteja disponível para qualquer software comercial e, em menor grau, a usuários de 
versões de teste ou educacionais. Para projetos de software livre com comunidades amplas e ativas, espera-se, além das liberdades de acesso ao código-fonte, aprimoramento contínuo do software e alguma documentação do projeto, que é fundamental não apenas para a compreensão e estudo do código-fonte, mas também para o desenvolvimento e continuidade da comunidade voluntária de desenvolvedores. Observando-se os resultados da análise sistemática (TAB. 5 - APÊNDICE C), é possível verificar dados que corroboram estas percepções. Destes dados, pode-se inferir que quase todos os softwares cristalográficos (92\% do total) proveem algum tipo de suporte e documentação a seus usuários. Isso torna evidente, nestes requisitos, o atendimento às expectativas dos atores sociais. 


\section{ÍNDICE}

atores sociais, 38

célula unitária, 27

ciência dos materiais, 24

código-fonte, 36

construtivismo, 45

contatos atômicos, 27

cristais, 24

distâncias atômicas, 238

empilhamentos, 238

empoderamento, 71

especificação, 173

estruturas cristalinas, 24

funcionalidade, 39

implementação, 67

interação, 105

interatividade, 105

interface, 190

levantamento bibliográfico, 59

levantamento sistemático, 60

motivos (cristalográficos), 83

nuvem (computação em), 144

pesquisa-ação, 54

planos (cristalográficos), 84

positivismo, 45

pragmatismo, 46

protocolo de revisão, 62

redes espaciais, 82

requisitos, 135

Scrum, 134

síntese, 194

software, 34

software cristalográfico, 34 
sprints, 135

strings, 63

sub-redes (cristalográficas), 88

teoria crítica, 45

visualização, 198

vizinhanças atômicas, 70 


\section{REFERÊNCIAS BIBLIOGRÁFICAS}

1 ADDA, Y.; DUPOUY, J.-M.; PHILIBERT, J.; QUÉRÉ, Y. Rappels. Gif-surYvette: CEN Saclay, 1987. (Eléments de métallurgie physique, v. 1).

2 ADERHOLD, A.; JUNG, Y.; WILKOSINKSA, K.; GRAF, H.; FELLNER, D. W. Distributed 3D model optimization for the web with the common implementation framework for online virtual museums. In: DIGITAL HERITAGE INTERNATIONAL CONGRESS, 28 out.-1 nov. 2013, 2013, Marseille. Proceedings..., v. 2. Piscataway, NJ: Institute of Electrical and Electronics Engineers, 2013, p. 719-726.

3 AISH, R. Computer-aided design software to augment the creation of form. In: PENZ, F. (Ed.). Computer in architeture. London: Addison-Wesley Longman, 1992.

AISH, R.; SHEA, K.; GOURTOVAIA, M.' Towards integrated performancedriven generative design tools. Automat. Constr., v. 14, n. 2, p. 253-264, 2005.

5 ALCITE (calcium carbonate). Molymod® Crystal Structures Pre-Assembled model set. Sigma-Aldrich. [s.d.]. Disponível em:

$<$ http://www.sigmaaldrich.com/catalog/product/aldrich/z545643?lang=pt\&re gion=BR>. Acesso em: 18 fev. 2016.

6 ALLEN, F.H. The Cambridge Structural Database: A quarter of a million crystal structures and rising. Acta Cryst., Section B: Structural Science, v. 58, n. 3, p. 380-388, 2002.

7 ALMUTAIRI, A.A.; SARFRAZ, M.I.; BASALAMAH, S.; AREF, W.G.; GHAFOOR, A. A distributed access control architecture for cloud computing. IEEE Software Magazine, v. 29, n. 2, 2012.

AMAZON WEB SERVICES. Amazon EC2 - Hospedagem de servidor virtual. [s.d.]. Disponível em: <http://aws.amazon.com/ec2/>. Acesso em: 18 mar. 2016.

9 AMAZON WEB SERVICES. Amazon Route 53. [s.d.]. Disponível em: <http://aws.amazon.com/route53/>. Acesso em: 18 mar. 2016.

10 AMAZON WEB SERVICES. Definição de preço do Amazon EC2. [s.d.]. Disponível em: <http://aws.amazon.com/ec2/pricing/>. Acesso em: 18 mar. 2016.

11 AMAZON WEB SERVICES. Definição de preço do Amazon Route 53. [s.d.]. Disponível em: <http://aws.amazon.com/route53/pricing/>. Acesso em: 18 mar. 2016.

12 AMIN, M.A.; BAKAR, K.B.A.; AL-HASHIMI, H. A review of mobile cloud computing architecture and challenges to enterprise users. In: IEEE GCC CONFERENCE AND EXHIBITION, 7, 17-20 nov., 2013, Doha. Proceedings... [Doha]: [IEEE], 2013.

13 ANDERSON, L.W.; KRATHWOHL, D.R.; BLOOM, B.S. A taxonomy for learning, teaching and assessing: A revision of Bloom's taxonomy of educational objectives. [White Plains, NY]: Longman, 2001. 
14 ANGIONI, M. et al. Integrating XP Project management in development. Journal of Systems Architecture, v. 52, n. 11, p. 619-626, 2006.

15 APACHE SOFTWARE FOUNDATION. Apache ${ }^{\mathrm{TM}}$ Subversion $^{\circledR}$. Forest Hill, MD: Apache Software Foundation, [2015]. Disponível em:

<https://subversion.apache.org/>. Acesso em: 16 mar. 2016.

16 ARAÚJO, R.B.; KIRNER, C. Especificação e análise de um sistema distribuído de realidade virtual. In: SIMPÓSIO BRASILEIRO DE REDES DE COMPUTADORES, 14, maio 1996, Fortaleza. Anais... [Fortaleza]: Sociedade Brasileira de Computação, 1996.

17 ASKELAND, D.R., The Science and Engineering of Materials. London: Chapman \& Hall, 1990.

18 ATKINS, Peter W.; DE PAULA, Julio. Physical Chemistry. 8. ed. New York, Oxford University Press, 2014.

19 ATOM EDITOR. Atom 1.5.4. [San Francisco, CA]: [Atom Editor], [s.d.]. Disponível em: <https://atom.io/>. Acesso em: 15 mar. 2016.

20 AUER, K.; MILLER, R. Extreme programming applied: Playing to win. [S.I.]: Addison-Wesley, 2002. (The XP Series, 43).

21 AVISON, D.; BASKERVILLE, R.; MYERS, M. D. The structure of power in action research projects. In: KOCK, N. (ed.). Information systems action research: An applied view of emerging concepts and methods. v. 2. New York: Springer, 2007.

22 AVISON, D.; LAU, F.; MYERS, M.; NIELSEN, P. A. Action research. Communications of the ACM, v. 42, n. 1, p. 94-97, jan. 1999.

23 AZEVEDO, E.; CONCI, A. Computação gráfica - Teoria e prática. Rio de Janeiro: Campus, 2003.

24 BAARTMANS, B.G.; SORBY, S.A. Introduction to 3-D spatial visualization. Englewood Cliffs, NJ: Prentice Hall, 1996.

25 BAARTMANS, B.G.; SORBY, S.A. Making connections: Spatial skills and engineering drawings. Math. Teach., v. 89, n. 4, p. 348-353, 1996.

26 BARBOSA, J.F.V. Ambientes urbanos virtuais para a web. 2013. Dissertação (Mestrado) - Universidade do Porto, Porto.

27 BARDELLA, F. CrystalWalk Collection. Instructables. 2 abr. 2016. Disponível em: <http://www.instructables.com/id/CrystalWalk-Collection/>. Acesso em: 14 maio 2016.

28 BARDELLA, F.; GRUPO DE VISUALIZAÇÃO CIENTÍFICA EM MATERIAIS. CrystalWalk - Biblioteca D3. 2016. Disponível em: <http://cwd3.herokuapp.com/>. Acesso em: 14 mar. 2016.

29 BARDELLA, F.; GRUPO DE VISUALIZAÇÃO CIENTÍFICA EM MATERIAIS. CrystalWalk Code Repository. 2016. Disponível em: <https://github.com/gvcm/crystalwalk>. Acesso em: 19 fev. 2016.

BARDELLA, F.; GRUPO DE VISUALIZAÇÃO CIENTÍFICA EM MATERIAIS. CrystalWalk Design Pattern Version 4 (CW4P). 2016.

Disponível em: <https://github.com/gvcm/cw4p>. Acesso em: 19 fev. 2016. 
31 BARDELLA, F.; GRUPO DE VISUALIZAÇÃO CIENTÍFICA EM MATERIAIS. Crysta/Walk. 2016. Disponível em: <http://cw.gl>. Acesso em: 19 fev. 2016.

32 BARDIN, L. Análise de conteúdo. Tradução de Luís A. Reto e Augusto Pinheiro. 5. ed. Lisboa: Edições 70, 2009.

33 BARKER, A.; VARGHESE, B.; WARD, J.S.; SOMMERVILLE, I. Academic cloud computing research: Five pitfalls and five opportunities. In: USENIX WORKSHOP ON HOT TOPICS IN CLOUD COMPUTING, 17-20 jun., 2014, Philadelphia, PA. Proceedings... [Philadelphia, PA]: Usenix, 2014.

34 BARNES, M. Virtual reality and simulation. In: WINTER SIMULATION CONFERENCE, 28, 1996, [s.I.]. Proceedings... [S.I.]: IEEE Computer Society, 1996, p. 101-110.

35 BARRETT, C.S. Structure of metals. New York, NY; London: McGraw-Hill, 1943.

36 BARROS, A.J.S. e LEHFELD, N.A.S. Fundamentos de metodologia: Um guia para a iniciação científica. 2. ed. São Paulo: Makron Books, 2000.

37 BASKERVILLE, R.L. Investigating information systems with action research. Communications of the AIS, v. 2, n. 19, p. 4, out. 1999.

38 BASKERVILLE, R.L.; WOOD-HARPER, A.T. A critical perspective on action research as a method for information systems research. Journal of Information Technology, v. 11, n. 3, p. 235-246, 1996.

39 BATTISTA, M.T.; GRAYSON, H.W.; TALSMA, G. The importance of spatial visualization and cognitive development for geometry learning in preservice elementary school teachers. Journal for Research in Mathematics Education, v. 13, n. 32, p. 332-340, 1982.

40 BEAN, J. SOA and web services interface design: Principles, techniques, and standards. Burlington, MA: Morgan Kaufmann, 2010.

41 BECK, K.; ANDRES, C. Extreme programming explained: Embrace change. 2. ed. Boston, MA: Addison-Wesley Professional, 2004.

42 BECK, K.; BEEDLE, M.; VAN BENNEKUM, A.; COCKBURN, A.; CUNNINGHAM, W.; FOWLER, M.; GRENNING, J.; HIGHSMITH, J.; HUNT, A.; JEFFRIES, R.; KERN, J.; MARICK, B.; MARTIN, R.C.; MELLOR, S.; SCHWABER, K.; SUTHERLAND, J.; THOMAS, D. Manifesto para 0 desenvolvimento ágil de software. 2001. Disponível em: <http://www.manifestoagil.com.br/>. Acesso em: 7 maio 2016.

43 BEGUM, S.; KHAN, M.K. Potential of cloud computing architecture. In: INTERNATIONAL CONFERENCE ON INFORMATION AND COMMUNICATION TECHNOLOGIES, [s.I.], 2011. Proceedings... [S.I.]: IEEE, 2011.

44 BELL, J.B. Numerical simulation of Lewis number effects on lean premixed turbulent flames. Proceedings of the Combustion Institute, v. 31, n. 1, p. 1309-1317, 2007. 
45 BEN-CHAIM, D.; LAPPAN, G.; HOUANG, R.T. Visualizing rectangular solids made of small cubes: Analyzing and effecting students' performance. Educ. Stud. Math., v. 16, n. 4, p. 389-409, 1985.

BERNARD, R.M.; ABRAMI, P.C.; LOU, Y.; BOROKHOVSKI, E.; WADE, A.; WOZNEY, L.; WALLET, P.A.; FISET, M.; HUANG, B. How does distance education compare to classroom instruction? A meta-analysis of the empirical literature. Rev. Educ. Res., v. 74, n. 3, p. 379-439, 2004.

47 BESSANI, A.; ROMANO, P.; KAPITZA, R.; GOGOUVITIS, S. V.; CASCELLA, R. G.; PETCU, D.; KYRIAZIS, D. A look to the old-world sky: EU- funded dependability cloud computing research. ACM SIGOPS Oper. Syst. Rev., v. 46, n. 2, p. 43-56, jul. 2012.

48 BICUDO, M.A.V. Pesquisa em educação matemática. Pro-posições, v. 4, n. 10, p. 18-23, 1993.

49 BIOLCHINI, J.; MIAN, P.G.; NATALI, A.C.C.; TRAVASSOS, G.H. Systematic review in software engineering. System Engineering and Computer Science Department COPPE/UFRJ, Technical Report ES, v. 679, n. 05, p. 45, 2005.

50 BJERKE, B. Physically-Based Materials Study [UE4]. 2014. Disponível em: $<$ https://www.artstation.com/artwork/physically-based-materials-study-ue4>. Acesso em: 5 maio 2016.

51 BLOOM, B.S. et al. Taxonomy of educational objectives. New York: David Mckay, 1956.

52 BODNER, G.M., GREENBOWE, T.J.; ROBINSON, W.R. The introduction of crystallographic concepts using lap-dissolve slide techniques. J. Chem. Ed., v. 57, n. 8, p. 555-556, 1980.

53 BODNER, G.M.; CUTLER, A.R.; GREENBOWE, T.J.; ROBINSON, W.R. Multi-image or lap-dissolve slide techniques and visual images in the large lecture section, J. Chem. Ed., v. 61, n. 5, p. 447-449, 1984.

54 BODNER, G.M.; GUAY, R.B. The purdue visualization of rotations test. The Chemical Educator, v. 2, n. 4, p. 1-17, 1997.

55 BOSTOCK, M.; OGIEVETSKY, V.; HEER, J. D3 data-driven documents. IEEE Transactions on Visualization and Computer Graphics, v. 17, n. 12, p. 2301-2309, 2011. Disponível em: <http://vis.stanford.edu/files/2011-D3InfoVis.pdf>. Acesso em: 14 mar. 2016.

56 BOWMAN, D.A.; McMAHAN, R.P. Virtual reality: How much immersion is enough? Computer, v. 40, n. 7, p. 36-43, 2007.

57 BRAHIM, R.N.; BOARDMAN, S.J.; ABACHI, H. Development of an algorithm for functional modelling of parametric system design. In: INTERNATIONAL CONFERENCE ON COMPUTERS \& INDUSTRIAL ENGINEERING, 26, 15-17 dez., 1999, Melbourne. Proceedings... Melbourne: [s.n.], 1999, p. 147-152.

58 BRANSFORD, J.D; BROWN, A.L.; COCKING, R.R. How people learn: Brain, mind, experience, and school. Washington, DC: National Academy Press, 1999. 
59 BREBNER, P. Is your cloud elastic enough? Performance modelling the elasticity of infrastructure as a service (laaS) cloud applications. In: ACM/SPEC International Conference on Performance Engineering, 2012, Boston, MA. Proceedings... Boston, MA: ACM/SPEC, 2012, p. 263-266.

60 BRONOWSKI, J. Science and human values. New York: Harper Collins, 1990.

61 BRUER, J. Schools for thought. Cambridge: MIT Press, 1993.

62 BRYSON, S. Virtual reality in scientific visualization. Commun. ACM, v. 39, n. 5, p. 62-71, 1996.

63 BUERGER, M. Elementary crystallography. An introduction to the fundamental geometrical features of crystals. New York: Wiley, 1956.

64 BURDEA, G.; COIFFET, P. Virtual reality technology. Presence: Teleoperators \& Virtual Environments, v. 12, n. 6, p. 663-664, 2003.

65 BYRNE, C.M. Water on tap: The use of virtual reality as an educational tool. 1996. Tese (Doutorado) - University of Washington, Washington, DC.

66 BYRNE, E. Using action research in information systems design to address change: A South African health information systems case study. In: ANNUAL RESEARCH CONFERENCE OF THE SOUTH AFRICAN INSTITUTE OF COMPUTER SCIENTISTS AND INFORMATION TECHNOLOGISTS ON IT RESEARCH IN DEVELOPING COUNTRIES, [s.I.], 2005. Proceedings... [S.I.]: [SAICSIT], 2005, p.131-141.

67 CABRAL, M.; MONTES, A.; BELLOC, O.; FERRAZ, R.; TEUBL, F.; DORETO, F.; LOPES, R.; ZUFFO, M. Bi-manual gesture interaction for 3D cloud point selection and annotation using COTS. In: IEEE SYMPOSIUM ON 3D USER INTERFACES (3DUI), 9, 29-30 mar., 2014, Minneapolis, MN. Proceedings... [Minneapolis, MN]: IEEE, 2014.

68 CABRAL, M.; MONTES, A.; ROQUE, G.; BELLOC, O.; NAGAMURA, M.; Faria, R.R.A.; Teubl, F.; KURASHIMA, C.; LOPES, R.; ZUFFO, M. Crosscale: A 3D virtual musical instrument interface. In: IEEE Symposium on 3D User Interfaces (3DUI), 10, 23-24 mar., 2015, Arles. Proceedings... [Arles]: IEEE, 2015.

69 CADY, S.G. Use of pom pons to illustrate cubic crystal structures. J. Chem. Ed., v. 74, n. 7, p. 794, 1997.

70 CALLISTER, W.D.; RETHWISCH, D.G. Materials science and engineering: An introduction. New York: Wiley, 2007.

71 CARROLL, J.M. Minimalism beyond the Nurnberg Funnel. Cambridge, MA: MIT Press, 1998.

72 CASALICCHIO, E.; SILVESTRI, L. Architectures for autonomic service management in cloud based systems. In: IEEE SYMPOSIUM ON COMPUTERS AND COMMUNICATIONS, 2011, Kerkyra. Proceedings... [S.I.]: ISCC, 2011.

73 CCP14. CCP14. 2016. Disponível em: <http://www.ccp14.ac.uk/solution/structuredrawing/index.html>. Acesso em: 21 abr. 2016. 
74 CERVO, A.L.; BERVIAN, P.A. Metodologia científica: Para uso dos estudantes universitários. São Paulo: McGraw-Hill do Brasil, 1983.

75 CHAN, M.S.; BLACK, J.B. Learning Newtonian mechanics with an animation game: The role of presentation format on mental model acquisition. In: ANNUAL MEETING OF THE AMERICAN EDUCATIONAL RESEARCH ASSOCIATION, 2006, San Francisco. Program... [Washington, DC]: AERA, [2006].

76 CHANLIN, L. Animation to teach students of different knowledge levels. J. Instr. Psychol., v. 25, n. 3, p. 166-175, 1998.

77 CHECKLAND, Peter. Towards the coherent expression of systems ideas. Journal of Applied Systems Analysis, v. 18, p. 25-28, 1991.

78 CHEN, K. The structure of crystalline solids (slides). [S.I.]: [s.n.] [2002].

79 CHEN, M.; CAI, W; MA, L. Cloud computing platform for an online model library system. Mathematical Problems in Engineering, v. 2013, 2013.

80 CHEN, Y.; SHEN, Q.; SUN, P.; LI, Y.; CHEN, Z.; QING, S. Reliable migration module in trusted cloud based on security level-design and implementation. In: Parallel and Distributed Processing Symposium Workshops \& PhD Forum, 26, 2012, [s.I.]. Proceedings... [S.I.]: IEEE, 2012.

81 CLARK, R.E. Reconsidering research on learning from media. Review of educational research, v. 53, n. 4, p. 445-459, 1983.

82 CLARK, R.E.; FELDON, D.F. Five common but questionable principles of multimedia learning. In: MAYER, R. (Ed.). Cambridge handbook of multimedia learning. Cambridge: Cambridge University Press, 2005, p. 97116.

83 CLARKE, R. User requirements for cloud computing architecture. In: IEEE/ACM INTERNATIONAL SYMPOSIUM ON CLUSTER, CLOUD AND GRID COMPUTING (CCGRID), 10, 17-20 maio, 2010, Melbourne. Proceedings... [Melbourne]: IEEE, 2010.

84 CLEMENTI E., RAIMONDI D.L., REINHARDT W.P. (1967). Atomic Screening Constants from SCF Functions. II. Atoms with 37 to 86 Electrons. Disponível em: <http://scitation.aip.org/content/aip/journal/jcp/47/4/10.1063/1.1712084>. Acesso em: 7 maio 2016.

85 COLLINS, B.M. Data visualization: Has it all been seen before? In: EARNSHAW, R. (Ed.) Animation and scientific visualization: Tools \& Applications. [S.I.]: Academic Press, 1993, p. 3-28.

86 COLLINS, R. CSCW: an opportunity for action research. In: ACM CONFERENCE ON ORGANIZATIONAL COMPUTING SYSTEMS, 13-16 ago., 1995, Milpitas, CA. Proceedings... Nova York: ACM Press, 1995, p. 162-167.

87 COMPUTER EMERGENCY READINESS TEAM. Oracle Java 7 Security Manager Bypass Vulnerability. 2013. Disponível em: <https://www.uscert.gov/ncas/alerts/TA13-010A>. Acesso em: 19 fev. 2016. 
88 COOK, K.A.; THOMAS, J.J. (Ed.). Illuminating the path: The R\&D agenda for visual analytics. Los Alamitos, CA: IEEE, 2005.

89 COSTA, D.A.Q. Radia Store, Armazenamento e Preservação de Programas de Rádio. 2008. Dissertação (Mestrado) - Univ. Técnica de Lisboa, Lisboa.

90 COUGHLAN, P.; COGHLAN, D. Action research for operations management. International Journal of Operations \& Production Management, v. 22, n. 2, p. 220-240, 2002.

91 CRESWELL, J. Educational research: Planning, conducting, and evaluating quantitative and qualitative research. Upper Saddle River, NJ: Merrill Prentice Hal, 2002.

92 CSIKSZENTMIHALYI, M. Flow: The psychology of optimal experience. New York: Harper and Row, 1990.

93 CULLITY, B.D.; STOCK, S.R. Elements of X-ray diffraction. 3. ed. [S.I.]: Pearson, 2001.

94 DAIGNEAU, R. Service design patterns: Fundamental design solutions for soap/wsdl and restful web services. [S.I.]: Addison-Wesley, 2010.

95 DARCS COMMUNITY. Darcs 2.10.3. [S.I.]: [s.n.], [s.d.]. Disponível em: <http://darcs.net/>. Acesso em: 17 mar. 2016.

96 DASSAULT SYSTEMES SOLIDWORKS CORPORATION. Image Library. Solid Works. [s.d.]. Disponível em:

<https://www.solidworks.com/sw/image_library.htm>. Acesso em: 19 abr. 2016.

97 DATE, C.J. An introduction to database systems. [S.I.]: Pearson, 2004.

98 DAVISON, R.M. An action research perspective of group support systems: How to improve meetings in Hong Kong. 1998. Tese (Doutorado) - City University of Hong Kong, Hong Kong.

99 DAVISON. R.M.; MARTINSONS, M.G.; KOCK, N. Principles of canonical action research. Information Systems Journal, v. 14, p. 65-86, 2004.

DIsponível em: < https://www.semanticscholar.org/paper/Principles-ofcanonical-action-research-Davison-

Martinsons/ba1b6427af767b20d84fb878ffe0ab9538fe8ed4/pdf>. Acesso em: 14 maio 2016.

100 DEMO, P. Pesquisa e construção do conhecimento: Metodologia científica no caminho de Habermas. 2. ed. Rio de Janeiro: Tempo Brasileiro, 1994.

101 DEVERIA, A. WebGL - 3D Canvas graphics. Can I use. [s.d.]. Disponível em: <http://caniuse.com/\#feat=webgl>. Acesso em: 17 mar. 2016.

102 DEVI, T.; GANESAN, R. Platform-as-a-Service (PaaS): Model and security issues. Indonesian Journal of Electrical Engineering, v. 15, n. 1, p. 151-161, jul. 2015. 
103 DEVILLIERS, M.R. Three approaches as pillars for interpretative information systems research: development research, action research and grounded theory. In: ANNUAL RESEARCH CONFERENCE OF THE SOUTH AFRICAN INSTITUTE OF COMPUTER SCIENTISTS AND INFORMATION TECHNOLOGISTS ON IT RESEARCH IN DEVELOPING COUNTRIES, [s.I.], 2005. Proceedings... [S.I.]: [SAICSIT], 2005, p. 142151.

104 DICK, B. Approaching an action research thesis: An overview. Action Research and Evaluation On Line (AREOL), 1997.

105 DIXON, J.K. Limited English proficiency and spatial visualization in middle school students' construction of the concepts of reflection and rotation. Biling. Res. J., v. 19, n. 2, p. 221-247, 1995.

106 EASTERBROOK, S., SINGER, J., STOREY, M-A., DAMIAN, D. Selecting empirical methods software engineering research. In: SHULL, F.; SINGER, J.; SJØBERG, D.I.K. (Ed.). Guide to advanced empirical software engineering. [S.I.]: Springer-Verlag, 2007.

107 ECLIPSE FOUNDATION. Eclipse Mars.2 (4.5.2). Ottawa: Eclipse Foundation, [s.d.]. Disponível em: <https://eclipse.org/>. Acesso em: 15 mar. 2016.

108 ENUNES, E.P.S. Um método para avaliar a aquisição de conhecimento em Ambientes Virtuais de Aprendizagem Tridimensionais Interativos. 2014. Tese (Doutorado) - Universidade de São Paulo.

109 ERNST, M. Version control concepts and best practices. [S.I.]: [s.n.], set. 2012. Disponível em:

$<$ https://homes.cs.washington.edu/ mernst/advice/version-control.html>. Acesso em: 1 mar. 2016.

110 ESCHER, M.C. Belvedere (litografia). 1958. Disponível em: <https://en.wikipedia.org/wiki/File:Belvedere,_by_M._C._Escher.jpg>. Acesso em: 26 abr. 2016.

111 ESCHER, M.C. Waterfall (litografia). 1961. Disponível em: <https://en.wikipedia.org/wiki/File:Escher_Waterfall.jpg>. Acesso em: 26 abr. 2016.

112 ESTUBLIER, J.; LEBLANG, D.; CLEMM, G.; CONRAD, R.; TICHY, W.; HOEK, A.W.D. Impact of the research community on the field of software configuration management: summary of an impact project report. ACM SIGSOFT Software Engineering Notes, v. 27 n. 5, set. 2002.

113 EWALD, P.P. Fifty Years of X-Ray Diffraction. Boston: Springer US, 1962.

114 EWALD, P.P.; HERMANN, C. Strukturbericht: 1913-1928. [S.I: s.n.], 1943.

115 FAIRCHILD, K.M. Information management using virtual reality-based visualizations. In: WEXELBLAT, A. (Ed.). Virtual reality: Applications and explorations. San Diego, CA: Academic Press Professional, 1993, p. 45-74.

116 FAIRCHILD, K.M., POLTROCK, S.E.; FURNAS, G.W. SemNet: Threedimensional graphic representations of large knowledge bases. In: GUINDON, R. Cognitive science and its applications for human-computer interaction, [S.I.]: Morgan Kaufmann Publishers, 1988, p. 190-206. 
117 FELKNOR, B. Laboratory scientist draws "atoms-in-depth" using computeroriented graphic technique. The News: Oak Ridge National Laboratory, 2 abr., 1965, p. 1. Disponível em:

<http://www.umass.edu/molvis/francoeur/ortep/ortepnews.html>. Acesso em: 10 mar. 2016.

118 FERRANCE, E. Action research. Providence, RI: Northeast and Island Regional Education Laboratory (LAB), Brown University, 2000.

119 FERRAZ, A. P. C. M.; BELHOT, R. V. Taxonomia de Bloom: Revisão teórica e apresentação das adequações do instrumento para definição de objetivos instrucionais. Gestão \& Produção (on-line), v. 17, n. 2, p. 421-431, 2010.

120 FERREIRA, L.F. Usando objetos educacionais baseados em realidade virtual em ambientes de apoio a construção de conhecimento e aprendizagem de técnicas videocirúrgicas. Novas Tecnologias na Educação, v. 2, n. 1, 2004.

121 FIELDING, R.T. Architectural styles and the design of network based software architectures. 2000. Dissertação (Ph.D) - University of California, Irvine, CA.

122 FINK, A. The survey handbook. Thousand Oaks: Sage, 2003. v. 1.

123 FOLEY, J.; RIBARSKY, B. Next-generation data visualization tools. In: ROSENBLUM, L.; EARNSHAW, R.A.; ENCARNACAO, J.; HAGEN, H.; KAUFMAN, A.; KLIMENKO, S.; NIELSON, G.; POST, F.; THALMANN, D. (Ed.). Scientific Visualization: Advances and Challenges. [S.I.]: Academic Press, 1994, p. 103-127.

124 FOOTE J.D.; BLANCK H.F. A demonstration of hexagonal close-packed and cubic close-packed crystal structures. J. Chem. Ed., v. 68, n. 9, p. 777, 1991. Disponível em: <http://pubs.acs.org/doi/abs/10.1021/ed068p777>. Acesso em: 18 fev. 2016.

125 FREDERICK, P.B. What's real about virtual reality? IEEE Comput. Graph. Appl., v. 19, n. 6, p. 16-27, 1999.

126 FRIENDLY, M.; DENIS, D.J. Milestones in the history of thematic cartography, statistical graphics, and data visualization. 2001. Disponível em: <http://www.datavis.ca/milestones/>. Acesso em: 1 mar. 2016.

127 FURNESS, T.A.; WINN, W.; YU, R. Global change, VR and learning, A report for the NSF of workshops. The impact of three dimensional immersive VE on modern pedagogy. [S.I.]: [s.n.], 1997.

128 GERSHON, N.D. From perception to visualization. Computer Graphics, v. 26, n. 2, p. 414-415, 1992.

129 GIL, A.C. Métodos e técnicas de pesquisa social. 4. ed, reimp. São Paulo: Atlas, 2008.

130 GIMP TEAM. GNU Image manipulation program (Gimp) 2.8.16. [S.I.]: Gimp Team, 2015. Disponível em: <https://www.gimp.org/>. Acesso em: 15 mar. 2016. 
131 GIT PROJECT. Git. [S.I.]: [s.n.], [s.d.]. Disponível em: <https://gitscm.com/>. Acesso em: 17 mar. 2016.

132 GOBERT, J. Introduction to model-based teaching and learning in science education. International Journal of Science Education, v. 22, n. 9, p. 891894, 2000.

133 GORELIK, E. Cloud computing models. 2013. Dissertação (Mestrado) Massachusetts Institute of Technology, Cambridge, MA.

134 GORTON, I. Essential software architecture. [S.I.]: Springer, 2011.

135 GRAEF, M. de; McHENRY, M.E. Structure of materials. An introduction do crystallography, diffraction, and symmetry. New York: Cambridge University Press, 2007.

136 GRAŽULIS, S.; DAŠKEVIČ, A.; MERKYS, A.; CHATEIGNER, D.; LUTTEROTTI, L.; QUIRÓS, M.; SEREBRYANAYA, N.R.; MOECK, P.; DOWNS, R.T.; LE BAIL, A. Crystallography Open Database (COD): An open-access collection of crystal structures and platform for world-wide collaboration. Nucleic Acids Research, v. 40, n. D1, p. D420-D427, 2012.

137 GRUDIN, J. Computer-supported cooperative work: History and focus. Computer, v. 27, n. 5, p. 19-26, 1994.

138 GRUDIN, J. Computer-supported cooperative work: History and focus. Computer, n. 5, p. 19-26, maio 1994.

139 GRUDIN, J. Eight challenges for groupware developers. Communications of the $A C M$, v. 37, n. 1, p. 92-105, 1994.

140 GRUMAN, G. How to kill Java dead, dead, dead. Info World, San Francisco, 15 jan. 2013. Disponível em:

<http://www.infoworld.com/article/2613404/java/how-to-kill-java-dead--dead-dead.html>. Acesso em: 21 abr. 2015.

141 GUAY, R. Purdue spatial visualization tests. West Lafayette: Purdue Research Foundation, 1977.

142 GUY, A. Physical metallurgy for engineering. London: Addison-Wesley, 1962.

143 HAMMOND, Christopher. The basics of crystallography and diffraction. Oxford: Oxford University Press, 2009.

144 HANCOCK, D. Viewpoint: Virtual reality in search of middle ground. IEEE Spectrum, v. 32, n. 1, p. 68, 1995.

145 HAND, C. Other faces of virtual reality. In: Multimedia, hypermedia, and virtual reality International Conference, 1, 14-16 set., 1994, Moscou. BRUSILOVSKI, P.; KOMMERS, P.; STREITZ, N. (Ed.). Multimedia, hypermedia, and virtual reality: Models, systems, and application. [S.I]: Springer Science \& Business Media, 1996, p. 107-116.

146 HANSEN, P.F. Science of construction materials. Berlin: Springer-Verlag Berlin Heidelberg, 2009.

147 HARRISON, A.; TREAGUST, D. A typology of school science models. International Journal of Science Education, v. 22, n. 9, p. 1011-1026, 2000. 
148 HASSAN, S.A.Z. Star. A proposed architecture for cloud computing applications". In: INTERNATIONAL CONFERENCE CLOUD COMPUTING TECHNOLOGIES, APPLICATIONS AND MANAGEMENT (ICCCTAM), 2012, Dubai. Proceedings... [S.I.]: ICCCTAM, 2012.

149 HAYS, T.A. Spatial abilities and the effects of computer animation on shortterm and long-term memory comprehension. J. Educ. Comput. Res., v. 14, n. 2, p. 139-155, 1996.

150 HERMAN, T.; MORRIS, J.; COLTON, S.; BATIZA, A.; PATRICK, M.; FRANZEN, M.; GOODSELL, D. S. Tactile teaching: Exploring protein structure/function using physical models. Biochemistry and Molecular Biology Education, v. 34, n. 4, p. 247-254, 2006.

151 HEROKU DEV CENTER. Dyno types. 2016. Disponível em: $<$ https://devcenter.heroku.com/articles/dyno-types>. Acesso em: 9 maio 2016.

152 HEROKU DEV CENTER. GitHub Integration. 2015. Disponível em: <https://devcenter.heroku.com/articles/github-integration>. Acesso em: 9 maio 2016.

153 HEROKU DEV CENTER. Limits. 2016. Disponível em: <https://devcenter.heroku.com/articles/limits>. Acesso em: 9 maio 2016.

154 HEROKU. Heroku Postgres. [s.d.]. Disponível em: <https://addons. heroku.com/heroku-postgresql>. Acesso em: 9 maio 2016.

155 HIGHSMITH, J. Agile project management, Creating innovative products. [S.I.]: Addison-Wesley, 2004.

156 HIGHSMITH, J.A. Adaptive software development: A collaborative approach to managing complex systems. New York: Dorset, 2000.

157 HOFFMANN, M.; VANECEK Jr., G. Fundamental Techniques for Geometric and Solid Modeling. In: Manufacturing and automation systems: Techniques and technologies, v. 48, n. 4, p. 101-167, 1991.

158 HOGUE, J. R.; ALLEN, R. W.; PELZ, C. A.; MARKHAM, S.; HARMSEN, A. Methodology and improvements in aircrew parachute descent virtual reality simulation training. In: ANNUAL SAFE ASSOCIATION SYMPOSIUM, 39, 911 out., 2000. Proceedings... [S.I.]: [SAFE Association], [2000].

159 HOPP, W. J.; SPEARMAN, M. L. To pull or not to pull: What is the question? Manufacturing \& Service Operations Management, v. 6, n. 2, p. 133-148, 2004.

160 HSIAO, J.W.D. Computer support for collaborative learning. 1999. Disponível em:

<http://www.edb.utexas.edu/csclstudent/Dhsiao/theories.html\#construct>. Acesso em: 20 abr. 2011

161 HUK, T. Who benefits from learning with 3D models: the case of spatial ability. J. Comput. Assist. Lear., v. 22, n. 6, p. 392-404, 2006.

162 HWANG, K.; FOX, G.; DONGARRA, J. Distributed and cloud computing: From parallel processing to the internet of things. [S.I.]: Morgan Kauffmann Publishers, 2011. 
163 INKSCAPE TEAM. Inkscape 0.91. Disponível em: <https://inkscape.org>. [S.I.]: Inkscape Team, 2015. Acesso em: 15 mar. 2016.

164 INSTITUTO BRASILEIRO DE GEOGRAFIA E ESTATÍSTICA (IBGE).

Pesquisa Nacional por Amostra de Domicílios (Pnad). Brasília: IBGE, 2014. Disponível em:

<http://www.ibge.gov.br/home/estatistica/populacao/trabalhoerendimento/p nad2014/default.shtm>. Acesso em: 16 mar. 2016.

165 INTERAGENCY GROUP ON ADVANCED MATERIALS. Materials Genome Initiative for Global Competitiveness. [S.I.]: [s.e.], 2011. Disponível em:

$<$ https://www.whitehouse.gov/sites/default/files/microsites/ostp/materials_ge nome_initiative-final.pdf>. Acesso em: 18 fev. 2016.

166 INTERNATIONAL UNION OF CRYSTALLOGRAPHY (IUCR).

Crystallographic software list. 2016. Disponível em:

<http://www.iucr.org/resources/other-directories/software>. Acesso em: 2 mar. 2016.

167 ISO/IEC. Standard 17789: 2014. Information technology - Cloud computing - Reference architecture. 2014.

168 JAIN, A.; KUMAR, R. A taxonomy of cloud computing. International Journal of Scientific and Research Publications, v. 4, n. 7, jul. 2014.

169 JMOL. Colors. [s.d.]. Disponível em: <http://jmol.sourceforge.net/jscolors/>. Acesso em: 7 maio 2016.

170 JUDY, K.H.; KRUMINS-BEENS, I. Great Scrums need great product owners: Unbounded collaboration? And collective product ownership. In: HAWAII INTERNATIONAL CONFERENCE ON SYSTEM SCIENCES (HICSS), 47, 2014, [s.I.]. Proceedings... [S.I.]: HICSS, 2014, p. 463.

171 JUNG, C.G. Über die Entwicklung der Persönlichkeit. Olten: Walter-Verlag, 1972. (v. 17).

172 JURENKA, V. Virtualization using Docker platform. 2015. Dissertação (Mestrado) - Masaryk University.

173 KALAWSKY, R.S. The science of virtual reality and virtual environments: A technical, scientific and engineering reference on virtual environments. [S.I.]: Addison-Wesley, 1993.

174 KASPERSKY LAB. Kaspersky Lab report: Evaluating the threat level of software vulnerabilities. [s.d.]. Disponível em:

<http://media.kaspersky.com/documents/business/misc/Kaspersky_Lab_Re port_Software_Vulnerabilities_final.pdf>. Acesso em: $18 \mathrm{fev} .2016$.

175 KEEHNER, M.; MONTELLO, D.R.; HEGARTY, M.; COHEN, C. Effects of interactivity and spatial ability on the comprehension of spatial relations in a 3D computer visualization. In: ANNUAL CONFERENCE OF THE COGNITIVE SCIENCE SOCIETY, 26, 5-7 ago., 2004, Chicago. Proceedings... Mahwah: Cognitive Science Society, 2004, p. 1576.

176 KELLY, I.L. Comparison of virtual models and hands-on models for teaching crystallography. 2001. Dissertação (Mestrado) - Purdue University. 
177 KIDAHL N.K.; BERKA L.; BODNER G.M. Crystal model kits for use in the general chemistry laboratory. J. Chem. Ed., v. 63, n. 1, p. 62, 1986. Disponível em: <http://pubs.acs.org/doi/abs/10.1021/ed063p62?journalCode=jceda8>. Acesso em: 18 fev. 2016.

178 KITCHENHAM, B.; CHARTERS, S. Guidelines for performing systematic literature reviews in software engineering. Technical Report EBSE-2007-01. 2007. Staffordshire: School of Computer Science and Mathematics, Keele University, [s.d.].

179 KITTEL, C. Introduction to solid state physics. 7. ed. New York: John Wiley \& Sons, 1996 [1953].

$180 \mathrm{KOCK}, \mathrm{N}$. The three threats in action research: A discussion of methodological antidotes in the context of an information systems study. Decision Support Systems, v. 37, p. 265-286, 2004.

181 KRAUSE, S.; DECKER, J.C.; NISKA, J.; ALFORD, T.; GRIFFIN, R. Identifying student misconceptions in introductory materials engineering classes. Age, v. 8, p. 1, 2003.

182 KRAUSE, S.; KELLY, J.; BAKER, D.R. Remodeling instructional materials for more effective learning in introductory materials classes. In: ASEE ANNUAL CONFERENCE, 119, 10-13 jun. 2012, San Antonio.

Proceedings... San Antonio, American Society for Engineering Education, 2012.

183 KRAUSE, S.; STERLING, A.; KELLY, J.E.; STEHLIK, D.; ISAACS-

SODEYE, O.; BAKER; D.R. Development of a crystal spatial visualization survey for introductory materials classes. In: ASEE ANNUAL CONFERENCE, 119, 10-13 jun. 2012, San Antonio. Proceedings... San Antonio: American Society for Engineering Education, 2012.

184 KRICKL, Robert. World largest crystal structure model. International Year of Chrystallography. 2014. Disponível em: <http://www.iycr2014.org/outreach/largest>. Acesso em: 10 mar. 2016.

185 KRISHNA ANNE, V.P.; PONNAM, V.S.; PRAVEEN, G. A significant approach for cloud database using shared-disk architecture. In:

INTERNATIONAL CONFERENCE ON SOFTWARE ENGINEERING, 6, 5-7 set., 2012, Indore. Proceedings... [S.I.]: [IEEE], 2012.

186 KRUEGER, M.W. Artificial reality II. [S.I.]: Addison-Wesley, 1991, p. 18.

187 KULKARNI, G.; WAGHMARE, R.; PALWE, R.; WAYKULE, V.; BANKAR, H.; KOLI, K. Cloud storage architecture. In: TELECOMMUNICATIONS, SYSTEMS, SERVICES, AND APPLICATIONS (TSSA), 7, 30-31 out., 2012, Denpasar. Proceedings... [S.I.]: [IEEE], [2012].

188 KURT, T.; ARICI, Y.; KURÇ, Ö. A cloud based workflow for a finite element analysis preprocessor. In: INTERNATIONAL CONFERENCE ON PARALLEL, DISTRIBUTED, GRID, AND CLOUD COMPUTING FOR ENGINEERING, (PARENG), 4, 24-27 mar., 2015, Dubrovnik.

Proceedings... [S.I.]: [Civil-Comp Press], [2015]. 
189 LAING, M. An inexpensive kit for constructing models of crystals. J. Chem. Ed., v. 74, n. 7, p. 795, 1997.

190 LAMPE, U.; HANS, R.; STEINMETZ, R. Will Mobile Cloud Gaming Work? Findings on Latency, Energy, and Cost. In: IEEE INTERNATIONAL CONFERENCE ON MOBILE SERVICES (IEEE MS), 2, 27 jun.-2 jul., 2013, Santa Clara Marriot, CA. Proceedings... p. 103-104.

191 LAMPESBERGER, H. Technologies for web and cloud service interaction: A survey. Service Oriented Computing and Applications, fev. 2015, p. 1-40.

192 LATTA, J.N.; OBERG, D.J. A conceptual virtual reality model. IEEE Computer Graphics and Applications, v. 14, n. 1, p. 23-29, 1994.

193 LEAL NETO, R.M. [Comunicação pessoal]. 2016.

194 LEAP MOTION, INC. Arm HUD widget: Like a smartwatch for your entire arm. [s.d.]. Disponível em: <http://blog.leapmotion.com/arm-hud-widget-likesmartwatch-entire-arm/>. Acesso em: 21 abr. 2016.

195 LEFRANÇOIS, G.R. Teorias da aprendizagem. São Paulo: Cengage Learning, 2008.

196 LISENSKY, G.C.; COVERT, J.C.; MAYER, L.A. Solid State Model Kit Instruction Manual. Publication 94-007. Madison: Institute for Chemical Education, 1994.

197 LIU, F.; TONG, J.; MAO, J.; BOHN, R.B.; MESSINA, J.V.; BADGER, M.L.; LEAF, D.M. NIST Cloud computing reference architecture. Special Publication NIST-SP (500-292). [S.I.]: NIST, 2011.

198 LOELIGER, J.; McCULLOUGH, M. Version Control with Git. [S.I.]: O'Reilly Media, 2012.

199 LORD, T. A look at spatial abilities in undergraduate women in science majors. J. Res. Sci. Teach., v. 24, n. 8, p. 757-767, 1987.

200 LU, Y.; LIU, Y.; DEY, S. Cloud mobile 3D display gaming user experience modeling and optimization by asymmetric graphics rendering. IEEE Journal Of Selected Topics In Signal Processing, v. 9, n. 3, p. 517-532, abr. 2015.

201 MAGNETIC RESONANCE RESEARCH FACILITY. 3T Neuro Images. [s.d.]. Disponível em:

<https://www.medicine.uiowa.edu/mri/images/3t_neuro/>. Acesso em: 19 abr. 2016.

202 MANN, A.W. Models for simple, close-packed crystal structures. J. Chem. Ed., v. 50, n. 9, p. 652, 1973. Disponível em:

<http://pubs.acs.org/doi/abs/10.1021/ed050p652>. Acesso em: 18 fev. 2016.

203 MANN, C.; MAURER, F. A case study on the impact of Scrum on overtime and customer satisfaction. In: AGILE DEVELOPMENT CONFERENCE, 2005. Proceedings... [S.I.]: IEEE Computer Society, 2005, p. 70-79.

204 MARCONI, M; LAKATOS, E.M. Técnicas de pesquisa: Planejamento e execução e pesquisas, amostragens e técnicas de pesquisas, elaboração, análise e interpretação de dados. 3. ed. São Paulo: Atlas, 2003. 
205 MASSE, M. REST API Design Rulebook. [S.I.]: O'Reilly Media, 2011.

206 MATHIASSEN, L.; CHIASSON, M.; GERMONPREZ, M. Style composition in action research publication. MIS Quarterly, v. 36, n. 2, p. 347-363, 2012.

207 MAUS, J. PET-MIPS-anim.gif. Wikimedia Commons. 2006. Disponível em: <https://commons.wikimedia.org/wiki/File:PET-MIPS-anim.gif>. Acesso em: 21 abr. 2016.

208 McCORMICK, B.H. Visualization in scientific computing. ACM SIGBIO Newsletter, v. 10, n. 1, p. 21, 1988.

209 McGEE, M.G. Human spatial abilities: Psychometric studies and environmental, genetic, hormonal, and neurological influences. Psychol. Bull., v. 86, n. 5, p. 889-918, 1979.

210 McMAHAN, R.R. Exploring the effects of higher-fidelity display and interaction for virtual reality games. 2011. Dissertação (PhD) - Virginia Polytechnic Institute and State University. Disponível em: $<$ https:/theses.lib.vt.edu/theses/available/etd-12162011-140224/>. Acesso em: 14 mar. 2016.

211 MEDEIROS, A.; MEDEIROS, C.F. de. Possibilidades e limitações das simulações computacionais no ensino da física. Revista Brasileira de Ensino de Física, v. 24, n. 2, jun. 2002.

212 MERCURIAL COMMUNITY. Mercurial 3.7.2. [S.I.]: [s.n.], [s.d.]. Disponível em: <https://www.mercurial-scm.org/>. Acesso em: 17 mar. 2016.

213 MICROSOFT CORPORATION. Microsoft $\Theta$ Office $\Theta 365$. Redmond: Microsoft Corporation, 2016.

214 MIKKONEN, T.; TAIVALSAARI, A. Cloud computing and its impact on mobile software development: Two roads diverged. The Journal of Systems and Software, v. 86, n. 9, p. 2318-2320, set. 2013.

215 MILGRAM, P.; TAKEMURA, H.; UTSUMI, A.; KISHINO, F. Augmented reality: A class of displays on the reality-virtuality continuum. Proceedings of Telemanipulator and Telepresence Technologies, v. 2351, p. 282-292, out. 1994.

216 MINAYO, M.C.S. Ciência, técnica e arte: O desafio da pesquisa social. In: MINAYO, M.C.S. (Org.). Pesquisa social: Teoria, método e criatividade. Petrópolis, RJ: Vozes, 2001, p. 9-29.

217 MOREIRA, M.A. Teorias de aprendizagem. São Paulo: EPU, 1999.

218 MUTAVDZIC, R. Cloud computing architectures for national, regional and local government. In: INTERNATIONAL CONVENTION ON INFORMATION AND COMMUNICATION TECHNOLOGY, ELECTRONICS AND MICROELECTRONICS (MIPRO), 33, 2010. Proceedings... [S.I.]: [s.n.], [2010].

219 NAVAZO, I. Extended octree representation of general solids with plane faces: Model structure and algorithms. Computers \& Graphics, v. 13, n. 1, p. 5-16, 1989. 
220 NECKER, L.A. LXI. Observations on some remarkable optical phænomena seen in Switzerland; and on an optical phænomenon which occurs on viewing a figure of a crystal or geometrical solid. Philosophical Magazine Series 3, v. 1, n. 5, p. 329-337, 1832.

221 OASIS®. Oasis® UDDI Specification TC. [s.d.]. Disponível em: <https://www.oasis-open.org/committees/uddi-spec>. Acesso em: 17 mar. 2016.

222 OCK JR., N.F.; MCQUEEN, R.J.; SCOTT, J.L. Can action research be made more rigorous in a positivist sense? The contribution of an iterative approach. Journal of Systems and Information Technology, v.1, n.1, p. 124, 1997.

223 OGUNNAIKE, B.A.: RAY, W.H. Process dynamics, modelling, and control. New York: Oxford University Press, 1994.

224 OJOG, I.; JESUS, M.A.E.; GONZALEZ, A.; FLORES, B. A cloud scalable platform for DICOM image analysis as a tool for remote medical support. In: INTERNATIONAL CONFERENCE ON EHEALTH, TELEMEDICINE, AND SOCIAL MEDICINE (eTELEMED), 24 fev.-1 mar., 2013, Nice.

Proceedings... [S.I.]: [s.n.], 2013.

225 OLANDER, D.R. Fundamental aspects of nuclear fuel elements. Springfield: Nat. Techn. Inf. Service, US Dept. of Commerce, 1976.

226 ORACLE. Oracle V.M. VirtualBox. User Manual - 2013. Oracle: [s.I.], 2015. Disponível em: <https://www.virtualbox.org/>. Acesso em: 11 mar. 2016.

227 OSMANI, A. Patterns for large-scale JavaScript application architecture. Disponível em: <http://addyosmani.com/largescalejavascript/>. Acesso em: 21 abr. 2015.

228 OWEN, G.S. Definitions, history, and goals of visualization. 1999.

Disponível em:

$<$ http://www.siggraph.org/education/materials/HyperVis/visgoals/visgoal0.ht $\mathrm{m}>$. Acesso em: 12 maio 2010.

229 PADILHA, A.F. Materiais de engenharia: microestrutura e propriedades. São Paulo: Hemus, 1997.

230 PARISI, T. WebGL: Up and running. [S.I.]: O'Reilly Media, 2012.

231 PARK, O.C.; GITTELMAN, S.S. Selective use of animation and feedback in computer-based instruction. Educ. Tech. Res., v. 40, n. 4, p. 27-38, 1992.

232 PATTRASITIDECH, A. Comparison and evaluation of 3D mobile game engines. 2014. Dissertação (Mestrado) - Chalmers University of Technology, University of Gothenburg, Gothenburg.

233 PAVLINIC, S.; BUCKLEY, P.; BURNS, J.; WRIGHT, T. Computing in stereochemistry $-2 D$ or 3D representations? In: BEHRENDT, $H_{\text {.; }}$ DAHNCKE, H.; DUIT, R.; GRÄBER, W.; KOMOREK, M.; KROSS, A.; REISKA, P. (Ed.). Research in science education - Past, present, and future. Dordrecht: Kluwer Academic Publishers, 2001, p. 295-300.

234 PELLEGRINO, J.W.; ALDERTON, D.L.; SHUTE, V.J. Understanding Spatial Ability. Educ. Psychol., v. 19, n. 3, p. 239-253, 1984. 
235 PETRIDIS, P.; DUNWELL, I.; FREITAS, S. de, PANZOLI, D. An engine selection methodology for high fidelity serious games. In: INTERNATIONAL CONFERENCE ON VIRTUAL WORLDS AND GAMES FOR SERIOUS APPLICATIONS (VS-GAMES), 16-18 set., 2010, Skövde. Proceedings... [S.I.]: [s.n.], [2015], p. 27-34.

236 PETRIDIS, P.; DUNWELL, I.; PANZOLI, D.; ARNAB, S.; PROTOPSALTIS, A.; HENDRIX, M.; FREITAS, S. de. Game engines selection framework for high-fidelity serious applications. International Journal of Interactive Worlds, v. 2012, p. 1, 2012.

237 PHATAK, M.; KAMALESH, V.N. On cloud computing deployment architecture. In: INTERNATIONAL CONFERENCE ON ADVANCES IN ICT FOR EMERGING REGIONS (ICTer), 11, 29-30 set., 2010, Colombo. [S.I.]: [University of Colombo; IEEE], [2010].

238 PHILIP, G.C. Software design guidelines for event-driven programming. Journal of Systems and Software, v. 41, n. 2, p. 79-91, maio 1998.

239 PIAGET, J.; INHELDER, B. The child's conception of space [ $\mathrm{La}$ Représentation de l'espace chez l'enfant]. Tradução do francês de F.J. Landgon e J.L. Lunzer. London: Routledge \& Kegan Paul, 1956 [1948].

240 PILGRIM, M. HTML5: Up and running. [S.I.]: O'Reilly, 2010.

241 PINTO, G. An example of body-centered cubic crystal structure: The atomium in brussels as an educative tool for introductory materials chemistry. J. Chem. Ed., v. 89, n. 7, p. 921-924, 2012.

242 PLOTNIKOVA, L.; TRIVAILO. Advanced virtual reality simulations in aerospace education and research. In: COSPAR SCIENTIFIC ASSEMBLY INTERNATIONAL ASTRONAUTICAL FEDERATION CONGRESS, 34, 2002. IAF abstracts. [S.I.]: [s.n.], p. 653

243 POSTGRESQL GLOBAL DEVELOPMENT GROUP. 8.14. JSON Types. [s.d.]. Disponível em:

<http://www.postgresql.org/docs/current/static/datatype-json.html>. Acesso em: 9 maio 2016.

244 PREECE, J. Design de Interação: Além da interação homem-computador. Porto Alegre: Bookman, 2005.

245 PUBSUBJS. Introducing PubSubJS, a Library for doing publish/subscribe in JavaScript. Roderick, Ulricehamn, 12 out. 2012. Disponível em: $<$ http://roderick.dk/2010/10/12/introducing-pubsubjs-a-library-for-doingpublish-subscribe-in-javascript/>. Acesso em: 21 abr. 2015.

246 PUNDSACK, M. App Sleeping on Heroku. 2013. Disponível em: $<$ https://blog.heroku.com/archives/2013/6/20/app_sleeping_on_heroku>. Acesso em: 9 maio 2016.

247 QUEAU, P. Le virtuel. Vertus et vertiges. Paris: Champ Vallon; Ina, 1993.

248 RADOSEVIC, I.; BALATINAC, I. Architecting for the Cloud. 2014. Dissertação (Mestrado) - Mälardalen University, Suécia. 
249 RAGAN, E.; BOWMAN, D.A.; KOPPER, R.; STINSON, C.; SCERBO, S.; McMAHAN, R.P. Effects of field of view and visual complexity on virtual reality training effectiveness for a visual scanning task. IEEE Transactions on Visualization and Computer Graphics, v. 21, n. 7, p. 794-807, 2015. Disponível em: <http://ieeexplore.ieee.org/xpl/articleDetails.jsp?arnumber=7042312>. Acesso em: 14 mar. 2016.

250 RCS MAINTAINERS. Official RCS Homepage. 14 out. 2011. Disponível em: <https://www.cs.purdue.edu/homes/trinkle/RCS/>. Acesso em: 16 mar. 2016.

251 REED-HILL, R.E. Princípios de metalurgia física. 2. ed. Rio de Janeiro: Guanabara Dois, 1982.

252 REED-HILL, R.E.; ABBASCHIAN, R. Physical metallurgy principles. Boston: PWS Publishing Company, 1994.

253 REQUICHA, A.G.; ROSSIGNAC, J.R. Solid modeling and beyond. IEEE Computer Graphics and Applications, v. 12, n. 5, p. 31-44, set. 1992. Disponível em: <http://excelsior.biosci.ohiostate.edu/ carlson/history/PDFs/solid-modeling92.pdf> Acesso em: 12 maio 2016.

254 REQUIREJS. RequireJS. [s.d.]. Disponível em: <http://requirejs.org/>. Acesso em: 19 fev. 2016.

255 RICHARDSON, L.; RUBY, S.; HANSSON, D.H. Restful web services. [S.I.]: O'Reilly Media, 2007.

256 RISING, L.; JANOFF, N. S. The Scrum software development process for small teams. IEEE Software, v. 17, n. 4, p. 26-32, 2000.

257 ROBERTSON, G.G.; MACKINLAY, J.D.; CARD, S.K. Cone trees: Animated $3 D$ visualizations of hierarchical information. In: ACM CONFERENCE ON HUMAN FACTORS IN COMPUTING SYSTEMS, 27 abr.-2 maio, 1991, Chicago. Proceedings... New York: ACM Press, 1991, p. 189-194.

258 RODGER, R. Beginning mobile application development in the cloud. [S.I.]: Wrox, 2011.

259 RODRIGUES, A.M.; FARIA, R.R.A., BELLOC, O.; ZUFFO, M.K. A virtual musical instrument for 3D performance with short gestures. In: INTERNATIONAL SYMPOSIUM ON COMPUTER MUSIC MULTIDISCIPLINARY RESEARCH (CMMR), 12, 5-8 jul., 2016, São Paulo. Proceedings... São Paulo: [s.n.], 2016.

260 ROTH, W.M.; BOWEN, G.M. Why students may not learn to interpret scientific inscriptions. Res. Sci. Educ., v. 32, n. 3, p. 303-327, 2002.

261 ROUSSOS, M. Learning and building together in an immersive virtual world. Presence: Teleoperators \& Virtual Environments, v. 8, n. 3, p. 247-263, 1999.

262 SACKS, R.; EASTMAN, C. M.; LEE, G. Parametric 3D modeling in building construction with examples from precast concrete. Automat. Constr., v. 13, n. 3, p. 291-312, 2004. 
263 SAKELLARI, G.; LOUKAS, G. A survey of mathematical models, simulation approaches and testbeds used for research in cloud computing. Simulation Modelling Practice and Theory, v. 39, p. 92-103, dez. 2013.

264 SAKURAMBO. A right-handed three-dimensional Cartesian coordinate system with the $+z$ axis pointing towards the viewer. Wikimedia Commons. 2007. Disponível em: <https://commons.wikimedia.org/wiki/File:

3D_coordinate_system.svg >. Acesso em: 19 abr. 2016.

265 SARKAR, S.; GANESAN, R.; SRIVASTAVA, M.; DHARMASANKAR, S. Cloud based next generation service and key challenges. In:

INTERNATIONAL CONFERENCE ON SYSTEM ENGINEERING AND MODELING (ICSEM), 7-8 abr., 2012, Kuala Lumpur. Proceedings... [Kuala Lumpur]: [s.n.], [2012].

266 SAWICKI, B.; CHABER, B. Efficient visualization of 3D models by web browser. Computing, v. 95, n. 1, p. 661-673, jan. 2013.

267 SCHOENFELD, A.H. What's all the fuss about metacognition? In:

SCHOENFELD, A.H. (Ed.). Cognitive science and mathematics education. Hillsdale, NJ: Lawrence Erlbaum Associates, 1987, p. 189-215.

268 SCHROEDER, R. Virtual reality in the real world: History, applications and projections. Futures, v. 25, n. 9, p. 963-973, 1993.

269 SCHROEDER, W. J.; AVILA, L. S.; HOFFMAN, W. Visualizing with VTK: A tutorial. IEEE Computer Graphics and Applications, p. 20-27, 2000.

270 SCHWABER, K.; BEEDLE, M. Agile software development with Scrum. [S.I.]: Prentice Hall, 2002.

271 SCHWARZENBACH, D. Crystallography. Tradução do francês de A.A. Pinkerton. Chichester: John Wiley \& Sons, 1996 [1993].

272 SCRUMM ALLIANCE®, INC. The 2015 state of Scrum report. Disponível em: <https://www.scrumalliance.org/why-scrum/state-of-scrum-report/2015state-of-scrum>. Acesso em: 29 fev. 2016.

273 SHACKELFORD, J.F. Ciência dos materiais. 6. ed. São Paulo: Pearson Brasil, 2008.

274 SHANNON, R.D.; PREWITT, C. Effective ionic radii in oxides and fluorides. Acta Crystallographica Section B: Structural Crystallography and Crystal Chemistry, v. 25, n. 5, p. 925-946, 1969.

275 SHEPARD, A. Case for computer-based multimedia in adult literacy classrooms. Encyclopedia of Educational Technology. San Diego, CA: [s.n.], 2003. Disponível em:

<http://www.etc.edu.cn/eet/articles/adultliteracy/index.htm>. Acesso em: 22 out. 2013.

276 SHERMAN, W.R.; CRAIG, A.B. Understanding Virtual Reality-Interface, Application, and Design. Presence: Teleoperators \& Virtual Environments, v. 12, n. 4, p. 441-442, 2003.

277 SILVA, E.L.; MENEZES, E M. Metodologia da pesquisa e elaboração de dissertação. Florianópolis: Programa de Pós Graduação em Engenharia de Produção - Universidade Federal de Santa Catarina, 2000. 
278 SILVA, R.C. A falsa dicotomia qualitativo-quantitativo: Paradigmas que informam nossas práticas de pesquisa. In: ROMANELLI, G; BIASOLIALVES, Z.M. (Org.). Diálogos metodológicos sobre prática de pesquisa. Ribeirão Preto: Legis Summa, 1998, p. 159- 174.

279 SIME, R.J. Some models of close packing. J. Chem. Ed., v. 40, n. 2, p. 61, 1963. Disponível em: <http://pubs.acs.org/doi/abs/10.1021/ed040p61>. Acesso em: 18 fev. 2016.

280 SLATER, M.; STEED, A. A virtual presence counter. Presence:

Teleoperators \& Virtual Environments, v. 9, n. 5, p. 413-434, 2000.

281 SMAIL, B. Spatial visualization skills and technical drafts education. Educ. Res., v. 25, n. 3, p. 230-231, 1983.

282 SMART, L.E.; MOORE, E.A. Solid state chemistry: An introduction. 4. ed. [S.I.]: CRC Press, 2012.

283 SMITH, I.M. Spatial ability: Its educational and social significance. San Diego, CA: R.R. Knapp, 1964.

284 SOBOYEJO, W.]. Mechanical properties of engineered materials. Switzerland: Marcel Dekker, 2003.

285 SORBY, S.A. Educational research in developing 3-D spatial skills for engineering students. International Journal of Science Education, v. 31, n. 3, p. 459-480, 2009.

286 SORENSEN, R. The art of the impossible. In: GENDLER, T.S.; HAWTHORNE, J. (Ed.). Conceivability and possibility. [S.I.]: Clarendon Press, 2002, p. 337-368.

287 STEVE, A.; DAVID, B. Silicon mirage: The art and science of virtual reality. [S.I.]: Peachpit Press, 1992.

288 STRAUCH, C. NoSQL Databases. Lecture on Selected Topics on SoftwareTechnology Ultra-Large Scale Sites. Stuttgart: Stuttgart Media University, 2011. Disponível em: <http://www.christof-strauch.de/nosqldbs.pdf>. Acesso em: 2 mar. 2016.

289 SUSMAN, G.I., EVERED, R.D. An assessment of the scientific merits of action research. Administrative Science Quarterly, v. 23, n. 4, p. 582-603, 1978.

290 SUTCLIFFE, A. Designing for User Engagement: Aesthetic and Attractive User Interfaces. Synthesis Lectures on Human-Centered Informatics. Disponível em:

<http://www.morganclaypool.com/doi/abs/10.2200/S00210ED1V01Y200910 HCl005>. Acesso em: 1 maio 2016.

291 SZWACKI, N.G.; SZWACKA, T. Basic elements of crystallography. Singapore: Pan Stanford Publishing, 2010.

292 TAKEUCHI, H.; NONAKA, I. The new new product development game. Harvard Business Review, v. 64, n. 1, p. 137-146, 1986.

293 THIOLLENT, M. Metodologia da pesquisa-ação. 18. ed. São Paulo: Cortez, 2011. 
294 THON, J.-N. Immersion revisited. On the value of a contested concept. In: Fernandez, A.; Leino, O.; Wirman, H. (Ed.). Extending experiences. Rovaniemi: Lapland University Press, 2008, p. 29-43.

295 THREE.js - Working with Cameras. Script Tutorials. 2015. Disponível em: $<$ https://www.script-tutorials.com/webgl-with-three-js-lesson-9/>. Acesso em: 19 abr. 2016.

296 TILLEY, R.J.D. Crystals and crystal structures. Chichester: John Wiley \& Sons, 2006.

297 TIWARI, S. Professional NoSQL. Wrox, 2011.

298 TORI, R. Educação sem distância: As tecnologias interativas na redução de distâncias em ensino e aprendizagem. São Paulo: Senac, 2010.

299 TORRACA, G. Lectures on materials science for architectural conservation. Los Angeles, CA: Getty Conservation Institute, 2009.

300 TRAND, M.A.; WIGNALL, S.; LESLIE-PELECKY, D.L. Research experiences for teachers in materials science: A case study. In: MRS FALL MEETING, 2004, Boston. MRS Proceedings, v. 861. Boston: Materials Research Society, 2005.

301 TRIPP, D. Pesquisa-ação: Uma introdução metodológica. Educação e Pesquisa, v. 31, n. 3, p. 443-466, set.-dez. 2005

302 TSAI, W.; HUANG, Y.; BAI, X.; GAO, J. Scalable architectures for SaaS. In: IEEE INTERNATIONAL SYMPOSIUM ON OBJECT/COMPONENT/ SERVICE-ORIENTED REAL-TIME DISTRIBUTED COMPUTING WORKSHOPS (ISORCW), 15, 11 abr. 2012, Shenzen. Proceedings... [S.I.]: [IEEE], [2012].

303 U.S. NAVY. Parachute Training using VR. [s.d.]. Disponível em: $<$ http://www.news.navy.mil/view_single.asp?id=3523>. Acesso em: 12 maio 2010.

304 U.S. NAVY; NAVAL RESEARCH LABORATORY. Crystal Lattice Structures. [s.d.]. Disponível em: <http://cstwww.nrl.navy.mil/lattice/index.html>. Acesso em: 12 maio 2010.

305 UNESCO. Information and communication technologies in teacher education: A planning guide. Paris: Unesco, 2002. Disponível em: $<$ http://unesdoc.unesco.org/images/0012/001295/129533e.pdf>. Acesso em: 2 mar. 2016.

306 UNESCO. World education report: Teachers and teaching in a changing world. Paris: Unesco, 1998.

307 UNIVERSIDADE DE SÃO PAULO. Sistema Integrado de Bibliotecas (Sibinet). [s.d.]. Disponível em: <http://www.sibi.usp.br/>. Acesso em: 14 abr. 2016.

308 VAN VLACK, L.H. Elements of materials science: An introduction text for engineering students. 2. ed. Reading, MA: Addison-Wesley, 1966.

309 VAN VLACK, L.H. Physical ceramics for engineers. Reading, MA: AddisonWesley, 1964. 
310 VENDRUSCOLO, F.; DIAS, J.A.; BERNARDI, G. CASSAL, M.L. Escola TRI-Legal - Um ambiente virtual como ferramenta de apoio ao ensino fundamental através de jogos educacionais.Colabor@, v. 3, n. 9, 2005.

311 VERGARA, S.C. Projetos e relatórios de pesquisa em administração. 3. ed. São Paulo: Atlas, 2000.

312 VIMONLINE DEVELOPMENT. Vim. [S.I.]: VimOnline Development, [s.d.]. Disponível em: <http://www.vim.org/>. Acesso em: 15 mar. 2016.

313 VINCE, J. Virtual reality systems. [S.I.]: Addison-Wesley, 1995.

314 VIRTALIS. Virtalis. [s.d.]. Disponível em: <http://www.virtalis.com/>. Acesso em: 10 maio 2016.

315 VOGEL, O. Software architecture: A comprehensive framework and guide for practitioners. [S.I.]: Springer, 2011.

316 W3C. Definition of Open Standards. [s.d.]. Disponível em: <http://www.w3.org/2005/09/dd-osd.html>. Acesso em: 21 abr. 2015.

317 W3C. Extensible Markup Language (XML). [s.d.]. Disponível em: <http://www.w3.org/XML/>. Acesso em: 17 mar. 2016.

318 W3C. HTML5. A vocabulary and associated APIs for HTML and XHTML. [s.d.]. Disponível em: <http://www.w3.org/TR/2014/REC-html5-20141028/>. Acesso em: 21 abr. 2015.

319 W3C. Latest SOAP versions. [s.d.]. Disponível em: <http://www.w3.org/TR/soap/>. Acesso em: 17 mar. 2016.

320 W3C. Web Services Description Language (WSDL) 1.1. mar. 2001. Disponível em: <http://www.w3.org/TR/wsdl>. Acesso em: 17 mar. 2016.

321 WAERNER, M. 3D graphics technologies for web applications: An evaluation from the perspective of a real world application. 2012. Dissertação (Mestrado) - Institute of Technology, Linköping University, Linköping.

322 WANG, S.; DEY, S. Adaptive mobile cloud computing to enable rich mobile multimedia applications. IEEE Transactions on Multimedia, v. 15, n. 4, p. 870-883, jun. 2013.

323 WANG, S.; DEY, S. Cloud mobile gaming: Modeling and measuring user experience in mobile wireless networks. Mobile Computing and Communications, v. 16, n. 1, jan. 2012.

324 WARE, C. Viewing a graph in a virtual reality display is three times as good as a 2D diagram. Computer Graphics, v. 26, p. 2-195, 1994.

325 WATT, D.S. Building pathology: Principles and practice. Malden: Blackwell Publishing, 2008.

326 WEGENKITTL, R.; LOFFELMANN, H.: GROLLER, E. Visualizing the behaviour of higher dimensional dynamical systems. In: IEEE CONFERENCE ON INFORMATION VISUALIZATION, 27-29 ago., 1997, [s.I.]. Proceedings... [S.I.]: [IEEE], [1997], p. 119-125. 
327 WEIDONG, S.; YANG, L.; ZHU, L.; ENGELSMA, J. Scalable support for 3D graphics applications in cloud. In: IEEE INTERNATIONAL CONFERENCE ON CLOUD COMPUTING, 3, 5-10 jul., 2010, [s.I.]. Proceedings... [S.I.]: [IEEE], [2010], p. 346-353.

328 WEST, A.R. Solid state chemistry and its applications. Student edition. 2. ed. Chichester: John Wiley \& Sons, 2014.

329 WESTBROOK, R. Action research: A new paradigm for research in production and operations management. International Journal of Operations \& Production Management, v. 15, n. 12, p. 6-20, 1995.

330 WILSON, T.D.; STREATFIELD, D.R. Action research and users' needs. 2000. Disponível em: <informationr.net/tdw/publ/papers/action81.html>. Acesso em: 2 mar. 2016.

331 WOLFF, R.S.; YAEGER, L. Visualization of natural phenomena. New York: Springer, 1993.

332 XIU-FENG, Q.; JIAN-WEI, L.; PENG-CHUAN, Z. Secure cloud computing architecture on mobile internet. In: INTERNATIONAL CONFERENCE ON ARTIFICIAL INTELLIGENCE, MANAGEMENT SCIENCE AND ELECTRONIC COMMERCE (AIMSEC), 2, 8-10 ago., 2011, Dengfeng. Proceedings... [S.I.]: [IEEE], [2011].

$333 \mathrm{XU}, \mathrm{X}$. George. An exponential growth of computational phantom research in radiation protection, imaging, and radiotherapy: a review of the fifty-year history. Physics in medicine and biology, v. 59, n. 18, p. R233, 2014. Disponível em: <http://iopscience.iop.org/article/10.1088/00319155/59/18/R233>. Acesso em: 19 abr. 2016.

334 YERS, M.D. Qualitative research in information systems. Management Information Systems Quarterly, v. 21, n. 2, p. 241-242, jun. 1997.

335 YIN, R.K. Case study research - Design and methods. 3. ed. [S.I.]: Sage Publications, 2003. (Applied social research methods series, 5).

336 ZAKAS, N.C. High performance JavaScript. [S.I.]: Yahoo Press, 2010.

337 ZAKAS, N.C. Maintainable JavaScript. [S.I.]: O'Reilly Media, 2012.

338 ZELTZER, D. Virtual environments: Where are we going? International Dating Industry \& Internet Dating Conference, 12, 1990. Proceedings... [S.I.]: [s.n.], [1990].

339 ZHANG, L.; ZHOU, Q. CCOA cloud computing open architecture. In: IEEE INTERNATIONAL CONFERENCE ON WEB SERVICES (ICWS), 7, 6-10 jul., 2009, Los Angeles, CA. Proceedings... [Los Angeles, CA]: IEEE, [2009].

340 ZUFFO, J.A.; SOARES, L.P.; ZUFFO, M.K.; LOPES, R. de D. CAVERNA Digital: Sistema de Multiprojeções Estereoscópico Baseado em Aglomerado de PCs para Aplicações Imersivas em Realidade Virtual. In: SIMPÓSIO DE REALIDADE VIRTUAL, 4, set. 2001, Florianópolis. Anais... [Florianópolis]: [s.e.], 2001. 